Áine Níléime · Jim 0gg ·

Martina Rašticová - Debra Street .

Clary Krekula · Monika Bédiová .

Ignacio Madero-Cabib Editors
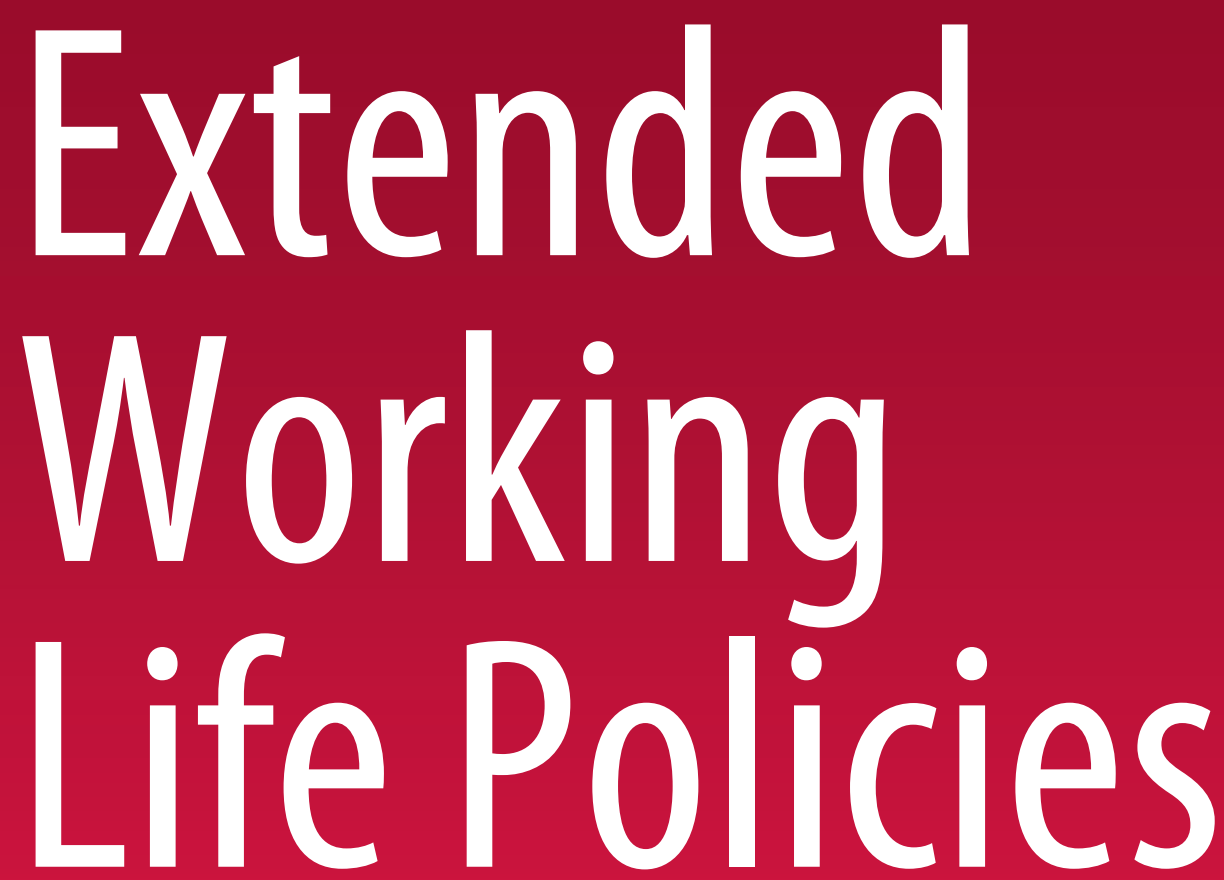

International Gender and Health

Perspectives

Springer Open 
Extended Working Life Policies 
Áine Ní Léime · Jim Ogg · Martina Rašticová . Debra Street . Clary Krekula · Monika Bédiová . Ignacio Madero-Cabib

Editors

\section{Extended Working Life Policies}

International Gender and Health Perspectives

Springer Open 


\section{Editors}

Áine Ní Léime

Institute for Life Course and Society

Jim Ogg

National University of Ireland, Galway

CNAV

Galway, Ireland

l'Unité de Recherche sur le Vieillisseme

Paris, France

\section{Martina Rašticová}

Debra Street

Department of Law and Humanity Sciences

Department of Sociology

Faculty of Business and Economics

Mendel University in Brno

University at Buffalo, State University

Buffalo, NY, USA

Brno, Czech Republic

\author{
Clary Krekula \\ Department of Social and \\ Psychological Studies \\ Karlstad University \\ Karlstad, Sweden
}

Ignacio Madero-Cabib

Institute of Sociology and

Department of Public Health

Pontificia Universidad Católica de Chile

Santiago, Chile

\author{
Monika Bédiová \\ Department of Law and Social Sciences, \\ Faculty of Business and Economics \\ Mendel University in Brno \\ Brno, Czech Republic
}

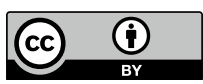

ISBN 978-3-030-40984-5

ISBN 978-3-030-40985-2 (eBook)

https://doi.org/10.1007/978-3-030-40985-2

(C) The Editor(s) (if applicable) and The Author(s) 2020. This book is an open access publication.

Open Access This book is licensed under the terms of the Creative Commons Attribution 4.0 International License (http://creativecommons.org/licenses/by/4.0/), which permits use, sharing, adaptation, distribution and reproduction in any medium or format, as long as you give appropriate credit to the original author(s) and the source, provide a link to the Creative Commons license and indicate if changes were made.

The images or other third party material in this book are included in the book's Creative Commons license, unless indicated otherwise in a credit line to the material. If material is not included in the book's Creative Commons license and your intended use is not permitted by statutory regulation or exceeds the permitted use, you will need to obtain permission directly from the copyright holder.

The use of general descriptive names, registered names, trademarks, service marks, etc. in this publication does not imply, even in the absence of a specific statement, that such names are exempt from the relevant protective laws and regulations and therefore free for general use.

The publisher, the authors and the editors are safe to assume that the advice and information in this book are believed to be true and accurate at the date of publication. Neither the publisher nor the authors or the editors give a warranty, expressed or implied, with respect to the material contained herein or for any errors or omissions that may have been made. The publisher remains neutral with regard to jurisdictional claims in published maps and institutional affiliations.

This Springer imprint is published by the registered company Springer Nature Switzerland AG

The registered company address is: Gewerbestrasse 11, 6330 Cham, Switzerland 


\section{Foreword}

Across OECD countries there has been a concerted push over the past decade and a half to get older people to delay retirement. This is in contrast to the earlier post-war period, when organisations, social partners and sometimes governments responded to an overall decrease in demand for labour by promoting early retirement/exit. This recent change has been influenced by demographic projections of population ageing and by the advocacy of international organisations such as the World Bank and the OECD. Such a policy focus has been presented positively in terms of helping to support extended working lives, and giving people greater choice over working longer. At an EU level, a positive development has been legislation to protect individuals from age discrimination, a move that began earlier in the USA. However, as this excellent volume convincingly argues, much of the policy in this area is inadequate, treats older people as a homogenous group, and does not consider the gendered consequences of pressures to work longer.

Writing in the UK context, one does not have to look very far to see how contentious pressures to extend working lives are. A recent survey has suggested that the prospect of extended working lives has caused significant concerns among the adult population. In the political field, one of the debates in the UK general election of 2020 was the treatment of women born in the 1950s who have been affected by rapidly rising state pension ages. In 2010 state pension age for women was 60, but this had risen to 65 in 2019 (matching male pension age) and will rise to 66 in 2020 (and beyond this in later years). The 'Women Against State Pension Age Increases' movement has argued that female state pension age increases were poorly communicated to the public. As a result, some women made financial plans based on a state pension of 60 , and now find themselves out of work and having to wait until 66 for a pension. The impact of financial pressures to work longer have arguably been particularly acute for women, given that women often amass lower pensions than men but are increasingly finding themselves single or remarried in older age. Such changes illustrate why this book on gender and extended working lives is so timely and so important. 
The first five chapters of the book provide a conceptual and empirical overview of policies to extend working lives across the countries covered in subsequent chapters. These earlier chapters draw out a number of important insights. For example, Krekula and Vickerstaff highlight the tendency across countries to base policies on assumptions of a male 'ideal worker'; these are clearly at odds with the employment and caring trajectories of many women. Likewise, Street and Ní Léime emphasise the precarity and insecurity facing many women, and, crucially, argue that the focus of policy has been about getting people to delay retirement, rather than supporting individuals to work longer. In related policy debates, health improvements among the older population are often given as a justification for delaying retirement. However, as these chapters point out, the reality is more complex than this. In some sectors of employment older people continue to be exposed to hazardous working conditions or hours of work. Health problems among older people continue to place limits on the capacity of some individuals to work, with 'healthy life expectancy' rising at a slower rate than life expectancy itself. It also is noteworthy that women have longer average life expectancy than men, which has implications for poverty in older age.

Chapters 6-39 gives individual accounts of extended working in 34 countries, covering both the policies themselves and a discussion about research on their impact. This represents an extremely valuable resource for anyone interested in developments in this area. The chapters show that across the countries covered the primary policy focus has been about delaying access to pensions, although some countries have done more than others to try and support extended working lives. Evidently, none of the countries discussed has done enough to address the problems associated with extended working lives, however, and the knowledge acquired from this volume gives us some of the tools to make the case for taking a more equitable approach.

David Lain

Newcastle University Business School Newcastle upon Tyne, England 


\section{Preface}

As populations across the globe are ageing, international organisations including the OECD have strongly encouraged national governments to adopt policies designed to impel citizens to work longer in a bid to reduce anticipated increased state pension costs. These policies include increasing state pension age, penalising early retirement and rewarding later retirement. These initiatives are frequently simplistic, one-size-fits all policies that were frequently introduced quickly and without adequate consideration of their implications for diverse groups of workers.

A group of scholars from diverse disciplines (sociology, economics, gender studies, political science, business studies) in individual countries began to explore the different gender and health implications of these policies for women and men and for workers in physically demanding and/or stressful jobs and for those in precarious work. In 2015, their collective efforts were advanced when they were awarded funding for a COST (Cooperation in Science and Technology) Action IS1409-to create a research network running for four years from April 2015 to April 2019. This enabled the original group to invite other researchers to join them to investigate extended working life policies across all 34 countries involved in the network. This book is the outcome of the COST Action IS 1409 collaboration, involving early career and experienced researchers. It offers a multidisciplinary, cross-national compendium of extended working life policy that is unprecedented in scope and depth.

Part I of the book contextualises the country chapters presented in Part II. Part I provides a wealth of information and analysis that problematises and complicates the typically simplistic narrative that is used to justify the introduction of extended working life policies. Chapter 1 sets out the empirical landscape of later working life, encompassing gender and health perspectives and drawing on international sources. Chapter 2 offers an overview of theoretical perspectives on and a critical discussion of the level and nature of political debate on the issue of extending working life. Chapter 3 presents the databases and indicators available for research on the topic. In Chap. 4 promising workplace policies are the topic. The concluding chapter for Part I argues that researchers and policy-makers should distinguish between 'delaying retirement' - which is the focus of current policies with negative 
implications and 'extending working life'-a more positive approach, which requires application of both pension and carefully considered employment policies. Part II includes 34 individual country chapters discussing extended working life at the national level.

The book will be essential reading for academics, non-governmental organisations and policy-makers who have an interest in ageing, gender, health and work. It provides both theoretical and empirical insights into this topical and increasingly important area of public policy.

Galway, Ireland

Áine Ní Léime

Paris, France

Jim Ogg

Brno, Czech Republic

Buffalo, USA

Martina Rašticová

Karlstad, Sweden

Brno, Czech Republic

Santiago, Chile

Debra Street

Clary Krekula

Monika Bédiová

Ignacio Madero-Cabib 


\section{Acknowledgements}

The editors wish to acknowledge that this book is based on the work of COST Action IS1409 and open access is funded by COST Final Action Dissemination Grant.

COST (European Cooperation in Science and Technology) is a funding agency for research and innovation networks. Our Actions help connect research initiatives across Europe and enable scientists to grow their ideas by sharing them with their peers. This boosts their research, career and innovation.
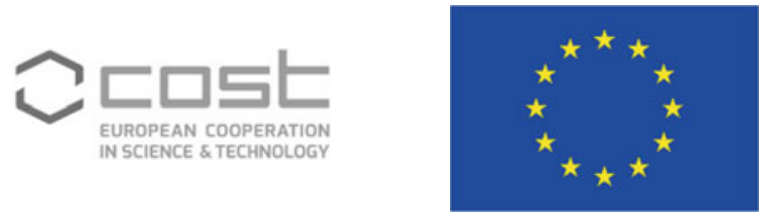

The editors would like to acknowledge Áine Teahan, and Maggie O'Neill who did an excellent job of proofreading and collating chapters and Christine de Largy who provided support throughout the process. They would also like to acknowledge all members of COST Action IS1409 whose work contributed to this book. 


\section{Contents}

Part I Challenges and Opportunities for Extended Working Lives

1 Introduction: Key Issues and Policies for Extending

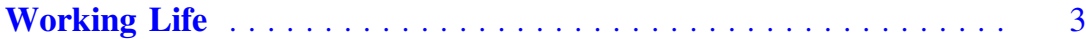

Jim Ogg and Martina Rašticová

2 The 'Older Worker' and the 'Ideal Worker': A Critical Examination of Concepts and Categorisations in the Rhetoric of Extending Working Lives

Clary Krekula and Sarah Vickerstaff

$3 \quad$ Data Issues and Indicators . . . . . . . . . . . . . . . . . . . . . . 47

Tindara Addabbo, Michaela Gstrein and Renata Siemieńska

4 Policy Toolkits on Employment and Ageing: A Conceptual Framework . . . . . . . . . . . . . . . . . . . . . . . . . . . . 69

Nata Duvvury, Jonas Radl, E. K. Sarter, Simone Scherger and Jeroen Spijker

5 Problems and Prospects for Current Policies to Extend

Working Lives

Debra Street and Áine Ní Léime

Part II Extended Working Life Policies: Country Experiences

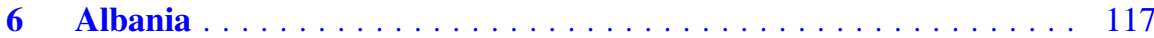

Merita Vaso Xhumari

7 Australia .

Elizabeth Brooke

8 Austria

Barbara Haas, Michaela Gstrein and Roland Bildsteiner 
9 Belgium . . . . . . . . . . . . . . . . . . . . 153

Nathalie Burnay and Patricia Vendramin

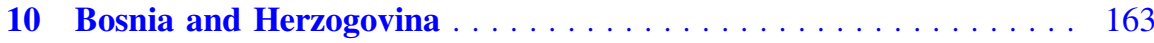

Nurka Pranjić and Maja Račić

11 Bulgaria . . . . . . . . . . . . . . . . . . . . . . . 173

Tihomira Trifonova and Kamellia Lillova

12 Chile . . . . . . . . . . . . . . . . . . . . . . . . 183

Ignacio Madero-Cabib, José De-Amesti and María-Soledad Herrera

13 Croatia . . . . . . . . . . . . . . . . . . . . . . 195

Siniša Zrinščak, Maja Vehovec and Drago Čengić

14 Cyprus . . . . . . . . . . . . . . . . . . . . . 205

Petroula M. Mavrikiou

15 Czech Republic . . . . . . . . . . . . . . . . . . . . . . . . . . . . . . 217

Martina Rašticová, Monika Bédiová, Jana Mikušová, Aneta Krejčová and Jiří Černý

16 Denmark . . . . . . . . . . . . . . . . . . . . . . . . . . . . . . . . . . 229

Per H. Jensen

17 Estonia . . . . . . . . . . . . . . . . . . . . . . . 241

Marge Unt, Margarita Kazjulja and Viivi Krönström

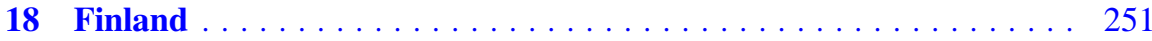

Laura Salonen, Antti Kähäri and Ilkka Pietilä

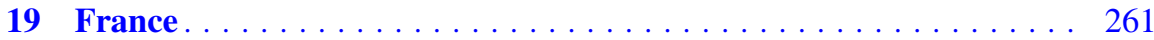

Julie Rochut and Jim Ogg

20 Germany . . . . . . . . . . . . . . . . . . . . 271

Laura Romeu-Gordo and E. K. Sarter

21 Greece. . . . . . . . . . . . . . . . . . . . . . . 283

Antigone Lyberaki and Thomas Georgiadis

22 Ireland . . . . . . . . . . . . . . . . . . . . . . 297

Áine Ní Léime, Dinali Wijeratne and Nata Duvvury

23 Israel . . . . . . . . . . . . . . . . . . . . . . . . . . . . . . . . . . . . 309

Orly Benjamin, Sarit Nisim and Dikla Segel-Karpas

24 Italy . . . . . . . . . . . . . . . . . . . . . . . . . . . . . 319

Tindara Addabbo

25 Lithuania . . . . . . . . . . . . . . . . . . . . . . . . . 329

Jolanta Pivoriene and Kristina Ambrazeviciute 
26 Netherlands . . . . . . . . . . . . . . . . . . . . . . . . 341

Maria Fleischmann and Thijs van den Broek

27 New Zealand . . . . . . . . . . . . . . . . . . . . . . 351

Judith A. Davey, Hannah Phillips and Fiona Alpass

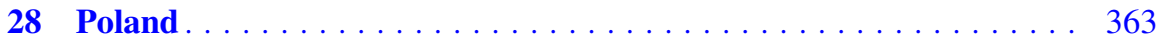

Renata Siemieńska

29 Portugal . . . . . . . . . . . . . . . . . . . . . . . . 373

Paula Albuquerque, Sara Falcão Casaca, Heloísa Perista

and Pedro Perista

30 Romania . . . . . . . . . . . . . . . . . . . . . . . . . . . . 385

Daniela Şoitu and Conţiu Tiberiu Șoitu

31 Serbia . . . . . . . . . . . . . . . . . . . . . 395

Mihajlo Jakovljevic, Mirjana Jovanovic, Olivera Milovanovic and Svetlana Radevic

32 Slovakia . . . . . . . . . . . . . . . . . . . . . 407

Anna Pilková and Juraj Mikuš

33 Slovenia.............................. 417

Tanja Rener and Ana Kralj

34 Spain . . . . . . . . . . . . . . . . . . . . . . . . . . . . . . . . . . 427

Jeroen Spijker, Juan Manuel García González and Dolores Puga

35 Sweden ............................... 439

Lars-Gunnar Engström, Satu Heikkinen and Clary Krekula

36 Switzerland . . . . . . . . . . . . . . . . . . . . . . 449

Nicky Le Feuvre, Maurice Avramito and Valérie Hugentobler

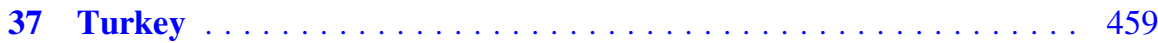

Murat A. Mercan

38 United Kingdom . . . . . . . . . . . . . . . . . . . . . . . . . . . . . . 469

Laura Airey and Jakov Jandrić

39 United States . . . . . . . . . . . . . . . . . . . . . . 481

Debra Street

Glossary . . . . . . . . . . . . . . . . . . . . . . . . . . . . . . . 495

Index . . . . . . . . . . . . . . . . . . . . . . . . . . . 499 


\section{Editors and Contributors}

\section{About the Editors}

Áine Ní Léime is Deputy Director of the Irish Centre for Social Gerontology at the National University of Ireland, Galway. She is a Fellow of the Gerontological Society of America and Chair of COST Action IS1409, an international research network on Gender, Health and Extended Working Life (2015-2019). Her current research focuses on older workers, gender and extended working life. She is currently Principal Investigator for Ireland on a NORFACE-funded project comparing experiences of older workers in Ireland, the Czech Republic, Sweden, Switzerland and the UK. She is Editor of Gender, Ageing and Extended Working Life: Cross-National Perspectives (2017), a Special Issue of Ageing \& Society and several journal articles on these topics.

Jim Ogg is Head of the Ageing Research Unit at the National Pension Fund (Caisse nationale d'assurance vieillesse), Paris, France and Honorary Research Fellow at the College of Human and Health Sciences, Swansea University. His research focuses on the sociology of the family in the context of ageing populations, the transition to retirement, social exclusion and housing environments. He is the Editor-in-Chief of the journal Retraite et Société and was previously the Deputy Editor of Ageing \& Society.

Martina Rašticová is Head of Department of Law and Social Sciences, Faculty of Business and Economics, Mendel University, Brno, Czech Republic. Her recent research is in age management, extended working life and work-life balance.

Debra Street is Professor of Sociology at the State University of New York at Buffalo, United States of America. Author of 80+ articles, chapters and working papers; a monograph; and co-editor of three books, Street researches the challenges of ageing societies, particularly health and income security over the life course. She 
is a Fellow of the Gerontological Society of America, an elected member of the National Academy of Social Insurance and recipient of the UB Gender Institute Janice L. Moritz Distinguished Lecturer and the CISP Outstanding Contributions to International Education awards. Street's research has been funded by the National Science Foundation, the National Institute on Aging, the International Council for Canadian Studies and the Robert Wood Johnson Foundation.

Clary Krekula is Professor of Sociology at Karlstad University. Her research focuses on critical age studies, ageing from an intersectional perspective, and time and temporality. She runs the national network AgeS: The Swedish Research Network on Age. She is currently conducting research on dynamics of inequality across the life course, self-employment later in life and the social and corporeal aspects of dancing among older people. She is co-editor of Gender, Ageing and Extended Working Life. Cross-National Perspectives (2017) and Introduction to Critical Age Studies (2017).

Monika Bédiová is a Researcher at the Department of Law and Humanity Sciences, Mendel University in Brno, Czech Republic. She has been working on research projects, publishing and her main research areas include diversity management and the issue of active ageing in the Czech Republic. She is the co-author of the monograph Work or Retire? (2018).

Ignacio Madero-Cabib is Assistant Professor of Sociology and Public Health at Pontificia Universidad Católica de Chile, Santiago, Chile. He serves as Deputy Director of the Center 'Millennium Nucleus for the study of the Life Course and Vulnerability (MLIV)' (http://mliv.cl). His current research focuses on the impact of cumulative social advantages and disadvantages on vulnerability among older people in different countries.

\section{Contributors}

Tindara Addabbo Department of Economics Marco Biagi, University of Modena and Reggio Emilia, Modena, Italy

Laura Airey University of Edinburgh Business School, Edinburgh, UK

Paula Albuquerque SOCIUS/CSG, ISEG-Lisbon School of Economics and Management, University of Lisbon, Lisbon, Portugal

Fiona Alpass School of Psychology, Massey University, Palmerston North, New Zealand

Kristina Ambrazeviciute The Law Institute of Lithuania, Vilnius, Lithuania 
Maurice Avramito HESSO, Applied University of Western Switzerland, Lausanne, Switzerland

Monika Bédiová Department of Law and Social Sciences, Faculty of Business and Economics, Mendel Universityin Brno, Brno, Czech Republic

Orly Benjamin Department of Sociology and Anthropology, Bar-Ilan University, Ramat Gan, Israel

Roland Bildsteiner BEST Institute of Continuous Vocational Qualification Training and Personnel Training, Vienna, Austria

Elizabeth Brooke Demography and Aging Unit, Melbourne School of Population and Global Health, University of Melbourne, Melbourne, VIC, Australia

Nathalie Burnay Transitions Institute, University of Namur, Namur, Belgium; IACCHOS Institute, Université of Louvain-la-Neuve, Louvain-la-Neuve, Belgium Drago Čengić Institute of Social Sciences Ivo Pilar, Zagreb, Croatia

Jiř́ Černý Department of Law and Social Sciences, Faculty of Business and Economics, Mendel Universityin Brno, Brno, Czech Republic

Judith A. Davey Institute for Governance and Policy Studies, Victoria University of Wellington, Wellington, New Zealand

José De-Amesti Pontificia Universidad Católica de Chile, Santiago, Chile

Nata Duvvury School of Political Science and Sociology, National University of Ireland, Galway, Ireland

Lars-Gunnar Engström Department of Social and Psychological Studies, Karlstad University, Karlstad, Sweden

Sara Falcão Casaca SOCIUS/CSG, ISEG-Lisbon School of Economics and Management, University of Lisbon, Lisbon, Portugal

Maria Fleischmann Department of Health Sciences, Vrije Universiteit Amsterdam, Amsterdam, The Netherlands

Thomas Georgiadis Department of Economics and Regional Development, Panteion University, Athens, Greece

Juan Manuel García González Department of Sociology, Universidad Pablo de Olavide, Seville, Spain

Michaela Gstrein WPZ Research, Vienna, Austria

Barbara Haas Department of Socioeconomics, Vienna University of Economics and Business, Vienna, Austria 
Satu Heikkinen Department of Social and Psychological Studies, Karlstad University, Karlstad, Sweden

María-Soledad Herrera Institute of Sociology, Pontificia Universidad Católica de Chile, Santiago, Chile

Valérie Hugentobler HESSO, Applied University of Western Switzerland, Lausanne, Switzerland

Mihajlo Jakovljevic Department of Global Health Economics and Policy, University of Kragujevac, Kragujevac, Serbia

Jakov Jandrić University of Edinburgh Business School, Edinburgh, UK

Per H. Jensen Centre for Comparative Welfare Studies, Aalborg University, Aalborg, Denmark

Mirjana Jovanovic Department of Psychiatry, University of Kragujevac, Kragujevac, Serbia

Antti Kähäri Department of Social Research, University of Turku, Turku, Finland Margarita Kazjulja School of Governance, Law and Society, Institute of International Social Studies, Tallinn University, Tallinn, Estonia

Ana Kralj Faculty of Social Work, University of Ljubljana, Ljubljana, Slovenia

Aneta Krejčová Department of Law and Social Sciences, Faculty of Business and Economics, Mendel Universityin Brno, Brno, Czech Republic

Clary Krekula Department of Social and Psychological Studies, Karlstad University, Karlstad, Sweden

Viivi Krönström School of Governance, Law and Society, Institute of International Social Studies, Tallinn University, Tallinn, Estonia

Nicky Le Feuvre Faculty of Political and Social Sciences, Lausanne University, Lausanne, Switzerland

Kamellia Lillova Institute for Population and Human Studies, Sofia, Bulgaria

Antigone Lyberaki Department of Economics and Regional Development, Panteion University, Athens, Greece

Ignacio Madero-Cabib Institute of Sociology and Department of Public Health, Pontificia Universidad Católica de Chile, Santiago, Chile

Petroula M. Mavrikiou Department of Business Administration, Frederick University, Nicosia, Cyprus

Murat A. Mercan Faculty of Business Administration, Department of Economics, Gebze Technical University, Kocaeli, Turkey 
Juraj Mikuš Faculty of Management, Comenius University in Bratislava, Bratislava, Slovakia

Jana Mikušová Department of Law and Social Sciences, Faculty of Business and Economics, Mendel University in Brno, Brno, Czech Republic

Olivera Milovanovic Faculty of Medical Sciences, Department of Pharmacy, University of Kragujevac, Kragujevac, Serbia

Áine Ní Léime Irish Centre for Social Gerontology, National University of Ireland, Galway, Ireland

Sarit Nisim Poverty Research Unit, Bar-Ilan University, Ramat Gan, Israel

Jim Ogg Ageing Research Unit, National Pension Fund (Cnav), Paris, France

Heloísa Perista CESIS-Centre for Studies for Social Intervention, Lisbon, Portugal

Pedro Perista CESIS-Centre for Studies for Social Intervention, Lisbon, Portugal Hannah Phillips School of Psychology, Massey University, Palmerston North, New Zealand

Ilkka Pietilä Faculty of Social Sciences, University of Helsinki, Helsinki, Finland Anna Pilková Faculty of Management, Comenius University in Bratislava, Bratislava, Slovakia

Jolanta Pivoriene Institute of Educational Sciences and Social Work, Mykolas Romeris University, Vilnius, Lithuania

Nurka Pranjić Department of Occupational Medicine, University of Tuzla, Tuzla, Bosnia and Herzegovina

Dolores Puga Spanish National Research Council—CSIC, Madrid, Spain

Maja Račić Department of Family Medicine, University of East Sarajevo, Foča, Bosnia and Herzegovina

Svetlana Radevic Faculty of Medical Sciences, Department of Social Medicine, University of Kragujevac, Kragujevac, Serbia

Jonas Radl University of Madrid, Madrid, Spain;

WZB Berlin Social Science Center, Berlin, Germany

Martina Rašticová Department of Law and Social Sciences, Faculty of Business and Economics, Mendel University in Brno, Brno, Czech Republic

Tanja Rener Faculty of Social Sciences, University of Ljubljana, Ljubljana, Slovenia

Julie Rochut Ageing Research Unit, National Pension Fund (Cnav), Paris, France 
Laura Romeu-Gordo Deutsches Zentrum für Altersfragen (DZA), Berlin, Germany

Laura Salonen Department of Social Research, University of Turku, Turku, Finland

E. K. Sarter Faculty of Business and Society, University of South Wales, Pontypridd, UK

Simone Scherger Bremen International Graduate School of Social Sciences, University of Bremen, Bremen, Germany

Dikla Segel-Karpas Department of Gerontology, University of Haifa, Haifa, Israel

Renata Siemieńska Institute of Sociology, M. Grzegorzewska University, Warsaw, Poland;

R. Zajonc Institute for Social Studies, University of Warsaw, Warsaw, Poland

Daniela Șoitu Department of Sociology and Social Work, Alexandru Ioan Cuza University of Iasi, Iasi, Romania

Jeroen Spijker Centre for Demographic Studies (CED), Barcelona, Spain

Debra Street Department of Sociology, The State University of New York at Buffalo, Buffalo, NY, USA

Conțiu Tiberiu Şoitu Department of Sociology and Social Work, Alexandru Ioan Cuza University of Iasi, Iasi, Romania

Tihomira Trifonova Sofia University “St. Kliment Ohridski”, Sofia, Bulgaria

Marge Unt School of Governance, Law and Society, Institute of International Social Studies, Tallinn University, Tallinn, Estonia

Thijs van den Broek Erasmus School of Health Policy and Management, Erasmus Universiteit Rotterdam, Rotterdam, The Netherlands

Maja Vehovec Institute of Economics, Zagreb, Croatia

Patricia Vendramin IACCHOS Institute, Université of Louvain-la-Neuve, Louvain-la-Neuve, Belgium

Sarah Vickerstaff School of Social Policy, Sociology and Social Research, University of Kent, Canterbury, UK

Dinali Wijeratne Irish Centre for Social Gerontology, National University of Ireland, Galway, Ireland

Merita Vaso Xhumari University of Tirana, Tirana, Albania

Siniša Zrinščak Faculty of Law, University of Zagreb, Zagreb, Croatia 


\section{List of Figures}

Fig. 1.1 Employment rate 55-59 year age group (\%).

Source Eurostat $(2019 b) \ldots \ldots \ldots \ldots \ldots \ldots$

Fig. 1.2 Employment rate of 60-64 year age group (\%).

Source Eurostat (2019b) . . . . . . . . . . . . . . . . . . . . . . . . 9

Fig. 1.3 Effective retirement age, OECD average.

Source OECD (2019) . . . . . . . . . . . . . . . . . . . . . . . 10

Fig. 1.4 Employment rates (\%) by gender in age group 65-69 years.

Source Eurostat (2019b). Last extract 19/12/2017 . . . . . . . . . . 11

Fig. 1.5 Gender pay gap, \% of average gross hourly earnings of men.

Source Eurostat (2019b). The indicator measures the difference between average gross hourly earnings of male paid employees and of female paid employees as a percentage of average gross hourly earnings of male paid employees. . . . . . . . . .

Fig. 1.6 Gender gap in pensions, pensioners aged 65-79, 2016; \%.

Source Eurostat, EU-SILC. Notes 2010 data for HR; data sorted by data for 2016. Pensions at a Glance, Vol. 1, 2018, p. $68 \ldots \ldots \ldots \ldots \ldots \ldots \ldots$. . . . . . . . . . . . . . . . 14

Fig. 1.7 Healthy life years in absolute value at 65-women (2010-2016). (1) 2011 instead of 2010. (2) 2015 instead of 2016. Source Eurostat (online data code: hlth_hlye). . . . . . . 16

Fig. 1.8 Health life years in absolute value at 65-men (2010-2016). (1) 2011 instead of 2010. (2) 2015 instead of 2016. Source Eurostat (online data code: hlth_hlye). . . . . . . . . .

Fig. 1.9 Labour market flexibility and employment rate of older workers. Source (Breinek et al. 2018; Eurostat 2017) data base, Fraser Institute (2016) . . . . . . . . . . . . . . . . . .

Fig. 1.10 Dimensions of precariousness by gender and educational attainment (15-64, EU-28, 2014). Source Madarova et al. 2017, p. 2018, according to LFS, calculations based on 2014 microdata. Note excluding those whose main status is a student (except for DE and UK due to data availability). . . . . . . . . 
Fig. 3.1 Factors impacting on extended working life or the retirement decision. Source Authors' own additions (highlighted) or emphasized to Hasselhorn and Apt (2015: 24), Fig. 2 . . . . . 57

Fig. 15.1 Reasons for retirement in the Czech Republic.

Source Šimandlová (2014) . . . . . . . . . . . . . . . . . . . . 219

Fig. 15.2 Health reasons diminishing chances of finding a job. Source Šimandlová (2014) . . . . . . . . . . . . . . . . . . . . . . . . 219

Fig. 15.3 Stereotypes and external barriers in the labour market according to Czech seniors in the age group 50-64. Source Šimandlová $(2014)$. . . . . . . . . . . . . . . . . . . . . . . . . . . 220

Fig. 15.4 The reasons for discrimination in the Czech Republic. Source STEM (2007) . . . . . . . . . . . . . . . . . . . . 220 


\section{List of Tables}

Table 3.1 Grid showing a selection of data sets with relevant

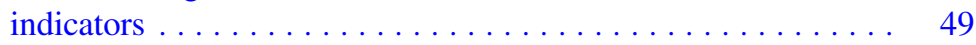

Table 3.2 Probability of being income poor by age group ........ 61

Table 3.3 Income poverty and material deprivation by gender-50-64

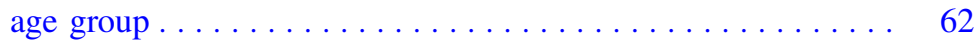

Table 3.4 Summary: Differences in attitudes toward older people in selected countries . . . . . . . . . . . . . . . . . . 64

Table 3.5 Factors impacting on extended working life (EQLS, wave 3),

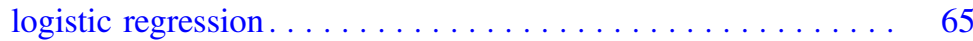

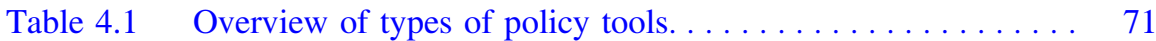

Table 4.2 Definition and examples of policy tool kits . . . . . . . 72

Table 5.1 State pension age/normal retirement age. . . . . . . . . . . 99

Table 6.1 Some indicators of the pension system in Albania, 1990-2016 . . . . . . . . . . . . . . . . . . . . . . . . . . . 121

Table 6.2 The share of older people working after retirement age,

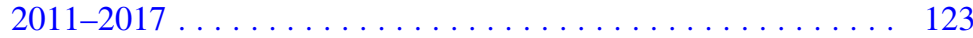

Table 8.1 Employment and part-time rate of older workers, pension

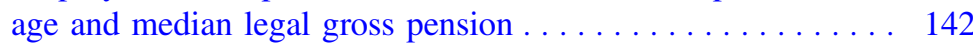

Table 8.2 Legal entitlement to different forms of pension . . . . . . . . 144

Table 9.1 Main reasons for stopping work amongst economically inactive persons in Belgium who receive a pension 2012 (\%) ........................ 155

Table 9.2 Part-time employment amongst men and women aged 50-64 years as a percentage of total employment $(\%) \ldots \ldots .158$

Table 9.3 Persons aged 50-69 years who reduced their working hours in a move towards retirement $2012(\%) \ldots \ldots \ldots \ldots 158$

Table 10.1 Labour force participation of older workers over the age of 65 by gender in Bosnia and Herzegovina, in the period 1950-2010 (percentage) . . . . . . . . . . . . . . . . 165

Table 12.1 Labour force participation (\%) by gender and age group . . . . 184

Table 12.2 Labour force participation (\%) of individuals aged 65+ . . . . 184 
Table 14.1 Employment by age between 2010-2017 for older men and women in Cyprus . . . . . . . . . . . . . . . 207

Table 14.2 Share of recipients of minimum income benefits in the population aged 65 and over by benefit (2013 and latest

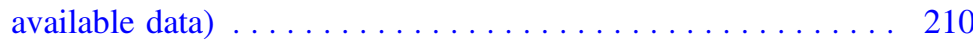

Table 21.1 Labour market outcomes of older workers by gender in Greece $2001-2019 \ldots \ldots \ldots \ldots \ldots$. . . . . . . . . . . 286

Table 27.1 Participation rates (\%) at age 65 plus by sex-projections

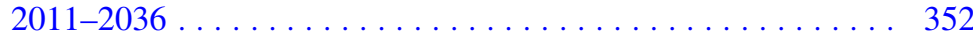

Table 33.1 At-risk-of-poverty rate, by age and gender (in \%).

Source Statistical Office of the Republic of Slovenia 2018. . . 420

Table 34.1 Proportion of the population employed by age and sex. 1986-2015 . . . . . . . . . . . . . . . . . . . . . . . . . . . . 429

Table 36.1 Share of salaried and self-employed [men aged 55-64 years, women aged 55-63 years] who contribute to the different

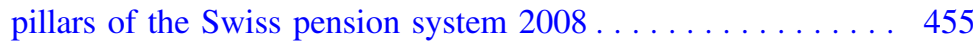

Table 36.2 Gender pension gap by type of pension entitlement $2012 \ldots 456$

Table 36.3 Gender pension gap by type of pension and marital

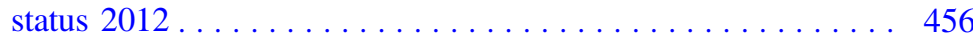

Table 37.1 Labour force participation rates for older workers in Turkey . .

Table 37.2 The reasons for not being in the Labour Force

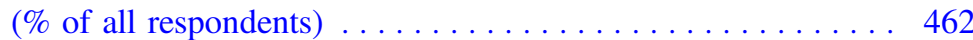

Table 37.3 Part-time worker ratios (\% of all workers) . . . . . . . . . 465

Table 38.1 Proportion in full- and part-time employment, by gender

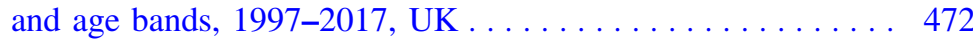

Table 39.1 Median annual income received from each source among women and men aged 65 and older who received any income from each source................. 486 
Part I

Challenges and Opportunities for Extended Working Lives 


\title{
Chapter 1 \\ Introduction: Key Issues and Policies for Extending Working Life
}

\author{
Jim Ogg and Martina Rašticová
}

\begin{abstract}
Extended working life policies have been widely promoted in Europe and in wider international settings. However, to date, these policies have not, for the most part, taken sufficient account of the gender and health dimensions of working longer. This chapter outlines the empirical and policy landscapes that are present in Europe and several other countries. It examines the different meanings of 'extended working life' and the indicators used to justify raising the age of eligibility for a pension. Gender and health inequalities related to extended working life, such as gender pay and pension gaps and differential life expectancy rates are presented. The influence of the labour market on the employability of older workers is examined in the context of economic downturns and digitalisation. The chapter concludes that policy initiatives which meet the diverse needs of older workers and which address gender and health inequalities related to extended working should be a priority for governments and employers in the years ahead.
\end{abstract}

\section{Introduction}

As populations age, extending the working life appears to be widely accepted and promoted by governments (OECD 2006, 2018). Without exception, all countries with modern economies have responded since the beginning of the 21 st century in one way or another to the financial challenges for pension systems arising from increased life expectancy and ageing populations. Policies to extend working life vary in their content and scope, but in 2019 they are ubiquitous, each based on the premise that unsustainable pension systems must be reformed, and public spending reduced or contained. Perhaps the most visible measure of these policies has been the

J. Ogg $(\bowtie)$

Ageing Research Unit, National Pension Fund (Cnav), Paris, France

e-mail: jim.ogg@cnav.fr

M. Rašticová

Department of Law and Social Sciences, Faculty of Business and Economics, Mendel University in Brno, Brno, Czech Republic

e-mail: martina.rasticova@mendelu.cz 
increase in age of eligibility for pensions. This reform to pension systems has taken place throughout Europe and further afield, with many countries having also passed legislation to raise the pension age even further in years to come. Ireland provides an example that is typical of many European countries, where in 2014, the state pension age increased from 65 to 66 years and will increase again to 67 in 2021 and to 68 in 2028.

However, raising the pension age is only one of a series of measures designed to extend the working life. In recent years, a 'quiet revolution' has also taken place, whereby pensions and life expectancy are linked mainly in the form of the replacement of defined benefit pensions with defined contribution pensions. The link between age and pension type matters because traditional defined benefit pensions featured stable pension benefits where risks are shared collectively and could not be outlived (usually based on a combination of income and years of employment). In contrast, defined contribution pensions (where the level of contributions, and not the final benefit, is pre-defined and no final pension promise is made) individualises the risk of investments since pension levels depend on the duration of contributions and the performance of investments (OECD 2011). The shift to defined contribution pensions, for example, was a major feature of Sweden's reforms in 1994, and many countries have since implemented defined contribution schemes. Moreover, as life expectancy increases, individuals in a defined contribution scheme need to work longer to build up insurance contributions and secure an adequate income in retirement and therefore increasing the number of years of contributions continues to be a key feature of existing reforms. These two reforms-raising the state pension age and implementing defined contribution pensions-increase the length of time necessary in a working career to access a pension.

Extended working life policies are therefore a reality both within Europe and in wider international settings. Nonetheless, interleaved with this reality are 'the complex social, economic and political circumstances [that] are all part of the empirical landscape of extended working lives' (Street 2017: 3). Increasingly, the implementation of universal, 'one size fits all' policies are being questioned. Extending the working life depends on the availability of jobs. As labour markets today respond to globalised economic trends, unemployment continues to hamper attempts to extend the working life. Moreover, low-paid, unskilled workers bear the brunt of economic downturns, and older workers in these sectors of the labour market are particularly vulnerable. Unemployment and more generally the replacement of secure life-time jobs by insecure poorly paid work affects workers of all ages, with consequences for family life and intergenerational relations. Parents who financially support children in their passage to adulthood and beyond have lower margins to save for retirement. Political backdrops also influence the tactics used to extend the working life. In countries whose welfare systems are based on the principle of social solidarity, such as France, the mutualisation of risks still plays an important role in reducing poverty in old age and redistributing income. Where political ideologies tend to focus more on individual responsibility and redistributive mechanisms are weak, such as in the United Kingdom (UK), certain individuals are more exposed to the risk of poverty in old age. 
This book deals with two specific aspects of the empirical landscape of extended working life policies, namely gender and health. Although there are diverse perspectives to extended working life, gender and health consistently prevail as key dimensions. To date, policies extending the working life have not, for the most part, taken sufficient account of these two dimensions. A clear example in the case of gender concerns the shift towards equality in retirement ages between men and women. Many countries used to have lower retirement ages for women but have, over the years, raised women's retirement age to the same as men, sometimes very quickly. Such is the case in the UK, where in 1995 the government brought in measures to increase the retirement age of women from 60 to 65 (the retirement age of men) between 2010 and 2020. Some countries still retain a gender gap in retirement age. In Bulgaria, the statutory pension age in 2017 was 64 years for men and 61 years for women (OECD 2018). These gender gaps in retirement age can affect women in different ways. On the one hand, allowing early access to a non-contributory publicly funded pension for women can be a socially protective measure against poverty. On the other hand, the shift to defined contribution pensions and the requirement to increase the length of working life for pension eligibility can have adverse consequences for women. Women are still more likely than men to have career breaks for bringing up children as well as subsequently facing difficulties in re-entering the labour market (Blackburn et al. 2016). Under these conditions, even with gender parity in retirement ages, many women may be obliged to work past retirement age to secure an adequate income in old age. Furthermore, 'quick' changes to parity in pension ages means that women who planned their adult working lives with an earlier pension age in mind have little time to adjust to the new reality of being compelled to work longer for the level of benefits they initially expected to receive.

As far as health inequalities are concerned, large differences exist among populations both between and within countries. Life expectancy at age 65 years is under 15 years in Lithuania, Latvia, Hungary and Romania, whereas it is 19 years or above in Spain, Switzerland, France and Iceland (Eurostat 2019a). Within the UK, large regional disparities exist, with as much as 10 years life expectancy at birth differences for men. Men in Glasgow can expect to live until the age of 73.4 years compared to 83.4 years for their counterparts in the London borough of Kensington and Chelsea (Office of National Statistics 2016). A number of factors have been identified as plausibly being responsible for the excess mortality, and consequently lower life expectancy, in the northern regions of England. These include socioeconomic, environmental (including working conditions), educational and lifestyle factors (Hacking et al. 2011). Certain types of occupation and working environments increase significantly the risk of ill health and reduce the capacity of individuals to extend their working life. The health dimension of extended working life should therefore be a major preoccupation for many countries, both in terms of ensuring social justice regarding early pension eligibility criteria for those workers exposed to lifelong hazardous working conditions as well as promoting safer working environments and wellbeing in the work place to encourage older workers to remain in the labour force. 
The two dimensions of gender and health therefore interact and present specific challenges for policies that aim to extend the working life. Importantly, the higher life expectancy of women compared to men and the fact that women spend longer time in retirement than men incorporates both the gender and health dimensions of extended working life. A longer life expectancy for women has consequences for income in old age, especially bearing in mind higher rates of poverty among older women compared to men. More than $20 \%$ of women aged 65 and above are at risk of poverty or social exclusion in the EU, compared to $15 \%$ of men aged 65 and above (OECD 2018). Access to health care for these women can pose a major problem, especially given that women are more likely to experience incapacities in old age than men (Fouweather et al. 2015). Whether health care is affordable and accessible depends, in part, on income adequacy and given the disadvantaged position of women compared to men regarding levels of retirement income, gender and health interact in the context of extending the working life. Access to health care is just one example of where gender and health interact, but there are many more instances linking the different lifecourses of men and women in the public and private spheres to health outcomes (Crimmins et al. 2011; Oksuzyan et al. 2008).

The book is divided in two parts, with all the chapters confronting the gender and health dimensions of extended working life by providing key information and details on how men and women are currently experiencing the end of their careers and how policy measures affect men and women differently in terms of their current and future health. In this first chapter, we set the stage by presenting the empirical and policy landscapes that characterise the trend of extended working life. Chapter 2 explores the processes that lead to increased social insecurity and inequality, relating changes within the organisation of work to wider political and economic developments in both national and international contexts. Chapter 3 provides an overview of relevant quantitative data sets from which the effects and potential consequences of extended work life can be systematically analysed, focussing on publicly available data for people aged 50 years and above that contain gender-sensitive measures and indicators for health and socio-economic wellbeing. The fourth chapter documents the importance of policy toolkits for understanding employment and ageing, presenting a conceptual framework that can be applied in different cross-national settings. Part One concludes with a chapter that provides a critical reflection on problematic and promising trends associated with extending working lives and highlights trajectories for future research and potential policy directions. Part Two of the book features 32 country-specific chapters, with each providing up-to-date information on current issues relating to extended working life as it plays out in specific national contexts.

In this first chapter of Part One, we begin by focussing on the different meanings of 'extended working life' and explore the discourses that are activated to promote it. 


\section{The Semantics of Extended Working Life}

'Extended working life' can be understood in several ways and there is considerable debate concerning the indicators used to justify working longer. As we have seen, perhaps the most common interpretation of 'extended working life' is the later age at which an individual becomes eligible for a pension. Extended working life in this sense thus distinguishes clearly between paid work and retirement, and the focus is on lengthening the years in employment prior to retirement. In this context, 'extended working life' has been a key component of the active ageing agenda, and many countries have placed extended working life at the centre of active ageing policies (Boudiny 2013; Walker 2006). 'Extended working life' is thus advocated as a key to the sustainability of pension systems, an adjustment to the increasing ratio of the retired population aged 65 and above to the working-age population (European Commission 2018a, b).

Policies that have been implemented to extend working lives with the goal of reforming pension systems include raising retirement ages, increasing the number of required years of pension system contributions during the working life to qualify for benefits and, importantly, closing exits to early retirement. Regarding the latter, it is astonishing in many countries to see how hastily policies that once promoted early retirement have been reversed. From being widely promoted in the 1990s as a lever to combat unemployment, early retirement schemes have all but vanished in the space of a few years in most countries. As can be seen in the Dutch chapter, measures such as the VUT regulation (Vervroegd uittreden, literally: early exit) once 'offered generous possibilities of exiting the labour market around age $60 \ldots$ providing older workers with an income of about $70-80 \%$ of their last monthly wage'. Only a few years later, from the beginning of the 21 st century, such early retirement mechanisms were anathema to successive governments struggling to grasp the financial implications of ageing populations. By 2018, most countries had implemented measures whereby the level of pension income is rewarded by delaying retirement past the full or normal retirement age and penalised through earlier retirement (European Commission 2018a, b). Within active ageing agendas that are orientated towards extending the working life, some emphasis is also placed on policies that seek to improve working conditions (Wainwright et al. 2019; Burnay 2019) and to ensure the training and re-training of workers (Lössbroek and Radl 2018; Phillipson and Ogg 2010). Extending the duration of working lives before retirement is therefore seen as an effective measure to sustain pension systems fiscally in the face of demographic ageing. A further aim of policy objectives is to ensure that extending working lives prior to retirement will also result in higher levels of pension income, thus addressing the question of income adequacy in old age. However, as detailed throughout this book, there are good reasons for concern that this objective of higher or more secure old age incomes will not be achieved universally.

In 2010, the European Commission set a target that $75 \%$ of the population aged 20-64 should be in employment by 2020 (Europe 2020 Monitoring Platform 2019). Given very different national labour markets, it was clear that such a target was, 
inevitably, globally unachievable, and it can be interpreted as another example of a 'one size fits all' policy. Figures 1.1 and 1.2 show the employment rates of men and women respectively for the 55-59 and the 60-64 year age groups for the European countries that are included in this book. In the age group 55-59, several countries already have employment rates at or above $75 \%$ for both men and women: Iceland, Switzerland, Czech Republic, Sweden, Germany, Denmark, Norway and Lithuania. Greece and Croatia are two countries where rates are lower than $60 \%$ for both men and women, and where labour market conditions seem unlikely to provide a foundation for $75 \%$ participation to be a realistic goal. By and large, EU employment rates in the 55-59 year old group are higher for men than for women. There are exceptions to that pattern, mainly to be found in countries that were formerly part of the Soviet Bloc: Lithuania, Estonia Latvia and Bulgaria (Finland is the fifth country in the Figure where employment rates are higher for women than for men in the 55-59 year age group). These relatively high rates of women's employment could be explained by the fact that this generation of women under state socialism had to work, either for economic or political reasons.

Employment rates in the age group 60-64 show wide variations. Apart from Iceland, where rates are only slightly lower than in the age group 55-59, all countries have lower employment rates in this older age group. Large decreases in labour force participation for individuals age 60-64 are found in France, Belgium and

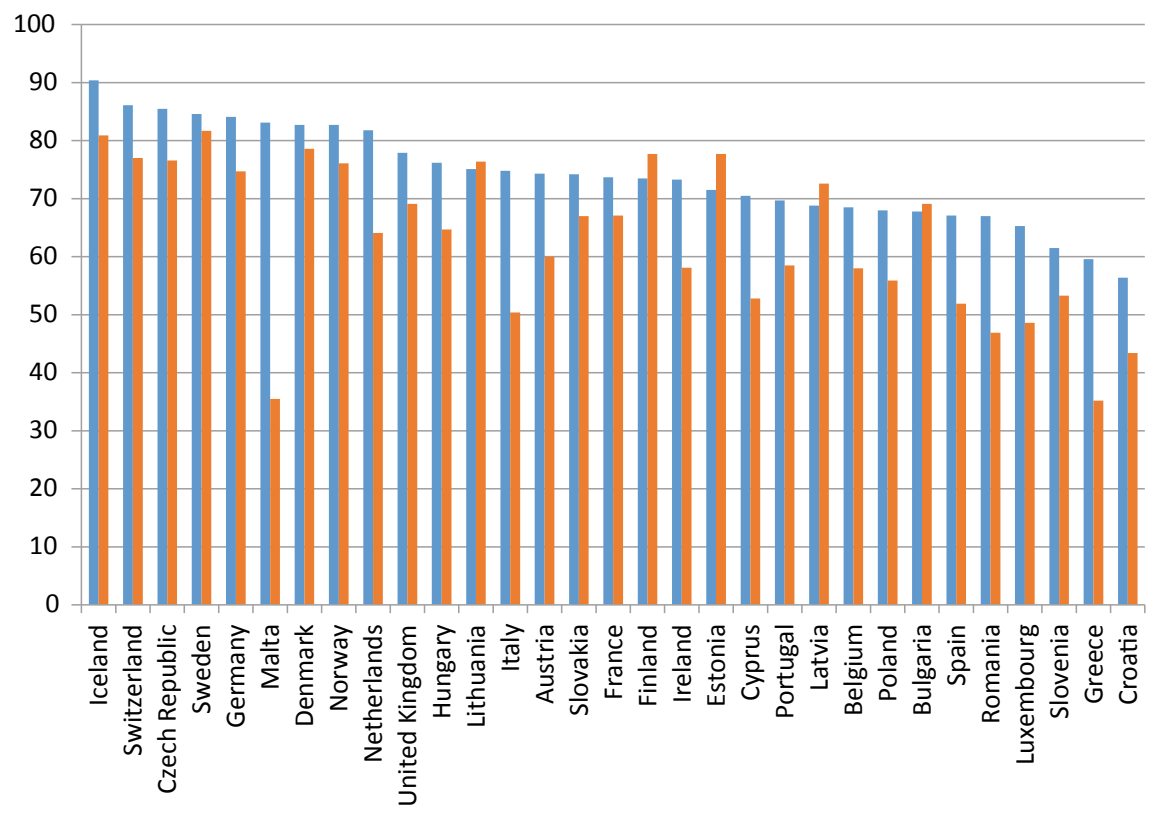

Men 2016 Women 2016

Fig. 1.1 Employment rate 55-59 year age group (\%). Source Eurostat (2019b) 


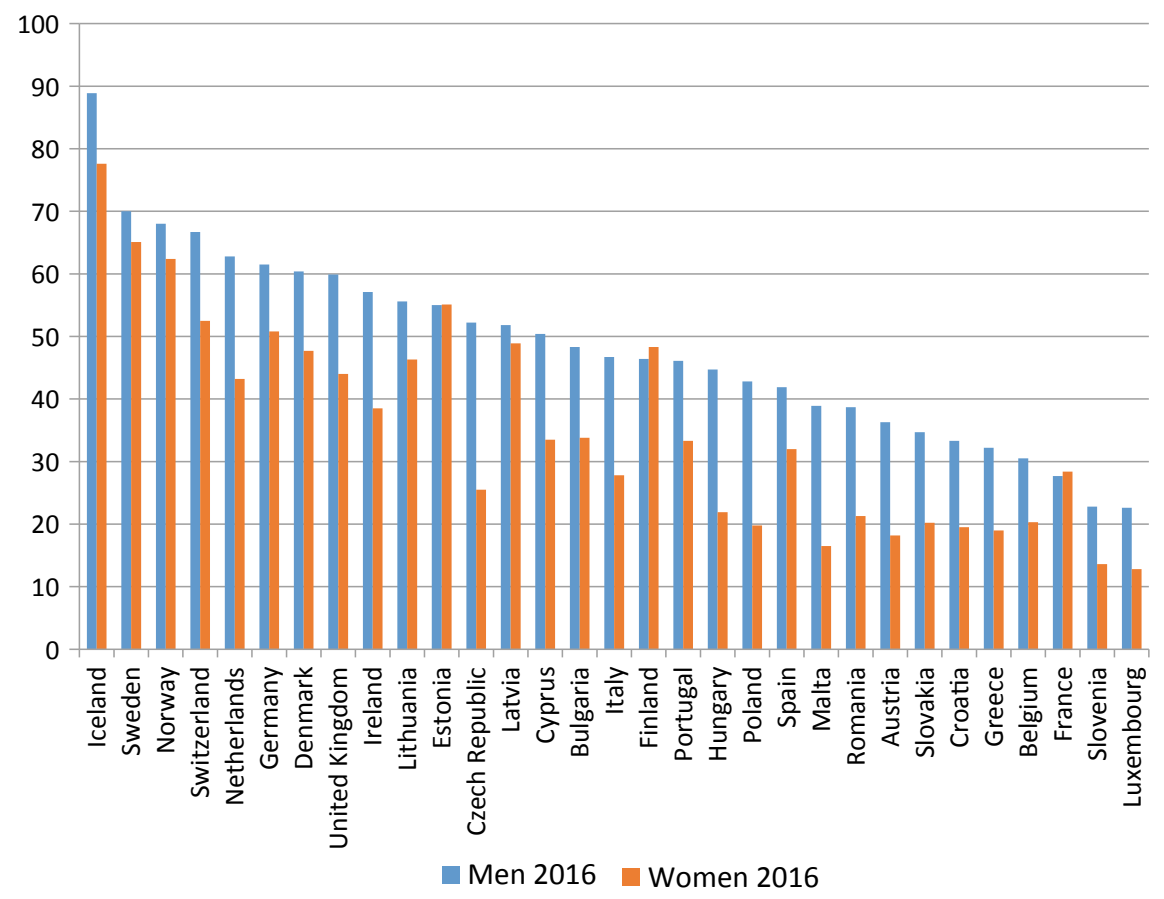

Fig. 1.2 Employment rate of 60-64 year age group (\%). Source Eurostat (2019b)

Luxembourg. In some countries where the gender gap in employment rates was slight in the age group 55-59, it widens moderately or substantially in the 60-64 year age group (Czech Republic, Bulgaria, Denmark and Lithuania) with higher employment rates for men. In yet other countries where gender equality is more pronounced, such as Sweden, Denmark and Finland, there is more gender parity in employment rates in both the age groups 55-59 and 60-64.

For the non-European countries presented in this book, extended working life has become increasingly the norm since the beginning of the 21 st century. Australian men and women have high rates of labour force participation in the age group 60-64 (in 2015, 64\% and 46\% respectively, cf. Australian chapter) and high rates of older worker participation exist also in New Zealand (cf. New Zealand chapter); a large majority of Chilean men in the age group 60-64 participate in the labour force (in $2015,80.6 \%$ of men compared to $37.6 \%$ for women, cf. Chilean chapter); in Israel, the majority of women in 2017 (52.3\%) were in paid employment (cf. Israeli chapter). In Turkey, labour force participation for women in the 60-64 age group is relatively low (in 2017, 16.5\%, whereas for men the respective figure was $45.8 \%$; cf. Turkish chapter).

Figure 1.3 shows clearly the rise in the average retirement age that has been occurring since the year 2000 . 


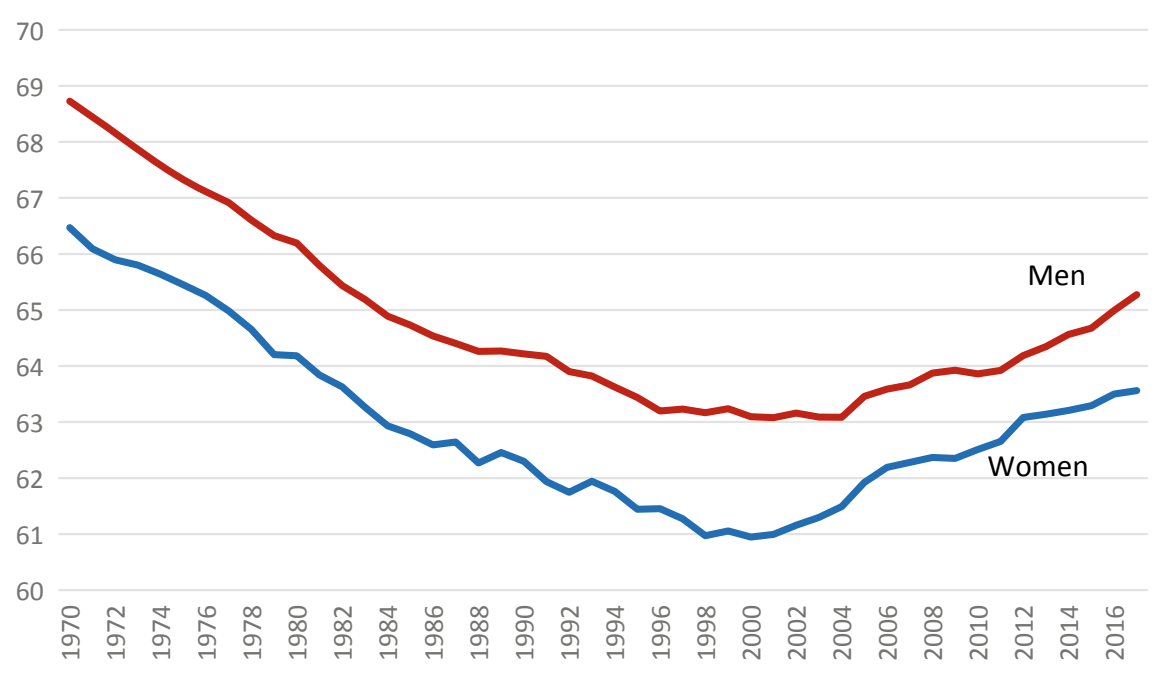

Fig. 1.3 Effective retirement age, OECD average. Source OECD (2019)

As countries raise the statutory retirement age, the two age groups of 55-59 and 60-64 generally capture that period of the life course where retirement is either no longer possible or penalised in cases of early retirement. According to the OECD, in some countries...the penalty for early retirement is severe and can lead to a pension suspension until the minimum conditions are met (age and/or seniority)' (OECD 2018: 115). Yet 'extended working life' can refer not only to that period of the life course before retirement, but also paid work beyond pension age (Scherger 2015). Many countries have introduced policies that encourage individuals to work beyond the statutory retirement age. These measures can take different forms. For example, in France, le cumul emploi-retraite, which allows a retired individual who receives a state pension to receive also an income from paid employment and la surcote, which increments the value of a pension for workers who have paid full insurance contributions and who continue to work past the legal age of retirement. According to OECD data (2014), the proportion of the population of individuals aged 65 years and above in paid work in 2012 varied from around $5 \%$ to $25 \%$ in OECD countries, figures which both indicate the extent of the phenomenon as well as suggesting different causes and national trends.

Generally, higher proportions of men than women continue to work past retirement age (Eurofound 2012) (Fig. 1.4). Working past retirement age can be due to a combination of individual, workplace level, institutional and structural factors. In general the evidence suggests that there are two broad categories of workers who remain employed beyond retirement age - those who need to work for financial reasons and those who do so for self-fulfilment. For example, the results of a recent French study on individual motives for working past retirement illustrate the polarity that is found in many countries. For most people, the reasons for working past retirement age are primarily financial. The exception is for those individuals in higher 


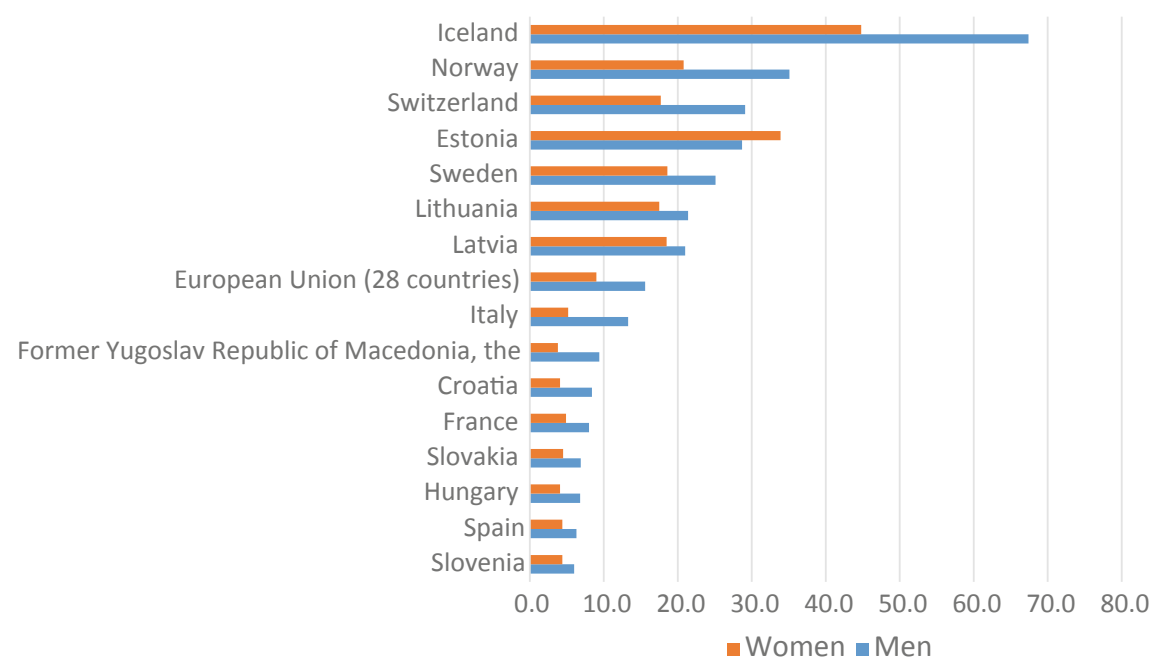

Fig. 1.4 Employment rates (\%) by gender in age group 65-69 years. Source Eurostat (2019b). Last extract 19/12/2017

income groups who cite interesting jobs and good quality work environments as the primary motives for remaining in work (Grosbois and Henry 2018). Moreover, it is possible that higher proportions of workers who are compelled to work beyond retirement age are disproportionately clustered in countries with weaker social protection and welfare schemes, such as Estonia, where employment rates in 2016 for the age group 65-69 are 34\% and 29\% respectively for women and men (Eurostat 2019b). As Unt et al. in the chapter on Estonia explain, 'the relatively low replacement rate of old-age pension makes staying in employment even after reaching the pension age an economic necessity for many older persons'. In the USA, a main objection to imposing mandatory retirement was 'to encourage those with modest pensions to continue working' (Lain 2015).

From a critical perspective, it has been argued that retirement has become a fragmented institution and that 'extended working life' is not an adequate term to capture the different pathways from work to retirement (Phillipson 2018). Seen from this standpoint, extended working life is not simply an opportunity for individuals to remain active and to contribute to national economies, but a response driven by neoliberal ideology to dismantle welfare states and even the institution of retirement itself. Thus the very notion of 'retirement' could be losing its denotation as a time during which a secure income is received based on paid work earlier in the life course, only to be replaced by insecure jobs and individual responsibility to secure income in old age. Given the failure of most governments to deal effectively with preventing economic crises, the delocalisation of labour, and the insecurity that increasingly characterises jobs at the beginning of the twenty first century, this is an important perspective from which to understand the discourse and processes of 
'extended working life.' This conundrum is taken up by Clary Krekula and Sarah Vickerstaff in Chapter Two.

Different interpretations of the meaning of 'extended working life' illustrate the complexity of the concept as well as challenging the assumption that working longer is inevitable. Indeed, 'the unavoidable obligation' of extending working lives has been questioned by demonstrating how different sectors of the UK population experience working longer and the need to consider flexible working hours and phased retirement as part of an overall policy approach to ageing populations (Vickerstaff 2010). Taking a much longer stance than the end of a working career, some commentators have suggested that it is the current paradigm of the life course that needs changing. The objective then becomes the goal of 'fuller' rather than 'extended' working lives (Phillipson 2018). One novel proposition concerns 'a reorganization of the life course that keeps the separation of preparation, activity and leisure, but alters the duration of these periods and multiplies their sequence' (Kunemünd and Scherger 2015: 311). In this framework, time sequences of adulthood would consist of periods of flexibility (career breaks, training, and leisure opportunities) throughout the life course in the context of social regulation protecting more vulnerable citizens. Kunemünd and Scherger argue that in addition to diminishing stress levels that are currently linked to continuous employment during adult life, career breaks would help women who could have more success re-entering the labour market than under current conditions. The notion of 'extended working life' would in turn lose its meaning as a term applied to the end of working careers.

\section{Addressing Gender and Health Inequalities}

Extended working life poses specific challenges for gender and health inequalities. In this section, we address the issues relating to gender pay and pension gaps together with the health implications of working in later life.

\section{The Gendered Dimension of Extended Working Life}

Although the gender gap in employment incomes and pensions has been a persistent feature of all countries, recent trends raise concern. Figure 1.5 shows that between 2014 and 2017, the gender pay gap narrowed in many countries, but increased in some (e.g. Portugal, Lithuania, Croatia). Financial crises, past and ongoing, adversely affect women since they are more likely than men to be employed in the temporary, low-skilled and part-time jobs that result from economic downturns. In addition, strong normative expectations concerning gender roles are reinforced by public policies with the result that the combination of paid and unpaid (family) work for women means 'that their earnings and later-life financial security have not, so far, kept pace 


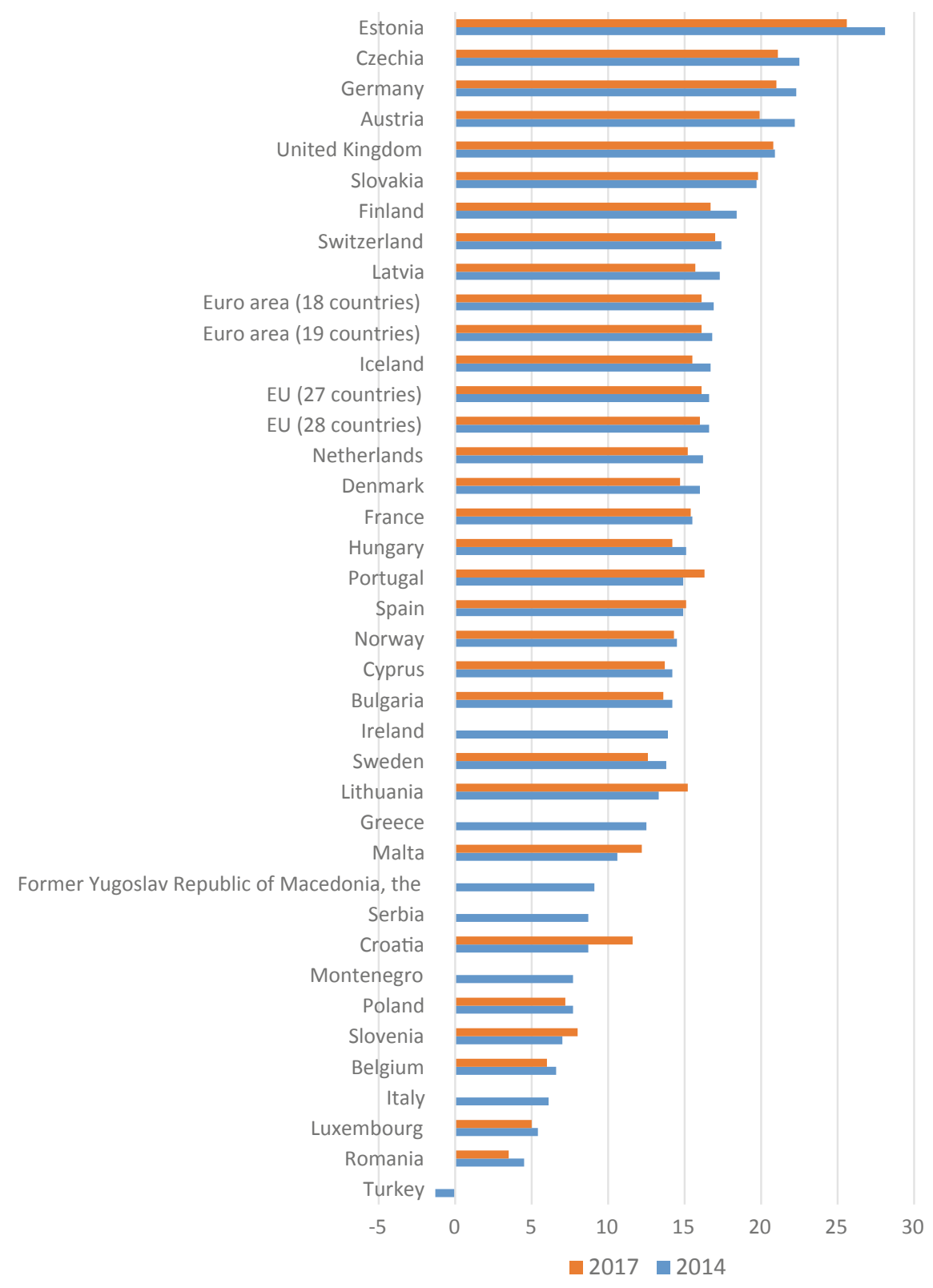

Fig. 1.5 Gender pay gap, \% of average gross hourly earnings of men. Source Eurostat (2019b). The indicator measures the difference between average gross hourly earnings of male paid employees and of female paid employees as a percentage of average gross hourly earnings of male paid employees 
60

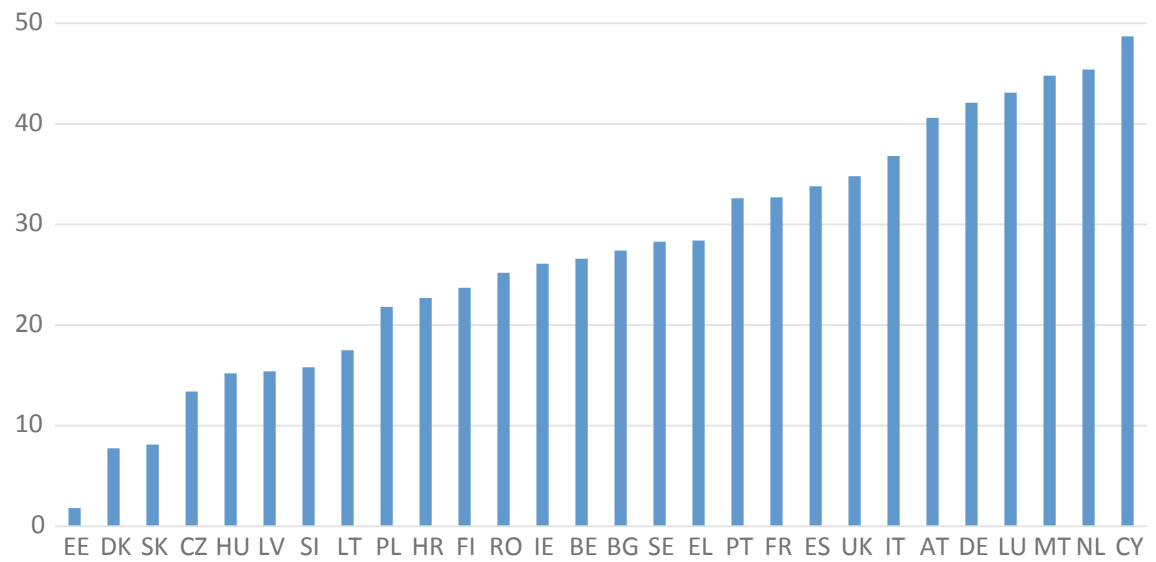

Fig. 1.6 Gender gap in pensions, pensioners aged 65-79, 2016; \%. Source Eurostat, EU-SILC. Notes 2010 data for HR; data sorted by data for 2016. Pensions at a Glance, Vol. 1, 2018, p. 68

with men's' (Street 2017: 11). For example, in the Czech Republic, it is very common for women to withdraw from the labour market during the first years of each child's life (2-3 years) thus decreasing their pension contributions. In countries where child care continues to be predominately undertaken by women (see, for example, chapters on Italy and Germany) gender pension gaps are large (see Fig. 1.6). Furthermore, these gendered patterns of childcaring are also shaped by the availability of affordable child care facilities. The Netherlands provides an example. Dutch women enter the labour market, on average, later than many other European counterparts in part because of limited support for working parents (Thévenon 2011). Young mothers tend to stay at home to look after pre-school children and although this does not influence their state pension because of the universal, flat-rate character of Dutch pensions, it does significantly affect occupational pensions and individuals saving accounts, as can be seen in the high gender pension gap that is present in the Netherlands (Fig. 1.6). Achieving comparable pension income levels as men under these conditions would entail working longer than men. The situation is similar for women from the Czech Republic. Although there are credits to the pension system for labour-market absences during periods when caring for children up to four years old, occupational defined contribution pensions work to the disadvantage of Czech women whose child care responsibilities keep them out of the labour market earlier in the life course.

Marital and partnership status are also associated with extended working life. Married women are less likely than married men to be employed and more often cite family responsibilities as their most important reason for not working (Majeeda 
et al. 2015; Office for National Statistics 2013). The gendered employment disparity at older ages is partially the result of the coordinated retirement decisions and the fact that men typically marry younger women, reinforced by the heavier caregiving commitments of women for older family members. Traditional gender roles within couples-men as 'bread-winners', women as 'home makers-influence patterns of extended working life, although there is not necessarily a simple pattern where husbands 'lead' and wives 'follow'. Radl and Himmelreicher (2014) have examined retirement behaviour by means of event-history models, with a competing risks framework that distinguishes voluntary and involuntary work-exit transitions. The results show that spousal labour market participation plays a large role in work-exit transitions, even when retirement is involuntary. This finding questions the widespread belief that co-retirement is exclusively due to a preference for joint retirement shared among spouses. Moreover, widows and widowers tend to retire early in Germany, whereas no such pattern is found in Spain.

In a study by Pleau (2010) using American data from the Health and Retirement Study, re-entry in post-retirement employment for women was negatively associated with being married and having a high level of household wealth whereas for men, wealth had the opposite effect. Divorced and separated women had a greater likelihood of labour force re-entry in the post-retirement period than married women and the difference between married and divorced/separated women increased with the length of time out of the labour force, suggesting the presence of push factors for divorced and separated women that derive from economic vulnerability.

Finally, inequalities experienced early in the lifecourse can affect men and women differently in terms of later life outcomes. In a study by Hoven et al. (2018) where data from the Survey of Health, Ageing and Retirement in Europe (SHARE) with retrospective life history data on 5,857 older men and women across 14 countries were analysed, early adversity was linked to full-time employment over the lifecourse ending in retirement at age 60 or earlier. Their conclusion was that histories of employees with early retirement and discontinuous histories are part of larger trajectories of disadvantage throughout the life course, supporting the idea of cumulative disadvantage in life course research.

As far as pensions in the EU 28 are concerned, the gender gap ${ }^{1}$ ranges from 1.8 to $48.7 \%$ with an average of $37.2 \%$ for the individuals in the age group 65-79 (OECD 2018: 69). Recent trends (Fig. 1.6) suggest that 'while slight decreases in gender gaps in pensions have been observed in the EU on average since the crisis, the gaps remain almost stable, in many countries, including in those where it is highest' (OECD 2018: 70).

\footnotetext{
${ }^{1}$ The gender pension gap represents the difference between the average pre-tax income received as a pension by women and compared to men.
} 


\section{The Health Dimension of Extended Working Life}

It is common to find in policy documents on extended working life the claim that the general improvement in the health of older populations allows increased labour force participation (cf. OECD 2018). Up to a point, this is true. Improvements in medical treatment, healthier lifestyles, and improved health and safety conditions at work have permitted many individuals to remain at work in better health for much longer periods than their predecessors 50 years or more ago. However, in some employment sectors, workers are still exposed to hazardous conditions or long hours of arduous work that take a toll on their health and reduce significantly the capacity to extend their working lives. The inequalities in health that are systematically related to social class and which are present throughout the lifecourse also adversely affect the ability of certain individuals to work longer. Many workers in ill or declining health therefore leave the labour market early, passing into an administrative transition period of disability or unemployment before moving into retirement. Others in a similar state continue to work, but with little chance of improving their health. In a UK longitudinal study for example, it was unequivocally demonstrated that poor working conditions and hazardous occupations impact negatively on the health of workers who prolong their working lives (Matthews and Nazroo 2015).

An important component to the health dimension of extended working life is the measure of healthy life years (also called disability-free life expectancy) which is defined as the number of years that a person is expected to live in a healthy condition. Figures 1.7 and 1.8 show the healthy life years expectancy at age 65 for women and men among the EU-28 countries and once again large difference can be observed.

In addition to healthy life years disparities, it should be noted that new illnesses, particularly relating to psychological stress, are appearing in working populations, which also pose a major challenge to advocates of extended life policies. Quality of

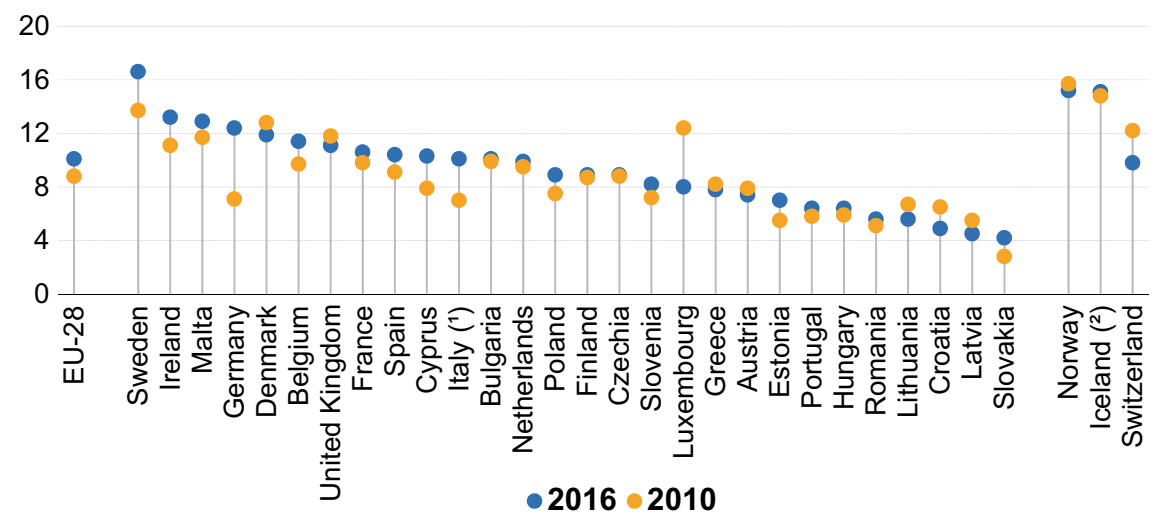

Fig. 1.7 Healthy life years in absolute value at 65-women (2010-2016). (1) 2011 instead of 2010. (2) 2015 instead of 2016. Source Eurostat (online data code: hlth_hlye) 


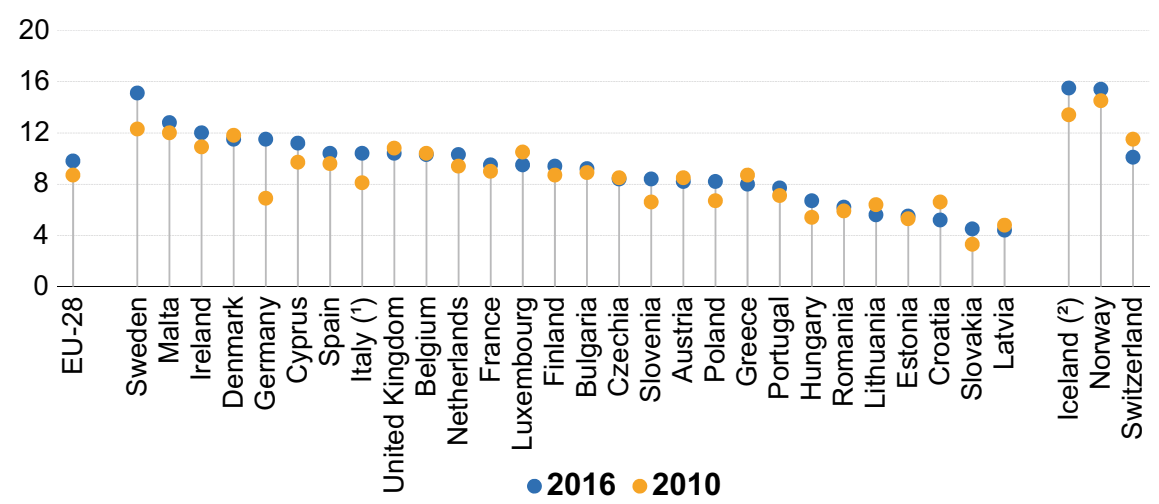

Fig. 1.8 Health life years in absolute value at 65-men (2010-2016). (1) 2011 instead of 2010. (2) 2015 instead of 2016. Source Eurostat (online data code: hlth_hlye)

life in the workplace has, or is, becoming a major issue for most countries. More research is needed to establish the link between working conditions and extended working life, but mention should be made of two important models in occupational health care that measure the quality of working conditions. The first is The Job Demands-Resources (JD-R) model (Bakker and Demerouti 2007; Demerouti et al. 2001) which can be used to predict employee burnout and engagement, and consequently organisational performance. At the heart of the JD-R model lies the assumption that whereas every occupation may have its own causes of employee wellbeing, these factors can be classified in two general categories (i.e., job demands and job resources), thus constituting an overarching model that can be applied to various occupational settings, irrespective of the particular demands and resources involved. Such a model might also serve for policies makers to define different conditions for retirement for different occupations. The second model is the Work Ability Index (Ilmarinen 2007) which takes into account the demands of work, the worker's health status and resources in relation to their length of employment and occupational status. These and other measures of the quality of working conditions that take into account differences across occupations will be an important part of an increasingly multi-disciplinary research approach to extended working life.

\section{Labour Market Influences on the Employability of Older Workers}

Prospects for extended working life are inextricably linked to changing conditions in the labour market, particularly in response to globalisation and competing economies. One important aspect of changing labour markets is the demand by employers for greater flexibility in terms of employment contracts and number of hours worked. 
Sociologists engaged in social stratification research have paid attention to the adverse effects of globalisation and the growing demand for flexibility (Blossfeld et al. 2015). Social stratification processes are disproportionately experienced by the most vulnerable groups in labour markets. Workers in low status jobs, with low skill levels and human capital endowments are increasingly exposed to rising employment instability and income insecurity (Blossfeld et al. 2005, 2015; Breen and Goldthorpe 1997; Scherer et al. 2004) and by extension, barriers to pensionbuilding. Many unskilled workers are entrapped in low-quality and 'dead-end' jobs with little prospect of changing their jobs. This has been referred to as the 'scarring thesis' which explains the experience of unemployment or employment in low-level jobs as being partly the result of flexibilisation, which has an enduring negative effect on the worker's future career in terms of employment stability and earnings (Booth et al. 2002; DiPrete et al. 1997; Gangl 2003, 2006; Golsch 2003; Kalleberg 2000; Muffels and Luijkx 2008).

Despite the negative effect of unemployment or low level employment on the life courses of many workers, the demand by older workers, particularly women, for jobs with flexible working hours has been steadily increasing in many EU countries, notably Australia, Belgium, Denmark, Finland, Italy, Lithuania, Netherlands, New Zealand, Portugal, Slovakia, Spain, Sweden and the United Kingdom. In some countries the flexibility of the labour market more broadly has also been increasing since the mid 1980s, and in recent years due to the growth of the 'gig' economy, characterised by short-term contracts and freelance work. In periods of economic growth, the offer of part-time jobs increase, but then seems to decline in economic downturns. On the one hand, some researchers suggest that an increase in flexible job offers has a negative impact on the chances for older workers of finding work (Blau and Shvydko 2007; Muffels 1998). On the other hand, traditional rigidities in the labour market (such as a lack of opportunities for part-time employment) impose restrictions on job opportunities for workers of all ages and not only older workers. In addition, some older workers may welcome the opportunity to work-part-time (Burnay 2019).

As the data in Fig. 1.9 suggest, there is a weak positive correlation between the employment rate of older workers and the degree of flexibility in the labour market as measured by the Fraser Institute indicators. Those indicators show the degree of labour market regulation concerning minimum wage, hiring and laying off, degree of collective bargaining centralisation, working hours, lay-off related costs and mandatory contributions (a higher rate means less regulation). In general, a more responsive labour market favours labour market participation for older workers. However, not all regulations have the same effect, although high employer costs related to laying off and long working hours appear to have the most significant negative impact on the employability of older workers.

Another important aspect of labour-market flexibility that could contribute to extending working lives, especially for persons with health problems, is the possibility of working from home. High work-from-home rates can be observed in western European countries such as Luxemburg, Austria, and the Netherlands, and in general in other northern European countries. These trends are associated with weaker 




Fig. 1.9 Labour market flexibility and employment rate of older workers. Source (Breinek et al. 2018; Eurostat 2017) data base, Fraser Institute (2016)

industrial economies and higher service economies. The traditionally heavy industrial countries such as the Czech Republic, Hungary, Poland, Slovakia, and Germany have only moderate rates of work-from-home (Breinek et al. 2018).

\section{Older Workers in the Era of Digitalisation}

The current era of digitalisation in the work place (referred to as 'Industry 4.0') is characterised by a general trend towards a knowledge society in which production, services, and administration are information driven and computer oriented. This process results in less labour-market rigidity and the loss of certain jobs, both of which are a major feature of the 4.0 revolution. How the Industry 4.0 trends contribute to the challenges and potential of extended working life are only just now being considered. New labour organisation principles are being introduced whereby employees and employers need to adapt and transform; new skills are required which in turn will have an impact on employment rates. As a consequence, labour market, education, and social welfare policies will need to take account of these transformations and ensure that both workers and employers are equipped to deal with the consequences of digitalisation in the work place.

How is work changing in the digital economy? According to the Federal Minsitry (2015), 54\% of workers in Germany used a computer with an internet connection in their work in 2014. It is not only in offices that digital work is becoming the norm; in factories, too, the use of computerised, interconnected machines is widespread. Almost a quarter of production is already fully or highly automated in Europe today. Digital work also makes possible a wider range of working arrangements, such as 
telework, and new forms of work, such as crowdworking (Re-imagining work, Green paper, Work 4.0 2015). Crowdworking is the process of distributing work, generally broken down into smaller tasks, to crowdworkers via digital platforms. The work can be given either to a company's own employees (internal crowdworking) or to third parties (external crowdworking), who are often solo self-employed individuals working for many customers worldwide (https://www.deutschland.de/en/topic/ business/crowdworking-in-germany-working-life-of-the-future).

The impact that automation and robotics will have on jobs and incomes, particularly with respect to potentially vulnerable groups in the labour market such as older workers, remains unknown. Some trends indicate that automation can cause labour-market polarisation not just in terms of the demand for qualifications, but also in terms of the level of wages. Demand may be channelled into specific qualification requirements at extremes, that is, for either low-skilled or high-skilled labour. This trend has already begun in the USA (Frey and Osborne 2013), although as Hall and Soskice (2001) note, it is associated more with non-regulated economies than, for example, in Scandinavian countries or the Netherlands where job protection policies are more widespread. Releasing middle-skilled and some high-skilled workers from professions that can be automated or implemented with a lower number of workers into jobs that require only low skills can result in wage polarisation, thus weakening the middle classes and leading to the risk of destabilising society.

This tendency can also be accentuated by the transfer of the middle-skilled labour force from industrial to service sectors where salaries tend to be lower. A loss in income can also result when low-skilled workers compete with better and larger middle-skilled work force more flexible to do any job. As a result, low-skilled workers may have to take even lower-level odd jobs or be pushed out of the formal labour market entirely.

It will be important to react quickly to the trends atrophying middle-range skilled jobs by creating an environment that encourages the take-up of training by older workers. Older workers can then keep abreast of technology advances to improve their career opportunities. This would increase employment rates and limit the polarisation of wages. Informal methods of learning and education also can play an important role and often they lead to quicker positive results than formal methods (Industry 4.0 impact on the CR labour market 2017).

In the final report on an EU digitilisation/job quality study by Ghailani et al. (2018), the impact of digitalisation on the health of workers, both physical and mental, was a key issue. In terms of physical health, vision problems as a result of the intensive use of computers, but also musculoskeletal disorders such as tendinitis or back problems caused by prolonged immobility, were prominent. Reduced physical activity-less need to move around - following the digital transition can also generate cardiovascular problems linked to a risk of increasing obesity. Several respondents also reported an increase in physical fatigue. The digitalisation of work is also perceived by public employment service workers as having significant implications for mental health. They point to the higher incidence of stress, caused by an increased workload and changes in the organisation and pace of work. As a result, there is a high exposure to psycho-social pathologies, such as depression, mental exhaustion 
or burnout. Among the psycho-social risks, the issue of harassment resulting from interaction with users is the subject of contradictory positions in terms of physical and mental health. For other workers, the transition to digital working has led to an increase in digital harassment, particularly because users expect faster reactions and faster processing of their files when using digital tools. While physical harassment has decreased, there has been an increase in virtual harassment (Ghailani et al. 2018, p. 32).

The new era of digitalisation could increase gender inequalities, especially for older women in precarious jobs. The link between gender, precarious work, education, and digitalisation has been well demonstrated. The European Institute for Gender Equality (2017), EIGE provides some insights from its work on the gender aspects of digitalisation. Science, technology, engineering and mathematics (STEM) are the most gender-segregated subjects in the education system. Over the past decade, the percentage of women graduates in STEM subjects in the EU has decreased, from 23 to $22 \%$. This gender division is mirrored in the labour market, where the share of women in STEM occupations is $14 \%$, with almost no change over the past decade. These gender divisions across ICT workplaces indicate that the ability of women to enter and stay in ICT jobs is dependent on the critical mass of women who are already there. The proportion of employees in precarious employment decreases with age, up to 55-59 years. Nevertheless, women with low and medium qualifications have a high risk of precariousness throughout their working lives (Fig. 1.10).

Digitalisation will change the demand for labour in many ways and these transformations need to be brought to the attention of policy makers and politicians who are often not aware of the consequences for older workers.

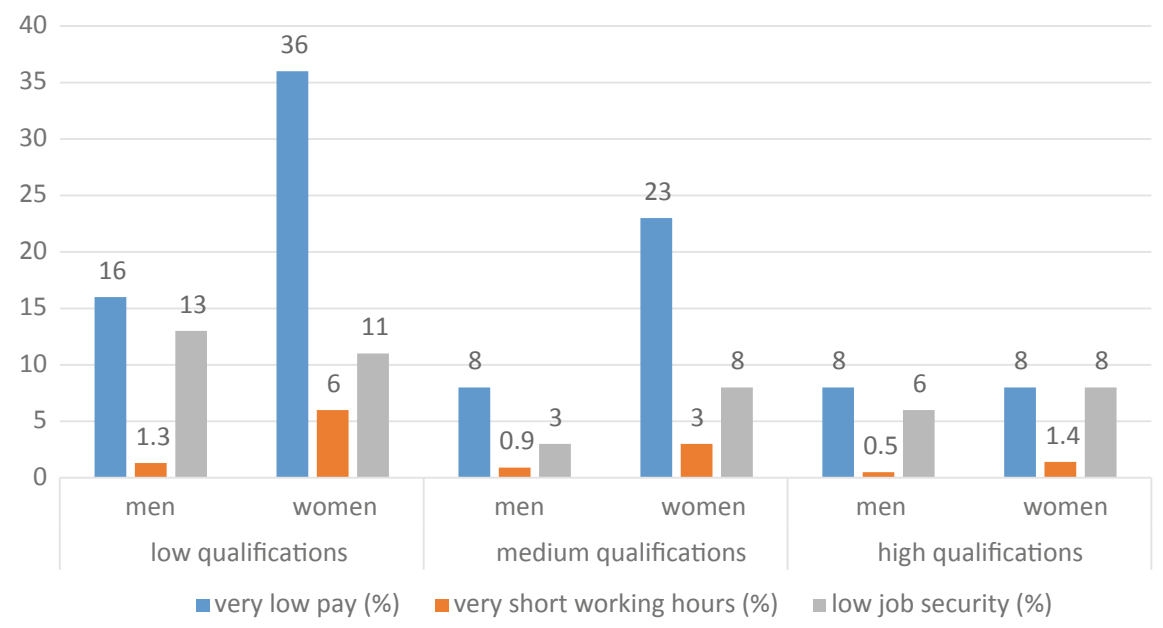

Fig. 1.10 Dimensions of precariousness by gender and educational attainment (15-64, EU-28, 2014). Source Madarova et al. 2017, p. 2018, according to LFS, calculations based on 2014 microdata. Note excluding those whose main status is a student (except for DE and UK due to data availability) 
An analysis of the impacts of such processes on the labour market can be based on previously developed scenarios for particular environments in the European countries.

- In which areas will jobs disappear and in which areas will new ones be created? How can a sustainable high employment rate be attained, particularly in the $50+$ age group?

- What knowledge and skills will be required and how will older workers, especially women, be affected?

- How and where will such knowledge and skills be acquired?

- How can labour and professional flexibility be improved while securing adequate wages and equal access to the benefits of a reasonable social protection network and social insurance across age, gender and different health conditions of employees?

- What changes will be necessary in education, employment, and social policies and what new legislation will need to be implemented that takes into account the particular needs of older workers? (ibid.)

In summary, digitalisation needs to be accompanied by appropriate social changes. Decent, secure and healthy working conditions should be priorities. Innovative policies that involve the participation of older workers in decisions that affect their quality of life in the work place will be needed. Intergenerational perspectives can also play a large part in this process, especially in the informal learning of IT skills and sharing experience. The involvement of social partners to identify ways in which workers can fulfil their individual preferences regarding their working hours, by striking a balance between companies' flexibility requirements and workers' needs, is also a key area to develop.

\section{Labour Force Shortages and Older Workers in Periods of Economic Upturns}

Many European countries have expanding economies but lack an adequate labour forces to meet demand. For example, in 2019, although the average unemployment rate in EU-28 was 6.4\%, rates ranged from $1.9 \%$ in the Czech Republic to $10.2 \%$ in Italy, $14 \%$ in Spain and $18.5 \%$ in Greece (Eurostat 2019b). The demand for a suitably skilled labour force could, in theory, be met by extending working lives for workers whose skills are in demand. Nonetheless, it should be emphasised that in the longterm and particularly with regard to the sustainability of pension systems, policies should move beyond those that address only older workers to a more integrated approach that takes the realities of both labour markets and individual lifecourses into account. According to Lacina (2018) four strategies requiring long-term rather than mid-term solutions can be adopted to deal with labour shortages: increase the domestic birth-rate; import a labour force from abroad; replace human labour by automation; boost work productivity. A fifth strategy which should be also proposed 
is to set up conditions which involve higher numbers of people 50 plus on the labour market, currently the employment rate in EU in this age group is only $58.7 \%$ in 2018.

Attempts to increase the birth rate have been unsuccessful in advanced countries. It is difficult to find incentives - mostly financial ones-in countries with growing standards of living where more children are often perceived as impeding professional career development and opportunities to enjoy rising incomes. Even in the second and third generations of immigrants, who traditionally had larger families than native born populations in the past, birth rates have declined substantially as a result of better standards of living and adaption to the life styles of advanced economies. In Germany, pro-immigration campaigners point to the successful integration of Turkish Gastarbeiters in the 1960s. Central and Eastern European countries evoke the example of the successful integration of the Vietnamese community or Ukrainian workers. However, the integration experience of previous migration waves is hardly applicable today.

As far as an expected breakthrough in applying automation and robotics to industries as well as to services (such as legal services and banking) is concerned, a significant reduction can be expected in the demand for labour. This does not stimulate much confidence that there will be a significant demand for older workers who are expected to work longer, since even the most optimistic forecasts expect reductions in the number of working hours. How will these changes affect the most vulnerable groups of the population, especially working women over the age of 55 with caring responsibilities? Possible answers to this question are likely to be a combination of all the above approaches, although the priorities of economic policy makers will determine the weight assigned to such components at the national level and whether the resulting combination will have a chance to succeed in the context of competing political ideologies.

\section{Concluding Remarks}

The evidence presented in this chapter on how extended work life policies are being implemented in Europe and beyond provides a clear case for governments and employers to address urgently the gender and health inequalities related to working longer. In the following chapters, there are many examples of how this can be done, both at the European level and within national contexts. The challenge ahead is to meet both the needs of individuals who choose to extend their working life and those individuals for whom extended working life poses a constraint to their expected retirement age or worse contributes to negative health outcomes. This will require providing different pathways to retirement and above all, addressing the gender and health inequalities over the lifecourse and throughout the working life. 


\section{References}

Bakker, A. B., \& Demerouti, E. (2007). The job demands-resources model: State of the art. Journal of Managerial Psychology, 22(3), 309-328. Retrieved June 29, 2019, from https://doi.org/10. 1108/02683940710733115.

Blackburn, R. M., Jarman, J., \& Racko, G. (2016). Understanding gender inequality in employment and retirement. Contemporary Social Science, 11(2-3), 238-252.

Blau, D., \& Shvydko, T. (2007). Labor market rigidities and the employment behaviour of older workers. IZA. Discussion Paper No. 2996. Retrieved June 29, 2019 from ftp.iza.org.

Blossfeld, H. P., Skopek, J., Triventi, M., \& Buchholz, S. (2015). Gender, education and employment. Cheltenham: Edward Elgar.

Blossfeld, H. P., Klijzing, E., Mills, M., \& Kurz, K. (Eds.). (2005). Globalisation, uncertainty, and youth in society. London: Routledge.

Booth, A. L., Francesconi, M., \& Frank, J. (2002). Temporary jobs: Stepping stones or dead ends? Economic Journal, 112(480), 189-213.

Boudiny, K. (2013). 'Active ageing': From empty rhetoric to effective policy tool. Ageing \& Society, 33(6), 1077-1098.

Breen, R., \& Goldthorpe, J. H. (1997). Explaining educational differentials: towards a formal rational action theory. Rationality and Society, 9(3), 275-305. Retrieved June 29, 2019, from https://doi. org/10.1177/104346397009003002.

Breinek, P., Franc, A., \& Litzman, M. (2018). Postavení starších pracovníků na trhu práce a strategie politik zaměstnanosti. In M. Rašticová \& M. Bédiová (Eds.), Práce, nebo důchod? Senioři, trh práce a aktivní stárnutí (pp. 31-41). Brno: Barrister and Principle Publishing.

Burnay, N. (2019). Belgian temporary workers at end of working life: An intersectional lifecourse analysis. Ageing \& Society, 1-23. https://doi.org/10.1017/S0144686X18001368.

Crimmins, E. M., Kim, J. K., \& Solé-Auró, A. (2011). Gender differences in health: Results from SHARE, ELSA and HRS. European Journal of Public Health, 21, 81-91.

Demerouti, E., Bakker, A. B., de Jonge, J., Janssen, P. P. M., \& Schaufeli, W. B. (2001). Burnout and engagement at work as a function of demands and control. Scandinavian Journal of Work, Environment \& Health, 27(4), 279-286.

DiPrete, T. A., de Graaf, P. M., Luijkx, R., Tahlin, M., \& Blossfeld, H. P. (1997). Collectivist versus individualist mobility regimes? Structural change and job mobility in four countries. American Journal of Sociology, 103(2), 318-358.

European Commission. (2018a). The 2018 ageing report. Economic \& budgetary projections for the 28 EU member states (2016-2070). Retrieved March 5, 2019, from https://ec.europa.eu/info/ publications/economic-and-financial-affairs-publications_en.

European Commission. (2018b). Pension adequacy reports, vols. 1 and 2. Brussels: DirectorateGeneral for Employment, Social Affairs and Inclusion.

European Institute for Gender Equality. (2017). Gender equality index 2017 measuring gender equality in the European Union 2005-2015. Retrieved March 4, 2019, from file://C:/Users/pc/Downloads/20177277_mh0517208enn_pdf.pdf.

Eurofound. (2012). Income from work after retirement in the EU. Luxembourg: Publications Office of the European Union.

Europe 2020 Monitoring Platform (2019). The Lisbon Strategy in short. Retrieved June 30, 2019, from https://portal.cor.europa.eu/europe2020/Profiles/Pages/TheLisbonStrategyinshort.aspx.

Eurostat. (2017). Employment and unemployment (Labour force survey), database. Retrieved June 30, 2019, from https://ec.europa.eu/eurostat/statistics...php/Employment_statistics.

Eurostat. (2019a). Life expectancy by age and sex. Retrieved March 5, 2019, from http://appsso. eurostat.ec.europa.eu/nui/show.do?dataset=demo_mlexpec\&lang=fr.

Eurostat. (2019b). Employment rates by sex, age and citizenship. Retrieved March 5, 2019, from http://appsso.eurostat.ec.europa.eu/nui/show.do?dataset=lfsa_ergan\&lang=en.

Federal Ministry of Labour and Social Affairs Directorate-General for Basic Issues of the Social State (2015). RE-I MAGINING WORK, Green paper, Work 4.0. Retrieved 
June 30, 2019, from https://www.bmas.de/SharedDocs/Downloads/DE/PDF-Publikationen/ arbeiten-4-0-green-paper.pdf;jsessionid=8F47DE00EC1BD9588FB96936AE44AB7B? blob $=$ publicationFile $\& v=2$.

Fouweather, T., Gillies, C., Wohland, P., Van Oyen, H., Nusselder, W., Robine, J.-M., et al. (2015). For the JA: EHLEIS Team. Comparison of socio-economic indicators explaining inequalities in Healthy Life Years at age 50 in Europe: 2005 and 2010. European Journal of Public Health, 25(6), 978-983.

Fraser Institute. (2016). Economic freedom of the world: 2016 annual report. Vancouver: Fraser Institute. Retrieved June 30, 2019, from https://www.fraserinstitute.org/studies/economicfreedom-of-the-world-2016-annual-report.

Frey, C. B., \& Osborne, M. (2013). The future of employment: How susceptible are jobs to computerisation?. Oxford: Oxford Martin School.

Gangl, M. (2003). The only way is up? Employment protection and job mobility among recent entrants to European labour markets. European Sociological Review, 19(5), 429-449.

Gangl, M. (2006). Scar effects of unemployment: An assessment of institutional complementarities. American Sociological Review, 71(6), 986-1013.

Ghailani, D., Peña-Casas, R., \& Coster, S. (2018). The impact of digitalisation on job quality in European public services. The case of homecare and employment service workers. Final Report. Retrieved June 30, 2019 from https://www.epsu.org/sites/default/files/article/files/ FINAL\%20REPORT\%20EPSU\%20DIGITALISATION\%20-\%20OSE\%20June\%202018.pdf.

Golsch, K. (2003). Employment flexibility in Spain and its impact on transitions to adulthood. Work, Employment \& Society, 17(4), 691-718.

Grosbois, G., \& Henry, M. (2018). Profiter de la retraite le plus longtemps possible, la principale motivation de départ. Questions Retraite et Solidarité, les études, juillet 2018-2023.

Hacking, J. M., Muller, S., \& Buchan, I. E. (2011). Trends in mortality from 1965 to 2008 across the English north-south divide: comparative observational study. British Medical Journal, 342, d508. Retrieved June 27, 2019 from https://www.bmj.com/content/342/bmj.d508.full.

Hall, P., \& Soskice, D. (2001). Varieties of capitalism: The institutional foundations of comparative advantage. Oxford: Oxford University Press.

Hoven, H., Dragano, N., Blane, D., \& Wahrendorf, M. (2018). Early adversity and late life employment history. A sequence analysis based on SHARE. Work, Aging and Retirement, 3, 238-250.

Industry 4.0 impact on the CR labour market. (2017). Dopady Průmyslu 4.0 na trh práce v ČR, Národní observatoř zaměstnanosti a vzdělávání Národní vzdělávací fond, o.p.s.[Industry 4.0 impact on the CR labour market. (2017). National observatory of employability and education National Education Fund o.p.s.]. Retrieved June 30, 2019, fromwww.nvf.cz/cms/.../dopadyprumyslu-4.0-na-trh-prace-v-cr.pdf.

Ilmarinen, J. (2007). The work ability index (WAI). Occupational Medicine, 57, 160.

Kalleberg, A. L. (2000). Nonstandard employment relations: Part-time, temporary and contract work. Annual Review of Sociology, 26(1), 341-365.

Kunemünd, H. \& Scherger, S. (2015). Open questions and future prospects: Towards new balances between work and retirement? In S. Scherger (Ed.), Paid work beyond pension age. Comparative perspectives (pp. 298-315). Basingstoke: Palgrave Macmillan.

Lacina, L. (2018). Evropa je ve výhodnější pozici. Retrieved June 30, 2019, from. http:// ceskapozice.lidovky.cz/lek-na-nedostatek-pracovni-sily-migrace-fc5-/debata-jana-machacka. aspx?c=A180906_101742_machackova-debata_houd.

Lain, D. (2015). Work beyond age 65 in England and the USA. In S. Scherger (Ed.), Paid work beyond pension age. Comparative perspectives (pp. 31-56). Basingstoke: Palgrave Macmillan.

Lössbroek, J. \& Radl, J. (2018). Teaching older workers new tricks. Workplace practices and gender training differences in nine European countries. Ageing \& Society. First View. Published online: August 22, 2018. Retrieved October 11, 2018 from https://doi.org/10.1017/ S0144686X1800079X. 
Majeeda, T., Forder, P., Mishra, G., Kendig, H., \& Byles, J. (2015). A gendered approach to workforce participation patterns over the life course for an Australian baby boom cohort. Journal of Vocational Behavior, 87, 108-122.

Matthews, K., \& Nazroo, J. (2015). Later-life work, health and wellbeing: Enduring inequalities. In S. Scherger (Ed.), Paid work beyond pension age: Comparative perspectives (pp. 257-259). Basingstoke: Palgrave Macmillan.

Muffels, R. J. A. (1998). Ageing and flexibilisation. Caveats for challenges for the welfare state. Sociological Review, 34, 285-303.

Muffels, R., \& Luijkx, R. (2008). Labour market mobility and employment security in Europe: 'Trade-off' or 'flexicurity'? Work Employment \& Society, 22(2), 221-242.

Office for National Statistics. (2013). Women in the labour market. Retrieved March 4, 2019, from https://www.ons.gov.uk/employmentandlabourmarket/peopleinwork/ employmentandemployeetypes/articles/womeninthelabourmarket/2013-09-25.

Oksuzyan, A., Juel, K., Vaupel, J. W., \& Christensen, K. (2008). Men: Good health and high mortality. Sex differences in health and aging. Aging Clinical and Experimental Research, 20, 91-102.

OECD. (2006). Ageing and employment policies. Live longer work longer. Paris: OECD Publications.

OECD. (2011). Life expectancy links. The quiet revolution in pension policy. Retrieved October 11, 2018, from http://www.oecd.org/social/soc/39468250.pdf.

OECD. (2014). Labour force statistics by sex and age. Paris: OECD.

OECD. (2018). Pensions at a glance 2017. OECD and G20 indicators. Paris: OECD Publishing. Retrieved March 4, 2019, from http://dx.doi.org/10.1787/pension_glance-2017-en.

OECD. (2019). Ageing and employment policies-Statistics on average effective age of retirement. Retrieved March 5, 2019, from http://www.oecd.org/els/emp/average-effective-age-ofretirement.htm.

Office of National Statistics. (2016). Health state life expectancies, UK: 2013 to 2015. Statistical Bulletin. November 29, 2016. Retrieved October 11, 2018, from https://www.ons.gov. uk/peoplepopulationandcommunity/healthandsocialcare/healthandlifeexpectancies/bulletins/ healthstatelifeexpectanciesuk/2013to2015.

Phillipson, C. (2018). 'Fuller' or 'extended working lives? Critical perspectives on changing transitions from work to retirement. Ageing \& Society, 39(3), 629-651.

Phillipson, C., \& Ogg, J. (2010). Active ageing and universities: Engaging older learners. London: Universities UK.

Pleau, R. L. (2010). Gender differences in postretirement employment. Research on Aging, 32(3), 267-303.

Radl, J., \& Himmelreicher, R. K. (2014). The influence of marital status and spousal employment on retirement behavior in Germany and Spain. Research on Aging, 37(4), 361-387.

Scherer, K. R., Wranik, T., Sangsue, J., Tran, V., \& Scherer, U. (2004). Emotions in everyday life: Probability of occurrence, risk factors, appraisal and reaction patterns. Social Science Information, 43(4), 499-570.

Scherger, S. (Ed.). (2015). Paid work beyond pension age. Comparative perspectives. Basingstoke: Palgrave Macmillan.

Street, D. (2017). The empirical landscape of extended working lives. In Á. Ní Léime, D. Street, S. Vickerstaff, C. Krekula \& W. Loretto (Eds.), Gender and extended working life: Cross-national perspectives. Bristol: Policy Press.

Thévenon, O. (2011). Family policies in OECD countries: A comparative analysis. Population and Development Review, 37(1), 57-87.

Vickerstaff, S. (2010). Older workers: The 'unavoidable obligation' of extending our working lives? Social Compass, 4(10), 869-879. 
Wainwright, D., Crawford, J., Loretto, W., Phillipson C., Robinson, M., Shepherd, S., et al. (2019). Extending working life and the management of change. Is the workplace ready for the ageing worker? Ageing \& Society, 39(11), 2397-2419.

Walker, A. (2006). Active ageing in employment: Its meaning and potential. Asia Pacific Review, 13(1), 78-93.

Open Access This chapter is licensed under the terms of the Creative Commons Attribution 4.0 International License (http://creativecommons.org/licenses/by/4.0/), which permits use, sharing, adaptation, distribution and reproduction in any medium or format, as long as you give appropriate credit to the original author(s) and the source, provide a link to the Creative Commons license and indicate if changes were made.

The images or other third party material in this chapter are included in the chapter's Creative Commons license, unless indicated otherwise in a credit line to the material. If material is not included in the chapter's Creative Commons license and your intended use is not permitted by statutory regulation or exceeds the permitted use, you will need to obtain permission directly from the copyright holder.

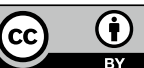




\title{
Chapter 2 \\ The 'Older Worker' and the 'Ideal \\ Worker': A Critical Examination \\ of Concepts and Categorisations \\ in the Rhetoric of Extending Working \\ Lives
}

\section{Clary Krekula and Sarah Vickerstaff}

\begin{abstract}
Policies supporting longer working lives have to a great extent described older people as the problem. In this chapter we challenge this description by looking critically at some of the assumptions underlying the extending working life agenda. The chapter begins with a discussion about the homogeneous representations of increased life expectancy, where we show that the neglect of growing differences in longevity takes privileged aging as the starting point. Next we discuss the use of the concept of gender equality to illustrate how male life courses are taken as the norm. The chapter then considers how increased individualization and the conditions that work organizations provide frames older people as all the same leading to widening inequalities amongst those in retirement. All taken together, extended working life leads to be an individualization of the risks of working life. Based on an analysis of the debates at the country level we further argue that the extended working life agenda is a top-down process and a globally spread implementation of an economically based political project.
\end{abstract}

Keywords Individualization $\cdot$ Neoliberalism $\cdot$ Life expectancy $\cdot$ Gender equality and extended working life $\cdot$ Older worker

\section{Introduction}

The working populations in many of the countries covered by this book are ageing, increased longevity coupled with a declining birthrate has led governments everywhere to look for ways to encourage people to work for longer and delay retirement.

C. Krekula $(\bowtie)$

Department of Social and Psychological Studies, Karlstad University, Karlstad, Sweden

e-mail: clary.krekula@kau.se

S. Vickerstaff

School of Social Policy, Sociology and Social Research, University of Kent, Cornwallis NE,

Canterbury, UK 
Some of this focus on the older population has been positive with age discrimination legislation acknowledging the pernicious impact of ageism on employment prospects and access to goods and services. The abolition of mandatory retirement ages in some countries has opened up the possibility that people can choose to extend their working lives if work is available. Other policy changes have been less benign such as the raising of state pension ages and a general tightening of the criteria for accessing disability pensions or state benefits. Whilst the policy agenda has focused on retirement systems the developments to encourage extended working lives have tended to put the emphasis on individuals, and on how we can be persuaded to do the right thing and carry on working (Krekula and Vickerstaff 2017).

The policy argument for longer working lives has to a great extent described older people as the problem, and their current retirement trends as selfish, uninformed, outdated and as a threat to welfare provision, and therefore has focused on making them delay their retirement by creating favourable conditions for those who are able and willing to continue working (Krekula and Vickerstaff 2017; Krekula et al. 2017; Smeaton and White 2016; Vickerstaff and Loretto 2017). As populations age the implication almost becomes that there are too many older people, or at least too many not working. In many countries this has also manifested itself in discussions of intergenerational fairness, in which baby boomers are typified as profiting at the expense of younger generations, despite the acknowledged differences within the boomer cohort. Reliance on intergenerational arguments has the effect of constructing older people as a homogeneous group in distinction and potentially at odds with other age cohorts. The early retirer is being recast as a selfish baby boomer (Willetts 2010). All of these debates depict the political initiatives on extended working lives as necessary to rescue the economy and the welfare state from the burden (i.e. the cost) of an ageing population. The policy discussion tends to disconnect the development of ageing populations from wider social, political and economic trends, neglecting the broader context of globalization and austerity.

In this chapter we look critically at some of the assumptions underlying the extending working life agenda. The chapter begins by considering the underlying mantra that as we live longer we should work longer (OECD 2006). It is typically taken for granted that life expectancy is increasing and therefore it is reasonable to expect that people can work for longer. This fails to adequately consider three aspects of life expectancy namely that there are sharp social gradients in longevity with working class people often not enjoying the same life expectancy as more middle class groups; second whilst we live longer we do not necessarily remain healthy for longer and thirdly, in conditions of continuing austerity it appears that increases in longevity are slowing or even starting to reverse for some groups. The assumption that increasing longevity is happening uniformly privileges the experiences of some groups and sets the tone for the extending working lives policy agenda. Extended working life is recurrently discussed, in both policies as well as more critical works, in relation to what it means from a gender and gender equality perspective. We therefore also discuss the notions of what gender equality constitutes and the consequences it has for policies supporting extended working life. 
The second part of the chapter investigates how policy building on this tendency to homogenize older workers as an undifferentiated category, leads to a progressive individualization of responsibility for finding and sustaining work and saving for retirement. The chapter concludes by arguing that policies towards extended working lives are built on a set of assumptions that too often ignore the realities of ageing populations and which, as such, are likely to reinforce patterns of social insecurity and precarity in society at large.

\section{Privileged Older People and Men as the Norm}

Policies aim to change something, and therefore they frame the problems to which they are seen as the solution (Bacchi 2009). Policies on extended working life are, thus, not objective entities, rather, they are proactive by focusing on some aspects and playing down others (Bacchi 1999, 2009, 2012). Constructions of categories and key concepts are a central means in these processes, like policies, they carry basic assumptions (Ahmed 2007, 2012). As a consequence, categories such as 'older workers' and key concepts such as 'gender equality' are not neutral when used in policies, they construct something and has therefore real consequences. With this starting point, this section proceeds by placing emphasis on the groups of older people that constitute the norm in European policy. Our discussion focuses on the arguments in the European Commission's white paper on Adequate, Safe and Sustainable Pensions (2012) since it is a formal document containing proposals for the European Union (EU) and which aims to, based on a debate with stakeholders including the European Parliament and the European Council, create political consensus on issues regarding retirement age and the design of the pension system (Eur-lex 2018).

\section{The Privileged Life Course as the Norm}

In European policies, demographic changes are used as a basis for the debate on retirement age and pension systems, and the ageing population is described as a major challenge to pension systems, as one of the largest public expenditure items, and as a common concern amongst all member countries (e.g. European Commission 2012). Against this background, the linking of the retirement age with increases in life expectancy and restriction of access to early retirement schemes and other early exit pathways are presented as two central means to maintain an adequate income in retirement. Member countries are, thus, recommended to link the retirement age to gains in life expectancy since this "could result in budgetary savings representing more than half of the projected increase in pension expenditure over the next 50 years" (European Commission 2012:10). Consequently, many European countries have moved in this direction. During the period 2014-2017, Croatia, Czech Republic, Greece, Finland and Portugal linked their retirement age to life expectancy 
(European Commission 2018; see also chapters from Estonia and Spain in this volume). Other countries, e.g. the Netherlands, have decided to implement this in the coming years (see chapter from the Netherlands in this volume) and in some countries, such as Austria and Sweden, this measure has been raised in the political debate (see chapters from Austria and Sweden in this volume).

The reasoning for linking retirement age to life expectancy is created through a homogenisation of the older population. An example of this can be seen in the European Commission (2012:2), which presents a merged future prognosis for the EU countries; 'By 2060, the life expectancy at birth for males is projected to increase by 7.9 years and by 6.5 years for females, when compared to 2010'. This homogenous construction also shows in the discussion about the necessity to balance time spent in work and retirement, where it is stated that 'Currently, about one third of adult life is spent in retirement and, with unchanged policies, this share would increase in line with future gains in life expectancy' (European Commission 2012:7).

The data on increased life expectancy are, in themselves, correct if we look at the aggregate level of older people as a homogenous group. However, this type of homogenous group does not exist in reality. As has been recurrently noted, there is no uniform group of older people; variations in the life course tend rather to deepen as people grow older, based on, for example, gender, education, finances and family situation (Bal and Jansen 2015). This also applies to life expectancy. The statement above for the large population of older people in Europe therefore constitutes a disregard for the great differences in life expectancy that exist between countries (see for example Majer et al. 2011), and also downplay the differences in length of life that exist within countries based on for example profession, education or social class (see for example Tarkiainen et al. 2013; Statistics Sweden 2018a, b; Marmot 2010). Whilst'open methods of coordination' allow EU countries to take into account their own specificities, opening up the possibility that linking life expectancy rates to retirement ages could vary from place to place, the argument feeds into the "common sense' argument that we are all living longer in contrast to previous generations. A later report in 2018 , whilst moderating the argument slightly sustains the view that life expectancy is increasing and hence people will need to work for longer and does little to suggest remedies for those unable to continue working: "Although the duration of working life is increasing, the duration of retirement is expected to grow even faster, as life expectancy continues to increase." and this is framed as a bad outcome for all countries: "As life expectancy improves, longer working lives will be vital to enable men and women to acquire adequate pensions" (European Commission 2018:15-17).

The construction of a uniform life expectancy age for the large collective of older people in Europe does not, however, mean that there is a lack of awareness regarding the great differences that exist between groups of older workers. In parallel with the homogenised statistics, the Commission's White Paper (2012), for example, emphasises the need for 'taking into account the fact that the ability to work-and to find employment - differs widely between individuals, and that life expectancy and health status at age 60 or age 65 tends to be lower for manual workers who started working at a young age' (2012:7). This comment is, however, neither followed up 
in the document, nor is it problematised in relation to the overall argument of the Commission that life expectancy ought to affect the retirement age. Thus, the latter can continue being used as a building block in the rhetoric of the Commission in support of extended working life, while the varying life expectancy of different groups is turned into a non-question in this line of reasoning.

The homogenous descriptions of life expectancy are particularly important to emphasise from a gendered class perspective, since research indicates that life expectancy also declines for gendered groups of older people. For example, a decline in male life expectancy is reported, most likely due to stress and negative health lifestyles, in Russia, Ukraine, Belarus and Kazakhstan (Cockerham 2012). Swedish statistics follow the same line, showing a declined life expectancy among groups of people with a low level of qualifications. During the period 2012-2017 the remaining average life expectancy at the age of 30 dropped from 51.2 to 51 years for women with only compulsory education. At the same time, the remaining life expectancy increased from 53.3 to 54.3 years for men of the same age. During the same period, the remaining life expectancy at age 65 also decreased from 17.8 to 17.5 years for single persons with only compulsory education, while it increased from 21.9 to 22.7 years among cohabiting persons with post-secondary education. Overall, the difference between the groups with the highest and lowest average life expectancy increased at age 65 from 4.1 years in 2012 to 5.2 years in 2017 (Statistics Sweden $2018 \mathrm{a}, \mathrm{b})$. The gaps in life expectancy are even greater in some other countries, for example in the UK there is a ten year gap in male life expectancy between men born in some parts of the south of England and those born in central Glasgow in Scotland (Office for National Statistics 2018). The development in Sweden should be seen in the light of the fact that pensions there are calculated based on both life income and life expectancy for each cohort. Those who live a shorter life than the estimated length of life and thereby only use a portion of their estimated pension, are not compensated for the fact that they live off their pension during a shorter period of time. This means that people with a shorter life expectancy indirectly subsidise those with longer life expectancy in the same cohort, which primarily increases the gap between blue-collar and white-collar workers (Lindberg 2017).

The focus on life expectancy also neglects the rates for healthy life expectancy which have not improved at the same pace. There are also gender differences in so far as women typically live longer than men and have more years in poor health. There has been no discussion of pegging pension ages to healthy life expectancy. To take England as an example, 2013-15 data on the healthy life expectancy at birth for men was 63.4 years and for women 64.1 years; at this point state pension age was in the process of rising to 66 for both women and men (Public Health England 2017).

The discussion above shows the central role which the construction of a uniform life expectancy plays in policies on extended working life and how they neglect differences between groups of older people. The argument that retirement age ought to be linked to gains in life expectancy does not take into account groups where life expectancy de facto is decreasing. It also ignores that there already is, in the countries where pensions are based on life expectancy, an injustice in the form of groups with 
lower average life expectancy subsidising those who are able to take out their pension over a longer period of time (Lindberg 2017). This line of reasoning connects to Hughes' (1995) argumentation that categorisations (e.g. "older workers") reproduce notions of uniform well-demarcated categories, which, by extension, construct some groups as a norm and others as subordinate. In the above discussed rhetoric, homogenisation contributes to creating an object, the imaginary collective of older people, around which a policy agenda can be created, in this context, towards an extended working life.

\section{Contradictory Definitions of Gender Equality}

Gender equality is defined in many different ways depending on the context. It can be understood as both ideological and as a political concept to describe equality between women and men. With reference to working life, the concept is often used to emphasise women's and men's equal participation and it has mainly been used as a starting point to highlight a lower proportion of women in different organisational contexts. This type of quantitative gender equality has, however, been discussed from several different starting points, where Hernes (1987) distinguishes three central arguments: The resource argument, which is based on women being expected to have specific resources and experiences that differ from those of men and therefore are assumed to complement men; the justice argument, which concerns democracy and emphasises that women, since they constitute half of the population, should be represented to the same extent; and the interest argument, where women and men are assumed to have different, and also contradicting interests, and thus women need to represent themselves. In contemporary gender equality research, it has been pointed out that the resource argument has been transformed into a profitability argument, where gender equality in the sense of equal participation is justified also by it contributing to increased productivity for organisations since women are assumed to contribute with other skills than men (Skjeie and Teigen 2005). Gender equality in work organisations has also been described as an issue which concerns qualitative aspects, with a focus on gender relations in organisations and on men and masculinity as the norm (Rönnblom 2011). Further, Ahmed (2007, 2012; see also Krekula et al. 2019) argues that key concepts, such as gender equality discourses, circulate via the documents of organisations, and that in this circulation they are associated with additional ideas, which leads to new meanings. There are, therefore, reasons to emphasise how gender equality is understood in policies on extended working life and the strategies which develop as a result, and how much room for change the different definitions create for organisations and for the individuals within them.

When the European Commission's White paper (2012) discusses gender in relation to extended working life, it is women as a category that is highlighted. This is done explicitly by stressing that sustainable pension systems are dependent on raising employment rates among groups where this is regarded as low, 'such as women, migrants and youths' (European Commission 2012:6). 
In the White paper, the concept of gender inequality is used in two contradictory ways. It is portrayed as an obstacle to extended working life and the paper emphasises that increasing pension eligibility ages depends on better opportunities for older women and men to stay in the labour market. As examples of measures to move in this direction, the paper mentions the adaptation of work places, the promotion of lifelong learning, policies aiming at reconciling work, private and family life, and the need to combat 'gender inequalities and age discrimination' (European Commission 2012:7). However, there is no clarification as to what types of gender inequalities within work organisations they are referring to; nor is there any mention of whether the inequality is assumed to affect women or men. This relates to previous remarks that gender equality is often seen as an obvious and common political objective, which means that gender inequality tends to be understood as something that 'is' rather than something that is 'done' (Rönnblom 2011).

The reconciliation of work and family life as a prerequisite for labour force participation among older people is, however, emphasised clearly, which also can be found in discussions on the differences in employment rates for women and men in the age group 55-64 years. Here, the importance of shedding light on gender aspects of extended working lives is mentioned, 'including measures that facilitate the reconciliation of work and care responsibilities and reduce gender gaps in employment and pay' (European Commission 2012:12). The goal to increase labour force participation among women correlates with national government strategies, including from Sweden, where it is stated that participation in working life on equal terms is a core area for the promotion of gender equality in the labour market (Government Bill 2005/06:155, for a discussion see Krekula 2012, 2014). These formulations on gender equality as dependent on caring responsibilities are in accordance with comprehensive international research which has shown that women's possibilities to take part in paid employment depend on their caring responsibilities (Korabik et al. 2008). They also relate to studies which have illustrated that older people's ability to work is related to whether an individual is caring for close family members or not (Lewis 2006; Dewilde 2012; see also corresponding discussions in several of the more in-depth country chapters).

By not stating the aspects in workplaces that are assumed to contribute to inequality which counteracts an extended working life, the White paper inhibits the development of strategies to fight inequality and to create prerequisites for increased labour force participation among both women and men. In these arguments, (in)equality appears as a vaguely defined phenomenon, which has to do with factors both within and outside the work organisation.

However, the document also points out the need to equalise pensionable ages for women and men since it can contribute to raising the labour force participation among older workers and to increasing income for women (European Commission 2012:12). Even though it is not stated more specifically what is meant by this type of equalisation of retirement ages for women and men, it may be assumed that it refers to a raise in women's retirement age to the same age as men in the countries where women today have a lower retirement age than men. It is, thus, men who constitute the norm that women are expected to strive to imitate. Even though it is reasonable that 
the higher retirement age sets the baseline in policies designed to encourage extended working life, the underlying assumptions contribute to the life styles and life courses that relate to the higher retirement age constituting a norm. This accords with the discussion in many of the country chapters here, which emphasises that women's early retirement means a financial loss for them. In these arguments, women's and men's different retirement ages appear as the gender inequality that both needs to be and can be solved by changing current pension systems, where the implicit rhetoric is that this will raise women's income. The unspoken starting point seems to be that women and men have the same prerequisites to work later in life. As pointed out by Nentwich (2006), this discourse of sameness ignores differences which may exist between men and women. Using sameness as a starting point runs directly counter to the above-mentioned definition which, on the contrary, stresses differences between women and men and how gendered conditions in personal as well as professional life create challenges for gender equality in relation to an extended working life.

The two definitions of gender equality also relate to two different strategies. The first mentioned definition of gender equality is based on the assumption that women and men have different prerequisites to work later in life and highlights the need to change the conditions in work organisations as well as in other social contexts that limit these. The second definition which is based on sameness between women's and men's conditions, is instead used to justify changes in pension systems and, thus, in women's retirement actions. It has, in other words, a disciplining function (Foucault 1991). In the first definition, it is practices and processes in working life and social organisation that are the problem seen from the perspective of raised retirement age, in the second it is women's behaviour.

Another starting point in the reasonings quoted above on how women's income can be raised through changes in the retirement age, is that changed pension systems affect/constrain individuals' retirement age. Even though this receives some support in research, retirement trends from several countries do, however, point towards the relationships between pension systems and current retirements being more complex. In some countries, research shows that raised general retirement age changes women's and men's retirement behaviour to different extents. The examples from the country chapters also indicate that early retirement might continue to be the norm after the retirement ages have changed.

In this section, we have illustrated that there are intended target groups behind formulations of homogeneity among older people in the discussed document in the form of privileged older people and men, as opposed to women, not as a large collective. It is the same groups that also, in several research studies, have been emphasised as those with the best prerequisites to live up to the goals of extended working life (for example see Lain and Loretto 2016). The political ambitions of connecting retirement age to life expectancy are, thus, based on a form of privileged ageing and turn this into a rhetorical and political norm. It relates to what has also been noted in national documents, for example, in Swedish policies aimed towards extended working life where the policies are adapted to those who are willing and able to continue working later in life (Krekula et al. 2017). Against this background, it comes as no surprise that comprehensive research has shown that an extended 
working life does not come in 'one size fits all', but rather creates inequality among groups of older people (for example Lain et al. 2019). Consequences in the form of precarious conditions for groups of older people and greater inequality between older people are instead a result of the starting points of the document in question, where the privileged older people constitute the intended target group of the policy actors.

The formulation of retirement ages has effects far beyond a secure income when leaving working life. Arza and Kohli (2008) have argued that they also regulate labour markets by facilitating an ordered transition out of employment and enable employers to manage their work force by offering instruments for the shedding or replacement of workers. It also contributes to biographical planning by creating a predictable sequence and timing between work and retirement, and provides workers with a legitimate claim to compensation for their "lifelong" work and thus with a stake in the moral economy of work societies. Our discussion above illustrates that retirement ages, in both rhetoric and practice, also construct social categorizations such as homogenous older workers and which has the effect of privileging some older adults over others.

\section{Individualization of Responsibility and Risk}

The assumption of a homogenized group of older people as the basis for changing both pension systems and retirement behaviour analysed in the previous section feeds into the more general processes of individualization characteristic of neo-liberal societal change. The policy target for these economic and political changes at the macro level is the individual adult worker (Lewis 2002, 2007), sometimes characterized as young or old but rarely acknowledged as gendered, raced, classed or abled. This individual is an idealized economic free agent shorn of their individual biographies and social connections (Krekula and Vickerstaff 2017:31). An idealized economic agent based on a 'masculinized occupational life course' (Grady 2015). Welfare state retrenchment has progressively led to the framing of policy as enabling individual 'choices' and 'freedoms' and demanding individual responsibility, what Rubery has characterized as the neo-liberal project to 'deregulate, decollectivize and depoliticize the employment relationship' (2015:633). Policies aimed at encouraging people to work for longer are a mixture of permissive such as age discrimination legislation and the ending of mandatory retirement ages and involuntary such as state pension age rises. The former are lauded as extending individual rights, freeing people from the tyranny of being forced to stop working simply because they reach a certain age. They can also be seen as disrupting biographical planning as individuals now are expected to decide when to retire: it is less likely to happen automatically on reaching a given age.

In the field of pensions, the move from Defined Benefit to Defined Contribution schemes shifts the risks to individuals who are now more responsible for managing their own savings and retirement transitions and their own risks (Vickerstaff and Cox 
2005). Another aspect of this discourse is the moral undertow of the imperative for active ageing (and active saving) that we should all be keeping fit and active, able to work and economically productive rather than becoming a drain on public resources (Vickerstaff and Loretto 2017; Moulaert and Biggs 2013). This narrative of individual responsibility replaces an earlier sense of moral economy in which the reproduction of labour meant that the young and old had privileged positions in society based on their future and past contributions. Macnicol (2015:21) goes further: "A central tenet of neoliberalism is that old age should not be a specially protected stage of life.... Older people should therefore be forced to work later in life".

This neoliberal discourse of helping individuals to help themselves neglects the realities of profound structural inequalities of opportunity and outcome between people. In addition, reliance on the undifferentiated and homogenized category of 'older worker' discussed above masks the heterogeneity of the older working population and the substantial inequalities that exist within age cohorts. Bal and Jansen have argued that heterogeneity increases with age; they argue that variability within an older age group increases with the accumulation of life experiences leading to an amplification of differences (2015:131).

Understanding the desirability or feasibility of extending working lives therefore requires a differentiated picture of the older population, their work histories, health, family circumstances and locations. It is well understood, though often ignored in public policy, that women and men typically have different work histories. Women are more likely to have breaks in their work histories for child and other care responsibilities, they are concentrated in certain fields of employment such as the public sector, health and education and are subject to persistent patterns of discrimination in access to work and promotion all of which result in gender pay gaps which translate into gender pension gaps (for the extent of these see European Commission 2018:68-78). The productivist slant of neo-liberal policies also neglects the relationship between paid work and unpaid work, denying the necessary interrelationship between employment and household labour, caring, volunteering and community work of various sorts.

The idealized adult worker (unencumbered by caring responsibilities) is also expected to be fit and healthy and to keep themselves such, whilst research demonstrates clear social and class gradients in health with members of lower social classes much more likely to suffer from limiting health conditions at earlier ages than those in higher social classes as discussed above (Marmot 2010). It is well documented that health is a major factor in people's withdrawal from the labour market before state pension ages and hence the imperative to work for longer may simply not be available to those suffering from chronic health conditions in their fifties and early sixties (Carr et al. 2018). Much public policy on the desirability of working for longer stresses the health benefits of continuing to work and staying active for both physical and mental health. Whilst possibly true for those enjoying their work and able to do it, there are significant numbers of people who may be damaged by continuing to work: those in physically arduous areas of work or under considerable stress who may already be soldiering on with existing health conditions that could be worsened by staying in work (Lain et al. in press). 
Health is not the only factor which differentiates the experiences and opportunities of the older population. Class differences in employment prospects are felt throughout the life-course and the impact of disadvantage may start early, back in childhood. Recent studies in the UK using the longitudinal 1958 Birth Cohort study demonstrate the role of childhood experiences of social disadvantage and mental health issues in shaping labour force participation and early labour market exit among older adults (Fahy et al. 2017; Clark et al. 2017). Hence the 'choice' to carrying on working in your sixties and beyond may well have been compromised much earlier in life.

We have made the argument that policy frames older people as all the same and therefore recommends solutions to the 'problem' of the ageing population that disadvantage certain groups and are likely to lead to widening inequalities amongst those in retirement. It is important to also consider how policies are implemented and along with the individualization of responsibility that many policy changes imply the trend in policy towards extending working lives has put greater emphasis on employers to deliver longer working lives; it is to this we turn now.

\section{Who Wants to Employ Older Workers?}

So far we have discussed the macro level policy changes and the impacts at the individual level but this is to neglect a key aspect of extending working lives-the meso level of work organisations. Macnicol (2015) amongst others (see Vickerstaff et al. 2003) have made the point that it is ultimately employers who will extend workers lives, either by retaining them into later age or by being more willing than hitherto to recruit at older ages.

In countries such as the US with little employment protection and a weak welfare state safety net the role of employers in delivering extended work careers is key (OECD 2018:14). In many of the countries covered in this volume we have seen a retrenchment in welfare policy, making it more difficult to take disability pension routes out of the labour market. This along with other policy changes, such as the ending of mandatory retirement ages and rising ages for state pension entitlement have the effect of further putting the onus on employers to deliver extended working lives, for example by offering new later career options; supporting flexible or partial retirement and considering and facilitating job redesign (Phillipson et al. 2018).

We are seeing a rise in the numbers of older people in the labour market in many countries but evidence suggests that this is mainly the result of people staying in employment longer, that is through retention rather than unemployed older workers coming back into work (see Lain and Loretto 2016). As Martin (2018:18) put it:

The bad news is that the increase in older worker employment rates was not driven by an increased willingness on the part of employers to hire older workers as their share of the labour force has increased. Instead, in virtually every country, the rise in older worker employment reflected an increase in their retention rate within firms, i.e. older workers staying on longer with the same firm. The bulk of OECD countries did not record an increase in the hiring rate 
for older workers over the past two decades. Thus, it seems that there are still large barriers against hiring older workers.

Despite legislation against age discrimination in many countries there is still widespread ageism in the labour market and a preference for hiring prime age or 'ideal workers' (Karpinska et al. 2011; Kulik et al. 2016). Ageism takes place in different areas of the workplace: Older workers are not being considered for job interviews (Furunes and Mykletun 2010); long term unemployment increasing from age 45 (Statistics Sweden 2017); they experience less wage increase (Brooke 2003); they receive less training and development and are passed over for promotion (Taylor and Walker 1998; Duncan and Loretto 2004; Krekula 2018) and they are disregarded when it comes to training for new technology (Furunes et al. 2006). Studies show that ageism is related to intentions to resign or retire (Bennington 2001; Hofstetter and Cohen 2014; Schermuly et al. 2014; von Hippel et al. 2013), and that it constitutes a risk for long-term sickness and contributes to work disengagement (Volpone and Avery 2013). This indicates that the possibility and willingness to extend their working life is limited due to ageism in work organisations. It also indicates that those older workers that lack the option to leave risk being locked in ageistic work organisations, with the above-mentioned consequences.

\section{Final Remarks}

The homogenized older worker, that is both the rhetorical corner-stone and the target of extending working lives, and the 'ideal worker' sought after by employers and embodied in much social policy are in themselves manifestations of deeply entrenched discriminatory views and practices. They privilege the healthy, fit and available for work rendering those with caring responsibilities, health or ability issues either invisible, neglected or at worst morally culpable. The extending working lives agenda by taking the privileged and male life course as the norm neglects the histories of current older workers and their many and various paths to retirement. This is most clearly exemplified by the reliance on a fictional account of increasing life expectancy that fails to acknowledge either differences within age cohorts or the very real significance of healthy life expectancy. Linking state retirement age to an aggregate measure of life expectancy is likely to do increasing damage to already disadvantaged groups.

Extended working life policies are, as discussed above, designed for the privileged older people, for 'those who are able and willing' to work longer (Krekula et al. 2017). For those who lack the prerequisites to extend their working life, the twosided rhetoric of freedom combined with responsibility portrays this as a personal problem and failure. From this perspective, policies towards extended working life do not appear as something which takes place in a vacuum. Rather, extended working life leads to an individualization of the risks of working life and can therefore be 
understood as processes which contribute towards a normalization of the precarization in society at large. Lorey (2015) discusses these processes of individualised risk using the concept of governmental precarisation and claims that neoliberal governing proceeds primarily through social insecurity and that precarisation is therefore the rule rather than the exception.

Finally, let us reflect on the above in relation to the debate on extended working life which is held at a national level. The country chapters illustrate that the routes in the direction towards extended working lives have been somewhat different and that they had different points in time. Together they illustrate, however, that it is about a top-down process where the increasing proportion of older people engendering fears about rising pension costs have been used as a starting point to change the pension system and raise retirement ages. The country chapters also show that this has taken place by, for example, synchronising women's and men's retirement ages where these have differed and by recurrently connecting retirement ages to life expectancies. These processes follow, throughout, the arguments which can also be found in the European Commission's White paper (2012 and later report 2018). This illustrates how basic assumptions of extended working life have circulated from European policy into national policy and practice (Ahmed 2007, 2012), and that constructions of homogenous life expectancies and notions of gender equality have been central in these processes. Together, this shows that the processes leading towards extending working lives are about a globally spread implementation of an economically based political project. This correlates to what has previously been pointed out-that the urge to extended working lives is not based on a social movement, unlike the project to increase women's labour force participation which in many countries has been the subject of feminist struggle (Krekula and Vickerstaff 2017). It also indicates that pension systems which were previously aimed at increasing welfare, nowadays, are widely regarded as a tool to strengthen national economies.

Even though there are exceptions (see e.g. chapters from Croatia and Switzerland in this volume on how the implementation of a new pension model is met by protests in Croatia and how attempts to change full retirement ages have been rejected by Swiss voters), the country chapters show that these fundamental changes to the pension systems have been met by a fairly limited debate. To the extent that political and social resistance has formed against raised retirement ages and changed pension systems, this in many countries is based on activities within trade union organisations, together with a political left and feminist organisations (see e.g. chapters from the Netherlands, Spain and Switzerland in this volume).

The limited debate is remarkable in the light of the comprehensive shift in the view on welfare and intergenerational solidarity found herein, where previous ambitions of protecting and enhancing rights have shifted towards a focus on individual responsibility (Lewis and Giuillari 2005; Krekula et al. 2017). The absence of a more comprehensive debate and social resistance can be seen as an expression of the advancement and dominance of mainstream economic discourse, which is recurrently captured in descriptions of contemporary societies as characterised by neo-liberal ideals and financial capitalism where economic values are prioritised (see e.g. Harvey 2006; Hudson 2012; Macnicol 2015). More specifically, we also see a 
neoliberal view that we cannot afford ageing, and that an ageing population is seen as an economic burden rather than as an opportunity and as a result of health, social and democratic development.

\section{References}

Ahmed, S. (2007). 'You end up doing the document rather than doing the doing': Diversity, race equality and the politics of documentation. Ethnic and Racial Studies, 30(4), 590-609. https:// doi.org/10.1080/01419870701356015.

Ahmed, S. (2012). On being included. Racism and Diversity in Institutional Life. Durham, London: Duke University Press.

Arza, C., \& Kohli, M. (2008). Pension reform in Europe. Politics, policies and outcomes. London: Routledge.

Bacchi, C. (1999). Women, policy and politics: The construction of policy problems. London: SAGE Publications.

Bacchi, C. (2009). Analysing policy: What's the problem represented to be?. Frenchs Forest: Pearson.

Bacchi, C. (2012). Why study problematizations? Making politics visible. Open Journal of Political Science, 1(2), 1-8. https://doi.org/10.4236/ojps.2012.21001.

Bal, M. P., \& Jansen, P. G. W. (2015). Idiosyncratic deals for older workers: Increased heterogeneity among older workers enhance the need for I-Deals. In M. P. Bal, D. T. A. M. Kooiji, \& D. M. Rousseau (Eds.), Aging workers and the employee-employer relationship (pp. 129-144). Heidelberg: Springer.

Bennington, L. (2001). Age discrimination: Converging evidence from four Australian studies. Employee Responsibilities and Rights Journal, 13(3), 125-134.

Brooke, L. (2003). Human resource costs and benefits of maintaining a mature-age workforce. International Journal of Manpower, 24(3), 160-283.

Carr, E., Fleischmann, M., Goldberg, M., Kuh, D., Murray, E. T., Stafford, M. S. et al. (2018). Occupational and educational inequalities in exit from employment at older ages: Evidence from seven prospective cohorts. Occupational and Environmental Medicine, 1-19.

Clark, C., Smuk, M., Lain, D., Stansfeld, S., Carr, E., Head, J., et al. (2017). Impact of childhood and adulthood psychological health on labour force participation and exit in later life. Psychological Medicine, 47(9), 1597-1608. https://doi.org/10.1017/S0033291717000010.

Cockerham, W. C. (2012) Review article. The intersection of life expectancy and gender in a transitional state: The case of Russia. Sociology of Health \& Illness, 34, 6, 943-957. https://doi. org/10.1111/j.1467-9566.2011.01454.x.

Dewilde, C. (2012). Life course determinants and incomes in retirement: Belgium and the United Kingdom compared. Ageing \& Society, 32, 587-615.

Duncan, C., \& Loretto, W. (2004). Never the right age? Gender and age-based discrimination in employment. Gender, Work and Organization, 11(1), 95-115.

Eur-lex. (2018). Access to European Union law. Glossary of summaries. Retrieved April 13, 2013, from https://eur-lex.europa.eu/summary/glossary.html\#W.

European Commission. (2012). White paper. An agenda for adequate, safe and sustainable pensions. Brussels, February 16, $2012 \operatorname{COM}(2012) 55$. Retrieved October 12, 2018, from https://eur-lex.europa.eu/legal-content/EN/TXT/PDF/?uri=CELEX:52012DC0055\&qid= $1488203863476 \&$ from $=\mathrm{EN}$.

European Commission. (2018). Pension adequacy report 2018. Current and future income adequacy in old age in the EU (Vol. 1). Retrieved April 11, 2019 from https://ec.europa.eu/eurostat/ publications/all-publications. 
Fahy, A., Smuk, M., Lain, D., van der Horst, M., Vickerstaff, S., Stansfeld, S., et al. (2017). Longitudinal associations between adversity, socioeconomic position, and engagement in education during childhood and labour force participation and exit in later adulthood. Social Science and Medicine, 183, 80-87.

Foucault, M. (1991). Discipline and punish: The Birth of the prison. London: Penguin Books Ltd. Furunes, T., Mykletun, R. J., \& Solem, P. E. (2006). Lederes holdninger til eldre arbeidstakere. Oslo: University of Stavanger and Norwegian Social Research.

Furunes, T., \& Mykletun, R. J. (2010). Age discrimination in the workplace. Scandinavian Journal of Psychology, 51(1), 23-51.

Government Bill. (2005/06):155. Makt att forma samhället och sitt eget liv-nya mål i jämställdhetspolitiken [The power to shape society and one's own life: New goals for gender equality policy]. Stockholm: The Ministry of Enterprise, Energy and Communications.

Grady, J. (2015). Gendering pensions: Making women visible. Gender, Work and Organization, 22(5), 445-458.

Harvey, D. (2006). A brief history of neoliberalism. Oxford: Oxford University Press.

Hernes, H. (1987). Women and the welfare state: Essays in state feminism. Oslo: Norwegian University Press.

Hofstetter, H., \& Cohen, A. (2014). The mediating role of job content plateau on the relationship between work experience characteristics and early retirement and turnover intentions. Personnel Review, 43(3), 350-376.

Hudson, M. (2012). Finance capitalism and its discontents. Washington: Islet.

Hughes, D. (1995). Significant differences. The construction of knowledge, objectivity, and dominance. Women's Studies International Forum, 18(4), 395-406.

Karpinska, K., Henkens, K., \& Schippers, J. (2011). The recruitment of early retirees: A vignette study of the factors that affect managers' decisions. Ageing \& Society, 31(4), 570-589.

Korabik, K., Lero, D. S., \& Whitehead, D. L. (Eds.). (2008). Handbook of work-family integration: Research, theory, and best practices. London: Academic Press.

Krekula, C. (2012). With Equality on the Agenda: An Age Perspective on Swedish Gender Mainstreaming. In M. Jansdotter Samuelsson, C. Krekula \& M. Åberg (Eds.), Gender \& Change: Power, politics and everyday practices (165-177). Karlstad: Karlstad University Press. http:// jamda.ub.gu.se/bitstream/1/864/1/gender_change.pdf.

Krekula, C. (2014). Ageing in the context of gender equality mainstreaming. Paper presented at the 22nd Nordic Congress of Gerontology, Gothenburg July 25-28, 2014.

Krekula, C. (2018). Time, precarisation and age normality: On internal job mobility among men in manual work. Ageing and Society. https://doi.org/10.1017/S0144686X1800137X.

Krekula, C., \& Vickerstaff, S. (2017). Theoretical and conceptual issues in the extending working lives Agenda. In A. Ní Léime, D. Street, S. Wickerstaff, C. Krekula, \& W. Loretto (Eds.), Gender and extended working life: Cross-national perspectives (pp. 27-52). Bristol: Policy Press.

Krekula, C., Engström, L-G., \& Alvinius, A. (2017). Sweden: An extended working life policy which neglects gender and health considerations. In A. Ní Léime, D. Street, S. Vickerstaff, C. Krekula, \& W. Loretto (Eds.), Gender and extended working life: Cross-national perspectives (pp. 157-174). Bristol: Policy Press.

Krekula, C., Karlsson, S., Engström, L.-G., \& Grip, L. (2019). Communicating equality through policy documents: On legitimacy, double logic, and stable translations. Gender, Work \& Organization. https://doi.org/10.1111/gwao.12376.

Kulik, C. T., Perera, S., \& Cregan, C. (2016). Engage me: The mature-age worker and stereotype threat. Academy of Management Journal, 59(6), 2132-2156.

Lain, D., \& Loretto, W. (2016). Managing employees beyond age 65: From the margins to the mainstream? Employee Relations, 38(5), 646-664. https://doi.org/10.1108/ER-04-2015-0062.

Lain, D., Van der Horst, M., \& Vickerstaff, S. (2019). Extending working lives: Feasible \& desirable for all? In S. J. Czaja, J. B. James, J. Grosch, \& J. Sharit (Eds.), Current and emerging trends in aging and work. London: Springer.

Lewis, J. (2002). Gender and welfare state change. European Societies, 4(4), 331-357. 
Lewis, J. (2006). Work/family reconciliation, equal opportunities and social policies: The interpretation of policy trajectories at the EU level and the meaning of gender equality. Journal of European Public Policy, 13(3), 420-437.

Lewis, J. (2007). Gender, ageing and the 'new social settlement': The importance of developing a holistic approach to care policies. Current Sociology, 55(2), 271-286.

Lewis, J., \& Giullari, S. (2005). The adult worker model family, gender equality and care: The search for new policy principles and the possibilities and problems of a capabilities approach. Economy and Society, 34(1), 76-104.

Lindberg, E. (2017). Pensionssveket. Ett ohållbart pensionssystem. Katalys-Institut för facklig idéutveckling, No: 36. Retrieved February 13, 2019, from https://www.katalys.org/wp-content/ uploads/2017/07/Katalys-No.-36.pdf.

Lorey, I. (2015). State of insecurity. Government of the precarious. London: Verso Futures.

Macnicol, J. (2015). Neoliberalising old age. Cambridge: Cambridge University Press.

Majer, I. M., Nusselder, W. J., Mackenbach, J. P., \& Kunst, A. E. (2011). Socioeconomic inequalities in life and health expectancies around official retirement age in 10 Western-European countries. Journal of Epidemiology and Community Health, 65, 972-979. https://doi.org/10.1136/jech.2010. 111492.

Marmot, M. (2010). Fair society, healthy lives: Strategic review of health inequalities in England post 2010. Retrieved February 12, 2019, from https://www.marmotreview.org.

Martin, J. P. (2018). Live longer, work longer: The changing nature of the labour market for older workers in OECD Countries, IZA DP No. 11510, Bonn. Retrieved June 20, 2019, from https:// www.econstor.eu/bitstream/10419/180528/1/dp11510.pdf.

Moulaert, T., \& Biggs, S. (2013). International and European policy on work and retirement: Reinventing critical perspectives on active ageing and mature subjectivity. Human Relations, 66(3), $22-41$.

Nentwich, J. (2006). Changing gender: The discursive construction of equal opportunities. Gender, Work and Organization, 13, 499-521. https://doi.org/10.1111/j.1468-0432.2006.00320.x.

OECD. (2006). Live longer, work longer. Retrieved April 30, 2019, from http://www.monitoringris. org/documents/strat_reg/live_longer_work_longer.pdf.

OECD. (2018). Ageing and employment policies: United States 2018 working better with age and fighting unequal ageing. OECD publishing. Retrieved June 3, 2019, from https://read.oecd-ilibrary.org/employment/ageing-and-employment-policies-united-states2018_9789264190115-en\#page23.

Office for National Statistics (ONS). (2018). Health state life expectancies, UK: 2015 to 2017. Retrieved May 31, 2019, from https://www.ons.gov.uk/peoplepopulationandcommunity/ healthandsocialcare/healthandlifeexpectancies/bulletins/healthstatelifeexpectanciesuk/ 2015to2017\#females-in-the-london-borough-of-camden-expected-to-live-865-years-in-2015to-2017-the-highest-across-all-local-authority-areas-in-the-uk.

Phillipson, C., Shepherd, S., Robinson, M., \& Vickerstaff S. (2018). Uncertain futures: Organisational influences on the transition from work to retirement. Social Policy and Society, online first. Retrieved June 20, 2019, from https://doi.org/10.1017/ s1474746418000180, https://www.cambridge.org/core/services/aop-cambridge-core/content/ view/9B73C43EE68C0B71F2242797806A5C48/S1474746418000180a.pdf/uncertain_futures_ organisational_influences_on_the_transition_from_work_to_retirement.pdf.

Public Health England. (2017). Health profile for England 2017. Retrieved May 31, 2019, from https://www.gov.uk/government/publications/health-profile-for-england/chapter-1life-expectancy-and-healthy-life-expectancy.

Rubery, J. (2015). Change at work: Feminisation, flexibilisation, fragmentation and financialisation. Employee Relations, 37(6), 633-644.

Rönnblom, M. (2011). Vad är problemet? Konstruktioner av jämställdhet i svensk politik [What's the problem? Constructions of gender equality in Swedish politics]. Tidskrift för genusvetenskap Journal of Gender Studies, 2, 33-56. 
Schermuly, C. C., Deller, J., \& Büsch, V. (2014). A research note on age discrimination and the desire to retire. Research on Aging, 36(3), 382-393.

Skjeie, H., \& Teigen, M. (2005). Political constructions of gender equality: Travelling towards a gender balanced society? Nordic Journal of Women's Studies, 13, 187-197. https://doi.org/10. 1080/08038740600590004.

Smeaton, D., \& White, M. (2016). The growing discontents of older british employees: Extended working life at risk from quality of working life. Social Policy and Society, 15(3), 369-385.

Statistics Sweden. (2017). Arbetslösa 20-64 år efter ålder och tid i arbetslöshet 2017. Retrieved May 8, 2019, from https://www.scb.se/sv_/Hitta-statistik/Temaomraden/Jamstalldhet/Fordjupningar/ I-och-utanfor-arbetskraften/Arbetsloshet/Arbetslosa-2064-ar-efter-alder-och-tid-i-arbetsloshet$2017 /$.

Statistics Sweden. (2018a). Medellivslängden ökar mest för högutbildade. Demografisk analys: Livslängdstabeller efter utbildningsnivå. Retrieved April 9, 2019, from https://www.scb.se/hittastatistik/statistik-efter-amne/befolkning/befolkningsframskrivningar/demografisk-analys/pong/ statistiknyhet/demografisk-analys-livslangdstabeller-efter-utbildningsniva/.

Statistics Sweden. (2018b). Stora demografiska skillnader i Sverige. Demografisk analys: Skilda världar?-Det demografiskt delade Sverige. Retrieved April 9, 2019, form https://www.scb.se/ hitta-statistik/statistik-efter-amne/befolkning/befolkningsframskrivningar/demografisk-analys/ pong/statistiknyhet/demokratisk-analys-skilda-varldar-det-demografiskt-delade-sverige/.

Tarkiainen, L., Martikainen, P., \& Laaksonen, M. (2013). The changing relationship between income and mortality in Finland, 1988-2007. Journal of Epidemiology and Community Health, 67, 21-27.

Taylor, P., \& Walker, A. (1998). Employers and older workers: Attitudes and employment practices. Ageing \& Society, 18, 641-658.

Vickerstaff, S., \& Cox, J. (2005). Retirement and risk: The individualisation of retirement experiences? Sociological Review, 53(1), 77-95.

Vickerstaff, S., Cox, J., \& Keen, L. (2003). Employers and the management of retirement. Social Policy and Administration, 37(3), 271-287.

Vickerstaff, S., \& Loretto, W. (2017). The United Kingdom-A new moral imperative: Live longer, work longer. In A. Ní Léime, D. Street, S. Vickerstaff, C. Krekula, \& W. Loretto, (Eds.), Gender, ageing and extended working life: Cross-national perspectives (pp. 175-192). Bristol: Policy Press.

Volpone, S. D., \& Avery, D. R. (2013). It's self defense: How perceived discrimination promotes employee withdrawal. Journal of Occupational Health Psychology, 18(4), 430-448.

von Hippel, C., Kalokerinos, E. K., \& Henry, J. D. (2013). Stereotype threat among older employees: Relationship with job attitudes and turnover intentions, Psychology and Aging, 28(1), 17-27.

Willetts, D. (2010). The Pinch: How the baby boomers took their children's future-and why they should give it back. London: Atlantic Books Ltd.

Open Access This chapter is licensed under the terms of the Creative Commons Attribution 4.0 International License (http://creativecommons.org/licenses/by/4.0/), which permits use, sharing, adaptation, distribution and reproduction in any medium or format, as long as you give appropriate credit to the original author(s) and the source, provide a link to the Creative Commons license and indicate if changes were made.

The images or other third party material in this chapter are included in the chapter's Creative Commons license, unless indicated otherwise in a credit line to the material. If material is not included in the chapter's Creative Commons license and your intended use is not permitted by statutory regulation or exceeds the permitted use, you will need to obtain permission directly from the copyright holder. 


\title{
Chapter 3 \\ Data Issues and Indicators
}

\author{
Tindara Addabbo, Michaela Gstrein and Renata Siemieńska
}

\begin{abstract}
This chapter documents a variety of national and cross national quantitative data sets and indicators for people aged 50 and over, which also include gender-sensitive measures and/or indicators for health and socio-economic wellbeing. Special attention is given to longitudinal data sets with indicators on relevant lifecourse events covering child care activities, workforce participation and employment history. We give illustrative examples of some indicators and data sets as they pertain to issues associated to the duration of working lives. The context for this exploration of data sets starts with the definition across European countries of extended working life, which relates to institutional factors, norms, attitudes and status of labour markets and their implications for wellbeing in later life, accounting for gender issues where possible.
\end{abstract}

Keywords Gender $\cdot$ Extended working life $\cdot$ Indicators $\cdot$ Drivers/barriers for work $\cdot$ Poverty $\cdot$ Values

\section{Introduction}

In the face of population ageing, sustainable budgets and relatively early retirement in at least some European countries, extending the working lives of both men and women has become one of the main EU policy targets (European Commission 2012: 9). However, longer working lives are shaped both by gender and health status, underscoring the importance of investigating the possible effects of gender- and health-related

T. Addabbo $(\square)$

Department of Economics Marco Biagi, University of Modena and Reggio Eilia, viale Berengario 51, 41121 Modena, Italy

e-mail: tindara.addabbo@unimore.it

M. Gstrein

WPZ Research, Vienna, Austria

R. Siemieńska

Institute of Sociology, M. Grzegorzewska University, Warsaw, Poland

R. Zajonc Institute for Social Studies, University of Warsaw, Warsaw, Poland

(C) The Author(s) 2020

Á. Ní Léime et al. (eds.), Extended Working Life Policies, https://doi.org/10.1007/978-3-030-40985-2_3 
issues on actual decisions to extend work. The issues are further complicated by non-standard definitions of extended working life in different country-contexts. This relates to nation-specific institutional factors, norms, attitudes and status of labour markets, each having varied implications on later life health, work and wellbeing from the perspective of similarities and differences in women's and men's experiences.

Which impact factors might be relevant? Besides differences in labour market activity, retirement options and traditional retirement patterns, 'complexity in retirement also derives from the fact that distinct social groups may undergo different processes and, hence, display varied retirement behaviour. For example, women at higher working age typically have different kinds of jobs and often lower income than men of the same age, they work substantially more often part-time, have different roles in private life, and in most countries leave work at a younger age than men. In consequence, decisions about retirement may be assumed to involve a varied set of criteria and follow different decision-making processes among women and men, which also needs to be reflected in research' (Hasselhorn and Apt 2015: 22).

The scientific work in Working Group 3 (WG3) of COST action IS1409 thus revolved around data that could elucidate the health and gender implications of extended work. The goal of the COST Action was to advance scientific knowledge about gendered impacts of extended working life on the health and economic wellbeing of older workers in Europe and to support evidence-based gender-sensitive future policy. The tasks of WG3 were (1) to identify and map national and international data sets for people aged 50 and over; (2) to investigate the availability of appropriate gender-sensitive measures and indicators; and, (3) to discuss the possible development of novel measures through creative use of existing data, by answering the following questions:

- What data sources are available?

- What indicators are available?

- Should new indicators be developed to enable gender analysis etc.?

\section{Data Sets and Indicators-An Overview}

What data sources are available? An overview of relevant quantitative data sets and indicators on people aged 50 with gender-sensitive measures and indicators for health and socio-economic wellbeing is shown in Table 3.1.

WG3 developed a grid with information on available data sets, summarising the geographical spread and population covered and the type of data collected (quantitative/qualitative) as well as brief information on content. Surveying the datasets for relevant information, the grid shows datasets with varying breadth of coverage of gender specific indicators, psychological and physical health indicators, and life course indicators. Other technical information was also gathered, such as year(s) of 


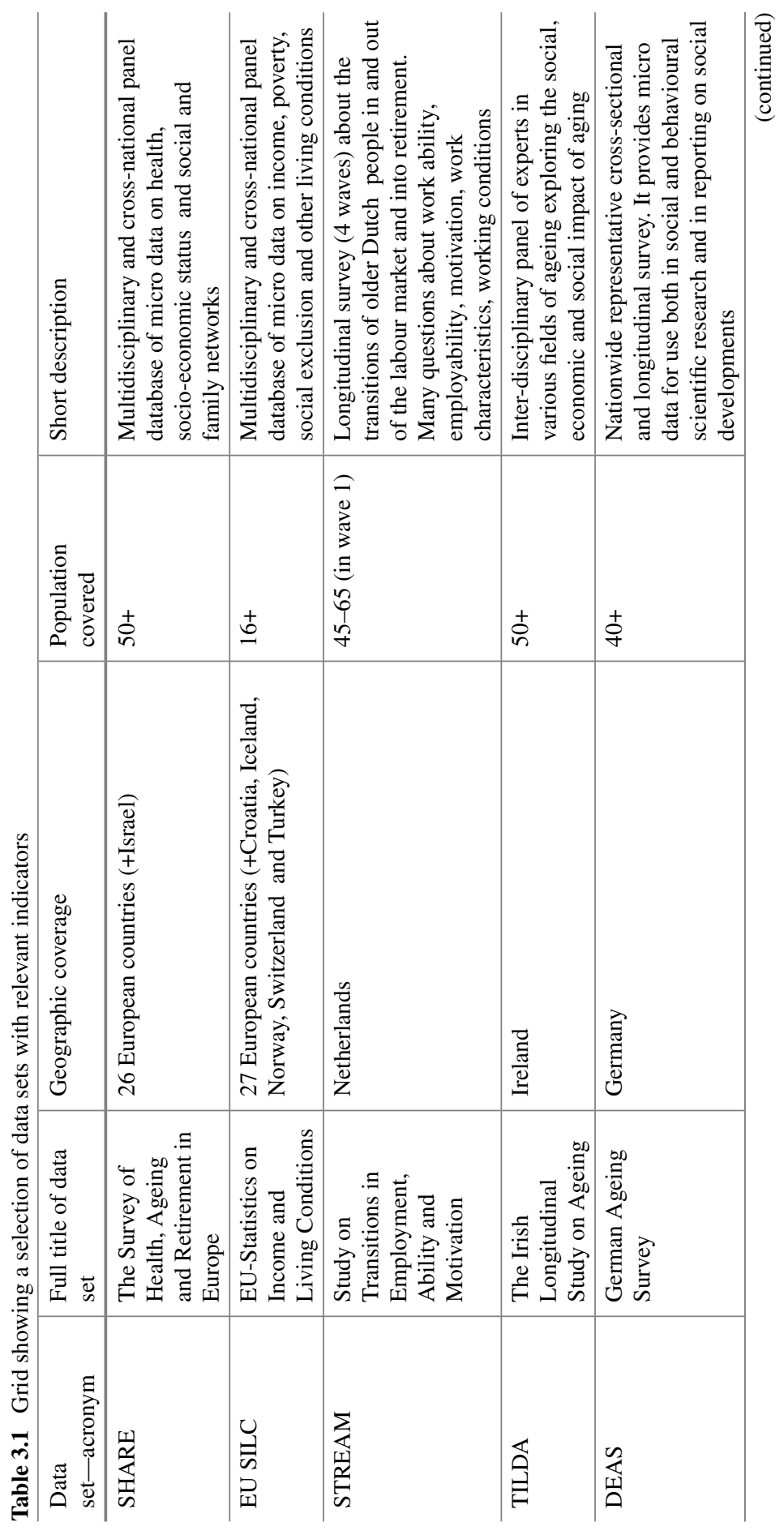




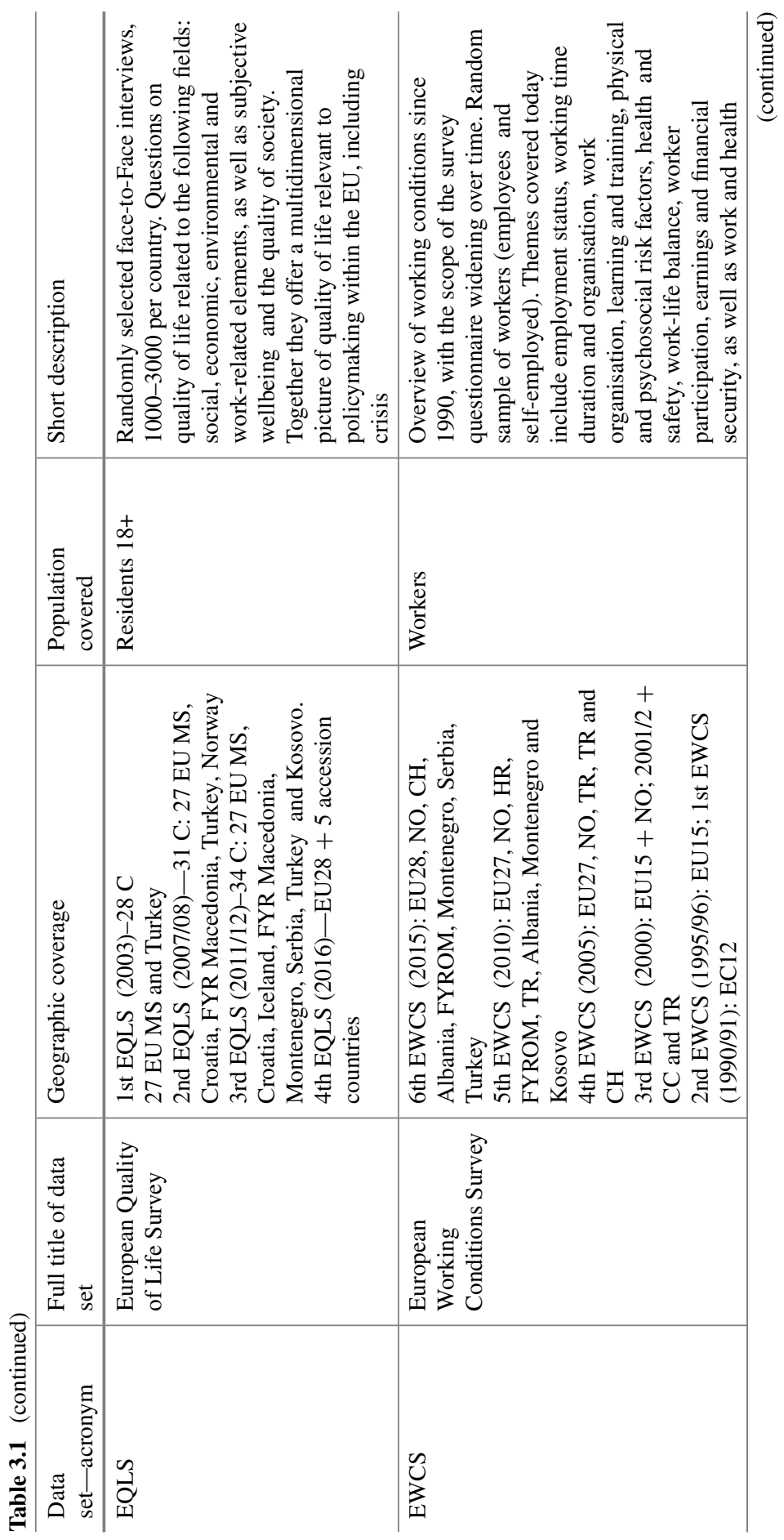




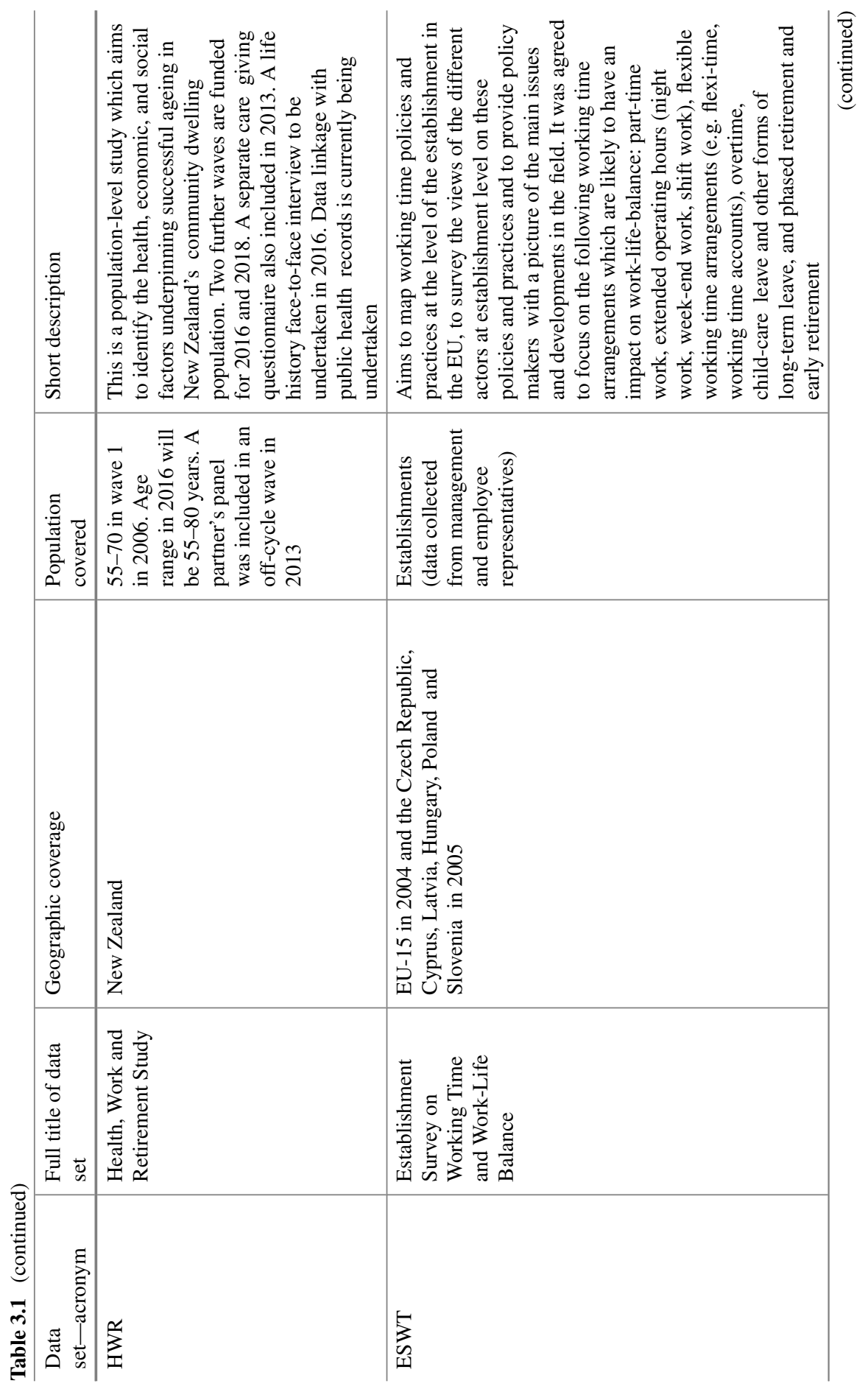




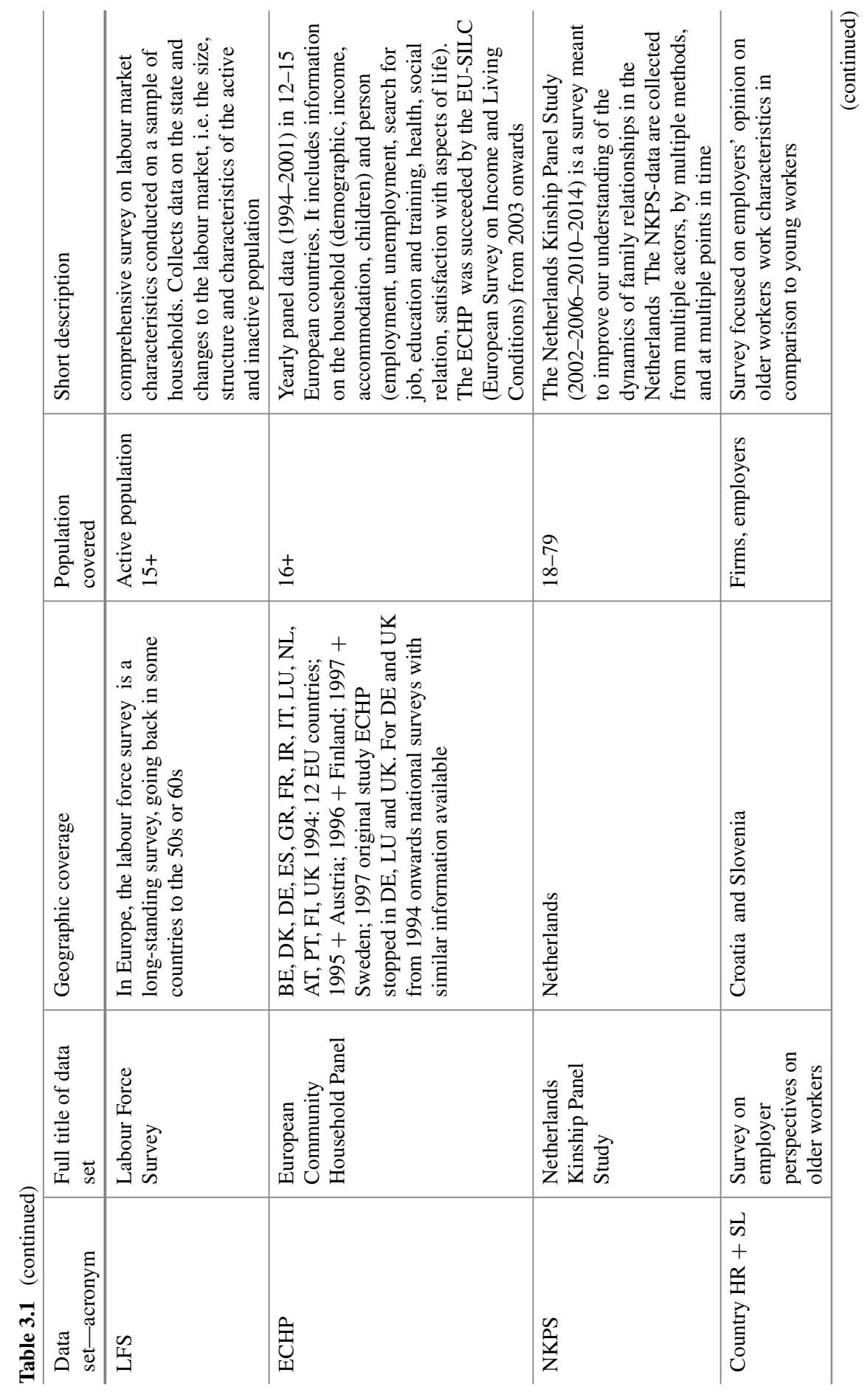




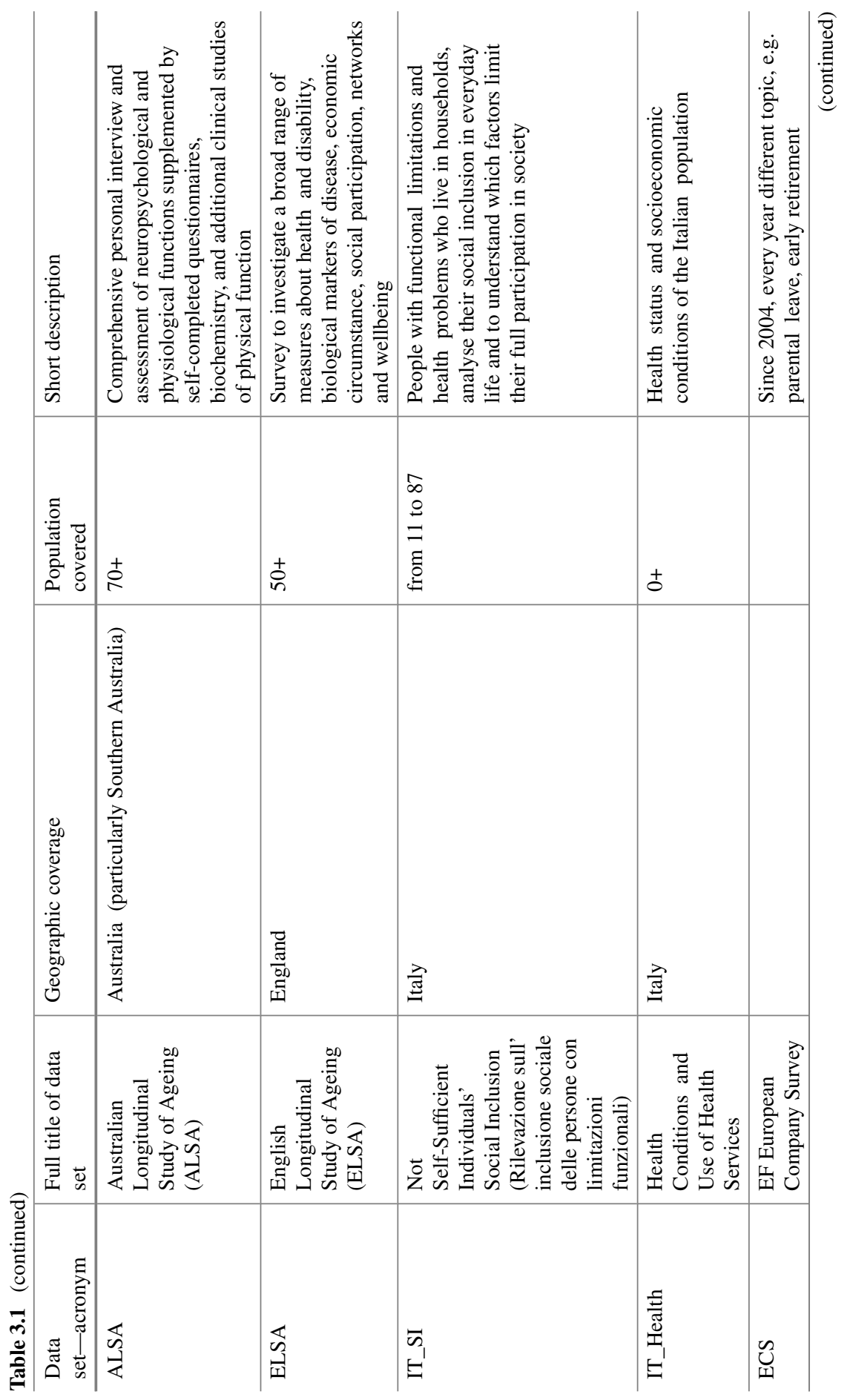




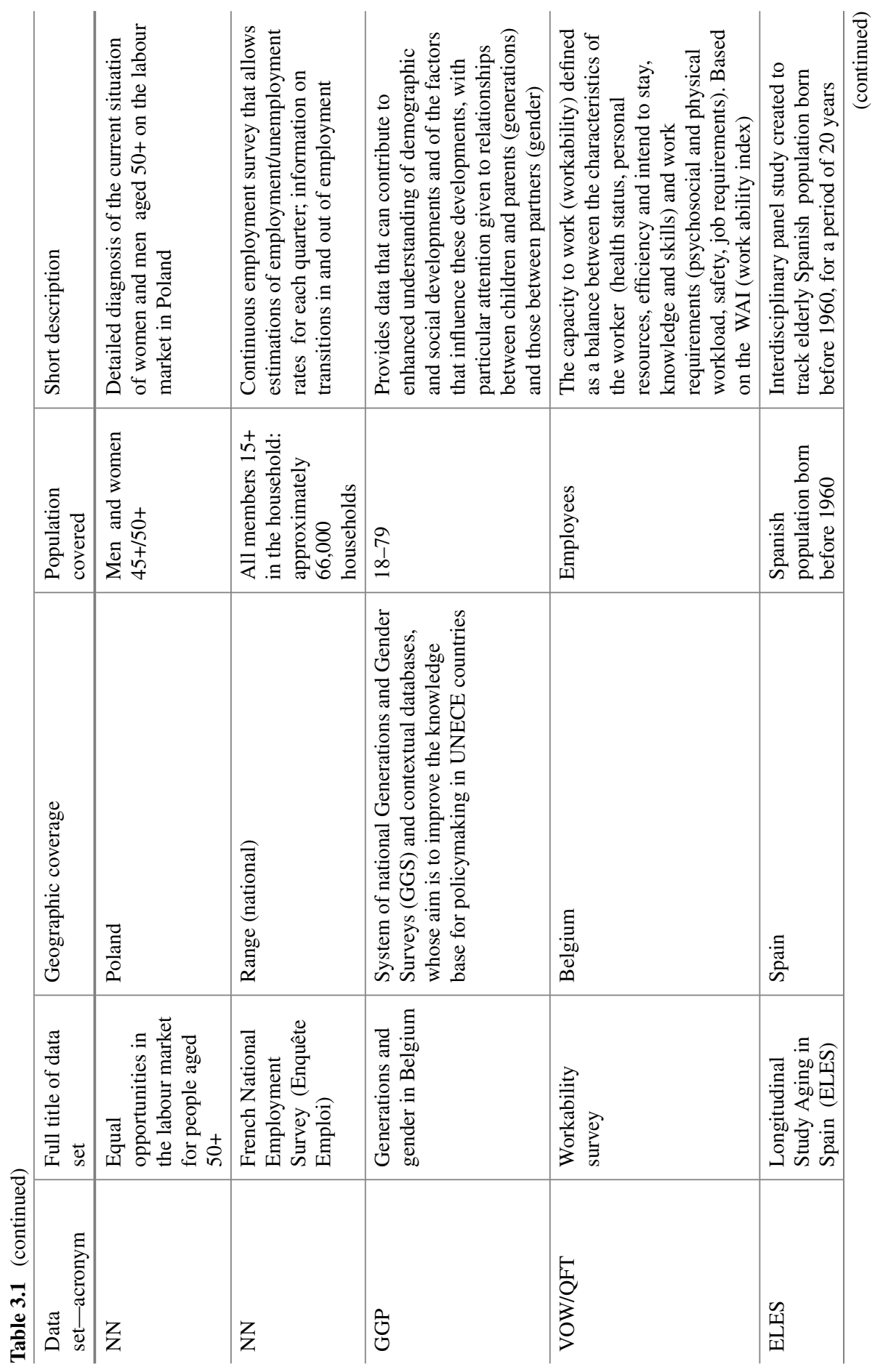




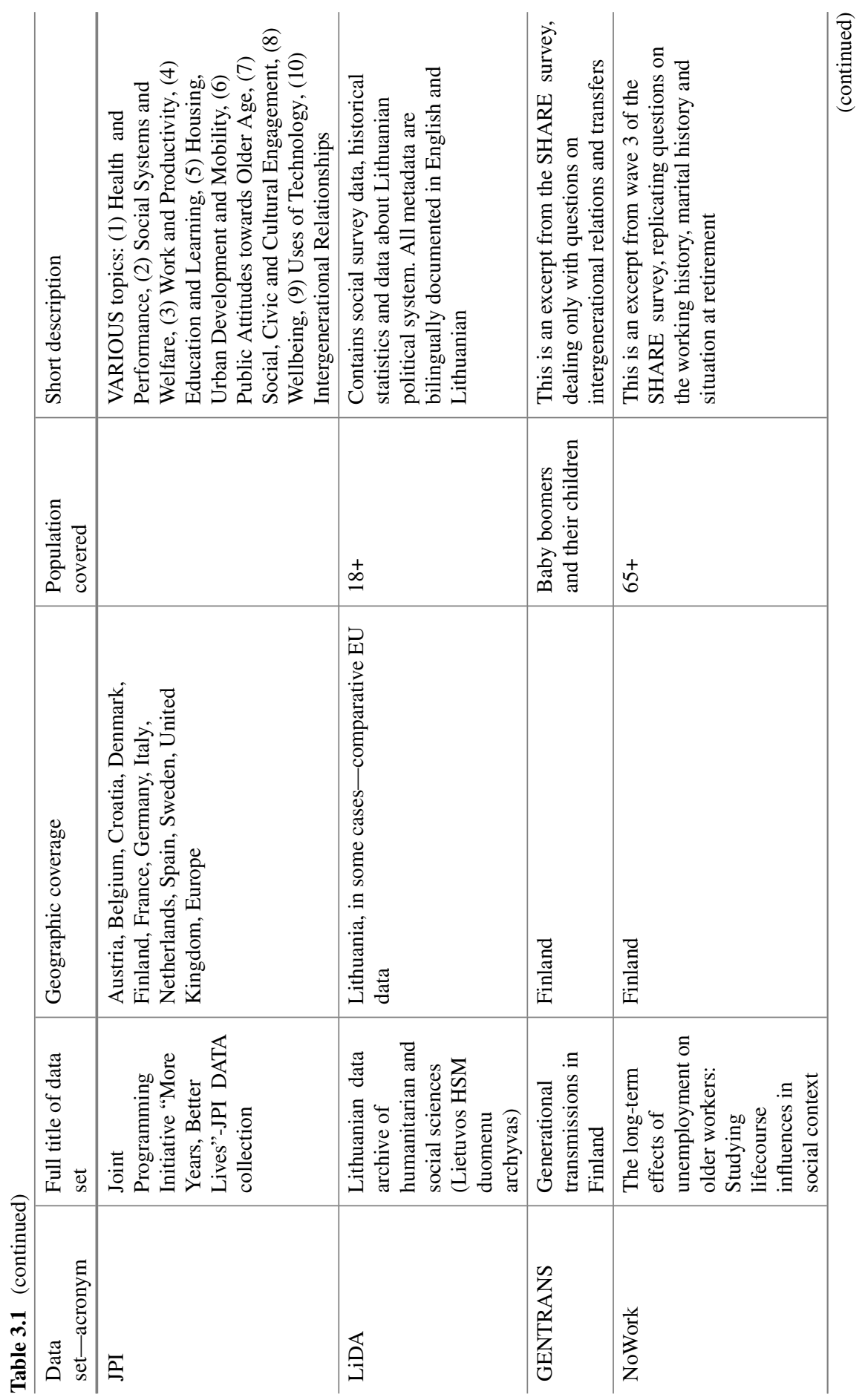









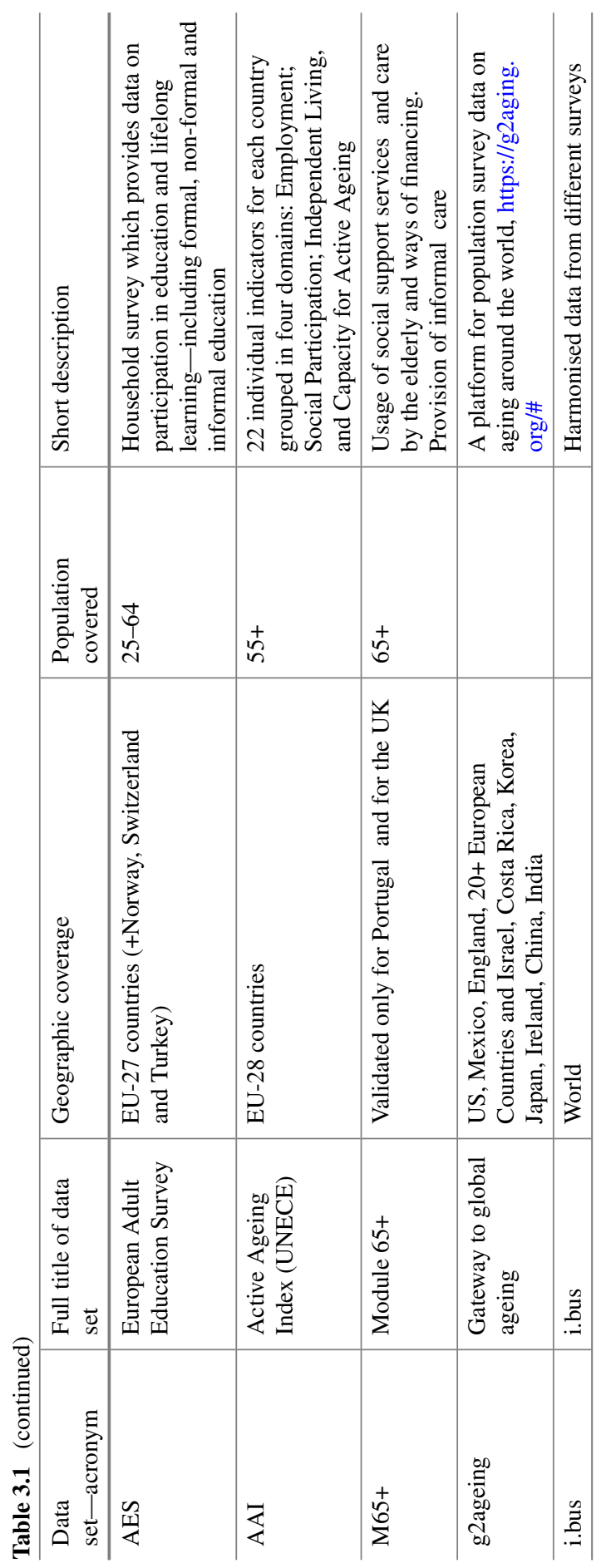


data collection, number of waves and participants, statistical representativeness and access.

The following data sets (listed in terms of acronyms, for more information refer to Table 3.1) were investigated: SHARE, EU SILC, STREAM, TILDA, DEAS, EQLS, EWCS, HWR, ESWT, LFS, ECHP, NKPS, Country HR+SL, ALSA, ELSA, IT_SI, IT-Health, ECS, GGP, VOW/QFT, ELES, JPI, LIDA, VOW/QFT, ELES, JPI, GENTRANS, NoWork, IGDC, EUROMOD, EHIS, EHSIS/EDSIM, LFS ad hoc module 2011, AES, AAI, M65+, LIS, g2ageing, i.bus, Equal opportunities in the labour market for people aged 50+, French National Employment Survey, Enquête Emploi.

In addition to the specific data sets WG3 reviewed, there are widely available country and group indicators in Eurostat or the OECD databases. Various publications include lists or links to other data collections, with, for example, g2ageing offering harmonised survey data for worldwide comparison (i.e. the USA, Mexico, England, 20+ European Countries and Israel, Costa Rica, South Korea, Japan, Ireland, China and India). Special attention is devoted to longitudinal data sets reporting indicators on relevant lifecourse events ranging from childcare activities to workforce participation and employment history.

What factors influence extended working life? The 2015 final report of the EU Joint Program Initiative, "More Years Better Lives" via the "Extended Working Life and its Interaction with Health, Wellbeing and Beyond" initiative (Hasselhorn and Apt 2015) characterizes retirement as a (long-term) process determined by interactions across multiple life domains. The report offers a chart, shown below in Fig. 3.1, which summarises various influences on peoples' retirement decisions. To reflect this COST action's specific focus on gender and health, two additional boxes-lifecourse events and gender-have been included. The health box in the original chart has also been highlighted to indicate the expanded focus of WG3.

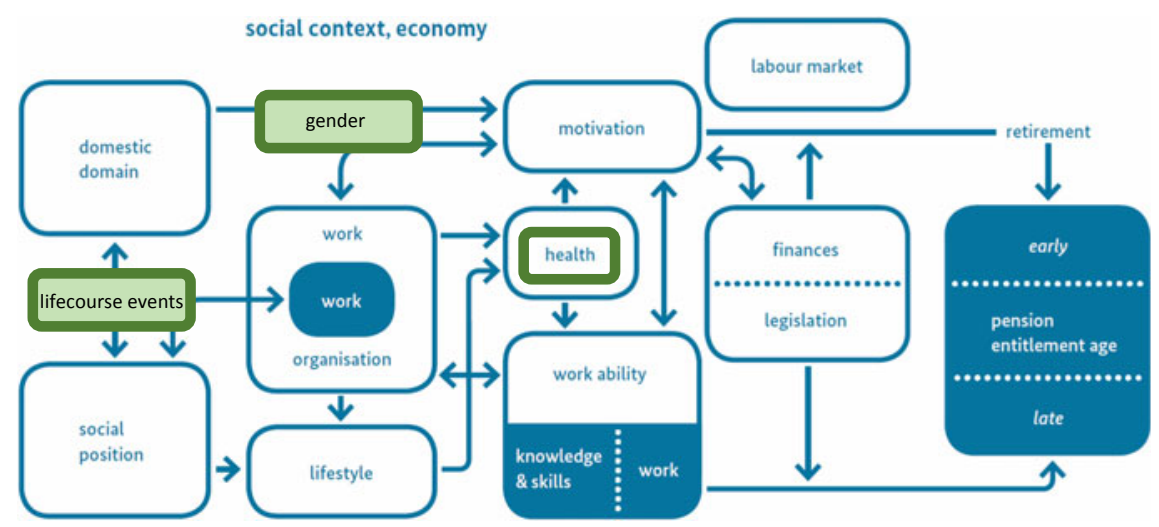

Fig. 3.1 Factors impacting on extended working life or the retirement decision. Source Authors' own additions (highlighted) or emphasized to Hasselhorn and Apt (2015: 24), Fig. 2 
Besides different labour market activity, retirement options and traditional retirement patterns, 'complexity in retirement also derives from the fact that distinct social groups may undergo different processes and, hence, display varied retirement behaviour. For example, women at higher working age typically have different kinds of jobs and often lower income than men of the same age, they work substantially more often part-time, have different roles in private life, and in most countries leave work at a younger age than men. In consequence, decisions about retirement may be assumed to involve a varied set of criteria and follow different decision-making processes among women and men, which also needs to be reflected in research' (Hasselhorn and Apt 2015: 22).

With population ageing used as the rationale to pursue a policy goal to extend working life, the role of gender and health as drivers of, or barriers to, extended working life are important factors to take into account. The collection of mostly quantitative data sets (see the grid provided in Table 3.1) offers information on the coverage of three relevant topics in each of the listed data sets:

- gender specific indicators

- psychological and physical health

- information on most relevant events (lifecourse).

For gender specific indicators, information and variables in many data sets could be relevant for gender sensitive analyses. Indicators in the data sets WG3 reviewed cover a range of variables, from data on household composition/information/children, to work engagement, care obligations, time spent on care and household activities, work life balance, quality of life, working conditions, sharing of resources, satisfaction with time use, family and social networks, subjective wellbeing, flexible work practices, retirement planning, decision making (e.g. care, spending), norms regarding (child) care, reasons for working part-time or un/under-employment, unpaid (domestic and care) work and effort, paid care work, grandparental childcare, work force participation, educational attainments. Obviously, not all data sets contain every variable needed to support gendered analyses. Some data sets also offer a summary of basic statistics: demographic, geographic, social, economic, health, and education characteristics or employment key figures by gender. From a gender perspective, an important gap remains to be filled by a joint collection of data on unpaid care and housework, matched with income and paid work data. There are only a few sources of data that collect these two items amongst them EU-SILC 2010 survey for 25 EU Member States (all except Ireland and Cyprus) within the intra-household sharing of resources ad hoc module matched with the income and wealth variables collected each year, HWR for New Zealand, GGP for Belgium and ELES for Spain. Such an integrated data set could allow researchers to analyse the implications of extended working life on care work and on time allocation by gender, as well as care provided to grandchildren and to dependent relatives not living in the household. Wider availability of gender sensitive data would support evaluations of the effort and costs of care provision and the interaction with extended working life and new work-life balance needs. 
Concerning psychological and physical health, data sets offer widely differing variables. Some focus mainly on objective measures, while others rely more on subjective perceptions. The data sets listed in Table 3.1 cover various aspects of physical health, cognitive function, behavioural risks, mental health and health care. The variables cover a gamut of topics, from self-assessed health including health status, chronic illness or condition and limitation in activities because of health problems; to personal feelings and perceptions of one's situation (at work, in society, etc.), work life balance or pressure felt; current personal mobility and physical restrictions, and psychological wellbeing (within a set of wellbeing indicators). Other conceptual categories explored in at least some datasets include satisfaction with life, prevalence of diseases (physical and mental); health lifestyles; cognitive functioning assessment for older age groups; certified disabilities and type; participation/access to various life domains (work, education, internet, etc.), independent living; physical safety; share of healthy life expectancy; social connectedness; physical exercise, and mental wellbeing.

Information on relevant lifecourse events is found only in some data sets (like ELES, SHARE, NKPS, ELSA, HWR, STREAM, TILDA, DEAS), despite the analysis of lifecourse events being such an important precursor to understanding choices and barriers associated with extended working life. While some events can be reconstructed from existing household data and/or work-related information (e.g. household size, number of children, part-time work, numbers of hours at work, etc.), others need to be explicitly asked to be available for the analysis (e.g. information on past impact factors, upcoming obligations or future plans related to retirement, etc.). Variables in the longitudinal data sets typically cover retrospective information on life-course events, including childhood, workforce participation and employment history, work quality, housing, health and disability, SES, education, discrimination and major life events. Other relevant indicators show the prevalence of unpaid caring and its effect on work/earnings, marital and work histories, timing of childbirths, economic and educational activity, long and short term absence from work for health reasons, obstacles to finding employment/a job, unemployment, and information on other individuals in the household, partnership and children, to name only a few. Social participation, effort and reward, employment details, job characteristics, professional career, earnings, occupational pension contributions or receipts, pre-retirement working conditions, motivation for life decisions, and retirement decisions appear in some longitudinal data sets. They also sometimes cover poverty, living arrangements, taxes and benefits, inequality, nationality/migration background, participation in educational programmes. For example, SHARELIFE (3rd module of 2008/9 and 7th module of 2017) is based on lifecourse analyses.

Given that health and employment are closely interrelated, keeping people healthy for longer (as well as offering good employment conditions) can increase or extend their labour market participation. The reduction of premature mortality (World Health Organization 2018) due to unnecessary risk factors and contra-productive individual behaviour is an overall goal taken up in the latest joint OECD/EU (2018) Health at a Glance report on the State of Health in the EU cycle. What is the actual labour market outcome, especially for the older age group? As found in a comparison of 
14 European countries in OECD/EU (2016), the prevalence of one or more chronic diseases (such as cardiovascular diseases, diabetes, cancer, musculoskeletal diseases and mental health conditions) and behavioural risk factors (obesity, heavy smoking, heavy alcohol drinking) reduces the likelihood of employment of 50-59 year-olds. Women appear to be more affected on all measures than men. As the OECD/EU report points out, chronic diseases and behavioural risk factors also lead to lower productivity, fewer hours worked and lower wages (OECD/EU 2016: $25 \mathrm{ff}$ ). In addition, people with chronic diseases are more likely to become disabled, unemployed or to take-up early retirement schemes.

The European Quality of Life Survey (Eurofound 2017) allows to detect the effects of care on the likelihood of being employed by age, gender and country, showing an increasing number of carers that, due the extended working age, are in paid work and an increase in work-life balance stress indicators.

\section{Applications}

In this section WG3 provides analytic applications using selected indicators and data sets to issues connected to the duration of working life and to the impact of different employment statuses on wellbeing.

\section{The Impact of Different Working Conditions on Income Poverty and Material Deprivation by Age}

The EU-Statistics on Income and Living Conditions (EU-SILC) contains a wide set of indicators on household socioeconomic conditions that can be used to analyse the impact of different dimensions of wellbeing by age group and according to working conditions. In this application, we demonstrate that EU SILC data, with special reference to a country, can be used to analyse to what extent employment status protects against the risk of income poverty and material deprivation by gender and age group.

For this analysis, the poverty line is defined as $60 \%$ of the median equivalent disposable income calculated using the OECD modified equivalence scale. We use the Eurostat material deprivation definition according to which a household is materially deprived if it is not able to afford at least three of the following needs: one week holiday a year; keeping the house warm; handling unforeseen expenses; paying the mortgage, bills, deferred payments; protein intake; washing machine; colour television; car; telephone.

In Table 3.2, we show the results, in terms of average marginal effects of each variable included in the model, of the impact on the probability of being income poor of different variables including the type of job by estimating a probit model with IT 
Table 3.2 Probability of being income poor by age group

\begin{tabular}{|c|c|c|c|}
\hline \multicolumn{4}{|c|}{ Average marginal effects } \\
\hline & $20-49$ & $50-64$ & $65-74$ \\
\hline Age & $\begin{array}{l}-0.00179 \\
(-1.61)\end{array}$ & $\begin{array}{l}-0.004366^{*} \\
(-2.30)\end{array}$ & $\begin{array}{l}-0.00516 \\
(-1.04)\end{array}$ \\
\hline Female & $\begin{array}{l}0.0317^{*} \\
(1.97)\end{array}$ & $\begin{array}{l}0.0399^{*} \\
(2.27)\end{array}$ & $\begin{array}{l}-0.0549 \\
(-1.62)\end{array}$ \\
\hline Single & $\begin{array}{l}0.00721 \\
(0.39)\end{array}$ & $\begin{array}{l}0.0683^{* * *} \\
(3.69)\end{array}$ & $\begin{array}{l}0.0714^{* *} \\
(2.91)\end{array}$ \\
\hline $\begin{array}{l}\text { With } \\
\text { children }\end{array}$ & $0.0191(1.17)$ & $\begin{array}{l}0.0372^{*} \\
(2.10)\end{array}$ & $0.0882(1.90)$ \\
\hline Secondary & $\begin{array}{l}-0.0884^{*} \\
(-2.01)\end{array}$ & $\begin{array}{l}-0.0897^{* * *} \\
(-3.32)\end{array}$ & $0.0568(1.69)$ \\
\hline High school & $\begin{array}{l}-0.177^{* * *} \\
(-4.07)\end{array}$ & $\begin{array}{l}-0.134^{* * * *} \\
(-4.96)\end{array}$ & $0.0273(0.78)$ \\
\hline Tertiary & $\begin{array}{l}-0.247^{* * *} \\
(-5.48)\end{array}$ & $\begin{array}{l}-0.227^{* * * *} \\
(-6.55)\end{array}$ & $\begin{array}{l}-0.0188 \\
(-0.37)\end{array}$ \\
\hline Part-time & $0.0438(1.38)$ & $\begin{array}{l}0.0785^{*} \\
(2.27)\end{array}$ & $\begin{array}{l}-0.0427 \\
(-1.28)\end{array}$ \\
\hline $\begin{array}{l}\text { Full-time } \\
\text { temporary }\end{array}$ & $\begin{array}{l}-0.0224 \\
(-0.59)\end{array}$ & $0.0157(0.35)$ & $\begin{array}{l}0.152^{* *} \\
(2.84)\end{array}$ \\
\hline $\begin{array}{l}\text { Full-time } \\
\text { permanent }\end{array}$ & $\begin{array}{l}-0.141^{* * *} \\
(-4.24)\end{array}$ & $\begin{array}{l}-0.0778^{*} \\
(-2.12)\end{array}$ & $\begin{array}{l}-0.0704 \\
(-1.49)\end{array}$ \\
\hline $\begin{array}{l}\text { Self } \\
\text { employed }\end{array}$ & $0.0113(0.36)$ & $\begin{array}{l}0.0703^{*} \\
(1.97)\end{array}$ & $\begin{array}{l}-0.0480 \\
(-1.48)\end{array}$ \\
\hline Chronic ill & $\begin{array}{l}-0.0331 \\
(-1.66)\end{array}$ & $0.0108(0.62)$ & $\begin{array}{l}-0.0300 \\
(-0.96)\end{array}$ \\
\hline South & $\begin{array}{l}0.147^{* * * *} \\
(11.47)\end{array}$ & $\begin{array}{l}0.146^{* * * *} \\
(9.56)\end{array}$ & $\begin{array}{l}0.0755^{* *} \\
(2.84)\end{array}$ \\
\hline Pseudo $\mathrm{R}^{2}$ & 0.183 & 0.191 & 0.432 \\
\hline $\begin{array}{l}\mathrm{N} \text { of } \\
\text { observations }\end{array}$ & 4652 & 3644 & 305 \\
\hline t statistics & In parentheses & & \\
\hline
\end{tabular}

SILC 2015 data. Marginal effects refer to three different models estimated according to the age group of the reference person in the household, and compare the results obtained. As shown in Table 3.2, being a woman increases the probability of income poverty by $3 \%$ points both for 20-49 and 50-64 age groups, while living alone increases the probability of being income poor for people in age groups 65-74 and $50-64$ by $7 \%$ points. Being employed part-time or being self-employed increases the risk of income poverty in the 50-64 age group (by $8 \%$ points for part-timers and 7\% points for full-timers), while being employed as permanent full-time significantly reduces the probability of being income poor for $20-49$ (by $14 \%$ points) and for 
50-64 (by $8 \%$ points). Working full-time as a temporary employee increases by $15 \%$ points the probability of being income poor in the 65-74 age group.

We next analysed the 50-64 years old group, to understand how the same employment status differently affects the probability of being income poor or materially deprived by gender (Table 3.3). In this age group, working part-time is found to increase (with respect to other employment statuses) the risk of income poverty only for women by $17 \%$ points, while working full-time on a permanent contract is found to reduce the risk of income poverty only for men (by $9 \%$ points). Turning to material deprivation, men with a full-time temporary contract are more exposed to the risk of being materially deprived; their probability of material deprivation increases by $12 \%$ points if employed full-time with a temporary contract.

Table 3.3 Income poverty and material deprivation by gender-50-64 age group

\begin{tabular}{|c|c|c|c|c|}
\hline \multicolumn{5}{|c|}{ Average marginal effects } \\
\hline & \multicolumn{2}{|l|}{ Poverty } & \multicolumn{2}{|c|}{ Material Deprivation } \\
\hline & Women & Men & Women & Men \\
\hline Age & $\begin{array}{l}-0.00128 \\
(-0.31)\end{array}$ & $\begin{array}{l}-0.00512^{*} \\
(-2.47)\end{array}$ & $0.00539(1.44)$ & $\begin{array}{l}-0.000892 \\
(-0.39)\end{array}$ \\
\hline Single & $0.0670^{*}(2.16)$ & $0.0624^{* *}(2.61)$ & $\begin{array}{l}-0.0125 \\
(-0.43)\end{array}$ & $0.0351(1.38)$ \\
\hline With children & $\begin{array}{l}-0.0453 \\
(-1.02)\end{array}$ & $0.0447^{*}(2.24)$ & $0.00202(0.05)$ & $\begin{array}{l}-0.00689 \\
(-0.32)\end{array}$ \\
\hline Secondary & $\begin{array}{l}-0.127^{*} \\
(-2.02)\end{array}$ & $\begin{array}{l}-0.0793^{* *} \\
(-2.69)\end{array}$ & $0.00148(0.03)$ & $\begin{array}{l}-0.119^{* * *} \\
(-3.64)\end{array}$ \\
\hline High school & $-0.116(-1.93)$ & $-0.138(-4.61)$ & $\begin{array}{l}-0.0935 \\
(-1.63)\end{array}$ & $\begin{array}{l}-0.192^{* * *} \\
(-5.95)\end{array}$ \\
\hline Tertiary & $\begin{array}{l}-0.226^{* * *} \\
(-3.43)\end{array}$ & $\begin{array}{l}-0.221^{* * *} \\
(-5.29)\end{array}$ & $\begin{array}{l}-0.164^{* *} \\
(-2.76)\end{array}$ & $\begin{array}{l}-0.260^{* * *} \\
(-6.47)\end{array}$ \\
\hline Part-time & $0.166^{*}(2.45)$ & $0.0458(1.16)$ & $0.0775(1.24)$ & $0.0313(0.68)$ \\
\hline $\begin{array}{l}\text { Full-time } \\
\text { temporary }\end{array}$ & $0.0891(0.95)$ & $0.00165(0.03)$ & $0.105(1.09)$ & $0.125^{*}(2.21)$ \\
\hline $\begin{array}{l}\text { Full-time } \\
\text { permanent }\end{array}$ & $\begin{array}{l}-0.0102 \\
(-0.14)\end{array}$ & $\begin{array}{l}-0.0947^{*} \\
(-2.34)\end{array}$ & $\begin{array}{l}-0.0930 \\
(-1.35)\end{array}$ & $\begin{array}{l}-0.00372 \\
(-0.08)\end{array}$ \\
\hline Self-employed & $0.0884(1.33)$ & $0.0591(1.50)$ & $\begin{array}{l}-0.0950 \\
(-1.74)\end{array}$ & $0.00165(0.04)$ \\
\hline Chronic ill & $\begin{array}{l}-0.0302 \\
(-0.83)\end{array}$ & $0.0256(1.32)$ & $0.0789^{* *}(2.62)$ & $0.0607^{* *}(3.07)$ \\
\hline South & $0.130^{* * *}(4.12)$ & $0.148^{* * *}(8.40)$ & $0.201^{* * *}(8.04)$ & $0.150^{* * *}(8.35)$ \\
\hline Pseudo $R^{2}$ & 0.181 & 0.204 & 0.241 & 0.139 \\
\hline Observations & 860 & 2784 & 860 & 2784 \\
\hline t statistics & \multicolumn{4}{|l|}{ In parentheses } \\
\hline
\end{tabular}

${ }^{*} \mathrm{p}<0.05,{ }^{* *} \mathrm{p}<0.01,{ }^{* *} \mathrm{p}<0.001$

Source Authors' analysis, IT SILC 2015 data 


\section{Attitudes Towards Extended Working Life Across European Countries}

The World Values Survey (WVS 2012) is a global research project that explores people's values and beliefs, their stability or change over time and their impact on social and political development of societies in different countries of the world. WVS began in 1981 and quickly became one of the most widely-used and authoritative cross-national and time-series surveys.

The general purpose of the WVS is to promote the advancement of social sciences. The WVS is the largest non-commercial, cross-national, time series investigation of human beliefs and values ever executed, currently including interviews with almost 400,000 respondents. Moreover, the WVS is the only academic study covering a full range of global variations, from very poor to very rich countries, in all of the world's major cultural zones. WVS shows pervasive changes in what people want out of life and what they believe. In order to monitor these changes, the EVS/WVS has executed seven waves of surveys from 1981.

The survey seeks to use the most rigorous, high-quality research designs in each country. The WVS consists of nationally representative surveys conducted in almost 100 countries using a common questionnaire. Representative national samples of each country are interviewed, using a standardised questionnaire that measures support for democracy, tolerance to foreigners and ethnic minorities, support for gender equality, the role of religion and changing levels of religiosity, the impact of globalisation, attitudes toward the environment, work, family, politics, national identity, culture, diversity, insecurity, subjective wellbeing, among others (WVS).

Using this source of data, we have analysed how stereotypes and discrimination arise toward people aged over 70. Attitudes toward people over 70 as potential labour force workers, as well as stereotypes and discrimination in countries with differing social welfare regimes, cultures, demographic and economic situations are analysed together with individual characteristics (gender, age, education, life satisfaction) and a broader system of values affecting the different attitudes alongside stereotypes and discrimination. In other words, individual characteristics and contextual variables are included in analyses of situations in selected European and non-European countries. Table 3.4 shows basic differences in attitudes towards older people in compared countries.

\section{An analysis of gender and health as drivers or barriers of extended working life for the older age groups in Europe (European Quality of Life Survey).}

Based on above described drivers and barriers to extended working life (e.g. Hasselhorn and Apt 2015), the idea of this research was to test the impact of various personal factors on work in later life and to quantify some main drivers and barriers to extended working life for the older age groups in Europe. It should be mentioned that the focus was not on social framework conditions-which admittedly are different in different EU countries - but on personal characteristics of potential workers in the older age group. The main aim was to determine and quantify the overall effect of gender and health on work (likelihood) in older age groups. 
Table 3.4 Summary: Differences in attitudes toward older people in selected countries

\begin{tabular}{|c|c|c|}
\hline & $\begin{array}{l}\text { The lowest } \\
\text { acceptance/opinion }\end{array}$ & $\begin{array}{l}\text { The highest } \\
\text { acceptance/opinion }\end{array}$ \\
\hline $\begin{array}{l}\text { Perceived social position: } \\
\text { people in their } 70 \mathrm{~s}\end{array}$ & $\begin{array}{l}\text { Above } 50 \% \text { of population: } \\
\text { Estonia, Poland, Romania, } \\
\text { Sweden, Ukraine }\end{array}$ & $\begin{array}{l}\text { Above } 30 \% \text { of population: } \\
\text { Cyprus, Germany, USA }\end{array}$ \\
\hline $\begin{array}{l}\text { People over } 70 \text { : are seen as } \\
\text { friendly }\end{array}$ & $\begin{array}{l}\text { Above } 15 \% \text { of population: } \\
\text { Belarus, Estonia, Poland, } \\
\text { Spain, Ukraine }\end{array}$ & $\begin{array}{l}\text { Above } 60 \% \text { of population: } \\
\text { Cyprus, Germany, } \\
\text { Netherlands, Romania, } \\
\text { Slovenia, USA }\end{array}$ \\
\hline $\begin{array}{l}\text { People over 70: are seen as } \\
\text { competent }\end{array}$ & $\begin{array}{l}\text { Above } 25 \% \text { of population: } \\
\text { Estonia, Poland, Romania, } \\
\text { Slovenia, Spain, USA }\end{array}$ & $\begin{array}{l}\text { Above } 50 \% \text { of population: } \\
\text { Estonia, Germany, Sweden }\end{array}$ \\
\hline $\begin{array}{l}\text { People over 70: viewed with } \\
\text { respect }\end{array}$ & $\begin{array}{l}\text { Below } 10 \% \text { of population: } \\
\text { Estonia, Germany, Poland, } \\
\text { Slovenia, Sweden, Ukraine }\end{array}$ & $\begin{array}{l}\text { Above } 70 \% \text { of population: } \\
\text { Belarus, Cyprus, the } \\
\text { Netherlands, Poland, } \\
\text { Romania, Slovenia }\end{array}$ \\
\hline $\begin{array}{l}\text { Older people get more than } \\
\text { their fair share from the } \\
\text { government }\end{array}$ & $\begin{array}{l}\text { Below } 15 \% \text { of population } \\
\text { "the lowest disagreement": } \\
\text { Sweden, USA }\end{array}$ & $\begin{array}{l}\text { Above } 90 \% \text { of population } \\
\text { "The highest disagreement": } \\
\text { Estonia, Germany, Poland, } \\
\text { Spain, Ukraine }\end{array}$ \\
\hline $\begin{array}{l}\text { Companies that employ } \\
\text { young people perform better } \\
\text { than those that employ people } \\
\text { of different age }\end{array}$ & $\begin{array}{l}\text { Below } 45 \% \text { of population } \\
\text { "the lowest disagreement": } \\
\text { Belarus, Cyprus, Romania, } \\
\text { Ukraine }\end{array}$ & $\begin{array}{l}\text { Above } 75 \% \text { of population } \\
\text { "The highest disagreement": } \\
\text { Estonia, Germany, } \\
\text { NetherlandsPoland, Slovenia, } \\
\text { Spain, Sweden, USA }\end{array}$ \\
\hline $\begin{array}{l}\text { Is a } 70 \text {-year old boss } \\
\text { acceptable }\end{array}$ & $\begin{array}{l}\text { Below } 50 \% \text { of population } \\
\text { "the lowest acceptance": } \\
\text { Belarus, Poland, Romania, } \\
\text { Slovenia }\end{array}$ & $\begin{array}{l}\text { Above } 45 \% \text { of population } \\
\text { "The highest acceptance": } \\
\text { Germany, Spain, USA }\end{array}$ \\
\hline $\begin{array}{l}\text { Is a } 30 \text {-year old boss } \\
\text { acceptable }\end{array}$ & $\begin{array}{l}\text { Above } 15 \% \text { of population } \\
\text { "the lowest acceptance": } \\
\text { Cyprus, Poland, Slovenia, } \\
\text { Sweden, USA }\end{array}$ & $\begin{array}{l}\text { Above } 65 \% \text { of population } \\
\text { "the highest acceptance": } \\
\text { Belarus, Estonia, } \\
\text { Netherlands, Romania, Spain, } \\
\text { Ukraine }\end{array}$ \\
\hline
\end{tabular}

Source Author's own calculations from WVS data

The analysis relies on data from the 2011/12 European Quality of Life Survey (EQLS 2012) by the Dublin based European Foundation for the Improvement of Living and Working Conditions (Eurofound). The survey is undertaken every four years and covers a range of indicators, such as employment, income, education, housing, family, health and work-life balance. It also looks at subjective topics, such as people's levels of happiness, how satisfied they are with their lives, and how they perceive the quality of their societies.

The analysis focused on the probability of working in later life, with gender, health, education, family status and the size of the household of the respondent as 
Table 3.5 Factors impacting on extended working life (EQLS, wave 3), logistic regression

Probability of working $=\mathrm{f}$ (gender, health, education, family status, size of $\mathrm{HH}$ )

\begin{tabular}{|c|c|c|c|c|}
\hline & $\begin{array}{l}\text { Wave } 3,50-65 \text { years } \\
(\mathrm{n}=9.871)\end{array}$ & Std. error & $\begin{array}{l}\text { Wave } 3,65+\text { years }(\mathrm{n} \\
=8.966)\end{array}$ & Std. error \\
\hline Gender $(0 \mathrm{~m}, 1 \mathrm{f})$ & $-0.367^{* * *}$ & 0.045 & $-0.449^{*}$ & 0.180 \\
\hline $\begin{array}{l}\text { Q42 in general, } \\
\text { would you say your } \\
\text { health is ... (increase } \\
\text { means getting worse) }\end{array}$ & $-0.594^{* * * *}$ & 0.026 & $-0.526^{* * *}$ & 0.097 \\
\hline Secondary & $1.380^{* * *}$ & 0.071 & $1.0533^{* * *}$ & 0.281 \\
\hline Tertiary & $1.994^{* * *}$ & 0.084 & $1.713^{* * *}$ & 0.297 \\
\hline Married_partner & -0.109 & 0.091 & -0.395 & 0.331 \\
\hline Separated & 0.175 & 0.095 & 0.307 & 0.354 \\
\hline Widowed & $-0.541^{* * *}$ & 0.111 & $-1.252^{* *}$ & 0.364 \\
\hline $\begin{array}{l}\text { Household size (incl. } \\
\text { children) }\end{array}$ & $0.174^{* * *}$ & 0.027 & 0.200 & 0.136 \\
\hline Constant & -0.096 & 0.129 & $-3.356^{* * *}$ & 0.495 \\
\hline
\end{tabular}

${ }^{*} \mathrm{p}<0.05,{ }^{* *} \mathrm{p}<0.01,{ }^{* * *} \mathrm{p}<0.001$

Source Author's own calculation, EQLS data for EU28

input factors. Table 3.5 shows some logistic regression results for the 50-65 and 65+ year old respondents.

Table 3.5 shows the results of the regression, with statistically significant results highlighted in bold. For both age groups, as well as for the 35-49-year-old respondents (not shown here), lower self-reported health has a negative impact on all respondents' probability to work - thus also in later life showing a higher effect for the 50-65 age group, who are more likely not to return to paid employment. Education, and the type of job one holds, also play a role. Not unexpectedly, attaining higher than primary education has a positive effect on work, with tertiary education having a stronger influence than secondary education. Family status and household size matter, in that they impact on available funds and finances needed. While being married does not have a statistically significant effect in these data, being separated has some effect in the 50-65 age group. Being widowed significantly reduces the likelihood of work for both older age groups. One explanation could be found in the existence of survivor benefits that reduce financial pressure, while social issues might also play a role, e.g. more (unpaid) engagement in the extended family. Household size was found to impact positively on work for the 50-65-year olds, indicating that larger households might include younger (or older) family members and thus have larger financial needs. 


\section{Concluding Remarks}

WG3's contribution to the COST Action on the one hand has been to identify a wide set of data sets (mainly quantitative, but also including some qualitative data) that can be used to investigate the implications of extended working life from a gender and health perspective. In this chapter, we show just three possible applications using three different data sets: EU SILC to analyse the impact of different working conditions on wellbeing by age group and by gender; WVS to detect attitudes towards people aged over 70, allowing a cross-national analysis; and EQLS to analyse how factors such as health and marital status affect extended working life.

We refer in this chapter to indicators that can be constructed from existing data to measure different dimensions of wellbeing and their interaction with gender and extended working life. However, we want to point out that (more) gender-relevant variables (such as time devoted to unpaid care and housework) should be integrated into the existing reporting and surveys on income and working conditions to account for and monitor the interaction of extended working life with important sources of gender inequalities that are rooted in the current social reproduction gender structure.

\section{References}

Eurofound. (2017). European quality of life survey 2016: Quality of life, quality of public services, and quality of society. Publications Office of the European Union, Luxembourg.

European Commission. (2012). White paper: An Agenda for Adequate, Safe and Sustainable Pensions, SWD (2012) 8, Brussels, February 16, 2012 COM (2012) 55. http://ec.europa.eu/ transparency/regdoc/rep/1/2012/EN/1-2012-55-EN-F1-1.Pdf. Accessed 8 November 2018.

European Quality of Life Surveys (EQLS). (2012). 3rd wave 2011/12. Retrieved June 10, 2017, from https://www.eurofound.europa.eu/surveys/european-quality-of-life-surveys/ european-quality-of-life-survey-2012.

Hasselhorn, H. M., \& Apt, W. (2015, Editors). Understanding employment participation of older workers: Creating a knowledge base for future labour market challenges. Retrieved January 2019, from https://www.jp-demographic.eu/wp-content/uploads/2015/07/JPIUEP_Brochure.pdf.

OECD/EU. (2018). Health at a glance: Europe 2018: State of health in the EU cycle. Paris: OECD Publishing. Retrieved January 4, 2020, from https://doi.org/10.1787/health_glance_eur-2018-en.

OECD/EU. (2016). The labour market impact of ill-health. In Health at a glance: Europe 2016. Paris: OECD Publishing. Retrieved March 12, 2017, from https://doi.org/10.1787/health_glance_ eur-2016-4-en.

World Health Organization. (2018). European health report 2018. More than numbers-evidence for all. Retrieved January 4, 2020, from http://www.euro.who.int/en/data-and-evidence/ european-health-report/european-health-report-2018/european-health-report-2018.-more-thannumbers-evidence-for-all-2018.

World Values Survey (WVS). (2012). Retrieved November 15, 2018, from http://www. worldvaluessurvey.org/wvs.jsp. 
Open Access This chapter is licensed under the terms of the Creative Commons Attribution 4.0 International License (http://creativecommons.org/licenses/by/4.0/), which permits use, sharing, adaptation, distribution and reproduction in any medium or format, as long as you give appropriate credit to the original author(s) and the source, provide a link to the Creative Commons license and indicate if changes were made.

The images or other third party material in this chapter are included in the chapter's Creative Commons license, unless indicated otherwise in a credit line to the material. If material is not included in the chapter's Creative Commons license and your intended use is not permitted by statutory regulation or exceeds the permitted use, you will need to obtain permission directly from the copyright holder.






\title{
Chapter 4 \\ Policy Toolkits on Employment and Ageing: A Conceptual Framework
}

\author{
Nata Duvvury, Jonas Radl, E. K. Sarter, Simone Scherger \\ and Jeroen Spijker
}

\begin{abstract}
Policy toolkits provide useful information and can be drawn upon as guidance in different stages of the policy-making process. This chapter reviews existing policy toolkits on employment and ageing, aiming to distil a conceptual categorisation intended to inform research uptake strategies. As a basis, we develop a clear definition of policy toolkits and propose a typology of policy tools that consists of four types: (1) good practice, (2) social indicators, (3) programme evaluation and (4) forecasts, projections and simulations. We also describe the underlying relationship between research and policy-making, and provide a synthetic overview of toolkits available for ageing-related issues in the area of employment and pensions. We conclude with the observation that effective policy toolkits hinge on the prior formulation of clear policy goals and that different policy goals may not always be congruent with each other or be simultaneously achieved.
\end{abstract}

Keywords Policy toolkits $\cdot$ Policy cycle $\cdot$ Programme evaluation $\cdot$ Population ageing $\cdot$ Extended working

\author{
N. Duvvury $(\varangle)$ \\ School of Political Science and Sociology, National University of Ireland, \\ Galway, Ireland \\ e-mail: nata.duvvury@nuigalway.ie \\ J. Radl \\ University of Madrid, Madrid, Spain \\ e-mail: jradl@clio.uc3m.es \\ WZB Berlin Social Science Center, Berlin, Germany \\ E. K. Sarter \\ Faculty of Business and Society, University of South Wales, South Wales, UK \\ S. Scherger \\ Bremen International Graduate School of Social Sciences, \\ University of Bremen, Bremen, Germany \\ J. Spijker \\ Centre for Demographic Studies (CED), Bellaterra, Barcelona, Spain \\ (C) The Author(s) 2020




\section{Introduction}

This chapter gives an overview of policy toolkits focusing on ageing-related issues in the area of employment and pensions. The figurative notion of policy toolkit does not have a well-defined meaning. Intuitively, it refers to a set of items that aid in the development or assessment of policies. Given this ambiguity, it is beyond the scope of the current paper to examine all existing proposals for policy tools or toolkits. Instead, we will exclusively focus on analytical policy tools, which are used to assess the efficacy and efficiency of existing policies in the area of ageing. In other words, rather than attempting to provide a full inventory of the previous work in the field, this chapter explores the existing knowledge with the objective to identify pervasive practices regarding the link between research and policies. To this aim, it proposes a clearer definition of policy toolkits and a typology of policy tools, which is subsequently used to provide a synthetic overview of toolkits available in the broader field of ageing. Then we spell out the underlying conception of the relationship between research and policy-making that informs the analysis of specific policies. We also raise some critical questions regarding the public role of policy toolkits in the concluding section.

\section{What is a Policy Toolkit?}

Policy tools or toolkits are a common end product of any policy driven research. 'Policy toolkits' are conceived here as comprehensive sets of recommendations for the setup or reform of policies that are based on insights gained from research. In other words, the primary objective of policy toolkits is to inform policy makers of the key parameters that need to be considered for specific policy decisions relevant to a particular issue. Toolkits (a) establish the existing evidence that is relevant to a given policy goal (e.g. extending working life), (b) lay out the potential solutions, (c) address their applicability across contexts and (d) assess their long-term impact.

This initial conceptualisation is still markedly broad as the referenced tools and their finality can be conceived in a myriad of ways. An important distinction refers to whether the purpose of the tools is analytical or strategic. An analytical toolkit aims to identify which policies best achieve certain given objectives. By contrast, a strategic toolkit aims to influence the policy process in a particular way that has been established a priori. Informing and influencing policies is the main purpose of think tanks and many interest groups are similarly looking for ways to effectively advocate their political goals. For example, toolkits for civil society organisations in Africa have been released by both an alliance of NGOs and the UN Developmental Programme (Sonke Gender Justice Network 2013) as well as by the Catholic Church (CAFOD 2005). Additionally, more technical or implementation-oriented toolkits consisting of concrete guidelines exist that inform or instruct policy-makers concerned with reforming existing policy schemes or setting up new ones. An example 
of an implementation-oriented toolkit is the Policy Toolkit for Strengthening Health Sector Reform published by the Latin American and Caribbean Regional Sector Reform Initiative (Scribner and Brinkerhoff 2000), a joint effort of the US Agency for International Development and other organisations, which primarily addresses government officials. Similarly, the OECD (2010) has produced a Consumer Policy Toolkit directed at policy makers, which reviews policy tools and gives guidelines on developing an adequate consumer policy. The present chapter focuses exclusively on analytical toolkits.

The audiences of policy tools are not only politicians, policy makers and public administration, but also (other) social scientists as well as the interested public audience in general: the tools are also used in the wider debate around the mentioned policy issues, and can serve the articulation of public opinions in democratic societies. At the same time, it is the least complex tools that are more often used in wider debates as they lend themselves more readily to addressing general audiences.

\section{A Typology of Tools}

As a framework to map existing analytical policy tools, we propose the following typology: (1) good practice; (2) social indicators; (3) programme evaluation; (4) simulation and forecast. Table 4.1 gives an overview of the different tool types and their key properties. The order used here follows the degree of technical complexity.

We speak of toolkits if various similar tools are provided as a package. For example, the OECD Employment Outlook periodically publishes a series of standardised labour market indicators (e.g. employment rate, long-term unemployment rate) broken down by multiple variables (country, sex, age, etc.). Each report can thus be understood as a toolkit containing a set of tools.

Each type of policy tool functions in a different way, given its distinct purpose, as we explain in more detail below. In addition, some of the strengths and weaknesses of each type of policy tool are also briefly discussed. Definitions and concrete examples of each type of policy toolkit are provided in Table 4.2.

Table 4.1 Overview of types of policy tools

\begin{tabular}{l|l|l|l|l}
\hline Tool type & $\begin{array}{l}\text { Technical } \\
\text { sophistication }\end{array}$ & Mechanism & Strength & Weakness \\
\hline Good practice & Low & Imitation & Simplicity & Transferability \\
\hline Social indicators & Medium & Quantification & Comparability & Reductionism \\
\hline $\begin{array}{l}\text { Programme } \\
\text { evaluation }\end{array}$ & High & Experiment & Specificity & $\begin{array}{l}\text { Costly } \\
\text { implementation }\end{array}$ \\
\hline $\begin{array}{l}\text { Forecast, } \\
\text { projection \& } \\
\text { simulation }\end{array}$ & High & Statistical model & Flexibility & $\begin{array}{l}\text { Dependence on } \\
\text { assumptions }\end{array}$ \\
\hline
\end{tabular}

Source Own elaboration 
Table 4.2 Definition and examples of policy tool kits

\begin{tabular}{|c|c|c|}
\hline Toolkit type & Definition & Examples \\
\hline Good practice & $\begin{array}{l}\text { Identification of well-functioning } \\
\text { policies through expert opinions and } \\
\text { public discourse establishing the quality } \\
\text { of a certain policy }\end{array}$ & $\begin{array}{l}\text { - The EU Learning Programme (2012) } \\
\text { provides a Peer Review of Older } \\
\text { Workers in Public Service } \\
\text { - The European Observatory of } \\
\text { Working Life (EurWORK) provides } \\
\text { case studies of companies as best } \\
\text { practice examples, amongst others } \\
\text { covering the issues of the "ageing } \\
\text { workforce" and of "workers with care } \\
\text { responsibilities" (Eurofound 2015) } \\
\text { - Care credits to accumulate pension } \\
\text { entitlements for childcare (Duvvury } \\
\text { et al. 2018) }\end{array}$ \\
\hline $\begin{array}{l}\text { Social } \\
\text { indicators }\end{array}$ & $\begin{array}{l}\text { Use of clearly defined measures to } \\
\text { assess the outcomes that current policies } \\
\text { produce in specific societal domains, } \\
\text { especially from a comparative } \\
\text { perspective }\end{array}$ & $\begin{array}{l}\text { - Old-age dependency ratio as part of } \\
\text { the Europe 2020 Strategy indicators } \\
\text { (Eurostat 2017) } \\
\text { - Social inequality indicators, e.g. } \\
\text { poverty rates; social spending as a } \\
\text { percentage of GDP; deprivation } \\
\text { indices; gender gap index (World } \\
\text { Economic Forum 2017) } \\
\text { - Employment trends of older workers } \\
\text { during the economic recession that } \\
\text { coincides with policy reform aimed at } \\
\text { supporting older workers (Eurofound } \\
\text { 2012) }\end{array}$ \\
\hline $\begin{array}{l}\text { Programme } \\
\text { evaluation }\end{array}$ & $\begin{array}{l}\text { Measurement of efficacy and efficiency } \\
\text { of policy programmes, the sound } \\
\text { accounting of budgets applying clear } \\
\text { financial concepts, or experimental } \\
\text { research designs applied to examine the } \\
\text { causal effect of a given policy or public } \\
\text { intervention }\end{array}$ & $\begin{array}{l}\text { - Impact of automatic enrolment into } \\
\text { tax-qualified defined-contribution } \\
\text { pension plans (Madrian and Shea } \\
\text { 2001) } \\
\text { - Retaining workers through } \\
\text { firm-provided training, including older } \\
\text { workers (Picchio and van Ours 2013) } \\
\text { - Effects of Finnish pension reform on } \\
\text { firms' incentive to hiring older } \\
\text { employees (Ilmakunnas and } \\
\text { Ilmakunnas 2015) } \\
\text { STAR program, RCT increasing } \\
\text { flexibility in the workplace (Moen } \\
\text { et al. 2016) }\end{array}$ \\
\hline $\begin{array}{l}\text { Forecasts, } \\
\text { projections } \\
\text { and simulation }\end{array}$ & $\begin{array}{l}\text { Based on statistical models, forecasts, } \\
\text { projections and simulations infer from } \\
\text { observed policy outcomes and their } \\
\text { causes to potential future outcomes } \\
\text { under clearly determined scenarios and } \\
\text { certain ancillary conditions }\end{array}$ & $\begin{array}{l}\text { - OECD Pensions at a Glance: } \\
\text { Simulated "Net pension wealth" per } \\
\text { country (OECD 2017) } \\
\text { - Mortality forecasts by socioeconomic } \\
\text { characteristics (Spijker 2014) } \\
\text { - Ansah et al. (2015) compare } \\
\text { projections up to year } 2040 \text { of persons } \\
\text { aged 60-79 and aged } 80+\text { with } \\
\text { functional disability in Singapore with } \\
\text { and without accounting for the } \\
\text { changing educational composition of } \\
\text { the Singaporean elderly }\end{array}$ \\
\hline
\end{tabular}




\section{Good Practice}

The most basic analytical tool consists of the identification of good practice policies. The status of 'good practice' is attained based on the positive assessment of a policy or practice, typically through expert opinions or public discourse. It is the simplest, yet possibly also the most powerful analytical tool. It emphasises the virtues of a particular case that achieves good results, stressing the elements or defining features that are deemed responsible for its outstanding performance. The identification is usually based on predominantly qualitative analysis which employs interpretative research methods involving a case-oriented and context-sensitive perspective. Ultimately, this tool aims at imitation as the main implementation mechanism.

However, this tool rests on the often problematic assumption that the model of 'good practice' can be simply copied partly or entirely to improve the functioning of other cases. Moreover, the acquisition of the status as 'good practice' is often based on merely anecdotal evidence. Lacking a systematic method for comparison, the outstanding position that is discursively assigned to certain pioneer cases, role models or prototypes, can be incidental. What practice is en vogue and counts as the 'best' is partly subject to dynamics of herd mentality and groupthink. Not unlike the fashion cycle, perceptions of boom or bust can also change quickly as fresh empirical evidence becomes available. For example, the German model of publicly subsidised private pensions (Riester-Rente) were first considered a failure as uptake was slow initially, then deemed good practice during a number of years as participation rates rose at a healthy pace, and now seriously questioned again as projected benefit levels disappoint and administration costs turn out too high given the moderate average performance of funds (Hagen 2018). Therefore, it is important to maintain a critical distance and not place too much weight on the presumed superiority of a given practice over others before it has been put to a more rigorous test, e.g. through more technically refined policy tools such as social indicators or programme evaluation (which are described in detail below).

There are two classes of 'good practice' that are relevant in the present context: (a) good practice in legislation and public welfare programmes on the one hand, and (b) good practice at the workplace level on the other.

In the realm of legislation, a famous case of a 'good practice' is the switch to a non-financial or notional defined contribution system of pensions in Sweden, which is considered the first major pension reform in an advanced industrial society to react to the challenges posed by population ageing. By adjusting benefits according to average life expectancy and economic growth it offered a systematic solution that would ensure system sustainability (Glans 2008). Many international observers took note as the reform tackled a common problem many other countries were facing in a similar manner. The system was celebrated in the pension policy discourse and several of its components were adopted in other national pension reforms (see, e.g. Palmer 2000). As another example, in 2014 the German parliament passed legislation introducing a minimum wage, thereby ending a decade-long controversy in the country on the subject. In the public debate on the issue, the presence of minimum wage 
regulations in most other advanced economies was a powerful argument. In addition, a commission of trade union and business representatives evaluates the minimum wage every two years, which led to the recent increase from $8.50 €$ to $8.84 €$ per hour. Interestingly, by introducing the system of regular monitoring, stakeholders are building a body of evidence to influence further policy development.

While both 'good practices' mentioned here are examples of large-scale systemic welfare state reforms, smaller pieces of legislation can also become 'good practice'. For example, in the 'employer toolkit' for managers of older workers published by the UK Department for Work and Pensions (2016), it is recommended to limit exposure to night work for workers over 60 and increase rest periods (despite recognising that there exists no robust evidence that shift work has more adverse consequences for the wellbeing of older workers). An extensive report of good practice based on company case studies recommends work groups that are of mixed age (European Commission 2006: 145). These are typical examples of good practice at the workplace level.

\section{Social Indicators}

Social indicators are "[e]asily identified features of a society which can be measured, which vary over time, and are taken as revealing some underlying aspect of social reality' (Scott and Marshall 2005: 61). They are clearly defined quantitative measures assessing the outcomes that current policies produce in specific societal domains. Social indicators are often established as time series to ease comparability and are used in all fields of policy. Examples for social indicators in the field of old age and work are the unemployment rate among 55-64 year-old persons, poverty rates among people of pension age, or average replacement rates offered by national pension schemes.

An indicator usually consists of a single figure that contains the relevant information in a very condensed form. At the same time, there are often variations of one and the same indicator (e.g. poverty levels based on different poverty definitions). In some cases (such as poverty), these variations reflect a lack of agreement on which is the most appropriate measure of an underlying matter. Other indicators, by contrast, are highly standardised and conventional (for example mortality rates). Social indicators are based on administrative data, censuses or large social surveys. They are particularly useful for comparing outcomes over time, between gender, age or social groups, between spatial units (such as cities, regions, countries) or between administrative units. Due to their condensed form, social indicators are very powerful and attractive tools which are easy to use and to disseminate.

Still, as they are so condensed it is of paramount importance to understand the origin of an indicator, i.e. (the generation of) its data base and its mathematical derivation, in order to interpret it accurately. Their reductionism is thus also the weakness of social indicators, as they can be easily drawn upon or understood in oversimplifying or erroneous ways. Misinterpretations can arise, for example, if the content of what the indicator measures is misconceived, if trends are misread or if 
variations across different subpopulations are not adequately shown. As a famous Churchill quote illustrates ('I only believe in statistics that I doctored myself'), social indicators carry the risk of being instrumentalised in detrimental ways.

Notably, not every quantitative measure relating to policy outcomes is a social indicator. Rather, social indicators are those measures which are seen as capturing a crucial aspect of policy outcomes, such as the distribution of resources, economic performance, etc. What kinds of measures become important and conventional as social indicators is the result of social processes, in particular the interaction of social sciences and policy practice, in the course of which the related measure becomes charged with meaning (see section "Good Practice" for further details).

Nowadays, social indicators are widely used on different policy levels, be they local, regional, national, or international. Complex infrastructures producing and reporting social indicators have been established (at least) on national and international levels. International organisations like Eurostat, the Organisation for Economic Co-operation and Development (OECD) or the International Labour Organisation (ILO), use a multitude of social indicators for reports on various features of societies. While indicators are frequently compared between countries and over time, similar reporting systems often exist on national and regional levels.

\section{Programme Evaluation}

Programme evaluation refers to the measurement of the efficacy and efficiency of public policies or workplace practices. It focuses on comparing costs and benefits of a given programme, thus calculating the effectiveness and productivity of specific investments. This puts decision-makers in the public and private sector in the position to make informed choices about the efficient allocation of resources. To be capable of comparing inputs and outputs in an orderly manner, programme evaluation is based on the precise definition of the aims of the programme, the sound accounting of budgets and clear definitions of the applied financial concepts. Often, pre-defined 'performance indicators' (which share many features of the social indicators described in the foregoing section) are used to measure outputs.

The gold standard to measure the efficacy and efficiency of a policy programme or intervention consists of the application of an experimental research design. Simply comparing participants with non-participants or measuring the output of interest before and after participation in the programme may lead to flawed results because of possible confounding factors, selection effects and environmental influences. Rather, a rigorous impact assessment aims to find out whether a possible change in the target population has indeed been a direct consequence of the programme, or possibly would have happened anyway. The causal effect of the programme is identified by means of comparison with a counter-factual scenario in which the programme does not exist. Therefore, such programme evaluations characteristically involve closed 
experiments with treatment and control groups (or sometimes natural experiments), ${ }^{1}$ to examine the direct effects of a given policy reform or public intervention. To further illustrate this tool type, Text Box 4.1 provides an example of a US programme evaluation of an organisational redesign policy aimed at facilitating flexibility in the workplace.

Programme evaluation can also be used for the appropriate fine-tuning of policy programmes, to check whether there are problems in their implementation (this also falls under the label of process evaluation), whether given programmes work better for certain subgroups of the population or segments of the economy, etc. Sometimes, rather than employing an experimental design, the evaluation of public policies is based on a dense narrative or process tracing of the policy and its success. In these instances, the boundary to 'good practice' tools (described above) is blurred as both approaches rely on "soft" methods for the measurement of performance.

The strength of programme evaluations resides in their analytical power and especially in the elegance of the experimental design. As it ideally produces clear-cut estimates of the causal impact of a programme, it is highly appealing to decision-makers who can convincingly demonstrate tangible results to stakeholders. The proven impact and cost-benefit relation of a particular programme may also serve as performance threshold for similar programmes, thereby providing validated measurement scales that allow benchmarking the efficacy and efficiency of policy interventions in different areas.

\section{Text Box 4.1: Example of a Programme Evaluation}

The STAR programme is a prime example of a program evaluation in the context of extending working lives policies. The study was carried out by Phyllis Moen, Erik Kojola, Erin L. Kelly and Yagmur Karakaya and published in the journal "Work, Employment and Retirement" in 2016. The policy evaluated in this randomised controlled trial was called "Support. Transform. Achieve. Results", a programme that targeted workers aged 50 to 64 years. This organisational intervention was carried out in the IT division of a large US company. The intervention involved three elements:

(1) participatory training sessions in which working groups discussed ideas to increase employees' working time flexibility by improving the efficiency of work processes;

(2) training sessions for supervisors to become more mindful of employees' private affairs and aware of possible work-life imbalances in their organisations;

(3) evaluating measures to focus on results over hours at the workplace rather than "face time", e.g. by avoiding inefficient meetings requiring unnecessary physical presence.

The authors report substantial effects on expectations of later retirement measured five years after the introduction of STAR: "the likelihood of expecting to retire later, at age 67 or older, is on average $10.3 \%$ points higher for those in STAR, net of all other factors" (Moen et al. 2016: 330). Although the exact mechanisms behind this

\footnotetext{
${ }^{1}$ Experimental designs may also be statistically 'simulated' by matching methods if detailed data on the policy programme and participants as well as non-participants are collected.
} 
positive outcome are not unambiguously clear, the findings convincingly demonstrate that flexibility interventions are capable of altering retirement expectations. By making working conditions more accommodating for older workers, later retirement becomes a more attractive option.

The most important disadvantages of this methodology are pragmatic in nature. Implementation issues include elevated costs, work intensity and time requirements, especially if oversimplifying approaches like before-after-comparisons are to be avoided. Evaluating a public policy of a certain scale is a demanding task because often many actors are involved who need to be coordinated to ensure the proper setup of the experiment (e.g. compliance with assignment to treatment status, avoidance of contamination effects, etc.). Since programme evaluation usually involves considerable personnel costs and time requirements, there is the risk that eventual efficiency gains will be outweighed by the administrative and other costs of implementing the evaluation. Finally, as was the case with 'good practice', the functioning of a policy programme is always to some extent context-dependent, and it is possible that a given programme will not work in the same way in a different social environment.

\section{Forecasts, Projections and Simulations}

Projections, forecasts and simulations usually serve to predict future outcomes (in the case of projections and forecasts) or to speculate on potential outcomes (simulations) of a policy or several interrelated policies. They usually refer to the aggregate level of outcomes, ${ }^{2}$ not to the individual level, and involve several indicators that have been collected through large-scale surveys, censuses or administrative data. Based on models using advanced statistical methods, this type of tool serves to infer from past and current policy outcomes and their causes to future or potential outcomes in order to establish clearly determined scenarios of what will happen or of what might happen if certain ancillary conditions change in a specific way.

In more detail, projections and forecasts often target an important social indicator. Forecasts extrapolate past changes and current influences on the targeted measure into the future, while projections are based on specific assumptions regarding ancillary conditions. $^{3}$ As the latter are often uncertain, projections are frequently based on different scenarios. Typical examples of this are population projections, which are usually established on the basis of several different scenarios regarding births, deaths and net-migration (e.g. Tabeau et al. 2001). Simulations work quite differently as they recreate real individual-level events. Moreover, assumptions about ancillary conditions tend to involve changes that are currently not very probable. For example,

\footnotetext{
${ }^{2}$ Sometimes, outcomes for individual model cases are simulated or projected as well, as for example pension benefits following from different types of earning trajectories assuming the formula for the calculation of pensions or other parameters are modified.

${ }^{3}$ Note that the usage and definitions of the terms projections and forecasts vary across disciplines.
} 
a simulation may be combined with projections in order to answer so-called "what if" questions, such as what would happen if a certain policy was introduced or ceased, or what would have happened if it had not been introduced. As can be seen from the above example, boundaries between projections and forecasts on the one hand, and simulations, on the other, can be fluid.

Projections, forecasts and simulations become more complex the more ancillary conditions are included into the underlying statistical model. In most cases, projections and forecasts can only provide a simplified prediction of the future, because it is not possible to include all ancillary conditions in the model. Moreover, trends and ancillary conditions can change in unpredictable ways, for example due to unforeseen events, such as wars or economic crisis. Generally, results are more precise for the nearer than for the far future.

Projections, forecasts and simulations are very challenging tools to assess policy results, as they require detailed quantified assumptions about the crucial influences on the outcome of interest. The latter can only be derived from good statistical explanations of the past or very good theories-simple extrapolations from past trends to the future, without any ancillary assumptions, will often produce inadequate projections.

As projections, forecasts and simulations can help to speculate about the future in a systematic way and to assess potential outcomes of a policy, they can be crucial for political planning. As other tools, however, they have to be adequately understood and interpreted to fully exploit their potential, and not doing so might result in consequential fallacies about the success or failure of policies. An adequate understanding of projections, forecasts and simulations importantly also includes the uncertainties inherent in each of these tools. Therefore, these types of tools tend to be targeted at expert audiences, be they policy experts or social scientists.

In addition to these four different types of tools, it should be mentioned that "policy briefs' are common synthetic toolkits which can combine the insights from several or all of the four types of analysis tools to recommend a compact set of policies. Recent examples in the area of ageing are the Gender Extended Working Life Policy Briefs (e.g. Ardito et al. 2018; Lössbroek et al. 2018).

\section{Interaction of Toolkits and Policy Processes}

While a typology of toolkits provides a useful categorisation to delineate policy toolkits by types, it provides little insight into the effectiveness of these toolkits. In this regard, it is critical to understand the policy process which these tools aim to inform. To study how policy toolkits influence actual policy decisions, some researchers focus on the ways in which policies are produced, captured and packaged as 'knowledge products' (such as national policies or service frameworks) and/or how these knowledge products are then transferred to the realm of practice. Such approaches discuss the existence of a 'gap' between research and practice, which is usually manifest in the low uptake of research evidence, in the patchy implementation of 
policies, and in stakeholder behaviour defending particular interests. According to these approaches, it is important to rethink knowledge and policy utilisation, and in fact, to frame knowledge and policy as integral element of practice, rather than apart from it (Gkeredakis et al. 2011).

\section{Policies}

Policies are actions aiming to achieve certain outcomes in response to 'some sort of problem that requires attention' (Birkland 2011: 8). While the term policy encompasses a wide range of actions and legislation, in the context of this chapter, the interactions between policy toolkits and regulatory policies are in focus. Commonly, a distinction is drawn between public policies and other policies such as company policies. Public policies are 'ultimately made by governments' (Birkland 2011: 9) at various levels. Especially in the European Union (EU) supranational policies have been increasingly influential for policy-making in the member states. Next to supranational and national policies, in a number of countries, such as for instance Germany, Spain or the US, legislative competences also exist at subnational level. The extent to which these subnational authorities can pass legislation varies distinctively from country to country. Policy-making at these different levels thus never stands alone, but is structurally embedded in a multi-level surrounding. In addition to public actors, the private sector also influences policy making. Particularly in the area of extended working life, corporate practices and workplace arrangements regarding older employees are a critical component of the broader policy framework.

\section{Policy-Making and Policy Toolkits}

In order to assess the impact of policy toolkits, it is important to take account of the way policy-making works. The most influential and most commonly applied framework for policy analysis is the concept of the policy cycle. It emphasises 'the political process as a continuous process of policy-making' (Jann and Wegrich 2007: 44) that consists of different phases or stages, which serve heuristic purposes. In practice, the different stages might not be clearly distinguishable as temporal phases (Sabatier 2007). In addition, not all phases necessarily form part of every policy process. The most common framework of the policy cycle, distinguishes four phases of policy-making: (1) Problem recognition and agenda-setting, (2) policy formulation and adoption, (3) policy implementation, and (4) policy evaluation.

(1) The starting point of every policy process is the identification of a given development, trend or situation as a problem that requires political action (Jann and Wegrich 2007). Agenda-setting has been characterised as 'an ongoing competition among issue proponents to gain the attention of media 
professionals, the public, and policy elites' (Dearing and Rogers 1996: 1-2). Policy tools and expertise can support efforts to put a specific problem on the political agenda. Especially toolkits that provide accurate and reliable information about the current state of society, ongoing trends or expected developments - such as social indicators and forecasts - can provide the basis for the identification of societal issues and their wider ramifications. In this way, they can become an important part of the assessment of the situation and of a particular problem being articulated as political issue. Finally, analytical policy tools can contribute to legitimising political action (Barkenbus 1998).

(2) Once a political issue has become part of the political agenda, the goals of the policy dealing with it have to be defined, alternative routes of action considered and a decision on the course of action has to be adopted. Within this stage, a different set of policy tools gains importance: Here, policy toolkits that provide insights into potential implications of different policy designs, key factors for minimising negative side effects or unintended consequences-such as good practices, evaluation of previous policies or simulations-are especially valuable tools that can aid the formulation of a policy. Good practice and policy evaluation can draw the attention to relevant features of institutional arrangements, helping to identify an adequate route for political action.

(3) Once a specific policy is adopted, its implementation can leave considerable space for interpretation that affects outcomes. Policies are thus interpreted and applied during implementation, influencing their shape and outcomes (Sabatier and Mazmanian 1980). In this phase, policy toolkits can provide information about factors that enable or impede a successful implementation.

(4) The last stage of the policy cycle is the evaluation of policies and of their implementation. Previous evaluations, indicators and good practice examples can be used in the course of this evaluation. In this way, policy analysis becomes an integrative part of the political process. For instance, based on best practice examples and the evaluation of similar existing policies, lessons can be learnt and depending on its outcome, either a new policy cycle is started or the policy process is terminated.

In brief, the role of policy toolkits is clearest in the evaluation stage, where policy outputs are systematically examined and analysed, but policy toolkits can provide important input during the other stages as well. Due to the inherent particularities of every stage of the policy cycle, different types of policy toolkits can gain importance to different degrees in these stages. Toolkits providing information on societal developments, trends and problems are helpful in the initial stage of the policy cycle, and toolkits offering detailed insights on policy features can be used in policy formulation as well as during the stage of implementation. The role of analytical toolkits in the first stages of the policy cycle is contingent on the specific circumstances. In democratic societies, in principle all policies are subject to public debates regarding their legitimacy and the efficient use of resources. Policy toolkits provide a sound empirical basis for this analytical task and thus fulfil a crucial function at the interface between research and practice. 


\section{Discussion and Conclusions}

This chapter has defined policy toolkits as evidence-based sets of recommendations to create or change specific policies. We have developed a typology of tools and provided a structured overview of examples of existing policy toolkits in the area of employment and pension reforms in ageing societies. Furthermore, we have placed policy toolkits within a conceptual framework of the overall policy process, and have shown how toolkits may enter the different stages of the policy cycle. The identified policy toolkits need to be further reviewed to better understand their effectiveness in improving the policy process. We have also suggested that it is critical to understand the policy cycle and understand which stage of the cycle the policy toolkit is addressing.

This conception of policy toolkits inevitably entails some limitations. As a precondition for the development of toolkits for policy analysis, there needs to be at least a tentative consensus on the societal goals and challenges that said policies aim to address. Notably, this starting point implies a normative position that has a political dimension and is influenced by national and international debates involving diverse sets of actors and stakeholders. The objectives established by the European Commission include the promotion of healthy and active ageing to guarantee the sustainability of European welfare states, but also the inclusiveness and social cohesion of European societies. In the public debate, these goals are arguably widely shared across European societies as well as among different social actors and segments of the population. However, these goals are also notoriously vague, and discordant voices that criticise the ideological connotations of the 'active ageing' paradigm (e.g. van Dyk et al. 2013), highlight the adverse effects of extending working life on gender equality (Ní Léime and Street 2017), or question the scope of the demographic 'burden' in the first place (e.g. Spijker and McInnes 2013). There is also the more general debate on the extent to which social sciences actually should be judged by their capacity to produce "useful" knowledge in the first place (e.g. Demers 2011).

Moreover, it can be questioned to what extent the different policy goals are congruent with each other, and can be simultaneously achieved. To a certain extent, the two sets of goals - those pertaining to efficiency and those pertaining to equality - are in fact at least partially competing with each other. Thus trade-offs between them need to be negotiated. In this case, is the main benchmark for public policies the extent to which they contribute to economic efficiency or whether they help attenuate social inequalities in terms of health, gender, class or other dimensions of stratification? Obviously, it should be on democratically elected politicians, not scientists or technocrats, to establish the order of political priorities which applied research should adhere to. 


\section{References}

Ansah, J. P., Malhotra, R., Lew, N., Chiu, C. T., Chan, A., Bayer, S., \& Matchar, D. B. (2015). Projection of young-old and old-old with functional disability: Does accounting for the changing educational composition of the elderly population make a difference? PLOS ONE, 10(5). https:// doi.org/10.1371/journal.pone.0126471.

Ardito, C., Neves, R., \& Spijker, J. (2018). Policy brief on health in late career. GenderEWL Policy Document 2. Galway: NUI Galway.

Barkenbus, J. (1998). Expertise and the policy cycle. Tennessee: Energy, Environment, and Resources Centre: University of Tennessee. Retrieved March 21, 2016, from http://www.gdrc. org/decision/policy-cycle.pdf.

Birkland, T. (2011). An introduction to the policy process: Theories, concepts and models of public policy making. New York: Routledge.

Catholic Agency for Overseas Development (CAFOD). (2005). Monitoring government policies: A toolkit for civil society organisations in Africa. London: CAFOD.

Dearing, J., \& Rogers, E. (1996). Agenda-setting. Thousand Oaks: Sage.

Demers, D. (2011). The ivory tower of babel: Why the social sciences are failing to live up to their promises. New York: Algora.

Department for Work and Pensions. (2016). Employer toolkit: Guidance for managers of older workers. Retrieved April 8, 2016, from https://www.gov.uk/government/collections/age-positive.

Duvvury, N., Sarter, K., Wijeratne. D., \& Vehovec, M. (2018). Policy brief on gender, pensions and pension planning. GenderEWL Policy Document 4. Galway: NUI Galway.

EU Learning Programme. (2012). PES and Older Workers: Toolkit for public employment services. Retrieved February 27, 2019, from https://ec.europa.eu/social/main.jsp?catId=1163\&intPageId= 3459\&langId=en.

Eurofound. (2012). Impact of the recession on age management policies. Retrieved February 27, 2019, from http://www.eurofound.europa.eu/sites/default/files/ef_files/pubdocs/2011/75/en/ 4/EF1175EN.pdf.

Eurofound. (2015). European Observatory of Working Life-EurWORK. Case studies. Retrieved September 25, 2018, from https://www.eurofound.europa.eu/observatories/eurwork/case-studies.

European Commission. (2006). Ageing and employment: Identification of good practice to increase job opportunities and maintain older workers in employment. Final Report. Retrieved April 8, 2016, from http://ec.europa.eu/social/BlobServlet?docId=214\&langId=en.

Eurostat. (2017). Smarter, greener, more inclusive? Indicators to support the Europe 2020 Strategy (2017 ed). Luxembourg: European Union.

Gkeredakis, E., Swan, J., Powell, J., Nicolini, D., Scarbrough, H., Roginski, C., et al. (2011). Mind the gap: Understanding utilisation of evidence and policy in health care management practice. Journal of Health Organization and Management, 25(3), 298-314.

Glans, E. (2008). Retirement patterns during the Swedish pension reform (p. 9). Working Paper Series. Uppsala Universitet: Department of Economics.

Hagen, K. (2018). Mängel der Riester-Rente sprechen fürein Standardprodukt, DIW-Wochenbericht (Vol. 85, No. 23, p. 494). Deutsches Institut fürWirtschaftsforschung (DIW), Berlin. ISSN 18608787.

Ilmakunnas, P., \& Ilmakunnas, S. (2015). Hiring older employees: Do the age limits of early retirement and the contribution rates of firms matter? Scandinavian Journal of Economics, 117(1), $164-194$.

Jann, W., \& Wegrich, K. (2007). Theories of the policy cycle. In F. Fischer, G. Miller, \& M. Sidney (Eds.), Handbook of public policy analysis: Theory, politics, and methods (pp. 43-63). Boca Raton: Taylor \& Francis.

Lössbroek, J., Radl, J., \& Warwas, I. (2018). Age management: Workplace practices promoting older workers' employability. GenderEWL Policy Document 1. Galway: NUI Galway.

Madrian, B., \& Shea, D. (2001). The power of suggestion: Inertia in 401(k) participation and savings behaviour. Quarterly Journal of Economics, 116(4), 1149-1187. 
Moen, P., Kojola, E., Kelly, E. L., \& Karakaya, Y. (2016). Men and women expecting to work longer: Do changing work conditions matter? Work, Aging and Retirement, 2(3), 321-44.

Ní Léime, A., \& Street, D. (2017). Gender and age implications of extended working life policies in the US and Ireland. Critical Social Policy, 37(3), 464-483.

Organisation for Economic Co-operation and Development (OECD). (2010). Consumer Policy Toolkit. Paris: OECD.

Organisation for Economic Co-operation and Development (OECD). (2017). Pensions at a Glance 2017. Paris: OECD.

Palmer, E. (2000). The Swedish pension reform model: Framework and issues (Social Protection Discussion Paper 12). Washington, DC: The World Bank.

Picchio, M., \& van Ours, J. C. (2013). Retaining through training even older workers. Economics of Education Review, 32, 29-48.

Sabatier, P. (2007). The need for better theories. In P. Sabatier (Ed.), Theories of the policy process (pp. 3-17). Boulder: Westview Press.

Sabatier, P., \& Mazmanian, D. (1980). The implementation of public policy: A framework for analysis. Policy Studies Journal, 8(4), 538-560.

Scott, J., \& Marshall, G. (2005). Oxford dictionary of sociology. Oxford: Oxford University Press.

Scribner, S., \& Brinkerhoff, D. (Eds.) (2000). Policy toolkit for strengthening health sector reforms IPC technical notes. Washington, DC: Latin American and Caribbean Health Sector Reform Initiative (LAC HSR), U.S. Agency for International Development. Retrieved February 27, 2019, from https://www.hfgproject.org/policy-toolkit-strengthening-health-sectorreform-september-2000/.

Sonke Gender Justice Network. (2013). Policy advocacy toolkit: How to influence public policy for social justice and gender equality in Africa. Johannesburg: Men Engage Alliance.

Spijker, J. (2014). Socioeconomic determinants of mortality in Europe: Validation of recent models using the latest available data and short-term forecasts. In J. Anson \& M. Luy (Eds.), Current perspectives in mortality research (pp. 35-78). Switzerland: Springer International Publishing.

Spijker, J., \& MacInnes, J. (2013). Population ageing: The timebomb that isn't? British Medical Journal, 347. https://doi.org/10.1136/bmj.f6598.

Tabeau, E., van den Berg Jeths, A., \& Heathcote, C. (Eds.). (2001). Forecasting mortality in developed countries: Insights from a statistical, demographic and epidemiological perspective (Vol. 9). The Netherlands: Springer.

van Dyk, S., Lessenich, S., Denninger, T., \& Richter, A. (2013). The many meanings of "active ageing". Confronting public discourse with older people's stories. Recherches Sociologiques et Anthropologiques, 44(1), 97-115.

World Economic Forum. (2017). The Global Gender Gap Report 2017. Geneva: WEF.

Open Access This chapter is licensed under the terms of the Creative Commons Attribution 4.0 International License (http://creativecommons.org/licenses/by/4.0/), which permits use, sharing, adaptation, distribution and reproduction in any medium or format, as long as you give appropriate credit to the original author(s) and the source, provide a link to the Creative Commons license and indicate if changes were made.

The images or other third party material in this chapter are included in the chapter's Creative Commons license, unless indicated otherwise in a credit line to the material. If material is not included in the chapter's Creative Commons license and your intended use is not permitted by statutory regulation or exceeds the permitted use, you will need to obtain permission directly from the copyright holder.

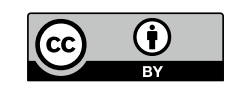




\title{
Chapter 5 \\ Problems and Prospects for Current Policies to Extend Working Lives
}

\author{
Debra Street and Áine Ní Léime
}

\begin{abstract}
This chapter condenses several of the key take-away points from earlier chapters on empirical, theoretical, and policy issues elucidated in Part One and provides readers with additional context to consider in their understanding of gender and health issues in the country-specific chapters upcoming in Part Two. First, we detail the central problematics associated with ageing populations and the policy initiatives taken so far to extend working lives. Next, we argue that for effective policymaking that would enable extended working lives, it is important to consider the interests of all of the actors affected and to pay attention to different problems that are highlighted by thinking through different levels of analysis-macro, meso, and micro. Further, we challenge the dominant rhetorical frame that policy initiatives undertaken recently have been about extending working lives, arguing instead that most countries' initiatives have been about delaying retirement. This has been embodied by policies very different from those that would be needed to ensure that older workers can remain employed longer in dignified, appropriate, and adequately compensated jobs. Both gender differences and variations in health status differentially empower older workers to continue in employment. Finally, we conclude that research and policymaking that improves understanding and the potential for extended working lives is essential, and that it must be sensitive to variations among differently advantaged sub-groups of older people.
\end{abstract}

Keywords Pension policy $\cdot$ Delayed retirement $\cdot$ Extended working life $\cdot$ Gender $\cdot$ Health $\cdot$ Older workers $\cdot$ Lifecourse

\section{Introduction}

As earlier chapters attest, there are many challenges posed by the changing compositions of national populations. This volume touches on several major issues associated

\section{Street $(\bowtie)$}

Department of Sociology, The State University of New York at Buffalo, 430 Park Hall, Buffalo, NY, USA

e-mail: dastreet@buffalo.edu

\section{Á. Ní Léime}

Irish Centre for Social Gerontology, National University of Ireland, Galway, Ireland

(C) The Author(s) 2020

Á. Ní Léime et al. (eds.), Extended Working Life Policies, https://doi.org/10.1007/978-3-030-40985-2_5 
with population ageing and the resources needed to sustain it; that is, the interactions between demographic change and later life work, pensions (whether public or private sector) and income security in old age; and the lifecourses of ageing individuals with different social attributes. Although population ageing is occurring everywhere, efforts to extend working lives take place in national contexts, where demographic processes occur at different rates, and within distinctive economic and labour market conditions, policy legacies, and political climates. Many individual characteristics are routinely associated with unequal outcomes in terms of work and income security at older ages, ranging from race/ethnicity to level of education, as well as gender and health-two of the foci of this book. Further, there are overarching questions: Are the institutions of the 20th century up to the task of meeting the needs of $21 \mathrm{st}$ century citizens, given rapid and sweeping demographic, labour market, and political changes? Is there an optimal combination of policies, unrealised potential for effective public/private responsibility and provision, or not-yet-tapped capacity of families that can be identified to provide health and income security for older people? Governments around the world struggle to find the right policy mix to meet the health care and financial needs of older women and men, and are confronted by rapidly evolving labour markets and patchworks of policy changes. The context of such overarching institutional changes as they pertain to extended work and the outcomes they generate are among the main themes of this volume because they are matters of concern and policy action in nearly all nation states and transnational institutions.

Using data from 34 countries (mainly in the EU), research presented in Part Two of this volume documents the main trends in extended working life policies and their gender and health implications for current and future workers. In general, details in most of the country-specific chapters demonstrate that policies designed to 'extend working life' - that is, policies and practices that support available, adequately paid and meaningful employment within the capabilities of workers (whether physically, or in terms of skills) for later life work - are enacted only rarely. When constructive extended working policies are enacted, as in the Finnish case, there can be positive effects for the health and wellbeing of some older workers, regardless of gender. However, because 'delaying retirement' rather than 'extending work' policies dominate the political landscapes of most of the country-specific cases considered in this volume, many countries' current policies have the perverse effects of reproducing (at best) or exacerbating (at worst) gender inequalities and health risks for vulnerable older workers.

\section{The 'Unaffordable' Older Population}

A conundrum universally agreed is that growing proportions of older people everywhere will increase the need for social spending within limited national resources, regardless of the country under consideration. The growing demands for public spending on pensions, health and social care systems, in turn, suggest sustainability concerns in the context of national budgets. Multi-faceted concerns arising directly 
from the growth of older populations occur against an even broader and more complex backdrop. That includes fewer 'working age' people to contribute to national tax bases; the transition from industrial to post-industrial and from national/local to global labour markets; large and still growing proportions of women in employment; and, a singular lack of adequate social care options across the lifecourse in most affluent countries. What remains contested, however, is whether earlier pension promises for an ageing population are truly 'unaffordable' or 'too expensive' for welfare states to honour (see Higgs and Gilleard 2010). To date, societies have been able to afford their increasing older populations and changing dependency ratios through changes in labour market participation (particularly the influx of women workers) and efficiencies that have increased productivity at work. Perhaps a more pertinent approach than the one currently in vogue would abandon assertions of unaffordability and instead focus on what policy changes are required to ensure a dignified and adequately resourced later life for older people.

All the foregoing suggests the need for careful policy planning and attention to variation and detail. Yet, as earlier chapters have demonstrated, policymaking around extending working life has tended to encompass simplistic, one-size-fits all approaches that ignore the realities that shape predictably different lifecourses of men and women, or of older people who experience work-limiting poor health or disabled versus healthy individuals. Despite the superiority of carefully designed social policies, the neoliberalist political agenda in many countries has foreclosed progressive action. The transcendence of neoliberalist tendencies in most countries' political economies has instead seen governments committed to reining in public sector spending, even if it means dismantling traditional social insurance and safety net programmes. This is consistent with beliefs about the limits on state intervention typical of the neoliberal turn and has contributed to tax cuts and deregulation, stagnant wages, struggling national labour markets, austerity and a departure from universalist social policies, all culminating in increased income inequality and insecurity for individuals. It is no surprise that the main idea gaining the most traction and dominating international policy circles is the 'live longer, work longer'solution (OECD 2006).

\section{Live Longer, Work Longer}

Three intertwined issues undergird the logic of the 'live longer, work longer' catchphrase and seem to hint at the potential for the relatively straightforward idea of extended working lives to resolve the mismatch between the demand for and the supply of resources for growing numbers of older people. First is the optimism engendered by the triumph of human ageing-an 'average person' in affluent countries now lives a longer, healthier life than at any other time in human history. To enthusiasts for extending working lives, this suggests that there is an increased individual capacity for working longer that can, for most older people, be taken for granted. Second are constraints imposed by attempting to balance state budgets and 
manage social policy spending under current national fiscal and political circumstances. Many affluent countries are experiencing economic challenges, including low rates of growth accompanied by national debts and deficit spending, with increasing shortfalls expected for the future. Tax cuts in many countries have led to reduced resources in national treasuries. Inexorable increases in the cost of providing health and pension benefits are linked to the growing tranche of older people in national populations. In light of the apparent disconnect between earlier social policy promises and states' fiscal capacity to meet them (at least in the eyes of extended working life proponents) makes limiting pension promises for current and future retirees seem prudent. A third component of the 'work longer' argument focuses on whether pension systems designed for 20th century demographics and labour markets are suitable for current and future older people. After all, pension systems in most countries were initially designed for the male breadwinner/female homemaker model of industrial economies when life expectancy was significantly lower than it is now, and when larger families (and the assumption of the availability of unpaid caregivers within them) were the norm. Since then, the influx of women into paid work, changes in family forms, and the transformation to post-industrial economies have left most countries with health, social care, and pension systems that have failed to fully 'keep up' with the times. Although many other factors play into the 'problem', these three themes together suggest that the most obvious policy choice should be to keep workers in employment to older ages, delaying the age of entitlement for pensions benefits (and years of receiving them) to mitigate the pressure on national budgets as populations age. Proponents regard extended work as the most obviously desirable solution to the conundrum presented by growing costs associated with ageing populations.

Yet, as Ogg and Rašticová in Chap. 1 have observed, the extended work solution is neither as simple nor empirically as appealing as it appears at first glance. Further, the real world circumstances in the countries where the single prescription of extended work must be applied vary substantially. Krekula and Vickerstaff further underscore several fundamental problems of 'live longer, work longer' at the theoretical level. As they point out in Chap. 2, the imprecise and evolving use of the language that frames policy debates assumes that privileged people and men are representative of the normative experiences implied by the notion of working longer. This has foreclosed important avenues of discussion about extending work for people with much more varied lifecourse trajectories than are acknowledged by policymakers.

Challenging some of the key assumptions embedded in the conflated work longer/delay retirement argument points to the importance of the availability of high quality data for evidence-based decision-making. In the third chapter, Addabbo, Gstrein and Siemieńska discuss some of the untapped potential for policymakers and researchers alike to capitalise on existing data and use various research techniques to tease out the implications of extended working lives for individuals with different social characteristics. Despite the range of datasets Addabbo and colleagues identify, weaving together comprehensive data that could unpack the interconnectedness of women's and men's differing lifecourses (such as employment histories, health statuses and caring responsibilities) in conjunction with representative organisational data (that simultaneously accounts for the practices and preferences of employers) is 
not currently possible. In fact, the lack of systematic data about employer behaviour, particularly because so much is proprietary and unavailable to either policymakers or researchers, is a serious impediment to an empirical understanding of how and which older workers could 'work longer' and for which particular employers. Quantitative data from representative national and international samples, particularly when from time series data over long periods, have noteworthy utility for understanding the interactions among policy effects, organisational behaviour, and individual outcomes. But representative longitudinal studies are relatively rare and very expensive, and often lack the data to flesh out nuances and distinctions among people's lived experiences. To supplement quantitative data, qualitative research is also needed for more refined understanding of the influences of family circumstances, employment trajectories, health statuses and caring histories under particular work and pension policy regimes for later life outcomes.

Such data limitations operate in tandem with policymaking that overlooks even the already well-documented (in)capacities of many disadvantaged subgroups of older workers and the precursors to low incomes for many retirees. To restate the obvious, this is especially the case for individuals (mostly women) with heavy caring responsibilities, workers in physically demanding and stressful occupations, people with impaired health and physical capacities, those in precarious and low paid employment, or whose careers have been spent in vanishing industries. Vulnerable workers have the deepest stake in adequate state pensions provided at an appropriate age, because they among all workers have the least capacity to generate employment alternatives. Yet rather than protecting that group best, in most instances the sweeping introduction of older ages of eligibility for pensions without readily available employment for older workers has and will continue to hurt vulnerable sub-groups of older people the most.

The fact is that policies are made (whether lacking data or ignoring it) by building on or departing from existing policy regimes that have established the 'ground rules' or starting points for individual expectations and later policy innovations. In confronting similar problems, policy learning can and does occur across regions and nations, which emphasises the value of policy toolkits discussed in Chap. 4 by Duvvury and colleagues. They highlight processes likely to generate good practices, committed to making practices and outcomes more transparent, especially if working longer must be a dominant approach for the future. Combining insights gleaned from data analysis and policy exemplars can provide firmer empirical ground for estimating the effects of policy choices associated with extended working lives, documenting how policies and individuals' lifecourses and workplace experiences intersect, and developing policies and practices to improve income security in retirement for more people with varied lifecourses and social characteristics. 


\section{Paradoxes in the 'Big Ideas' in the Debate}

There are several paradoxes, some of which are discussed below, that contribute to concerns over outcomes related to the impact of health statuses and gender differences in the extended work debate.

\section{Precarity Versus Flexibility}

One woman's flexibility is another's precarity. One of the recommendations to employers in the quest to extend working lives is for employers to permit flexible working arrangements for their employees. Focusing on the potential for flexible work to help employees remain employed to older ages, the expectation is that for many workers a range of flexible arrangements-phased retirement, opportunities for part-time work, home-based working, among others-would encourage persistence in the labour market at older ages. However, it is uncertain whether there is sufficient labour market flexibility routinely available, particularly in private sector employment, for good choices about working hours or whether a soft exit from paid work is available for many older workers who would like to take advantage of it. There is another problem at the other end of the flexibility spectrum, which highlights the qualitative difference between flexibility that is chosen, and 'flexibility' that is imposed. More and more workers in precarious positions must work flexibly if they are to work at all-in seasonal or short-term work, zero hours contracts, or the 'gig' economy for example (Standing 2011). They may find incomes and hours from such non-standard employment insufficient to meet their needs, yet be in the only jobs they can find. In the case of workers who want to remain employed, but in non-standard or full-time work arrangements, flexibility for individuals gives them additional resources when they choose to extend work as they approach the end of their working lives. However, some work is so precarious that, while it may benefit the flexible needs of the firms offering it, it actually invokes anxiety and insufficient security and income for the precariously employed (Burnay 2018).

\section{Choice Versus Compulsion}

A huge body of literature notes the importance of autonomy for psychological wellbeing, and certainly having choices about whether to continue working or to stop at older ages are important considerations (Calvo et al. 2009). If individuals extend their working life because a job is perceived as meaningful, interesting, and rewarding (monetarily and intrinsically), choosing to work longer is a positive experience (Ní Léime and Street 2019). In a six-year study of a panel of older Dutch workers, for example, researchers found that both workers who retired voluntarily and those who continued working had higher levels of life satisfaction than workers who were 
retired involuntarily, emphasising the importance of autonomy for measures linked to satisfaction with life. The researchers concluded that their study 'clearly demonstrate[s] that an organizational exit that occurs at the 'right time' and on the basis of one's own volition represents the best case scenario when it comes to the prospect of experiencing late life psychological well-being' (Hershey and Henkens 2013: 242). In contrast, being desperate to remain in work or become employed at older ages because financial needs cannot be met otherwise is stressful and unpleasant for individuals who have no other choice but to settle for a poor job (Burnay 2018). In terms of extended work, for many individuals being compelled to remain in or try to find any job, even if poorly paid, physically demanding, dangerous, boring, or fleeting, is a recipe for unpleasant compulsion related to extended work (Vickerstaff 2010).

\section{Good and Good Enough Jobs}

The job elite-people in stable employment, with good wage and benefit packages, secure positions, and interesting work-have jobs whose bundle of characteristics may be appealing enough to entice workers to remain in the labour force to older ages, or perhaps even to love their jobs so much that they imagine they will never want to leave them (see for example, Dorfman 2002, 2009). Such good jobs are the exception rather than the rule, however. For most workers, the best they can hope for is a good enough job, one that is feasible to perform within their skillset and physical capacities and which can sustain incomes until a later retirement date is reached. The third, implicit category of work is the 'not good enough job'. Many older individuals have little choice, if they are to be employed at all, but to settle for low quality work-done under adverse or stressful conditions, at relatively low levels of pay, and without certainty that hours or duration of work will generate income sufficient to meet current needs or to enable pension contributions (Ní Léime and Street 2019). Job quality obviously matters critically in the context of extending working lives because raising state pension ages means that many older workers are compelled to work longer in low paid stressful jobs (Hunefeld et al. 2019) because they typically do not have occupational/private pensions which might allow them to retire sooner. This has negative implications for their health and means that many will miss out on any healthy years in retirement, something that many workers believe they are entitled to at the end of already long working lives (Kim 2011; Pond et al. 2010).

\section{Ageism}

Extended working life relies on the assumption that employment is readily available to older workers. Yet there is ample evidence that is not the case. Age discrimination by employers is widespread in relation to recruitment, retention and re-employment of older workers (EU-OSHA et al. 2017; Karpinska et al. 2011; Neumark et al. 2015; Russell et al. 2008). This can lead to situations where labour markets have low levels of unemployment generally, but where older workers experience problems becoming 
employed or re-employed after a 'certain' age (Lahey 2008). When state pension ages are increased and older workers face age discrimination, this can force them into involuntary unemployment. Beyond generic ageism, there is also substantial evidence that age discrimination in the workplace is gendered. In many occupations, employers consider women 'too old' at younger ages than men (Clarke and Griffin 2008; Duncan and Loretto 2004; Handy and Davy 2007).

The foregoing are but a few of the paradoxes that beleaguer clarity in the 'live longer, work longer' formulation. Other factors that contribute to the myriad relationships among gender, health, and extended working life revolve around the different levels of analysis - macro, meso, or micro - that confound the issues as currently debated. Nonetheless, researchers and policy makers need increased engagement with the complexities involved if they hope either to comprehensively understand the social contexts within which extended work might occur or to optimise extended work policies and practices. Understanding the role of actors at different levels of analysis, and the entrenched interests that inform their preferences can contribute to more clarity as to which policies could be effective, and which seem less likely to work.

\section{Macro, Meso and Micro Perspectives}

Debates about working longer unfold very differently for actors with different interests and institutional locations, (transnational institutions, governments, employers, individuals) including the varied perspectives and realities of actual people being required to meet new expectations to 'live longer, work longer'. How to balance the realities of older citizens' experiences, the changing structure of labour markets, and the increased demands on social, health and pension systems they represent is far from settled, not least because the debates occur in different national contexts and individual circumstances. For example, at the macro level, transnational actors ranging from the World Bank to NGOs to the European Union and the OECD, weigh in with advice on targets and expectations for extending work in countries within their orbits of influence. The advice on offer is often provided quite generically with a dogmatic commitment to increasing retirement ages-while mainly ignoring the very tangible cross-national, multi-cultural and regional barriers to accomplishing extended work goals without causing genuine hardship among defined groups of older people. National policymakers, responsible for enacting policies to benefit citizens of all ages, must simultaneously attempt to reconcile the fewer workers/shrinking tax base + more pensioners $=$ higher pension spending/budget strain equation, while weighing also how policy choices shape electoral politics. Private employers have very different concerns that shape, at least indirectly, the ageing population/extended working lives/adequate benefit provision nexus, since their activities structure labour markets (Mulders et al. 2014). Differing corporate/private sector concerns on extended work and pensions are no surprise, since corporations have fiduciary responsibilities to generate profits to ensure shareholder investment returns and to expand business, not 
to provide social rights. Except in countries such as Poland, France, and Finland, where trade unionism and/or social partnership is still strong, meso level engagement in extending work/delaying retirement is mostly episodic and at the margin of debates. Households and individuals, too, have varying perspectives on the 'best' approach to extend working lives (or whether extended work is possible at all), shaped by factors ranging from the age, gender, education, health status and employment conditions of individuals located within the constraints of individual and family resources and national labour markets and policy regimes. There is rarely individual level consultation on the merits of macro level policies or meso level practices that will be applied to improve the employment prospects of older workers (see Chap. 2).

Current policy debates fluctuate in their terminology, whether the frame is 'extending working life' or 'delaying retirement', an issue to which we return later in this chapter. For now, the starting point of our argument is that conflation of the two phrases as nearly synonymous is based on mistaken assumptions that policies reflecting one concept could be the same for the other-despite very different conceptual connotations of each proposed policy remedy (see also Chap. 2). Treating the goals of delaying retirement and extending work as interchangeable obfuscates serious policy considerations; masks the potential, problems, and inequalities inherent in each approach; and mystifies and muddies important debates that should occur within the 'live longer, work longer' construct. After all, 'extending work' sounds somewhat more positive than its more negative and less desired 'delaying retirement' counterpart. We argue, instead, that treating delayed retirement and extended work as more or less equivalent is a conceptual error, because the goals logically associated with each are different. Acknowledging the distinctions matters, as it is important for researchers to be precise and for policymakers to be more nuanced about policies that so fundamentally affect individuals' later lives. To be sure, concerns associated with 'extending work' and 'delaying retirement' overlap somewhat, but they are decidedly not identical.

Take the 'delaying retirement' construct and the different interests this particular policy approach encompasses. Delaying retirement is a national social policy choice that imposes new limitations on when individuals are entitled to full state pensions. State-mandated retirement delays are designed mainly to serve state fiscal interests, rather than those of individuals who must either postpone their transition from work to retirement, or suffer permanent financial penalties. As for employing organisations, there is no robust evidence that employers are particularly eager to postpone retirement for most of their employees (see for example Mulders et al. 2014), although the shrinking number of employers still offering defined benefit occupational pensions would also see a fiscal savings via later retirement. The interests of the state do not necessarily align with the interests of the organisations or individuals affected by delayed retirement, providing a plausible rationale for casting the issue more as a matter of extending work than delaying retirement.

In contrast to the 'delay retirement' approach, careful conceptualisation of 'extending work' requires policies that could actually support individuals, with a wide range of employability characteristics, working to older ages. Effective policies for extending working lives require distinctive approaches that address the realities 
of current and future labour markets and the supply and demand for older workers (including especially job opening/skills mismatches), the quality of work conditions and wages, the health and physical capacities of potential older workers, and the willingness of organisations to employ them. Further, effective extending work policies would have to take into account the varied lifecourses of individuals in different types and sectors of employment, the normative expectations surrounding unpaid carework in national cultures, new family forms and structures in which individual workers are embedded, varied socioeconomic circumstances, and the vagaries of localised labour markets.

Despite competing interests among different actors, what has occurred so far in the 'live longer, work longer' policy space has been a mainly one-sided exercise of assumed economistic imperatives rather than social needs. There is scant evidence that citizens or employers have lobbied governments to enact policies to extend working lives, nor is there much evidence that governments have enacted effective policies that enhance older individuals' employability, although there have been some attempts to do so in a few countries, notably Austria, Finland, France and Germany (Chaps. 2, and 3; see OECD 2017b). Anti-age discrimination legislation or the removal of mandated retirement ages in several countries could be construed as reflecting the interests and preferences of some organisations and individuals that support working longer. Yet, anti-age discrimination legislation appears to have had little effect on workplace realities and the desire to work longer is concentrated in a relatively privileged (and small) subset of national populations.

Far more important than employers' and individuals' preferences in the policy arena have been the actions of macro level actors. Some international organisations have pronounced the unavoidable need for individuals to work longer; others have set targets for achieving such goals (European Commission 2018; OECD 2006, 2013, 2017b). National governments have taken up the 'work longer' baton, but mainly by focusing on legislation that raises pension ages and facilitates the trend away from defined benefit pensions to defined contribution retirement savings schemes. This is what defines the 'delay retirement' approach. Cross-nationally it is well-developed and pervasive. To the extent that governments have promoted any 'extend work' initiatives, they have in most countries been piecemeal, limited, and exhortatory rather than thought-through, comprehensive and mandated (see country chapters; OECD 2017b). The contrasts between the two approaches-delaying retirement or extending work-are discussed in the following section.

\section{Delaying Retirement or Extending Work?}

Who wants to delay retirement? The short and most obvious answers are fairly straightforward, but vary across and within different levels of analysis. We also caution that while some interests are obvious and dominate, complexities also abound. Still, at the macro level, most governments are enthusiastic about the prospects of 
delayed retirement. Far less is known about the preferences for encouraging delayed retirement among meso level organisations and employers. For example, there may be different perspectives on delayed retirement between public and private sector employers. While public sector practices may be somewhat more transparent, private sector businesses' position on delaying retirement unfolds mainly in a black box. There are a few notable exceptions where companies occasionally champion hiring older people, for example as in Do It Yourself (DIY) stores such as B\&Q in the UK, because of the assumed appeal of age-contemporary staff to older customers. At the micro level, many older workers prefer not to be compelled to delay retirement past long-established normal retirement ages (Ní Léime and Street 2019). The job elites-stably employed and highly-remunerated individuals and professionals - may sometimes prefer to delay retirement and remain employed. However, job elites' circumstances are not representative of older workers, whose employment conditions and financial circumstances are very different. Across these three levels of analysis and considering the interests of actors within them, the desirability of delaying retirement varies considerably. Most governments want delayed retirement, but few individuals do. The stance of employers - the key 'brokers' between states and individuals that connect the structures and security of retirement, the experiences of older workers, and the value of pension benefits-is largely unknown (although see Barnes et al. 2009; Mulders et al. 2014).

As mentioned earlier, policies can encourage or require people to postpone anticipated retirement dates. Governments impose new conditions for public pension entitlement, accomplished most directly by raising the age of entitlement for full retirement benefits (incrementally or in a single instance) as in most countries considered in this volume. Many also restrict eligibility for early retirement (either by increasing the age of eligibility for reduced pensions, or by reducing the value of pensions accessed before state pension age, as has occurred in Finland, Greece, Italy or Germany (see relevant country chapters). Retirement delays can also be accomplished somewhat less directly. The indirect approach can include substantially increasing the cost, length or number of contributory periods required of individuals to earn full benefits, as happened in Ireland and elsewhere. It can also occur by giving higher pensions to those who delay accessing their pension (as in over half of the countries considered in Part Two including Denmark, Estonia, Finland, France, Greece, Israel, Poland, the UK and the US), or by allowing workers to combine pensions with paid employment (as in France, Ireland, Netherlands, Poland, UK and others). Not all workers experience the effects of delayed pensions similarly. Being compelled to wait longer for a pension is a very different prospect for older individuals who have little to no income in the immediate years before qualifying for a pension, or who cannot find adequate employment in the aftermath of a redundancy, than for the job elites whose work is simultaneously intrinsically rewarding, very lucrative and preferred.

At the macro level and from the perspective of the state, delaying retirement has several perceived advantages. Political contestation aside, accomplishing the policy goal is straightforward. Workers who expected to retire at younger ages (previously established in national pension policies) must wait until the newly mandated older 
age is reached. Older pension ages reduce the value of state pension promises to some current and all future pensioners, and raise contributory costs in PAYG systems, at least against the yardstick of previously established retirement ages. Thus, delaying retirement postpones claims on PAYG first tier contributory social insurance pensions, and saves governments money on social pensions paid out of general revenues, unless some expensively unintended consequence like higher health and social care costs come into play. International policy experts, informed by neoliberal principles, claimed that state pension systems were unaffordable and unsustainable. Following their advice to raise retirement ages has saved countries several years of pension benefit outflows, appearing to improve the fiscal circumstances of the state by bringing contribution increases/benefit decreases into play and thus appealing to proponents of 'unaffordability' arguments. Further, some governments reduced the value of or eliminated social and defined benefits pensions that had explicitly promised predictable pension income in later life by transitioning to individualised defined contribution pensions. In most places, governments have changed regulations and, in some cases, their own social security systems in ways that have shifted more responsibility for ensuring retirement income away from governments onto individuals.

With rare exceptions, the actions and preferences of employers are an essential conduit to extended work/delayed retirement for most people, but employers' roles are seldom invoked except tangentially in policy debates and studies on delayed retirement (see Chap. 2). For example, relatively little about employers' responsibilities is discussed in policy debates concerning delayed retirement or extended work, or is enacted into law. Instead soft policy measures such as 'awareness campaigns' and/or codes of practice (non-legally binding) are the preferred mechanisms for employers (OECD 2017b). Neither are employers typically required to take action to make it possible for their employees to delay retirement, nor to hire older workers seeking jobs. There are instances, for example in Italy, Spain and Finland, where employers are given incentives to hire older workers (OECD 2017b) but they are not compelled to do so except to earn the subsidy. Instead, policymakers and policy papers exhort employers to create desirable working conditions to retain, and when possible, to attract older workers through adapted work places, re-training, or flexible work arrangements, but with no requirement to do so. For example, codes of practice which are not legally binding are provided for employers, and employees in Ireland, providing guidance on best practice in negotiating retirement/extending working life (OECD 2017b). The neoliberal turn mentioned earlier has, in most countries, also been a contributing factor to employers converting traditional defined benefit (DB) occupational pensions to defined contribution (DC) schemes, further undermining later life income security for workers with occupational benefits.

Overall, the shift in pension types DB pensions to DC savings has delivered predictably adverse outcomes for many women workers and those with low income or precarious jobs, particularly in the private sector. As employment relations have become more flexible in recent decades, at least some private sector workers have lost occupational retirement plans entirely, with recourse only to individual retirement savings beyond state pensions. Further, depending on the investment achievements 
of such individualised schemes - whether occupational DC or individual retirement savings-means that luck-based windfalls are possible in hot markets, and catastrophic losses during recessions, as in the aftermath of the 2008 global financial crisis (Duvvury et al. 2017). In ideal circumstances, DC retirement savings plans may actually have some perverse effects in vibrant markets if delayed retirement is a universal goal, since windfalls can nudge people to retire early when times are good. However, many people (especially women) have insufficient surplus income to contribute to DC or individual accounts and even when they do, they could be desperate to stay in work even during periods of high unemployment, to try to recover from investment losses in periods such as the aftermath of the 2008 global financial crisis.

At the individual level, the expectation that retirement can or must be delayed doubtless varies by individual circumstances. Previously, at least some could have managed to persist in work until they reached the retirement age established by earlier policies, or could receive bridging benefits until the state pension kicked in by qualifying for disability or unemployment benefits that took health status and employability in the immediate pre-retirement years into account. However, for many individuals, remaining employed for the extra years now required in most countries may be impossible. Recourse to disability and unemployment benefits has been severely restricted in many countries (OECD 2017b) despite the extent of layoffs and redundancies that pushed people out of jobs, relegating some to a status of 'not working, not retired' and rendering their financial plight grave.

Such discouraged workers - that is, older individuals who want to work but who have given up active job seeking because they cannot find employment-exist in something of a limbo status and are understudied. Yet social scientists know that long durations of labour market risks doubly stigmatizing discouraged older workers, who already experience the effects of systemic ageism. Such individuals could hardly be considered early retirees, at least in the voluntary sense of choosing or being in a position to retire - that is, needing or wanting to retire. Nonetheless, after some lengthy period of being unemployed, discouraged older workers might choose to self-identify as "retired" rather than "unemployed," thus shedding a stigmatized identity (see Heslin et al. 2012; Froidevaux et al. 2019). How large this "limbo" group of older people is for each country featured in this volume is difficult to ascertain due to data constraints. However, the OECD estimates that discouraged workers are a significant part of labour forces, and analysis of US Health and Retirement Survey (HRS) indicated that over half of retired older Americans characterized themselves as wanting to work but being involuntarily pushed or encouraged out of employment (Johnson and Gosselin 2018), clarion calls for extending work aside. While many factors go into individual employment and retirement decisions, it is certain that changes to state pension policies, including age for receiving full retirement benefits, are strongly structuring individual level experiences (see Börsch-Supan et al. 2019 , for an economic analysis of features of pension systems that encourage early retirement or delayed retirement). 


\section{Changes in the Average Age at Retirement for Men and Women}

Many women have had their retirement plans disrupted even more than men by increases in state pension ages. This is because several countries had until relatively recently (Germany, UK) or still have (Albania, Austria, Bulgaria, Chile, Czech Republic, Israel, Lithuania, Poland, Romania, Slovakia, Slovenia, Switzerland and Turkey, mainly former Soviet and/or countries with conservative gender norms) lower state pension ages for women than for men. Consequently, women have had to or will have to adjust more quickly to having to work longer (see Table 5.1, with gender differentiated retirement ages highlighted in bold). Having a lower state pension age for women, although often touted as an advantage, is associated with higher women's poverty in old age, since pension systems are increasingly being linked to participation in paid employment (EIGE 2017).

Adjustments to 'pre-retirement' policies — early retirement, disability pensions, extended unemployment insurance are intertwined with the extend work/delay retirement agenda. Many governments (e.g. in Finland, France, Greece, Italy, Germany, Switzerland) have removed early retirement options or give actuarially reduced pensions for those who access their pensions before state pension age, for example in Switzerland where early retirement in the public pension's scheme is possible from age 63 for men and age 62 for women. The full pension benefit value is reduced by $6.8 \%$ for each year of early claiming (OECD 2017a). Following the encouragement of the OECD and other international organisations, several other governments (including Austria, Belgium, Bulgaria, Finland) have made it more difficult to access disability pensions - which used to be another route of exit from employment for older workers.

Of all the pension related policies, the one that is most consistent or bridges to extended work is the ability to continue working while being in receipt of a pension. This is possible in several countries including Australia, Estonia, France, Ireland and Poland, among others. Another popular policy present in several countries is one that allows workers to accrue higher benefits through postponing retirement/more years of work. The latter is possible in at least 15 of the countries under consideration (Denmark, Estonia, Finland, France, Greece, Israel, Poland, Portugal, Slovakia, Slovenia, Spain, Sweden, Switzerland, UK, US).

There is ample evidence that women already have lower pension incomes approaching retirement and tend to be more reliant than men on safety net state pensions due to their different lifecourse trajectories, which typically include more periods away from formal paid employment for caring (Bettio et al. 2013; Dewilde 2013; Ginn et al. 2001; Ní Léime et al. 2017). Some of the pension reform policies advocated by the OECD and implemented by several countries such as increasing the number of contributions necessary to access a minimum and maximum state pension, make it even more difficult for those who provide most informal care (women) to build up adequate pensions (OECD 2006, 2013).

An assumption underlying extended working life policies is that an undifferentiated 'adult worker' model of working life prevails across most countries and that it is 
Table 5.1 State pension age/normal retirement age

\begin{tabular}{|c|c|c|}
\hline Country & $\%$ of population aged $65+^{\mathrm{a}}$ & Pension age/retirement age in $2016^{\mathrm{b}}$ \\
\hline Albania & 12.23 & $\begin{array}{l}65 \text { for men; } 60 \text { for women gradual } \\
\text { increase to } 2024 \text {. To equalise for men } \\
\text { and women by } 2056 \text { at age } 67\end{array}$ \\
\hline Australia & 25 & $\begin{array}{l}65 \text { for men and women. Will increase } \\
\text { to } 67 \text { by } 2023\end{array}$ \\
\hline Austria & 30.5 & $\begin{array}{l}65 \text { for men; } 60 \text { for women. The } \\
\text { retirement age for women will } \\
\text { increase to } 65 \text { between } 2024 \text { and } 2033\end{array}$ \\
\hline Belgium & 30.6 & 65 To be 66 in 2025 and 67 in 2030 \\
\hline Bosnia and Herzogovina & 14.4 (CIA 2017) & 65 \\
\hline Bulgaria & 19.5 (CIA 2018) & $\begin{array}{l}64.2 \text { men; } 61.2 \text { women. To increase to } \\
65 \text { years by } 2029 \text { (men) by } 2037 \\
\text { (women) }\end{array}$ \\
\hline Chile & 11.1 (CIA 2018) & $\begin{array}{l}\text { 65: men; 60: women. Proposal in } \\
2018 \text { to EWL }\end{array}$ \\
\hline Croatia & 19.9 & $\begin{array}{l}65 \text { for men. To increase to } 65 \text { by } 2030 \\
\text { for women. To increase to } 67 \text { for all } \\
\text { from } 2031 \text { to } 2038\end{array}$ \\
\hline Cyprus & 12.4 & $\begin{array}{l}\text { 65: men and women. To increase } \\
\text { every five years aligned to changes in } \\
\text { life expectancy } 2023\end{array}$ \\
\hline Czech Republic & 19.4 & $\begin{array}{l}\text { 63: men; } 62 \text { years } 4 \text { months: women } \\
\text { (2016). To increase to } 66 \text { yrs, } \\
8 \text { months for both by } 2019 \text {. To } \\
\text { increase by } 2 \text { months per birth cohort } \\
\text { (unlimited) }\end{array}$ \\
\hline Denmark & 19.4 & $\begin{array}{l}65 \text { years (2016). To increase } \\
\text { gradually to } 67 \text { years from } 2019 \text { to } 22 \\
\text { and to } 68 \text { in } 2030 \text {. Then increases } \\
\text { directly linked to life expectancy }\end{array}$ \\
\hline Estonia & 20.2 & $\begin{array}{l}63 \text { years. To increase gradually to } 65 \\
\text { by } 2026 \text { for all }\end{array}$ \\
\hline Finland & 21.5 & $\begin{array}{l}65 \text { years To increase in line with life } \\
\text { expectancy subject to maximum of } \\
2 \text { months per year }\end{array}$ \\
\hline France & 19.8 & $\begin{array}{l}66 \text { years, } 7 \text { months (for people born in } \\
\text { 1954). Age of full-rate pension to } \\
\text { increase from } 65 \text { to } 67 \text {, depending on } \\
\text { the year of birth, by } 2022\end{array}$ \\
\hline Germany & 22.4 & $\begin{array}{l}65 \text { and } 4-5 \text { months. To increase to } 67 \\
\text { (for those born in 1964) }\end{array}$ \\
\hline
\end{tabular}


Table 5.1 (continued)

\begin{tabular}{|c|c|c|}
\hline Country & $\%$ of population aged $65+^{\mathrm{a}}$ & Pension age/retirement age in $2016^{\mathrm{b}}$ \\
\hline Greece & 21.1 & $\begin{array}{l}67 \text { (With } 40 \text { years, can retire at age } \\
62 \text { ) }\end{array}$ \\
\hline Ireland & 13.3 & $\begin{array}{l}\text { 66. To increase to } 67 \text { in } 2021 \text { and } 68 \\
\text { in } 2028\end{array}$ \\
\hline Israel & 11.6 & $\begin{array}{l}67 \text { for men. } 62 \text { for women to increase } \\
\text { to } 64 \text { by } 2022\end{array}$ \\
\hline Italy & 21.7 & $\begin{array}{l}66 \text { years and seven months with } \\
\text { minimum } 20 \text { years contributions. To } \\
\text { increase in line with life expectancy } \\
\text { to } 67 \text { in } 2021\end{array}$ \\
\hline Lithuania & 19.9 & $\begin{array}{l}\text { In } 2017 \text {, the old-age retirement age is } \\
62 \text { years for women and } 63 \text { years and } \\
6 \text { months for men (Ministry for } \\
\text { Social Security and Labour 2017) }\end{array}$ \\
\hline Netherlands & 19.1 & $\begin{array}{l}65.5 \text { (2016). To increase to } 66 \text { in } 2018 \\
\text { and } 27 \text { in } 2021 \text {. To increase linked to } \\
\text { increase in life expectancy }\end{array}$ \\
\hline New Zealand & 15.6 & $\begin{array}{l}\text { Ten years' residency since age } 20 \\
\text { (including five years after age } 50 \text { ) } \\
\text { entitles people to public pension } \\
\text { from age } 65\end{array}$ \\
\hline Poland & 17.5 & $\begin{array}{l}\text { Poland restored statutory retirement } \\
\text { age of } 65 \text { for men and } 60 \text { for } \\
\text { women, reversing } 2013 \text { commitment } \\
\text { to increase the age to } 67 \text { by } 2020 \text { for } \\
\text { men and by } 2040 \text { for women. In } \\
\text { October } 2017 \text {, statutory retirement } \\
\text { age decreased by } 14 \text { months }\end{array}$ \\
\hline Portugal & 20.3 & $\begin{array}{l}\text { The normal age of retirement with an } \\
\text { old age pension was } 66 \text { years and } \\
2 \text { months in } 2016 \text {, to be increased by } \\
\text { linking to life expectancy gains. Age } \\
\text { of retirement can be reduced by } \\
4 \text { months for each year's } \\
\text { contributions exceeding } 40 \text { yrs }\end{array}$ \\
\hline Romania & 16.8 & $\begin{array}{l}65 \text { : men; } 60 \text { years and } 8 \text { months: } \\
\text { women. Plan to increase women's to } \\
65\end{array}$ \\
\hline Serbia & 19 & $\begin{array}{l}65(\text { men); } 61 \text { (women) (Milovanovic } \\
\text { et al. 2016). To increase and equalise } \\
\text { retirement age by } 2032 \text { at age } 65\end{array}$ \\
\hline
\end{tabular}


Table 5.1 (continued)

\begin{tabular}{|c|c|c|}
\hline Country & $\%$ of population aged $65+^{\mathrm{a}}$ & Pension age/retirement age in $2016^{\mathrm{b}}$ \\
\hline Slovakia & 16 & $\begin{array}{l}62 \text { years for men, lower for women } \\
\text { with children ( } 58.25 \text { for women with } \\
5 \text { or more). To increase to } 62 \text { for } \\
\text { women by } 2024 \text {. To increase in line } \\
\text { with life expectancy from } 2017\end{array}$ \\
\hline Slovenia & 20.1 & $\begin{array}{l}59 \text { years, } 4 \text { months (men); } 59 \text { years } \\
\text { (women). To increase to } 60 \text { in } 2018 \\
\text { (men); } 60 \text { in } 2020 \text { (women) }\end{array}$ \\
\hline Spain & 18.2 & $\begin{array}{l}65 \text { years, four months (all). To } \\
\text { increase to } 67 \text { in } 2027\end{array}$ \\
\hline Sweden & 20.4 & $\begin{array}{l}\text { From age } 61-\text { unlimited deferral } \\
\text { possible. Retirement age } 65 \\
\text { (guarantee pension) }\end{array}$ \\
\hline Switzerland & 18.3 & 65 (men) and 64 (women) \\
\hline Turkey & 7.8 & $\begin{array}{l}60 \text { (men) } 58 \text { (women) To increase to } \\
65 \text { for men and women by } 2044\end{array}$ \\
\hline United Kingdom & 18.2 & $\begin{array}{l}65 \text { (men and women) by } 2018 \text {. To } \\
\text { increase to } 66 \text { by } 2020 \text { and } 67 \text { by } 2028\end{array}$ \\
\hline United States & 16 & $\begin{array}{l}\text { Normal retirement age }=66 . \text { To } \\
\text { increase to } 67 \text { by } 2022\end{array}$ \\
\hline
\end{tabular}

${ }^{\mathrm{a}}$ Source Central Intelligence Agency (2018)

${ }^{\mathrm{b}}$ Source OECD, (OECD 2017a) Pensions at a Glance, unless otherwise indicated various countries and amended with subsequent legislative updates

therefore easy for women to continue working past traditional retirement age. However, even a cursory comparison of pension policies and reforms across countries indicates that there is a wide variation in pension systems with 13 out of the 34 countries studied still retaining lower pension ages for women than for men, thus making the increase in pension ages more punitive for women (see Table 5.1). This partly reflects a wide variation in gendered social norms regarding caring and a variation in family friendly policies which would support women both to work and to provide child and elder care (Ní Léime and Loretto 2017; country chapters, this volume).

\section{Health}

Average healthy life expectancy at birth is 64.2 years for women and 63.2 years for men in the European Union (Eurostat 2019). Against this backdrop, setting retirement ages at 67 or more, as advocated by the OECD, is very high, offering little or no time for healthy years in retirement for many older workers. Most evidence points to lower life expectancies and poorer health for workers in low-paid, physically demanding occupations and lower socio-economic status (Majer et al. 2011; Marmot and Bell 
2012). There is increasing recognition of a strong relationship between health (phys$\mathrm{ical} / \mathrm{mental} / \mathrm{stress}$ ) conditions across the lifecourse limiting the realistic potential for extending working life (EU-OSHA 2016). Physically demanding work is a predictor of disability retirement (Pohrt and Hasselhorn 2015). There is considerable evidence that workers in construction, manufacturing and services sectors are more susceptible to work-related chronic health conditions such as musculo-skeletal disorders (MSDs) and workers aged 55+ report health as a reason for wanting to retire within the next five years (EU-OSHA et al. 2017). Violence, harassment and stress are more likely to be reported by workers aged 55+ in the health, transport and education sectors as reasons for planning to retire in the next five years (Eurofound 2015). A higher proportion of managers and professionals aged 55+ in the EU28 (75-80\%) compared to workers in elementary occupations, manufacturing and craft workers (60-65\%) report that they will be able to work at age 60 (Eurofound 2015). This varies by country with over $80 \%$ of workers in Ireland, Portugal the Netherlands and Sweden expecting to work at age 60 , compared to $55-61.5 \%$ of those in Croatia, Hungary, Poland, Slovenia and Slovakia. However, a recent report by major EU agencies on the working conditions of older workers (EU-OSHA et al. 2017) recommends further research on specific situations related to job, occupation and sector to investigate implications of working in each occupation on possibilities for extending working life.

\section{Changing Employment Trends}

Employment trends away from the manufacturing and clerical jobs available in the mid-late twentieth century in Europe and North America due to globalisation and automation combined with many older workers' lower levels of education and age discrimination, leave few good choices for many older workers. In fact, older workers are likely to be forced into the only readily available jobs-low-paid precarious employment in the services sector (EU-OSHA et al. 2017; Standing 2011). While there may be fewer physically demanding jobs in the future with the introduction of digitisation, not only does it eliminate jobs workers already do, this can also result in more sedentary jobs, which in turn can cause damage to backs, necks and other MSD. The impact of such changes on the health of workers both across the lifecourse and as they grow older in terms of their employability at later ages is not yet well understood. Older workers (aged 55 and over) tend to have lower education and many may not have training in digitisation (Eurofound 2017). To ensure that such workers are employable, governments and employers would need to provide training for those who are unemployed and/or whose current jobs may be about to change to keep abreast of new technology. Carefully designed training might safeguard against a mismatch of skills with available jobs so that older workers are not disadvantaged. Yet, there is evidence that older workers are less likely than younger workers to participate in training, suggesting that they may be less employable (Eurofound 2017). 
In fact, what the country reports in Part Two show is that there are not many promising initiatives to support older workers' employment-only a few rather underdeveloped initiatives in a small number of countries. For the most part, (and with the exception of countries such as Finland and Austria) rather than taking a coordinated comprehensive approach, even the handful of countries with explicit supportive extended work policies (versus delayed retirement policies) are mainly involved with employment opportunities offered by a small cadre of exemplar employers. This very limited foray into extended work policies and practices belies the utility of 'extended working life' for current policy initiatives and emphasises instead the 'delaying retirement' agenda that has been enacted almost everywhere. Taking seriously the need to describe accurately policies and practices with real potential to extend work poses several questions. What would programmes to extend working lives need to look like if they were to work for more than a handful of workers? What would employers need to do to make extended working lives more possible? Could most older workers reasonably be expected to work longer? Are there categories of older people who could not? If extended work is possible for some, will there be sufficient training offered to enable older people to be trained appropriately for existing job vacancies, rendering them able to adapt to rapidly transforming job markets and real employment opportunities? Can researchers and policymakers actually identify the employment sectors where extending work would be most possible? Answers to such questions emphasise the gaps in knowledge about employment prospects for older individuals, and point to some directions for future research and more attentive policymaking attuned to the life circumstances of older people presumed able to extend their working lives.

\section{Current Extended Working Life Debates and Their Potential Policy Futures}

Participants in extended working life policy debates often prefer language that is relatively vague and which emphasises the positive side of policies governments plan to enact. Transnational and national policy elites have asserted that taking advantage of increased longevity means more years in work. The tendency is to use positive but non-specific rhetoric associated with the hegemonic 'active ageing' agenda and to 'naturalise' the idea of extending working lives. The sleight of hand invoked by 'extending working life' language masks the more specific and less optimistic formulation invoked by 'delaying retirement', obfuscating both the intent and outcomes likely to be associated with the policies that are actually enacted. Public audiences have been conditioned for decades with messaging about 'too many, too expensive' applied to ageing populations (see, for example, Willetts 2010; also see early Street and Quadagno 1993 and later Higgs and Gilleard 2010 critiques). If the sense of unavoidably having to work longer is insufficient to motivate older individuals to try to accomplish what for many is impossible, the spectre of intergenerational conflict 
has always lurked in the background as a rough and ready rationale for postponing entitlement to retirement benefits (Higgs and Gilleard 2010; Quadagno 1990; Street and Quadagno1993). The inevitable conclusion drawn from the way debates about extended work/delaying retirement unfold is that, with rare exceptions, everyone everywhere must work longer.

Perusal of the country chapters in Part 2 demonstrates that there are many additional topics not fully covered in this concluding chapter for Part One, which are essential to understand if future older people are to have any meaningful prospect for retirement. Sociologist Myles (1989) characterised retirement as 'the right to stop working before wearing out', but increasingly, employment is drying up, pension promises are being withdrawn and retirement in the future may be an elusive goal for many individuals if the focus of policy action continues to be on delaying retirement rather than extending meaningful, dignified work.

Taking a gendered perspective on the 'live longer, work longer' framework, persistent gaps in pay compared to men during their working lives both deprives many women of the surpluses they would need to save for their own retirements and ensures that their earnings-related state pensions are calculated on lower lifetime earnings. Consequently, the gender pay gap reaches into and magnifies in multiple ways the even greater gaps between women and men in retirement. On top of lower pay, the hit to lifetime earnings due to the additional time that (mainly) women spend outside of paid employment or in part-time or temporary positions to perform carework for children, disabled family members, and frail elders, and their pay disadvantages multiply. Time out of work for childcare, even when partially compensated by credited time built into state pension contribution formulas, ensures that many women miss out on early career advancement, pay rises and occupational pension credits, which then become compounded over a lifetime of work. The compounding effects of earlier lifecourse time out of employment is not the only issue for older workers with care responsibilities. Adaptations such as temporary or part-time work in the face of heavy caring responsibilities for older family members deprive their unpaid family caregivers - typically women-of income in the years leading up to retirement. As state retirement ages increase, women appear likely to be disproportionately affected by persistent gaps in pay and breaks from employment needed to perform the unpaid work their societies expect them to do.

Another emerging topic associated with extending work involves demographic changes whose contours are not yet entirely clear. For example, one concern about income sufficiency in old age (and thus pension costs) has been the greater longevity of women. Although women experience the onset of chronic conditions at earlier ages than men, women also live longer. This highlights the risk of policies that delay retirement, in that many women may be unable to continue to work and save, despite the likelihood of living longer on lower incomes. While the various gender gaps - in longevity, pay, and pensions - have so far insured that older women will be more likely to live in poverty than older men, the longevity gap at least seems to be narrowing somewhat (Glei and Horiuchi 2007). How the decreasing longevity gap might play into the tension between 'delaying retirement' and 'extending work' is not clear. Another demographic trend is recent evidence of declines in life expectancy 
among subsets of ageing populations in affluent countries-fluctuations in many countries, but likely a trend in at least the US and the UK (Ho and Hendi 2018). Many factors contributing to longevity are systematically linked to social advantage and disadvantage, and it appears that growing social inequalities may contribute to more and earlier deaths among some of the most vulnerable groups of older people. This vulnerable category often includes individuals with low levels of education who started work at young ages, at least compared to those with higher levels of education and later onset of employment. They have experienced the lifetime disadvantages associated with lower levels of education, early employment in unskilled or semiskilled jobs, often with high physical demands, low pay and job insecurity. Rarely are policy remedies developed to compensate, but there are some exceptions. In Austria, there are provisions for people involved in heavy physical work for a certain period to retire earlier (OECD 2017b). A blanket mandate for working to older ages in already long working lives for such vulnerable people seems, at face value, to be inequitable. Recognition of some earlier lifecourse employment disadvantages can be built into policies to extend work, too, but that has not yet happened widely. Still, developing these kinds of policies would make extended work that is adequate, dignified, and feasible for different categories of workers possible to accomplish.

On a more positive note, there are some policy changes in several countries that permit workers who want to postpone retirement until later ages not only to make that choice but to reward them for it. For example, in countries like the United States, Denmark, France and others individuals who postpone receiving state pension benefits beyond the normal retirement age (up to a maximum) receive actuarially determined permanent increases to pension benefits for doing so. Not surprisingly, this is especially appealing to professionals who enjoy their work, but could also benefit other workers whose health and capabilities permit them to work longer. Other policies permit individuals who reach the new higher state pension ages to both work and receive state benefits at the normal retirement age (without penalty), encouraging individuals who can combine pension income and employment income to stay on the job. Unfortunately, both of these examples of pension-linked policies that provide some good choices to extend working life are of the greatest value to the job elite who have already experienced lifetimes of high quality employment rather than most workers in most countries. At the other end of the employment quality spectrum, such policies seem entirely irrelevant for individuals whose job characteristics, health status or caring responsibilities render a choice to continue working impossible.

The foregoing highlights another challenge. An inescapable reality is that, for all the rhetoric surrounding the need for public/private partnerships and individual thrift to ensure later life income adequacy as populations age, only states can guarantee a predictable later life income. The proliferation of private/individual savings schemes for retirement that rise and fall with the fortunes of financial markets, employers' replacement of DB with DC retirement plans, the declining value of states' pensions and the fact that earlier promises by governments cannot now be depended upon is the current situation of the ongoing public/private partnership. This will affect current workers in the future (not just older people now) blurring the locus of responsibility 
for later life income security. Pensions were designed initially, after all, to ensure a floor of protection for retirees because their needs could not be met entirely through employment, individual thrift, or family support. In the latter half of the 20th century, expanding state pension systems and robust occupational defined benefits pensions provided a pension income guarantee that established the institution of retirement for most workers. But will retirement persist into the future?

The relationship between public and private responsibility that institutionalised retirement income systems has been transformed. The advent of DC retirement savings that have come to dominate the occupational benefit sector has shifted outcomes from a pension promise to investment (or loss) potential, and previously shared social responsibility onto individuals (Russell 2014). The individualisation of retirement income responsibility has exposed some in recent generations to potentially greater reward (higher retirement incomes) when economic markets are thriving, but to serious risk when markets fall-as in 2008-or worse if they fail, as in the Great Depression (Russell 2014). It also raises a more fundamental issue. One of the partners in the retirement income guarantee of the last century, that is, employers that provided traditional DB occupational pensions, no longer has the fiduciary responsibility to keep a pension promise to employees, only to provide a savings and investment mechanism in DC schemes. Not only that, but employers' role in policies considered to extend working lives is, at best, relatively undefined and unclear despite claims that population ageing requires public/private partnerships to find solutions to the 'problem'. What is the appropriate role for private sector organisations in the face of population ageing? Can they be compelled to provide employment for older workers, or to stop discriminating based on age or to provide secure occupational pensions?

The relationship between declining health status and disability is complicated. Sometimes a person is not completely disabled, but neither can they perform all the activities of their usual employment. For instance, individuals may perceive their health to be good, yet still have decrements to strength or stamina, or suffer disabilities associated with repetitive tasks, such as back or knee problems, which make accomplishing job tasks difficult or impossible. Others experience age-related onset of chronic health conditions that interfere with employment, or the combination of poor health and declining physical abilities or overwhelming stress that prevent them doing what had been their usual employment at younger ages. The complexity of establishing a 'fair' approach to compensation in such situations needs to be considered in the context of policies to extend work. As the example of Austria shows, one strategy is for governments to allow workers in physically demanding jobs to retire earlier. There, a measure was introduced with specific rules for claiming early retirement for long-term employees engaged in strenuous work for at least 10 of the 20 years immediately preceding retirement age ('heavy labour pension') (OECD 2017b). A similar system facilitating earlier retirement for physically demanding jobs exists in France, but many countries have no such provisions. The longevity gap between individuals with low lifetime earnings and the top 5 or $10 \%$ of workers (and thus the length of time different individuals can expect to receive retirement income benefits) presents another complexity in reforms intended to be equitable in terms of extended work or delayed retirement. 
If an individual has the skills needed for hard physical labour, such as construction or personal care jobs, but no longer has the physical ability to work in that area, what could possibly be the prospects for continued employment? In some countries, including Belgium, governments subsidise the wages of those who are forced to take lower paid work if they are no longer able to continue with heavy work (OECD 2017b). Although job training or skills re-training are often touted as the answer to the job capacity/job availability/skills mismatch, the fact is that there is very little systematic evidence that suggests training increases employability beyond a handful of individuals (Fadula 2018). For example, in a carefully designed evaluation of federallyfunded job training programmes conducted for the US Bureau of Labour concluded that evidence from the evaluation of nationwide training funded by the Adult and Dislocated Worker programs 'does not have positive impacts in the 30 months after study enrolment' (Mathematica 2017: xxxiii). Logically, it seems as though training should work. However, training is decidedly not a panacea. The hollowed out middle of employment opportunities that has accompanied de-industrialisation and off-shoring limit employment possibilities. Job training on offer frequently diverges from preparing trainees for the skills that local employers need. High local unemployment rates and low demand for workers can render training ineffective if the desired outcome is landing a training-related job with decent pay and stable employment. And from an individual perspective, post-training outcomes may be poor because of how difficult it is for people to uproot and job seek outside their immediate locales and supportive social networks, or to relocate speculatively to areas where job openings consistent with new training might be available.

Unemployment rates are higher in some countries than others, but even the most robust labour markets have barriers to older workers' employment. Most employers prefer the cheapest labour they can find and this attribute is usually characteristic of first time job seekers. For example, even in the vibrant US job market with very low official levels of unemployment, older workers who became unemployed in the aftermath of the 2008 financial crisis remained unemployed for significantly longer spells than younger workers (Street and Tompkins 2017). Once unemployed, older workers typically have the longest periods of unemployment (if they can find work at all) and often end up underemployed (in jobs with less job security and/or pay than previous employment) or discouraged (and not counted in national unemployment statistics at all). Some countries recognise this situation and provide policies aiming to address these issues. For example, in Poland, Romania and Spain, the government provides subsidies to employers who hire unemployed older workers (OECD 2017b). In other countries, such as Belgium, governments supplement the wages of workers who have been forced to move to a lower paid non-physically demanding job in the same company as they become less able to perform their previous more physically taxing role (OECD 2017b). 


\section{Concluding Thoughts}

Pensions reflect economic relationships and national pension policies reside within technocratic realms. But what has been lost in most current debates is the fact that it is not only the national economic and demographic circumstances that must be considered to get extended working life policies right, but also the moral economy of ageing — the value societies place on older people — as well. The rhetorical flourishes of the extended working life debate have been fraught with crisis language and scaremongering, starved of emphasis on the connection between the lifelong contributions that older people have made to their entitlement to benefits. The challenge of ageing populations and scarce resources are seldom framed in the context of how to develop effective, sustainable policies that take into account the disproportionate advantages and disadvantages that are currently and will in the future be experienced by older people (see Phillipson 2019).

What does it really mean if societies accept the idea that pensions - and the older people who depend on them-are unaffordable? What entity can be responsible for provision of income security in old age? The responsibility increasingly is being shifted away from public or employer responsibility where risks could be shared and onto individuals and families. But if countries are struggling to plan effectively in the face of relatively more older people/fewer younger workers - what then are families expected to do? Families face the challenge of bridging an increasing number of provision gaps with more older members/fewer young members, albeit on a smaller scale and with decidedly fewer resources to pool risks.

A more optimistic perspective could take advantage of promising practices in some countries that can be adapted to the particular cultural contexts and political economies of others. In countries like Finland and Belgium, policies to extend good quality work (and not simply delay retirement) have been implemented. For example, following evidence-based research and discussion between the social partners, a number of measures were introduced in Finland to enhance working conditions for older workers. These included improving preventive health measures at work to address issues of not only physical but also psychological wellbeing for older workers. There are a range of flexible working arrangements for older (and all) workers in Finland. The Finnish Ministry for Social Affairs emphasised the necessity of employers, employees and government collaborating to improve health at work. Finland worked with the European Agency for Safety and Health at Work to introduce campaigns to promote an integrated management approach to the problem of musculoskeletal disorders (MSDs), emphasising that employers, employees and government should work together to tackle MSDs (OECD 2017b). In Belgium, an Employment Opportunity Plan was introduced in 2013, for all older workers in private firms with more than 20 employees. Employers may choose from a number of measures aimed at recruiting or retaining older workers. Next, the Flexible and Workable Work Act (2017) reformed training and, more importantly, improved working conditions for older Belgian workers throughout their careers, enabling them to work longer, rather than simply increasing state pension age. In other countries, 
such as France and Poland, their relatively low ages for entitlement to full retirement benefits hint that (if labour markets can provide jobs for older workers), it might be possible to emulate other countries' practices by gradually phasing in extensions of working lives for individuals who, by international comparison, are relatively 'early' retirees. But in many countries, assertions that future pensions are unaffordable and policies must change to make them less expensive (or rhetorically, more sustainable) by extending work for entire populations is an impoverished pathway to the more holistic goal of extending working lives. In fact, the typical approach to 'affordability', rather than honouring the contributions of older citizens and dignifying later life work seems instead to guarantee low incomes in old age, expanding rather than contracting the legions of older people who already struggle on limited incomes. On average, women, workers with low lifetime earnings, and people with physical frailty or poor health will be chief among the older citizens whose poverty will be 'baked into' most extended working life/delayed retirement regimes as they are currently configured.

A richer debate about extended work would incorporate attention to the unavoidable links between earlier lifecourse experiences and variation in life chances for adequate later life outcomes that are systematically associated with gender, health status and other social characteristics (Phillipson 2019). For example, explicit attention to temporal issues would require more focus on minimising systemic disadvantages associated with essential unpaid caregiving, whether for child or elder care. There is wide variation among countries in terms of addressing (or not) unavoidable breaks in employment associated with caregiving to avoid perpetuating lifelong disadvantages for carers. The amount and value of public pension contributions credited to carers who must reduce hours of work or leave employment to care, if provided at all, vary and the issue of accounting for carers' socially necessary and valuable unpaid work is seldom addressed in extended work and pension policy debates, to the disadvantage of (mostly) women. Or, consider the work effort of individuals with relatively low levels of education who often enter paid work-frequently in un- or semi-skilled jobs_-during their late teen years. Policies designed to extend working lives would recognise that starting employment up to a decade younger than highly educated professionals is already an extension of working lives, merely at the younger end of the lifecourse. Exhorting such early workers to avoid newly defined 'premature' or 'early' retirement once they have reached the earlier-established pension age hardly seems equitable. That is especially true given that globalisation and automation have decimated many formerly good paying jobs, sectoral disruptions in labour markets force redundancy and economic downturns eliminate jobs, or physical limitations and caring responsibilities limit employment capacity. The structural character of such impediments to extended working lives demonstrates the need for comprehensive and appropriately refined policies that take lifecourse issues seriously, since the interconnectedness of lifecourse trajectories and later life outcomes is undeniable.

The last words on the problems and possible merits of extended working lives will be rendered far in the future. In this volume, we have tried to complicate the conversation and the country chapter authors have communicated the current state of the extended working life debates in their own countries. It is obvious that, with very 
rare exceptions, there is not much yet to be optimistic about in terms of thoughtful and effective policy outcomes. There are occasional forays into devising programmes that can help, such as the Finnish and Belgian policy measures described above, suggesting that policy innovations can be designed to facilitate extending work. But examples of effective extended work policies are few and far between. The Finnish experience demonstrates the need for debate, evidence-based research and an integrated approach among partners-employers, employees, trade unions and government (national, regional and local) to devise appropriate policies to achieve good quality employment for older workers (Takala et al. 2015). The international focus so far has NOT been on extended working life policies that would deliver adequately compensated, appropriate jobs for older workers, but rather on delaying retirement benefits to later ages. We have argued that, although the two processes have some obvious overlaps, they are two distinctly different ways of thinking about policy approaches for ageing populations and that serious attempts to extend working lives will require policies that take that goal seriously.

The complexities associated with extending working life highlighted here cannot be addressed by simplistic unilateral policies imposed by governments. If we are to avoid deepening existing health and financial inequalities in later life associated with working in particular kinds of often low-paid, precarious, physically demanding or stressful occupations, more nuanced policies need to be designed. The realities of local labour markets and older workers' skills mean that globalisation and digitisation/automation have to be taken into account for reform proposals to make sense. Similarly, if we are to ensure that gender inequalities and the disadvantages experienced by individuals with poor or diminishing health are not to be further entrenched, reforms must recognise and compensate for the existing gender and health inequalities embedded in pensions, pay, and employment participation, and the imbalance in unpaid caring responsibilities that exist. There is a need for coherent and imaginative policies devised in cooperation between employers, trade unions, government and workers to address occupational health and gender equalities in pension building across the lifecourse and to ensure that extending working life is an appealing choice rather than a punitive imposition.

\section{References}

Barnes, H., Smeaton, D., \& Taylor, R. (2009). An ageing workforce: The employer's perspective. Brighton: Institute for Employment Studies.

Bettio, F., Plantenga, J., \& Smith, M. (Eds.). (2013). Gender and the European Labour Market, Routledge.

Börsch-Supan, A., Hanemann F., Beach, B., Halimi, D., Harding, S., van der Waal, M. Watanabe, D., \& Staudinger, U. M. (2019). Older adults' integration in the labour market: A global view. Ageing \& Society, 1-19. https://doi.org/10.1017/s0144686x19001454.

Burnay, N. (2018). Belgian temporary workers at end of working life: An intersectional lifecourse analysis. Ageing \& Society, 1-23. https://doi.org/10.1017/s0144686x 18001368.

Calvo, E., Haverstick, K., \& Sass, S. A. (2009). Gradual retirement, sense of control, and retirees' happiness. Research on Aging, 31(1), 112-135. 
Central Intelligence Agency. (2017, 2018). World factbook. Retrieved July 1, 2019, from https:// www.cia.gov/library/publications/the-world-factbook/geos/ez.html.

Clarke, L. H., \& Griffin, M. (2008). Visible and invisible ageing: Beauty work as a response to ageism. Ageing \& Society, 28(5), 635-674.

Dewilde, C. (2013). Lifecourse determinants and incomes in retirement: Belgium and the United Kingdom compared. Ageing and Society, 32(4):587-617. https://doi.org/10.1017/ S0144686X11000407.

Dorfman, L. (2002). Stayers and leavers: Professors in an era of no mandatory retirement. Educational Gerontology, 28(1), 15-33. https://doi.org/10.1080/036012702753304467.

Dorfman, L (2009). Ten years later: A follow-up study of professors still working after age 70 . Educational Gerontology, 35(11), 1032-1045. https://doi.org/10.1080/03601270903212294.

Duncan, C., \& Loretto, W. (2004). Never the right age? Gender and age-based discrimination in employment. Gender, Work \& Organization, 11, 95-115.

Duvvury, N., Ní Léime, Á., \& Callan, A. (2017). Erosion of pension rights. Experiences of women in Ireland. European Journal of Cultural and Political Sociology. https://doi.org/10.1080/23254823. 2017.1381034.

EIGE. (2017). Gender, ageing and economic independence-EIGE. In EU-OSHA, Cedefop, Eurofound, \& EIGE (Eds.) Joint report on towards age-friendly work in Europe: A life-course perspective on work and ageing from EU agencies (pp. 60-70). Luxembourg: Publications Office of the European Union.

EU-OSHA, European Agency for Safety and Health at Work (2016). The ageing workforce: Implications for occupational safety and health-A research review. Retrieved July 6, 2019, from https://osha.europa.eu/en/tools-and-publications/publications/saferand-andhealthier-work-any-age-ageing-workforce-implications.

EU-OSHA, Cedefop, Eurofound, \& EIGE. (2017). Joint report on towards age-friendly work in Europe: a Life-course perspective on work and ageing from EU agencies. Luxembourg: Publications Office of the European Union.

Eurofound. (European Foundation for the Improvement of Living and Working Conditions). (2015). Sustainable work over the life course: Concept paper. Luxembourg: Publications Office of the European Union.

Eurofound. (2017). Working conditions at different ages and policies for extending working livesEurofound. In EU-OSHA, Cedefop, Eurofound and EIGE (Eds.) Joint report on towards agefriendly work in Europe: A life-course perspective on work and ageing from EU agencies (pp. 14 33). Luxembourg: Publications Office of the European Union.

European Commission. (2018). Pension adequacy report. Luxembourg: Publications of the European Union.

Eurostat. (2019). Healthy life year statistics. Retrieved July 4, 2019, from https://ec.europa.eu/ eurostat/statistics-explained/index.php/Healthy_life_years_statistics.

Fadula, L. (2018, January 4). America's perennial failure at worker retraining, The Atlantic. Retrieved July 10, 2019, from https://www.theatlantic.com/education/archive/2018/01/why-isthe-us-so-bad-at-protecting-workers-from-automation/549185/.

Froidevaux, A., Hirschi, A., \& Wang, M. (2019). Identity incongruence and negotiation in the transition from work to retirement: A theoretical model. Organizational Psychology Review, 8(4), 228-255. https://doi.org/10.1177/2041386619830754.

Ginn, J., Street, D., \& Arber, S. (Eds.). (2001). Women, work and pensions: International issues and prospects. Buckingham: Open University Press.

Glei, D. A., \& Horiuchi, S. (2007). The narrowing sex differential in life expectancy in highincome populations: Effects of differences in the age pattern of mortality. Population Studies, 61(2), 141-159.

Handy, J., \& Davy, D. (2007). Gendered ageism: Older women's experiences of employment agency practices. Asia Pacific Journal of Human Resources, 45(1), 85-99.

Hershey, D. A., \& Henkens, K. (2013). Impact of different types of retirement transitions on perceived satisfaction with life. The Gerontologist, 54(2), 232-244. https://doi.org/10.1093/geront/ gnt006. 
Heslin, P. A., Bell, M. P., \& Fletcher, P. O. (2012). The devil without and within: A conceptual model of social cognitive processes whereby discrimination leads stigmatized minorities to become discouraged workers. Journal of Organizational Behavior. https://doi.org/10.1002/job.1795.

Higgs, P., \& Gilleard, C. (2010). Generational conflict, consumption and the ageing welfare state in the United Kingdom. Ageing \& Society, 30(2010), 1439-1451.

Ho, J. Y., \& Hendi, A. S. (2018). Recent trends in life expectancy across high income countries: retrospective observational study. British Medical Journal, 362, k2562. http://dx.doi.org/10.1136/ bmj.k2562.

Hunefeld, L., Gerstenberg, S., \& Huffmeier, J. (2019). Satisfaction and mental health of temporary agency workers in Europe: A systematic review and research agenda. Work and Stress, 1-29.

Johnson, R. W., \& Gosselin, P. (2018). How secure is employment at older ages? Urban Institute. Retrieved January 16, 2020, from Tinyurl.com/y43zwj8d.

Karpinska, K., Henkens, K., \& Schippers, J. (2011). The recruitment of early retirees: A vignette study of the factors that affect managers' decisions. Ageing \& Society, 31(4), 570-589.

Kim, I. (2011). Welfare States, flexible employment and health: A critical review. Health Policy, 104(2), 99-127. https://doi.org/10.1016/j.healthpol.2011.

Lahey, J. (2008). Age, women, and hiring: An experimental study. Journal of Human Resources, 43, 30-56. https://doi.org/10.3368/jhr.43.1.30.

Majer, I. M., Nusselder, W. J., Mackenbach, J. P., \& Kunst, A. E. (2011). Socioeconomic inequalities in life and health expectancies around official retirement age in 10 Western-European countries. Journal of Epidemiology and Community Health, 65, 972-979. https://doi.org/10.1136/jech.2010. 111492.

Marmot, M., \& Bell, M. (2012). Fair society, healthy lives. Public Health, 126(1 Supplement), S4-S10.

Mathematica Policy Research. (2017, May). Providing public workforce resources to job seekers: 30-month impact findings on the WIA adult and displaced worker programs. Retrieved July 10, 2019, from https://www.dol.gov/asp/evaluation/completed-studies/WIA-30mo-main-rpt.pdf.

Milovanovic, O., Radevic, S., \& Jovanovic, M. (2016). Legal framework and retirement policies in Serbia from 1990 to 2016-Gendered perspective. Frontiers in Public Health, 4, 208. Retrieved July 2, 2019, from https://doi.org/10.3389/fpubh.2016.00208.

Ministry of Social Security and Labour. (2017). Social statistics. Retrieved March 13, 2019, from https://socmin.lrv.lt/en/administrative-services/social-statistics.

Mulders, J. O., van Dalen, H. P., Henkens, K., \& Schippers, J. (2014). How likely are employers to rehire older workers after mandatory retirement? A vignette study among managers. De Economist, 162(4), 415-431.

Myles, J. (1989). Old Age and the Welfare State. University of Kansas Press.

Neumark, D., Burn, I., \& Button, P. (2015). Is it harder for older workers to find jobs? New and improved evidence from a field experiment. NBER Working Paper 21669, National Bureau of Economic Research, Cambridge, MA.

Ní Léime, Á., \& Loretto, W. (2017). Gender perspectives on extended working life policies. In Á. Ní Léime., D. Street, S. Vickerstaff, C. Krekula, \& W. Loretto (Eds.) Gender ageing and longer working lives: International analysis from a critical perspective (pp. 53-76). Bristol: Policy Press.

Ní Léime, Á., \& Street D. (2019). Working later in the USA and Ireland: Implications for precariously and securely employed women. Ageing \& Society, 39(10), 2194-2218.

Ní Léime, Á., Street, D., Vickerstaff, S., Krekula, C., \& Loretto, W. (Eds.). (2017). Gender, ageing and extended working lives: International analysis from a critical perspective. University of Bristol, UK: Policy Press.

OECD. (2006). Live longer, work longer. Paris: OECD Publishing. https://doi.org/10.1787/ 9789264035881-en.

OECD. (2013). Pensions at a glance 2013: OECD and G20 Indicators. Paris: OECD Publishing. http://dx.doi.org/10.1787/pension_glance-2013-en.

OECD. (2017a). Pensions at a glance 2017: OECD and G20 indicators. Paris: OECD Publishing. Retrieved July 2, 2019, from http://dx.doi.org/10.1787/pension_glance-2017-en. 
OECD (2017b). Key policies to promote longer working lives. Various countries. Retrieved July 3, 2019, from https://www.oecd.org/els/emp_Key\%20policies_Final.pdf.

Phillipson, C. (2019). 'Fuller' or 'extended' working lives? Critical perspectives on changing transitions from work to retirement. Ageing \& Society, 39(3), 629-665.

Pohrt, A., \& Hasselhorn, H. M. (2015). Domain: Work factors. In H. M. Hasselhorn \& W. Apt (Eds.), Understanding employment participation of older workers: Creating a knowledge base for future labour market challenges, Berlin: Federal Ministry of Labour and Social Affairs. Retrieved July 6, 2019, from http://www.jp-demographic.eu/wp-content/uploads/2015/07/JPIUEP_Brochure1. pdf.

Pond, R., Stephens, C., \& Alpass, F. (2010). How health affects retirement decisions: Three pathways taken by middle-older aged New Zealanders. Ageing \& Society, 30, 527-545.

Quadagno, J. (1990). Generational equity and the politics of the welfare state. International Journal of Health Services, 20(4), 631-649. https://doi.org/10.2190/k8be-3mhc-hpwv-e4lg.

Russell, J. (2014). Social insecurity 401( $k$ )s and the retirement crisis. Boston, MA: Beacon Press.

Russell, H., Quinn, E., King O'Riain, R., \& McGinnitty, E. (2008). The experience of discrimination in Ireland: Analysis of the QNHS equality module. Dublin: The Equality Authority and the Economic and Social Research Institute.

Standing, G. (2011). The precariat: The new dangerous class. New York, NY: Bloomsbury.

Street, D., \& Quadagno, J. (1993). The state, the elderly and the intergenerational contract: Toward a new political economy of aging. In K. W. Schaie \& W. A. Achenbaum (Eds.) Societal impact on aging: Historical perspectives (pp. 130-150). New York, NY: Springer.

Street, D., \& Tompkins, J. (2017). Is 70 the new 60? Extending American women's and men's working lives, In Á. Ní Léime, D. Street, S. Vickerstaff, C. Krekula, \& W. Loretto (Eds.) Gender, ageing and extended working lives: International analysis from a critical perspective (pp. 195217). Bristol: Policy Press, University of Bristol, UK.

Takala, E. P., Seitsamo, J., Henriksson, L., Härmä, M., Husman, P., Gould, R., Nivalainen, S., \& Kuivalainen, S. (2015). National report: Finland. In: H. M. Hasselhorn \& W. Apt (Eds.) Understanding employment participation of older workers: Creating a knowledge base for future labour market challenges. Berlin: Federal Ministry of Labour and Social Affairs. Retrieved July 7, 2019, from http://www.jp-demographic.eu/wp-content/uploads/2015/07/JPIUEP_Brochure1. pdf.

Vickerstaff, S. (2010). Older workers: The unavoidable obligation of extending our working lives. Sociology Compass, 4(10), 869-879.

Willetts, D. (2010). The Pinch: How the baby boomers took their children's future-And why they should give it back. London: Atlantic Books.

Open Access This chapter is licensed under the terms of the Creative Commons Attribution 4.0 International License (http://creativecommons.org/licenses/by/4.0/), which permits use, sharing, adaptation, distribution and reproduction in any medium or format, as long as you give appropriate credit to the original author(s) and the source, provide a link to the Creative Commons license and indicate if changes were made.

The images or other third party material in this chapter are included in the chapter's Creative Commons license, unless indicated otherwise in a credit line to the material. If material is not included in the chapter's Creative Commons license and your intended use is not permitted by statutory regulation or exceeds the permitted use, you will need to obtain permission directly from the copyright holder. 


\section{Part II \\ Extended Working Life Policies: Country Experiences}




\title{
Chapter 6 \\ Albania
}

\author{
Merita Vaso Xhumari
}

\begin{abstract}
This chapter analyses the most important policies influencing the gender and health implications of the extension of working life in Albania post 2000. Parametric reforms of social insurance will gradually increase and equalise retirement ages for men and women to 67 years by 2056, and extend the insurance period to 40 years by 2032. During the period 1993-2016, the average real retirement age has increased from 53.2 to 63.2 years old. People have the right to receive the pension and continue working and paying contributions, but if they postpone receiving pensions after retirement age, the pension amount increases by $0.5 \%$ each month; in the case of early retirement, the pension amount reduces by $0.6 \%$ each month. New types of private sector employment_part-time, self-employment, family businesses, remote working - have opened opportunities to extend working life beyond retirement age. However, high levels of unemployment, informal work, lack of adequate skills, and insufficient public services create difficulties, especially for women, to extend working life. To fully address the complexity of extending working lives, an integrated approach should involve all relevant policy areas including education, health, employment and social protection, as well as engaging stakeholders, public authorities, businesses and civil society.
\end{abstract}

Keywords Lifecourse $\cdot$ Pension $\cdot$ Retirement ages $\cdot$ Gender $\cdot$ Health $\cdot$ Labour market

\section{Introduction}

The lifecourse perspective encompasses all dimensions of an individual's professional and family life, influenced by the social and institutional context. Socioeconomic and demographic changes have influenced continuous parametric pension reforms in Albania since the beginning of the 1990s. In June 2014, Albania was granted candidate status by the European Union and this promoted institutional reforms. Due to changes in demographic patterns of fertility, life expectancy and

\section{V. Xhumari ( $\varangle)$}

University of Tirana, Rr. Myslym Shyri P.12, Tirana, Albania

e-mail: xhumarimerita@gmail.com

(C) The Author(s) 2020

Á. Ní Léime et al. (eds.), Extended Working Life Policies, https://doi.org/10.1007/978-3-030-40985-2_6 
migration, the old age dependency ratio nearly doubled (from $8.6 \%$ in 1989 to $16.7 \%$ in 2011) and is expected to grow to $32.9 \%$ by 2030 (INSTAT, SDC, UNFPA 2015a). By 2031, a gender old age dependency ratio estimated at $31 \%$ for men and at $37 \%$ for women refers to a higher life expectancy at birth estimated at 80.1 years for women and 77.0 years for men (INSTAT 2017b). In 2016, Albania had a low share of the population above 65 years old (16.3\%), compared to $19.2 \%$ in EU28 countries (Institute of Statistics, Institute of Public Health, and ICF 2018: 11).

The Demographic and Health Survey 2008-2009 in Albania showed that one in two households have at least one member who has migrated within or outside Albania (Institute of Statistics, Institute of Public Health, and ICF 2010). As is the case elsewhere, migration particularly involves young adults, who migrate for reasons of employment and educational opportunities and for family reasons; migration is still dominated by young adults, but in addition to men, women increasingly go abroad as well (INSTAT, SDC, UNFPA 2015b: 21-22). Younger generations working abroad remain a potential source of support for their older parents left at home, by sending remittances and by covering expensive medical interventions, thus acting as a guarantor for older Albanians. The Albanian family continues to be a strong source of social protection for older people. This may be one reason why people are reluctant to pay social insurance contributions and why approximately $40 \%$ of employment is informal (World Bank and wiiw 2019). Promotion of formal employment for women is especially important for increasing their social inclusion, social insurance contributions and striving for higher pensions, as their life expectancy is higher compared to men.

In the framework of European integration, Albanian legislation has pursued a process of harmonisation with Acqui Communitarie, and national strategies have been enacted to guarantee human rights, gender equality and an inclusive society. However, institutional capacities still remain weak, and active engagement of all community stakeholders, such as business organisations, trade unions and civil society, is very important in this context.

\section{Gender and Employment in Albania}

The Labour Force Survey (LFS) 2016 showed that Albania's labour force participation rate decreased from $2011(68.5 \%)$ to $2016(66.2 \%)$, with a constant gender gap of about $16 \%$ fewer women than men in paid work. In 2016, the unemployment rate of 27.4\% for Albanians aged 15-29 illustrates great pressure for new labour market entrants (INSTAT 2016). High unemployment rates, even for those with higher education (32\% according to European Commission 2016), encourages employers to shed older employees as soon as they reach the retirement age, without considering whether older workers want to stay longer in the labour market.

In 2016, 40.2\% of Albanians were self-employed in agriculture (dominated by women). The non-market services sector-where activities such as public administration and other services are included-is the second most important sector for 
women's employment (20\%). The Labour Force Survey 2016 also showed that $42 \%$ of women were outside of the labour force, compared to $26 \%$ of men, although women's labour force participation increased from 50\% in 2013 to $58 \%$ in 2016 (INSTAT 2017a: 52). The reasons why women aged 55+ are outside the labour market are due to early retirement for about $40 \%$ and due to family engagement for $20.1 \%$, compared to one per cent for men on family engagement.

Reconciliation of paid work with family responsibilities is important when considering extending working life. Only $46 \%$ of employed Albanian women and $50 \%$ of men work full-time 40-48 h per week (INSTAT 2017b). In the European Quality of Life Survey (EQLS) (Eurofound 2019), Albanian women report greater difficulty in fulfilling family responsibilities when compared with men. Recent changes in the Labour Code (2015) aim to facilitate maternity leave and care for sick family members, to legislate a maximum of 48 working hours per week for employees in the private sector, and to encourage employers to improve working conditions. If employees work more than $48 \mathrm{~h}$ per week and work on Sundays, it is not sufficient for the employers just to pay additional money, as happened in the past; employees now have the right to take a break.

\section{Transformation of Pension System}

From a lifecourse perspective, transition from employment to retirement is regulated mainly by two basic laws: Labour Code 136/2015 and Law no. 7703 (dated 11.05.1993) on 'Social Insurance in the Republic of Albania'. The general public system of social insurance is composed of: (1) compulsory, (2) voluntary, (3) supplementary social insurance. It is a pay-as-you-go (PAYG) model. Since 2015, the social pension was introduced as a means-tested benefit for Albanian residents above age 70 . Fully funded defined contribution private pension schemes were only started after 2005.

Reformation of the pension system started in 1993, with parametric changes that unified retirement ages at 60 years for all categories of men and at 55 years for all categories of women, for a transitional period until 2024 (Law no. 7703 dated 11.05.1993, amended in 2002). Previously, there were differences in retirement ages across three categories of professionals, and a five year difference between women and men. Category I professions (miners, metallurgists, geologists etc.) had the lowest retirement ages (45 for females and 50 for males); category II, teachers, had a retirement age of 50 for females and 55 for males; and category III, civil servants, had a retirement age of 55 for females and 60 for males. The retirement age for employees in agriculture cooperatives was 65 years old for both women and men. The unification of the eligibility criteria for pensions was imposed by the new political and economic system in Albania, which allows freedom of choice of profession, place of work, and place of residence. This created opportunities and increased mobility for people from rural to urban areas, from employment in state enterprises to the private sector, from employment to self-employment, and so on. 
Meanwhile, the minimum insurance period for an old age pension was increased from 15 to 20 years, with a maximum of 35 years for a full pension for both women and men. As the contributory principle was established, the period of university studies was considered as an insurance period for women when they retired and the state will pay the minimum level of contributions. The social insurance fund was separated from the state budget to clearly identify revenue from contributions and subsidies from the state budget. A new semi-public autonomous administration was established, governed with participation of representatives from the government, the trade unions and the employers' organisations.

In the beginning of the transition to a market economy, there was tension between using pension policy as a quick fix while also assuring the long-term sustainability of new social insurance institutions (Xhumari 2011). Through the introduction of early retirement, the pension system helped older workers who were unemployed within five years of reaching state retirement age. The early retirement pension was calculated at the rate of $60 \%$ of the average monthly wage. Beneficiaries get a regular pension calculated at $70 \%$ of the minimum monthly wage for the minimum pension, once they reach official retirement age. Albanians did not hesitate to apply for early retirement. As a consequence, the number of pensioners increased and contributors declined, changing the dependency ratio from 4.5:1 in 1990 to almost 1:1 from 1993 until now. The replacement rate of old age pensions decreased from $70 \%$ to around $40 \%$ during the same period. Since 1993, the formula for calculating pensions considered all contributions paid throughout the working period. Social insurance contributions shared between employers and employees increased initially up to $45.9 \%$ of wages, but gradually decreased in 2009 to $24.5 \%$ of wages. However the state budget still needed to subsidise the social insurance fund from 1.8\% of GDP in 1993 to $1.89 \%$ of GDP in 2016 (Social Insurance Institute of Albania 2017).

The second wave of pension reform (2002) increased retirement ages, adding five years for both men (60-65 years old) and women (55-60 years old) during a transitional period (2002-2024), while the minimum insurance period for old age pensions was reduced from 20 to 15 years. The termination of employment as an eligibility criterion for old age pension was abolished, so pensioners may have a pension and continue working and paying social insurance contributions. Early retirement was a right for everybody provided they have 35 years of insurance period, within three years before the official full retirement age, with benefits reduced by $0.6 \% /$ month. For late retirement, pension benefits increase by $0.5 \% /$ month for 4 years, for Albanians working after the official retirement age (Law no. 7703 dated 11.05.1993).

The last wave of pension reform in 2015 aimed to gradually equalise the retirement age for women and men, with a likely increase to 67 years old by 2056 and an extension to the insurance period for a full old age pension from 35 to 40 years by 2029 for men and by 2032 for women. The formula for calculation of pensions in respect to the contribution principle was also changed. Limitation of the maximum benefit amount to twice the minimum pension was abolished to encourage people to pay higher contributions if they want to earn higher benefits. A basic non-contributory pension was introduced for Albanians above age 70 without any source of income 
Table 6.1 Some indicators of the pension system in Albania, 1990-2016

\begin{tabular}{l|l|l|l}
\hline Main indicators/Year & 1990 & $1993^{\mathrm{a}}$ & 2016 \\
\hline $\begin{array}{l}\text { Share of } \\
\text { pensioners/total } \\
\text { population }\end{array}$ & $9.8 \%$ & $13.4 \%$ & $19 \%$ \\
\hline $\begin{array}{l}\text { Formal age of } \\
\text { retirement }\end{array}$ & $45-65$ years old & $50-65$ years old & $\begin{array}{l}55-65 \text { years old, still in } \\
\text { the process of } \\
\text { increasing }\end{array}$ \\
\hline $\begin{array}{l}\text { The average real age of } \\
\text { retirement }\end{array}$ & 57.1 & 53.2 & 63.2 \\
\hline $\begin{array}{l}\text { Maximum insurance } \\
\text { period for a full old age } \\
\text { pension }\end{array}$ & $15-25$ & $20-35$ years & $\begin{array}{l}35 \text { years, still in the } \\
\text { process of increasing }\end{array}$ \\
\hline $\begin{array}{l}\text { Replacement rate } \\
\text { (average old age } \\
\text { pension/average wage) }\end{array}$ & $74.2 \%$ & $56.4 \%$ & $41.7 \%$ \\
\hline $\begin{array}{l}\text { Dependency ratio } \\
\text { (number of } \\
\text { pensioners/number of } \\
\text { contributors) }\end{array}$ & $4.5: 1$ & $1.6: 1$ & $1.1: 1$ \\
\hline $\begin{array}{l}\text { Percentage of social } \\
\text { insurance } \\
\text { contributions/wage }\end{array}$ & $19 \%$ & $42.5 \%$ out of which & $27.9 \%$ out of which \\
\hline $\begin{array}{l}\text { Subsidy from state } \\
\text { budget to social } \\
\text { insurance budget as } \% \\
\text { of GDP }\end{array}$ & - & 1.80 & 1.89 \\
\hline $\begin{array}{l}\text { Sorce for pensions } \\
\text { Instions }\end{array}$ & $21.6 \%$ for pension & \\
\hline
\end{tabular}

Source INSTAT www.instat.gov.al and Social Insurance Institute www.issh.gov.al aLaw no.7703, dated 11.05.1993 'On Social Insurance in the Republic of Albania'

(Law no. 7703 dated 11.05.1993, amended in 2015). As a result, the main indicators of the social insurance system changed during the period of reforms 1990-2016, as shown in Table 6.1. Although the years of working life was extended from 53 years in 1993 to 63 years in 2016, the share of pensioners to total population continued to increase.

\section{Debate on Extended Working Life}

While the approaches varied - particularly with regard to the choice between parametric and systemic reforms and over the introduction of funding-in all cases, reforms typically focused on issues of pension sustainability rather than benefit adequacy (Holzmann 2007). As the Albanian Government, with the assistance of the World Bank after 1990, was designing the reform intended to secure the financial 
sustainability of the social security system, pensioners' organisations, academics and trade unions were arguing to support social sustainability and the adequacy of benefits. For example, trade unions advocated early retirement for older workers as the only way to manage their dire unemployment situation. Trade unions also opposed increased retirement ages, especially for miners and other occupations where longer employment was unreasonable. Only in 2014 did the trade unions succeed in establishing a pension scheme for the employees that have worked underground in mines. This category will be eligible for full old age pensions with a lower retirement age at 55 years old and 30 years of insurance period, where at least 12.5 years was in mining at underground (Law no.150/2014: Art.3).

Reflecting the new Law on Higher Education and Science Research (2015), professors are allowed to negotiate to keep their positions longer, instead of being 'sent into retirement' automatically by a unilateral decision of the employer. A supplementary PAYG scheme for them was added to other supplementary schemes for civil and military service.

The opportunity to extend working life beyond the official retirement age is mainly for employees in the private sector and self-employed people. There are cases of older teachers, nurses, doctors, engineers, lawyers and economists who have moved to work in the private sector following enforced retirement from the public sector. However, flexibility in the transition to retirement is not available to everyone, as it requires the agreement of the employer in both public and private sectors. Research should identify sectors where later life employment is in demand by Albanian employers, and how this would be possible for anyone who wants to continue to work.

The low replacement rate of pensions, reduced from $70 \%$ of the wage in 1993 , to $41.7 \%$ in 2016, has been another topic in debates between the government and the pensioners' associations, academics and trade unions. At the centre of debates was respecting the contribution principle to encourage people to pay more contributions and the ILO Convention no. 102/1952 on Minimum Standards of Social Security, ratified by the Albanian Government since 2005. However, prospects for extending working life and the employability of older workers should not be seen only as an individual choice to guarantee the living standards they are used to. There are few jobs available for older workers that are consistent with their abilities and health status.

The new PAYG pension system is based on solidarity between the younger and older generations, and the intra cohort solidarity of old age pensioners. The intra cohort solidarity is distinguished by a high level of redistribution from those with higher pensions to those with lower pensions, characterised as the 'egalitarianism of the pension system' (Broka 2018). The old age pension benefit is progressive, with a greater proportion of benefits earned for contributions at minimum wage (with a replacement rate of $70 \%$ ), whereas the replacement rate is $35 \%$ for contributions of those with higher wages, up to 5 times more than the minimum wage (the ceiling for payment of contributions). This high level of redistribution, unsupported even in the socialist regime, has demotivated workers from paying contributions on higher levels. By law, employers and the self-employed pay contributions based on the minimum wage defined each year by the Government, but often employees in the 
private sector declare just the minimum wage for payment of contributions, as it has the highest return for benefits. As a result, about $90 \%$ of old age pensions are at the minimum level of benefits necessary to survive. One of the directors of the Trade Union Institute argues that even the amount of contributory minimum pensions does not meet the minimum standards of living (Telo 2016).

The paradox is that the definition of the official retirement age is taken more as a right of the employer (mainly the public sector) to get the employees out of employment into retirement, and less as a right of the employees to decide if they want to leave their job or to continue in work. Extending working lives should be broadly considered through the complexity of interventions into the labour market, enabling or requiring employers to offer flexibility for the transition to retirement. Such interventions are unavoidable if Albania aims to follow the objectives of the EU Strategy 2020 for extending the active age until 70. If this aim is to be met, it is not only through increasing the official retirement age of pension system, but through offering employment and training opportunities for older Albanians.

\section{Gender and Health Implications}

The Labour Force Survey (LFS) shows difficulties for the 55-65 age groups in finding a job once unemployed, although their unemployment rates are lower compared to the youngest age groups. The European Quality of Life Survey (EQLS) 2016 shows that obstacles to older workers staying in employment included lack of adapted workplaces and flexible working arrangements (Eurofound 2019). As Table 6.2 shows, few older workers have found it possible to extend their working activities beyond the state pension age. The Labour Force Survey 2011-2017 shows a very dynamic situation, changing from one year to the other, with a slight increase after 2015 of elderly Albanians working, shown on Table 6.2. Although women have a longer life expectancy than men and lower pensions, they tend to be less engaged in working outside the home after retirement age.

The employment status of those who continue working after retirement age is that own-account workers dominate at more than $60 \%$ in the case of men, and contributing family workers at more than 50\% for women (INSTAT, LFS 2017c). As for the higher

Table 6.2 The share of older people working after retirement age, 2011-2017

\begin{tabular}{l|l|l|l|l|l|l|l}
\hline Year & 2011 & 2012 & 2013 & 2014 & 2015 & 2016 & 2017 \\
\hline $\begin{array}{l}\text { \% of men aged 65 +/to total men of } \\
\text { this age group who continue working } \\
\text { after retirement age }\end{array}$ & 12.9 & 14.5 & 11.6 & 10.9 & 10.4 & 12.2 & 13.6 \\
\hline $\begin{array}{l}\text { \% of women aged 60 +/to total women } \\
\text { of this age group who continue } \\
\text { working after retirement age }\end{array}$ & 12.9 & 14.3 & 10.8 & 8.6 & 7.9 & 9.1 & 10.9 \\
\hline
\end{tabular}

Source INSTAT. Labour Force Survey 2011-2017. www.instat.gov.al 
employment of women in agriculture, they mainly comprise family workers. Changes in pension formula, increased retirement age and lengthening insurance periods have contributed to low pensions for women, who have an average of 29 years insurance period, compared to 31.1 for men (Social Insurance Institute 2017). While women receive pensions for an average of 25 years (compared to only 20 years for men), for most women the transition into retirement equates to a transition into poverty. Introduction of the social pension, as a means-tested social assistance for those above age 70 , is especially directed towards women, who have higher unemployment, lower contribution periods and greater life expectancy compared to men (Law no. 7703 dated 11.05.1993, amended in 2015).

The EQLS 2016 showed that depression increases with age, and is correlated with worries about income in old age, implying the need for adjustments to social protection to meet older Albanian women's needs (Eurofound 2019). Measuring inequalities in health provides important evidence to policymakers for developing equity-centred healthcare programmes. The promotion of safe working environments is important, given the increasing number of disabled women of working age. In 2014, a preventive healthcare policy offered free basic medical annual examinations (Check-Up) to the 40-65 age group; in 2016 that was extended to encompass the 35-70 age group. Population screening for the most prevalent disease prevention and early detection of disorders aims to improve health, to promote healthy lifestyles and to improve wellbeing in work. Most people who attend the check-up are women and most are aged 50-65 years. The initial data shows that about $18 \%$ of people who attended had hypertension and were unaware they had it (Compulsory Health Care Insurance Fund 2015).

The last Albanian Living Standard Measurement Survey (2012) confirmed that disability, chronic disease and depression are higher among older women than older men (INSTAT 2012a). The EQLS 2016 also shows a gender gap regarding health indicators in Albania. On average, 69\% of men and 52\% of women report 'good' and 'very good' health, which is a better rate than some Member States, but lower than the EU average of 73\% for men and 66\% for women (Eurofound 2019). This situation can be explained by the relatively young Albanian population, with a mean age 35.3 years (INSTAT 2012b). In the youngest groups, $92 \%$ of men and $79 \%$ women report 'good' or 'very good' health, compared to the older groups, who report 'good' or 'very good' in $36 \%$ of men and $26 \%$ of women. The EQLS (2016) also shows a gender and age pattern for risk of depression in all EU countries, which is higher for women compared to men. Among the 18-34 year old age group in Albania, $18 \%$ report being at risk of depression, compared to $45 \%$ at risk of depression for those aged above 65. Albanian women reported a higher risk of depression (35\%) compared to men (26\%) and this difference is more evident among older women (57\%) compared to men (33\%), although the longer life expectancy of women should be taken into account (Eurofound 2019). This can be taken into account as one of the factors influencing early retirement of women compared to men in Albania. There is an urgent need for an integrated approach to both prevention and improvement of health care in order to face the high burden of non-communicable diseases in transitional Albania (Institute of Public Health \& UNICEF 2014: 122, 134). This 
data from the EQLS and other INSTAT surveys should be used as an evidence base when considering the implications of future pension policy of increasing retirement ages.

\section{Policy Recommendations}

Different factors influence peoples' lifecourse decisions. Extending working life is affected by complex factors including institutional arrangements such as fixed retirement ages, demand for jobs, adequate skills, training, services available to facilitate women's employability, working conditions, and so on. Pension reforms that increase retirement ages and the insurance period, that discourage early retirement and create incentives to keep older workers in employment beyond retirement age, will necessarily depend on improvement in employment services, labour contracts and public services. Labour Code improvements, both in work-life regulations and support for women in their family responsibilities, need to be integrated with vocational training that is rarely offered by employers. Development of occupational pension schemes might have an impact on extending working life through flexible retirement ages.

Albanian society has experienced transformations with a rising symmetry in gender roles and in lifecourse organisation, although gender differences are evident. The gendered lifecourse patterns are distinguished by women having more family responsibilities, more difficulties in balancing work and family life, fewer employment opportunities and lower incomes compared to men. Having a longer life expectancy, women remain in later life for a longer period, enduring a lower standard of living, and are at higher risk of depression, material deprivation and health problems. The challenges to significant investments in human capital and public services frustrate Albania's convergence towards EU integration.

Effective policies for extending working life are a challenge and require an integrated approach. Socio-economic factors, including high youth unemployment, create pressure on older workers to leave their jobs at retirement age. There is limited literature and not much public debate on extending working life, as high unemployment and scarce jobs have led policy priorities to focus on youth employment and vocational education. As the analysis demonstrates, more societal action is needed to address inequalities and differences between women and men for full inclusion in Albanian society. Preventive healthcare is a priority, as risk of depression and health problems are higher among older women. Further research is needed on the gender and health implications of the potential for extended working life in Albania. 


\section{References}

Broka, K. (2018). Pensionet, e tashmja dhe e ardhmja. Tiranë: UETPRESS.

Compulsory Health Care Insurance Fund. (2015). Focus Bulletin No. 31, 2015. Retrieved December 26, 2019, from https://www.fsdksh.com.al/images/stories/publikimet/revista/Revista_FOKUS_ Dhjetor/Draft_Fokus_Shqip_18_dhjetor.pdf.

Eurofound. (2019). Life and society in the EU candidate countries, European quality of life 2016 series, Publications office of the European Union, Luxembourg, from https://www.eurofound. europa.eu/sites/default/files/ef_publication/field_ef_document/ef18032en.pdf.

European Commission. (2016). From university to employment: Higher education provision and labour market needs in the Western Balkans. Retrieved December 26, 2019, from http://www.lse.ac.uk/business-and-consultancy/consulting/assets/documents/FromUniversity-to-Employment.pdf.

Holzmann, R. (2007). Adequacy of retirement income after pension reforms in Central, Eastern, and Southern Europe. Vienna: ErsteStiftung Studies 006. Retrieved December 26, 2019, from http:// siteresources.worldbank.org/INTPENSIONS/Resources/Adequacy_Retirement_Income.pdf.

Institute of Statistics (INSTAT). (2017a). Statistical yearbook 2017. Retrieved December 26, 2019, from http://www.instat.gov.al/media/3655/vjetari-statistikor-2017.pdf.

Institute of Statistics (INSTAT). (2017b). Women and men in Albania. Retrieved December 26, 2019, from http://www.instat.gov.al/media/2316/burrat_dhe_grat_ne_shqiperi_2017_libri.pdf.

Institute of Statistics (INSTAT). (2017c). Labour force survey (LFS). Retrieved December 26, 2019, from http://www.instat.gov.al/al/temat/tregu-i-punës-dhe-arsimi/punësimi-dhe-papunësia/\#tab3.

Institute of Statistics (INSTAT). (2016). Labour force survey (LFS). Retrieved December 6, 2019, from http://www.instat.gov.al/media/1912/anketa-tremujore-e-forcave-t\%C3\% AB-pun\% C3\% ABs-t4-2016.pdf.

Institute of Statistics (INSTAT). (2012a). Living standards measurement survey. Retrieved December 26, 2019, from http://www.instat.gov.al/en/themes/social-condition/living-standardmeasurement-survey/\#tab2.

Institute of Statistics (INSTAT). (2012b). Population and housing census. Retrieved December 26, 2019, from http://www.instat.gov.al/media/3058/main_results_population_and_housing_ census_2011.pdf.

Institute of Statistics (INSTAT), SDC, and UNFPA. (2015a). Population ageing: Situation of elderly people in Albania. Retrieved December 26, 2019, from http://www.instat.gov.al/media/1582/ population_ageing_situation_of_elderly_people_in_albania.pdf.

Institute of Statistics (INSTAT), SDC, and UNFPA. (2015b). Youth in Albania, Challenges in changing times. Retrieved December 26, 2019, from http://www.instat.gov.al/media/1583/youth_in_ albania_challenges_in_changing_times.pdf.

Institute of Statistics, Institute of Public Health, and ICF. (2018). Albania demographic and health survey 2017-18. Retrieved December 26, 2019, from https://dhsprogram.com/pubs/pdf/FR348/ FR348.pdf.

Institute of Statistics, Institute of Public Health and ICF. (2010). Demographic and health survey 2008-09. Retrieved December 26, 2019, from https://dhsprogram.com/pubs/pdf/FR230/FR230. pdf.

Institute of Public Health \& UNICEF. (2014). National Health Report "Health status of the Albanian population". Retrieved December 26, 2019, from http://www.ishp.gov.al/wp-content/uploads/ 2015/04/Health-report-English-version.pdf.

Law no. 7703 dated 11.05.1993. Social insurance in the Republic of Albania amended. Retrieved December 26, 2019, from https://www.legislationline.org/documents/id/16420.

Law no. 150/2014. For the pensions of the employees that have worked in mining, at underground. Retrieved December 26, 2019, from http://www.issh.gov.al/wp-content/uploads/2014/02/Ligj_ 150_2014_Minatoret.pdf.

Law no.136/2015. Labour Code in the Republic of Albania. Retrieved December 26, 2019, from http://www.parliament.am/library/ashxatanqayinorensgrqer19/albania.pdf. 
Law no.80/2015. On Higher Education and Science Research in Higher Education Institutions in the Republic of Albania. Retrieved December 26, 2019, from http://arsimi.gov.al/wp-content/ uploads/2018/08/AKTET_NENLIGJORE.pdf.

Social Insurance Institute of Albania. (2017). Statistical Report. Retrieved December 26, 2019, from http://www.issh.gov.al/wp-content/uploads/2014/02/Perb_12_17-web1.pdf.

Telo, I. (2016). Popullsia e Shqipërisë dhe probleme të saj. Tiranë: Mirgeerabl.

World Bank \& The Vienna Institute for International Economic Studies (wiiw). (2019). Western Balkans Labour Market Trends 2019. Retrieved December 26, 2019, from http://documents. worldbank.org/curated/en/351461552915471917/pdf/135370-Western-Balkans-Labor-MarketTrends-2019.pdf.

Xhumari, M. (2011). Pension trajectories in Western Balkans 1990-2010. Tiranë: Pegi.

Open Access This chapter is licensed under the terms of the Creative Commons Attribution 4.0 International License (http://creativecommons.org/licenses/by/4.0/), which permits use, sharing, adaptation, distribution and reproduction in any medium or format, as long as you give appropriate credit to the original author(s) and the source, provide a link to the Creative Commons license and indicate if changes were made.

The images or other third party material in this chapter are included in the chapter's Creative Commons license, unless indicated otherwise in a credit line to the material. If material is not included in the chapter's Creative Commons license and your intended use is not permitted by statutory regulation or exceeds the permitted use, you will need to obtain permission directly from the copyright holder. 


\title{
Chapter 7 Australia
}

\author{
Elizabeth Brooke
}

\begin{abstract}
Although Australian women's labour force participation has increased sharply since the turn of the century, there is a dichotomy between their participation at the pre pension threshold of 65 and after. Women's gender segregation in low waged occupations is institutionalised through the neoliberal policy of individual enterprise agreements, reinforcing gender wage gaps. In combination, the gendered health effects of caregiving, disrupted careers and the experience of precarity shorten working lives, limiting wages and retirement incomes, ultimately impacting on women's economic status and class. Some gender responsive initiatives through the courts have been instituted supporting flexibility requests to employers applied to workers over 50 and employment entitlements by workers employed as casuals. Yet the lack of proactive 'joined up' gender and age policies across multidimensional domains enables the contradiction between public policies of women's extending working lives and reality to persist.
\end{abstract}

Keywords Older women $\cdot$ Workforce $\cdot$ Inequality $\cdot$ Retirement $\cdot$ Policy

\section{Introduction}

The Australian resources and commodities sectors have experienced recent downturns, largely due to reduced Chinese demand for Australian exports. Similar to other advanced economies, Australia's economy has restructured over the past 30 years and there has been a shift in employment from manufacturing sectors to services sectors, particularly health and social assistance. Often policies related to extended working lives are developed in response to political circumstances and tend to be inconsistent and unsystematic.

Since 2002 successive Australian Intergenerational Reports (IGRs) have called for increased older workforce participation to bolster productivity and reduce fiscal gaps attributed to the 'burden' of dependency. The Australian government's most

\section{E. Brooke (殴}

Demography and Aging Unit, Melbourne School of Population and Global Health, University of Melbourne, 203 Bouverie St, Carlton, 3052 Melbourne, VIC, Australia e-mail: ebrooke425@gmail.com 
recent 2015 IGR rationalised extending the pension age to 70 by 2035 to combat future intergenerational inequity (Commonwealth of Australia 2015). The Report invokes intergenerational equity principles, so that 'future generations will not only have to fund their own government services, they will be funding the services used by Australians today'. It also asserts intrinsic neoliberal principles of contracting government debt in order to move to a budgetary 'surplus' in 2019-20.

On 4th September 2018, Prime Minster Scott Morrison retracted this policy the week after his replacement of Prime Minister Turnbull. The new Prime Minister explained that pension deferral was 'no longer necessary' as the net operating balance will move into a projected surplus of Aus \$7.6 billion in 2019-20 (Budget 2017-2018). The policy change did not address underlying barriers limiting extended working lives, for instance age discrimination in recruitment and a lack of proactive coordinated government policies, but instead framed the debate purely in economistic terms.

Australian national data show that age related reasons for retirement are the main reason for ceasing final employment, 'reached retirement age/eligible for superannuation/pension' has been cited by $36 \%$ of men and $22 \%$ of women. The average age of recent retirees (those who have retired in the last five years) was 62.9 years, 63.6 years for men and 62.1 years for women, these ages are well below the potential pension eligibility age of 67 in 2025 (ABS 2017a).

\section{The Australian Gender Lens of Extended Working Lives}

Older women's labour force participation has increased sharply since the turn of the century. In 2000, women's labour force participation aged 60-64 was 20\%, which more than doubled to $46 \%$ in 2015. Much of this increase is cohort driven, associated with cultural changes related to gender roles and the higher levels of educational attainment. The far higher male rate increased at a lower rate, from $46 \%$ in 2000 to $64 \%$ in 2015 (Temple and McDonald 2017). Yet there is a dichotomy between labour force participation increases at pre pension ages and the pension threshold beyond 65 .

Despite the abolition of mandatory retirement, the pension eligibility age is linked with the traditional tripartite lifecourse stages of education, work and retirement. A 'structural lag' (White Riley et al. 1994) exists between legislation and the extension of working lives beyond pension ages. The current pension age is set at 67 increasing six monthly every two years from 65 in 2017 to 67 in 2023. Women's labour force participation after 65 increased to ten per cent in 2015, trebling from a low base of three per cent in 1995 (ABS 2018). Male labour force participation rates commenced from the base of ten per cent that women achieved in 2015, to $18 \%$ in 2015. Men over 65 were almost twice as likely to participate in the labour force than older women and were also more likely to be working full-time (47.5\% of men, compared to $24.2 \%$ of women) (ABS 2018). 
OECD policymakers have proposed extending working lives as an economistic policy response to the perceived urgency of countering the burgeoning welfare costs of the demographic 'tsunami' (Amalberti et al. 2016). Yet in the Australian context age and gender implications of extended working life policy require support for women extending their working lives beyond the standardised lifecourse stage of pension eligibility.

\section{Australian Retirement Incomes}

Australian retirement incomes are built on tripartite pillars: The first pillar is mainly wages income, together with savings and investment returns. The second pillar of publicly funded pensions, established in 1909, is based on a means-tested income support system. The majority of Australians (70\%) receive a part pension after eligibility criteria are met. The third pillar of Australian retirement incomes, the Superannuation Guarantee, instituted in 1992, is built on the privatised compulsory employer contribution to an employee's superannuation account, currently $9.5 \%$ and scheduled to increase to $12 \%$ by 2026 .

A cumulative, intersecting 'deaccumulation' trajectory of gendered age relations is structured within the retirement incomes system, based in women's low wages, and resulting in low superannuation balances and greater reliance on pensions than men (Brooke 2017). This 'deaccumulation' trajectory convoys the gender gap in wages of 22.4\% in 2017 (The Workplace Gender Equality Agency (WGEA 2017a) to greater reliance on pensions to the superannuation gender gap of $17.7 \%$ (WGEA 2017b).

\section{Pillar 1: Wages Income}

The gender wage gap is widest at the ages 45-54 when women earn on average under $20 \%$ of the male wage, calibrating age gender intersectionalities across the lifecourse. Women's lower wages are a consequence of broken career trajectories of 'productionist' relations, related to women's productivity in the paid workforce, due to their 'reproductive' responsibilities of childbirth and caregiving (McDowell 2014). Additionally the majority of low paid wage earners work in highly feminised service industries, such as in the caring professions, hospitality, retail, and cleaning (Clare 2017). Historically, female dominated occupations such as care work have attracted lower wages than male dominated occupations, structuring gender segregation of unequal wages.

Neoliberal policies of the individualisation of enterprise agreements and the shift from collective bargaining has created institutional gender wage gaps. The Work Choices policy legislation introduced by the Howard Liberal Party government in 
2006 entailed a shift to individualised workplace agreements from collective bargaining. The gender wage gap is higher for employees on individual enterprise agreements $(15.7 \%)$ compared with those on award rates or on collective agreements (13.1\%) (WGEA 2018). In 2018, a situation of partial deregulation prevailed; 59\% of the Australian workforce is on award rates or collective agreements, while $37 \%$ of employees have individual agreements, and are reliant on negotiations with their employers to set their wages (WGEA 2018). Full-time workers were more likely to set their pay by negotiation and more likely to state that they have been successful in obtaining a pay increase. Significantly, women under 40 were more likely to initiate the negotiation of a pay increase than women over 40 . This suggests that age and gender intersectionality privileged younger women in negotiation of wages. The Fair Work Commission was established with the power to set industrial agreements under the Commonwealth's Fair Work Act 2009 however individual enterprise agreements form a major industrial relations instrument.

\section{Pillar 2: Government Benefits}

Policies, which lower pension increases, are benchmarking pensions to the Consumer Price Index, replacing the current Male Total Average Weekly Earnings (MTAWE). In January 2017, more than 330,000 Age Pensioners had their Age Pension entitlements cut, with at least 100,000 of this group losing all Age Pension entitlements. Housing has been described as a latent 'fourth pillar' of retirement incomes, which assumes that most people will be living in their own homes in retirement, whether on a pension or superannuation. Significantly, home ownership is not taken into account as an asset within assessments of pension eligibility, which disadvantages female non-homeowners, particularly those who are low income, divorced and widowed, indicating intersections in gender and class inequalities.

Eligibility for Disability Support Benefits (DSPs) which applies to people with permanent medical and mental health disabilities are subject to work tests, in order to increase the group classified as having the capacity to work to $15 \mathrm{~h}$ or more per week (Department of Social Services 2018). This restriction targets the beneficiary group with the greatest reliance on household income derived from pension transfer payments. The government funded National Disability Insurance Scheme (NDIS) is creating a managed market for disability services in Australia for people aged under 65 based in privatised services. This limits the potential target group of older people with disabilities by age. 


\section{Pillar 3: The Superannuation Guarantee}

The Superannuation Guarantee has instituted the privatisation of retirement incomes by cost shifting from publicly funded pensions to income support by private employers. Average superannuation balances at the time of retirement in 2015-16 were Aus $\$ 270,710$ for men and Aus $\$ 157,050$ for women, $58.7 \%$ of the male balance. The median superannuation balance is significantly lower, at Aus $\$ 110,000$ for men and only Aus \$36,000 for women, reflecting the substantial proportion of men and women who have nil, or very little, superannuation (Clare 2017). Age and gender intersectionality show increases in the superannuation gender gap of $52.8 \%$ at ages 60-64 to 77.6\% at ages 75-79 (Clare 2017). This shortfall is exacerbated by women's greater longevity.

A policy countering women's low superannuation balances was proposed recently by the Australian Labor Party opposition. In September 2018, the Australian Labor Party proposed that if elected it would compensate women for 18 weeks paid parental leave away from the workforce through government superannuation contributions. This pledge would apply to 167,000 women and cost Aus \$400 million 'to make the economic security of women a priority at the next general Election' ('The Age' newspaper, September 19th 2018).

\section{Government Employment Policies}

\section{Financial Incentives}

The Work Bonus incentive to remain working after pension age enables a sliding scale of work hours to be combined with the pension and a tax-free income threshold. This will extend coverage to self-employed members from mid-2019. The Age Pension is paid to 2.41 million Australians. However, just 156,000 took advantage of the Work Bonus that allows them to keep more of their pension while working, indicating that this measure of delaying full retirement is underutilised. Given older women's significantly lower workforce participation after 65 and earlier retirement ages than men, and greater longevity, this financial incentive is a minor step in countering gender inequalities.

In the 2016-17, Budget the government initiated the Low Income Superannuation Tax Offset (LISTO). According to The Australian Association of Superannuation Funds (ASFA) approximately 3.1 million people will benefit from receiving the LISTO in 2017-18. It estimates that about $63 \%$ of the beneficiaries will be women (Clare 2017). However, this payment disadvantages low-income women who currently do not participate in the workforce. 


\section{Flexible Employment}

A key issue for policymakers is how people in later careers can provide care for growing numbers of older people unable to be fully independent due to their frailty. Among people aged 45-64 years, significantly more women than men are primary caregivers (70\% versus 30\%) and caregivers in general (59\% versus $41 \%$ ) (ABS 2015). Flexibilisation of working time within casual employment relations can further marginalise older women.

The Fair Work Act 2009 provides employees over 55 and other groups with a legal 'right to request' flexible working arrangements (e.g. hours of work, changes to start and finish times, patterns of work such as split shifts or job sharing). Employers can only refuse these requests on reasonable business grounds (Fair Work Commission 2018). While the 'right to request' flexible work is 'enshrined' in legislation, it has been underutilised. For example, a survey of 2000 Queensland large organisations found that flexible reduction of working hours was only adopted by one third and was most strongly correlated with expectations of a loss of staff to retirement by large, mainly public sector employers (Taylor et al. 2016). Recent legislation, however, aims to strengthen requests for flexibility, however, gender breakdowns of requests are unavailable. On 24th September 2018 the Full Bench of the Fair Work Commission agreed on a new clause so that employers will be obliged to discuss the request with employees and try to reach agreement 'that will reasonably accommodate the employees circumstances'. The Commission responded to 'significant unmet need' for workforce flexibility where 'a quarter of employees weren't happy with their working arrangements'.

\section{Education and Training}

Women's extended employment is associated with higher levels of educational attainment. Women aged 55-64 are less likely to have post school qualifications than men (54.6-63.4\%) respectively which decreases at ages 65-74 (42.8-56.6\%) (ABS 2017b). A study based on a nationally representative sample of 3000 people aged 45 to 74 revealed that those most likely to experience unmet demand for training were women, related to reducing risks of unemployment and under employment (Adair et al. 2016). The 45 and Up Study in New South Wales recruited 267,151 participants aged 45 years or older. Data from men and women aged 65 years or over at the baseline and first follow up showed that the odds of doing paid work increased with higher education level, and decreased by age, poorer physical function, and having health conditions. The association between education and work participation at 65 years or over was stronger among women than men. Education strengthened women's attachment to the labour market, allowing them to improve financial security by working for longer and higher educational qualifications had 
a 'health protective' effect (O'Loughlin et al. 2017a). However, proactive gendered education policies were not evident.

\section{Health Policies}

The relationship between health and extended working lives revealed by Australian national data indicates that apart from reaching 'retirement age', the second main reason given by persons for ceasing their last job was 'own sickness, injury or disability' (21\% of men and $12 \%$ of women) (ABS 2017a). Women were more likely to give family and caregiving reasons than men. They also retire from work earlier than men retire and are consequently less likely to retire for age related health reasons. Health status is influenced by many factors including caregiving and occupational health. A sample of 1,261 men and women aged 60 to 64 completed a sub study of the New South Wales 45 and Up Study. Around a third (32.5\%) of the sample were involved in some type of caregiving. Compared to non-carers, carers reported lower workforce participation (45.8\% versus $54.7 \%$ for non-carers) as well as poorer health, more mobility difficulties, lower quality of life and lower self-rated SES (O'Loughlin et al. 2017a, b). Significant differences were not found by gender. The longitudinal nationally representative Household and Income and Labour Dynamics in Australia Survey (HILDA) (2002-2011) compared the impacts on health and wellbeing of treatment groups aged 45 and over that made transitions into and out of work with control groups remaining in employment. A significantly higher proportion of treatment groups reported poor health in transitions from working to not working (Gong and Kendig 2017). With health status a key factor 'pushing' people out of work, jobs that require higher qualifications tend to involve fewer risks of acquiring a disability, meaning that people can work for longer.

\section{Older Worker Policies}

The Australian government instituted 'Restart' in 2014, a government subsidy paid to employers to employ a person who has been unemployed and on income security for at least six months. The subsidy has been underutilised, particularly by women. Employer subsidies within firms do not guarantee workforce capability and enable skills transferability within the mainstream labour market. Assisting displaced workers find a new job requires well designed active labour market policies, which include assistance with employment services, training initiatives linked with jobs and publically subsidised work experience programmes (Brooke 2008). A new multipronged programme 'More Choices for a Longer Life' package in the 2017 Federal Budget commencing in 2019 aims to institute measures including countering ageism, job subsidies, reskilling programmes, job placement and economic incentives. This 
more integrated programme yet to be evaluated may potentially provide future 'best practice'.

The experience of age discrimination in recruitment was reported in the 'Willing to Work' report (Australian Human Rights Commission 2016). Yet public policy reports have bifurcated discrimination based on age and discrimination based on gender. 'Willing to Work' subsumes women as a sub group with the foreground focus on age, rather than interconnecting age and gender discrimination. There is a hiatus in 'joined up' age and gender policies supporting extended working lives. An analysis of data from the Attitudes to Ageing in Australia Study (2015-2016) found that workers over 55 years were perceived to be more likely to be made redundant, less likely to be promoted and more likely to have difficulty adapting to change (O'Loughlin et al. 2017b). Yet nuanced forms of gender and age discrimination persist, such as exclusion from social relationships and deployment to undervalued work roles. Even positive stereotypes can ascribe attributes and perpetuate gendered and ageist discrimination. A gender focus in age discrimination government policy is yet to be implemented.

\section{Working Conditions and Precarity}

The Australian labour market demonstrates under both employment and work intensification and long working hours. In 2015, the OECD average proportion of workers in part-time employment was 17 per cent (defined by the OECD as people usually working fewer than $30 \mathrm{~h}$ per week in their main job) compared with Australia of 24\% (OECD 2016) The OECD ranks Australia 10th out of 38 for the proportion of its workers (13\%) working 'very long hours' (55 h or more per week defined by the OECD) (OECD 2016). According to the Household and Income Labour Dynamics of Australia (HILDA) survey overemployed workers report lower levels of satisfaction and mental health than well matched workers (Australian Institute of Health and Welfare (AIHW) 2017: 9). The (HILDA) Survey over a nine year follow up period (Waves 2 and 11) found that older workers who held poor quality jobs for most of the follow up period declined in their self-rated physical and mental health relative to voluntary retirees. Extended working lives mean that people will be 'exposed' to work for longer, and this exposure will occur at a life stage characterised by declining health (AIHW 2017).

The 'precariat' is subject to employment insecurity through employment conditions without entitlements and inadequate protection against arbitrary dismissal. The overall proportion of casual male employees increased from $21.0 \%$ to $23.1 \%$ 2007-2017 and the proportion of casual female employees increased from $26.2 \%$ to $27.1 \%$ (3). The mean probability of job loss among full-time casual employees is almost 20 among males, and more than 15 among females (AIHW 2017). The comparable proportions among full-time permanent employees are about half this (10\% and $8 \%$ respectively). As employment security declines and hours of work and 
earnings become less predictable, lower capacity to negotiate at work will engender poorer health and wellbeing (Elton et al. 2007).

Policies that improve working conditions for precarious workers

Active rather than passive employment creation policies are required which compensate for gendered interrupted career trajectories by supporting skills training and job placements designed to accommodate caregiving. Countervailing legal pathways however are emerging. Countering precarity requires future court decisions to strengthen non-standard working arrangements, 'casual' entitlements and to enshrine job security. A landmark case in the Federal Court in August 2018 found that a truck driver was not a 'casual' employee under employment law, because of his regular and continuous pattern of work during more than two years. This has opened the way for unions to claim entitlements for previously 'casual' workers.

\section{Conclusion}

Overall, the debate over women's extended working life has been largely invisible in the media and discussions of late career flexibility overshadowed by childcare. Gender responsive policies target childcare cost reductions earlier in women's lifecourse rather than supporting the income security of older women. The National Foundation for Australian Women, an advocacy organisation which reviews the effects of the Budget on women, including older women, propose that women's low superannuation balance is a key policy issue for the 2019 election. This policy has gained traction with the Labor opposition which has recognised that compensation is needed for women's' unequal access to financial security in retirement.

Government policies should address age and gender intersectionalities in order to challenge systemic inequalities. Inequalities between men and women's superannuation incomes in retirement has emerged as a future general election issue, while gender wage gaps across working lives is an emerging policy issue. Health effects of caregiving, reduced working time in the labour force and the experience of precarity limit women's secure incomes and affordable housing in retirement. The 'deaccumulation' cascade from low wages requires industrial relations protections to avert reliance on pensions and boost superannuation. Proactive gender responsive policies are lacking across health, education and employment to extend working lives that ultimately influence economic security and class. Combating disadvantage to support women's lower educational attainment requires governments to intercede with skills training aligned with economic development. Policies that contest the current inequalities of gendered careers should involve stakeholders in government, employers, unions and older women's own advocacy. Without coordinated institutional strategies, supporting gender responsive policies the reality of extended working lives will remain only an aspiration. 


\section{References}

ABS (Australian Bureau of Statistics). (2015). Disability, ageing and carers, Australia: Summary of findings. ABS cat. no. 4430.0. Canberra: ABS.

ABS. (2017a). Retirement and retirement intentions, Australia, July 2016 to June 2017. ABS cat. no. 6238.0. Canberra: ABS.

ABS. (2017b). Characteristics of employment, Australia, August 2017. ABS cat. no. 6333.0. Canberra: ABS.

ABS (Australian Bureau of Statistics). (2018). Labour force, Australia, detailed, quarterly, August 2018. ABS cat. no. 6291.0.55.003. Canberra: ABS.

Adair, T., Lourey, E., \& Taylor, P. (2016). Unmet demand for training among mature age Australians: Prevalence, differentials and perceived causes. Australasian Journal on Ageing, 35(1), 36-41.

Amalberti, R., Nicklin, W., \& Braithwaite, J. (2016). Preparing national health systems to cope with the impending tsunami of ageing and its associated complexities: Towards more sustainable health care. International Journal for Quality in Health Care, 28(3), 412-414.

Australian Institute of Health and Welfare (AIHW). (2017). Australia's welfare 2017. Canberra: Australian Government.

Brooke, E. (2017). The Australian empirical landscape of extended working lives: a gender perspective. In A. Ní Léime, D. Street \& C. Krekula (Eds.), Gender, ageing and longer working lives: International analysis from a critical perspective (pp. 79-97). Bristol: Policy Press.

Brooke, E. (2018). Workforce ageing in the Australasian Journal on Ageing: Laying the research foundations. Australasian Journal on Ageing, 37(1), 9-10.

Budget. (2017-18). Retrieved June 12, 2019, from https://www.budget.gov.au/2017-18/content/ glossies/overview/html/overview-22.html.

Clare, R. (2017). Superannuation account balances by age and gender. Canberra: Association of Superannuation Funds of Australia Limited.

Commission, Australian Human Rights. (2016). Willing to work. Canberra: Australian Government.

Commonwealth of Australia. (2015). Intergenerational report. Australia in 2055. Canberra: Commonwealth of Australia.

Department of Social Services, Australian Government. (2018). Retrieved June 12, 2019, from https://www.dss.gov.au/our-responsibilities/disability.

Elton, J., Bailey, J., Baird, M., Charlesworth, S Cooper, R., \& Ellem, B. (2007). Women and work choices: Impacts on the low pay sector. Summary report. Centre for Work + Life, Adelaide: University of South Australia.

Fair Work Commission. (2018). Retrieved June 12, 2019, from https://www.fairwork.gov.au/ employee-entitlements/flexibility).

Gong, C. H., \& Kendig, H. (2017). Impacts of voluntary and involuntary workforce transitions at mature ages: Longitudinal evidence from HILDA. Australasian Journal on Ageing, 37(1), 11-16.

McDowell, L. (2014). Gender, work, employment and society: feminist reflections on continuity and change. Work, Employment \& Society, 28(5), 825-837.

OECD. (2016). OECD employment outlook 2016. Paris: OECD Publishing.

O’Loughlin, K., Loh, V., \& Kendig, H. (2017a). Carer characteristics and health, wellbeing and employment outcomes of older Australian baby boomers. Journal of Cross-Cultural Gerontology, 32(3), 339-356. Doi:10.1007/s10823-017-9321-9.

O'Loughlin, K., Kendig, H., Hussain, R., \& Cannon, L. (2017b). Age discrimination in the workplace: The more things change.... Australasian Journal on Ageing, 36(2), 98-101.

Parliament House. https://www.aph.gov.au/About_Parliament/Parliamentary_Departments/ Parliamentary_Library/pubs/BriefingBook45p/WelfareCostSuperguide2018. Retrieved June 12, 2019, from https://www.superguide.com.au/smsfs/300000-retired-australians-to-lose-someor-all-age-pensionmentitlements\#January_2017).

Riley, M. W., Kahn, R., Foner, A., \& Mack, K. A. (1994). Age and structural lag: society's failure to find meaningful opportunities in work, family and leisure. Oxford England: John Wiley and Sons. 
Taylor, P., Earl, C., \& McLoughlin, C. (2016). Australian employer usage of the practice of offering reduced working hours to workers close to retirement: Extent and determinants. Australasian Journal on Ageing, 35(2), 13-17.

Temple, J. B., \& McDonald, P. F. (2017). Population ageing and the labour force: 2000-2015 and 2015-2030. Australasian Journal on Ageing, 36(4), 264-270.

Workplace Gender Equality Agency (WGEA). (2017a). WGEA data explorer. Retrieved June 12, 2019, from http://data.wgea.gov.au/overview.

Workplace Gender Equality Agency (WGEA). (2017b). Women's economic security in retirement. Insight paper. Canberra: Commonwealth of Australia.

Workplace Gender Equality Agency (WGEA). (2018). Gender and negotiation in the workplace. Canberra: Commonwealth of Australia.

Open Access This chapter is licensed under the terms of the Creative Commons Attribution 4.0 International License (http://creativecommons.org/licenses/by/4.0/), which permits use, sharing, adaptation, distribution and reproduction in any medium or format, as long as you give appropriate credit to the original author(s) and the source, provide a link to the Creative Commons license and indicate if changes were made.

The images or other third party material in this chapter are included in the chapter's Creative Commons license, unless indicated otherwise in a credit line to the material. If material is not included in the chapter's Creative Commons license and your intended use is not permitted by statutory regulation or exceeds the permitted use, you will need to obtain permission directly from the copyright holder. 


\title{
Chapter 8 Austria
}

\section{Barbara Haas, Michaela Gstrein and Roland Bildsteiner}

\begin{abstract}
This chapter deals with the labour market situation of older (50+) workers and pension policies in Austria, a country where gender differences are strongly pronounced over the entire lifecourse. The target of recent policies is not primarily to tackle the negative effects of the system for women, but to decrease pension costs by discouraging early retirement and inducing employers to keep and/or employ older workers. However, this will have some gendered effects since recent policy changes will increase women's lower legal retirement age stepwise (60) to match that of men (65) in 2033. Although caring time already partly contributes to pension payments, this does not substantially decrease the large gender pension gap.
\end{abstract}

Keywords Gender • Extended working life - Austrian pension system • Health • Pension policies

\section{Gender and Employment in Austria}

Men and women tend to follow different educational and employment paths leading to gender segregated labour markets and to large gender pay and pension gaps. Due to the long tradition of the modified male breadwinner model in Austria, men work continuously full-time while women, especially mothers, tend to exit the labour market for several years after childbirth and re-enter into, more or less family-friendly part-time jobs.

\section{B. Haas ( $\square)$}

Department of Socioeconomics, Vienna University of Economics and Business,

Welthandelsplatz 1, 1020 Vienna, Austria

e-mail: Barbara.Haas@wu.ac.at

M. Gstrein

WPZ Research, Mariahilfer str. 115/16, 1060 Vienna, Austria

e-mail: michaela.gstrein@wpz-research.com

R. Bildsteiner

BEST Institute of Continuous Vocational Qualification Training and Personnel Training,

Vienna, Austria 
Table 8.1 Employment and part-time rate of older workers, pension age and median legal gross pension

\begin{tabular}{l|l|l}
\hline & Women & Men \\
\hline Employment rate of 55-64 year old workers (a) & $\begin{array}{l}51.8 \% \text { (in 2018) } \\
34.3 \% \text { (in 2009) }\end{array}$ & $\begin{array}{l}77.3 \% \text { (in 2018) } \\
54.5 \% \text { (in 2009) }\end{array}$ \\
\hline $\begin{array}{l}\text { Part-time rate of 55-64 year old workers in \% of } \\
\text { employment (a) }\end{array}$ & $51.7 \%$ (2018) & $12.4 \%$ (2018) \\
\hline Average effective retirement age (b) & 61.1 years & 63.0 years \\
\hline $\begin{array}{l}\text { Average effective retirement age for disability pension } \\
\text { (b) }\end{array}$ & 52.8 years & 56 years \\
\hline $\begin{array}{l}\text { Average old age pension of new pensioners in 2015 } \\
\text { without additional payments (c) }\end{array}$ & 1,009 Euro & 1,514 Euro \\
\hline $\begin{array}{l}\text { Median legal pension, gross (2014) } \\
\text { Blue-collar worker (d) }\end{array}$ & 784 Euro & 1,557 Euro \\
\hline $\begin{array}{l}\text { Median legal pension, gross (2014) } \\
\text { White-collar worker (d) }\end{array}$ & 1,208 Euro & 2,320 Euro \\
\hline
\end{tabular}

Source (a) Eurostat (2019), (b) OECD (2019), (c) BMASK (2017b), (d) Wöss and Türk (2017)

In 2018, the employment rate of men aged 15-64 years $(82.3 \%)$ exceeded the rate of women (71\%). Similarly, only $51.8 \%$ of women aged between 55 and 64 have participated on the labour market, while this rate for men was $77.3 \%$ in 2018 (Eurostat 2019). The proportion of persons aged over 50 years in total employment (without the marginally employed) increased from $19.7 \%$ (2010) to $25.7 \%$ (2016) (WKÖ 2017), but it is still low from an international perspective.

The above table summarises the main employment and pension indicators for men and women in Austria (Table 8.1).

The above figures reveal that the pension-related gender gap in Austria is strongly pronounced, in terms of pre-pension employment, exit age and pension level. There is a long-standing debate about women's high risk of poverty in old age. With the recent change in pension calculation (taking into account the last 40 years instead of only the last years before retirement), unpaid care time (and other absences from the labour market) reduces pension levels (Mayrhuber 2017).

\section{Research on Extended Working Life in Austria}

There is little academic debate on the gender effects of extended working life (EWL) policies in Austria. While non-academic studies by state or non-university institutions are mainly descriptive, economists dominate academic studies by applying quantitative modelling to study the determinants of employment participation and retirement age (Schnalzenberger et al. 2014). Austria is often included in international comparisons, but the results shown on aggregate level are not very informative (Mairhuber et al. 2015). 
Administrative social security data for the entire Austrian workforce show that old workers '(...) face a higher probability of a transition to early retirement, in particular if they are unemployed.' (Ichino et al. 2016). One of the main reasons for extending working life is to enable or increase pension payments. Monetary incentives for extending working life, however, are more relevant for men than for women (Hanappi et al. 2014). In general, having a strong intrinsic motivation to work, having better (perceived) health and enjoying good working conditions increases the age of retirement (Statistik Austria 2017). Interestingly, both men and women initially plan to work longer than they actually do (Staubli and Zweimüller 2013).

A range of studies conclude that it is the combination of education, gender and class that matters. 'The lower the social position, the higher the early retirement intentions. Women leave their jobs at a younger age than men. People who spend more time in education retire later.' (Mairhuber et al. 2015). Independent from gender and age, more highly educated people are more likely to enjoy training on the job and might thus stay longer.

Furthermore, extending working life increases the propensity for workers to become informal caregivers for a frail elderly partner. A range of quantitative analyses show that caregivers in Austria exhibit higher levels of perceived work-family conflict. Gender differences in the perception of experienced physical care burden differ (Schneider et al. 2013; Trukeschitz et al. 2013).

Studies on the labour demand side are scarce. The Austrian seniority principle (where income automatically increases with age) negatively affects the extension of working life (Müllbacher et al. 2014), since older employees become increasingly expensive. An evaluation of a layoff tax for older workers ('Malus system') suggests that higher penalty payments would induce companies to keep older workers (Schober et al. 2011). The Austrian Public Employment Service has provided one of the first studies on age discrimination in Austrian companies. The authors found large differences across branches and evidence for negative attitudes towards older workers, who are generally seen as unwilling or unable to adapt to change (AMS 2014).

\section{Pension System and Extended Working Life Pension Policies in Austria}

Austria has been known for its '(...) "early retirement" culture in an earningsrelated pension system offering a high income replacement rate at an early age.' (Biffl and Isaac 2007). Against the background of increasing budgetary constraints, due to ageing and increasing pension costs for baby boom generations, there has been a major shift in making efforts towards extending working life since the mid-1980s. These reforms are in line with the corporatist Austrian welfare state paradigm, which tends to guarantee a social standard of a once achieved social position. The average gross replacement rate of the statutory pension scheme (theoretical replacement rate, TRR) is comparatively high at $78.1 \%$ (based on the law of 2014) (Blank and Blum 2017). 
The Austrian pension system consists of three pillars. Firstly, the statutory pension scheme, which is the dominant pillar. It is not a social provision, but an insurance benefit based on monthly social security contributions and overall working life income. There is a disability pension for those incapable of working and there are survivor benefits for widows/widowers and orphans. The second pillar, a supplementary personal pension scheme (most often the classical voluntary life insurance) plays a minor role. Thirdly, there are (optional) occupational pension schemes (where employers and employees share the contribution cost) depending on collective agreements and varying by sectors (BMASK 2017a, b).

Although there is no minimum pension in Austria, retirees with low earningrelated benefits receive a means-tested top-up (Ausgleichszulage) so that their overall benefit in 2020 amounted to $€ 966.65$ per month for a single person household and $€ 1,472$ for couples (GV 2020; PV 2017b). There are 14 annual payments. Adjustment of the safety-net income is discretionary (OECD 2016). In 2016, approximately $69 \%$ of means-tested top-ups were paid to women, a result of the on average low level of female pensions - showing the high importance of women's reliance on widow pensions (BMASK 2017b). Beside the means-tested top-up for pension, there is a means-tested minimum income scheme (bedarfsorientierte Mindestsicherung) (Table 8.2).

Policies relating to the harmonisation of the different Austrian pension systems have restricted access to early retirement and already show some effects. The average effective retirement age increased to approximately 61 years for women and 63 years for men in 2018 (excluding disability pension) (see Table 8.1, OECD 2019). 'Invalidity pensions' and 'Heavy work pensions' are now of less importance than previously. Moreover, employees report less health problems (psychological problems) and stay longer in employment (BMASK 2017b). In 2017, the introduction of 'vocationally oriented medical rehabilitation measures facilitate the return of the partially disabled to the labour market' (OECD 2019).

Table 8.2 Legal entitlement to different forms of pension

\begin{tabular}{l|l|l}
\hline & Women & Men \\
\hline $\begin{array}{l}\text { Legislated pensionable age: } \\
15 \text { years of pension security insurance }\end{array}$ & $\begin{array}{l}60 \text { years (raised to } 65 \text { for birth cohorts } \\
1968+)\end{array}$ & 65 years \\
\hline $\begin{array}{l}\text { Corridor pension ('Korridorpension', } \\
\text { since 2005; early retirement): allowing } \\
\text { a reduction in paid working hours after } \\
40 \text { years of pension security payments }\end{array}$ & $\begin{array}{l}62 \text { years (available with rising female } \\
\text { retirement age from 2028 onwards) }\end{array}$ & 62 years \\
\hline $\begin{array}{l}\text { Heavy labour pension: } \\
\begin{array}{l}15 \text { years of pension security insurance } \\
10 \text { years of 'hard work' (defined in } \\
\text { collective agreements) during the last } \\
20 \text { years }\end{array}\end{array}$ & 60 years & 60 years \\
\hline
\end{tabular}

Source BMASK (2017b), Bildsteiner (2019) 
The Austrian system now provides financial incentives to work longer by providing higher pensions for delayed retirement (and similarly penalising early retirement). For those retiring between the ages of 65 and 68 the pension is increased by $4.2 \%$ per year, however there are no additional increments after 68 . Workers defer their labour market exit, continue to pay contributions and thus increase their pension entitlements (OECD 2016). In Austria it is usually possible simultaneously draw a pension and earn money. However, age matters, if pensioners below the age of 65 earn more than a minimum threshold of earnings (€469.66 per month in 2020) the pension is fully withdrawn. After age 65, unlimited earnings from work and pension receipt are permitted (Arbeiterkammer Oberösterreich 2017b; GV 2020; OECD 2016; PV 2017b).

Gross income replacements rates (based on 40-45 years of labour market activity, and retirement between 62 and 65 years) theoretically amount to 60-80\% of monthly average life income. However, longer years in education, increasingly disrupted working careers and changes in pension policies (e.g. extending years relevant for the pension amount) have led to reduction and will continue to lead to reductions in the actual pension levels. Given the traditional gender imbalance in care and to increase gender pension equality, years of childcare are considered for pension entitlement (four years per child are credited, with overlaps counting only once) (Horstmann and Hüllsman 2009).

From a macro-perspective, the Austrian Pension Insurance (PV 2017a) confirmed that the pension system after adaptation is now sustainable, with relatively moderate budget increases until 2060. The Organisation for Economic Co-operation and Development argues, however, for an 'increase in the statutory retirement age, and augmentations in contributions or reductions in benefits.' (OECD 2019).

\section{Extended Working Life Employment Policies}

According to the Austrian Ministry for Social Affairs the current pension system is evaluated as successful in extending longer working lives (BMASK 2017b). Respective policy measures are as follows (BMWA 2015):

- Part-time retirement, qualification measures for older working age, more money for training and life-long learning (AMS 2015).

- Reduction of incidental wage costs through the programme 56/58 plus, which reduces the employee costs by $6 \%$ (12\%) for the 56/58 (60+) year old workers.

- Until recently, firms were granted advantages and cost reductions for employing workers aged 50+. Employers not employing or laying off workers aged 50+ have incurred penalty payments. With the targets for the employment integration of older workers (set at the beginning of the bonus-malus system in 2013) met, this measure was withdrawn (Noedis 2018; Bildsteiner 2019).

- Measures to enhance employability (e.g. socioeconomic enterprises, creating a third labour market) (Schneider and Maier 2013; Foerdermanagerin 2017). 
- In 2011, the 'fit2work' initiative by the Austrian Government (www.fit2work.at) introduced a system of case-by-case management to assist firms in planning on how to keep or re-integrate older workers (e.g. by switching from manual to intellectual work). In addition, the Pension Insurance may bear the cost arising from necessary treatment and/or rehabilitation (Eichmann and Saupe 2014).

\section{Health Policies}

The Survey of Health, Ageing and Retirement in Europe, (SHARE release 1) suggests that older Austrians are generally healthier than their European counterparts, and that the relatively good health conditions are spread quite evenly among the population (Stiglbauer 2006).

Findings on older workers' health differ substantially between studies. There is evidence that employees with a higher professional status, in a standard employment contract enjoy comparably good health and wellbeing (Arbeiterkammer Oberösterreich 2017a; Eichmann and Saupe 2014: 199; Schober and Winter-Ebmer 2011). The extent of work matters especially for men, a longer working life is strongly connected with better health (Hanappi et al. 2014; Wiedenhofer-Galik 2014). Part-time employment, mainly comprised of female workers, may also increase a person's perceived wellbeing (Statistik Austria 2009).

Good employment conditions help to keep people healthy and are thus a prerequisite for extending work participation. Effective health-related 'active ageing' measures can be realised in the following way (Eichmann and Saupe 2014):

- Working time: new shift plans, part-time retirement, partial retirement

- Work environment: offering age-based career options, mixed-aged working teams, shifting or sharing of tasks, ergonomic working places

- Qualification, professional training, old-young worker tandems.

According to labour market experts, these health-related measures are still to be improved in Austria. The observed low labour market participation of workers aged 55-64 is strongly connected to the lack of sufficient efforts in contributing to a healthy life at the workplace. Moreover, the European Agency for Safety and Health at Work (2013) has found a general lack of employee information and knowledge in Austria. Compared with other countries, only a small proportion (11\%) of employees know about relevant health programmes for their own workplace (e.g. Eichmann and Saupe 2014).

In recent years, some health-related initiatives have been taken. The abovementioned 'fit2work' is only one of them. Another example is The NESTORGOLD (BMASK 2018) developed in 2010 by the Ministry of Social Affairs, the Ministry of Science, social partners and the Public Employment Service. Companies receive a three year seal of quality, when they sign the NESTORGOLD Charter, provide a company workshop and realise specific measures on age- and ageingappropriateness (e.g. adult education, health promotion and employee-friendly hours 
of work). Another example is the initiative Work and Ageing (Arbeit and Alter) by the Austrian social partners, a platform to promote healthy ageing in work (IV et al. 2018). Health is one of the pillars including continuous learning, work, workplace and age-effective leadership. It should, however, be noted that gender is often not acknowledged as a relevant category.

\section{Debate on Extended Working Life}

In Austria, there is little media debate about gender and health effects of pension reforms or EWL policies. Media headlines predict an ageing-related increase of the already high pension costs, which could endanger the sustainability of the welfare state. A problem is foreseen in the retiring baby boom generation. The debate addresses various options about how to implement effective counter-measures. One is to link retirement age and contribution payments more strongly to the growing life expectancy by increasing social security contributions. However, labour costs in Austria are already among the highest in Europe, making this a disputed and potentially ineffective solution.

Firstly, the right-populist government (Österreichische Volkspartei [ÖVP] and Freiheitliche Partei Österreichs [FPÖ] between 2017 to mid-2019) has implemented far reaching labour market reforms, stating that the recent economic recovery does not justify any public intervention for older workers. Consequently, special measures and subsidies to integrate unemployed older workers into the labour market have been abandoned (e.g. Aktion 20.000).

Secondly, in 2018 a highly controversial work time law has recently extended daily working hours from 10 to 12 h/day, and 60 hours per week. Previously only some collective agreements included such options; this is now possible in any sector. While in principle, the employee could refuse, social partners representing employees' interests criticise the new work time law as it increases the power of employers. Future evaluations should address to what extent paid working hours have increased and affected women's and men's health.

Finally, non-governmental organisations and labour representatives draw attention to the precarious situation of vulnerable groups, such as single mothers, people with a migration background, families with many children, and the old-age pension of women as well as widows. It is emphasised that a substantial proportion of women, especially those combining paid work with unpaid work and care, suffer from low income and low pensions, mainly due to disruptive career breaks and a lack of care facilities. In this context, critics point out that the social partners in Austria are particularly interested in representing full-time employees in secure positions, while the weakest groups on the labour market, especially part-time working women, need stronger support (Eichmann and Saupe 2014).

The Austrian debate therefore revolves around higher exit ages and thus extended working life to keep the (pay-as-you-go) pension scheme sustainable and statutory schemes—-still the main pension pillar in Austria—at stable and inclusive values 
(BMASK 2016). While raising pension ages is generally seen to be in line with the requirements of a longer life span, the employee representatives (AK-Chamber of Labour, ÖGB-Austrian Trade Unions) criticise prevailing gender inequalities over the entire lifecourse (e.g. segregated labour markets and gender pay gaps) (Mairhuber 2016). Women, especially carers with disruptive careers suffer from old-age poverty. The Austrian Economic Chambers (WKÖ 2018) are by contrast mainly concerned with the competitiveness of the economy, skills gaps and labour availability. Future studies will show to what extent recent changes, especially in prolonging the daily working time to $12 \mathrm{~h}$, does affect the (health) situation of men and women on the labour market and the respective age of retirement as well as retirement preferences. Working conditions are crucial to the maintenance of health among older workers (Steiber and Kohli 2017).

\section{Conclusion}

The foremost aim of the Austrian pension reforms is to keep welfare state expenditure at sustainable levels. Measures to narrow the gap between the numbers of employed and pensioners show some success, but strong gender differences prevail. The decrease in pension benefits by extending the calculation span to a person's entire lifetime earnings will affect all, but more strongly women, who tend to interrupt their working career for care or often work in part-time jobs.

Care was and is the responsibility of Austrian women, unpaid and with low recognition in the public sphere. As a consequence, gender differences in all life domains are large and persistent. Health and wellbeing, however, vary by the intersection of age, gender, migration background and social class position. Evidence suggests that a higher professional status and/or good working conditions are strongly linked with healthy and extended working lives, for men and women.

More in-depth academic research on the gender and health effects of EWL policies is still needed. The main obstacles in applying quantitative methods are the lack of longitudinal data (especially panels) and problems in matching register and survey data. Innovative research designs (qualitative and mixed methods) could complement the prevailing focus on economic issues (costs and benefits). More research is also needed on the variation in retirement behaviour by different sectors and regions, the importance of working conditions and the quality of work upon health and wellbeing of persons with diverse characteristics. It would be worthwhile to address the gap in studies on ageism, age discrimination and diversity management in Austria. 


\section{Policy Recommendations}

In Austria, caring for children, older or disabled persons contributes to pension entitlement, which is mainly relevant for women. However, this financial acknowledgement does not fully compensate for unpaid work and results in large gender pension gaps. In addition, extending the calculation of pensions to the entire working life should be gender and social class-proofed.

Policy measures need to address the challenge that women's risk of working in a low-income job in Austria is among the highest in Europe. There is a long tradition of gender segregation not only in the educational system but also in the labour market, resulting in large gender employment and gender pay gaps. Although in recent decades we have witnessed an increase in care facilities for children of different age groups, this increase does not meet current demand (also in full-time school systems and afternoon leisure centres). Most notably, affordable and attractive institutional care facilities for older or frail people are limited.

Although the Austrian ministries regularly praise employers for being a role model in 'family friendliness' or 'diversity management', there is further need for large public campaigns addressing gender differences and health problems. Research has shown that older workers have a low propensity to find a job when unemployed. Furthermore, many employees would like to extend working life, but are often unaware of existing measures of 'active ageing'. Employers as key stakeholders are responsible for improving working conditions by offering jobs with secure contracts, allowing flexible working hours and control over one's schedule.

\section{References}

Arbeiterkammer Oberösterreich (Chamber of Labour Upper Austria). (2017a). A. Stöger, J. Kalliauer, Arbeitsplätze gestalten, Gesundheit erhalten: Ältere Arbeitnehmer brauchen Perspektiven. Retrieved September 4, 2017, from https://media.arbeiterkammer.at/ooe/presseunterlagen/2017/ PKU_2017_03_17_AeltereArbeitnehmer.pdf.

Arbeiterkammer Oberösterreich (Chamber of Labour Upper Austria). (2017b). Retrieved August 4, 2018, from https://www.arbeiterkammer.at/beratung/arbeitundrecht/pension/pensionsformen/ Frueher_in_Pension.html.

AMS (Public Employment Service). (2014). Altersspezifische Personalpolitik. Und der Beitrag des AMS, Franziska Haydn, Ehrenfried Natter and Magdalena Tauber. Retrieved August 4, 2018, from http://www.forschungsnetzwerk.at/downloadpub/Endbericht_altersspezifischePersonalpolitik.pdf.

AMS (Public Employment Service). (2015). Der Arbeitsmarkt für Ältere-eine Einstellungssache. Retrieved September 4, 2017, from http://www.ams.at/arbeitsmarktdaten.

Biffl, G., \& Isaac, J. E. (2007). The challenge of ensuring a healthy workforce in an ageing society. Austria and Australia in comparison. Austrian Economic Quarterly, 12(3), 144-157.

Bildsteiner, R. (2019). Chancen und Risiken der Arbeitszeitverkürzung, -flexibilisierung und verlängerung für ältere Menschen in Österreich aus einer Genderperspektive. Wien: Wirtschaftsuniversität Wien. Masterarbeit (unpublished Master Theses). 
Blank, F., \& Blum, S. (2017). Kindererziehungszeiten in der Alterssicherung: Ein Vergleich sechs europäischer Länder. Wirtschafts- und Sozialwissenschaftliches Institut WSI Working paper. Retrieved September 9, 2018, from http://hdl.handle.net/10419/155680.

BMASK (Federal Ministry of Labour and Social Affairs). (2016). Ministerratsvortrag zu Pensionen. Retrieved September 9 2018, from https://www.sozialministerium.at/cms/site/attachments/5/8/1/ CH3434/CMS1456830811588/ministerratsvortrag_pensionen.pdf.

BMASK (Federal Ministry of Labour and Social Affairs). (2017a). Social report. Social policy development and measures. Social policy analyses. Retrieved March 1, 2017, from www. sozialministerium.at/broschuerenservice.

BMASK (Federal Ministry of Labour and Social Affairs). (2017b). Pensionsmonitoring. Retrieved March 1, 2017, from https://www.sozialministerium.at/cms/site/attachments/7/3/8/CH3434/ CMS1489129708729/170309_pensionsmonitoring_langfassung_jahresbericht_2016_pdfua. pdf.

BMASK (Federal Ministry of Labour and Social Affairs). (2018). The NESTORGOLD Auszug 2018/09 seal of quality. Retrieved August 10, 2018, from https://www.sozialministerium. at/siteEN/Social_Policy_Consumers/Social_Issues/Austrian_Senior_Citizens_Policy/ Employment_and_Occupation/.

BMWA (Federal Ministry of Economics). (2015). Österreichisches Reformprogramm für Wachstum und Beschäftigung. Teil III Detailausführungen. Federal Ministry of Economy. Retrieved March 1, 2017, from https://www.bka.gv.at/DocView.axd?CobId=38348.

Eurostat. (2019). Employment statistics by age, gender and citizenship. Retrieved January 3, 2020, from https://appsso.eurostat.ec.europa.eu/nui/show.do?dataset=lfsa_ergacob\&lang=en, https:// appsso.eurostat.ec.europa.eu/nui/submitViewTableAction.do.

Eichmann, H., \& Saupe, B. (2014). Überblick über Arbeitsbedingungen in Österreich. Follow-up Studie. Sozialpolitische Studienreihe. Retrieved June 11, 2019, from https://broschuerenservice. sozialministerium.at/Home/Download?publicationId=263.

Foerdermanagerin. (2017). Retrieved September 11, 2018, from https://foerdermanagerin.at/2017/ 04/21/wien-unterstuetzt-social-entrepreneurs/.

GV (Government) Austria. (2020). Ausgleichszulage. Retrieved January 3, 2020, from https://www.oesterreich.gv.at/themen/arbeit_und_pension/pension/Seite.270224.html\# AllgemeineInformationen.

Hanappi, T., Müllbacher, S., \& Heil, E. (2014). Auswirkungen von finanziellen Anreizen auf das Pensionsantrittsalter. Eine Analyse mit dem Mikrosimulationsmodell IREA. Retrieved September 13, 2018, from https://www.ihs.ac.at/publications/lib/IHSPR6501143.pdf.

Horstmann, S., \& Hüllsman, J. (2009). The Socio-economic impact of pension systems on women. Retrieved September 13, 2018, from http://epub.wu.ac.at/4061/1/se_in_austria.pdf.

Ichino, A., Schwerdt, G., Winter-Ebmer, R., \& Zweimüller, J. (2016). Too old to work, too young to retire. Journal of the Economics of Ageing. http://dx.doi.org/10.1016/j.jeoa.2016.07.001.

IV (Industriellenvereinigung), AK (Arbeiterkammer), ÖGB (Österreichische Gewerkschaftsbund), WKÖ (Wirtschaftskammer). (2018). Arbeit \& Alter. Retrieved September 13, 2018, from http:// www.arbeitundalter.at/cms/Z03/Z03_50/home.

Mairhuber. (2016). Anhebung vom Frauenpensionsalter als Scheindiskussion. Retrieved September 9, 2018, from https://awblog.at/warum-das-niedrigere-frauenpensionsalter-gerechtfertigt-ist/.

Mairhuber, I., Prammer, W., \& Steinbauer, B. (2015). Joint Programme Initiative (JPI) Understanding employment participation of older workers (UEP)-Austrian national report. Wien. Retrieved September 13, 2018, from http://www.jp-demographic.eu/wp-content/uploads/2015/07/JPIUEP_ Brochure.pdf.

Mayrhuber, C. H. (2017). Erwerbsunterbrechungen, Teilzeitarbeit und ihre Bedeutung für das Frauen-Lebenseinkommen. Wien: Arbeitsmarktservice Österreich. 
Müllbacher, S., Fink, M., Hofer, H., \& Titelbach, G. (2014). Relevanz und Auswirkungen des Senioritätsprinzips am österreichischen Arbeitsmarkt. Studie im Auftrag des Sozialministeriums. Wien: Institut für Höhere Studien. Retrieved September 20, 2018, from https://www. sozialministerium.at/cms/site/attachments/2/3/8/CH3434/CMS1459844692841/23_studie_ relevanz_und_auswirkungen_des_senioritaetsprinzips_am_oesterreichischen_arbeitsmarkt.pdf.

Noedis. (2018). Bonus-Malus für ältere Dienstnehmer. Retrieved August 12, 2018, from https:// www.noedis.at/cdscontent/?contentid=10007.771259.

OECD. (2016). Health at a glance: Europe 2016, state of health in the EU cycle. http://dx.doi.org/ 10.1787/9789264265592-en.

OECD. (2019). OECD economic surveys: Austria 2019, OECD publishing, Paris. Retrieved January 3, 2020, from http://www.oecd.org/economy/surveys/Austria-2019-OECD-economicsurvey-overview.pdf. http://dx.doi.org/10.1787/888934025366.

PV (Pensionsversicherung). (2017a). Die PVA informiert: aktuelle zahlen zum pensionssystem in Österreich. Retrieved December 10, 2018, from https://www.pensionsversicherung.at/cdscontent/ ?contentid=10007.784577.

PV (Pensionsversicherung). (2017b). Ausgleichszulage. Retrieved September 6, 2017, from http://www.pensionsversicherung.at/portal27/pvaportal/content?contentid=10007.707597\& viewmode $=$ content.

Schnalzenberger, M., Schneeweis, N., Winter-Ebmer, R., \& Zweimüller, M. (2014). Job quality and employment of older people in Europe. Labour. https://doi.org/10.1111/labr.12028.

Schneider, H., \& Maier, F. (2013). Social entrepreneurship in Österreich. Retrieved April 17, 2018, from http://epub.wu.ac.at/4061/1/se_in_austria.pdf.

Schneider, U., Trukeschitz, B., Mühlmann, R., \& Ponocny, I. (2013). 'Do I stay or do I go?'-job change and Labour market exit intentions of employees providing informal care to older adults. Health Economics, 22, 1230-1249.

Schober, T., \& Winter-Ebmer, R. (2011). Ältere Arbeitnehmer, gesundheitliche Einschränkungen und Übergänge in den Ruhestand. Linz: Institut für Volkswirtschaftslehre. Johannes Kepler Universität. Retrieved September 9, 2018, from https://www.sozialministerium.at/cms/ site/attachments/2/0/9/CH3434/CMS1459845112536/01_share_endbericht.pdf.

Schober, T., Schnalzenberger, M., \& Winter-Ebmer, R. (2011). Kündigung unter Strafe-Beschäftigungsförderung für Ältere in Österreich. Wirtschaft und Gesellschaft, 3, 1-12.

Statistik Austria. (2009). Arbeitsunfälle und arbeitsbezogene Gesundheitsprobleme. Modul der Arbeitskräfteerhebung 2007. Wien: Statistik Austria. Retrieved September 9, 2018, from http:// www.statistik.at/wcm/idc/idcplg?IdcService=GET_PDF_FILE\&RevisionSelectionMethod= LatestReleased \&dDocName $=035625$.

Statistik Austria. (2017). Pensionen und Renten (Pensions). Retrieved September 6, 2018, from http://www.statistik.at/web_de/statistiken/menschen_und_gesellschaft/soziales/ sozialleistungen_auf_bundesebene/pensionen_und_renten/index.html.

Staubli, S. T., \& Zweimüller, J. (2013). Does raising the early retirement age increase employment of older workers? Journal of Public Economics, 108, 17-32. https://doi.org/10.1016/j.jpubeco. 2013.09.003.

Steiber, N., \& Kohli, M. (2017). You can't always get what you want: Actual and preferred ages of retirement in Europe. Ageing \& Society, 37(2), 352-385.

Stiglbauer, A. (2006). Raising older workers' employment rates in Austria. In Workshops Proceedings of OeNB Workshops on Strategies for Employment and Growth in Austria, March 3, No. 10 (pp. 161-186).

Trukeschitz, B., Schneider, U., Mühlmann, R., \& Ponocny, I. (2013). Informal eldercare and workrelated strain. Journals of Gerontology. Series B, Psychological Sciences and Social Sciences, 68(2), 257-267.

Wiedenhofer-Galik, B. (2014). Einflussfaktoren auf eine Ausdehnung der Erwerbsphase. Statistische Nachrichten, 7(2014), 512-524. 
WKÖ (Chamber of Commerce). (2017). Beschäftigte über 50, erstellt 1/2017. Retrieved August 1, 2018, from https://www.wko.at/service/system/404.html?error=404\&errorRequest=/statistik/ wgraf/2017_04_besch\%E4ftigung_ab_50_2010-2016.pdf.

WKÖ (Chamber of Commerce). (2018). Flexible Arbeitszeit bringt's: Für Mitarbeiter, Unternehmer und Standort. Retrieved August 1, 2018, from https://www.wko.at/Content.Node/kampagnen/ arbeitszeit-neu/start.html.

Wöss, J. \& Türk E. (2017). Alles, was Sie schon über die Pensionsversicherung wissen wollten. FALTER, 27a/15 (pp. 16-17). Retrieved August 10, 2018, from https://media.arbeiterkammer.at/ pdf/falter_pensionen.pdf.

Open Access This chapter is licensed under the terms of the Creative Commons Attribution 4.0 International License (http://creativecommons.org/licenses/by/4.0/), which permits use, sharing, adaptation, distribution and reproduction in any medium or format, as long as you give appropriate credit to the original author(s) and the source, provide a link to the Creative Commons license and indicate if changes were made.

The images or other third party material in this chapter are included in the chapter's Creative Commons license, unless indicated otherwise in a credit line to the material. If material is not included in the chapter's Creative Commons license and your intended use is not permitted by statutory regulation or exceeds the permitted use, you will need to obtain permission directly from the copyright holder. 


\title{
Chapter 9 \\ Belgium
}

\section{Nathalie Burnay and Patricia Vendramin}

\begin{abstract}
Belgium is characterised by a low rate of employment for older people, though recent measures taken by national and regional governments have increased this rate. However, the extension of working life generates an increase in inequalities, especially for women. Having drastically reduced the legal provisions allowing people to leave the labour market before the legal retirement age, the Belgian federal government has adopted a series of measures aimed at extending working life. These reforms target both older workers and companies. The trade unions are trying to resist, however neo-liberal logic is gradually penetrating the Belgian framework.
\end{abstract}

Keywords Time credit $\cdot$ Collective agreement $\cdot$ Informal caregivers $\cdot$ Extended working life $\cdot$ Gender $\cdot$ Physically demanding $\cdot$ Stressful jobs

\section{Introduction}

Traditionally, social protection in Belgium has been characterised by adherence to a conservative regime. Since the establishment of the modern social protection system in December 1944, the Bismarckian model has been favoured. This system is based on a community of reference, with the worker at the centre of the system: s/he must be protected against temporary or permanent exclusion from the labour market. Thus, there is a generous social protection system, which is somewhat similar to the Scandinavian social-democratic model. The Belgian system relies on powerful trade unions; the unionisation rate is above $60 \%$ of workers. The government only intervenes when social negotiations fail. Thus, trade unions in Belgium are a very important counter-power. Rather left or centre-left, they have been very active over the past four years, dealing with a centre-right and nationalist federal government. In terms of extending working life, their main concern has been to improve working

\footnotetext{
N. Burnay $(\varangle)$

Transitions Institute, University of Namur, Namur, Belgium

e-mail: nathalie.burnay@unamur.be

N. Burnay $\cdot$ P. Vendramin

IACCHOS Institute, Université of Louvain-la-Neuve, Louvain-la-Neuve, Belgium
}

(C) The Author(s) 2020

Á. Ní Léime et al. (eds.), Extended Working Life Policies, https://doi.org/10.1007/978-3-030-40985-2_9 
conditions, allowing older workers to remain in the labour market. In this way, the quality of employment is a key issue, not only for older workers, but for all workers.

However, the Belgian model has also been built on a low level of defamilialisation (Esping-Anderson 1990). The model is generous, however it favours a male breadwinner model by combining important but differing types of aid: cohabitants, predominantly women, systematically receive fewer social benefits than heads of households, predominantly men.

For some years now, the Belgian social protection system has been undergoing profound changes, notably through the introduction of market principles into the heart of public affairs. There is severe criticism of a mode of state functioning characterised by excessive bureaucracy and a lack of effective management, which allegedly predisposes recipients of social assistance to disempowerment, if not to perpetual dependence on assistance. This penetration of neo-liberal logic into the welfare system led to a call for the development of quasi-markets, in which publicand private-sector service providers compete for public funding in a logic of marketisation. The concept of marketisation is a broad concept that covers a broad span of arrangements where private sector organisations contract with public sector bodies to deliver a welfare service in exchange for public funds (Brown and Potoski 2003).

\section{Pensions and End of Career}

The pension system in Belgium is based on a capitalisation principle: today's working people pay today's pensioners. There are three pillars in the Belgian system. The first is a statutory pension, the amount of which is determined by the number of years of contribution and depends heavily on the status of the worker: civil servants receive a much higher pension than workers in the private sector, and the self-employed receive only a limited pension. The second pillar, optional in the private sector, is paid by the employer and does not concern the public sector. The third pillar is paid for by the worker through insurance that is partially tax-deductible.

The most recent statistics on the amounts received by men and women in retirement show that the differences between male and female pensioners are particularly striking. The average difference is $€ 612.90$ (before tax) per month for those who have been employed throughout their careers and $€ 907.62$ per month for those alternating careers in self-employment and public service employment. The first cause of the significant difference between women's and men's pensions is the wage gap that still exists for the same job: the hourly wage difference between men and women is still $7.6 \%$ in Belgium (Le Soir 2018). The amount of the pension is based on the salary. This also explains the impact of the 'glass ceiling,' i.e., the difficulty for women to access the highest-level and best-paid jobs, on women's eventual pensions. Part-time work, which currently concerns almost one in two women but only one in ten men, is another major cause of the gap between men's and women's pensions. Moreover, women make greater use than men of strategies such as career breaks that, for some, may have an influence on the calculation of the pension. 
The legal retirement age, which is now 65, will be 66 in 2025 and 67 in 2030. The rules regarding age and career conditions for access to early retirement will also change progressively. The minimum age for early retirement was previously 62 years; it increased to 62.5 years in 2017 and to 63 years in 2018. Early retirement was accessible after 40 years of work; in 2017 this increased to 41 years, and it will increase further to 42 years in 2019 (Federal Pension Service 2019). There are some exceptions to this general scheme for heavy occupations. The federal government adopted this measure in order to increase the rate of employment amongst older workers, which is very low in Belgium compared to the European Union. In 2017, employment rates among older workers aged 55-64 years in Belgium were 53.8\% for men and $42.8 \%$ for women, although the Belgian $48.3 \%$ rates have been increasing steadily for the past several years (more than 30\% since 2004) (Eurostat 2019). This significant increase results from the development of policies favouring the retention of older workers, as well as from two other factors affecting the labour market: a general increase in the rate of participation amongst women and an increase in educational levels. The employment rate for people aged 65-69 years is very low in Belgium. In 2017, only 5\% in this age bracket were still working (Conseil supérieur du travail 2018), despite a relaxation of the measures for combining work and pension that occurred in 2017.

A special module of the 2012 Labour Force Survey identified the main reasons for stopping work amongst economically inactive persons who receive a pension. Table 9.1 shows some differences between men and women in Belgium. Higher proportions of women than men stop working due to health problems or disability and due to family and care related reasons, while higher proportions of men than women stop working due to favourable financial arrangements for leaving or because they become eligible for a pension.

Concerning health issues encountered at the end of the professional career, a special module of the Labour Force Survey (2013) shows that for both sexes, the two most widespread work-related health problems among those aged 55-64 years are musculoskeletal disorders and mental health problems (stress, depression, and

Table 9.1 Main reasons for stopping work amongst economically inactive persons in Belgium who receive a pension $2012(\%)$

\begin{tabular}{l|l|c}
\hline & Women & Men \\
\hline Favourable financial arrangements for leaving & 9 & 13.7 \\
\hline Lost job and/or could not find a job & 7.3 & 7.5 \\
\hline Had reached the maximum retirement age & 7.8 & 8.2 \\
\hline Had reached eligibility for a pension & 20.5 & 23.5 \\
\hline Other job-related reasons & 8.9 & 9.0 \\
\hline Own health or disability & 18.0 & 16.1 \\
\hline Family or care-related reasons & 6.5 & 2.5 \\
\hline
\end{tabular}

Source Labour Force Survey (LFS) (2012) 
anxiety). In Belgium, the prevalence of both kinds of problems in this age group is higher for women, with 59.4\% of women aged 55-64 years reporting musculoskeletal disorders and $22.6 \%$ reporting stress, depression, or anxiety compared to $55.8 \%$ and $18.3 \%$ respectively for men (Vendramin and Valenduc 2014).

In 2006, national trade unions negotiated a measure that allows reduction of working time at end of career while guaranteeing social benefits (notably in terms of pensions) for full-time workers; this system of 'time credit' was very popular during the first decade of the 2000s. This has contributed to the extension of careers and to an increase in the employment rate of older workers (Burnay 2011). The time credit system appeared in Belgium in a context marked by a high level of early retirement. In this context, the system was considered to be a career extension tool, since it largely replaced the use of early retirement (use of which decreased in the 2000s) — and as a tool for reorganising working time. In this chapter, we are specifically interested in the system dedicated to older workers, but other types of time credit systems exist, for example, parental leave, palliative care or informal caregiver leave. The time credit system for workers at end of career established the right for workers aged 55 years or older (or possibly 50 years or older in heavy occupations) to reduce their working time until retirement, with a financial compensation from the National Employment Office. Several criteria are considered: the employee must have been in the company for at least 24 months, and must have a career as an employee for at least 25 years (equivalent periods included). In practice, this time credit system allows full-time employees working five days a week to reduce their weekly working hours by one fifth (by one day or two half days per week). Moreover, the time credit before retirement is partly considered when calculating the employee's pension. The decade from 2002 to 2012 can be considered as the golden age of partial retirement, since the time credit system provided a number of advantages (individual right, pension calculation, flexibility in the reduction of the number of hours). However, the current government (and the previous one) has reduced access to this time credit system.

The time credit system is an alternative to early retirement of older workers. From a historical point of view, Belgium can be characterised by a low activity rate amongst older workers, which is largely explained by the development of the pre-pension system. The pre-pension system was developed in 1973 with several aims, including regulation of the labour market and integration of young unemployed people. Despite some reforms in the 1990 s, the system remained very popular for both employees and employers until 2012, when radical changes began. At that time, pre-pension was renamed 'unemployment with company supplement', and early retirees aged 60 and older, who were previously exempt from searching for jobs, became obliged to remain available on the labour market. This new name replacing 'early retirement' is both symbolic and practical. Symbolically, the reform focuses on the payer, which is the unemployment insurance system rather than a pension fund. From a practical standpoint, the rules for access to the system have been narrowed. The minimum age for being an 'unemployed person with company supplement' has been increased from 58 to 60 years, with at least 40 years of career. However, a longer transitional period exists for women. 
The success of the time credit system is undeniable. In 2003, the numbers of recipients of time credit aged 25-49 years were 3,911 for men and 14,723 for women, and in 2007 they were 6,491 for men and 33,877 for women, representing a more than twofold increase over four years in this age group. More strikingly, among those aged 50 and older, there were 34,914 men and 33,054 women receiving a time credit in 2008, compared to 13,972 men and 8,829 women in 2003. In contrast, early partial retirement (which has since become 'partial unemployment with company supplement') decreased drastically (Office National de l'emploi 2019).

However, the success of the time credit system must be seen in the light of two phenomena: inequality of access by gender and the impact of the economic crisis of 2007-2009. The gender difference is clearly visible in the group aged 25-49 years, where the time credit for parental leave is used more by women than by men. For the group aged 50 years and older, the differences are relatively small compared to the younger age groups. However, one can assume that the type of time credit used to reduce working time differs by gender. The number of people making use of time credit is also linked to economic cycles, it decreases when employment rates decline.

The decade from 2002 to 2012 was marked by a shift in public policies related to career. The time credit system and career breaks were seen as substitutes for the early retirement culture and the organisation of working time. The question then arises whether the development of specific working time schemes for end of career represented an interim measure aiming to increase employment rates or a path to the management of sustainable careers. The reforms began in 2012 and those enacted by the last government (which came into force in 2015) would appear to support the first hypothesis of a temporary measure to increase older workers' employment rates. It seems, considering the timing of these reforms, that the time credit system has been merely a parenthesis between a period of early exit from the labour market and a period of extended full-time careers.

Amongst the consequences of the time credit system has been a high level of parttime employment in Belgium. Indeed, the Belgian labour market is characterised by a significant proportion of part-time work, over the whole professional lifecourse (particularly for women) but also at end of career. This proportion increases significantly among over-50s, suggesting that part-time work is being used as a way of reducing working time for those approaching retirement. From 2000 to 2015, the part-time employment rate increased for both sexes, but it increased more for men than for women, for whom the part-time rate was already quite high (4.8\% for women compared to $7.1 \%$ for men; Table 9.2). One in two women over 50 years old are now working part-time.

In addition, a special module of the Labour Force Survey (2012) measured the proportion of workers who had reduced their working hours before moving into full retirement. It showed that the practice was widespread in Belgium, especially for men (Table 9.2). However, things are now changing in Belgium: since 2015, the federal government has reduced access to specific working time reduction schemes dedicated to older workers, which were extremely popular (Table 9.3). 
Table 9.2 Part-time employment amongst men and women aged 50-64 years as a percentage of total employment $(\%)$

\begin{tabular}{l|c|l|l|l|l}
\hline & 2000 & 2005 & 2010 & 2015 & Increase 2000/2015 \\
\hline Men & 5.9 & 10.5 & 14.9 & 13.3 & +7.1 \\
\hline Women & 45.4 & 46.5 & 49.8 & 50.2 & +4.8 \\
\hline
\end{tabular}

Source Labour Force Survey $(2000,2005,2010,2015)$

Table 9.3 Persons aged 50-69 years who reduced their working hours in a move towards retirement $2012(\%)$

\begin{tabular}{l|l|l|l|l}
\hline & \multicolumn{2}{|l|}{ Still employed } & \multicolumn{2}{l}{ Not employed } \\
\cline { 2 - 5 } & Men & Women & Men & Women \\
\hline EU 28 & 6.7 & 6.1 & 7.4 & 5.7 \\
\hline BE & 15.4 & 11.0 & 26.0 & 17.0 \\
\hline
\end{tabular}

Source Labour Force Survey (2012)

\section{Older Workers and Management Practices}

In an effort to increase employment rates amongst older workers, the Belgian government has introduced binding measures for companies. Since 2015, any company with more than 20 workers must set up a plan to keep older workers in the workforce (CCT104). This plan must be negotiated with union representatives in the companies. Several themes are included in this legal obligation:

Selection and hiring of new workers.

Development of workers' skills and qualifications, including access to training.

Career development and career support within the company.

Possibilities of obtaining through internal transfer a position adapted to the evolution of the worker's faculties and skills.

Opportunities to adapt working time and working conditions.

Workers' health, prevention, and possibility of remedying physical and psycho-social obstacles to retention in work.

Systems for the recognition of acquired skills.

However, initial analyses show that companies have developed few new strategies (Vendramin and Burnay 2017). To meet legal obligations, they either reuse pre-existing measures within the organisation or enter into legal arrangements such as time credit; few companies are truly innovative. Despite these legal attempts, older workers continue to suffer from discrimination even though an anti-discrimination law was adopted in 2003. Moreover, gender differences are not considered. These strategies are general measures that are not necessarily adapted to the local environment. 


\section{Care Policies and Informal Caregivers}

Supporting informal caregivers is increasingly considered among health and social care professionals, health insurers, federal and regional authorities, and researchers in Belgium. Indeed, care provided by family members, friends, and neighbours remains a central and essential part of the long-term care system. However, the availability of informal caregivers may decline due to societal changes, such as the growing integration of women into the labour market, changing family structures, and declining family size. Moreover, providing informal care may have negative consequences for the caregivers' physical and psychological health, and may affect their participation in the labour market. Not surprisingly, ways to support informal caregivers constitute an important part of current discussions - on both national and international levels - on how to ensure the sustainability of the long-term care system.

Before 2014, there was no specific legal status for informal caregivers that would guarantee access to particular social rights (KCE-Belgian Healthcare Knowledge Centre 2014). There are several protective measures stemming from social security or labour law, and in some sectors there are legal options for combining care and work. However, these measures were not linked to the status of caregiver. Since 12 May 2014, there has been legal recognition of informal caregivers taking care of people with disabilities or dependency needs. In order to be recognised as a caregiver, one needs to have reached the age of majority and not be under guardianship, and be a sibling or have an affective, confident, close, or geographic relationship to the care recipient. The period of caregiving must last for at least six months, and must comprise on average $20 \mathrm{~h} /$ week. Caregiving for individuals with severe care needs must take place in a non-professional setting, but the informal caregiver must collaborate with at least one professional care provider.

In several preliminary discussions, concerns were raised about the correct level of decision-making; whether the recognition of caregivers should be a federal competence, given the fact that aid to individuals is a community competence. The advising bodies aired other concerns, such as the risk of a cut-off of investment in domestic aid services, competition between professional care providers and informal caregivers, and inequality between recognised and non-recognised caregivers.

\section{Chronic Disabilities}

Belgium has nearly 400,000 long-term patients, i.e., approximately one in 20 Belgians between the ages of 20 and 64 years. This number has doubled in the last 15 years. A report from the National Institute for Disability and Health Insurance (INAMI 2014) highlights that for the first time (data 2014) the budget dedicated to disability insurance was higher than that dedicated to unemployment, which is a key issue in a country such as Belgium, where unemployment benefits are among the most favourable in Europe. From 2010 to 2014, the budget dedicated to disability 
insurance increased by $24.67 \%$. The explanation suggested by INAMI is that this increase is not only due to the ageing of the working population, but also to the increased participation of women (including older women) in the labour market. Consequently, the number of beneficiaries subject to insurance payments increased too. However, more importantly, the retirement age for women has been gradually aligned with that of men. Since 2009, the retirement age has been 65 years for both sexes (before 1997 it was 60 for women). This measure implies inter alia that women can now rely on disability insurance for a longer time and/or at an older age.

Since 2017, the federal government has been preparing a major reform of this sector, as the cost of these payments is too high to be borne by social security. The government intended to save $€ 100$ million on long-term disability payments in 2017. For the government, the new measures are based on a policy of 'activating the sick' and a philosophy of flushing out fraudsters and punishing profiteers. The trade unions reacted strongly against these measures and denounced a policy embedded in a neoliberal perspective. When a physician recognises a long-term illness, the worker must be offered another job better suited to his/her health situation. Where no solution can be proposed, the employer may dismiss the worker without financial compensation. In 2017, according to the trade unions, more than $70 \%$ of those summoned were declared permanently unfit and then dismissed. These figures were confirmed by the Minister of Employment, who had to admit that adapted work had indeed been offered in less than three out of ten cases (Vif 2018).

\section{Debate in the Media}

The current debate about extended working life in the media and mainstream press in Belgium is structured around two central topics. The first is not new and concerns consequences of the latest measures taken in the field of long-term illness that we mentioned in the previous section.

The second is indirectly connected with current events. Indeed, the Belgian federal government is currently negotiating with social partners in order to define a list of demanding jobs - an umbrella term for employment that is unusually stressful, contributes to greater potential physical injury and/or increases the risk of mental or physical work-related disabilities. The central aim of these negotiations is to draw up a list of occupations considered as physically demanding. This list is at the core of intense negotiations because the occupations included in this list would allow older workers to leave the labour market early without penalty on the amount of their pension.

Two direct consequences can be determined and have actually been discussed in the media. Firstly, occupations included in the list so far will be unfavourable for women, especially in the care sector, for which few occupations are included. Secondly, the amount available under this reform is structurally insufficient to cover all the occupations concerned. At the end of 2018, no agreement had been signed between social partners and the federal government. The media have adopted a critical position but each position is presented with the same weight and the same importance. 


\section{References}

Brown, T., \& Potoski, M. (2003). Transaction costs and institutional explanations for government service production decisions. Journal of Public Administration Research and Theory, 13(4), 441468.

Burnay, N. (2011). Ageing at work: Between changing social policy patterns and reorganization of work time. Population Review, 50(2), 150-165.

Esping-Anderson, G. (1990). The three worlds of welfare capitalism. Cambridge: Policy Press.

Eurostat. (2019). Employment rates by sex, age and citizenship. Available at: http://appsso.eurostat. ec.europa.eu/nui/show.do?dataset=lfsa_ergan\&lang=en. Accessed February 172020.

Federal Pension Service. (2019). Retrieved February 26, 2019, from https://www.onprvp.fgov.be/ FR/profes/benefits/retirement/age/Pages/default.aspx.

INAMI (Institut National d'Assurance Maladie-Invalidité). (2014). Statistiques des indemnités 2014. https://www.inami.fgov.be/fr/statistiques/indemnites/2014/Pages/statistiques-invalidite. aspx. Accessed January 142019.

KCE (Belgian Healthcare Knowledge Centre). (2014). KCE Report 223s: Support for informal caregivers: An exploratory analysis. Retrieved April 17, 2019, from https://www.aidants-proches. be/shared/File/kce-223s-support-informal-caregivers-appendix.pdf.

Labour Force Survey (LFS). (2012). Special module on transition to retirement.

Labour Force Survey (LFS). (2000, 2005, 2010, 2013, 2015, 2019). Employment and unemployment. https://ec.europa.eu/eurostat/data/database. Accessed January 142019.

Le Soir. (2018). Pensions: 613 euros de moins pour les femmes. Retrieved February 17, 2020, from https://www.lesoir.be/148029/article/2018-03-28/pensions-613-euros-de-moins-pour-lesfemmes.

Office National de l'emploi. (2019). Retrieved March 29, 2019, from https://www.onem.be/fr/ documentation/statistiques.

SPF Emploi, travail et concertation sociale. (2018). Conseil supérieur de l'emploi: rapport 2018. https://emploi.belgique.be/fr/publications/conseil-superieur-de-lemploi-rapport-2018. Accessed January 142019.

Vendramin, P., \& Valenduc, G. (2014). A gender perspective on older workers' employment and working conditions (Working Paper 2014.03). European Trade Union Institute (ETUI). Retrieved April 17, 2019, from https://www.etui.org/Publications2/Working-Papers/A-gender-perspectiveon-older-workers-employment-and-working-conditions.

Vendramin, P., \& Burnay, N. (2017). Gestion des âges dans les entreprises en Belgique : la difficile construction d'alternatives au départ anticipé. Retraite et Société, 75, 45-66.

Vif, L. (2018). Désormais, les malades de longue durée peuvent être licenciés sans frais. Retrieved March 29, 2019, from https://www.levif.be/actualite/belgique/desormais-les-maladesde-longue-duree-peuvent-etre-licencies-sans-frais/article-opinion-796441.html?cookie_check= 155419214. 
Open Access This chapter is licensed under the terms of the Creative Commons Attribution 4.0 International License (http://creativecommons.org/licenses/by/4.0/), which permits use, sharing, adaptation, distribution and reproduction in any medium or format, as long as you give appropriate credit to the original author(s) and the source, provide a link to the Creative Commons license and indicate if changes were made.

The images or other third party material in this chapter are included in the chapter's Creative Commons license, unless indicated otherwise in a credit line to the material. If material is not included in the chapter's Creative Commons license and your intended use is not permitted by statutory regulation or exceeds the permitted use, you will need to obtain permission directly from the copyright holder.

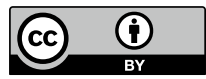




\title{
Chapter 10 \\ Bosnia and Herzogovina
}

\author{
Nurka Pranjić and Maja Račić
}

\begin{abstract}
Similar to other European countries experiencing growth in their 65+ populations, Bosnia and Herzegovina have also been affected by an intensive population ageing process. This national phenomenon affects the pension system, the health system and the labour market. A brief description of extending working life in the socio-economic context in Bosnia and Herzegovina, including gendered statistics on employment for older workers and pension coverage, is presented in this chapter. There is a discussion on extended working life policies, pension reforms, pensions systems and policy, and relevant employment and health policies for older workers. Flexible employment policies and training for older workers have not yet been introduced in Bosnia and Herzegovina. Future policy recommendations are also discussed.
\end{abstract}

Keywords Extended working life $\cdot$ Health policies $\cdot$ Pension reform $\cdot$ Employment $\cdot$ Gender

\section{Introduction}

The challenges of an ageing population have only recently gained attention in Bosnia and Herzegovina. In the late twentieth century and especially in the early twentyfirst century the proportion of older people in the national population increased. Yet, recommended pension reforms cannot be expected if most citizens are unaware of the issues or if many oppose the reforms presumed to be necessary (Pijalović et al. 2018). This chapter discusses the country's socio-economic context and its pension system and relevant legislation. Next, gender differences in employment rates and pension coverage among older people are discussed. The chapter outlines the main

\footnotetext{
N. Pranjić ( $\square)$

Department of Occupational Medicine, University of Tuzla, Univerzitetska 1,

75000 Tuzla, Bosnia and Herzegovina

e-mail: pranicnurka@hotmail.com

M. Račić

Department of Family Medicine, University of East Sarajevo, Foča, Bosnia and Herzegovina
} 
challenges facing the current pension system and prospects for extended working life, health policies and the debate on extended working life, and offers some policy recommendations.

\section{The Socio-Economic Context in Bosnia and Herzegovina}

The post-communism transition process and social reforms in Bosnia and Herzegovina have both been very slow. Partly due to the legacy of war (1992-1995), pension reforms relating to demographic challenges ahead have mostly been ignored. Additionally, a lack of official data has delayed this process. The war left a drastic demographic legacy, with a fall in the total population from 4.3 million to the current 3.7 million (Pijalović et al. 2018). Bosnia and Herzegovina, unlike other transition countries, entered the transition phase war torn and with significant human and infrastructural losses. By 1995, the Gross Domestic Product (GDP) had shrunk to less than a third of its pre-war level (Stumpf 2010). Despite receiving international aid, Bosnia and Herzegovina's migration and demographic changes have made social, pension and health funds especially vulnerable. The share of total public pension spending as a percentage of GDP has increased from 3.3\% in 1996 (World Bank 1997) to 9.4\% in 2012 (World Bank 2016).

Bosnia and Herzegovina have had a large budget deficit for years. This deficit is financed by borrowing, so the current external debt of Bosnia and Herzegovina is around $30 \%$ of GDP. Almost 30\% of the state budget is spent on public employees' wages, while $38 \%$ is transferred through the social benefits system. There is no industrial base that will allow the country to repay loans in the future (Bošnjak 2016).

The population in Bosnia and Herzegovina is ageing. It is estimated that by 2060 , persons 65 years of age and older will represent more than $30 \%$ of the population, compared to $15 \%$ in 2010 (UN DESA 2010, 2015). Older people in Bosnia and Herzegovina belong to a highly vulnerable social group. The key issues faced by older people are a low monthly income, increased living costs, high morbidity of cardiovascular and malignant diseases, and related mortality rates. The illiteracy rate of $2.82 \%$ is higher than in neighbouring countries (Council of Ministers of Bosnia and Herzegovina 2017). In 2014, women outlived men by 4.6 years on average and one third of women live alone, compared to only $15 \%$ of men. Loss of a spouse makes older women more vulnerable to the risk of poverty (USAID 2016).

\section{Gender and Employment in Bosnia and Herzegovina}

The employment rate in Bosnia and Herzegovina is lower than in other European countries. The unemployment rate averaged 42.2\% from 2007 until 2018, reaching a high of $46 \%$ in 2013 and a record low of 35\% in 2018 (Trading Economics 2019). 
Among employed persons, over three quarters (75.8\%) are employees, $20.7 \%$ are self-employed and $3.5 \%$ are unpaid family workers. The pattern is similar for men and women, although a much lower percentage of women than men are self-employed ( $15.2 \%$ compared to $23.9 \%$ of men). A significantly higher proportion of women are unpaid family workers (6.6\% compared to $1.7 \%$ of men) (Husković et al. 2017; Khare et al. 2011). The proportion of self-employed people is higher in Bosnia and Herzegovina than the average across the EU. A higher proportion of self-employed people in Bosnia and Herzegovina are small farmers, and a greater proportion of selfemployment is found in the informal sector than in the EU. Among the estimated 77,000 self-employed people, 74\% are men (USAID 2016).

Working age women have lower educational attainment levels than men. A considerably higher proportion of women than men have only a primary education $(49 \%$ compared to $29 \%$ respectively), with a similar gap in favour of men in secondary education (60.9\% compared to $41.7 \%$ respectively). More men than women are employed among individuals between 45 and 54 years of age. While employment opportunities for women increase with higher educational levels, those opportunities are accompanied by longer waiting periods until they obtain a permanent contract. Women dominate employment in the pre-university level education sector. There is evidence that men are more likely to be selected for professional positions than women (Somun-Krupalija 2011; USAID 2016).

Two out of three economically inactive persons in Bosnia and Herzegovina are women, and two out of three working age women are not in paid work (the inactivity rate is $66 \%$ for women of working age, and $45 \%$ for men). Bosnia and Herzegovina have a Gender Inequality Index (GII) value of 0.166 (GII reflects gender-based inequalities in three dimensions: reproductive health, empowerment, and economic activity), ranking it 37 out of 160 countries in the 2017 index (UNDP 2019).

According to 2015 United Nations data, the labour force participation of older workers over the age of 65 in Bosnia and Herzegovina has decreased sharply from 1950 to 2010, as shown in Table 10.1 (UN 2015).

In 2010, the employment rate among workers aged 65 and above was $12.3 \%$ (21.2\% for men and only $5.8 \%$ for women). In Bosnia and Herzegovina, a gender gap in the activity rate that favours men is high across all age groups, although it has decreased in the 2013-2015 period. The gender gap rate is the highest for the 25-49 age groups $(27.3 \%)$. In the 50-64 age group, two out of three women and one out of two men are inactive in the formal labour market. The gender gap here can be

Table 10.1 Labour force participation of older workers over the age of 65 by gender in Bosnia and Herzegovina, in the period 1950-2010 (percentage)

\begin{tabular}{l|l|l|l|l|l}
\hline Labour force participation $65+$ & $1950(\%)$ & $1970(\%)$ & $1990(\%)$ & $2000(\%)$ & $2010(\%)$ \\
\hline Women & 11.0 & 14.6 & 7.2 & 6.5 & 5.8 \\
\hline Men & 61.6 & 51.3 & 27.4 & 23.9 & 21.2 \\
\hline Total & 31.1 & 30.6 & 14.9 & 13.7 & 12.3 \\
\hline
\end{tabular}

Source Population Division, DESA, United Nations (2010) 
partially explained by an earlier retirement age for women than for men. Women over the age of 50, particularly those with lower education, are a hard-to-employ group once they become unemployed and very often get discouraged and stop looking for work (USAID 2016).

Poorer members of the population and residents of rural areas participate less in the workforce. The labour force participation gap between men and women is $20 \%$ among the wealthy and $31 \%$ among poorer people (World Bank 2016). In rural areas, the gap is $30 \%$ in favour of men. The gender gap in unemployment is low. In 2018, the unemployment rate for men aged 15-64 was 27\%, and 30\% for women (UNDP 2018). The gender difference in unemployment rates is similar across age groups. Among older age groups, the unemployment gap is higher in favour of men, at around 4 or 5\% (World Bank 2017). Self-employed women and single mothers are in particularly difficult situations. Self-employed women cannot take advantage of maternity leave that would enable them to act as employers of themselves, and they do pay contributions such as pensions and health insurance during maternity leave (Elwan 2015; USAID 2016).

\section{Pension System and Extended Working Life Policies in Bosnia and Herzegovina}

The Pension and Disability Insurance System in Bosnia and Herzegovina is a classic Bismarckian type labour-based system of social insurance with a progressive 'single pillar' (De Zwager and Gressmann 2009). Accrual of pension rights is based on payment of contributions, and the level of the final pension benefit is determined by the level of salary/wage during the active insurance period, adjusted for annual accrual rates (Investopedia 2018). Contributions are paid into an autonomous extra budgetary fund and are mandatory for all employed persons. The existing pension system is based on traditional principles of social insurance: principle of legality; rights from pension insurance, conditions for acquiring those rights and quantification of those rights as defined by law; principle of intergenerational solidarity (reciprocity and solidarity) (Bartlett and Xhumari 2007; Bošnjak 2016; Huskić et al. 2009).

The pension system in Bosnia and Herzegovina has two components: a public pension system (age pension and disability pension) and voluntary, private pension insurance (open voluntary pension funds with no limitations on membership and closed voluntary funds where membership is limited to specific groups, e.g. employees of specified employers). The risks covered by pension and disability insurance are: old age, disability, death and physical disability. Rights arising from these risks are: the right to an old-age pension, disability and family pension, as well as the right to an allowance for physical disability. Over $80 \%$ of older persons are pensioners; of these, about $10 \%$ receive wartime disability allowances and about $5 \%$ receive social welfare. As a condition for receiving an old-age pension, an insured person is entitled to an old-age pension when he or she attains 65 years of age and at least 15 years of 
insurance, or at least 20 years of pensionable service, or when he/she attains 40 years of insurance service regardless of his/her age (Article 40 of the Law on Pension and Disability Insurance 2018). Pension insurance is mandatory for: a person employed on a labour contract, a self-employed person, clerics and farmers. A person who does not pay compulsory insurance may pay voluntary insurance under certain conditions, as provided for by the law. An insured person has the right to financial compensation in the case of physical damage caused by injury at work or occupational diseases or if they need care. A person not involved in the compulsory insurance system can pay voluntary insurance (there is no legal obligation to do so) under certain conditions. Voluntary pension funds fall into Pillar III of pension insurance, a voluntary component of the pension system (Bošnjak 2016; Pijalović et al. 2018).

The high spending on pensions is partly the result of many people receiving disability pensions at pre-retirement age. Many working-age people receive pensions, but $39 \%$ of older people may not be collecting any state pension (Agency for Statistics of Bosnia and Herzegovina 2017).

\section{Pension Reforms in Bosnia and Herzegovina}

Pension reforms in the Federation of Bosnia and Herzegovina (one entity in Bosnia and Herzegovina), have been only minimal, although broader reforms have been considered necessary. New legislation on Pension Insurance in the Federation of Bosnia and Herzegovina was enacted in March 2018. Even though this legislation addresses the long-term fiscal sustainability problems in the pension system, the PAYG system still prevails. The defined benefit system of the past is being replaced by the introduction of a defined contributions system. Requirements for receiving an early old-age pension will be significantly stricter than before. The requirement for early retirement in 2018 for men was 35.5 years of paid pension insurance and 60.5 years of age, while for women it was 30.5 years of pension insurance and 55.5 years of age. This limit will increase for both men and women every year by half a year of age and half a year of paid pension insurance before reaching the 40year limit of paid pension insurance. A more rigorous set of benefit reductions has been introduced, which act as a disincentive to early retirement (4\% annual reduction compared to prior $0.5 \%$ reduction for each year below age 65) (Law on Pension and Disability Insurance 2019). In the first months after the adoption of the new law, $39 \%$ of the elderly population (65 years of age and older) may not be collecting any increase in state pension. Legislation created an increase that applied to 54,785 pensioners whose pensions increased by $10 \%$, and another 53,454 who received an increase of $5 \%$. Another outcome of the reform was that the deficit of the pension insurance fund was reduced and now stands at approximately 526,631 million euro (Pijalović et al. 2018).

In the Republika Srpska (RS) (one of two entities in Bosnia and Herzegovina), the right to a retirement pension can be reached at 65 years of age (if she or he has been paying insurance contributions for at least 15 years). An insured person who 
has not reached the age of 65 but who has 40 years of work experience and insurance contributions can retire at the age of 60 . Women may retire earlier than men; at age 58 if they have paid 35 years' pension insurance. A widow is entitled to a family pension if, when her husband dies, she is over the age of 50 or over 45 and incapable of working (Bošnjak 2016).

The situation in pension funds is very similar in both entities of Bosnia and Herzegovina. For example, approximately $58 \%$ of all funds available in the Federation of Bosnia and Herzegovina are for old-age pensions, $16 \%$ for disability and $25 \%$ for family pensions. The share of old-age pensions has been increasing in both entities. The average size of pension benefits in both entities is very low. Average pensions in the Federation of Bosnia and Herzegovina and RS in December 2016 amounted to approximately 189 and 175 euro per month, respectively. From 2010 to 2016, the average values of pensions have been mostly stagnant while the number of pension beneficiaries has been increasing (Pijalović et al. 2018).

Fifty four percent $(346,682,171$ persons) of the population over age 65 have no pension at all, since a large part of the working age population has never paid any contributions (Kepeš 2012). In 2006, the average monthly pension for those receiving it (including old-age, disability and survivors' pensions) was 126 euro per month. The amount of average pension is almost the same between the Federation of Bosnia and Herzegovina and RS. In relative terms, the average pension is $31.6 \%$ of the average gross wage. However, in view of the pension formula and the fact that the average total number of insurance contributions is 33 years, the replacement rates documented above suggest that there are certain pensioners who have had short periods of contributions but who have managed to be eligible for pensions (Huskić et al. 2009).

\section{Employment Policies to Extend Working Life}

Older people in Bosnia and Herzegovina face a high risk of poverty due to the lack of policies protecting their rights, with more than half of those over the age of 65 excluded from the pension system because they have never paid pension contributions. Older people who are excluded from the pension system live in poverty, often receive social financial assistance and eat in public kitchens. Women are poorer compared to men. About $58 \%$ of women have an average monthly pension of 60 euro compared to $49.5 \%$ of men (Huskić et al. 2009). There are no anti-age discrimination policies or anti-gender discrimination policies. There is a notable lack of both qualitative and quantitative research on extending working life (Schwab et al. 2017). 


\section{Health Policy in Bosnia and Herzegovina}

Given that older people are more prone to diseases and are the most frequent users of health care services, this affects both quality of life and life expectancy (WHO 2016). Health insurance in the Federation of Bosnia and Herzegovina covers only older people who receive pensions (people who do not have pensions are excluded from health insurance). The increase in the proportion of persons aged 65 years and above in the total population affects the dependency ratio, which is high at $48 \%$. This high dependency ratio contributes to increased health protection costs, which significantly increase as people age (World Bank 2017).

Persons with disabilities in Bosnia and Herzegovina find themselves in an extremely difficult situation, facing discrimination because they live in Bosnia and Herzegovina and not in other European countries where protections for disabled persons are more widespread. Authorities and the private sector do not implement affirmative measures related to the employment and rehabilitation of their workers (OSCE 2012). The most common forms of violation of the rights of people with disabilities in Bosnia and Herzegovina are in the areas of social protection, health, education, rights of access to information and employment. Even where laws exist to regulate this area, there is evidence of discrimination in practice (OSCE 2012). In Bosnia and Herzegovina, more women than men have some form of disability (Agency for Statistics of Bosnia and Herzegovina 2017). Women with disabilities face multiple types of discrimination; they are socially excluded and have poor access to all services (Fransioli 2013).

\section{Debate on Extended Working Life}

Decisions about whether to retire or to extend working life are beset with multiple uncertainties. This is exacerbated by a general lack of seeking active and purposeful information in relation to retirement, pensions and extending working life, and a lack of policy attention or initiatives associated with extended work. Engagement with these issues can be characterised as a passive process of acquiring information in an ad hoc manner from different sources, including the mass media, but with scant attention from the state. In April 2018, in the news (Balkans Aljazeera 2018), a comment on the retirement age of 67 years and extended working life was published, which pointed out that as soon as workers retire they depart directly to the cemetery. The government seems unaware of the health and continued employment problems associated with unhealthy workplaces. All stakeholders are focused on whether pensioners can live on their pensions and not on other measures related to extending working life. 


\section{Policy Recommendations}

In Bosnia and Herzegovina, a coherent strategy to integrate older workers in the labour market must be developed. Since many industrial workers and workers engaged in physically demanding jobs begin work at an early age, it is equitable to allow such people to retire earlier, perhaps conditioned on the number of years worked rather than linking pensions to chronological age. Incentives should be created for older employees to work longer. The issue of unsafe and unhealthy workplaces and their implication for ill-health and disability among workers, and the consequences for pensions, need to be addressed at a government level. There is a need for high quality data collection and further research on the gender and health implications of precarious employment to ensure healthy ageing, flexible employment policies and lifelong learning policies for all Bosnia and Herzegovina employees.

\section{References}

Agency for Statistics of Bosnia and Herzegovina. (2017). Demography and social statistics: Labour force survey 2017: Preliminary data. Sarajevo: Agency for Statistics of Bosnia and Herzegovina.

Balkans Aljazeera. (2018). News: Retirement at age 67 or a direct departure of workers to the cemetery. Retrieved April 1, 2018, from https://www.balcans.aljazeera.net.

Bartlett, W., \& Xhumari, M. (2007). Social security policy and pension reforms in the western Balkans. European Journal of Social Security, 9(4), 1-29.

Bošnjak, N. (2016). The pension system of Bosnia and Herzegovina: The problems and perspectives. European Journal of Multidisciplinary studies, 1(2), 186-194.

Council of Ministers of Bosnia and Herzegovina. (2017). Retrieved July 11, 2017, from https:// www.export.gov/article?id=Bosnia-openness-to-foreign-investment.

De Zwager, N., \& Gressmann, W. (2009). Maximizing the development impact of migration related financial flows and investment from Austria to Bosnia and Herzegovina. IASCI and IOM Report, prepared for OeEB.

Elwan, N. (2015). Bosnia and Herzegovina: Gender disparities in endowments, access to economic opportunities and agency. Sarajevo: World Bank, Agency for statistics of Bosnia and Herzegovina, FBosnia and Herzegovina Institute for Statistics and RS Institute for Statistics.

European Commission-Europe. (2008). The pension system: Social protection and social inclusion in Bosnia and Herzegovina. Luxembourg: Office for Official Publications of the European Communities, Publications Office of the European Commission Directorate.

Fransioli, E. G. (2013). Report on the status of Women's Rights in Bosnia and Herzegovina 2013. Human rights paper 2. Sarajevo: Open Centre.

Huskić, H., Halilčević, E., Osmanbegović, S., \& Osmanović, A. (2009). Report of pension reform in Bosnia and Herzegovina: The First Assessment. Budapest: ILO (International Labour Organization).

Husković, S., Simić, I., \& Isaković, J. (2017). Labour force survey 2017: Preliminary data. The First Release. Sarajevo: Agency for statistics of Bosnia and Herzegovina, Demography and Social Statistics.

Investopedia. (2018). Accrued benefit. Retrieved July 31, 2018, from http://www.investopedia.com/ terms/a/accrued-benefits.asp.

Kepeš, N. (2012). Identification and Etiology of the current state and status of third-age person in Bosnia and Herzegovina. Gračanica: Smile (Psychosocial Assistance and Volunteer Development Society). 
Khare, S., Ronnas, P., \& Shnuchiyeva, L. (2011). Employment diagnostic analysis: Bosnia and Herzegovina. Working Paper ILO (International Labour Organization) No. 86. Geneva: International Labour Office: Employment Sector.

Law on Pension and Disability Insurance in Federation Bosnia And Herzegovina. (2019). Sarajevo: Official Gazette, No. 93/2019.

OSCE [Organization for Security and Co-operation in Europe]. (2012). The right to social protection in Bosnia and Herzegovina: Concerns on adequacy and equality. Sarajevo: OSCE Mission to Bosnia and Herzegovina.

Parliament of the Federation of Bosnia and Herzegovina. The Law on Pension and Disability Insurance. (2018). Official Gazette 13/18.

Pijalović, V., Lazović-Pita, L., Peštek, A., \& Martinović, D. (2018). The analysis of perceptions and attitudes related to ageing in the Federation of Bosnia and Herzegovina. Public Sector Economics, 42(3), 255-278.

Schwab, K., Samans, R., Zahidi, S., Leopold, T. A., \& Ratcheva, V. (2017). The Global Gender Gap Report 2017. Geneva: World Economic Forum.

Somun-Krupalija, L. (2011). Gender and employment in Bosnia and Herzegovina: A country study (Working Paper ILO WP 4/2011). Geneva: ILO, International Labour Office, Bureau for Gender Equality.

Stumpf, M. H. (2010). Reflections on the Bosnia Debt restructuring. Law and Contemporary Problems, 73(4), 301-315.

Trading Economics. (2019). Bosnia and Herzegovina: Unemployment rate. Retrieved May 2009, from https://tradingeconomics.com/bosnia-and-herzegovina/unemployment-rate.Ac.

UN [United Nations]. (2015). World population ageing: Report ST/ESA/SER.A/390. Department of Economic and Social Affairs, Population Division. New York: United Nations Office.

UN DESA [The Department of Economic and Social Affairs of the United Nations Secretariat]. (2010). World Economic Vulnerability Report: Highlights. Retrieved May 6, 2019, from http:// www.un.org/esa/policy/publications/wespwevm/monitor4.

UN DESA [United Nations, Department of Economic and Social Affairs, Population Division]. (2015). World population prospects: The 2015 revision, key findings and advance tables (Working Paper No ESA/P/WP 241). New York: United Nations.

UNDP. (2018). Bosnia and Herzegovina United Nations Development Reports. New York: United Nations Development Programme.

UNDP. (2019). Human Development Report 2019: Inequalities in Human Development in the 21 st century. Briefing note for countries on the 2019 Human Development Report Bosnia and Herzegovina. New York: United Nation Development Programme.

USAID [United States Agency for International Development]. (2016). Gender analysis report for Bosnia and Herzegovina: Monitoring and evaluation support activity (measure Bosnia and Herzegovina). Washington, DC: USAID/ Bosnia and Herzegovina, Contract No. AID-168-C-1400003.

WHO [World Health Organization]. (2016). Social protection income and health inequalities: Review of social determinants of health divide in the WHO European region. Copenhagen: WHO Regional Office for Europe.

World Bank. (1997). Bosnia and Herzegovina: From recovery to sustainable growth (country study). Washington, DC: The World Bank.

World Bank. (2016). Pensions database GP social protection pensions spending 4Q2016. Washington, DC: The World Bank.

World Bank. (2017). Population ages 65 and above (\% of total). Washington, DC: The World Bank. 
Open Access This chapter is licensed under the terms of the Creative Commons Attribution 4.0 International License (http://creativecommons.org/licenses/by/4.0/), which permits use, sharing, adaptation, distribution and reproduction in any medium or format, as long as you give appropriate credit to the original author(s) and the source, provide a link to the Creative Commons license and indicate if changes were made.

The images or other third party material in this chapter are included in the chapter's Creative Commons license, unless indicated otherwise in a credit line to the material. If material is not included in the chapter's Creative Commons license and your intended use is not permitted by statutory regulation or exceeds the permitted use, you will need to obtain permission directly from the copyright holder.

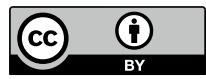




\title{
Chapter 11 \\ Bulgaria
}

\author{
Tihomira Trifonova and Kamellia Lillova
}

\begin{abstract}
This chapter focuses on older workers and extended working life in Bulgaria, considering of ageing biological, chronological, social and mental/cognitive aspects. Key factors involved in the discussion are financial security, pension arrangements and health, social and workplace characteristics. The demographic situation in Bulgaria has recently been defined in national debates as 'one of greatest challenges facing the country in the 21 st century'. The uses a gender perspective on employment, pension and health policies, and reflects on the on-going debate on extended working life.
\end{abstract}

Keywords Population ageing $\cdot$ Extending working life $\cdot$ Employment policies Pension reforms $\cdot$ Gender and health implications

\section{Gender and Employment in Bulgaria}

Bulgaria's longstanding experience of fertility rates below replacement level, accompanied by the emigration of young people, has resulted in national population decline since 1989. State demographic policy has been pro-natalist, although those policies have been ineffective. By early 2012 the population aged 15+ neither working nor searching for paid employment was over three million, meaning that nearly half of the national working age population was not included in economic activity, production or income generation, but nonetheless participated in the consumption of income (through pensions, social assistance and other social payments) (Vladimirova 2012). Almost two thirds (57\%) of those outside the workforce are female, with particularly high proportions in other social groups such as Roma, people with low education, people with no professional qualifications and people with disabilities (Vladimirova 2011). The increasing rate of disabilities is largely due to the quality of healthcare

\footnotetext{
T. Trifonova $(\bowtie)$

Sofia University “St. Kliment Ohridski”, 82 Dunav Street, 1202 Sofia, Bulgaria

e-mail: tiho@gateway.bg

K. Lillova

Institute for Population and Human Studies, Sofia, Bulgaria

(C) The Author(s) 2020

Á. Ní Léime et al. (eds.), Extended Working Life Policies, https://doi.org/10.1007/978-3-030-40985-2_11
} 
and working and living conditions. For natural reasons of advanced age, over $40 \%$ of economically inactive persons are aged $65+$.

There are differences in the total working time of Bulgarian men and women (Rangelova 2014). Both men and women in employment are predominantly in fulltime employment. Unpaid caregiving and domestic labour is mostly done by women. A frequent reason given to dismiss women from employment is that their partner has a business or employment, while no such justifications is given for men. Young women often have problems getting hired because they have young children or are of childbearing age, while young men do not encounter any difficulties related to (potential) fatherhood. These gendered differences contribute to a deepening gap in income after retirement. Higher work insecurity of women translates into income insecurity after retirement (Rangelova 2014).

The economic circumstances of Bulgaria's ageing workforce are multidimensional: the size of the labour force is diminishing; labour quality is impaired by skills losses resulting from emigration; the impact on the wages paid by employers is negative-all of this disrupts the stability of social systems. These processes have affected women even more negatively than men.

Over years of social transformations in Bulgaria, women's work situations have become stratified. Gender disadvantages are greater at higher age and for those with lower human capital. The greatest differences in earnings between women and men occur among those with primary or lower education level (women earn $69.8 \%$ of men's income) and those with basic education (women earn $70.8 \%$ ); differences are smaller between men and women with higher education at bachelor's or master's-degree level (75.5\%), and are lowest between people with doctoral degrees $(88.7 \%)$ (Stoyanova and Kirilova 2008). Although women's labour force participation increased in recent decades, the gender pay gap persists despite women being more likely than men to attain tertiary education. Given the relative equality that has been achieved between men and women in education, and similar labour market involvement on a full-time basis, the persisting gender pay gap requires further explanation.

The family is subject to special protection by law, with a series of measures to protect working mothers against pre-and post-natal employment dismissal. Various types of paid leave are provided for pregnancy, childbirth, child adoption, raising children up to two years of age, for medical examinations, attending to a sick family and so on. Employers have certain obligations regarding the health protection of pregnant women and mothers of children up to the age of six, and mothers who take care of children with disabilities (LC 1986). Parents of children up to eight years of age are also entitled to unpaid parental leave for a period of six months without losing length-of-working years' time, which counts for the pension contributions.

Limited research has been conducted exploring the interplay of gender, work and retirement topics in Bulgaria. The focus of academic debate is on pension reform and its consequences at a macro-level, and on the economic implications of the demographic crisis. Income inequalities across the lifecourses of Bulgarian women with different educational levels have not yet been investigated, nor have the implications of extended working life. 


\section{The Pension System and Extended Working Life Policies in Bulgaria}

The pension system in Bulgaria has undergone many changes since the 1990s, but the current model was introduced in 2000 (SIC 2000). The main objectives were to ensure pensions reflect the individual contributions made to the social security system, to strengthen and stabilise the Pensions Fund, and to introduce a new structure comprising three pillars - one solidary (state-based on social insurance) and two capital (market-based). The opportunity for early retirement of workers in precarious and physically demanding or risky work (the first and the second labour categories) was preserved, and also for some specific professions (military and police officers, teachers, ballet dancers and so on). For these groups, the required retirement age is gradually increasing (from 53 to 55 for the military and police officers, from 42 to 45 for ballet dancers starting since 1 January 2017), while the length of service has remained the same. People who have accumulated the required length of service may retire up to one year earlier with a reduced pension. The July 2015 amendment allowed employers to dismiss workers at retirement age and completed length of service with one month's notice.

Public pension contributions fell twice since 2000 (from $32 \%$ in 2000 to $16 \%$ in 2010), and remained at a low level of $17.8 \%$ for the next six years. People born after 1959 make reduced contributions of $12.8 \%$ to the state pension fund. The remaining part of the contribution (5\%) is transferred to the second pillar. Cohorts born after 1959 will receive reduced state pension benefits at their retirement (NSSI 2015, 2017a; SIC 2000) but they will have second pillar pensions.

Contributions are determined on the insurable income, between lower and upper limits. The minimum insurable income is set according to economic activities and professional groups but is no less than the minimum monthly salary for the country (460лв or $€ 236$ for 2017); the maximum insurable income is the same for all professions (2600лв or $€ 1329$ for 2017) (SSSBA 2017).

Pension reform in Bulgaria aims to achieve a pension age of 65 for both women and men-by 2029 for men and 2037 for women, up from 64.2 for men and 61.2 for women since 2018. In 2027 the number of years of contribution from employment to earn a full pension will be fixed at 37 years for women and 40 years for men. Currently, women can retire at 61 with 35 years and four months of work. For specific professions with an early retirement option, the retirement age will also gradually increase (by two years on average). Overall, the frequency of retirement aged people employed is growing. The most important reason by far given for this decision is economic ( $86.6 \%$ of working pensioners), that is, to maintain an income that can provide a good standard of living. Avoiding isolation is also important $(13.4 \%$ point out reasons such as opportunities for social contact, satisfaction with the work activity, and so on) (NSI 2012).

Leading economic analysts at the Institute for Market Economics define the pension instalments as having the same effect as a tax on labour market supply and demand (IME 2013). An extended working life pension policy introduced in 2007 
changed the formula for pension calculations. With this new formula, if a person is entitled to a pension and continues working, the accrual rate for each year of contributable service increases during the post-retirement age period. Before 2012, the accrual rate was 3\%, and was later increased to 4\% (NSSI 2015). In 2012-2013 the retirement age and the required years of work were increased by four months. If people lost their jobs, older workers were obliged to register at the labour bureau as unemployed. The result was an increase in the number and rates of unemployed people age 50+ and especially 55+. A programme entitled 'Assistance for retirement' of the Employment Agency was developed to provide matching employment for unemployed older workers until they reach retirement age. No data or conclusions have been published on the impact of this programme.

The number of people receiving pensions has been increasing in absolute terms over the past ten years. This is partly due to pensions (such as disability payments) that are actually a form of social assistance because they complement the main pension. Some pension categories are not related to labour activity. Those include social pensions for old age, granted to people aged 70 when the annual income of a member of their household is less than the guaranteed minimum income established in the country in the previous 12 months. This social monthly pension is 120.98 лв, (€62), one-third of the amount that is set as the poverty line (314лв or $€ 160$ for 2017); and social disability pension, granted to adults (16+) with more than $71 \%$ disability (NSSI 2017b).

\section{Extended Working Life Employment Policies}

Public policy for extended working life, i.e. postponing retirement, is often nullified by the practice of business organisations dismissing older employees after the age of 55. The actual reason is not so much the officially claimed reduced labour productivity of older workers (Vladimirova 2012) but the higher price of their labour due to supplements for longer years of professional experience. On the positive side, family policies exist. The availability, provision and accessibility of kindergartens, and the quality and diversity of service provision is a public policy (mostly at local government level) but also increasingly part of the corporate policies. Together with opportunities for parental leave provided to both parents, this creates better conditions for achieving equality in the working lives of men and women.

Over the last decade, the economic activity and employment of the older workforce has increased, especially for women (Rangelova 2016; Borissova-Marinova 2016). Older age employment increases mainly in the age group 55-64 years $(58.2 \%$ in 2017) and is lowest for people aged $65+$, mostly due to the increase in the statutory age and the minimum length of working years for retirement. As quoted in the Eurostat database (Eurostat 2017; NSI 2017), the employment rate for men aged $55-64$ is higher than for women of the same age $(62.5 \%$ and $54.3 \%$ respectively for 2017). About $40 \%$ of the unemployed and about $50 \%$ of long-term unemployed 
are over 50 years of age (EA 2016). To promote the employment of people over 50 , measures are being implemented, such as encouraging employers to create new jobs and hire the unemployed and long-term unemployed; flexible employment; promoting entrepreneurship; motivational training; adult education and so on (EPA 2002; EA 2016).

According to the results of the 'Transition from work to retirement' survey, the main reason for continued work after reaching the retirement age is to earn enough income for oneself and one's family. Respondents reported that safer and healthier work conditions would increase the motivation to continue one's active work life. People in pre-retirement age are more conservative in their attitude to the employment of retired persons because they perceive them as an imminent threat to their own jobs. There are two main reasons for the studied cohort's support for extended working life: salaries are generally higher than pensions, and longer working life means higher future pensions (NSI 2012). In Bulgaria, as elsewhere, women dominate in sectors with lower pay levels, while men generally work in those with higher pay levels and on management and governance positions. Gender disparities in pensions are consequently high.

\section{Employment Obstacles Faced by Older People}

Employers are generally unwilling to invest in the training of people over 40 and especially over 50, despite still having at least 10 years of expected economic activity. At the same time workers' qualifications were acquired decades ago and the technology level of modern production has changed skill requirements dramatically. Discrimination often occurs on this basis. Although older retired people are not those at the highest poverty risk in Bulgaria, they nonetheless represent more than a quarter of those in poverty and nearly one seventh of those in deep poverty.

Bulgarian legislation regarding anti-discrimination and equal treatment is fully harmonised with European regulations and international norms. Nevertheless, cases of unequal treatment and direct or indirect age discrimination exist and are quite widespread. The results of a national representative survey of the Research Institute of Societies and Knowledge show that women (60.5\%) more often than men $(55.4 \%)$ perceive being over 50 as problematic in the context of continued employment. In the capital city, this share is $73 \%$ for women. Older age is an obstacle from the perspective of $19 \%$ of employers and is among the most frequently quoted $(15.5 \%)$ reasons for rejected job applicants. Discrimination against people over 50 on the labour market is double that experienced in younger age groups; in the case of multiple discriminations, age is one of the significant accompanying criteria. There are still employers who include an age limit in recruitment announcements, excluding part of the workforce from the opportunity even to apply for a job. As human rights organisations' surveys show, this discrimination at entry is facilitated by individuals' low awareness levels and poor legal knowledge of their rights, uncertainty as to which 
institutions to address to defend their rights, and not least by the passive behaviour of the institutions that tolerate age discrimination.

\section{Health Policies}

Population ageing has serious public and economic consequences for Bulgaria's healthcare system. Higher costs are not due to ageing alone, but also due to unhealthy ageing. Many Bulgarians still lack necessary health promotion knowledge and preventive care. The efforts of general practitioners and specialised medical professionals, so far, seem ineffective, but their efficacy cannot currently be assessed because no toolkit exists for registering the results in the National Framework Agreement. There are no programmes for early detection of diseases before the emergence of clinical symptoms.

Several diseases such as cardio-vascular, cerebrovascular and cancer are much more frequent among older people compared with younger counterparts. The fear of competition and employment dismissal increases stress and stress-related diseases. Stress rates are especially high for those aged 45+ who have been trapped in unemployment, creating serious barriers to returning to employment and even greater problems relating to having interrupted careers.

Morbidity from chronic diseases is high, despite its downward trend since 1996. Among older Bulgarians there is particularly high frequency of cardiovascular diseases, respiratory system diseases, digestive system diseases, and neoplasms. Cardiovascular diseases and neoplasms are the main reason for chronic reduced work capacity and disabilities (34.2\% and $20.8 \%$ respectively in 2016). These diseases are related to risk factors that include lifestyle (smoking, alcohol consumption, poor diet and lack of physical activity), and are the main causes of death and account for over $80 \%$ of all deaths $(78.6 \%$ for men and $84.5 \%$ for women in 2016). The mortality rates of middle-aged men (40-65 years) are considerably higher than those of women (Lillova 2018) and the average life expectancy is 71.2 years for men and 79.2 years for women (7 years more).

Adapting Bulgaria's healthcare system to the needs of its ageing population requires optimisation, modernisation and rationalisation. Predictable problems are increasing healthcare costs, accounting for the needs of an older workforce, financing and development of additional health services, provision of complex health services for senior citizens, increasing health knowledge among all age groups, and promoting healthy lifestyles, in particular among people over 50 .

\section{Debate on Extended Working Life}

The public debate on extended working life is dominated by what is understood as a demographic crisis and the stability of the pension system. Demographic ageing is 
regarded as a major challenge for Bulgaria (Voynova 2013). There is a widespread belief that social security is failing in its purpose today but will do so much more in the future. The fear of losing future pensions weakens intergenerational solidarity. Arguments that future pensions cannot be guaranteed dissuades people from paying contributions now.

A leading argument in ongoing public discussions is that pension reform is allegedly leading to informal employment without social protection and higher unemployment among older people. Pension reform was based on the assumption of longevity in good health, preserved productivity and possible access to employment for most people. However, a large proportion of both employers and employees do not support the idea of extended working life. The attitude of the employees is due to fear of insecurity and impoverishment. Employers explain their reluctance to hire older people due to the cost of higher social security contributions and perceived diminishing productivity and qualifications of older workers (Slavyanska 2017).

Public surveys show that people up to the age of 65 are more inclined to work than cease their economic activity earlier because they (1) feel fit enough to work; or (2) wish to avoid reducing their income (NSI 2012; Mihova 2013). The desire for early retirement is driven by fatigue, deteriorated health, or having a safe income in the form of a pension. In the case of early retirement, only one third of early retirees intend to live only on their pensions; the rest intend to continue earning. The main preferences are for flexible employment and the majority are not ready to accept any job available. Only 30\% express readiness to get involved in formal employment programmes (National Employment Action Plans).

\section{Gender and Health Implications}

The trend of employment growth among the adult labour force is mainly due to the extended retirement age and fear of income insecurity. One explanation is that the active employment policies pay more attention to providing employment to the unemployed in pre-retirement age than to stimulating more prolonged and productive employment. Since women form the majority of people outside the workforce, active employment policy can have a positive influence on them, in particular on women with low or no qualifications who could potentially provide paid care and thus secure some income after retirement. However, no systematic research has been done so far on the health implications of extended working life in the country.

Increasingly, Bulgarian workers want to develop in their professions, improve their qualifications, stay at work longer, have higher incomes and be secure in their old age. Yet women are still the first choice at times of mass dismissal of workers and, combined with a persistent pay gap, therefore suffer from greater income insecurity during both work and retirement. Older people and pensioners are a substantial group among impoverished Bulgarians. Merging social assistance with the social security system lays a burden on the latter and prevents the implementation of an adequate 
policy to the groups most at risk. The differences between men and women's financial situation after 60 are very substantial. While the poverty rate among men aged $60+$ is around $20 \%$, it is $30 \%$ among women of the same age. This gap widens in the age group 75+, but that is not reflected in policies. Extended working life without accompanying complementary policies is likely to have negative implications specifically for women, with unknown health consequences but clearly negative psychological consequences.

The socially significant gender differences grow with age and so does the pay gap. Although they have longer life expectancy, women more often suffer from fatigue and various chronic health problems, which reduces their ability for extended work (Zlatanova 2015). However, very low pensions have led to very high proportions of retired women living in poverty in Bulgaria. At the same time, employers are not willing to retain older employees in the workforce except in isolated cases (e.g. the national shortage of teachers). Understanding the complexities of shaping responsive policies will necessitate further research on the topic.

\section{Policy Recommendations}

Policies for integration and support of older workers should assist their participation in the economy to stop the loss of their knowledge and experience. The specific measures to implement this policy may vary, but should include both national level policies and the efforts of both public and private sector organisations.

Pension reforms have contributed to insecure employment and greater unemployment of older workers. Reforms were based on the hypothesis of longer life in good health, preserved productivity and access to employment for the majority of this population, which for many older Bulgarians are invalid assumptions. It is important to preserve the option of earlier retirement for some workers, for several reasons: it may be impossible for them to remain at work contrary to their wish (dismissal or performance difficulties); when they are unemployed with slim chances of finding a job or the job they are offered is low-qualified and low-paid, and would reduce their future pension substantially etc. Those who opt for early retirement can receive employment income, but at the expense of social security instalments in proportion to their years of service and legally established retirement age. This arrangement will not decrease expected levels of contributions to the social security system. The benefit will be the right to make a choice and reduced morbidity because of stress and cardio-vascular diseases. The right to an informed and supported choice when considering retirement would be a huge step towards true democracy and control over one's own life. 


\section{References}

Borissova-Marinova, K. (2016). Razlichia po pol pri rabotnata sila na vazrast nad 55 godini v Balgaria i stranite ot ES [Gender differences of labour force aged over 55 in Bulgaria and EU countries]. Nasselenie Review, 34(3), 9-30.

EA. (2016). Godishen obzor 2016 [Annual review 2016]. Sofia: Sofia Employment Agency, Ministry of Labour Force and Social Policy.

EPA. (2002). Zakon za nasarchavane na zaetostta [Employment promotion act]. Retrieved June 10, 2017 from https://www.lex.bg/bg/laws/ldoc/-12262909.

Eurostat Database. (2017). Retrieved November 8, 2018 from https://ec.europa.eu/eurostat/data/ database.

IME. (2013). Pensionnata sistema na Balgaria v chisla i grafiki [The pension system of Bulgaria in numbers and graphs]. Sofia: Sofia Institute for Market Economics.

LC. (1986). Kodeks na truda [Labour code]. Retrieved June 11, 2017 from https://www.lex.bg/bg/ laws/ldoc/1594373121.

Lillova, K. (2018). Ostaryavane na naselenieto i dalgoletie v Balgaria (1947-2015) [Population ageing and longevity in Bulgaria (1947-2015)]. Nasselenie Review, 36(1), 25-65.

Mihova, G. (2013). Natsionalni spetsifiki na ostaryavaneto na naselenieto v Balgaria [National particularities of population ageing in Bulgaria]. Nasselenie Review, 33(1-2), 176-194.

NSI. (2012). Statisticheski godishnik 2012 [Statistical yearbook 2012]. Sofia: Sofia National Statistical Institute.

NSI. (2017). Statistical data: Demographic and social statistics. Retrieved November 15, 2017 from http://www.nsi.bg.

NSSI. (2015). Analiz na pensiite za osiguritelen stazh i vazrast za perioda 2000-2014 [Analysis of retirement pensions for the period 2000-2014]. Sofia: Sofia National Social Security Institute.

NSSI (2017a). Analiz na pensiite za osiguritelen stazh $i$ vazrast za 2010-2016 [Analysis of retirement pensions for 2010-2016]. Sofia: National Social Security Institute.

NSSI (2017b). National Social Security Institute. http://www.nssi.bg/pensions.

Rangelova, R. (2014). Dzhendar aspekti pri pensionnata vazrast [Gender aspects at retirement age]. In P. Naydenova, et al. (Eds.), Demografskata situatsia i razvitieto na Balgaria [The demographic situation and the development of Bulgaria] (pp. 763-775). Sofia: Prof. M. Drinov Publ. House.

Rangelova, R. (2016). Promeni v zdravnia status na zastaryavashtata rabotna sila v Balgaria [Changes in the health status of the ageing labour force in Bulgaria]. Nasselenie Review, 34(3), $51-65$.

SIC. (2000). Kodeks za socialno osiguryavane [Social security code]. Retrieved June 12, 2017 from https://www.lex.bg/bg/laws/ldoc/1597824512.

Slavyanska, V. (2017). New Knowledge Journal of Science, 6(1). ISSN 2367-4598 (Online). National Science Fund of Bulgaria.

SSSBA. (2017). Zakon za byudzheta na Darzhavnoto obshtestveno osiguryavane za 2017 [State social security budget act 2017]. Retrieved June 17, 2017 from https://www.lex.bg/bg/laws/ldoc/ 2136949160.

Stoyanova, K., \& Kirilova, A. (2008). Dzhendar neravenstva v platenia i neplatenia trud v Balgaria [Gender inequalities in paid and unpaid labour in Bulgaria]. Sofia: Prof. M. Drinov Publ. House.

Vladimirova, K. (2011). Politikite za zaetost i ravnopostavenostta na mazhete i zhenite na pazara na truda [Employment policies and equality between men and women in the labour market]. In Natsionalnite izmerenia na politikite na ES za razvitie i zaetost. Novite predizvikatelstva, svarzani sas zaetostta i pazarite na truda [National dimensions of EU development and employment policies. The new challenges related to employment and labour markets] (pp. 277-342). Sofia: Ciela.

Vladimirova, K. (2012). Upravlenie na choveshkite resursi: politiki za resurs ili potentsial za razvitie i sotsialen progres [Human resource management: Policies on resource or potential for development and social progress]. UNWE Yearbook. Retrieved June 11, 2017 from http://unwe-yearbook. org/en/journalissues/list/44. 
Voynova, E. (2013). Demografskata promyana: nay-golyamoto predizvikatelstvo za Balgaria prez 21-vi vek: Natsionalna strategia za demografsko razvitie na naselenieto i natsionalna kontseptsia za nasarchavane na aktiven zhivot na vazrastnite hora [Demographic change: the biggest challenge for Bulgaria in the 21st century. National strategy for demographic development and national concept for promoting active ageing]. In Inovativni podhodi za nasarchavane na zdravosloven, aktiven i dostoen zhivot na vazrastnite hora [Innovative approaches to promote healthy, active and dignified lives of the elderly people] (pp. 13-29). Sofia Ministry of Labour Force and Social Policy. Retrieved May 14, 2017 from https://www.mlsp.government.bg/index. php?section=POLICIESI\&lang $=\& I=289$.

Zlatanova, V. (2015). Stareene i neravenstva [Ageing and inequalities]. Sofia: OMDA.

Open Access This chapter is licensed under the terms of the Creative Commons Attribution 4.0 International License (http://creativecommons.org/licenses/by/4.0/), which permits use, sharing, adaptation, distribution and reproduction in any medium or format, as long as you give appropriate credit to the original author(s) and the source, provide a link to the Creative Commons license and indicate if changes were made.

The images or other third party material in this chapter are included in the chapter's Creative Commons license, unless indicated otherwise in a credit line to the material. If material is not included in the chapter's Creative Commons license and your intended use is not permitted by statutory regulation or exceeds the permitted use, you will need to obtain permission directly from the copyright holder.

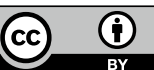




\title{
Chapter 12 \\ Chile
}

\section{Ignacio Madero-Cabib, José De-Amesti and María-Soledad Herrera}

\begin{abstract}
During the last three decades Chile has experienced an unprecedented demographic transition due to increased life expectancy and decreased childbirth. This is expected to cause important challenges to economic, health and cultural dimensions among older people in Chile. Furthermore, this is a developing country characterised by a liberal labour market and pension policies and by a male breadwinner culture-locating women in care and domestic tasks at the expense of labour market participation. This means that gender plays a key role in the challenges associated with an ageing population. We discuss public policies and recent academic research on the economic, health, and cultural dimensions of ageing in Chile.
\end{abstract}

Keywords Older people $\cdot$ Extended working life policy $\cdot$ Gender $\cdot$ Health $\cdot$ Chile

\section{Introduction}

In $1990,9 \%$ of the population were aged $60+$; this has now increased to $16 \%$ of the population and is expected to reach $25 \%$ in 2035 (Bravo and Hughes 2018; CEVE UC 2018). As in many countries, Chile displays significant gender gaps in relation to employment and pension income. However, this nation holds one of the lowest rates of women in paid work across the Organisation for Economic Co-operation and Development (OECD) member countries (OECD 2017). Scholars have mainly attributed this gendered context to persistent social norms that associate women with both

\footnotetext{
I. Madero-Cabib ( $\square)$

Institute of Sociology and Department of Public Health, Pontificia Universidad Católica de Chile, Santiago, Chile

e-mail: i.maderocabib@uc.cl

J. De-Amesti

Pontificia Universidad Católica de Chile, Santiago, Chile

M.-S. Herrera

Institute of Sociology, Pontificia Universidad Católica de Chile, Santiago, Chile
} 
domestic and care work (Madero-Cabib et al. 2019a). We now focus on understanding this scenario specifically among older individuals.

\section{Labour Force Participation of Older People}

Data from a national survey in Chile (CASEN 2015) shows that from 2006 onwards an increasing proportion of older individuals have participated in the labour force (Table 12.1). Specifically, $72.6 \%$ of men in the 60-64 age group were working in 2006 , as compared to $80.6 \%$ in 2015 . Women display a similar trend, although labour force participation rates are considerably lower.

As seen in Table 12.2, labour force participation in Chile among individuals aged $65+$ is clearly higher than in the OECD average (OECD 2015, 2017).

One explanation behind the high labour force participation among people beyond statutory retirement age in Chile are the financial obligations faced by many workers without adequate pension savings for later life. Indeed, as recent studies show (Centro UC Políticas Públicas 2017; CEVE 2018), 'financial needs' (64.5\%) are the most important motive for extending working lives, while 'health problems' $(66.5 \%)$ and 'having other duties' (18.1\%) are the main reasons for leaving the labour market.

One of the main ways older Chilean adults remain active in the labour market is self-employment (CEVE 2018). However, as previous literature indicates, most selfemployment among older adults is in the informal sector (Huenchuan et al. 2007; Vives et al. 2017), which often entails precarious working conditions (Centro UC Políticas Públicas 2017).

Table 12.1 Labour force participation (\%) by gender and age group

\begin{tabular}{l|l|r|r|r|r|l}
\hline & Age group & 2006 & 2009 & 2011 & 2013 & 2015 \\
\hline \multirow{2}{*}{ Men } & $60-64$ & 72.6 & 73.7 & 74.7 & 78.1 & 80.6 \\
\cline { 2 - 7 } & $65+$ & 29.4 & 25.2 & 26.0 & 29.4 & 36.1 \\
\hline \multirow{2}{*}{ Women } & $60-64$ & 29.3 & 27.5 & 29.1 & 34.6 & 37.6 \\
\cline { 2 - 7 } & $65+$ & 9.4 & 7.4 & 7.9 & 9.5 & 13.3 \\
\hline
\end{tabular}

Source CASEN (2015)

Table 12.2 Labour force participation (\%) of individuals aged 65+

\begin{tabular}{l|r|r|l|l|l|l}
\hline & 1996 & 2000 & 2004 & 2008 & 2012 & 2016 \\
\hline Chile & 18.7 & 17.3 & 17.0 & 19.8 & 23.0 & 24.3 \\
\hline OECD countries & 9.7 & 9.0 & 11.0 & 12.2 & 13.2 & 14.4 \\
\hline
\end{tabular}

Source OECD (2017) 


\section{Working Conditions of Older Workers}

Average income is one indicator of older workers' working conditions. The average income of older workers in Chile (65+) is equal to $67 \%$ of the average income of the rest of the population, while in OECD countries this statistic is $86.2 \%$ (CAPSP 2015; OECD 2013). Average income for people aged 65+ in Chile is about $€ 458$ per month, and there is a substantial gap between men (about $€ 541$ per month) and women (about $€ 291$ per month) (CAPSP 2015).

Access to occupational training is another indicator of good working conditions. In one study, $20.8 \%$ of older workers say they would like to continue learning new work-related competences (Programa Adulto Mayor UC 2013). However, another study indicates that only $4 \%$ of workers aged $60-74$ have been in an $8+$ hour job training session during the last year (Centro UC Políticas Públicas 2017).

The evaluation of health risks in the workplace also measures working conditions. Vives et al. (2017) assessed exposure to labour risks in four different domains: hygiene, ergonomics, security and psychosocial wellbeing. They found that $20 \%$ of individuals aged 70+ are employed in jobs that expose them to high temperatures and solar radiation. The most common ergonomic risks for older workers are harsh positions, repetitive tasks, and working while standing. Regarding psychosocial risks at work, $20 \%$ of older individuals believe that time allocated to work is insufficient for performing their tasks adequately, $50 \%$ believe that their jobs involve excessive concentration, and $45 \%$ state that their jobs are highly exhausting (Vives et al. 2017; Centro UC Políticas Públicas 2017).

\section{Recent Pension Reforms}

In 1981, during the dictatorship of Augusto Pinochet, Chile was the first country to entirely replace a public defined-benefit pay-as-you-go pension scheme (PAYG scheme) with a private mandatory defined-contribution individual-retirementaccount pension scheme (IRA scheme). Since then, every employee must contribute $10 \%$ of their monthly salaries to their pension savings. The savings are administered by private institutions called Pension Fund Administrators (AFPs), for-profit companies that invest pension savings in different economic and financial activities.

During the 2000s, the Chilean pension system was the target of multiple criticisms. The main critiques were (1) the absence of a strong welfare net for people with low pension savings, (2) the unjustified administration fees for AFPs (about $2.6 \%$ of workers' salaries), and (3) the gender inequalities both in replacement rates and pension income (Arenas de Mesa et al. 2006). To address some of these issues, in 2008 the Chilean government, led by President Michelle Bachelet, implemented an important pension system reform, which aimed to strengthen the non-contributory dimension of pensions as a way to reduce old age poverty and to address gender gaps 
in pensions (Cumsille 2015; Todd and Joubert 2011). Regarding gender inequalities, with the objective of compensating for women's interruptions in pension contributions - mainly caused by pregnancy and periods of child rearing-the 2008 reform introduced a new pension subsidy, consisting of an economic bonus in which, for each child-born or adopted-women receive a once off contribution equal to roughly $€ 663$ into their private pension accounts. Another measure stated that in the case of a divorce, a judge is allowed to take up to $50 \%$ of the individual pension savings of either member of the couple and reallocate it to the personal account of the other member.

Despite the changes introduced in 2008, by 2014 the Chilean pension system still presented several deficiencies (Mesa-Lago 2015; Barr and Diamond 2016). The government at the time commissioned an Advisory Committee to identify existing weaknesses in the pension system and suggested policy measures to overcome them. The analyses of the Advisory Committee indicated three main limitations of the pension system: (1) low pension incomes, (2) low replacement rates, and (3) gender inequalities. For instance, official statistics show that in Chile between 2007 and 2014 the monthly pension median was about $€ 112$ (for women approximately $€ 57$ and for men approximately $€ 152$ ). The commission elaborated several recommendations. Among other measures, they proposed (1) strengthening and expanding public subsidies for pension incomes, both in terms of coverage (from $60 \%$ to $80 \%$ ) and amount of income (by 20\%); (2) that not only workers but also employers contribute to pension savings (about 5\% of worker's salary); (3) that self-employed individuals contribute to their pensions by promoting financial incentives; (4) that a portion of the new employers' contributions goes to a shared fund which benefits those with lower pension incomes; and (5) reducing gender gaps by equalising the retirement age of men and women, and eliminating the use of gendered mortality rates to calculate individual monthly pensions.

\section{Debate on Extended Working Life in Chile}

In October 2018, President Sebastián Piñera announced a new bill that aims to improve the living standards of current and prospective retirees, which is now being discussed in Congress. Among other measures, this new bill proposes to provide moderate financial incentives from the state for those who extend their working life beyond statutory retirement age. However, what this bill project also aims, beyond providing incentives, is for individuals to have longer occupational careers and therefore to postpone retirement, for them to access a salary for a longer life period (a salary often higher than a pension income), as well as to increase the accumulated fund of pension savings.

This is the very first time a bill aiming to foster extended working life is proposed in Chile. It is a policy measure that stresses individual accountability for dealing with poverty risks in old age. Yet, this policy focus strongly differs from the viewpoint of some members of the Advisory Committee on pensions, union leaders, members of 
non-governmental organisations, and academic scholars, who have instead claimed for responsibly increasing welfare and public benefits to prevent and eliminate high poverty ratios among men and women in old age. They have specifically claimed that these welfare and public benefits are especially relevant in the frame of the IRA pension system in Chile, which mainly relies in contributory programs, and non-contributory gains for individual pension accounts are very scarce. These public benefits are even more relevant if we consider that, according to a recent Chilean study on pension contributions histories (Madero-Cabib et al. 2019b), only about half of people currently aged 65 contributed continuously to a pension fund during their thirties, forties and fifties; while the rest of people from this cohort either did not contribute (e.g. people working in the informal sector), or they remained permanently inactive (mostly women focused on care and domestic tasks at the expense of labour market participation). Therefore, the new bill corresponds to a policy measure with a very specific focus: it aims to ameliorate poverty in old age not by increasing welfare state benefits, but primarily by individualising the responsibility of keeping a decent living status after the retirement transition.

Furthermore, specialised literature in Chile points out that the reflection on the extension of labour-force trajectories should consider not only the financial benefits of later retirement, but other occupational aspects such as the possibility of working fewer hours per week, working conditions that protect individuals' physical integrity, accessible public transport, as well as reduced transport costs for older workers (Madero-Cabib et al. 2019c). On the other hand, it is of utmost importance to reflect on the differentiated impact of these policy measures between men and women who, especially in Chile, have very different labour-force trajectories during adulthood, with women often being in longer periods of inactivity (Madero-Cabib et al. 2019b). Finally, a crucial assumption of these policy measures is that most older workers will be healthy enough to remain active in the labour market until later ages, which is why it is essential to consider the advantages and disadvantages for health fostered by these public policies (Azar et al. 2019; Baumann and Madero-Cabib In Press; Madero-Cabib et al. In Press).

\section{Voluntary Contributions to Pension Funds}

The Chilean pension system provides the option for workers who want to match the AFP contributions, to voluntarily contribute towards a supplementary private pension fund. This fund in Chile is known as Aporte Previsional Voluntario (APV) and is administered exclusively by private bureaus. To make APVs financially attractive, the state offers economic incentives to individuals who contribute to them, notably the reduction of some taxes. The 2008 pension reform introduced an additional voluntary pension fund that works similarly to APVs, but also requires the employer to contribute to the employee's fund, known as APVC (or Collective APV). If employers contribute, their contributions are excluded from corporate taxes. However, in spite of tax exemptions and benefits, the overall coverage of these two plans (APV 
and APVC) is still very low, in 2014 only $0.2 \%$ of contributors had an APV and an even smaller fraction had an APVC (CAPSP 2015). Therefore, one proposal of the Advisory Committee for the 2015 pension reform was to increase the number of employers contributing to the APVC.

Voluntariness can also be analysed in the regular contributions to the AFP. This is because monthly pension contributions into private accounts are only mandatory for employees, but not for self-employed individuals. Chile is one of the few countries in the OECD (along with Australia, Denmark, Mexico, and Switzerland) in which self-employed workers are excluded from pension coverage. In Chile, only $6 \%$ of selfemployed workers contribute to their pension funds. However, pension contributions by the self-employed will be mandatory from 2019 onwards.

\section{Health Dimension of the Ageing Context in Chile}

As already mentioned, a main assumption of extending working lives is that the vast majority of older individuals will have adequate health status in order to keep active in the labour market until later ages (Madero-Cabib et al. 2019d). In this section, we discuss some of the most crucial health issues among current older people in Chile.

\section{Disability in Old Age}

Disability in older adults has been extensively addressed in Chile. One example of this is the National Study of Disability conducted twice by the Ministry of Social Development with two main aims: (1) to provide a detailed analysis of the living conditions of the disabled population, and (2) to find the most appropriate way of addressing disability issues through public policies. Results of the latest version of this study (2016) indicate, firstly, that $38.3 \%$ of the older adult population $(30.3 \%$ of men, and $44.3 \%$ of women) report having a partial $(20.8 \%)$ or severe disability $(11.6 \%)$. Secondly, only $16.5 \%$ of older disabled people remain active in the labour market (compared to $40.6 \%$ of older non-disabled people). Thirdly, older disabled individuals who continue working earn an average salary of about $€ 334$, compared to approximately $€ 500$ for older non-disabled people. Finally, $51 \%$ of older disabled people report being dependent, $62.8 \%$ report a long-term health condition, and $73.9 \%$ of dependent and disabled older people are cared for by informal caregivers (mainly unpaid women). 


\section{Disability Insurance}

The Chilean Pension System includes a Survival and Disability Insurance (or SIS Insurance). After the 1981 pension reform, every worker had to contribute not only $10 \%$ of their salary for pension savings but an additional percentage to SIS insurance. The 2008 pension reform introduced three crucial changes to this benefit. First, the SIS insurance contribution had to be paid exclusively by employers. Second, the disabled worker receives a SIS insurance pay out rate equal to 50 or $70 \%$ (depending on the degree of disability) of his/her average income during the 10 years before becoming disabled. To be eligible, a disabled individual has to prove his/her disability to a Medical Board of the Pension Regulator and be under 65. Finally, the 2008 pension reform introduced a Solidarity Disability Insurance targeting the poorest $60 \%$ of the population.

\section{Dependency, Dementia and Caring in Old Age}

A recent study analysed the risk factors of dependency in older Chilean adults (Cheix et al. 2015). The authors identified that besides the well-documented negative effect of ageing, there are some psychosocial factors, such as a higher educational level, close and consistent contact with family, and activities such as reading or exercise, that delay the onset of dependency in old age. This research also focused on the caring of older dependent workers, which is often informally provided by female family members. The authors mention that caring for older dependent adults can have negative effects both on the subjective wellbeing (causing stress, depression and physical fatigue) and the financial wellbeing (no work income and interruptions in pension contributions) of caregivers. The research concludes by calling for a more active role of the state in the provision of universal caregiving for dependent older people.

Further studies on health issues in old age indicate that dependency is much more prevalent among low socioeconomic groups (i.e. poorest and less educated people) (Fuentes-García et al. 2013) and that dementia (experienced by $7 \%$ of individuals aged 60+ in Chile) is a major determinant of dependency (Thumala et al. 2017). The latter study also underlines that despite the impact of dementia on older people's lives, this condition is not classified as one of the key diseases which are financially supported by the state, and is therefore not prioritised in health services.

Another recent study evaluated the economic costs of dementia in Chile (Hojman et al. 2017). Using primary data researchers identified three main dimensions of total economic costs associated with dementia: (1) direct medical costs, (2) direct social costs, and (3) indirect costs (i.e. those costs related to informal caregiving). Contrary to what occurs in developed countries, indirect costs in Chile represent $75 \%$ of total costs, and it is inversely related to socioeconomic status; in poorer households in which low incomes do not allow people to afford formal care, family members have 
no choice but to assume the caregiver role. And, once again, women have the biggest burden of informal caregiving. The authors emphasise, therefore, that socioeconomic status and gender are key factors related to the cost of dementia.

\section{Cultural Dimension of the Ageing Context in Chile}

\section{Attitudes and Opinions on Retirement and the Pension System}

Another task performed by the Advisory Committee on the 2015 pension reform was to develop a survey that examined attitudes and opinions towards the pension system and retirement. One of the survey questions (a multiple-choice question) referred to the way in which respondents planned to finance their lives after retirement. Most of them answered 'through private pension accounts in AFPs' (55\%), followed by 'through personal savings' (35\%), and 'through state subsidies' (22\%), while $15 \%$ of respondents answered 'they have not thought about it yet'. Another question asked pensioners whether they would be willing to work five years beyond the retirement age to increase their pension savings. Only $29 \%$ of individuals were in favour, while $48 \%$ were against. Finally, $71 \%$ of retirees declared that their pension income is not sufficient to cover their everyday needs (CAPSP 2015).

Another study highlights that most people aged 65+ negatively evaluate the performance of the current pension system in Chile (Browne and Valdes 2017). However, workers aged 25-60 have a slightly more critical view of the pension institution than retirees did. For instance, whereas $55 \%$ of retirees state that their economic status declined after retirement, 58\% of workers aged 25-60 believe that after retirement their economic status will decline. Additionally, $13 \%$ of retirees state that economic status increased after retirement and only $8 \%$ of workers aged $25-60$ expect it to increase after retiring.

\section{Age Discrimination Against Older People}

According to some studies in Chile, negative stereotypes towards older people (or ageism) are related to the perceived deterioration of their cognitive, biological and social performance (Abusleme and Guajardo 2013; Thumala et al. 2017). In total, $72.9 \%$ of Chileans think that older adults are not able to manage on their own (Thumala et al. 2015); although this kind of ageism exists mostly among higher educated young people (Arnold et al. 2008). Another study that examined ageist stereotypes, specifically within work organisations, found that negative expectations of older workers are often associated with a decrease in their cognitive and physical skills, which in turn impacts their labour performance (Nazar and Figueroa 2015). The authors of this research claim that in Chile there are still few measures to prevent 
ageism, not only within work organisations but in society as a whole. In other words, as it currently occurs with racism, classism and sexism, ageism should also be seriously considered as an expression of discrimination against a vulnerable social group (Butler 2005; Thumala et al. 2017).

\section{Conclusion: Towards a Lifecourse Framework to Better Understand Ageing Contexts}

The substantial increase in life expectancy has led an increasing number of Chilean scholars and policymakers to devote more attention to economic, health, and cultural dynamics during the last stage of life. In this chapter, these dynamics have been discussed in light of gender differences. We would like to reflect on some ideas that we must consider when elaborating on measures that promote economic, health, and cultural inclusion of older men and women.

We suggest that policy measures that seek to foster economic and physical wellbeing in old age should not exclusively focus on promoting extended labour force participation in old age, but also to consider other life experiences and previous stages of lifecourse. This perspective-which in international literature is known as 'lifecourse sensitive policy approach' (Leisering, 2003; Madero-Cabib and Fasang, 2016 - indicates that adequate social and individual conditions in old age rely on multiple experiences across the lifecourse such as: (1) the transition to the labour market once compulsory education is finished in early adulthood; (2) risk prevention policies as well as the promotion of healthy lifestyles in workplaces across the whole occupational trajectory; (3) adequate possibilities of balancing family and work life in middle adulthood; (4) public transport and mobilisation policies in cities and towns designed with older adults in mind; (5) the presence of strict anti-age discrimination policies.

In other words, policy measures that seek to promote economic, health, and cultural inclusion among older women and men should consider that wellbeing in old age is neither a phenomenon exclusively associated with work, nor is it only dependent on what occurs in old age. Instead, this is a process that depends on experiences in other dimensions of life such as family, education, transportation, diet, cultural values, sports, health, and work, which are confronted by people from infancy to old age, through early, middle and late adulthood. We hope that the discussion held in this chapter about the ageing context in Chile will contribute to a better and more informed reflection on the development of wellbeing in old age and of extended working life policies in this country.

Acknowledgements This work was supported by CONICYT/FONDECYT/INICIACION/N 11180360, CONICYT/FONDAP/Nº15130009, CONICYT/FONDECYT/REGULAR/ ${ }^{\circ} 1171071$, and Millenium Science Initiative of the Ministry of Economy Development and Tourism, Chile, Grant "Millenium Nucleus for the Study of the Life Course and Vulnerability (MLIV)". 


\section{References}

Abusleme, M., \& Guajardo, G. (2013). El maltrato hacia las personas mayores en la Región Metropolitana, Chile. Santiago, Chile: SENAMA-Universidad de Chile.

Arenas de Mesa, A., Bravo, D., Behrman, J. R., Mitchell, O. S., \& Todd, P. E. (2006). The Chilean pension reform turns 25: lessons from the social protection survey. National Bureau of Economic Research.

Arnold, M., Thumala, D., Urquiza, A., \& Ojeda, A. (2008). Young people's images of old age in Chile: Exploratory research. Educational Gerontology, 34(2), 105-123.

Azar, A., Staudinger, U., Slachevsky, A., Madero-Cabib, I., \& Calvo, E. (2019). From snapshots to movies: The association between retirement sequences and aging trajectories in limitations to perform activities of daily living. Journal of Aging and Health, 31(2), 293-321.

Barr, N., \& Diamond, P. (2016). Reforming Pensions in Chile. Polityka Spoteczna, 1(12), 4-9.

Baumann, I., \& Madero-Cabib, I. (In Press). Retirement trajectories in countries with flexible retirement policies but different welfare state regimes. Journal of Aging and Social Policy.

Bravo, D., \& Hughes, E. (2018). Encuesta Calidad de Vida del Adulto Mayor e Impacto del Pilar Solidario. Santiago, Chile: Centro UC Encuestas y Estudios Longitudinales.

Browne, M., \& Valdes, S. (2017). De la decepción de los pensionados al temor de los ocupados. Santiago, Chile: Centro CLAPES UC.

Butler, R. (2005). Ageism: Looking back over my shoulder. Generations, 29(3), 84-86.

CASEN. (2015). Adultos Mayores (Síntesis de Resultados). Santiago, Chile: Ministerio de Desarrollo Social.

Centro UC Políticas Públicas. (2017). Adultos Mayores: un activo para Chile. Santiago, Chile: Pontificia Universidad Católica de Chile.

CEVE UC. (2018). Trabajo y personas mayores en Chile: Lineamientos para una política de inclusión laboural. Santiago, Chile: Pontificia Universidad Católica de Chile.

Cheix, M. C., Herrera Ponce, M. S., Fernandez Lorca, M. B., \& Barros Lezaeta, C. (2015). Risk factors of dependency of Chilean older adults and consequences on informal caregiving. América Latina Hoy, 71, 17-36.

CAPSP [Comisión Asesora Presidencial sobre el Sistema de Pensiones]. (2015). Informe final. Santiago, Chile: Gobierno de Chile.

Cumsille, B. (2015). The chilean pension system: Gender inequalities in contribution densities. Doctoral Dissertation. University of Texas, Austin.

Fuentes-García, A., Sánchez, H., Lera, L., Cea, X., \& Albala, C. (2013). Socioeconomic inequalities in the onset and progression of disability in a cohort of older people in Santiago, Chile. Gaceta Sanitaria, 27(3), 226-232.

Hojman, D. A., Duarte, F., Ruiz-Tagle, J., Budnich, M., Delgado, C., \& Slachevsky, A. (2017). The cost of dementia in an unequal country: The case of Chile. PloS One, 12(3).

Huenchuan, S., González Ollino, D., Paredes, M., \& Guzmán, J. M. (2007). Protección y participación en la vejez: escenarios futuros y políticas públicas para enfrentar el envejecimiento en Chile. Santiago, Chile: CEPAL.

Leisering, L. (2003). Government and the life course. In J. Mortimer \& M. Shanahan (Eds.), Handbook of the life course (pp. 205-225). New York: Kluwer Academic.

Madero-Cabib, I., \& Fasang, A. (2016). Gendered work-family life courses and financial well-being in retirement. Advances in Life Course Research, 27, 43-60.

Madero-Cabib, I., Undurraga, R., \& Valenzuela, C. (2019a). How have women's employment patterns during young adulthood changed in Chile? A cohort study. Longitudinal and Life Course Studies, 10(3), 375-397.

Madero-Cabib, I., Biehl, A., Sehnbruch, K., Calvo, E., \& Bertranou, F. (2019b). Pension regimes built on precarious foundations: Lessons from a longitudinal study of pension contributions and labor-force trajectories in Chile. Research on Aging, 41(10), 961-987. 
Madero-Cabib, I., Palomo, R., \& Jofré, M.-S. (2019c). Incrementar la edad legal de jubilación y extender la trayectoria laboral? Apuntes para la discusión sobre empleo en personas mayores en Chile. Revista Latinoamericana de Derecho Social, 29, 145-175. http://bit.ly/2krkaqU.

Madero-Cabib, I., Azar, A., \& Pérez-Cruz, P. (2019d). The influence of cumulative advantages and disadvantages on health inequalities among older women in Chile. International Journal of Public Health, 64(8), 1203-1214.

Madero-Cabib, I., Corna, L., \& Baumann, I. (In Press). Aging in different welfare contexts: A comparative perspective on later-life employment and health. The Journals of Gerontology: Series B.

Mesa-Lago, C. (2015). Reformas estructurales y Re-reformas de pensiones, y sus efectos en el bienestar social: El caso de Chile. Política Y Sociedad, 52(3), 719-739.

Nazar, G., \& Figueroa, C. A. (2015). Creencias estereotípicas sobre el desempeño laboural de trabajadores mayores en Chile. Psicoperspectivas, 14(1), 114-125.

OECD. (2013). Pensions at a glance 2013: OECD and G20 indicators. Paris: OECD Publishing.

OECD. (2015). Pensions at a glance 2015: OECD and G20 indicators. Paris: OECD Publishing.

OECD. (2017). Labour force participation rate (indicator). Retrieved Mars 11, 2019 from https:// data.oecd.org/emp/labour-force-participation-rate.htm.

Programa Adulto Mayor UC. (2013). Chile y sus mayores. Resultados Tercera Encuesta Nacional Calidad de Vida en la Vejez. Santiago, Chile: Pontificia Universidad Católica de Chile y Caja Los Andes.

Thumala, D., Arnold, M., Massad, C., \& Herrera, F. (2015). Inclusión y Exclusión social de las personas mayores en Chile (Ediciones Servicio Nacional del Adulto Mayor). Santiago, Chile: SENAMA-FACSO Universidad de Chile.

Thumala, D., Kennedy, B. K., Calvo, E., Gonzalez-Billault, C., Zitko, P., Lillo, P., et al. (2017). Aging and health policies in Chile: New agendas for research. Health Systems \& Reform, 3(4), 253-260.

Todd, P., \& Joubert, C. (2011). How the design of a pension system influences old age poverty and gender equity: A study of Chile's private retirement accounts system. Working Paper. Retrieved March 11, 2019 from http://www.unc.edu/ joubertc/Draft_GenderPension.pdf.

Vives, A., Molina, A., Gray, N., \& González, F. (2017). Envejecimiento y trabajo en Chile: propuesta para el monitoreo de la salud laboural. In I. Irarrázaval, E. Piña, \& M. Letelier (Eds.), Propuestas para Chile. Concurso Políticas Públicas 2016 (pp. 17-49). Santiago, Chile: Salesianos Impresores.

Open Access This chapter is licensed under the terms of the Creative Commons Attribution 4.0 International License (http://creativecommons.org/licenses/by/4.0/), which permits use, sharing, adaptation, distribution and reproduction in any medium or format, as long as you give appropriate credit to the original author(s) and the source, provide a link to the Creative Commons license and indicate if changes were made.

The images or other third party material in this chapter are included in the chapter's Creative Commons license, unless indicated otherwise in a credit line to the material. If material is not included in the chapter's Creative Commons license and your intended use is not permitted by statutory regulation or exceeds the permitted use, you will need to obtain permission directly from the copyright holder.

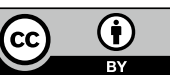




\title{
Chapter 13 \\ Croatia
}

\section{Siniša Zrinščak, Maja Vehovec and Drago Čengić}

\begin{abstract}
The chapter gives an overview of the Croatian socio-economic situation and pension, employment and health policies. Lower levels of employment in general, and particularly for older workers is one of the main features of the socioeconomic situation. Early retirement is common and the active ageing paradigm is neither discussed nor implemented. In the Croatian context, limited research exists around workplace issues such as caring, health and pension inequalities. The pension system is a mixed system, based on three pillars and characterised by a very unfavourable dependency ratio. This system undergoes constant changes which are in many cases contradictory, particularly in relation to the penalisation of early retirement and the equalisation of pensionable age for men and women. Employment policies have undergone many changes in recent years, mostly related to a move towards more flexible working arrangements. In summary, the gender and health aspects of extending working life still need to be publicly discussed and researched.
\end{abstract}

Keywords Pension $\cdot$ Employment $\cdot$ Gender $\cdot$ Older workers $\cdot$ Croatia

\section{Introductory Notes: Socio-Economic Situation, Retirement Practices, and Older Workers}

Croatia has very low labour participation among the older population. According to Eurostat data the employment rate of older workers (55-64) in Croatia was $42.8 \%$ in 2018 compared with the EU average of $58.7 \%$ (Eurostat 2019). While the average for the EU rose from $45.8 \%$ in 2009 , the Croatian figures increased more slowly from $39.4 \%$. This difference is not only the result of a very low employment rate

\author{
S. Zrinščak $(\bowtie)$ \\ Faculty of Law, University of Zagreb, Trg R. Hrvatske 3, 10000 Zagreb, Croatia \\ e-mail: sinisa.zrinscak@pravo.hr \\ M. Vehovec \\ Institute of Economics, Zagreb, Croatia \\ D. Čngić \\ Institute of Social Sciences Ivo Pilar, Zagreb, Croatia \\ (C) The Author(s) 2020 \\ Á. Ní Léime et al. (eds.), Extended Working Life Policies, \\ https://doi.org/10.1007/978-3-030-40985-2_13
}


in general, but has also been encouraged by policies which informally encourage early retirement (despite official rhetoric). In 2018, the unemployment rate was $8.4 \%$ compared to 6.8 for the EU28 (Eurostat 2019). While this represented a fall from $17.4 \%$ in 2013 , this change has been mainly attributed to high levels of emigration particularly since Croatia joined the EU in 2013, rather than increased employment.

Croatia, along with Italy, are among EU countries with the lowest number of total years in employment. The duration of working life was only 32.4 years in 2018 (Eurostat 2019). There are also gender differences as the average working life for women was 3.7 years shorter than for men.

Bađun (2011) reported that Croatia has 12,000 per 100,000 beneficiaries of invalidity pensions, the highest number in Europe. This number includes former soldiers from 'Homeland War' between 1991 and 1995. Individuals receiving invalidity pensions are generally young ( $43 \%$ are under 59 years of age), and on average they enter the pension system at 52.6 years old. In recent years there has been increased interest in the field of validity particularly relating to invalidity pensions and other disability benefits (Stubbs and Zrinščak 2015).

The widespread use of early retirement as a policy option is reflected in population attitudes. Research has shown that more than $40 \%$ of employed people want early retirement (men slightly more than women). Just under $40 \%$ fear that their health might influence their work ability before the legally prescribed age of retirement. Desire for early retirement more prevalent among people with lower levels of education (57\% with primary education or no primary education, $47 \%$ with secondary education and $29 \%$ with college or university degree). People with poorer health also report high desire for early retirement. $60 \%$ of men expect to be retired by 65 years old and only $6 \%$ expect to retire after 65 . The proportion of women who want to retire at 65 and at 60 is similar (36-37\% respectively). Comparable to men, only $6 \%$ of women expect to be retire after 65 (Akrap et al. 2013).

The paradigm of active ageing in Croatia is present in debates among experts on how to deal with the 'third age population' and it has been periodically mentioned in EC/EU reports on the working life (e.g. European Commission 2012; Kaliterna et al. 2014; Bejaković 2015). However, issues such as training, part-time work, or reducing hours for older workers have not been systematically explored.

So far, researchers in Croatia have not analysed the EWCS (European Working Condition Survey) database. One study explored the quality of working life among employees aged 50+ comparing Croatia with other EU countries (Galić et al. 2019). With the exception of medical research, systematic research on ageing is limited. The concept of active ageing is touched upon very superficially, mainly by pointing out the need to focus on it (Zrinščak 2010, 2012; Spajić-Vrkaš et al. 2013; Obadić 2018). Research on age management is a rare (Pološki-Vokić and Grgurić 2011), as is age discrimination, which is studied mainly from a legal point of view (Grgurev 2011; Zekić Eberhard 2014; Bodiroga-Vukobrat and Martinović 2011). Recent research based on SHARE data will provide new analyses (Strmota 2017). Thus, there is an urgent need to have more research on topics related to ageing and late work employment. 
There is only one pioneering study of employers' attitudes toward older workers (Vehovec 2008). Employers from Croatia and Slovenia agree that older employers perform better than their younger counterparts in relation to willingness to work hard, reliability, attentiveness, professionalism, decision making competence, loyalty and honesty and integrity.

\section{Research Insights: Notes on Caring, Health and Pension System}

There is little research on caring in Croatia and the studies which are available mainly explore work-life balance, i.e. how work influences domestic obligations, particularly caring for children and other dependant family members. Research suggests that work characteristics, (primarily work hours, experience of work and perception of job safety) impact on work-family conflict. Family factors also influence work-family conflict, the most important factor influencing work-family conflict is care for older and disabled people (Dobrotić and Laklija 2009). Research on caring for older people is scarce, existing studies are mainly orientated towards policy highlighting that the majority of care is provided by family and elder care is performed by family and other non-formal organisations, whereas formal care is underdeveloped and even ignored by the authorities (Rusac et al. 2011; Bađun 2015; Dobrotić 2016).

Health in the work place is an interdisciplinary topic. The majority of research papers have focused on health from a medical point of view, however one paper has taken an economic perspective (Bađun 2017). Bađun (2017) reported difficulty in comparing the costs of occupational injuries and illnesses in Croatia with costs in other countries, mainly due to variation in components included and methods applied. As the financial costs of occupational injuries and illnesses are significant, even without including the costs to workers, the authors' recommendation was to put additional efforts into prevention. In addition, it is necessary to develop data transparency within the Croatian Health Insurance Fund's expenditures to facilitate clear tracking of costs. It is also recommended that occupational injuries be distinguished from occupational illnesses and that records of accidents at work must be the same in all official sources.

There are some studies on pension inequalities due to special pension rules applied to some categories of pensioners (Bađun 2009; Vukorepa 2017). Bađun reviewed all retirees who were granted pensions under favourable conditions and Vukorepa analysed workers in arduous and hazardous jobs. The scope of such jobs or the actual level of their arduousness and hazardousness has changed over time due to technological advancements and the development of health and safety measures. 


\section{Notes on Policy Issues}

\section{Pension Policies}

The pension system in Croatia is a mixed system, based on three pillars (Stubbs et al. 2018). The first one is a pay-as-you-go (PAYG) system financed by obligatory contributions paid by employees and managed by the Croatian Pension Insurance Institute. The second and third pillars are fully funded contribution schemes, while the second one is obligatory and the third one voluntary. The mixed system was introduced in 2002, replacing the old system exclusively based on the PAYG scheme. Despite some state incentives, the third voluntary pillar has remained underdeveloped, there were only 359,098 people included at the end of 2019.

There are several critical issues connected with the pension system. The pension system is characterised by a very unfavourable dependency ratio that was $82 \%$ or 1.21 contributors for every pensioner at the end of 2018 (CBS 2019a). Also, early retirement has been widespread as the average contribution is 30 years, while only $20 \%$ of pensioners have 40 or more qualifying years in 2018 (Ministry of Labour and Pension System 2018). This is reflected in the financial instability of the system and the fact that it does not provide basic security in old age. The average pension equals to $41.78 \%$ of average salary, while the EU average is $58 \%$. The at-risk-ofpoverty rate was $19.3 \%$ in 2018 , but $28.1 \%$ for men aged 65 and above, and $31.3 \%$ for women in the same age group. For one-person households 65 years and over the at-risk-of-poverty was $48.1 \%$ in 2018 (CBS 2019b). Expenditure for all types of pensions amounted to 10.5 per cent of the GDP in 2017, which was a slightly lower than was the EU28 average (11\%), but slightly higher than in many other Central and Eastern European countries.

The problems associated with pension and employment policies are nicely summarised in the Country Report Croatia 2016 (European Commission 2016) which indicated that low activity rates are mainly the result of early retirement for men, while for women family care responsibilities also play a major role. Early retirement mostly concerns men, and the impact can be seen by the fact that more than half of inactivity in the age group 40 to 44 years is due to early retirement. For women, retirement is the predominant reason not to work in the 55 to 59 age groups. It should be stressed that with $12 \%$ of the working age population in some form of retirement, Croatia tops the EU ranking.

The instability of the pension system is a result of a number of partial and contradictory reforms, which have made the system opaque and confusing: for example, currently there are 18 different laws that relate to the pension system. This can be illustrated with attempts to prolong working age before retirement. In 2011 an incentive to work longer was introduced, through addition of $0.15 \%$ for each month of later retirement. On the other hand, penalties for early retirement were reduced from 0.34 to $0.15 \%$ in 2007 (the election year), which meant that the pensions from early retirement were only nine \% lower than pensions at the statutory pension age, in comparison with $20.4 \%$ difference prior to the reform. In 2011 the size of the 
penalty was changed in relation to the number of contribution years. In 2014 policy changed again and the penalty varies again from six to $20.4 \%$, however those who have 60 years and who have at least 41 years of contributions can receive a full pension, without penalties. Early retirement penalties were also abandoned for those individuals unemployed for at least two years as a result of the bankruptcy of their employers. There are few incentives for people to work longer as many laws in the public sector do not allow individuals (with a few exceptions) to work after the age of 65. Income tax also favours retirement as an option over working.

In December 2018, the Parliament adopted a set of new pension legislation, entered into force in January 1st, 2019. One of the main aims was to promote gender equalisation by standardisation of the pensionable age for both men and women ( 65 in 2027 and 67 in 2031). Some dispensation measures are also envisaged for early retirement as well to allow some groups of pensioners to work once retired without a reduced pension. There have been fierce debates on the proposed measures over the application of a different pension formula for pensioners who were covered only by the first (PAYG) pillar and those who were in the first (PAYG) and second (fully funded) pillar and which would result in a lower pension for the second category. These debates ended with the Parliament's decision to retain a pension model with two pillars, and with adoption of the pension formula, which would not penalise people who pay mandatory benefits to the first and second pillars with a lower pension. However, the opposition to the rise of pensionable age and to gender equalisation was quite strong. Trade unions organized the collection of citizens' signatures for holding of national referendum for cancellation of adopted changes. As the campaign was successful and trade unions collected much more than needed $10 \%$ of voters' signatures, the Government gave up and the Parliament again changed the law, by which the pensionable age was again set to 65 , and the gender equalisation will happen only in 2030 .

\section{Employment Policies}

Regarding specific employment policies covering measures such as flexible employment, training and the creation of good working conditions for older workers, Croatia does not have any well-designed policy to effectively address these domains.

Recently, flexible employment has been promoted by politicians as one of the milestones of the future employment and labour market policies. Given that Croatia has one of the strictest sets of employment protection regulations (World Bank 2011; Matković 2013; Račić 2013; Kunovac 2014), there was an absence of flexible employment in the Croatian labour market prior to the new Labour Act.

After a long and intense public debate, the Labour Act was adopted by the Croatian Parliament on 15 July 2014, with the aim to increase the number of people employed, to create a legal framework that enables employers to develop more flexible business models and to adapt to market demands, while maintaining employee protection and combating the grey economy. The main amendments were greater 
flexibility in working hours; easier cancellation of employment contracts in certain cases; encouragement of atypical forms of employment.

In parallel with the new legislation, there has been a rise in the number of various part-time and precarious jobs in Croatia, especially among young and first-time workers. According to Butković's and Samardžija's study (2016), the introduced changes primarily targeted non-standard types of employment, which contributed to a further segmentation of the Croatian labour market, widening the gap between well protected workers on standard contracts and other workers who increasingly face uncertainty. According to the new empirical research, the majority of employed have an open-ended contract (71\%) and one fifth have a fixed-term contract (21\%). "This is very similar to the Labour Force Survey Results for 2017 which recorded $68 \%$ of workers with open-end contracts and $21 \%$ with fixed-term contracts (Butković and Samardžija 2019). Some other studies have also documented different non-standard forms of employment, such as temporary, seasonal, self-employment etc. (Vukorepa et al. 2017; Murati 2016; Novaković 2016). However, besides new forms of fixedterm work, it seems that other forms of non-standard or precarious work are generally less wide-spread than in most other EU member states. Statistical data and available analyses on this topic seem to be insufficient.

Buković and Matković have explored trends and challenges regarding vocational education and training (VET) in Croatia (Buković and Matković 2018). Their findings point towards several strengths of the Croatian VET system: support for investment, high level of ownership among VET participants and graduates, widespread (if not extensive) experience of workplace training, as well as perception of relevance and quality that is not deviating from the EU average. However, VET in Croatia is hardly seen by citizens as an attractive or prestigious choice, and is perceived as lacking in terms of social inclusion and mobility. "Results also indicate strong selectivity and social stratification between general education and VET tracks. The fact that such views are shared by many who experienced Croatian VET system makes the matter even more salient. This is an issue worth addressing, via inclusion/mobility policies, but those need more sound evidence base" (Buković and Matković 2018).

Women in the labour market are protected in relation to pregnancy and motherhood. There is a statutory maternity leave starting from 28 days before the expected due date and lasting up to 70 days after birth. After that, parental leave is possible, for duration of 8 months, or to a maximum of 30 months for twins and for the third or subsequent child. However, women are frequently discriminated in relation to their pregnancy or caring needs. Although this is illegal, employers tend to question women about their intention of having children or they do not renew the contract if a woman becomes pregnant (Galić and Nikodem 2009).

\section{Health Policies}

As stated above, Croatia has a very high number of invalidity pensions, mainly due to the Homeland war in the 1990s. There are two categories of invalidity pensions within 
the first pillar system - for non-occupational and occupational risks-covering longterm benefits for those facing permanent loss of work capacity, whether total or partial (Stubbs et al. 2018). Entitlement to an invalidity pension requires fulfilment of the following conditions: partial or total disability and completion of the necessary qualifying period. There has been a change in the law, and from 2014 disability is assessed based on residual work capacity, involving reassessment every three years. There is also the possibility of random check-ups.

Pensioners receiving invalidity pensions (including war veterans) made up approximately $25 \%$ of the total number of pensioners (Stubbs et al. 2018). There has been a fall in the number of invalidity pensioners since 2015 which is a result of an administrative measure introduced in January 2015, whereby all 'total invalidity pensions' are to be converted to old-age pensions for all those beneficiaries reaching the age required for an old-age pension.

The Croatian health system is fiscally unsustainable. For many years, it has accumulated debts and almost every year there are partial health reforms which, unfortunately, have not yet resulted in a sustainable system. Comprehensive reforms are not yet on the horizon and if ever they occur, it is possible that they could be revoked under different political mandates.

\section{Debate on Extended Working Life}

As described above the opposition to extension of the working life is quite strong, and public debates do not touch any positive aspect of extension of working life. The main argument against rising of pensionable age is that the life expectancy in Croatia is lower than in the EU: for women it is 2.5 years lower, and for men it is 4.3 lower. The same argument is put against the gender equalisation. The idea to introduce a possibility to work after 65 (which at the moment is mandatory pensionable age in public sector) has been also put on hold and not included in the most recent legislation change.

\section{Conclusion}

This chapter has shown that although some data and research exist, in Croatia there is a large gap in terms of data, research and policies which address issues such as the working life of older population, active ageing, and the gender and health implications of extended working life, and the pension system. In parallel with the process of postcommunist transformation and in particular with the process of 'Europeanisation', concepts of active aging, gender equality, quality of the working life and extended working life have entered the Croatian social and political milieu, but they have so far not resulted in any clear and effective policies. It is hard to predict if, how, and 
when this can be changed in the future but an important step in this direction is to provide more data and research, in turn stimulating public debates on these issues.

\section{References}

Akrap, A., Barić, N., Gelo, J., Čipin, I., Smolić, Š., \& Strmota, M. (2013). The economics of ageing in Croatia. Research Results and Findings. Zagreb: The Faculty of Economics.

Bađun, M. (2009). Pension beneficiaries who have been granted pensions under more favourable conditions. Institute for Public Finance Newsletter, 44, 1-10.

Bađun, M. (2011). Why are there so many disability pensions beneficiaries in Croatia? Institute for Public Finance Newsletter, 56, 1-8.

Bađun, M. (2015). Non-formal long-term care for old and infirm persons. Institute for Public Finance Newsletter, 100, 1-9.

Bađun, M. (2017). Costs of occupational injuries and illnesses in Croatia. Archive of Industrial Hygiene and Toxicology, 68, 66-73. https://doi.org/10.1515/aiht-2017-68-2899.

Bejaković, P. (2015). Croatia: Working life country profile. Eurofound. Retrieved November 25, 2018 from https://www.eurofound.europa.eu/observatories/eurwork/comparative-information/ national-contributions/croatia/croatia-working-life-country-profile.

Bodiroga-Vukobrat, N., \& Martinović, A. (2011). The prohibition of age discrimination in labour relations: Report on Croatia. In M. Schlacher (Ed.), The prohibition of age discrimination in labour relations: Reports to the XVIIIth international congress of comparative law (pp. 261-273). Baden-Baden: Nomos.

Buković, N., \& Matković, T. (2018). Cedefop opinion survey on vocational education and training in Europe: Croatia. Cedefop ReferNet thematic perspectives series. Retrieved January 5, 2020 from http://libserver.cedefop.europa.eu/vetelib/2018/opinion_survey_VET_Croatia_ Cedefop_ReferNet.pdf.

Butković, H., \& Samardžija, V. (Eds.). (2016). Nonstandard work in Croatia: Challenges and perspectives in selected sectors. Zagreb: IRMO-Institute for Development and International Relations.

Butković, H., \& Samardžija, V. (2019). The digital transformation of the labour market in Croatia. Zagreb: IRMO-Institute for Development and International Relations.

CBS-Croatian Bureau of Statistics. (2019a). Statistical information 2019. Retrieved December 30, 2019 from https://www.dzs.hr/.

CBS-Croatian Bureau of Statistics. (2019b). Indicators of poverty and social exclusion. Retrieved December 30, 2019 from https://www.dzs.hr/.

Dobrotić, I. (2016). Development and difficulties of the eldercare system in Croatia. Društvena istraživanja, 25(1), 21-42.

Dobrotić, I., \& Laklija, M. (2009). Correlates of conflicts between family and work obligations in Croatia. Revija za socijalnu politiku, 16(1), 45-63.

European Commission (2012). Active ageing report. Special Eurobarometer 378. Retrieved December 2, 2018 from https://ec.europa.eu/eip/ageing/library/special-eurobarometer-378active-ageing_en.

European Commission. (2016). Commission staff working document: Country report Croatia 2016. Retrieved December 3, 2018 from http://ec.europa.eu/europe2020/pdf/csr2016/cr2016_croatia_ en.pdf.

Eurostat. (2019). Data-Labour market. Retrieved December 30, 2019 from https://ec.europa.eu/ eurostat/data/database.

Galić, B., \& Nikodem, K. (2009). Perception of gender equality and employment opportunities in Croatian society. The perspective of unemployed women. Revija za socijalnu politiku, 16(3), 253-270. 
Galić, Z., Parmač, Kovačić, M., \& Vehovec, M. (2019). Quality of working life among 50+ employees across the EU: A double jeopardy for Croatian older workers. Društvena istraživanja, 28(1), 69-87.

Grgurev, I. (2011). Age discrimination in employment relationship-Croatian legislation and acquis communautaire analysis. In Z. Leutar (Ed.), Social work and fight against poverty and social exclusion-professional focus on protection and promotion of human rights (pp. 31-48). Zagreb: Zaklada Marija de Mattias.

Kaliterna Lipovčan, L., Babarović, T., Brajša-Žganec, A., Bejaković, P., \& Japec, L. (2014). Trends in quality of life Croatia: 2007-2012. Luxembourg: Publication Office of the European Union.

Kunovac, M. (2014). Employment protection legislation in Croatia. Financial Theory and Practice, $38(2), 139-172$.

Matković, T. (2013). 'Flexicurity' through normalization? Changes in scope, composition and conditions of temporary employment in Croatia. In M. Koch \& M. Fritz (Eds.), Non-standard employment in Europe. Paradigms, prevalence and policy responses (pp. 84-102). Palgrave Macmillan.

Ministry of Labour and Pension System. (2018). Comprehensive Pension Reform. Internal document.

Murati, Z. (2016). New forms of employment on the labour market. Zagreb: Ministarstvo rada i mirovinskog sustava. Retrieved November 30, 2018 from http://www.mrms.hr/wp-content/ uploads/2016/11/5.-Novi-oblici-zapo\%C5\%A1ljavanja-na-tr\%C5\%BEi\%C5\%A1tu-rada-Z.Muratti.pdf.

Novaković, N. (2016). New models of flexible forms of employment. Radno pravo, 13(6), 5-17.

Obadić, A. (2018). Active ageing-education level: Advantage or barrier? In G. Družić \& I. Družić (Eds.), Models of development of Croatian economy (pp. 51-78). Zagreb: HAZU.

Pološki Vokić, N., \& Grgurić, L. (2011). Age management-the development of an effective model for Croatian organizations. Revija za socijalnu politiku, 18(2), 149-174.

Račić, D. (2013). Hard work and soft rights: Croatian workers in the European Union. Retrieved November 29, 2018 from https://bib.irb.hr/datoteka/880354.hw-hw_labour_D._Racic.pdf.

Rusac, S., Štambuk, A., Žganec, N., \& Ajduković, M. (2011). Long-term care for older people in Croatia. In A. Österle (Ed.), Long-term care in Central and South Eastern Europe (pp. 67-81). Frankfurt am Main: Peter Lang.

Spajić-Vrkaš, V., Vrban, I., \& Rusac, S. (2013). The rights of the elderly in the city of Zagreb-a pilot study. Zagreb: Zaklada zajednički.

Strmota, M. (2017). 50+ Population in the role of providers and receivers of informal care in Croatia. Revija za socijalnu politiku, 24(1), 1-18.

Stubbs, P., Vukorepa, I., \& Zrinščak, S. (2018). ESPN country profile. Croatia. 2017-2018. European Commission.

Stubbs, P., \& Zrinščak, S. (2015). Citizenship and social welfare in Croatia: Clientelism and the limits of 'Europeanization'. European Politics and Society, 16(3), 395-410.

Vehovec, M. (Ed.). (2008). New perspective on longer working life in Croatia and Slovenia. Zagreb: Friedrich Ebert Stiftung and The Institute of Economics.

World Bank. (2011). Employment protection legislation and labor market outcomes: Theory, evidence and lessons for Croatia. Retrieved November 28, 2018 from http://siteresources.worldbank. org/INTCROATIA/Resources/Croatia_Policy_Notes-Labor.pdf.

Vukorepa, I., Tomić, I., Stubbs, P. (2017). ESPN thematic report on access to social protection of people working as self-employed or on non-standard contracts. Retrieved November 28, 2018 from http://ec.europa.eu/social/keyDocuments.jsp?advSearchKey=ESPNsensw\& mode $=$ advancedSubmit \&langId $=$ en $\&$ policy Area $=\&$ type $=0 \&$ country $=34 \&$ year $=0$.

Vukorepa, I. (2017). Retirement policy changes for workers in arduous and hazardous jobs: Comparative overview and lessons for Croatia. Zbornik Pravnog fakulteta u Zagrebu, 67(1), $5-28$.

Zekić Eberhard, N. (2014). Age discrimination at Croatian market in the context of social awareness and European legal framework. Pravni vjesnik, 30(2), 329-343. 
Zrinščak, S. (2010). Active ageing and gender equality policies: The employment and social inclusion of women and men of late working and early retirement age. National Report Croatia: EGGSI Network.

Zrinščak, S. (2012). Active ageing, gender equality, and social inclusion. Revija za socijalnu politiku, 19(1), 73-81.

Open Access This chapter is licensed under the terms of the Creative Commons Attribution 4.0 International License (http://creativecommons.org/licenses/by/4.0/), which permits use, sharing, adaptation, distribution and reproduction in any medium or format, as long as you give appropriate credit to the original author(s) and the source, provide a link to the Creative Commons license and indicate if changes were made.

The images or other third party material in this chapter are included in the chapter's Creative Commons license, unless indicated otherwise in a credit line to the material. If material is not included in the chapter's Creative Commons license and your intended use is not permitted by statutory regulation or exceeds the permitted use, you will need to obtain permission directly from the copyright holder.

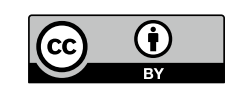




\title{
Chapter 14 \\ Cyprus
}

\section{Petroula M. Mavrikiou}

\begin{abstract}
The demographic challenge of an ageing population and the increasing diversity of working life call for a greater focus and deeper analysis of the opportunities and less favourable consequences of extended working life policies. The 15th principle of The European Pillar of Social Rights (2017) emphasises that everyone in old age has the right to resources that ensure living in dignity. However, currently these rights are not ensured properly, as there are big differences concerning gender, health, and employment among older adults in many countries. This chapter discusses the gender and health implications of the extension of working life in Cyprus.
\end{abstract}

Keywords Extended working life $\cdot$ Reforms $\cdot$ Cyprus pension system $\cdot$ Pension gap $\cdot$ Health $\cdot$ Policies

\section{Introduction}

Extended working life policies have implications for gender and for the health of citizens at European Union and international levels. Since 2014 the retirement age in Cyprus is 65 years for both men and women. Early retirement is penalised with a reduction in the pension for each month until a person reaches the age of 65 , and financed with an additional amount for each month for prolonging working life until the age of 68. In a country where the General Health System is yet to be fully implemented (it is expected in March 2020) there is a huge need to make reforms to improve the working and retirement experiences of Cypriot citizens.

This chapter briefly describes the situation in Cyprus in relation to gender and health implications of policies introduced to extended working lives. It discusses the current patterns on gender and employment in Cyprus, the pension system and pension policies, employment policies to extend working life, policies to reduce the risk of poverty and the health care system. The chapter concludes with some policy recommendations.

\section{P. M. Mavrikiou ( $\square)$}

Department of Business Administration, Frederick University, Nicosia, Cyprus

e-mail: p.mavrikiou@frederick.ac.cy 


\section{Gender and Employment in Cyprus}

Cyprus joined the EU in 2004 and the Eurozone in 2008. In 2015, approximately one third of women were at risk of poverty in Cyprus (European Institute for Gender Equality 2015). Since Cypriot women continue to act as the primary carers of children and dependents, they are more likely than men to work part-time, hold lower paid jobs, have lower social security contributions than men, and usually interrupt their social security contributions during pregnancy (Statistical Service of Cyprus 2012). The gender pay gap which is defined as the difference between the average gross hourly earnings of male and female employees as per cent of men's gross earnings was $16.1 \%$ in 2011, dropping to $13.7 \%$ in 2017 (Eurostat 2018).

The proportion of women working and their characteristics differ significantly between countries, particularly due to the institutions and attitudes governing the balance between private and work life which impact on the careers and thus the pay of women. In Cyprus, even though women overreach men in university degrees, their working patterns lead to a significant gender pay gap. These patterns include horizontal and vertical segregation in employment. Key decision making positions such as management, are dominated by Cypriot men while administrative and support staff positions are dominated by Cypriot women. For example, at European level, Cyprus has one of the smallest shares of women occupying higher positions such as management (21\%) (Eurostat 2018). There is also gender segregation in employment. Professions such as engineering are dominated by men while teaching is dominated by women. In 2012, $70 \%$ of employees working in the education and health sector were women while only $10 \%$ of the employees working in the construction were women; $72 \%$ of the employees working in the transportation and storage industry were men and $67 \%$ of the employees working in other production industries were also men (Statistical Service of Cyprus 2012). Some other factors that partly explain the gender pay gap are: education, type of work (full-time or part-time), rate of employment, marital status and motherhood. For example $15.6 \%$ of women in Cyprus work part-time (compared to $9.1 \%$ of men), and $11.3 \%$ of women (compared to $10.9 \%$ of men) in Cyprus are unemployed (Eurostat 2018).

Cyprus has one of the highest gender employment gaps for older workers among the EU member states. In 2010, the employment rate for men was $61.9 \%$ and $38.1 \%$ for women. Even though in 2017 the total employment rate was similar to that of 2010, the gender gap in employment rates of 2010 which was $23.8 \%$ dropped to 14.8 per cent (Statistical Service of Cyprus 2018). A time series of the last eight years regarding the employment rate for two age groups by gender is shown in Table 14.1.

Unemployment may be an obstacle to extending working life and maintaining quality of life. In Cyprus it is generally accepted by public opinion, and also evident from data, that it is quite difficult for those aged 55-64 to obtain a new full-time job. In recent publications of the Statistical Service of Cyprus of (2018), in 2017 the average rate of unemployment for women aged 55-64 was $2.98 \%$ compared to $7.01 \%$ for men. ${ }^{1}$

\footnotetext{
${ }^{1}$ Author's calculations. Calculations have as a base the total number of unemployed persons.
} 
Table 14.1 Employment by age between 2010-2017 for older men and women in Cyprus

\begin{tabular}{l|l|l|l|l|l|l}
\hline \multicolumn{6}{l}{ Age group } \\
\hline & $55-64$ & \multicolumn{2}{l}{$l$} & \multicolumn{2}{l}{} \\
\hline Year & Men $(\%)$ & Women $(\%)$ & Total $(\%)$ & Men $(\%)$ & Women $(\%)$ & Total $\%)$ \\
\hline 2010 & 61.9 & 38.1 & 56.3 & 73.7 & 26.3 & 12.8 \\
\hline 2011 & 62.4 & 37.6 & 54.8 & 72.1 & 27.9 & 11.1 \\
\hline 2012 & 61.8 & 38.2 & 50.7 & 71.9 & 28.1 & 9.5 \\
\hline 2013 & 60.8 & 39.2 & 49.6 & 73.2 & 26.8 & 7.8 \\
\hline 2014 & 60.2 & 39.8 & 46.9 & 72.8 & 27.2 & 7.2 \\
\hline 2015 & 58.6 & 41.4 & 48.5 & 70.2 & 29.8 & 7 \\
\hline 2016 & 57.6 & 42.4 & 52.2 & 68.4 & 31.6 & 7.3 \\
\hline 2017 & 57.4 & 42.6 & 55.3 & 73 & 27 & 7.6 \\
\hline
\end{tabular}

Source Labour Force Survey, 1999-2017. Statistical Service of Cyprus (2018)

In addition, there is a gender gap related to poverty in Cyprus. Nearly three in ten women are at risk of poverty or social exclusion This can be partly explained by women's lower lifetime earnings, due to caring responsibilities and due to their greater propensity to work part-time (Statistical Service of Cyprus 2017; European Institute for Gender Equality 2015: 33).

Until 2013, Cyprus was prospering, with the Services and Tourism sectors providing the main income of the country. The shocking financial crisis of 2013 completely changed the lives of Cypriots, as many people lost their jobs, and many middle class employees in Cyprus lost a high percentage of their life earnings due to the bail in ${ }^{2}$ of major banks. Nowadays, the crisis which significantly affected the public and bank sector where women are mainly employed, is declining and, after six years, Cyprus's economy is growing at a steady pace.

\section{Pension System and Pension Policies}

The first Social Insurance Scheme in Cyprus was introduced in January 1957 and it compulsorily covered all employees, with the exception of certain categories of agricultural workers. The self-employed and those workers exempted from compulsory insurance were given the right to be insured voluntarily. In 1980, a major reform introduced an earnings related insurance, replacing the previous scheme of flat rate contributions and benefits. Currently, there is only one Social Insurance Scheme (General SIS) where current contributions finance current pension expenditure-a

\footnotetext{
${ }^{2} \mathrm{~A}$ bail-in is the rescue of a bank that is on the brink of failure where creditors and depositors take a loss on their holdings, as opposed to a bail-out, which involves the rescue of a bank by external parties, typically governments that use tax-payers money.
} 
pay-as-you-go (PAYG) scheme-which covers all employed and self-employed people in the area controlled by the Republic of Cyprus (Social Insurance Services of Cyprus 2018).

The pension system in Cyprus currently comprises of three pillars: a General Social Insurance Scheme (GSIS), a compulsory earnings related scheme which covers every person gainfully employed in Cyprus, both in the public and private sector, including self-employed; the Social Pension Scheme, an income-tested scheme, which covers residents of Cyprus with no or low pension income (e.g. housewives); and Occupational Pension plans, which provide supplementary pensionable benefits to their members such as the Government Employees Pension Scheme, the Semi government Sector Employees Pension Schemes, the Voluntary Provident Funds, and other similar collective arrangements. The old age pension is payable at the statutory pensionable age of 65 for both men and women for both the private and the public sector, provided that the person has been insured for at least ten years and given other requirements.

Until 2013, the rate of contribution, for employees working in the private sector, was $17.9 \%$ on the monthly wage and was divided into $6.8 \%$ contributions paid by the employer, $6.8 \%$ paid by the employee and $4.3 \%$ paid by the State. For self-employed people the contribution was $16.9 \%$ of expected income: $12.6 \%$ was paid by the self-employed and $4.3 \%$ by the State. It is worth noting that until 2013, public and semi-public sector employees had no or very little contribution to the pension scheme as most of the contribution was paid by the State. Since 2014, contribution rates for private sector employees, increased to $20.2 \%$ on the monthly wage, divided into $7.8 \%$ paid by the employer, $7.8 \%$ by the employee and $4.6 \%$ paid by the State. For selfemployed people the rate of contribution is $19.2 \%$ on the expected income: $14.6 \%$ is paid by the self-employed and $4.5 \%$ by the State. Newcomers in the public and semi government service were affected negatively as their contribution is currently the same as the private sector, $7.8 \%$ for those employed after 2011 , while for permanent public sector employees, the contribution is still $3.95 \%$ for those employed before $2011^{3}$ (European Commission DG for Employment, Social Affairs and Inclusion 2018a: 123).

The gender gap in pensions is around $37.2 \%$ for pensioners aged $65-79$ in the EU-28. In Cyprus, the pension gap reaches $48.7 \%$ for the $65-9$ age group, one of the highest gaps in Europe. This gap may be attributed to the various inequalities that women are facing during their working life: as mentioned before Cypriot women continue to act as the primary carers of children and dependents; they are more likely than men to work part-time; they hold lower paid jobs; they have lower social security contributions due to the gender pay gap; and they usually interrupt their social security contributions during pregnancy (Statistical Service of Cyprus 2012). These factors are cumulative and they have an effect on women's pensions.

\footnotetext{
${ }^{3}$ On the 1st January 2019 all employees' contribution increased by $0.5 \%$.
} 


\section{Pension Policies to Extend Working Life}

In the last five years many pension reforms were introduced due to the financial crisis. In an attempt not only to extend working life, but also to secure the Social Security fund for the current and future generations, in 2013 pensionable age increased for all employees to 65 years for both men and women and early retirement was penalised for all workers to discourage early retirement. Early retirement, before the age of 65 , is penalised with $0.5 \%$ reduction in the pension for each month until the person reaches the age of 65. For example, for someone who retires at the age of 64 (12 months before the age of 65) s/he will experience a monthly reduction of six per cent from her/his expected pension. At the same time, there are financial incentives for prolonging working life until the age of 68. Postponement of pension entitlement comes with the benefit of increasing pension by $0.5 \%$ for each additional month of postponement (European Commission DG for Employment, Social Affairs and Inclusion 2018a).

\section{Employment Policies to Extend Working Life}

Currently there are no specific employment policies to extend working life targeting old employees. Protection from discrimination on the grounds of age is only covered by the right to equal treatment in employment as described by the Equal Treatment in Employment and Occupation Law of 2004 (L. 58(I)/2004). The Law harmonises the Directive 2000/78/EC and establishes a general framework for equal treatment in employment and occupation (Department of Labour and Equality Authority, Ombudsman 2018). This Law covers the industrial relations in both the private and public sector, and aims to fight discrimination on the grounds of age in terms of:

Access to employment, self-employment and work.

Selection criteria and terms of recruitment, in all sectors of activity and on all levels of professional hierarchy, including professional development.

Access to all types and levels of vocational orientation, training, further education and reorientation, including the acquisition of practical and professional experience.

Working conditions and terms of employment, including terms of dismissals and emoluments.

Membership and participation to employees or employers organisations.

\section{Policies for Reducing the Risk of Poverty in Cyprus}

Policies for reducing the risk of poverty are focused on the population age group of 65 years and over, families and other vulnerable groups. The old age pension is payable to an insured person who reaches the pensionable age of 65 and satisfies the relevant contribution conditions. If the person satisfies certain stricter insurance 
conditions then s/he is entitled to old age pension at the age of 63. For example miners, the only special arrangement for workers in hazardous/arduous occupations, can receive a pension at the age of 63 provided they have worked in a mine for at least 3 years, and they are also entitled to a one month reduction in the retirement age for every 5 month period they worked in a mine on condition that they are no longer engaged in that activity. They may not, however, retire before the age of 58 (European Commission DG for Employment, Social Affairs and Inclusion 2018b). If an insured person has reached the age of 68 but does not satisfy the insurance conditions for a statutory pension, s/he is entitled to a statutory lump sum instead of a pension if $\mathrm{s} /$ he has attained actual basic insurance of at least six insurance points 4 and 312 weeks have elapsed since the week of commencement of insurance.

For many decades and especially before 1974 many women were not in paid employment. They used to work in the fields without any salary or worked unpaid in the home. For those women who did not contribute to the Social Insurance scheme and who are not entitled to any other benefit after the age of 65 , are entitled to the Social pension. Any person who is not entitled any source of pension or other similar payment and whose monthly amount is equal to or greater than the monthly amount of the social pension is entitle to the social pension. Currently the monthly amount paid for the social pension is $€ 334.62$ for 13 months. Table 14.2 shows a breakdown comparison on the beneficiaries of minimum and social pension aged $65+$ between men and women for 2013 and 2015-2017. The table shows very clearly that the percentage of women who receive either minimum pension or social pension is much higher than the respective percentage of men.

In addition, the Guaranteed Minimum Income (GMI) is a financial benefit which is provided to all persons and/or families with income below a minimum threshold and increases with the size of the recipient unit. Currently, the level is set at $€ 480$ per month for a single person.

Many Cypriots consider their Provident fund as a mean to secure their retirement years, and pay their loans when they retire. The provident fund in Cyprus is one of the three pillars of the Social Insurance scheme; it is mainly provided by organisations and businesses in the private sector; is financed by contributions from employers

Table 14.2 Share of recipients of minimum income benefits in the population aged 65 and over by benefit (2013 and latest available data)

\begin{tabular}{l|l|l|l|l}
\hline \multirow{2}{*}{} & \multicolumn{2}{|l|}{$\begin{array}{l}\text { Beneficiaries aged 65+ as \% of } \\
\text { total population 2013 }\end{array}$} & \multicolumn{2}{l}{$\begin{array}{l}\text { Beneficiaries aged 65+ as \% of } \\
\text { total population, latest data } \\
\text { from year 2015-2017 }\end{array}$} \\
\cline { 2 - 5 } & Men & Women & Men & Women \\
\hline Minimum pension & 16.5 & 30.6 & 13.8 & 28 \\
\hline Social pension & 0.9 & 24.9 & 0.8 & 22 \\
\hline
\end{tabular}

Source European Commission DG for Employment, Social Affairs and Inclusion (2018c)

\footnotetext{
${ }^{4} \mathrm{An}$ insurance point is the result arrived by converting real and assimilated insurable earnings to insurance points.
} 
and employees and is considered a Supplementary pension scheme. Employees may decide according to collective bargaining to pay voluntary contributions for a private pension. The beneficiary usually receives the private pension as a lump sum payment at her/his retirement age or by monthly instalments in addition to the state pension provided through the General Social Insurance Scheme (GSIS). Private sector workers and private employers contribute equally and fairly to the social insurance scheme even though the private sector is paid less than the public sector in Cyprus. The pensions of the private sector worker will always be less than those of the public sector, complementary and voluntary schemes such as the provident funds help sustain the retirement income of people working in the private sector. According to administrative data, there were 1959 registered provident funds in 2014, of which approximately $41 \%$ have fewer than 10 members, $46 \%$ between 10 and 100 members and $13 \%$ have more than 100 members (European Commission DG for Employment, Social Affairs and Inclusion 2018a: 124). With the aim of strengthening and fortifying the sector, a new independent Single Supervisory Authority for Insurance and Occupational Pensions is to be established that will emerge from the consolidation of the two existing supervisory agencies, the Director of Social Insurance and the Ministry of Finance. Unfortunately, no gender breakdown statistical analysis exists for this type of pension.

Few policies directly target the reduction of the risk of poverty and the improvement of women's lives in Cyprus. These policies are usually associated with family e.g. maternity leave and rights. These rights comprise 18 weeks of maternity leave with possible extension under certain criteria, special rights for breastfeeding, protection of the rights of pregnant workers (and of adoptive mothers) when returning to work, and criminalisation of the dismissal of a pregnant worker (or/and adoptive mother). In addition to maternity leave a monthly allowance payable during the maternity leave period of 18 weeks is provided for pregnant women. In 2017, the Parliament of Cyprus voted on legislation introducing paid paternity leave for new fathers who may apply for two consecutive weeks' paid paternity leave during the first 16 weeks from the week of the birth or adoption of the child. Also a maternity lump sum amount is given to all women who have given birth while living in Cyprus, provided that she is a legal resident of Cyprus and that she or her husband fulfil their social insurance obligations. A widow receives a monthly payment provided she was living with her husband at the time of his death. Since 2018, a widower who is permanently incapable of self-support and maintained by his wife is entitled to pension. In addition, for those who legally reside in Cyprus and whose resources are insufficient to satisfy their special needs for care, the state provides homecare or long term care. Social Welfare Services employ carers who visit older people in need of care at their own premises and provide services according to their needs. Carers can also be employed by Community Councils or may be self-employed. The salary of the carers is paid by the state. Homecare service provides personal hygiene, house cleaning, washing of clothes, cooking, payment of bills, shopping, etc. When older people's individual needs cannot be met on a $24 \mathrm{~h}$ basis by their family or other supportive services, Social Welfare Services place older people in governmental, community or privately owned residential homes (Social Welfare Services 2014). 
Finally, unemployed people receive benefits from the Unemployment Scheme if they lose their job. This scheme stipulates that a person aged 16-63 employed in the Republic of Cyprus, or aged 64-65 but not eligible for the old age pension, may receive a weekly payment of $60 \%$ of their average weekly earnings based on contributions paid in the preceding year. However, self-employed people are not entitled to unemployment benefits.

\section{Healthcare and Policies}

In 2013, the Convention on the Elimination of All Forms of Discrimination against Women and the Committee on the Elimination of Discrimination against Women, among others urged the Republic of Cyprus to:

'Ensure universal access to health care and services for all women, with particular attention to migrant and elderly women, as well as the swift implementation of the National Health Insurance System' (United Nations 2013)

On November 10th 2017, Cyprus ratified the Council of Europe Convention on preventing and combating violence against women and domestic violence, also known as the Istanbul Convention. According to the last national survey on gender based violence, the levels of domestic violence against women in Cyprus is $28 \%$ while the age group which is at the highest risk is between 45-65 years (Mavrikiou, Apostolidou and Parlalis 2014).

The absence of a general health system and the lack of universal care, has impacted negatively the access to health care services for low income groups, women and especially older women. After decades of fruitless efforts, on the 1st of March 2019 all employees in Cyprus have started to contribute to the first phase of the General Health System with a flat contribution of $1.7 \%$ covering only out-of-hospital care, a contribution to be gradually increased to $2.65 \%$ by 2020 to also cover in-hospital care. The GHS has set a maximum annual amount of co-payments for each beneficiary in order to protect vulnerable groups (e.g. low income persons and/or persons with increased needs in medical care) and safeguard unhindered access of the population to the necessary healthcare services. The maximum annual amount of co-payments will be $€ 75$ for the recipients of the Guaranteed Minimum Income, low income pensioners and children up to the age of 21 , and $€ 150$ for the rest of the population (General Health System 2019).

Through the implementation of the General Health System every Cypriot citizen, based on the principles of social solidarity, justice and universality, both in regards to contributions and coverage, should enjoy lifelong, equal and unhindered access to high quality healthcare services, regardless of gender, age and class. 


\section{Debate on Extending Working Lives}

The issue of extending working lives in Cyprus with all its consequences, is solely a political discussion rather than an academic or research issue, and started with the financial crisis of 2013. The discussions are mainly between the government, the political parties and the affiliated trade unions. Trade Unions and social partners (mainly the left) ask for the state to implement Social EU directives, to design a national strategic plan for combating poverty and inequalities, to make a fairer distribution of wealth, to implement a fairer taxation system, to eliminate the gender pay gap, to treat men and women equally and to take positive measures for reconciliation of family and work life. Currently the media in Cyprus do not pay attention particularly to extended working life. Only occasionally newspapers and social media mention policies to extend working life. On the other hand though, the General Health System, lower paid pensioners and quality of life rank almost always first among newspaper headlines. However, political debates have never incorporated the element of gender in any discussion.

\section{Policy Recommendations}

Demographic changes and massive reforms in the pension system of Cyprus due to the economic and financial crisis of 2013 pushed Cypriots to work longer. To maintain a high quality of life during the working life of the Cypriots but also to live with dignity during their pension years, policy makers should consider ways to:

Minimise gender inequalities in the labour market and bridge the gender pay gap.

Improve further the financial incentives for prolonging working life until the age of 68 .

Reform the retirement paths of various vulnerable occupational/employment groups that have not been addressed in a comprehensive manner.

Narrow the gender pension gap and mitigate the effect of labour market inequalities on pensions.

Reform the third pillar of the pension system (occupational pensions) and better governing of the occupational pension funds in a way that will promote adequacy, sustainability, safety and transparency.

Provide affordable childcare or long term care services that may increase the number of female entrepreneurs or improve women's access to private sector labour market and leadership.

Promote further research and alternative angles in order to understand the issue of gender, health and extended working life in Cyprus. 


\section{References}

Department of Labour and Equality Authority, Ombudsman. (2018). Non-discrimination on grounds of age in the field of Employment and Occupation. A brief guide. Retrieved March 26, 2019, from http://www.mlsi.gov.cy/mlsi/dl/dl.nsf/all/149BC293DF0F2669C22580E600437F4C/\$file/ 3_Age\%20non\%20discrimination.pdf?openelement.

European Institute for Gender Equality. (2015). Beijing + 20: The 4th review of the implementation of the Beijing platform for action in the EU member states. Luxembourg: Publications Office of the European Union.

European Commission DG for Employment, Social Affairs and Inclusion. (2018a). Pension Adequacy Report 2018. Current and future income adequacy in old age in the EU (Vol. 2). Country profiles, Cyprus.

European Commission DG for Employment, Social Affairs and Inclusion. (2018b). CyprusStatutory pension. Retrieved March 14, 2018, from https://ec.europa.eu/social/main.jsp?catId= 1105\&langId=en\&intPageId=5007.

European Commission DG for Employment, Social Affairs and Inclusion. (2018c). Pension Adequacy Report 2018. Current and future income adequacy in old age in the EU (Vol. 1). Country profiles, Cyprus.

Eurostat. (2018). The Life of women and men in Europe-A Statistical Portrait 2018 Edition. Retrieved March 2, 2019, from http://www.cystat.gov.cy/mof/cystat/statistics.nsf/All/ E7FC794B82CC2BB4C22581BD003A338C/\$file/WomenMenEurope-DigitalPublication2018-EN-191018.pdf?OpenElement.

General Health System. (2019). Financing. Retrieved March 24, 2019, from https://www.gesy.org. $\mathrm{cy} /$ sites/Sites?d=Desktop\&locale=en_US\&lookuphost=/en-us/\&lookuppage=hiofinancing.

Mavrikiou, P. M., Apostolidou, M., \& Parlalis, S. (2014). Risk factors for the prevalence of domestic violence against women in Cyprus. The Social Science Journal, 51(2), 295-301.

Social Insurance Services of Cyprus. (2018). Historical Background. Retrieved September 14, 2018 , from http://www.mlsi.gov.cy/mlsi/sid/sidv2.nsf/page02_en/page02_en?OpenDocument.

Social Welfare Services. (2014). Public assistance, old persons and persons with disabilities. Retrieved April 1, 2019, from http://www.mlsi.gov.cy/mlsi/sws/sws.nsf/All/ 51950D3157907F4AC2256E7700387B35?OpenDocument.

Statistical Service of Cyprus. (2012). The statistical portrait of women in Cyprus, 2012. Retrieved September 10, 2018, from http://www.cystat.gov.cy/mof/cystat/statistics.nsf/ populationcondition_26main_en/populationcondition_26main_en?OpenForm\&sub=6\&sel=4.

Statistical Service of Cyprus. (2017). The Woman in Cyprus in Figures. Press Release.

Statistical Service of Cyprus. (2018). Labour Force Survey, 1999-2017. Retrieved November 12, 2018, from http://www.mof.gov.cy/mof/cystat/statistics.nsf/labour_31main_en/labour_31main_ en?OpenForm\&sub=1\&sel $=2$.

United Nations. (2013). Convention on the elimination of all forms of discrimination against women. Retrieved September 1, 2018, from http://www2.ohchr.org/english/bodies/cedaw/docs/ co/CEDAW.C.CYP.CO.6-7.pdf. 
Open Access This chapter is licensed under the terms of the Creative Commons Attribution 4.0 International License (http://creativecommons.org/licenses/by/4.0/), which permits use, sharing, adaptation, distribution and reproduction in any medium or format, as long as you give appropriate credit to the original author(s) and the source, provide a link to the Creative Commons license and indicate if changes were made.

The images or other third party material in this chapter are included in the chapter's Creative Commons license, unless indicated otherwise in a credit line to the material. If material is not included in the chapter's Creative Commons license and your intended use is not permitted by statutory regulation or exceeds the permitted use, you will need to obtain permission directly from the copyright holder.

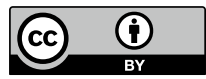




\title{
Chapter 15 \\ Czech Republic
}

\author{
Martina Rašticová, Monika Bédiová, Jana Mikušová, Aneta Krejčová \\ and Jiř́ Černý
}

\begin{abstract}
Ever-extending lifespans and low birth-rates (about 1.5 child per woman) contribute to the ageing of Czech society. By 2060, it is expected that just over one third of the Czech population will be aged 65 or over. By the 2060s, Czechs will be expected to retire at age 69 or later. Even with later retirement, the percentage of people entitled to an old-age pension will increase so that by the 2050s, approximately $28 \%$ of people may qualify for an old-age pension, compared with today's $20 \%$. Changes in demographic composition will also influence other indicators: the average age around 2050 might be between $48-50$ years, about ten years more than now. Politicians, managers and society leaders aim to find ways to successfully face this demographic challenge and enable everybody to have a sufficient level of economic, social, and health care provision. Most crucial in the near future is the adaptation of employment policies and pension reform. This chapter describes the situation regarding the employment of people over 50 years in the Czech Republic, research focused on extending working life, employment policies and characteristics of the pension system, paying special attention to gender differences.
\end{abstract}

\section{Introduction}

Czech social policy after 1989 has been affected by changes in the political scene and the new institutional rules accompanying that transformation. Although the Czech Republic's economy has been heavily transformed, structural unemployment could not be improved due to the inefficiencies of public institutions and public employment services (PES). The reform of these institutions is among the priorities of the European Employment Strategy (EES). From the 'European' perspective, the contribution of EES to the structure and quality of European social policies is entirely positive. In the Czech Republic, it is so mainly for promoting and accentuating the need of reform measures towards achieving the goals set in the national action plans.

M. Rašticová $(\bowtie) \cdot$ M. Bédiová · J. Mikušová · A. Krejčová · J. Černý

Department of Law and Social Sciences, Faculty of Business and Economics, Mendel University in Brno, Brno, Czech Republic

e-mail: martina.rasticova@mendelu.cz 
Although this recognition has not yet been followed by the necessary measures to accomplish those goals, such as providing job opportunities for older workers, the EES or the Czech employment strategy must be credited for its proactive stance in acknowledging problems of the labour market.

In the 1990s, employment policy in the Czech Republic was determined by the economic transformation. Among the main problems were low regional and professional labour mobility, badly targeted social benefits, heavy taxes, and non-existence of lifelong education. Also, the structural inconsistency of the demand and supply of labour played its role, resulting in growing unemployment. During that period, employees aged 50+ were not directly endangered by structural unemployment, as they were not among the most disadvantaged groups because older workers could opt for early retirement. The situation became worse only after parametric changes to the pension system that included early retirements being penalised with lower benefits and retirement ages being increased. Handicapped older workers and members of other disadvantaged groups who were less qualified joined the ranks of the long term unemployed. More recently, the 50+ group has contributed substantially to the unemployment rate, despite some signals of increased employment.

In the 55-59 age bracket, the unemployment rate reached $10.5 \%$ by the end of (2013) (76,400 unemployed) and was high also in the 50-54 age group $(63,700$ unemployed). For comparison, in 2008, the unemployment rate for the 55-59 age group was $7.5 \%$. Increased participation of older workers in the labour market in recent years may reflect the increasing retirement age. Another possible factor may be older Czechs' worse living conditions, resulting from the economic crisis. Individuals may face a number of other factors that undermine their ability to be employed at older ages such as lower education, health handicaps, and perceived lower adaptability to the changing conditions. Despite decreased job performance (in some instances) and the need to provide family care, older people in the labour market face an insufficient menu of flexible working arrangements, particularly part-time jobs. The position of older workers is also made more insecure by the stereotypical views of employers, who automatically assume worse performance, implying less willingness on their part to invest in the personal development of older workers (Czech Statistical Office 2013).

\section{Research Regarding Older Employees in the Czech Republic}

Quantitative research findings suggest that many in the 50-64 generation of the Czech Republic are now trying to stay in the labour market until the retirement age, mostly because of financial reasons and due to fears of difficulties in looking for new jobs (Šimandlová 2014). It is more difficult to find a new job in the 50+ age bracket. In the study by Šimandlová half of respondents aged 50-64, once unemployed, were unemployed for longer than one year; this category also included people who had been looking for jobs for over three years. In 2012, 22.7\% of long-unemployed people were in the 55+ age group. Unemployment and long-term unemployment 
are also among the main reasons for early retirement, chosen mostly by those who would otherwise have major difficulties finding jobs and those with hard manual jobs. While two thirds of men working aged 55-59 still work, less than one quarter of 60 and 64 years are employed. Half of women aged 55-59 are already retired. On an international scale, the Czech Republic has the third highest percentage of people aged 50-64 who are already retired. Generally, early retirements are unfavourable for many individuals because of pension cuts and limited opportunities for income alternatives, presenting no solution to the situation of older people with difficulties in finding jobs at pre-retirement ages due to insufficient income. Forty per cent of respondents of the 50-64 age bracket said being laid off was the reason for early retirement, which makes losing a job the most frequent reason for early retirement. Other reasons include early retirement with extraordinary severance packages $(29 \%)$ and bad health conditions (17\%). Only $4-5 \%$ of respondents said that they retired early because they wanted to enjoy life more or spend more time with their families (See Fig. 15.1). This seems to disprove the myth that people retire early to 'tend their gardens and enjoy their grandchildren'. Usually, Czechs retire early because of being laid off and being unable to find a new job (Fig. 15.1).

The respondents often said continuing work became a problem due to combined reasons such as age with bad health condition added or age and gender plus other combinations. Fewer than three quarters of respondents are without health problems limiting their performance (see Fig. 15.2). Thus, it may be difficult to find a job, say, for people living on partial disability pension, who might welcome a part-time job.

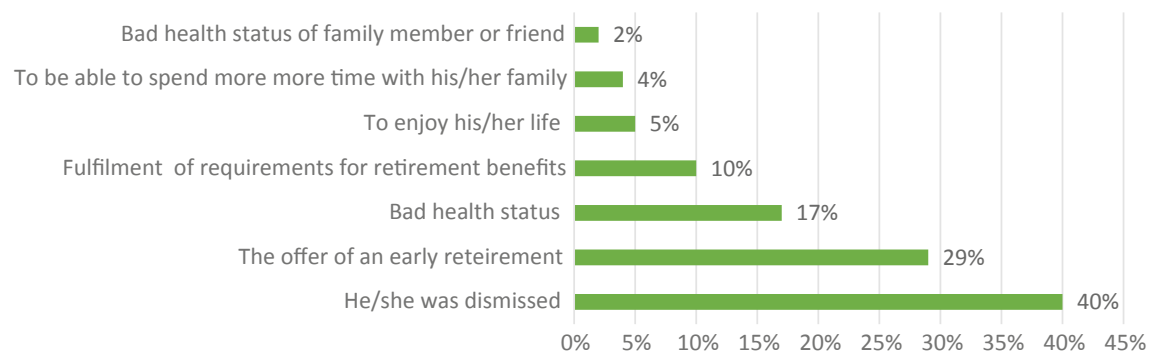

Fig. 15.1 Reasons for retirement in the Czech Republic. Source Šimandlová (2014)



Fig. 15.2 Health reasons diminishing chances of finding a job. Source Šimandlová (2014) 
The problem is that, generally, part-time jobs are few and poorly paid (Jouza 2017). According to the research, the potential solution of finding a part-time job is scarce for the 50-64 age bracket. Not only is there a current shortage of part-time jobs, but also wages are poorer than those of the full-time jobs, despite the same work (Jouza 2017). Additionally, the 50+ generation is sometimes dubbed the 'sandwich generation' because its members still have dependent children and have to care for ill parents or partners. Such carers are then in a difficult situation, finding it complicated to establish work life balance.

The loss of a job by an older person is regarded as a very negative life. Such experiences are corroborated by results from a quantitative enquiry, with $94 \%$ of the respondents seeing the loss of a job at a pre-retirement age as a major problem and $84 \%$ saying it is very difficult for people over 50 to find a new job. Further, seniors do not feel that the younger people appreciate their wisdom event (Šimandlová 2014). See Fig. 15.3.

Many employees in the Czech Republic are latently or even explicitly discriminating against older workers. According to some research in the Czech labour market (STEM 2007), this is mainly age discrimination (see Fig. 15.4). Nine out of ten

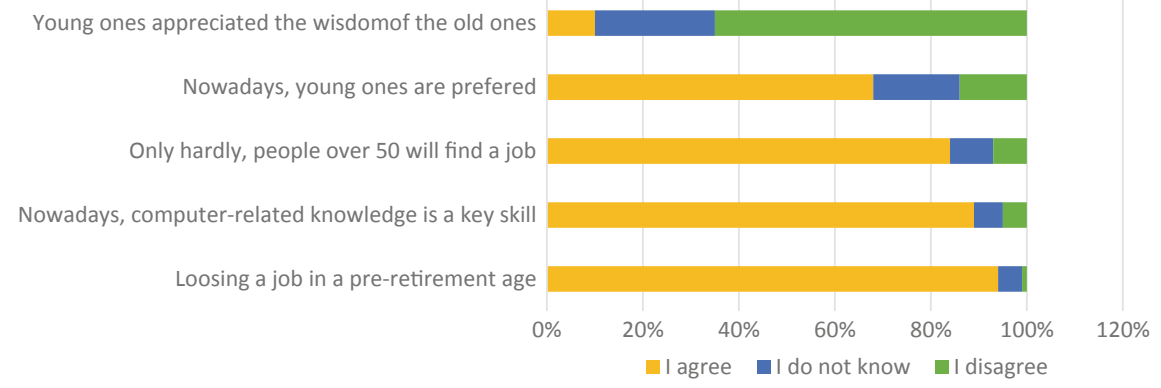

Fig. 15.3 Stereotypes and external barriers in the labour market according to Czech seniors in the age group 50-64. Source Šimandlová (2014)

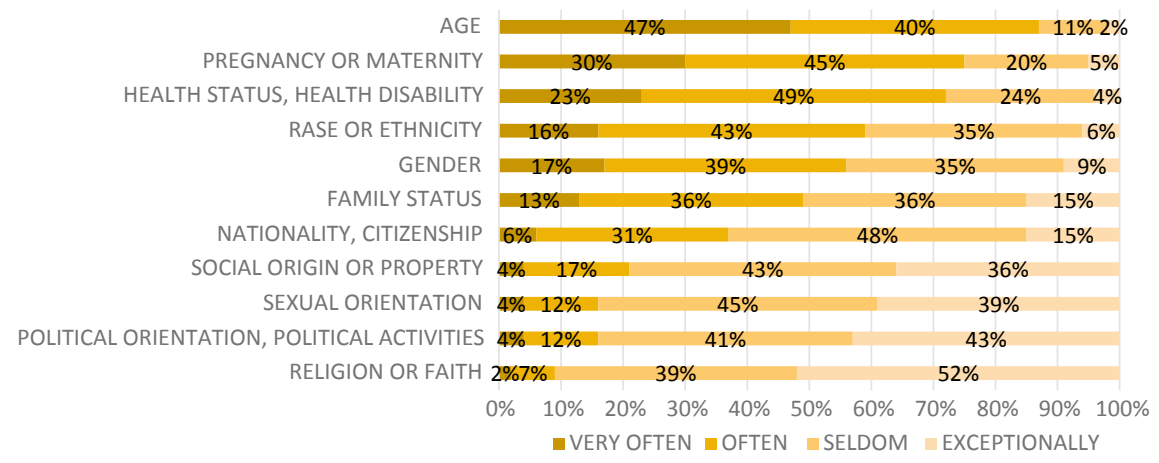

Fig. 15.4 The reasons for discrimination in the Czech Republic. Source STEM (2007) 
citizens $(87 \%)$ believe that people are often or very often put at a disadvantage on the grounds of age. According to age management researchers, age discrimination begins to be focused on the overall presence of age stereotypes and myths of age (Roscigno 2007; Rašticová and Kolářová 2015).

\section{Age Management and Senior Education in the Czech Republic}

Qualitative enquiries provided by Czech researchers from Alternative 50+ were trying to find out whether the employers work with the concept of age management (AM). Their findings showed that the majority of respondents $(86 \%)$ work with AM in some way; only $14 \%$ said that they did not work with such a concept (Šimandlová 2014).

Despite age discrimination, older employees are also characterised as having more loyalty and less pay requirements (Rašticová and Kolářová 2015). Regarding intergenerational cooperation, research results showed that cooperation with an older colleague is most convenient for employees of an age-mixed team; surprisingly that is least convenient for those in older teams which consists of the majority of older employees. This result needs further qualitative inquiry to better understand the arguments for and against cooperation with older employees in teams with different age composition. In keeping with the theory of management diversity, it appears the most resilient and, potentially, the most efficient working team is an age-mixed one (Rašticová and Pohanková 2017).

Rabušic (2006) provided a study focused on participation of the older Czech population in adult education activities based on a representative survey of adult education in the Czech Republic. Adult education, including senior education, is an important feature of knowledge society and another factor aimed at making older Czechs more active in the labour market. Data from Rabušic's survey also show that $22 \%$ of older Czechs participated in courses concerning their occupations, language and computer skills courses, courses in personality development and leisure-time activities, and educational activities concerning civic life. The same share of the population planned to attend a course in the next year. The participation of older Czechs in continuing education depends on their already achieved level of educationthe more educated the individual, the higher his/her contemporary participation. Whether older Czech people will participate similarly in the near future then depends significantly on whether they have already participated in the past (the correlation between past participation and intended participation in the near future is 0.69) (ibid). 


\section{Policies Regarding Late Employment}

\section{Development of Passive Employment Policy (PEP)}

Passive employment policy in the Czech Republic focuses on reducing the consequences of unemployment through financial benefits during the unemployment period. Since 1997, the unemployment rate has increased sharply. Due to the structural imbalance, which does not take into consideration different groups of the unemployed, the long-term unemployment (lasting 6-12 months) has afflicted mostly low-qualified workers, graduates with no previous experience, single parents with children, disabled people, etc. Consequently, passive unemployment spending has been increasing, not only because of the increased average value of monthly benefits, but also due to the increasing numbers of job-seekers participating in qualification training courses (eligible for a requalification benefit). According to the Employment Act of (2004), workers till the age 50 receive unemployment compensation for five months, older workers aged 50 and above require special arrangements regarding job mediation, so the unemployed in the 50-55 age group receive unemployment compensation for eight months while those older than 55 years receive it for 11 months.

\section{Active Employment Policy (AEP)}

Active employment policy is a collection of measures to ensure the maximum possible employment. Active employment policies (AEP) are pursued by the Ministry and the Public Employment Office (PEO) cooperating with other entities as needed given the situation in the labour market. The PEO tools are: qualification training courses, investment incentives (financial assistance to employers), community service, socially useful jobs, bridging allowance (to a self-employed person who is no longer a job seeker and who has been paid an allowance, serving as compensation for the operational costs incurred and paid in the period for which the bridging allowance is given), training allowance (received by the employer hiring a job seeker who is under special surveillance by the PEO), business plan change allowance (for an employer who, due to a changing business plan, can no longer offer to employees the weekly working hours as agreed), consultancy, support for the employment of disabled persons, and targeted programs to lower unemployment.

Since the very beginning, the main purpose of the AEP has been to keep the unemployment rate low. However, the finances allotted to the AEP have steadily declined in favour of passive compensation for incomes.

Pension system

The Czech pension system consists of a public pension scheme and a mandatory funded private scheme with voluntary entry. The public pension scheme has a basic element and an earnings-related part calculated according to a progressive formula. Currently, the pension scheme covers all the needs of Czech retirees; the risk to sustainability from the ageing of the Czech population emerges rather in the longer 
term after year 2035 (see e.g. Bezděk et al. 2003, who investigated fiscal implications of ageing in the Czech Republic), so further measures should be welcomed.

Two parts of the Czech pension system

The first pillar is the mandatory basic pension insurance, defined by benefits (DB) and funded on a running basis (pay-as-you-go $=$ PAYGO). The system is universal and provides for all economically active individuals; the legal regulation is the same for all the insured persons, there are no industry-specific schemes except for some variations in the so-called power sectors (e.g. soldiers, police, customs officers, firefighters). The pension from the basic pension insurance is drawn by more than $99 \%$ of the Czech population whose age is higher than the retirement age (currently set at 65).

Additionally, there is a voluntary complementary additional pension based on a defined contribution plan, in which employer, employee or both make contributions on a regular basis. The additional pension can be considered, according to EU terminology, the third pillar of the pension system. The third pillar also includes products offered by commercial insurance companies_-particularly life insurance. Pensions granted from the third pillar so far represent only a negligible portion of incomes of the retired. The second pillar, which is usual in EU member states (employer pension schemes), is absent in the Czech pension insurance system.

Until the end of 2012, the pension system in the Czech Republic rested upon two basic pillars: the first PAYGO pillar, with resources for the pay-out of state pensions generated from mandatory payment of pension insurance by persons and employers at a total of $28 \%$ of gross earnings; and the third pillar, voluntary individual pension insurance with state contribution, and the possibility of tax breaks and employer contributions. As of January 12013 , pension reform has ushered in changes to the mandatory first pillar and transformation of the voluntary third pillar, in terms of taxation and state allowances.

Types of benefits and components of each pension

The following pensions are provided from the basic pension insurance: oldage (including the so-called early old-age pension), disability, widow and widower, and orphan. Components of each pension are a basic assessment (which is a fixed amount identical for all types of pensions, regardless of the insurance duration and income) and a percentage assessment based on the insurance duration and income. Both employers and employees share contributions.

Periods of earnings-related unemployment insurance are credited in the pension system. The duration of unemployment insurance entitlement varies with age: five months up to age 50, eight months from 50 to 55 and 11 months for over $55 \mathrm{~s}$. In addition, up to three years spent unemployed without entitlement to unemployment insurance are also credited (but only one year of unemployment without benefits before the age of 55 is credited). The unemployment period used for the pension calculation is reduced to $80 \%$, meaning that if an individual had five years' unemployment over their career, this would count as four years for pension purposes. If the unemployment period is in the decisive (reference) period for the average assessment base calculation, this period is excluded from the calculation and only the income 
from which the premium is paid is used. Unemployed are people who have no job and at the same time they are older than 15 years, actively searching for a job, ready to start working within 14 days (except students, mothers on maternity leave, parents on parental leave, etc.)

If conditions which entitle a person to several pensions of the same type have been met for payment of old-age pension or disability pension, then only one type of the pension will be paid, specifically the higher one. If conditions have been met which entitle a person to old-age or disability pension and to widow or widower pension or orphan pension, then the higher one shall be paid in the full amount and one half of the percentage assessment shall be paid from the other pensions, unless the Act on pension insurance establishes otherwise.

Qualifying conditions with respect to gender and earnings-related

The standard retirement age is gradually being increased by two months per birth cohort without any upper limit for men (and later on for women too). The pension eligibility age for women is increased by four months and from 2019 by six months to be unified with men (fully for individuals born in 1975 at the age of 66 years and eight months). A minimum required 25 years' coverage will be gradually increased to 35 years, by one year per year from 2010 . However, people with 15 years' coverage (gradually increasing to 20 years) can receive a pension from an age five years higher than standard retirement age for males the same year of birth.

The earnings-related pension gives $1.5 \%$ of earnings for each service year. The earnings measure currently averages across all years starting from 1986, but it will gradually reach lifetime average. Earlier years' earnings are indexed by the growth of economy-wide average earnings. There is a progressive benefit formula, under which income thresholds are applied to reduce average career earnings into the calculation basis.

There are credits for labour-market absences during periods caring for children up to four years old (or older in case of severe disability). These years are then ignored in the calculation of earnings for pension purposes so that these absences do not reduce the assessment base (this approach is used for all non-contributory periods).

It is possible to retire three years (increasing in the future to five years, but no earlier than age 60) before the standard retirement ages subject to 25 years' coverage, increasing in line with general qualification conditions to 35 years. In the case of early retirement, the total accrual factor (i.e. number of years of contributions multiplied by the accrual rate) is permanently reduced. It is also possible to defer claiming the pension beyond the normal pension age; in this case, the total accrual factor is increased. There is no additional pension accrual for deferred retirement. It is also possible to combine pension receipt while continuing to work. 


\section{Debate}

The debate about the pension system is developing. In 2007, it took place between two extremes: on the one side, there was a relativist approach according to which it was enough to make merely cosmetic changes to the pension system. On the other side, there were radical proposals for privatisation of the pension system based on mandatory pension funds.

Political parties competed in presenting proposals for a change of the current system, which was generally regarded as unsatisfactory. While the Civic Democratic Party presented a concept of equal pensions (flat state pension), the Czech Social Democratic Party recommended the Swedish model.

Currently, the debate is focused on setting a fair pension insurance for all regarding their gender and other possible inequalities, which would take into consideration also different lifecourses and career opportunities of different groups of people. This debate was started in 2019 by the Czech Minister Maláčová, who is a member of the Czech Social Democratic Party, who also appointed a new 'Commission for Fair Pensions'. Members of this commission are policy makers from all parliament parties as well as researchers and academicians dealing with pension and extending working life topics. The debate includes also the discussion regarding flexible working conditions, gender pay gap and differentiation of pensions according to different job characteristics. A significant part of the debate focuses on income into the pension system, proportion of wages and pensions, and professional merit.

\section{Conclusion}

Czech social policy after 1989 was influenced by the changing political situation. Low regional and professional labour mobility, badly targeted social benefits, heavy taxes, and the lack of lifelong education were among the major problems. Also the structural imbalance of labour supply and demand played its role in shaping the potential for extended work to older ages. Initially, the 50+ workers were not directly threatened by structural unemployment, nor were they among the most disadvantaged groups, mainly due to the option of early retirement. The sustainability of the pension system started to turn for the better as a result of the changes in the pension system parameters (early retirements being penalised and retirement age increased). The growing participation of older workers in the labour market is obviously encouraged by the increasing retirement age, lower economic situation of retired Czechs, and a number of combined factors such as lower education, health handicaps, and perceived low adaptability to the changing conditions among older people.

The Czech Republic emphasises active employment policy. The AEP may result in keeping older workers in employment longer by offering qualification training courses enabling a change of profession, or by offering them a change of employment. The AEP has tools, discussed earlier, that may also support older workers' extended 
employment. Unfortunately, the AEP has, so far, not taken into consideration the insufficient willingness of the employers to employ elderly workers.

However, this particular situation of an aging work force concerns almost all advanced countries, and also brings a number of positives and hopes for the future. For the first time in human history, people have a realistic chance of living a long life in relatively good health. Worries about the economic burden and disharmony of the labour market due to the ageing of population as a challenge can provide inspiration for research, enquiries, and detailed analyses of policies and practices that could address such challenges. One of the avenues of research opening up is concerned with equal opportunities, focussing on the detection and elimination of explicit and latent forms of ageism. Next a redefinition will be necessary of productivity theories with respect to the new challenges to production and individual lives affected by automation, digitisation, robotisation, and artificial intelligence. Concerning the setting of employment policies and policies related to retirement timing, a resetting will probably be required of the present redistribution system.

\section{References}

Bezděk, V. et al. (2003). Fiscal implications of population ageing. Czech Journal of Economics and Finance. Retrieved December 11, 2018, from http://journal.fsv.cuni.cz/storage/956_05_562-591. pdf.

Employment Act, year 2004, number 435. (2004). Prague: Ministry of Labour and Social Affairs. Retrieved April 6, 2016, from https://portal.gov.cz/app/zakony/zakon.jsp?page=0\&nr= 435 2F2004\&rpp=15\#seznam.

Employment and unenployment according to VSPS results. (2013). Czech Statistical Office. Retrieved November 10, 2016, from https://www.czso.cz/csu/czso/zamestnanost-anezamestnanost-podle-vysledku-vsps-rocni-prumery-2013-ah3piojsce.

Jouza, L. (2017). Advantages and disadvantages of part-time work, E-pravo.cz. Retrieved December 12, 2018, from https://www.epravo.cz/top/clanky/vyhody-a-nevyhody-castecnych-pracovnichuvazku-106270.html.

Population forecast of the Czech Republic up to the year 2050. (2004). Czech Statistical Office (CZSO). Retrieved December 12, 2018, from https://www.czso.cz/csu/czso/populacni-prognozacr-do-r2050-n-g9kah2fe2x. Accessed 12 December 2018.

Rabušic, L. (2006). Adult education in pre-retirement and retirement age. In Proceedings of the Philosophical Faculty of the University of Brno. Masaryk University Brno. Retrieved April 6, 2016, from http://www.phil.muni.cz/wupv/home/Documents/sbornik-u11-mpsv-projekt/ 07Rabusic\%20U11.pdf.

Rašticová, M., \& Kolářová, I. (2015). Myths about ageing population. In Innovation Vision 2020: from Regional Development Sustainability to Global Economic Growth. Amsterdam: International Business Information Management Association (IBIMA).

Rašticová, M., \& Pohanková, S. (2017). Intergenerational cooperation in selected czech small and medium enterprises-research results. In P. Slavíčková (Ed.), Knowledge for Market Use 2017: People Economics-Desicions, Behavior and Normative Models (pp. 716-727). Olomouc.

Roscigno, V. J., et al. (2007). Age discrimination, social closure and employment. Social Forces, 86(1), 313-334.

STEM. (2007). Discrimination in the labour market. Retrieved June 7, 2017, from https://www. stem.cz/diskriminace-na-trhu-prace-973. 
Statistical Yearbook of the Czech Republic. (2016). Czech Statistical Office (CZSO). Retrieved December 12, 2018, from https://www.czso.cz/csu/czso/statisticka-rocenka-ceske-republiky2016.

Šimandlová, N. (2014). Research on barriers and challenges in the field of employment of persons $50+$ and carers in the 50+ group, report on quantitative and qualitative research on the status of $50+$ people and carers in the labour market and society. Report from quantitative and qualitative research. Alternativa 50+. Retrieved June 7, 2017, from http://alternativaplus.cz/wp-content/ uploads/2016/01/vyzkum-prekazek-a-vyzev.indd03_FINAL.pdf.

Open Access This chapter is licensed under the terms of the Creative Commons Attribution 4.0 International License (http://creativecommons.org/licenses/by/4.0/), which permits use, sharing, adaptation, distribution and reproduction in any medium or format, as long as you give appropriate credit to the original author(s) and the source, provide a link to the Creative Commons license and indicate if changes were made.

The images or other third party material in this chapter are included in the chapter's Creative Commons license, unless indicated otherwise in a credit line to the material. If material is not included in the chapter's Creative Commons license and your intended use is not permitted by statutory regulation or exceeds the permitted use, you will need to obtain permission directly from the copyright holder.

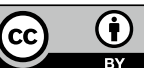




\title{
Chapter 16 Denmark
}

\author{
Per H. Jensen
}

\begin{abstract}
This chapter discusses the preconditions for high and rising female labour force participation rates among older workers in Denmark, marked by a highly developed welfare state and flexible labour markets. Main findings are that changing labour market practices of older women are conditioned by economic and symbolic stimuli encouraging older workers voluntarily to prolong their working life as well as measures combatting exclusionary mechanisms in the Danish labour market.
\end{abstract}

Keywords Employment $\cdot$ Gender $\cdot$ Older workers $\cdot$ Pension system $\cdot$ Labour markets $\cdot$ Work life quality

\section{Introduction}

Denmark is a prototypical egalitarian, Social Democratic and women friendly welfare state. For decades, Denmark has also been among the EU countries exhibiting high employment rates among older workers. Between 2000 and 2017, the employment rate among workers 55-64 years of age grew from 56 to $69 \%$. Employment rates among older women has increased substantially; from 47\% in 2000 to 65 in 2017. Among EU-28 countries in 2017 only Sweden, Finland, Lithuania, Estonia and Germany had older women's employment rates similar to Denmark (Eurostat n.d.-c).

Growth in employment among older workers in Denmark between 2000 and 2017 has occurred in a relatively favourable economic environment. Before the financial crises (i.e. 2000-2009) the overall unemployment rates varied between 3.4 and 5.5\%. Unemployment peaked in 2011 at $7.6 \%$; afterwards unemployment decreased to $5.7 \%$ in 2017 (Eurostat n.d.-a). Overall, the Danish economy did not suffer as severely from the financial crisis when compared with many other countries.

The Danish welfare state also helps to facilitate work life balance for women aged 55-64. Routine access to high quality child and eldercare institutions means

\footnotetext{
P. H. Jensen ( $\varangle)$

Centre for Comparative Welfare Studies, Aalborg University, Aalborg, Denmark

e-mail: perh@dps.aau.dk 
that women can participate in paid employment rather than provide unpaid care to grandchildren or frail elder parents or partners (Frericks et al. 2014).

Although Denmark represents a Social Democratic welfare state, for decades the Social Democratic Party has had limited control in government. Between 2000 and 2011 the government was led by the Liberal Party; between 2011 and 2015 by the Social Democratic Party, and since 2015 the government has again been led by the Liberal Party. Shifting governments has introduced measures to prolong working lives, and these measures have been oriented to both the supply and demand side of labour markets.

\section{Pension Policy}

The Danish pension system is regarded as sustainable and robust in relation to changing ageing demographics. It meets all requirements and recommendations from the World Bank (World Bank 1994); the World Bank recommends that pension systems are constructed as three pillars systems: a publicly managed system with mandatory participation, a privately managed mandatory savings system, and voluntary savings. The Danish pension system has been identified as the highest-ranking retirement income system annually from 2012 to 2017 by the Melbourne Mercer Global Pension Index (2017). The Melbourne Mercer Index compares retirement income systems around the world based on their adequacy, sustainability and integrity.

Although the Danish pension system may be adequate and sustainable, it is also very complex. Since the 1960 s, the Danish pension system has grown from a one pillar to a multi-pillar system; from a dominantly public to an increasingly private system and from a mainly collective to a more individualised system. The three major pillars of the Danish pension system are: (1) state organised pensions, (2) privately and collectively organised occupational pensions and (3) private and individual pension savings (for a historical description of the development of the Danish pension system see: Andersen 2011; Andersen and Jensen 2016).

Pillar one: All citizens above the state pension age (in 2017, 65 years of age) are entitled to a universal tax financed, flat rate, state pension. This basic pension is roughly $€ 9,980$ annually for a single pensioner in 2018. Full entitlement requires at least 40 years of residence in Denmark after age 15. People who do not fulfil these demands - but have been residents for at least 10 years-will receive a fraction of the pension, dependent on their years of residency in Denmark.

The rights based basic pension is topped up by different means-tested benefits. First is a means-tested pension- 'supplement' amounting to about $€ 10,800$ annually for a single pensioner in 2018. However, additional means-tested pensioner benefits exist, such as housing benefits (maximum annually is $€ 6,340$ ), support for heating (maximum $€ 680$ annually), supplementary pension benefits (maximum is $€ 2,400$ annually), and support for extraordinary expenses in particular health related expenses. 
The first pillar also includes a compulsory, contributory and fully funded supplementary benefit (ATP) covering all wage earners as well as unemployed and disability pensioners. The ATP is financed as a tax on labour costs. Contributions depending on working hours and remuneration and are rather low. The maximum annual ATP benefit amounts to about $€ 3,200$ for people who entered the labour market at the age of 18 and left the labour market at the age of 65 .

Pillar two: As an outcome of collective bargaining agreements, a formally private occupational pension scheme gradually emerged starting in the 1960s. Occupational groups have gradually been covered by different occupational pension schemes, and as of 1991, most segments were covered by occupational pensions. Pension contributions are negotiated among social partners and may differ between occupationsnormally contributions are at least $12 \%$ of wages and employers usually contribute two thirds and employees one third. The pension schemes are fully funded and pension savings are secured in pension funds, often administrated in close association with trade unions.

Occupational pension schemes are organised according to principles of defined contributions, meaning that individual pension benefits depend on individual contributions; returns on invested capital (the pension fund invests the money), and retirement age alongside adjustments due to changes in longevity. The system is stripped of any form of redistribution.

Pillar three: The third pillar is composed of an array of four different individual pensions saving schemes, encouraging personal pension savings, primarily administrated by banks or insurance companies. The four private saving schemes primarily differ in relation to the amount that is deductible from taxable income, the age at which pensions can be paid out, and the period of time the pensions are paid out.

For most Danish pensioners, their actual pension is made up of a combination of income from all three pillars. However, wage income as well as income from Pillar two and three has repercussions on pension income from Pillar one.

First, if a person living alone has an income from Pillar two and three of more than $€ 9,500$ per year, a deduction will be made in the means-tested pension-'supplement'. With an income of more than $€ 44,000$ from Pillar two and three, entitlements to the means-tested pension 'supplement' terminates.

Second, if a person entitled to the basic state pension has a wage income of more than $€ 43,000$ annually, deductions will be applied to the basic state pension. A wage income of more than $€ 76,000$ annually results in the basic state pension being terminated. However, if a person who works at least 1,000 hour per year decides to postpone his/her claims on the basic citizen based state pension, benefits will increase proportionally under a scheme called 'Opsat Pension'. If, for instance, a person postpones his/her take up of the basic pension by four years, the basic pension increase by $27 \%$, providing an incentive to postpone retirement (Amilon et al. 2008). If postponed by four years, the state pension amounting to $€ 9,980$ annually for a single pensioner, increases to $€ 12,675$ annually.

So far, the Danish pension system is perceived as socially sustainable. Pensioners who are solely dependent on income from pillar one (e.g. a woman who has been a housewife all her life and divorced at the age of 66) are well protected against 
relative poverty using EU's poverty definition as a yardstick-except for immigrants who have not had at least 40 years of residency. Only people who have had 40 years of residence in Denmark, Greenland or the Faroes between the age 15 and 65 are fully entitled to the universal tax-financed, flat rate, state pension. People who have resided less than 40 years in Denmark are only entitled to a fraction of the state pension (so called fraction pensioners). For instance, people having resided 20 years in Denmark are only entitled to $50 \%$ of the state pension. The rate of people $65+$ at risk of poverty or social exclusion in Denmark in 2015 was $9.9 \%$, compared to $17.4 \%$ across EU-28 (Eurostat n.d.-b).

The overall trend, however, is that Pillar two turns into the dominant part of the Danish pension system in terms of retirement income security, and may crowd out all of the means-tested pension benefits in Pillar one. In 2014, only 54\% of Danish pensioners received means-tested pension 'supplement' from Pillar one, and this proportion will decline in the future as Pillar two becomes fully implemented when those who were enrolled in the system from 1991 at the age of their retirement have paid lifelong contributions to the occupational pension system. That is, in the future the Danish pension system will primarily consist of the citizenship based state pension, ATP, occupational pensions and private pension savings.

As Pillar two matures, the Danish pension system becomes highly 'privatised' and is deemed economically sustainable. Basically, Pillar two and three are based on fiscal welfare principles. People do not pay taxes on income that is used to contribute to the pension system and pension funds themselves are wealthy. By 2015, assets held in these funds amounted to $201 \%$ of GDP. When pensions are paid out (from all three Pillars), they are subject to ordinary income tax. Therefore, the fully funded pensions will provide the state with income tax revenues from future pension payments. It has been calculated that future pensioners will become 'net contributors' to the welfare state. Future pensioners will even finance increasing expenditures to the health and eldercare sectors (Nielsen 2012).

From a gender perspective the occupational pension system is rather unequal. Each occupation bears its own pension risks, meaning that men (e.g. typified by engineers) and women (typified by nurses) are enrolled in different occupational pension schemes (Pillar two). Pay rates often vary in occupations dominated by one gender, with women's occupations typically paying less. This will give rise to gender differences in future pension benefits. The fact that women earn less on average (thus, contributions to occupational pensions are lower) and live longer (pension saving must stretch over a longer period) means that women's pensions will be systematically lower than for men. Further aggravating such gender inequalities is that women do not contribute to Pillar two during periods of maternity (Jørgensen 2008). 


\section{Recent Reforms in Pension Policies}

The Danish pension system was subject to major reforms in 2006 and 2011, where the major outcome was that the age for the basic state pension between 2019 and 2022 will gradually be raised from 65 to 67 . In addition, the state pension age was made dependent on life expectancy, using 1995 as baseline. Consequently, the state pension age will be raised to 68 years in 2030, to 69 in 2035 and to 70 in 2040, provided that life expectancy improves five years. Between 1995 and 2016, life expectancy has already risen more than five years, from 75.3 to 80.9 years. Therefore, the pensionable age seems likely to increase in the future, even beyond 70 years of age. Recent predictions estimate that those born between 1979 and 1982 will not be able to retire until they reach the age of 72, while the pensionable age for new-born Danes will be 76.5 years.

\section{Employment Policies}

Since the late 1990s, Denmark has initiated several measures to prolong working life. A compulsory retirement age was abolished in most professions, meaning that older workers are not forced to retire when they meet the state pension age. Furthermore, discriminatory arrangements in labour market policies were abolished as of January 1st 2007. Until 1996 older workers above the age of 50 did not—and unemployed in general - have the right of and obligation to 'activation' (e.g. job-training, education etc.), and until the 2006 reform older people above the age of 60 did not have the same rights and duties as unemployed people in general (Arbejdsministeriet 1997). This reflects that, until recently, older workers have been considered as peripheral and marginal components of the workforce by the public authorities.

Until 2006 the unemployment benefit system functioned as a de facto early exit/retirement pathway. Various regulations guaranteed that unemployment benefit recipients between 55-59 years of age would not lose their rights to unemployment benefits. When these rules were abolished as part of the 2006 reform, a senior job scheme was created, guaranteeing unemployed people 55 years of age (or older) having lost their rights to unemployment benefits to be offered a 'senior job'. The municipality of residency is obliged to provide the senior job to the person in question. Senior jobs must be in accordance with conditions set up in the collective agreements and ordinary jobs must not be converted into senior jobs. In 2015 about 4,500 people were enrolled in the senior job scheme (Finansministeriet 2016).

The 2006 and 2011 reforms also discouraged voluntary early exit/retirement with the aim of increasing labour supply. Until 2014, people with 25 years contribution to the early retirement scheme could freely choose to take up early retirement (between age 60 and 64). Chronologically, the scheme proceeds entitlements from Pillar one as the state pension age in 2014 was 65 ; early retirement benefits could be combined with income from Pillar one and two, and it is even possible to work while receiving early retirement benefits, but few do so. The early retirement benefit amounts to 
about $€ 28,000$ annually (subject to ordinary income tax) in 2018. The 2006 and 2011 reforms, however, reduced the duration of benefits from five to three years, meaning that early retirement benefits can only be claimed 3 years before the state pension age.

People who are eligible for the early retirement benefit, but who do not take up early retirement, are eligible to a tax-free premium of $€ 22,000$ when they reach the state pension age. Historically, there has been a strong gender bias among recipients of the early retirement benefit. In 2014, for instance, $58 \%$ of recipients were women and $42 \%$ men, most probably because retirement comes in couples, there is a tendency that Danish women leave the labour market when their older in age spouse retires (Friis 2011). As time progresses, however, the early retirement scheme becomes less valuable, primarily because income from Pillar two and three as of 2014 are fully deducted from the early retirement benefit.

On the demand side, public and private companies have been encouraged to employ senior management policies to address hiring and retainment of older workers. As of the late 1990s the Government launched so-called information campaigns designed to persuade employers to retain or recruit older workers. These information campaigns are anchored in social gerontological insights as well as the credo from American human resource management philosophy, epitomised as diversity management (Friis et al. 2008). These campaigns approach employers as rational actors. Consequently, it is expected that employers will change behaviours once fully informed about all the advantages of older workers. The campaigns bear some resemblance with the slogan of the civil rights movement in the USA, 'Black is beautiful', only in the Danish case it is 'Grey is beautiful'. Hiring and retaining older workers is presented as a win-win situation. The campaigns bring the message that older workers are equally productive compared to younger workers, and that diversity (including age diversity) in the workplace is good for business.

Information campaigns were communicated in the form of codes of good conduct, benchmarking, and the collection, analysis and spreading of good age management practices. Good examples were presented as routes worth following and emulating. As an integrated part of information campaigns, a senior praxis prize was awarded every year to a large, medium and small-sized companies whose policies and accomplishments regarding older workers were regarded as exemplary. The senior praxis prize is awarded by the Ministry of Employment and the minister him/herself presents the prize (Friis et al. 2008).

The various forms of age management campaigns have been accompanied with an age management consultancy scheme. From the late 1990s, Danish firms were offered five hours of free consultancy to help them formulate and implement age management. However, the consultancy scheme was abolished in 2009. When the Social Democratic government was formed in 2011 campaigns supporting employers' adaptation of age management policies were terminated. Still, age management seems to have integrated into Danish companies. About $50 \%$ of Danish firms with more than 10 employees report that they have a senior policy, part-time/flexible work hours as the most common instruments (Jensen and Møberg 2012). 


\section{Health Policies}

Until 2003, people aged over 50 could be awarded a disability pension if their labour market prospects seemed poor. In 2003 eligibility criteria were tightened and changed. While the earlier focus was on 'loss of employability', the focus after 2003 has been on 'working capacity', meaning that any working capacity should be used. Since 2003, several reforms have tightened the tests of work capacity. Most recently, a reform enacted in 2012 emphasised 'reablement', and it was decided that a person below 40 years of age could not be granted a disability pension. The effect has been that, between 2011 and 2017, the number of newly awarded disability pensions fell from 16,909 to 9,674 individuals. The disability pension is a tax financed benefit amounting to about $€ 30,000$ annually; $54 \%$ of recipients are women while $46 \%$ are men. These gender differences in disability pensioning are most probably, similar to Norway, attributable to women's poorer self-reported health, greater levels of mental distress, lower wages, and more unfavourable working conditions including job strain and less control over work (Claussen and Dalgard 2009).

As mentioned, the pension reform in 2011 raised the age of eligibility for early retirement from 60 to 64 years of age by 2022. However, it was recognised that not all beneficiaries of early retirement benefits would actually be able to work until the age of 64. Therefore, in 2011 a non-contributory senior disability pension was introduced for people unable to work, available up to 5 years before the pensionable age. Eligibility does not differ much from the 'ordinary' disability pension. In 2017, only about 1,000 persons had been awarded the senior disability pension.

As an alternative to disability pensions, a flex job scheme was introduced in 1998 to facilitate the employment of persons with disabilities, allowing them to lead an economically active life. Working hours are flexible, but basically wage and work conditions are similar to ordinary work conditions. Flex jobs carry a wage subsidy and in 2015 about 70,000, out of total labour force of 2,861,000, were employed as flex jobbers. About $61 \%$ of all flex jobbers are women while $39 \%$ are men. Again, these gender differences are most probably attributable to differences in health among men and women.

\section{Precarious Employment}

In 2017 about $21 \%$ of all employed older workers (55-64 years of age) were working part-time. Some gender differences do exist, $33 \%$ of all employed older women (55-64 years of age) were working part-time in 2017. A relatively small proportion of women working part-time do so involuntarily. Involuntary part-time employment as percentage of total part-time employment among older workers was $13 \%$, while involuntary part-time work among older women working was 14\%. In EU-28 involuntary part-time employment as percentage of the total part-time employment was 
$22.6 \%$ (Eurostat n.d.-d). That is, the proportion of older women engaged in involuntary part-time work is much lower in Denmark as compared to an EU-28 average (Eurostat n.d.-d).

Job security in general is rather low in Denmark and labour turnover is among the highest among OECD countries in Western Europe (OECD 2016). This is a result of low levels of employment protection, which form part of Danish flexicurity. Flexicurity is a mechanism that supposedly creates flexible labour markets. It consists of a combination or interaction between low levels of employment protection, generous unemployment benefits and active labour market policies (for a discussion of the Danish flexicurity model and its preconditions, see Jensen 2017). Older workers are vulnerable in highly flexible labour markets. As part of the 2006 reform, the EU directive from 2004 on age (direct and indirect) discrimination was enacted, but age and gender discrimination legislation is not able to safeguard older female or male workers. Courts always accept the reason for firing given by the employer. That is, the case is closed if employers have not explicitly referred to gender or age as a reason for layoffs or firings.

Overall quality of work conditions is high in Denmark. Already Gallie (2003) found that work life quality is relatively high in Denmark, and more recently Eurofound (2013) has found that overall employment quality in Denmark is among the highest in Europe (only surpassed by Finland).

\section{Danish Debate}

In Denmark at least two debates have structured ideas about prolonging working life: One associated with neo liberalism has argued that pension systems are economic unsustainable and function as disincentives to work. Demographic ageing will furthermore reduce the supply of labour in the future which supposedly is damaging for the economy. Therefore working longer has been conceived to be a necessity. These arguments were verbalised by the Economic Advisory Council (as off the late 1990s) and public commissions (e.g. the Welfare commission in the middle of the 1990s and the Labour Market commission in the late 1990s), and these ideas were adopted by the Liberal led government and transformed into reforms in 2006 and 2011. The 2006 Welfare reform was supported by the Social Democratic Party (and partially by trade unions) while the 2011 Retirement reform was objected by the Social Democrats and trade unions, while strongly supported by employers association.

Another parallel debate was based on activities in the Senior Policy Committee established by the Social Democratic government in 1999. This debate argued that early retirees are socially excluded and suffer from loss of citizenship due to poor health or because they are victims of ageist attitudes and discriminatory practices of employers. From this perspective, social integration or the opportunity to work longer is preconditioned by changes in employers' behaviour. To some extent this 
perspective was adopted by the Liberal led government in the 2000s. This led, as mentioned above, to measures such as information campaigns aimed at spreading good age management practices. These activities, however, terminated with the coming of the financial crisis and the formation of a Social Democratic government in late 2011 .

\section{Conclusion}

The employment rate of older women has been growing relatively fast since 2000 . These changes in older women's practices intersect with changing welfare policies and changing labour markets.

Within a framework of relatively low unemployment rates, the aim of shifting governments since 2000 has been to increase labour supply. Measures have been a combination of retrenchment (pension, disability, early retirement and unemployment benefit schemes) and the introduction of economic incentives encouraging prolongation of working life (e.g. Opsat Pension). These new trends in policies represent new ideas promulgated by the Economic Advisory Council as of 1998 and by public commissions (e.g. the Welfare Commission and Labour Market Commission) primarily staffed with supply side economists. Ideas were adapted by the Liberal led government leading to major reforms in 2006 and 2011 to be enacted as of 2014. Still, the Danish pension system continues to be rather generous in the face of retrenchment. Poverty among pensioners is relatively low.

In the years to come the Danish pension system will be increasingly developed as a privatised, fully funded defined contribution scheme. Pensioners will become net contributors to the welfare state as pension income is subject to ordinary income tax. Trends towards privatisation may lead to an increase in gender inequality in living conditions of pensioners. Pension funds are gender segregated which will lead to lower pensions in female dominated pension funds (women earn less and live longer than men live).

In parallel to this, measures with the aim of reducing social exclusion of older workers have been introduced including the abolition of the compulsory retirement age. Age biases in active labour market policies have been abandoned. New employment opportunities have been introduced (senior and flex jobs); this includes attempts to persuade employers to apply senior policies. In addition, older people may find it attractive to continue working because work life quality is relatively high. However, gender differences in working life continue to exist, women's working conditions are less favourable, contributing to women exiting the workforce earlier than men. 


\section{References}

Amilon, A., Bingley, P., \& Nielsen, T. H. (2008). Opsat Pension-Øger den arbejdsudbuddet?. Copenhagen: SFI.

Andersen, J. G. (2011). Denmark: The silent revolution toward a multipillar pension system. In B. Ebbinghaus (Ed.), The varieties of pension governance: Pension privatization in Europe (pp. 183209). Oxford: Oxford University Press.

Andersen, J. G., \& Jensen, P. H. (2016). Ældrepolitikken: Sociale og økonomiske udfordringer. In I. H. Møller \& J. E. Larsen (Eds.), Socialpolitik (pp. 321-345). Copenhagen: Hans Reitzels Forlag.

Arbejdsministeriet. (1997). Rapport fra det tvarministerielle udvalg om Forskelsbehandling af aldre. Copenhagen: Arbejdsministeriet.

Claussen, B., \& Dalgard, O. S. (2009). Disability pensioning: The gender divide can be explained by occupation, income, mental distress and health. Scandinavian Journal of Public Health, 37(6), $590-597$.

Eurofound. (2013). Quality of employment conditions and employment relations in Europe. Dublin: Eurofound.

Eurostat. (n.d.-a). Retrieved March 11, 2019, from https://ec.europa.eu/eurostat/tgm/table.do?tab= table \&init $=1 \&$ language $=$ en $\&$ pcode $=$ tps $00203 \&$ plugin $=1$.

Eurostat. (n.d.-b). Retrieved March 11, 2019, from https://ec.europa.eu/eurostat/tgm/table.do?tab= table\&init $=1 \&$ language $=$ en $\&$ pcode $=$ tespm090\&plugin $=1$.

Eurostat. (n.d.-c). Retrieved March 11, 2019, from https://ec.europa.eu/eurostat/web/productsdatasets/product?code $=$ tesem 050 .

Eurostat. (n.d.-d). Retrieved March 11, 2019, from http://appsso.eurostat.ec.europa.eu/nui/show. do?dataset=lfsa_eppgai\&lang=en.

Finansministeriet. (2016). Økonomisk analyse: Seniorjobordningen. Copenhagen: Finansministeriet.

Friis, K. (2011). Det er så yndigt at følges ad: Tilbagetrækningen fra arbejdsmarkedet set $\mathrm{i}$ et husstandsperspektiv. In J. G. Andersen \& P. H. Jensen (Eds.), Tilbagetrakning fra arbejdsmarkedet-årsager og effekter (pp. 137-159). Copenhagen: Frydenlund Academic.

Frericks, P., Jensen, P. H., \& Pfau-Effinger, B. (2014). Social rights and employment rights related to family care: Family care regimes in Europe. Journal of Aging Studies, 29(1), 66-77.

Friis, K., Jensen, P. H., \& Wègens, J. (2008). Seniorpraksis på danske virksomheder. København: Frydenlund Academic.

Gallie, D. (2013). Direct participation and the quality of work. Human Relations, 66(4), 453-473.

Jensen, P. H. (2017). Danish flexicurity: preconditions and future prospects. Industrial Relations Journal, 48(3), 218-230.

Jørgensen, M. (2008). Danskernes indbetaling til pension. København: SFI, 08:11.

Jensen, P. H., \& Møberg, R. J. (2012). Age management in Danish Companies: What, how, and How much? Nordic Journal of Working Life Studies, 2(3), 49-66.

Melbourne Mercer Global Pension Index. (2017). https://www.mercer.com.au/content/dam/mercer/ attachments/asia-pacific/australia/mmgpi-2017/au-2017-mmgpi-report.pdf?utm_medium= referral\&utm_source=web\&utm_campaign=mmgpi.

Nielsen, А. Ø. (2012). Pensionisterne betaler for sig selv. Forsikring \& Pension, Notat. Retrieved March 11, 2019, from https://www.forsikringogpension.dk/media/2334/pensionisterne-betalerfor-sig-selv.pdf. (18.12.2012).

OECD. (2016). Back to work: Denmark: Improving the re-employment prospects of displaced workers. Paris: OECD Publishing.

World Bank. (1994). Averting the old age crisis. Oxford: Oxford University Press. 
Open Access This chapter is licensed under the terms of the Creative Commons Attribution 4.0 International License (http://creativecommons.org/licenses/by/4.0/), which permits use, sharing, adaptation, distribution and reproduction in any medium or format, as long as you give appropriate credit to the original author(s) and the source, provide a link to the Creative Commons license and indicate if changes were made.

The images or other third party material in this chapter are included in the chapter's Creative Commons license, unless indicated otherwise in a credit line to the material. If material is not included in the chapter's Creative Commons license and your intended use is not permitted by statutory regulation or exceeds the permitted use, you will need to obtain permission directly from the copyright holder.






\title{
Chapter 17 \\ Estonia
}

\section{Marge Unt, Margarita Kazjulja and Viivi Krönström}

\begin{abstract}
This chapter aims to provide a broader context to understand extended working life in Estonia by describing the socioeconomic background, employment regime, pension system and extended employment patterns. Estonia is an ageing society with a decreasing working age population. Intriguingly, despite this decreasing working age population, the number of employed people has increased over recent years due to increasing activity rates and the prolonged working careers of older people. The employment rate of older women is especially high compared to other European countries. Overall, there are diverse reasons for the readiness to work beyond retirement age. These are related to the favourable tax system for working pensioners and relatively low pensions which make working an economic necessity. Older women who face higher poverty risks and higher care obligations combined with few opportunities to work part-time are especially vulnerable.
\end{abstract}

Keywords Ageing $\cdot$ Eastern Europe $\cdot$ Gender $\cdot$ Extended working life $\cdot$ Estonia $\cdot$ Pensions

\section{Introduction}

Estonia is an ageing society with a decreasing working age population. However, despite the decreasing working age population, the number of employed people has increased in recent years. The increase in absolute employment is boosted by economic growth and enabled by higher activity rates, especially the prolonged working careers of older people. This chapter provides a broader context for understanding extended working life in Estonia by describing the socio-economic context, employment regime, pensions system and policies designed to extend working lives.

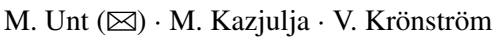

School of Governance, Law and Society, Institute of International Social Studies, Tallinn

University, Tallinn, Estonia

e-mail: marge.unt@tlu.ee 


\section{Gender and Employment in Estonia}

Estonia has one of the highest employment rates in the EU: 68\% in 2018 among 15-74 year olds. The overall employment rate for women was $8.6 \%$ lower than for men. A crucial contributor to the work force is the high labour market activity of older workers. In 2018, the employment rate of people aged 55-64 reached 69\%, putting Estonia in fourth place after Sweden (78\%), Germany (71\%) and Denmark $(69 \%)$ in Europe for this age-group. The employment rate of women aged 55-64 (72\%) was higher than that of men $(66 \%)$ which is exceptional in the EU as men tend to be more active in the labour market in most countries and in all age groups. It is notable that in the age group 65-74, the employment rate considerably exceeds the EU average; $28 \%$ for men and $25 \%$ for women (Eurostat database 2020c). Thus, for the 65-74 year age group the employment rate for men is 2.1 times higher than the European average and for women 3.4 times higher (Eurostat database 2020c own calculations).

In Estonia, a high employment rate for women was the norm during the Soviet occupation in the second half of the 20th century and this continues to be the dominant model. Labour market tensions were initially solved by pushing older workers, especially working pensioners out of the labour market (Unt and Saar 2016). Consequently, during the transition to a market economy in the 1990s, the employment rate of older people fell considerably. However, from the early 2000s, there has been an overall increase in the employment of people aged 50-74 from 44\% in 2000 to 53\% in 2010 and $61 \%$ in 2018, despite cutbacks in employment rates during the economic recessions.

In cohorts born between 1960 and 2004, women had a greater chance of obtaining higher education as they were more likely to attend general secondary schools, in contrast to men who were more likely to attend vocational schools (Saar et al. 2015). The gendered transitions in education translate into high levels of horizontal gender segregation in the labour market. Women are strongly overrepresented in social and personal services. In vertical gender segregation, women are more likely to obtain a professional position due to their higher educational qualifications. At the same time, women have been increasingly disadvantaged in obtaining managerial positions (Saar et al. 2015). The disadvantaged position of women in the labour market is also manifested via the highest gender wage gap in Europe. Based on Eurostat data, the hourly wage of women was one quarter lower than that of men in 2018. The biggest difference in wages was between men and women employed in financial and insurance activities. The causes of the gender wage gap have not yet been analysed from a lifecourse perspective. We can only assume that it may be related among other factors to very generous parental leave policies (100\% of previous earnings for 435 days) encouraging one parent to stay out of the labour market for an extended period as there is little flexibility in combining early childcare and work. As only $9 \%$ of parental leave takers are fathers (Estonian Statistical Office database 2019), this long career break is taken up mainly by mothers. All children between the ages of 1.5-7 should be guaranteed a kindergarten place by the municipality, although there 
is a shortage of childcare places for children under the age of three. Kindergarten fees cannot exceed $20 \%$ of the minimum wage. Thus, in general, the childcare system is well developed and affordable, but no early childcare places are provided and there is a scarcity of places for children between 1.5 and 3 years of age. Part-time work is comparatively rare. In 2018 , only $11.1 \%$ of the workforce, less than half the EU average worked part-time. Women mostly either work full-time or stay at home fulltime. The likelihood of having a part-time job increases with age both for men and women, although it is still considerably lower than the EU average. Partial retirement is not a typical way to exit the labour market. The high activity of older workers in the labour market is promoted by pension reforms and low pension benefits.

\section{Pension System and Pension Policies Extending Working Life in Estonia}

The Estonian pension system underwent a paradigmatic shift beginning in 1998, when the Parliament adopted a reform programme aiming to implement a three pillar system in Estonia. The first pillar is the public pension or state pension fund administrated by the government. The second pillar is a private pension, which is mandatory for newcomers in the labour market and to all those born after 1983 and voluntary for older cohorts. The aim is that the first and second pillar will together guarantee $40 \%$ of the net replacement rate. The third pillar is a voluntary pension scheme. The second and third pillar pension funds are not included in general government accounts and are managed by banks and insurance companies (Unt and Reiska 2017).

The general statutory pension age in Estonia in 2019 is 63.75 years for both women and men and one must have at least 15 years of tenure. The pre-reform statutory retirement age was relatively low in Estonia, having been set at 55 years for women and 60 years for men in 1956. At the beginning of the 1990s together with general pension reforms, the statutory retirement age was revised. In 2012, the statutory retirement age was 63 years for men and 61.5 years for women. It was equalised to 63 in 2016 and will gradually increase to 65 years by 2026 for both women and men. At the end of 2018, it was decided to link the pension age increase closer to life expectancy at the age of 65 from 2027 (not with healthy life expectancy). The increase in retirement age has not increased the take-up of early retirement (Puur et al. 2015).

There are only few early retirement opportunities available. Early retirement is possible for up to three years before the pension age with a reduction of the pension by $0.4 \%$ for every month remaining until the pension age is reached. For instance, early retirement 3 years before pension age reduces the pension by $14.4 \%$. It is not possible to combine working with early retirement schemes (Estonian Social Insurance board 2019). Few early retirement options are related to occupation. Only a limited number of occupations (for example, police officers, rescue workers, prison officials, civil 
aviation employees, test pilots, workers in jobs that are especially hard and extremely hazardous to health and so on) may retire early on full pensions. At the beginning of 2019 , about $9 \%$ of all retirees were in an early retirement pension scheme. However, entry into early retirement is highly dependent on the labour market situation, and it is one of the pathways during periods of high overall unemployment (Leppik 2018). This pathway is not offered to the employees by companies but is manifest as a survival strategy of individuals to take up early retirement in the eventuality of job loss. There is also an option for deferred pensions. In this case, the pension amount is increased by $0.9 \%$ for every month retirement is postponed after the general pension age. The number of people who have opted for a deferred old-age pension is still low, but the proportion has been increasing slightly. In 2017, four per cent of new retirees opted for a deferred pension (compared to six per cent who opted for the early retirement pension as shown above) (Leppik 2018). Thus, there are only a few opportunities for early retirement in Estonia. Another early retirement pathway has been disability pensions. However, one must note that there are strict criteria for disability benefits and theirs value is rather low (Unt and Saar 2016). During the 2016 reform the Estonian Unemployment Insurance Fund began to assess the level of working ability. The goal was to change people's attitudes towards those with decreased working ability and help them find and secure employment. As a result of reform the number of pensioners on disability/working ability decreased more than three times, from 97459 in 2016 to 28253 at the beginning of 2019.

Estonia also has one of the lowest net theoretical replacement rates in the European Union. In 2018, the average old-age monthly pension was $€ 441$ and the average monthly disability pension was $€ 269$. In cases where there is $100 \%$ loss of workability, the monthly disability pension was $€ 382$ (Estonian Social Insurance board 2019). The aggregate replacement ratio for pensions excluding other social benefits has been in the range of $45-55 \%$ over the last decade, which is at the lower end in Europe. Thus, in Estonia, transition into retirement increases the risk of poverty. In fact, Estonia has the highest at risk of poverty (AROP) rates (cut-off point $60 \%$ of medium equalised income after social transfers) of older persons (65 and over) in Europe. In 2018, the AROP rate for persons aged 65 and over was 46\%, while the AROP rate for older women $(52 \%)$ is significantly higher than for men $(35 \%)$ (Eurostat 2020a). The poverty risk for single older persons, the majority of whom are women is particularly high. A high proportion of retirees have an income level very close to the at risk of poverty threshold implying that relatively small changes in the ratio of pensions to work income may have an impact on the large proportion of pensioners falling below the AROP threshold. Material deprivation is much less widespread and only slightly higher than the EU average. In 2018, $12 \%$ of over 65 year olds were unable to carry out three items or more from the following list: to pay unexpected expenses, afford a one-week annual holiday away from home, a meal involving meat, chicken or fish every second day, the adequate heating of a dwelling, durable goods such as a washing machine, colour television, telephone or car, being confronted with payment arrears. There is a clear gender gap concerning material deprivation; older women (13\%) were more likely to experience economic hardship than men (9\%) (Eurostat database 2020b). 
Currently both the value of pensions and inequalities in pension income are rather low. However, pension inequality has increased and will continue to rise in the future as a larger part of the pension of each successive generation will depend less on the length of employment and more on the level of salary. The outcomes will be especially harmful for women's income in old age as the pension income will reflect the consequences of the high gender wage gap.

\section{Extended Working Life Employment Policies}

In Estonia, older age groups are among some of the most educated in the EU, and there is not a notable educational gap compared to younger cohorts. $29 \%$ of people aged $65-75$ years old and $36 \%$ of people aged 55-64 have tertiary education (Saar and Unt 2016). At the same time, research shows that older people have lower general skills. The gap between 20-24 and 60-65 year olds is especially large in the domain of problem solving in technology rich environments (Halapuu and Valk 2013). Furthermore, although older age groups are defined as a risk group by public employment office regulations, policies relating to the promotion of the employability of older workers are mostly underdeveloped and (re)training is seldom offered to older workers (Saar et al. 2011).

Both the readiness and the ability of older workers to remain in employment may depend not only on opportunities created through structural institutional characteristics, but also on the 'age culture' prevalent in a country. Overall, the majority of people believe in Estonia that older people are perceived positively. The share is very close to the average level of EU-28 (59\% believe that persons over 55 have a positive image vs $61 \%$ in EU-28), and Estonia is considerably more 'older people friendly' than most other Central Eastern European countries (European Commission 2018). In Estonia, approximately one third of the population believe that age discrimination is widespread, which is even less than the EU-28 average (42\%) (Lindemann and Unt 2016).

In this context, the Estonian Active Ageing Development Plan 2013-2020 has set as one of its key policy goals the extension of working lives and maintenance of economic activity and employability, while reducing unemployment and inactivity in older age groups (Sotsiaalministeerium 2013 via Leppik 2018). To support policy initiatives, the ministries have commissioned several analytical reports focusing on different aspects of policies to extend working lives (Aksen 2013; Nurmela et al. 2014, Puur et al. 2015). 


\section{Health Policies}

The crucial resource needed for prolonging working life is good health. In Estonia, life expectancy at birth is considerably lower than the EU average, on average 2.5 years lower. The gap between men and women is notably larger than the EU average; life expectancy is 73.8 years for men and 82.6 years for women in Estonia (Eurostat database 2019c). Given a faster rate of increase in the past decade, life expectancy is slowly catching up to the EU average, In addition, the gender gap has decreased as male life expectancy has risen faster, by 5.8 years compared to the increase of female life expectancy by 3.3 years.

The fundamental question is whether extra years of life are spent in good or bad health. In Estonia larger differences are observed in average healthy life years compared to the European Union. People live a disability free life on average for seven years less than in the EU and this difference has changed very little in recent years. Female healthy life expectancy in Estonia was 5.2 years shorter and male healthy life expectancy 9.1 years shorter than the EU average in 2016 (Eurostat database 2019d). Healthy life expectancy at birth was only 54.4 years for men and 59 years for women.

In 2016, the Government launched a Work Ability Reform, modifying the eligibility criteria and payment conditions of incapacity benefits-now called work ability allowances_combined with additional labour market policy measures that aim at increasing labour market participation and preventing early exit from employment. Among others, such measures include occupational rehabilitation, peer support, assistive work equipment and commuting benefits.

\section{Debate on Extended Work-Life Policies}

The most recent changes in the pension system were undertaken in December, 2018 and the legislation was discussed among policy makers, social partners, experts as well as in public debate. Also, the NGOs representing the voice of older people were engaged in the preparation of the changes in legislation, although there have been few heated debates. In 2016, there was a plan to increase the retirement age to 70 , but then it was tied to average life expectancy instead. There is no systematic review of the debates available, but one may assume that this decision was on the one hand pragmatic, but on the other hand also it has made the issue of extended working life more abstract and easier to 'sell' to a broader audience. The life expectancy component enables future increases in retirement age into one scheme and no concrete retirement age numbers or scenarios for different social groups have been presented in most of the articles published in media. There have been proposals made to tie the retirement age also to healthy life expectancy, but these proposals were rejected.

In short, the reforms in the pension system at the end of 2018 aimed at promoting longer working lives by tying the retirement age to life expectancy and allowing 
more flexibility in choosing when to retire, while later retirement means a higher pension. In order to counterbalance the increasing inequality of pensions, the amount of pension will be less dependent on previous salary in the future and more dependent on occupation (Piirits and Masso 2017; Leppik 2018).

Secondly, there has been a heated debate concerning the second pillar of the pension, which has gained a lot of media attention. One right wing party has promised to abolish or at least make the second pension pillar voluntary on their agenda. This idea is promoted in the context of the prominent public discourse in Estonia: the idea of the minimal state and greater individual freedoms to decide. In 2019, there is an ongoing debate in which most experts strongly oppose both options, but recommend several improvements in the existing system.

\section{Discussion: Gender and Health Implications and Policy Recommendations}

Estonia is an ageing society with a decreasing working age population, but with very high activity rates, especially among older workers. Perceived age discrimination is also lower than the EU-28 average. We can even foresee a further increase in employment in the future due to the gradually rising pension age, an increase in healthy life years and as the result of the workability reform in 2016. The favourable tax regime encourages employment after retirement and the low pension replacement rate makes work an economic necessity. However, there is clearly limited capacity to increase the size of the labour force for demographic reasons.

There are significant differences in the employment rates of older Estonians based on social groupings. Education is one of the key factors behind the positive outcomes of employment in later life, while the main challenge is the poor health status of older age groups as measured both by subjective and objective health indicators. Therefore, future policy initiatives need to focus on supporting the employability of those groups of older workers who are in the most vulnerable situations in the labour market due to low education, health restrictions, care obligations or other factors that have led to an early exit from employment. Some measures have already partially been introduced via workability reform. However, more cooperation is needed between active labour market measures and social support measures needed to guarantee access to work in the case of health restrictions.

Overall, the willingness to continue working beyond retirement age is very high in Estonia (Lindemann and Unt 2016). However, flexible work options should be supported and gradual retirement should also be further promoted as ways to promote the activity of older people. Another important area is the low share of older people participating in lifelong learning, and there should be more opportunities for updating and developing skills in late careers. Currently, care obligations which rest disproportionally on the shoulders of female family members are not well addressed. Elder care is very expensive and the majority of families are not supported financially 
by municipalities. This reduces the possibilities for family members with caring obligations to engage in paid work, especially when flexible working arrangements are not widespread.

\section{References}

Aksen, M. (2013). Eesti vanemaealiste tööturukäitumine ja seda mõjutavate tegurite analüüs (SHARE 4. laine andmetel). MA Thesis, Tartu University, Tartu, Estonia. Retrieved April 22, 2019, from http://share-estonia.ee/fileadmin/Merli_Aksen_MMRIMP.pdf.

European Commission. (2018). The 2018 pension adequacy report: Current and future income adequacy in old age in the EU. Luxembourg: Publication Office of the European Union.

Estonian Statistical Office database. (2019) (online data code: TKS07). Retrieved April 22, 2019, from http://pub.stat.ee/px-web.2001/dialog/statfile2.asp.

Estonian Social Insurance board. (2019). Retrieved March 20, 2019, from https://www. sotsiaalkindlustusamet.ee/en/pension-types-pensions-and-benefits.

Eurostat database. (2020a). At-risk-of-poverty rate by poverty threshold, age and sex (online data code: ilc_lio2). Retrieved January 13, 2020, from https://ec.europa.eu/eurostat/data/database.

Eurostat database. (2020b). Material and social deprivation rate by age and sex (online data code: ilc_mdsd07). Retrieved January 13, 2020, from https://ec.europa.eu/eurostat/data/database.

Eurostat database. (2020c). Employment rates by sex, age and citizenship (online data code: Ifsa_ergan). Retrieved January 14, 2020, from https://ec.europa.eu/eurostat/data/database.

Eurostat database. (2019c) Life expectancy by age and sex (online data code: demo_mlexpec). Retrieved March 25, 2019, from https://ec.europa.eu/eurostat/data/database.

Eurostat database. (2019d). Healthy life years (from 2004 onwards).

Halapuu, V., \& Valk, A. (2013). Täiskasvanute oskused Eestis ja maailmas. PIAAC uuringu esmased tulemused. Tartu: Haridus ja Teadusministeerium.

Leppik, L. (2018) Estonia. In P. Becker, J. Schütz, A. Zimmermann (Ed.), Ageing workforce, social cohesion and sustainable development. Political challenges within the baltic sea region (pp. 8-12). Berlin: Population Europe.

Lindemann, K., \& Unt, M. (2016). Trapped in 'involuntary' work in the late career? Retirement expectations versus the 'desire to retire'; in Estonia. Studies of Transition States and Societies, $8(3), 60-77$.

Nurmela, K., Osila, L., \& Leetmaa, R. (2014). A comparative analysis of the active ageing policies in the Baltic countries. Tallinn, Estonia: Praxis Centre for Policy Studies.

Piirits, M., \& Masso, M. (2017). The government of Estonia proposes to tie the pension age to life expectancy and increase solidarity in the state old-age pension. In: ESPN Flash Report (pp. 1-2).

Puur, A., Leppik, L., \& Klesment, M. (2015). Changes in pension take-up and retirement in the context of increasing the pension age: the case of Estonia in the 2000s. Post-Communist Economies, 27(4), 497-516.

Saar, E., Täht, K., \& Unt, M. (2011). Late careers and labor market exit to retirement. In E. Saar (Ed.), Towards a normal stratification order: Actual and perceived social stratification on post-socialist Estonia (pp. 143-176). Frankfurt am Main, Germany: Peter Lang Publisher House.

Saar, E., Täht, K., \& Unt, M. (2015). Segregated worlds of male and female labour market entrants in Estonia during the last decades? In P. Blossfeld, J. Skope, M. Triventi, \& S. Buchholz (Eds.), Gender, education and employment: An international comparison of school-to-work Transitions (pp. 325-345). Frankfurt am Main, Germany: Edward Elgar Publishing.

Unt, M., \& Saar, E. (2016). Determinants of retirement and late career in Estonia. In D. Hofäcker, M. Hess, \& S. König (Eds.), Delaying retirement: progress and challenges of active ageing in Europe, the United States and Japan (pp. 53-72). London, the UK: Palgrave Macmillan. 
Unt, M., \& Reiska, E. (2017) Estonia. In: D. Hofäcker, S. Schadow, J. Kletzing (Eds.), Long-term socio-economic consequences of insecure labour market positions, EXCEPT Working Papers, WP No 16. Tallinn University, Tallinn. Retrieved March 25, 2019, from http://www.except-project. eu/working-papers/.

Open Access This chapter is licensed under the terms of the Creative Commons Attribution 4.0 International License (http://creativecommons.org/licenses/by/4.0/), which permits use, sharing, adaptation, distribution and reproduction in any medium or format, as long as you give appropriate credit to the original author(s) and the source, provide a link to the Creative Commons license and indicate if changes were made.

The images or other third party material in this chapter are included in the chapter's Creative Commons license, unless indicated otherwise in a credit line to the material. If material is not included in the chapter's Creative Commons license and your intended use is not permitted by statutory regulation or exceeds the permitted use, you will need to obtain permission directly from the copyright holder.

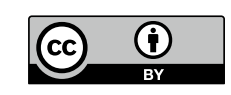




\title{
Chapter 18 \\ Finland
}

\section{Laura Salonen, Antti Kähäri and Ilkka Pietilä}

\begin{abstract}
Finland's population is ageing due to declining fertility and increasing life expectancy rates. This creates pressure to maintain high employment rates. Lately, Finland has focused on extending working careers by raising statutory pension age and facilitating part-time employment for pensioners. Finland faces high unemployment rates, low re-employment among over 55-year olds and high gender inequality in pension levels. Gender and educational inequality in pensions reflect the employment gaps and sectoral segregation that have accumulated along lifecourses. Finland aims to extend working life by promoting wellbeing at work, increasing labour market flexibility and supporting workers' competitiveness through various strategies. The latest reforms on unemployment activation and possible future reforms on the regional government, health and social services and basic income will likely affect pension intentions. To ensure equal levels of pensions, future reforms should focus on whole lifecourses and account for breaks in working life, such as parental leave and unemployment periods.
\end{abstract}

Keywords Working life $\cdot$ Pension $\cdot$ Gender $\cdot$ Health $\cdot$ Discrimination

\section{Introduction}

The Finnish economy has gained momentum after a period of poor economic performance. Challenges faced included the economic depression, which hit the country after 2008, adversities in electronic and forest industries, and a recession in Russia, an importer of Finnish goods. The Organisation for Economic Cooperation and Development (OECD) notes that strong economic performance and low inequality foster wellbeing in Finland. However, public resources are under pressure due to the ageing population, and work incentives need to be strengthened while maintaining strong social protection (OECD 2018b).

\footnotetext{
L. Salonen $(\bowtie) \cdot$ A. Kähäri

Department of Social Research, University of Turku, Turku, Finland e-mail: 1ksalo@utu.fi

I. Pietilä

Faculty of Social Sciences, University of Helsinki, Helsinki, Finland

(C) The Author(s) 2020

Á. Ní Léime et al. (eds.), Extended Working Life Policies, https://doi.org/10.1007/978-3-030-40985-2_18
} 
Due to declining fertility and increasing longevity, the population in Finland is ageing rapidly (OECD 2015). The sustainability of the pension system has been under debate, and governments have implemented several reforms aimed at extending working careers and raising the retirement age during the 21 st century. Currently, little research exists in Finland exploring the effects of policies aimed at extending working life in terms of gender and health. The following sections will review existing research on retirement, late work, flexible work, age discrimination and extended working life.

\section{Gender and Employment}

Finland was rated as the fourth most equal country in the world in 2018 (World Economic Forum 2018). Finland has a high gender equality in career length, labour market participation, employment rate and weekly working hours (Eurostat 2019; Järnefelt et al. 2013), but low gender equality in wages and median earnings (OECD 2018a). Finland has a dual breadwinner system and, when compared with other European countries, women seldom work part-time. In 2017, 17.4\% of women over the age of 15 engaged with part-time work as their primary profession in Finland, whereas the OECD average was $25.5 \%$ (OECD 2020). This is a result of various employment and educational policies, and generous family policies, which reduce incompatibility between labour force participation and childbearing. There has been a steady increase in the use of parental and paternity leave among fathers (Närvi 2018), however women still spend more time on parental leave. Despite high quality day-care services, many mothers avail of home care allowance that allows mothers to stay home with children until they turn three years old.

The gender wage gap is wide in Finland, at 16.5 percentage points in 2016, compared to the OECD average of 13.8 percentage points (OECD 2019a). This is largely due to a gender segregated labour market, where female professions are concentrated in low paid public sector occupations; women's representation in high paid occupations is lower than in other countries with smaller public sectors (Bettio and Verashchagina 2009; European Commission 2018). In 2015, Finland had the highest proportion of public sector employment filled by women (72.6\%) when compared to other OECD countries (average is 58.3\%) (OECD 2017a). In addition, women having fewer working hours (Statistics Finland 2017b), more widespread use of longer parental leave (Datta Gupta et al. 2008), and immigrant women having a poor attachment to the labour market (Shemeikka et al. 2017) contribute to the gender wage gap. Men, on the other hand, are more often in long term unemployment and excluded from the labour market (World Economic Forum 2018).

In general, the biggest problem in the Finnish labour market is high unemployment (Kyyrä and Pesola 2018). Finland matches the average European level of employment among 55-64 year old women, however the employment rate for men is much lower in Finland than the European average (Shemeikka et al. 2017: 143-145). In the general working population in 2017, men had higher levels of employment $(71.6 \%)$ 
than women did (68.5\%). However, among the 55-64 years old cohort, women had a higher employment rate (63.4\%) than men (61.7\%) (OECD 2018c, d). Growth in the employment of older workers has occurred primarily in the public sector (Shemeikka et al. 2017). Gender differences in the employment rate in this cohort are partially explained by the higher representation of women in the public sector, where working until old age pension is more common than in the private sector (Järnefelt 2014).

In Finland it is possible to work while receiving an old age pension. In 2017, 14\% of men and 7.6\% of women aged 65-74 years old were employed (Statistics Finland \& Labour Force Survey 2019). Old age pensioners who are still in employment are more likely to be male, have better health, have higher levels of education, and live with working spouses (Palomäki and Tuominen 2010). Since the 2017 pension reform, it has been possible to partially draw the accrued pension while on a partial old age pension, as the part-time pension was replaced by the partial old age pension. Previously the prerequisites to part-time pension were much tighter compared to the partial old age pension. Currently, around two thirds of partial old age pension retirees work. An additional pension will be earned for the work, but since it is subject to an early reduction, the amount of the full-time old age pension granted permanently will reduce by $0.4 \%$ a month. Even though partial old age pension decreases the old age pension in the long run, many choose partial old age pension to ease their tight economic situation (Järnefelt and Kautto 2017).

Women's more frequent employment gaps and involvement in low paid jobs accumulate across lifecourses and impact on their pension level in later life. In general, gender differences in pension incomes are more pronounced than gender differences in the lengths of working lives (Kuivalainen et al. 2018). At the end of 2017, an average overall monthly pension was $€ 1,874$ for men and $€ 1,476$ for women (ETK $2018 b)$. Gender gaps in both gross and net pension wealth are close to the OECD average (OECD 2019b, c). The gender difference in pensions declined between 1995 and 2007 but has since stagnated. In the last 15 years, earnings related pensions have increased for women (ETK 2018a).

\section{Extending Working Life Employment Policies}

The government, employers and workplace organisations have launched several measures to promote work capacity of all workers, with some focus on older workers (Järnefelt 2010:14). For example, the pension reform of 2005 increased flexibility by making it possible to combine the old age pension with work (Forma et al. 2005). Largely as a result of these reforms, working lives have lengthened in the 21 st century, especially among those aged 55-64 years old. Women's working lives have reached the same level as men. Increases in the employment rate among the older population are also explained by higher levels of education among the older generations (Martikainen et al. 2016). 
Most Finns do not continue working after the eligible retirement age. This is partly due to age discrimination (Larja et al. 2012), but the intention to work beyond retirement age also depends on human resource practices at work, job satisfaction, working conditions and trust at work (Muurinen et al. 2014; Salminen et al. 2018). Employees' willingness to continue working beyond minimum pension age is quite negative (Forma et al. 2005), but it has increased (Lehto and Sutela 2010). In 2005, around ten per cent intended to postpone their retirement; this deferral was more likely workers aged among men than women (Forma et al. 2005). Most employers are unwilling to hire over 55-year-olds, although employment sectors differ in attitudes (Tuominen and Takala 2006). At the turn of the 2000s, age management policies were implemented in several workplaces to improve older workers' working conditions and recruitment to promote age diversity (Naegele and Walker 2006; Shemeikka et al. 2017: 140). In 2015, five per cent had felt discriminated against because of age in Finland (Directorate-General for Justice and Consumers \& TNS Opinion \& Social 2015: 70). Overall, gender differences attributed to age discrimination have been reported as small, however these differences are more pronounced among older workers, where women reported having experienced age discrimination more often than men (Viitasalo et al. 2016).

In comparison with other European countries, Finland has lower levels of precarious work (Pyöriä and Ojala 2016). Finnish labour market regulation is described as individually protective and collectively collaborative, where industrial relations are based on collective negotiations. During the financial crisis of 2008-2013, Finland's proportion of precarious work increased to 13\%, surpassing 1990's recession levels. Consequently, a marginal group have experienced decreased job security due to the accumulation of uncertainty.

Several programmes for improving work ability and employment have been implemented over the last two decades, including the 'National Program on Ageing Workers (1998-2002)' that aimed to improve attitudes towards ageing workers (Ilmakunnas and Takala 2005). The Ministry of Social Affairs and Health adopted a strategy for social and health policy in 2011 titled 'Socially Sustainable Finland 2020', with a goal of extending employees' lifelong time at work by three years by 2020 (Ministry of Social Affairs and Health 2011).

\section{Pension Policies}

The Finnish pension scheme consists of a national pension and an earnings related pension. The earnings related system is a public private hybrid, partly funded through insurance companies. Earnings related pensions consider almost all earnings, while national and guaranteed pensions are based on residence and cover situations where earnings based pensions are inadequate (Barr 2013). In 2016, 59\% of pensioners received only earnings related pensions, seven per cent received only national pension and $34 \%$ of pensioners received both. More women received a combination of both pensions, whereas more men received the earnings only related pension (ETK and The Social Insurance Institution of Finland 2018). 
Statutory earnings related pensions have undergone two major reforms in the 2000s. The 2005 reform aimed to make the earnings related pensions more sustainable, increase employment of older workers, make the system more equitable, and decrease the use of voluntary early exit routes by abolishing early retirement schemes, such as individual early retirement pension and unemployment pension. Measures to increase employment of older workers included introducing a window of flexible retirement age, increasing accrual rates at older ages, increasing the actuarial adjustment of early retirement pensions, abolishing the cap on the replacement rate, and restricting access to early exit routes. Sustainability and equity goals were pursued by linking prefunding and pension benefits to life expectancy. This was addressed by applying benefits by lifetime earnings, identifying minimum ages for benefit computation and contribution requirement, changing the indexation rules, and redefining accrual for certain non-working episodes (Börsch-Supan 2005). The effects of this reform on employment and retirement were small but positive (Uusitalo and Nivalainen 2013). The expected rise in longevity, which sparked the 2005 reform, turned out to be greater than anticipated, and reaching a higher retirement age has been an aim in further government programs.

Another pension reform was implemented in 2017; the main motivations were lengthening careers, improving the age dependency ratio, and balancing the public economy. Consequently, the age requirements for entering the old age pension will increase for successive cohorts. For cohorts born after 1965, the limit will be linked with life expectancy. It is estimated that the retirement age for those born after 1970 will be 65 years old, and around 68 years for those born after 1995 . As the average life expectancy in women was 84 years and 78 years in men in 2016 (Statistics Finland 2017a), the pension reform will decrease the pension time relatively less for women compared to men (Kautto and Risku 2015).

The Finnish welfare system provides benefits for workers with health and work ability problems in the form of sickness allowance and disability pension. These benefits can be combined with working. The proportion of part-time and fixed term disability pensions has increased, and currently almost half of disability pensions are granted as fixed term (Nyman and Kiviniemi 2018). However, more could be done to more equally support part-time workers with work disabilities. For example, the public sector offers more flexible work environments, opportunities for employment with partial work ability, and an easier return to work from vocational rehabilitation than the private sector (Shemeikka et al. 2017). Another health related early exit route is through unemployment. While unemployment pension was abolished after the 2005 pension reform, in practice many move from long term unemployment to old age pension or disability pension (Riekhoff 2018).

\section{Health Policies}

Overall population health in Finland is relatively good. However, the gender difference in life expectancy in Finland is one of the highest in Western Europe and this may 
have implications for discussions about the link between the minimum retirement age and life expectancy. In addition, socioeconomic differences in life expectancy are large and increasing, especially in men (Tarkiainen et al. 2013). The Finnish healthcare system performs relatively well and health spending is slightly above the European Union average (Kangas and Blomgren 2014). The main foreseeable challenges in Finland are increasing health spending, socioeconomic and geographic differences in health, inequality in access to primary care, and men's high level of alcohol consumption. Occupational health care is funded by employers, ensuring a fast access to health care among the employed, but people outside the workforce have to wait longer to access services (OECD 2017b).

\section{Debate on Extending Working Lives}

The debate on extending working lives in Finland has mainly occurred in political discourse rather than among researchers. The target for retirement age in the government program was recorded for the first time in 1999 in Finland as a means to increase the employment rate, and to postpone the average exit age from the labour market by two to three years in the long run, thus reducing the pressure for rising pension costs. The negotiations of the 2005 pension reform started at the end of the 1990s among the social partners. Despite having a shared goal, proposed solution avenues differed among groups. Employers and the government proposed cutting pensions and blocking early retirement routes. In comparison, employees wanted to improve working conditions and give more responsibility to employers regarding early retirement costs. Trade unions had diverging interests, stemming from the differing career trajectories of the workers they represented. This manifested in disputes about the calculation of pension incomes. The Central Organisation of Finnish Trade Unions advocated for calculating pension incomes from the whole career, whereas Akava Special Branches (a multidisciplinary trade union and service organisation) considered this to be more beneficial for lower educated workers (Julkunen and Pärnänen 2005: 32-42). Considerations of the 2017 pension reform were sparked in 2010 when the Prime Minister asked these social partners (government, trade unions and employers) to reach an agreement regarding the extension of working lives, particularly among older workers.

In recent years, debates have centred around the 'Active employment model', which has been highly criticised among social partners (Eurofound 2018). The trade unions were against raising the pension age and sceptical regarding the employment opportunities and marginalisation of older people. Meanwhile, employers' organisations did not want the state to increase the regulation of the status of older workers. In November 2018, the Central Organisation of Finnish Trade Unions proposed a model where the order in which workers are laid off should be more determined by length of employment, favouring older workers (Kaukoranta 2018). The proposal raised concerns about a 'generation war' in the public. Some discussion has also 
taken place about extending working lives from the beginning of careers. Consequently, universities and student unions have criticised this approach, arguing that tertiary studies should be completed as quickly as possible without being interrupted by working. However, in general, the debates have ignored the element of gender almost entirely.

\section{Conclusion}

Extending careers has been a central topic in Finnish social policy. The goals articulated by the European Union Lisbon strategy regarding improved utilisation of potential workforces have served as a basis for Finnish policies. The participation of women and older workers has improved, however in Finland the emphasis has focused more on older workers, given that labour force participation of women is already quite high (Pärnänen 2011: 24-27). While Finland is a relatively gender equal country, gender differences in pensions reveal that there is a need for further policy development. Measures equalising the distribution in parental leave use, faster return to work after parental leave in women, decreasing unemployment rates, as well as preventing long-term work disability are needed. However, striving for more equal length of working life is not sufficient to eliminate gender inequality in pensions (Kuivalainen et al. 2018). Decreasing early exit from the labour market due to decreased work capacity and exclusion in general should be on the political agenda. In addition, socioeconomic inequality in pensions should be taken into consideration in reforms and in decision making. Finland is in the middle of planning large reforms, such as basic income and regional government, health and social services that will have a profound effect on the labour market and on pension behaviour. Gender and socioeconomic effects should be studied before any implementation of these reforms.

\section{References}

Barr, N. (2013). The pension system in Finland: Adequacy, sustainability and system design. Evaluation of the Finnish pension system part 1. Vaasa: Finnish Centre for Pensions.

Bettio, F., \& Verashchagina, A. (2009). Gender segregation in the labour market. Luxembourg: Publications Office of the European Union.

Börsch-Supan, A. (2005). The 2005 pension reform in Finland. Finnish Centre for Pensions, Working Papers 2005:1.

Datta Gupta, N., Smith, N., \& Verner, M. (2008). The impact of Nordic countries' family friendly policies on employment, wages, and children. Review of Economics of the Household, 6(1), 65-89.

Directorate-General for Justice and Consumers (European Commission) \& TNS Opinion \& Social. (2015). Discrimination in the EU in 2015. Special Eurobarometer, 437. European Union. https://publications.europa.eu/en/publication-detail/-/publication/d629b6d1-6d05-11e59317-01 aa75ed71a1/language-en. 
Eurofound. (2018). Annual review of working life 2017. Luxembourg: European Foundation for the Improvement of Living and Working Conditions.

European Commission. (2018). 2018 Report on equality between women and men in the EU. Luxembourg: Publications Office of the European Union.

Eurostat. (2019). Duration of working life-annual data. Retrieved March 11, 2019, from http:// appsso.eurostat.ec.europa.eu/nui/show.do?dataset=lfsi_dwl_a\&lang=en.

ETK (Finnish Centre for Pensions). (2018a). Conference 2018. Retrieved March 11, 2019, from https://www.etk.fi/en/research-2/research/seminars/conference-2018/.

ETK (Finnish Centre for Pensions) (2018b). Statistics on Pensioners in Finland. Finnish Centre for Pensions. https://www.etk.fi/en/statistics-2/statistics/pension-recipients/all-pensionrecipients/. Accessed 11 March 2019.

ETK (Finnish Centre for Pensions \& The Social Insurance Institution of Finland. (2018). Statistical yearbook of pensioners in Finland 2017. Statistics from the Finnish Centre for Pensions No. 10. Helsinki: Juvenes Print.

Forma, P., Tuominen, E., \& Väänänen-Tomppo, I. (2005). Who wants to continue at work? Finnish pension reform and the future plans of older workers. European Journal of Social Security, 7(3), $227-251$.

Ilmakunnas, S., \& Takala, M. (2005). Promoting employment among ageing workers: Lessons from successful policy changes in Finland. The Geneva papers on risk and insurance. Issues and Practice, 30(4), 674-692.

Järnefelt, N. (2010). Education and longer working lives. Helsinki: Finnish Centre for Pensions.

Järnefelt, N. (2014). Vanhuuseläkkeelle siirtyneiden työurat. In N. Järnefelt (Ed.), Sosioekonomiset erot-työurat, eläkkeelle siirtyminen ja eläkejärjestelmä Tampere: Juvenes Print-Suomen Yliopistopaino Oy. (pp. 33-61).

Järnefelt, N., \& Kautto, M. (2017). One third of partial old-age pension retirees not working. Finnish Centre for Pensions. Retrieved March 11, 2019, from https://www.etk.fi/en/tiedote/onethird-partial-old-age-pension-retirees-not-working/.

Järnefelt, N., Kautto, M., Nurminen, M., \& Salonen, J. (2013). Työurien pituuden kehitys 2000luvulla (Finnish Centre for Pensions, Reports No. 01). Helsinki: Finnish Centre for Pensions.

Julkunen, R., \& Pärnänen, A. (2005). Uusi ikäsopimus. Jyväskylä: SoPhi.

Kangas, O., \& Blomgren, J. (2014). Socio-economic differences in health, income inequality, unequal access to care and spending on health: A country-level comparison of Finland and 16 other European countries. Research on Finnish Society, 7, 51-63.

Kaukoranta, I. (2018). Irtisanomisjärjestys toisi turvaa ja selkeyttäisi nykytilannetta. SAK Blog. Retrieved March 11, 2019, from https://www.sak.fi/ajankohtaista/blogi/irtisanomisjarjestys-toisiturvaa-ja-selkeyttaisi-nykytilannetta.

Kautto, M., \& Risku, I. (2015). Laskelmia vuoden 2017 työeläkeuudistuksen vaikutuksista. Helsinki: Finnish Centre for Pensions.

Kuivalainen, S., Nivalainen, S., Järnefelt, N., \& Kuitto, K. (2018). Length of working life and pension income: empirical evidence on gender and socioeconomic differences from Finland. Journal of Pension Economics and Finance, 1-2. https://doi.org/10.1017/s1474747218000215.

Kyyrä, T., \& Pesola, H. (2018). The labor market in Finland, 2000-2016. IZA World of Labor, 421.

Larja, L., Warius, J., Sundbäck, L., Liebkind, K., Kandolin, I., \& Jasinskaja-Lahti, I. (2012). Discrimination in the finnish labor market. An overview and a field experiment on recruitment. Publications of the Ministry of Employment and the Economy No. 16. Helsinki: Ministry of Employment and the Economy.

Lehto, A.-M., \& Sutela, H. (2010). Ikääntyvien työpanos vahvassa kasvussa. Tieto \& Trendit, 2, $18-22$.

Martikainen, P., Murphy, M., Moustgaard, H., \& Mikkonen, J. (2016). Changes in the household structure of the Finnish elderly by age, sex and educational attainment in 1987-2035. Working papers, 88. Helsinki: Kela.

Ministry of Social Affairs and Health. (2011). Socially sustainable Finland 2020. Strategy for social and health policy. Helsinki: Ministry of Social Affairs and Health. 
Muurinen, C., Laine, M., Pentti, J., Virtanen, M., Salo, P., Kivimäki, M., et al. (2014). Vertical and horizontal trust at work as predictors of retirement intentions: The finnish public sector study. PLOS ONE, 9(9), e106956.

Naegele, G., \& Walker, A. (2006). A guide to good practice in age management., European Foundation for the Improvement of Living and Working Conditions Luxembourg: Eurofond.

Närvi, J. (2018). Isä hoitaa-vai hoitaako? Väestökyselyn ja haastattelujen tuloksia isien perhevapaiden käytöstä [Daddy takes care-or does he? Results of a population survey and interviews on fathers' use of family leaves]. Working paper, 1. Helsinki: National Institute for Health and Welfare.

Nyman, H., \& Kiviniemi, M. (2018). Katsaus eläketurvaan vuonna 2017. Eläketurvakeskuksen tilastoja, 6. Helsinki: Finnish Centre for Pensions.

OECD. (2015). Pensions at a Glance 2015: OECD and G20 indicators. Paris: OECD Publishing.

OECD. (2017a). Government at a Glance 2017. Paris: OECD Publishing.

OECD. (2017b). Health at a Glance 2017. Paris: OECD Publishing.

OECD. (2018a). Is the last mile the longest? Economic gains from gender equality in Nordic Countries. Paris: OECD Publishing.

OECD (2018b). OECD economic surveys: Finland 2018. Paris: OECD Publishing. Retrieved March 11, 2019, from https://doi.org/10.1787/eco_surveys-fin-2018-en.

OECD. (2018c). Table B2. Employment/population ratios by selected age groups-men. Retrieved March 11, 2019, from https://doi.org/10.1787/888933778934.

OECD. (2018d). Table B3. Employment/population ratios by selected age groups-women. Retrieved March 11, 2019, from https://doi.org/10.1787/888933778953.

OECD. (2019a). Gender wage gap. OECD. Retrieved March 11, 2019, from https://doi.org/10. 1787/7cee77aa-en.

OECD. (2019b). Gross pension wealth. OECD. Retrieved March 11, 2019, from https://doi.org/10. $1787 / 62$ cdd9d3-en.

OECD. (2019c). Net pension wealth. OECD. Retrieved March 11, 2019, from https://doi.org/10. 1787/c634eb4f-en.

OECD. (2020). Part-time employment rate. (indicator). https://doi.org/10.1787/f2ad596c-en. Accessed 17 February 2020.

Palomäki, L. M., \& Tuominen, E. (2010). Työssä käyvät eläkeläiset-erot muihin työssä käyviin ja eläkkeellä oleviin. Eläketurvakeskuksen keskustelualoitteita, 4. Helsinki: Finnish Centre for Pensions.

Pärnänen, A. (2011). Organisaation ikäpolitiikat: strategiat, instituutiot ja moraali (p. 255). Tilastokeskus: Tutkimuksia.

Pyöriä, P., \& Ojala, S. (2016). Precarious work and intrinsic job quality: Evidence from Finland, 1984-2013. The Economic and Labour Relations Review, 27(3), 349-367.

Riekhoff, A. J. (2018). Retirement trajectories in the Netherlands and Finland Institutional change, inequalities, de-standardisation and destabilisation. Tampere: University of Tampere.

Salminen, H., Vanhala, M., von Bonsdorff, M., \& von Bonsdorff, M. (2018). Perceived high involvement work practices and retirement intentions. Electronic Journal of Business Ethics and Organization Studies, 23(1), 29-36.

Shemeikka, R., Aho, S., Jokinen, E., Kaakinen, M., Korkeamäki, J., Mertala, S., et al. (2017). Työurien jatkaminen vaatii yhteisöllisyyttä ja yhteistoiminnallisuutta. Työurien jatkaminen vaatii yhteisöllisyyttä ja yhteistoiminnallisuutta, 38. Valtioneuvoston kanslia.

Statistics Finland. (2017a). Elinajanodote. Retrieved March 11, 2019, from http://www.stat.fi/org/ tilastokeskus/elinajanodote.html.

Statistics Finland. (2017b). Employment and unemployment 2017, 3. Working hours in 2017. Helsinki: Statistics Finland. Retrieved March 11, 2019, from http://www.stat.fi/til/tyti/2017/13/ tyti_2017_13_2018-04-12_kat_003_en.html.

Statistics Finland \& Labour Force Survey. (2019). 007-Population by labour force status, sex and age (5 yr). Retrieved March 11, 2019, from http://pxnet2.stat.fi/PXWeb/pxweb/en/StatFin/ StatFin_tym_tyti/statfin_tyti_pxt_007.px/chart/chartViewLine/?rxid=f4f38d5e-2065-425a8f75-1abab0de2f63. 
Tarkiainen, L., Martikainen, P., \& Laaksonen, M. (2013). The changing relationship between income and mortality in Finland, 1988-2007. Journal of Epidemiology and Community Health, 67, 21-27.

Tuominen, E., \& Takala, M. (2006). Ageing workforce and employers attitudes to employment of older persons. Working Papers, 5. Finnish Centre for Pensions.

Uusitalo, R., \& Nivalainen, S. (2013). Vuoden 2005 eläkeuudistuksen vaikutus eläkkeellesiirtymisikään, 5. Helsinki: Valtioneuvoston kanslian raporttisarja.

Viitasalo, N., Nätti, J., Ojala, S., \& Korvajärvi, P. (2016). Ikä-ja sukupuolisyrjintä työssä. Talous ja yhteiskunta, 4, 48-53.

World Economic Forum (2018). The global gender gap report 2018 (Insight Report). Switzerland: World Economic Forum.

Open Access This chapter is licensed under the terms of the Creative Commons Attribution 4.0 International License (http://creativecommons.org/licenses/by/4.0/), which permits use, sharing, adaptation, distribution and reproduction in any medium or format, as long as you give appropriate credit to the original author(s) and the source, provide a link to the Creative Commons license and indicate if changes were made.

The images or other third party material in this chapter are included in the chapter's Creative Commons license, unless indicated otherwise in a credit line to the material. If material is not included in the chapter's Creative Commons license and your intended use is not permitted by statutory regulation or exceeds the permitted use, you will need to obtain permission directly from the copyright holder. 


\title{
Chapter 19 \\ France
}

\author{
Julie Rochut and Jim Ogg
}

\begin{abstract}
France is characterised by a low labour force participation rate after of the age of 60. Recent and current reforms aim to increase the working life: raising the legal retirement age and increasing the duration of insurance contributions to obtain a full pension. Women have more career breaks, higher rates of part-time work and therefore lower pensions than men. Workers in hazardous jobs or with long careers can under certain conditions retire earlier than the legal age of 62 years. The gender inequalities observed in early years of employment are exacerbated in the latter part of the working life.
\end{abstract}

Keywords Gender · French pension reforms $\cdot$ Hazardous work

\section{Introduction}

France has a specific employment context with a relatively high unemployment rate and several measures that, until recently, have tended to make older workers leave the labour market prematurely. From 2003 governments have introduced reforms that encourage older workers to remain in the labour market.

\section{Gender and Employment in France}

The rise in the proportion of women in the labour market during the latter half of the twentieth century that has been a feature of many European countries is also present in France. Marchand and Thélot (1991) have identified two main phases in the development of women's work. The first phase, extending from the 1900s to the 1960s, was characterised by a decline in women's employment, after a full century of growth throughout the 19th century, while the second, beginning around 1965, saw a dramatic reversal of this trend. The turnaround in the 1960 s can be

J. Rochut $(\bowtie) \cdot$ J. Ogg

Ageing Research Unit, National Pension Fund (Cnav), Paris, France

e-mail: julie.rochut@cnav.fr 
attributed mainly to the massive entry of married women-with children-into the labour market, combined with a major shift in values, where the model of the working mother supplanted that of the stay-at-home or full-time mother.

Compared to other European countries, France displays an intermediary level of participation with $61 \%$ of women at work in 2015 , an increase of $8.5 \%$ since 1995 (Geraci and Lavigne 2017). However, in the 2000s, 70\% of French women experienced at least one career break since their first job compared with only $50 \%$ of men. Other than redundancy, the main reason for women's career breaks is for child-rearing.

The employment rate gap between men and women in the age group 55-64 years has been around five per cent since 2007 (compared to approximately $10 \%$ for women aged 25-54 years), and the unemployment rate is very similar between men and women (around 6\%). The employment rate of older workers has increased in recent years for both women and men: the proportion of women aged 50-64 in paid employment increased between 2007 and 2017 from 49.9 to $59.1 \%$ and that of men from 56.9 to $64.0 \%$. While women aged 50-54 or 55-59 are less likely to work than men of the same age, in 2017 women aged 60-64 are slightly more likely (29.8\%) to be in paid work compared to men $(28.6 \%$ ) (Beck and Vidalenc 2018) indicating the need for women to work longer in order to increase the level of their pension.

Although the proportion of women in part-time jobs has been stable in France at around 30\% between 1995-2015 (Geraci and Lavigne 2017) a larger proportion of women are in part-time jobs than men and this exposes women to greater risks of poverty in retirement.

Women also experience discrimination and inequality in terms of employment, career opportunities and salaries. The salary gap between men and women is about $15 \%$ (Eurostat 2016). The gender inequalities observed in early years of employment are exacerbated in the latter part of the working life. These differences are mainly due to the rise in female labour force participation experienced by baby boomers, which clearly differ from women of previous cohorts, many of whom permanently left the labour force after the birth of their first child. In 2012, one in four retired women had less than 25 years of accumulated working life (Hourriez 2015). A short working life is in turn reflected in significantly lower pension levels among women who are currently retired. In 2016, the mean gross State pension for men was $€ 1,739$ per month compared to $€ 1,065$ for women (Drees 2018). Pension levels for women are lower than for men, even when women have had a full working life, although the pension income gap has narrowed over recent years (see Chap. 1). Because women continue to experience gaps in their working life histories they increasingly work longer to maximise their pension (Bonnet et al. 2006).

A further gender difference in income levels in the context of extending working life concerns divorced women. As in other European countries, France's divorce rates have increased (Bellamy 2017) and the consequences of this trend have significantly lowered levels of income among divorced older women, mirroring those of widows, which may compel divorced women to remain in work longer.

Since 2000, the participation of older workers in the labour market has increased rapidly due to the decrease of early retirement measures, demographic changes and 
pension reforms - the employment rate of older workers (aged 55-64) has increased by $15 \%$ since 2003 . However, France has one of the lowest rates of employment in Europe for men aged 60-64: 27.7\% in 2016 (Eurostat 2017). Rates are also relatively low for women $(28.4 \%)$ compared to other European women in the same age group (approximately 48\%).

This increase for the 55-64 year old group has also gone hand in hand with a strong development of part-time work and a worsening state of health of this age group in the labour market. In 2016, workers over the age of 55 more often have part-time jobs than younger workers. A small proportion of these older part-time workers have more than one job. For older workers, part-time work is frequently due to personal, domestic and health reasons. Manual workers are 5.6 times more likely to report working part-time for health reasons than executives. Among older workers, gender and occupational status differences in part-time work are identical to those observed for part-time workers in mid-life careers. However, differences appear between the age groups 55-59 and 60-64, with part-time work being more widespread and with shorter hours among the latter group (Letroublon 2017).

This low participation is also a matter of family organisation. One-fifth of men and women aged 51-60 years care for a sick, elderly or disabled family member. Among these caregivers, 58.6\% are women (Prouet and Rousselon 2018) and the average time spent caring by women is significantly higher than men. Lifecourse lag (end of studies, age at maternity, end of working life, later mortality) increases the likelihood of multiple family obligations for older workers. Extended working life reduces the availability of informal carers but it can also increase incentives to continue earning through paid work to finance family obligations. The proportion of individuals who retire totally or partially because of family reasons is increasing.

\section{Pension System and Extended Working Life Pension Policies in France}

There are three pension tiers in France. A main public pension system provides income amounting to roughly 14 per cent of GDP (COR 2015). This main scheme for wage earners of the private sector is the most important public pension scheme, covering more than two thirds of the working population. Together with its complementary point-based public second pillar which is based on contributions deducted from wages, it provides the main source of income during retirement, with a median replacement rate of last earnings of $75 \%$ for continuous careers. For people born before 1948, 160 quarters validated were required. A quarter is validated on the basis of yearly earnings: an equivalent of $150 \mathrm{~h}$ paid for workers earning at least the minimum wages validates one quarter, regardless of the actual work duration. This validation gives entitlement for a future pension. Since the reforms, the number of quarters increases by one for every two generations to reach 172 quarters for the generation born in 1973 and thereafter. A supplementary voluntary private pension 
is the third tier, but it represents only two per cent of the total of retirement pensions and benefits received. In 2014, the average standard of living of retirees was slightly higher than in the overall population, the ratio between the two being $106.1 \%$ (103.3\% for women and $109.3 \%$ for men) (COR 2017). A systemic reform of the French pension system was announced by the Government at the end of 2019, based on the Swedish Pay-As-You-Go notional accounts system. However, the proposed reforms have been met with protest as the system disadvantages certain professions and rises significantly the minimum pension age (without a degressive penalty) from 62 to 64 years.

Several measures that aim to extend the working life have been recently implemented:

- Postponing the legal retirement age. The aim of these reforms has been to push back the age at which a worker is eligible for a full rate pension. Since 2010, the legal retirement age has been raised progressively by four months for each generation, for the birth cohorts 1951-1956, to reach 62 years for men and women. However, if workers do not have a full career, penalty points are applied that reduce the level of the pension. The age at which no penalty points are applied has been raised from 65 to 67 years. Since 2012, for workers with an unusually long career (those who started working before age 20 with a full career or more than 40 years worked) it is possible to retire at age 60 . Approximately 150,000 people retire each year at age 60 after a long career (75\% are men). Besides the positive effect on employment rates, increasing the statutory retirement age can also have an impact on other public insurance schemes, such as unemployment insurance, disability insurance or sick pay insurance. Older individuals already out of employment may not react to the incentives to return to work, and simply stay longer on the bridge between employment and retirement. Workers who for a long time expected to retire at age 60 may exit the labour market and use alternative schemes to fill their income gap until retirement. Recent evidence suggests that the increase in the legal retirement age from 60 to 62 has also increased the number of people resorting to unemployment or disability benefits in the years preceding retirement. This means that the objective of extending working life has only been partially achieved by increasing the retirement age: only $40 \%$ of people who would have normally retired at age 60 continue to work until age 61 , whereas one third remain unemployed, one-sixth receive disability or invalidity benefits, and one-sixth are out of the labour market completely (Rabaté and Rochut 2019).

- Surcote: pension premium. For workers retiring after the current legal age of 62 and having more than the required number of contributions for a full pension, a premium can be set under certain conditions to increase the pension. Each quarter contributed beyond the statutory retirement age increases the retirement pension by $1.25 \%$. Approximately $15 \%$ of pensions for employees in the private sector are paid each year with a premium (Berteau-Rappin 2018). Professional status is significantly associated with the choice to retire with a premium: being a manager and having a high income increases the probability of deferring retirement with a premium (Aouici and Rochut 2017). Moreover, workers who anticipate economic 
difficulties are also more likely to retire later with a premium. For instance, home buyers are more likely to extend working life, probably in order to pay off their mortgage.

- Décote: pension relief. If a worker decides to retire after the legal minimum age (62) and before the age of 67 but without a full number of contributions, a discount factor is applied. It is a discount coefficient applied for each missing quarter, inducing a decrease compared to the full rate. The discount of $1.25 \%$ (for a worker born before 1944) for each quarter missing (5\% per year) was gradually reduced to $0.625 \%$ (for a worker born after 1952). Only ten per cent of pensions paid each year are with a discount factor. The proportion is slightly higher for women than for men (11\% vs. $8 \%$ respectively).

- Mandatory retirement. The mandatory retirement age is the age at which an employer can choose to separate from an employee-without dismissal-even if the employee does not wish to leave. This age was set at 65 until 1 January 2009; it is now 70 years. Rabaté (2017) finds that mandatory retirement does affect retirement patterns: exit rates from employment are estimated to be six per cent higher when mandatory retirement is possible.

- Préretraite - preretirement or early retirement. Two types of preretirement exist. Private ones are implemented by firms. Although French companies are taxed for implementing early retirement, many continue to use early retirement measures. Companies may opt for the preretirement of employees when they restructure management, and employees take preretirement often in the context of planned job protection measures. However, the use of early retirement as a tool to manage age pyramids which was predominant in the years 1970-1980, has decreased. Since the mid-1990s, early retirement in the public pension system has experienced tightening conditions of access and public funding. A preretirement measure allows people to keep their level of wage before retirement. In 2009 only 50,650 employees from the private sector received a state preretirement pension compared to more than 200,000 employees in 1999 (Merlier 2010).

- Combination of employment and retirement-Gradual retirement: 'retraite progressive' and 'cumul emploi retraite'. After the abolition of early retirement as a government policy initiative, public authorities have encouraged extending working life through two measures. The retraite progressive measure eases the transition to retirement by allowing an individual to combine part-time work with drawing a proportion of their pension and enabling retirement contributions to be paid to increase further the value of the full pension. This dates from 1988 but is still very little used-only 8,000 people in 2016 and mostly women (70\%). The reasons for this low take-up are complex, but they include spin-off effects for second pillar pensions and a strong normative attachment to retirement on achieving eligibility. A combination of retirement and employment is more widespread, and more than 400,000 persons work and receive a retirement pension among a total of 14 million retirees, a proportion of less than three per cent. 


\section{Unemployment Policies}

'Convention d'assurance chômage'-Unemployment benefit conditions. The current unemployment insurance agreement defines a single benefit profile where the length of compensation is equal to the covered work experience. Since 1 October 2017, the maximum duration has been fixed to two years (730 days) until age 53, two and a half years (913 days) between age 53 to 54, and three years (1,095 days) from age 55 . The impact of a longer compensation for older workers is controversial since longer unemployment benefit duration can be seen either as a disincentive to re-enter paid employment or as a measure allowing more time to help unemployed workers find a job that fits their profile. The pension reforms announced in 2019 reform do not change unemployment benefit conditions for senior workers - the affiliation duration does not change and senior workers aged 57 years or more are not impacted by the decrease of the benefit.

\section{Health Policies}

Compte pénibilité-Hazardous working conditions account. Increased life expectancy and longer careers operate unevenly across occupations: many employees approach retirement age in deteriorated physical conditions. A personal account aimed at preventing the impact of harsh working conditions was introduced in 2016. Since October 2017, the definition of annual thresholds associated with each of the six occupational risk factors were set out in the Labour Code, defined as factors of strain (hyperbaric activities, high temperature, noisy environment, night work, work in alternating teams, repetitive tasks). Employers must identify employees for whom the threshold is exceeded for one or more factors. Hence, the account allows employees exposed beyond the thresholds to gain points, which can be used to fund either training opportunities to access less arduous jobs, or a reduction in working hours with wage loss compensation or retiring earlier with a maximum of two years earlier than the legal age of retirement.

\section{Debate on Extending Working Life}

Measures to extending working life remain unpopular among the general population. Many workers feel that promises made earlier in their career that set the retirement age to 60 have been broken. There is also a widespread view among the general population that older workers should give up their job for the benefit of younger workers who encounter difficulties in finding permanent jobs. Among the civic sector and trade unions, the debate on extending working life is focused on the need to protect long career workers and those with hazardous occupations. The precarious nature of jobs 
(short-term temporary contracts), closures and relocation of industries in localised areas where few alternative jobs are available are often evoked as major obstacles to extended working life.

According to Guillemard (2013), the organisation and structure of retirement systems play an important role in defining of 'old age' as a period of inactivity that follows a working career. She has analysed the phenomenon of early withdrawal from the labour market which was a strong feature of the French retirement system during the 1980s and 1990s. Following the oil crisis of 1973, French social policy converged by focusing on early withdrawal by older workers from the labour force. Far from providing workers with a secure retirement, policies directed towards early labour market exit were driven by economic uncertainties and rapidly changing organisational structures of employers.

Currently a reform of the retirement system is under consideration. The aim of the reform is to change the current system into a notional account system. However, the debate on pension age is still lively. Recently, the Minister of health gave a controversial interview in which she claimed that the minimum pension age should be 64 (instead of 62). The trade unions have reacted strongly claiming that it is a spurious debate because high unemployment persists and under these conditions the risk is to increase the precarity of older workers. The debate on extending working life is not finished.

\section{Gender and Health Implications of Extending Working Life?}

Firmly grounded in a lifecourse approach, research at the unit 'Ageing and Work' at the Centre for Employment Studies (Volkoff 2012), has studied gender differences relating to ageing, work and health. Attention is given not only to how ageing men and women adapt in relation to work but also how the workplace and employers' attitudes towards workers develop in the context of an ageing workforce. Several French epidemiological studies have demonstrated the effect of workplace conditions and organisational transformations for the ageing worker. David and colleagues (2001) observe that industries and business mostly regard the ageing of their workforce negatively, both in terms of financial cost and the capacity of workers to perform their jobs.

The ESTEV (enquête santé travail et vieillissement) panel survey clearly demonstrated that for both men and women, older manual workers had a higher prevalence of musculoskeletal disorders and high blood pressure than non-manual workers. Furthermore, even controlling by age and type of occupation, for both genders, health problems depend on the work's physical requirements or constraints (carrying heavy loads, efforts on tools, constraining postures, etc.), on the work schedule requirements (alternating, atypical schedules, etc.) and on other organisational choices such as the decisional latitude and high psychocognitive demand (David et al. 2001).

According to Chappert and Théry (2016), little research exists on certain aspects of working conditions and especially how they are experienced by women. These 
include gender differences in the exposure to hazardous risks, psychosocial risks, older workers, working hours and professions that are predominately mono-gender. Bouffartigues and colleagues (2010) have found that a higher proportion of women report a positive effect of work on their health than men. At the same time, women are more likely to experience higher levels of psychosocial problems.

Research has also been undertaken on the wider consequences of extending working life for social and voluntary participation, grandparenting and caring for older parents (Jolivet and Zahiri 2010). These studies focus on the potential consequences for intergenerational solidarity arising from increasing the length of the working life, both in the public and private domains. Concerning women, combining work and caring has increasingly attracted attention, given the fact that older women are key carers for both their ageing parents and grandchildren (Bonvalet et al. 2015; Le Bihan and Martin 2010).

Research has also been undertaken on life expectancy without disability and the implications for extending working life. As in other European countries, inequalities in life expectancy without disability exist between men and women but they are compounded by social factors among which work and career histories are prominent. Research has shown that not only do higher socio-professional groups have a greater life expectancy than manual workers, but also that manual workers have a greater number of average years spent with a disability (Cambois and Robine 2013). This phenomenon is known as the 'double penalty of manual workers'.

\section{Conclusion}

Extended working life in France is mostly being implemented by institutional measures such as pension eligibility rules. These are increasing the average age at which workers retire, but there is little evidence for the desire to extend working life. Many women are adversely affected by extended working life measures, in so far as they are obliged to work longer to secure an adequate income. Continued high rates of unemployment create structural barriers to government aims of reducing state expenditure on retirement pensions. Measures such as the harsh working conditions account and early retirement for long careers protect workers from the adverse effects of extended working life, although these measures have been politically difficult to introduce (often in the face of criticism by employers) and their future remain uncertain. Part-time jobs at the end of the career, could become more widespread and this needs to be addressed by policy makers.

\section{References}

Aouici, S., \& Rochut, J. (2017). Which factors influence premium deferred retirement decision? Paper presented at 13th Conference of the European Sociological Association, Athens, 
Greece. https://www.statistiques-recherches.cnav.fr/colloques-et-seminaires.html. Accessed 4 March 2019.

Beck, S., \& Vidalenc, L. (2018). L'emploi des seniors en hausse entre 2007 et 2017: plus de temps partiel et d'emplois à durée limitée [Increase of senior employment between 2007 and 2017: more part time]. Insee Focus $\mathrm{N}^{\circ}$ 119. https://www.insee.fr/fr/statistiques/3582878. Accessed 4 March 2019.

Bellamy, V. (2017). 236300 mariages célébrés en France en 2015, dont 33800 mariages mixtes [236 000 weddings in France in 2015, 33800 mixed-race marriage]. Insee Première, $n^{\circ} 1638$. https://www.insee.fr/fr/statistiques/2656612. Accessed 1 March 2019.

Berteau-Rappin, C. (2018). Prendre sa retraite: incidence des dispositifs de prolongation d'activité sur les parcours individuels [Retirement: impact of extending working life measures] Cahier de la Cnav, 11, 65-91

Bonnet, C., Buffeteau, S., \& Godefroy, P. (2006). Les effets des réformes des retraites sur les inégalités de genre en France [Impact of retirement reforms on gender inequalities in France]. Population, 61(1), 45-75.

Bouffartigues, P., Pendariès, J. R., \& Bouteiller, J. (2010). La perception des liens travail santé [Perception of health and labour relationship]. Revue française de Sociologie, 51(2), 247-280.

Bonvalet C., Clément C., Ogg J. (2015). Renewing the Family: A History of the Baby Boomers. Paris: INED Population Studies, Vol. 4.

Cambois E., \& Robine J-M. (2013). Les espérances de vie en bonne santé des Européens [Europeans healthy life expectancies]. Population \& Sociétés, 499, 1-4. https://www.ined.fr/fr/publications/ editions/population-et-societes/pdf. Accessed 1 March 2019.

Chappert, F., \& Théry, L. (2016). Égalité entre les femmes et les hommes et santé au travail. Comment le genre transforme-t-il l'intervention sur les conditions de travail? [Equality between men and women and occupational health]. Perspectives interdisciplinaires sur le travail et la santé. https://doi.org/10.4000/pistes.4882.

COR - Conseil d'orientation des retraites (2015). Évolutions et perspectives des retraites en France. Rapport annuel du COR Juin 2015. Paris: La Documentation française.

COR-Conseil d'orientation des retraites (2017). Évolutions et perspectives des retraites en France. Rapport annuel du COR Juin 2017. Paris: La Documentation française.

David, H., Volkoff, S., Cloutier, E., Derriennic, F. (2001). Vieillissement, organisation du travail et santé [Ageing, work organisation and health]. Perspectives interdisciplinaires sur le travail et la santé. https://doi.org/10.4000/pistes.3745, https://journals.openedition.org/pistes/3745? gathStatIcon=true\&lang=fr. Accessed 1 March 2019.

Drees_Direction de la recherche, des études, de l'évaluation et des statistiques (2018). Les retraités et les retraites. Paris: Drees.

Eurostat (2016). Gender pay gap database. https://ec.europa.eu/eurostat/statistics-explained/index. php/Gender_pay_gap_statistics. Accessed 1 March 2019.

Eurostat. (2017). Employment and unemployment (Labour force survey) database. https://ec. europa.eu/eurostat/web/lfs/data/database. Accessed 1 March 2019.

Geraci, M., \& Lavigne, A. (2017). Les écarts de pension entre les femmes et les hommes: un état des lieux en Europe [Gender pension gap: assessment in Europe]. Insee Référence Femmes, hommes l'égalité en question. https://www.insee.fr/fr/statistiques/2586548. Accessed 1 March 2019.

Guillemard, A. M. (2013). Prolonging working life in an aging world: A cross-national perspective on labor market and welfare policies toward active aging. In J. Field, R. J. Burke, \& C. L. Cooper (Eds.), The SAGE handbook of aging, work and society (pp. 60-73). London: SAGE.

Hourriez, J. M. (2015). Les revenus des retraités [Retirees' income]. Retraite et société, 1, 139-150. Jolivet, A., \& Zahiri, E. (2010). Travailler plus longtemps (Working longer). Paris: La documentation française.

Le Bihan-Youinou, B., \& Martin, C. (2010). Prise en charge d'un parent âgé dépendant et vie professionnelles [Caring old relatives and working life]. In A. Jolivet, E. Zahiri, \& E. Travailler (Eds.), plus longtemps (pp. 973-974). Paris: La documentation française. 
Letroublon, C. (2017). Les seniors au travail: la durée du travail est-elle plus faible à l'approche de la retraite ? (Seniors workers: which working hours?) Dares analyse $\mathrm{N}^{\mathrm{o}} 050$. https://dares.travailemploi.gouv.fr/IMG/pdf/2017-050.pdf. Accessed 3 March 2019.

Marchand, O., \& Thélot, C. (1991). Deux siècles de travail en France [Two centuries of work in France]. Paris: Etudes Insee.

Merlier, R. (2010). Les préretraites publiques en 2009: dix fois moins d'entrées qu'en 1999 [Public pre-retirement in 2009: ten times less entries than in 1999]. Dares analyse, $\mathrm{N}^{\mathrm{o}} 062$. https://dares. travail-emploi.gouv.fr/IMG/pdf/2010-062.pdf. Accessed 3 March 2019.

Prouet E., \& Rousselon J. (2018). Les seniors, l'emploi et la retraite [Seniors, employment and retirement]. Rapport France strategie. https://www.strategie.gouv.fr/publications/seniorslemploi-retraite. Accessed 3 March 2019.

Rabaté, S. (2017). Can I Stay or Should I Go? Mandatory Retirement and Labor Force Participation of Older Workers. PSE Working Papers n²017-19. https://halshs.archives-ouvertes.fr/halshs01521150. Accessed 3 March 2019.

Rabaté, S., \& Rochut, J. (2019). Employment and substitution effects of raising the statutory retirement age in France. Journal of Pension Economics and Finance. https://doi.org/10.1017/ S1474747218000392.

Volkoff S. (2012). Les "séniors" pourront-ils travailler plus longtemps? [Will seniors able to work longer?]. In M.-J. Thiel (Ed.), L'automne de la vie. Enjeux éthiques du vieillissement (pp. 109122). Strasbourg: Presses Universitaires de Strasbourg.

Open Access This chapter is licensed under the terms of the Creative Commons Attribution 4.0 International License (http://creativecommons.org/licenses/by/4.0/), which permits use, sharing, adaptation, distribution and reproduction in any medium or format, as long as you give appropriate credit to the original author(s) and the source, provide a link to the Creative Commons license and indicate if changes were made.

The images or other third party material in this chapter are included in the chapter's Creative Commons license, unless indicated otherwise in a credit line to the material. If material is not included in the chapter's Creative Commons license and your intended use is not permitted by statutory regulation or exceeds the permitted use, you will need to obtain permission directly from the copyright holder.

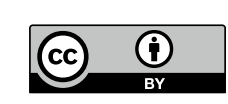




\title{
Chapter 20 \\ Germany
}

\author{
Laura Romeu-Gordo and E. K. Sarter
}

\begin{abstract}
Over the last few decades, the German pension system has undergone important changes, from the introduction of care credits to account for care responsibilities to the extension of working lives. This chapter provides an overview of recent pension reforms in Germany. Following a Bismarckian tradition, the German pension system is reliant on contributions made over the course of individual working lives. To account for the strong interdependency between employment and pension entitlements, this chapter embeds the overview of pension reforms in the broader context of recent developments in the labour market and policies aiming to facilitate reconciliation between work and family life and those supporting the extension of working lives.
\end{abstract}

Keywords Germany $\cdot$ Gender $\cdot$ Ageing $\cdot$ Pension policies $\cdot$ Employment policies $\cdot$ Extending working life

\section{Introduction: Gender and Employment in Germany}

Before German unification in 1990, very different public policies (and social realities) regarding the gender division of labour existed in the two German states. While public policies in East Germany encouraged high levels of employment and long working hours for women (Rosenfeld et al. 2004, p. 107), public policies in West Germany, especially tax and childcare policies, deterred women, especially mothers, from full-time employment. This often led to a short duration of employment followed by an early entry into the status of housewife (Berger et al. 1993, p. 56). After unification, the institutional transformation in East Germany caused important changes in female employment and careers. In the aftermath of unification, the employment rate of working mothers (Bonin and Euwals 2001, Bundesministerium für Familie, Senioren, Frauen und Jugend 2015: 30) and the rate of couples with

\footnotetext{
L. Romeu-Gordo ( $\square)$

Deutsches Zentrum für Altersfragen (DZA), Berlin, Germany

e-mail: Laura.Romeu-Gordo@dza.de

E. K. Sarter

Faculty of Business and Society, University of South Wales, Pontypridd, UK

(C) The Author(s) 2020

Á. Ní Léime et al. (eds.), Extended Working Life Policies, https://doi.org/10.1007/978-3-030-40985-2_20
} 
both partners working full-time decreased significantly (Klenner 2009). At the same time, women in West Germany increased their labour force participation (Simonson et al. 2011), albeit to a considerable extent in part-time and often in the low-paid sector. As Kelle and colleagues (2017), show it is especially women in West Germany who remain in part-time work for a prolonged period of time after the birth of the first child. Participation in low paid and part-time employment in general has consequences for the employment biographies of women beyond the family phase. The literature has shown that part-time employment often implies lower-grade career opportunities and a lower level of income than full-time work (Bardasi and Gornick 2008), which can lead to restricted late careers.

In 2018, the total employment rate for individuals aged 15-64 in Germany was $75.9 \%$, with a marked difference between the employment rate for women $(72.1 \%)$ and that of their male counterparts (79.6\%) (Destatis 2019). These employment rates were the result of a sharp increase in the total employment rate; over the previous ten years, the total employment rate for this age group rose by $5.9 \%$ points with a particularly sharp increase of $7.9 \%$ points for women and a slower yet significant increase of $3.9 \%$ points for men (Destatis 2019). Over the same period of time, the employment rate for those aged between 60 and 64 rose significantly, from $35.0 \%$ in 2008 to $60.4 \%$ in 2018 . At the same time, the gender employment gap in this age group narrowed. In $2008,43 \%$ of men and $27.2 \%$ of women in this age group were employed, leading to a gender gap of $15.8 \%$ points. In 2018 , in the same age group the employment rates were $65.5 \%$ for men and $55.6 \%$ for women, resulting in a gender gap of $9.9 \%$ (Destatis 2019). Despite these increases, the employment rates for older workers aged 60+ remain significantly lower than those of younger individuals. In this chapter, we review recent public policies aiming at prolonging working life in Germany with a special focus on the gender and health implications of such policies.

\section{Pension Policies}

Following a Bismarckian tradition, the German pension system relies on individual contributions to pension insurance, which are based on individual labour market participation. Since 1986, care credits exist to account for gendered working lives, namely for the fact that a considerable number of women interrupt their working lives as a result of care responsibilities (Frericks et al. 2008).

Over the last few decades, the German public pension system has undergone a long process of ongoing reforms. A strong motivation for these reforms was the rapid ageing of the German population: while the percentage of individuals aged 65 and older was $15.7 \%$ in 1996, it increased to $21.2 \%$ in 2016 (Gerostat 2018). In the 1990s, the pension reforms of 1992 and 1999 restricted existing early retirement options, which had been introduced in the 1970s to open up the opportunity of retiring before the statutory pension age of 65 (Berkel and Börsch-Supan 2004). This change affected women, unemployed individuals, and people with health problems 
disproportionately as they previously had the opportunity to retire at 60 . In addition, long-term insured individuals (for whom retirement had been previously available from 63 years onwards) were strongly affected (Berkel and Börsch-Supan 2004). At the same time, these reforms introduced a reduction of pension levels of $0.3 \%$ per month for early pension entry for individuals making use of early retirement options and an increase of pension level of $0.5 \%$ for each month for those who postponed their retirement entry (Bonin 2009).

In the 2000s, further reforms, which aimed to offset shortfalls in public pensions, changed the German statutory pension scheme considerably (Bonin 2009; Honekamp and Schwarze 2010). The so-called Riester reforms of 2001, in particular, marked a 'paradigm shift' (Mierzejewski 2015: 696) as they introduced 'a kind of privatisation' (Berner 2006: 499). More specifically, these reforms introduced supplementary pension pillars, which are not mandatory but publicly subsidised, either by tax deferral or deduction or direct subsidies to individual and occupational pension schemes. In addition, they reduced the amount of state pensions by about 4\% (Rüb and Lamping 2010). Grounded in divergent life expectancies, the contracts initially provided different conditions for women and men. Since 2005, contracts and pension levels do not distinguish between women and men (Hagen and Kleinlein 2011). Effecting a partial marketisation of the pension system (Hagen and Kleinlein 2011), this reform has been hailed as introducing 'fundamental changes which have overhauled basic policy ideas' (Rüb and Lamping 2010: 144). Over the following years, further changes were introduced to indexation, care credits, legislated pensionable age, pension options for self-employed and those with a long history of contributions to pension insurance (Brussig et al. 2016; Frericks et al. 2008; Natali 2018). Most importantly, in 2007, the legislated pensionable age was raised progressively from 65 to 67 years by 2032 and a penalty free option to retire at 65 was introduced for the long-term insured (Brussig et al. 2016). In 2014, care credits, which had been introduced in 1986 to account for the social value of care work as well as labour market implications resulting from caring for young children, were extended (crediting of an additional year for children born before 1992) (Brussig et al. 2016).

Given divergent employment rates and patterns and the existence of a gender pay gap in combination with a strong reliance of pensions on (previous) earnings, it comes as no surprise that a significant gender pension gap exists, which is remarkably bigger in Western than in Eastern Germany. In fact, the German overall gender pension gap $46 \%$ remains one of the highest in Europe (OECD 2019). While the introduction and extension of care entitlements may have a significant impact on women, caring responsibilities may lead to longer interruptions and part-time employment, so that the existing care credits cannot be expected to fully close the gender pension gap (Möhring 2014). In addition to entitlements deriving from contributions, pensioners receiving low or no pension are eligible to receive social aid through a means-tested scheme. More women than men receive social aid from age 65 onwards $(3.3 \%$ vs. $3.0 \%$ in 2017) (Kaltenborn 2019). No relevant reforms affected social aid. 


\section{Actors Intervening in the Pension Reforms Debate}

Traditionally, pension policy making in Germany has used a 'Grand Coalition' strategy (Busemeyer 2006), which was based in consensual policy making in which the two big parties (the Christian Democratic Union (CDU) respectively the Christian Social Union in Bavaria (CSU) as well as the Social democratic Party (SPD)) built a broad consensus to pass major pension reforms. While this relied on the major parties, other actors were part of the 'policy network of pension politics' (Busemeyer 2006: 412), namely policy experts from the Association of German Pension Providers (VDR), the Federal Agency for the Social Insurance of Employees (BfA) and the social partners (Busemeyer 2006).

Since then, the 'Grand Coalition' strategy was increasingly disregarded, first by the CDU in 1997 and then by the SPD reforms in 2000 (Ante 2008). For instance, in the pension reform of 2001, the SPD government looked for the support of the trade unions after having failed to create a consensus between CDU/CSU and SPD. As a result, this reform passed with the exclusion of the opposition parties. In comparison, the 'Sustainability of Pensions' law of 2004, which was adopted under a government formed by the SPD and the Green Party, was a more unilateral strategy from the government (Busemeyer 2006).

According to Trampusch (2005) the role of social partners has become less relevant in pension policy-making since the beginning of the 2000s. According to Ante (2008), the red-green coalition led to a more active government and a party system acting more autonomously from social partners. Furthermore, new actors have gain relevance in pension policy like new think tanks, 'party politicians', the finance minister, and the finance industry and media coverage, making the decision process more complex (Ante 2008).

\section{Low Paid Employment}

One of the major developments in the labour market in Germany over the past 20 years was the significant growth of the low pay sector. Between 1995 and 2013, the proportion of low paid workers, defined as those receiving less than two thirds of the median hourly wage (calculated based on real working times) among dependent employees increased sharply from $18.8 \%$ to $24.4 \%$ (Kalina and Weinkopf 2015). In the following years, the proportion of employees earning low wages remained at a similar level with $22.7 \%$ in 2016 (Kalina and Weinkopf 2018). Important regional differences between East and West Germany persist, both in terms of the level and the development of low paid work. In 2016, low paid workers accounted for about $35 \%$ of the workforce in East Germany. The share of low paid workers was significantly lower in West Germany (20.3\% in the same year) (Kalina and Weinkopf 2018). Also the development over time differed strongly. While the share of low paid workers in East Germany remained rather stable between 1995 (37.9\%) and 2013 (38.5\%) and 
decreased in the following years, it increased significantly in West Germany (from $14.6 \%$ in 1995 to $20.3 \%$ in 2013) (Kalina and Weinkopf 2015, 2018). The risk of being in low paid employment is above the population mean particularly for younger but also for older individuals. In 2016, 58.6\% for individuals aged up to 24 years of age were in low paid. While the risk for employees aged 55 and older is lower ( $25.1 \%$ in 2016) than for those under the age of 24 , it is still above the population mean. Low paid employment is furthermore gendered. In 2016, 29.2\% of female but only the $16.6 \%$ of male workers were low paid workers (Kalina and Weinkopf 2018). With women disproportionately involved in the growth of the low paid sector in recent decades and pension levels bound to contributions from employment, the growing involvement of women in low paid work means these women are only able to earn low pension rights.

One particularly important feature of the growth of a low paid sector in Germany are 'mini-jobs' (geringfügige Beschäftigung), jobs which generate an income of up to $€ 450$ per month or employment that is limited to up to 70 working days/year (Bachmann et al. 2016). Mini-jobbers do not contribute to all parts of the social security system. As for the low paid sector in general, employees working in mini jobs are predominantly female; in 2015 about two thirds of those who only held a mini job were women (Bachmann et al. 2016). Two important changes affected their situation over the last few years, first, their inclusion in the pension insurance system and second, the introduction of a minimum wage. While individuals could opt into pension insurance up to 2013, since then, mini-jobs are automatically subject to pension insurance if the individual does not opt out. If an employee decides to opt out, the employer still has to pay contributions to pension insurance (Bachmann 2016: 14). Another policy change in particular had important implications for employees working in low paying jobs. In 2015, a statutory minimum wage of $€ 8.50$ per hour was introduced. This generated considerable wage increases for people in low paying jobs in general (Pusch and Schulten 2017), and for those working in mini-jobs in particular (Bachman et al. 2016).

\section{Disability Pensions}

As the German pension system relies on contributions made over the lifecourse generated mainly through employment, health issues that affect an individual's labour market participation will negatively impact their pension entitlements. Until 2001, two different disability pensions existed. If an individual was not able to carry on regular employment, they received the full old age pension benefits in the form of a disability pension (Erwerbsunfähigkeitsrente, 'inability to work pension'). If an individual could no longer work in their former or similar employment due to disability, which required a similar degree of qualification, they received a different pension (Berufsunfähigkeitsrente, 'occupational disability pension'). Benefits resulting from the occupational disability pension were lower than those generated by the inability to work pension because the individual was still considered able to perform a job 
below their qualification to earn additional income. While these rules were broadly interpreted in the 1970s and early 1980s (Berkel and Börsch-Supan 2004), in 2001, the twofold system of disability pensions was abolished and both disability pensions were replaced by a unified disability pension (Erwerbsminderungsrente). The newly created disability pension no longer considers the qualification of the individual as it solely focuses on the number of hours an individual is still able to work (six or three hours a day). In addition, disability pensions today require a work history of at least five years of contribution in total and at least three years of contributions during the last five years. The proportion of individuals who are actively insured that receive a disability pension has decreased significantly over the last 20 years, from $8.9 \%$ in 1996 to only $4.6 \%$ in 2017 (4.5\% for men and 5.0\% for women) (Deutsche Rentenversicherung 2018). Over the past few decades, the underlying health problems that resulted in individuals receiving disability pensions changed. While in 1996 the most important diagnoses were musculoskeletal diseases (27.5\%), in 2017, mental health problems were the most common health problems among disability pensioners (43\%) (OECD 2018).

In 2014, pension reforms introduced changes to the provision of rehabilitation services that aimed to maintain or restore the capacity to work from pension insurance funds (Leistungen zur Teilhabe der Träger der Rentenversicherung). Following the general principle 'rehabilitation before pension', this program's primary aim is to try to avoid early exit from the labour market due to health problems by providing medical care and vocational integration measures. If rehabilitation is not possible, individuals who cannot work due to health issues can opt for a disability pathway (OECD 2018). A further pension reform in 2017 addressed health issues focusing on prevention and rehabilitation and introduced voluntary check-ups from the age of 45, which are financed by the statutory pension scheme (OECD 2018).

\section{Balancing Professional and Family Responsibilities}

Like other Western countries, Germany is experiencing an ageing demographic. In addition to care responsibilities for (small) children, this has led to increased needs for care for older people. Care for older people is mainly provided at home. About three quarters of people with care needs are cared for by family members (Destatis 2017), particularly women (Nowossadeck et al. 2016). As a response to the gendered nature of caregiving (and its implications for employment), public policies aim to ensure that women remain active in the labour market by easing this double burden for women of working age (or triple burden if they care for both small children and older people).

In addition to parental leave regulations focusing on care for children, two recent reforms aimed to improve the reconciliation of care responsibilities and paid work. The Home Care Leave Act (Gesetz über die Pflegezeit) of 2008 facilitated the reduction of working time for caregivers. The opportunities and conditions for temporarily switching from full-time to part-time employment or taking specific leave when 
caring for older parents were improved (OECD 2018). In 2015, the law for the better reconciliation of family, care and work (Gesetz zur besseren Vereinbarkeit von Familie, Pflege und Beruf) introduced the right to take a specific care leave for a period of up to 24 months. Furthermore, it is now possible to claim caring benefits (Pflegeunterstützungsgeld) for a period of up to one year if the carer needs to take extra leave. Carers can also get an interest free loan to compensate for up to half of the income lost due to care leave (OECD 2018).

\section{Employment Policies to Extend Working Life}

Over the last few decades, pension policies that restricted early retirement and delayed the legal retirement age were the main instruments introduced to prolong working lives. Other policies accompanying these pension policies aimed to increase the labour market participation of older workers and postpone retirement (OECD 2018). Measures to combat age discrimination in the labour market include the 2006 General Equal Treatment Act (Allgemeines Gleichbehandlungsgesetz-AGG), which aims to eliminate discrimination on the grounds of race or ethnic origin, gender, religion or beliefs, disability, age, or sexual orientation and sets sanctions in case of violation. An independent Anti-Discrimination Agency to support the legislative effort was set up at the Federal Ministry for Family Affairs, Senior Citizens, Women and Youth (BMFSFJ). In addition to working against age discrimination, more emphasis was given to training of older workers. One example of this approach is the program WeGebAU (Weiterbildung Geringqualifizierter und beschäftigter älterer Arbeitnehmer im Unternehmen), which was introduced in 2006. In order to improve employability, this program promoted further training in companies for low skilled workers and for workers aged 45 and above. At the same time, policies aimed to facilitate and promote lifelong learning. The law on the promotion of further training and social security in the unemployment insurance system (Arbeitslosenversicherungsschutz-und Weiterbildungsstärkungsgesetz), which was adopted in 2016, aimed to offer basic skill training courses (reading, writing, computer skills) and further training measures to individuals who are in employment but do not hold a vocational qualification. Furthermore, good practice in managing an age diverse workforce has been encouraged in collective agreements and individual employers and programs were developed to enhance job quality for older workers, like the 'Decreasing Work-Related Diseases Programme' funded by the German Federal Ministry of Labour and Social Affairs (BMAS) that ran from 2006 until 2010. This programme aimed to design measures to promote health and employability of older workers (OECD 2018). 


\section{Conclusion}

Over the last few decades, public policies affected significant changes to the German pension system. Particularly since the 1990s, reforms raised the statutory pension age, limited access to early retirement, and introduced a partial marketisation of pensions, which took the form of subsidised supplementary pension schemes. At the same time, the German labour market has undergone significant changes. Whereas female labour market integration in Western Germany has increased considerably over the last few decades, this increase was to a considerable degree based on part-time and low paid employment. While labour market developments resulted in an increased risk of low pension entitlements and insufficient future pension income, particularly for women, public policy reforms increased rather than decreased the risk of experiencing poverty in later life. Due to a combination of a high prevalence of career breaks, the predominance of (at least temporary) part-time work in female careers and the increased likelihood of working in low paid employment coupled with a pension system that relies on contributions generated through employment, the higher employment participation of women in West Germany has not led to considerable pension improvement for women (Simonson et al. 2012). In East Germany, women's pensions are negatively affected by increased part-time and low paid employment. Care credits, which were introduced and extended since the 1980 s, were not sufficient to improve female pensions as the German pension system still relies heavily on contributions made over the lifecourse and public policies on reconciliation of work and family responsibilities rely on a decreasing attachment to the labour market (by enabling career breaks and part-time employment). As a result, care credits remain but 'additions and adjustments to a deeply gendered system' (Frericks et al. 2008: 116), leaving gendered working lives a source for a significant gender pension gap.

Important changes to the pension system also changed the face of disability pensions. Recent reforms unified two different pensions schemes under one common scheme, whereby abolishing the previously important distinction between inability to work at all or to work in one's job or a job that requires a similar qualification. At the same time, public policies placed more importance on prevention and rehabilitation in order to avoid early labour market exit and promote the reintegration of individuals into the labour market. These measures could prove effective in retaining women (and men) in the labour market. However, while rehabilitation and reintegration are valuable aims, individuals with serious health problems may not be able to work longer. To date, the impact of these measures remains to be seen.

In Germany, pension policies played an important part in extending working life as changes in financial incentives over the last decades encouraged a progressive delay of retirement (Berkel and Börsch-Supan 2004). Yet, these reforms only take limited account of individuals who are not able to work until the statutory pension age and (at least partially) fail to consider the biographical perspective. They also take only limited account of individuals who have a long history of precarious employment and are not able to work longer due to health problems. Pension reforms that increase the legal retirement age without taking their situation into account will only worsen their 
financial situation. Labour market policies which aim to ensure stable and high quality employment at earlier stages of the employment careers are strongly needed. Finally, even if rehabilitation has redirected the focus to disability pensions, more attention needs to be afforded to prevention, especially in the case of mental health problems that have become the most common health problem among disability pensioners.

\section{References}

Ante, C. (2008). Pension policy reforms in Germany. Hertie School of Governance Working Paper No. 10, Berlin.

Bachmann, R., Bömer, M., Frings, H., Dürig, W., Höckel, L. S., \& Martinez Flores, F. (2016). Nachfolgestudie zur Analyse der geringfügigen Beschäftigungsverhältnisse (Minijobs) sowie den Auswirkungen des gesetzlichen Mindestlohns. Endbericht: Gutachten im Auftrag des Ministeriums für Arbeit, Integration und Soziales des Landes Nordrhein-Westfalen, RWI Leibniz-Institut für Wirtschaftsforschung. https://www.econstor.eu/bitstream/10419/162723/1/ 890676178.pdf. Accessed 15 August 2018.

Bardasi, E., \& Gornick, J. C. (2008). Working for Less? Women's part-time wage penalties across countries. Feminist Economics, 14(1), 37-72.

Berger, P. A., Steinmüller, P., \& Sopp, P. (1993). Differentiation of life-courses? Changing patterns of labour-market sequences in West Germany. European Sociological Review, 9(1), 43-65.

Berkel, B., \& Börsch-Supan, A. (2004). Pension reform in germany: The impact on retirement decisions. Finanzarchiv, 60(3), 393-421.

Berner, F. (2006). Riester Pensions in Germany: Do they substitute or supplement public pensions? Positions in the debate on the new public policy on private pensions. German Policy Studies, 3(3), $492-534$.

Bonin, H. (2009). 15 Years of pension reform in Germany: Old successes and new threats. IZA Policy Paper No. 11, Bonn.

Bundesministerium für Familie, Senioren, Frauen und Jugend (2017). Zweiter Gleichstellungsbericht. https://www.bmfsfj.de/blob/117916/7a2f8ecf6cbe805cc80edf7c4309b2bc/ zweiter-gleichstellungsbericht-data.pdf. Accessed 20 February 2019.

Bundesministerium für Familie, Senioren, Frauen und Jugend (2015): 25 Jahre Deutsche Einheit. Gleichstellung und Geschlechtergerechtigkeit in Ostdeutschland und Westdeutschland. https:// www.bmfsfj.de/blob/93168/8018cef974d4ecaa075ab3f46051a479/25-jahre-deutsche-einheitgleichstellung-und-geschlechtergerechtigkeit-in-ostdeutschland-und-westdeutschland-data.pdf. Accessed 04 January 2020.

Brussig, M., Knuth, M., Mümken, S. (2016). Von der Frühverrentung bis zur Rente mit 67. Der Wandel des Altersübergangs von 1990 bis 2012. Bielefeld: transcript.

Busemeyer, M. (2006). Moving the unmovable: Political strategies of pension reform in Germany. German Policy Studies, 3(3), 400-445.

Destatis (2019). Erwerbsbeteiligung. Erwerbstätige und Erwerbstätigenquote nach Geschlecht und Alter 2008 und 2018. Ergebnis des Mikrozensus. https://www.destatis.de/DE/Themen/Arbeit/ Arbeitsmarkt/Erwerbstaetigkeit/Tabellen/erwerbstaetige-erwerbstaetigenquote.html. Accessed 04 January 2020.

Deutsche Rentenversicherung (2018). Erwerbsminderungsrenten im Zeitablauf 2018. Statistik der Deutschen Rentenversicherung. https://bit.ly/2NX27qJ. Accessed 15 July 2019.

Frericks, P., Maier, R., \& de Graaf, W. (2008). Male norms and female adjustments: the influence of care credits on gender pension gaps in France and Germany. European Societies, 10(1), 97-119.

Gerostat. (2018). Deutsches Zentrum für Altersfragen, Berlin. https://doi.org/10.5156/GEROSTAT. Accessed 30 November 2018. 
Hagen, K., \& Kleinlein, A. (2011). Zehn Jahre Riester-Rente: kein Grund zum Feiern. DIW Wochenbericht, 78(47), 3-14.

Hohnekamp, I., \& Schwarze, J. (2010). Pension reforms in Germany: Have they changed savings behaviour? Pensions, 15(3), 214-225.

Kalina, T., \& Weinkopf, C. (2018). Niedriglohnbeschäftigung 2016 - beachtliche Lohnzuwächse im untereen Lohnsegment, aber weiterhin hoher Anteil von Beschäftigten mit Niedriglöhnen. Duisburg: Institut Arbeit und Qualifikation.

Kalina, T., \& Weinkopf, C. (2015). Niedriglohnbeschäftigung 2013: Stagnation auf hohem Niveau. IAQ-Report 2015-03. Duisburg: Institut Arbeit und Qualifikation.

Kaltenborn, B. (2019). Grundsicherung im Alter und bei Erwerbsminderung: ein statistisches Kompendium, Forschungsbericht für das Forschungsnetzwerk Alterssicherung (FNA) der Deutschen Rentenversicherung Bund, DRV-Schriften, Bd. 118, April 2019, Berlin.

Kelle, N., Simonson, J., \& Romeu Gordo, L. (2017). Is part-time employment after childbirth a stepping stone into full-time work? A cohort study for East and West Germany, Feminist Economics, 23(4), 201-224.

Klenner, C. (2009). Wer ernährt die Familie? Erwerbs- und Einkommenskonstellationen in Ostdeutschland. WSI Mitteilungen, 62(11), 619-626.

Mierzejewski, A. C. (2015). Paradigm shift: The Reform of the German Public Pension System in 2001. Journal of Policy History, 27(4), 695-721.

Möhring, K. (2014). Der Einfluss von Kindererziehungszeiten und Mütterrenten auf das Alterseinkommen von Müttern in Europa. Vierteljahrshefte zur Wirtschaftsforschung, 83(2), 139-155.

Natali, D. (2018). Recasting pensions in Europe: Policy Challenges and political strategies to pass reforms. Swiss Political Science Review, 24(1), 53-59.

Nowossadeck, S., Engstler, H., Klaus, D. (2016). Pflege und Unterstützung durch Angehörige, Report Altersdaten, 1/2016, DZA: Berlin.

OECD. (2018). Key policies to promote longer working lives. Country note (Germany) 2007 to 2017 https://www.oecd.org/els/emp/Germany\%20Key\%20policies_Final.pdf. Accessed 15 July 2019.

OECD. (2019). Pensions at a Glace 2019. How does Germany compare? https://www.oecd.org/ germany/PAG2019-DEU.pdf. Accessed 04 January 2020.

Pusch, T., \& Schulten, T. (2017). Mindestlöhne in Deutschland - Erfahrungen und Analysen. WSIMitteilungen, 70(7), 473-481.

Rosenfeld, R. A., Trappe, H., \& Gornick, J. C. (2004). Gender and work in Germany: Before and after reunification. Annual Review of Sociology, 30, 103-124.

Rüb, F. W., \& Lamping, W. (2010). German pension policies: The transformation of a defined benefit system into ... What? German Policy Studies, 6(1), 143-185.

Simonson, J., Romeu Gordo, L., \& Titova, N. (2011). Changing employment patterns of women in Germany: How do baby boomers differ from older cohorts? A comparison using sequence analysis. Advances in Life Course Research, 16, 65-82.

Simonson, J., Kelle, N., Romeu Gordo, L., Grabka, M. M., Rasner, A., \& Westermeier, C. (2012). Ostdeutsche Männer um 50 müssen mit geringeren Renten rechnen. DIW Wochenbericht, 79(23), $3-13$.

Trampusch, C. (2005). Sozialpolitik in Post-Hartz Germany. WeltTrends, 47(13), 77-90. 
Open Access This chapter is licensed under the terms of the Creative Commons Attribution 4.0 International License (http://creativecommons.org/licenses/by/4.0/), which permits use, sharing, adaptation, distribution and reproduction in any medium or format, as long as you give appropriate credit to the original author(s) and the source, provide a link to the Creative Commons license and indicate if changes were made.

The images or other third party material in this chapter are included in the chapter's Creative Commons license, unless indicated otherwise in a credit line to the material. If material is not included in the chapter's Creative Commons license and your intended use is not permitted by statutory regulation or exceeds the permitted use, you will need to obtain permission directly from the copyright holder.






\title{
Chapter 21 \\ Greece
}

\section{Antigone Lyberaki and Thomas Georgiadis}

\begin{abstract}
The simultaneous experience of rapid population ageing, deep recession and a conservative social protection system was behind the dramatic social adjustments during the Greek bailout 2010-2018, affecting diverse categories of citizens whose later life wellbeing was undermined. Older women are especially vulnerable, as they were disproportionately affected by reforms. Women who retire after 2016 face abrupt and dramatic retirement age hikes, while those who managed to retire early have already faced repeated cuts in pensions in their incomes. Their predicament is exacerbated by new obstacles and disincentives which discourage older workers. To make a dire employment situation even worse, unemployment among older workers (especially women) is especially hard to tackle. Long term care services provided by social protection are insufficient to cover demand, implying the need for continued informal care on the part of older women to fill gaps. Consequently, older women have had to shoulder a large part of adjustments, but will also be called to make up for retrenchment in key areas, such as caring for grandchildren and for elderly relatives- whilst being denied meaningful support to help their them respond. As long term developments unfold over the next decade, these gaps will deepen and the social predicament of older Greek women will be more pressing.
\end{abstract}

Keywords Greece $\cdot$ Women $\cdot$ Crisis $\cdot$ Pension system $\cdot$ Pathways to retirement

\section{Introduction}

The Greek financial crisis, started with per capita incomes falling in 2008, necessitated the largest international state bailout in history in 2010, and did not formally end until the expiry of the third consecutive bailout in 2018. With a duration of 10 years it is the longest financial crisis in the Western World-longer even than the interwar Great Depression (Meghir et al. 2017). The crisis is usually viewed

\footnotetext{
A. Lyberaki $(\bowtie) \cdot$ T. Georgiadis

Department of Economics and Regional Development, Panteion University, Athens, Greece e-mail: antiglib@gmail.com 
through a macroeconomic lens, focusing on austerity and its impacts. This emphasis obscures structural factors, both as causes of the crisis and as determinants of differential impact among demographic groups. Long term secular developments, such as population ageing, combined with an unreformed pension system to necessitate a rising stream of fiscal support to pension providers; grants to finance pension outlays were seen as a key cause of the country's fiscal collapse (Nektarios and Tinios 2020). In this setting, older women were in the cross-fire-as a group directly targeted by structural reforms, as victims of austerity but also as affected by changes in health and long term care.

The turbulent political economy of the period, as well as the urgency accorded to structural changes in the pension system by the 'troika' of international creditors (the International Monetary Fund, the European Central Bank and the European Commission) imply features that differentiate an account of the status of older people in Greece from that in other countries. First, the pace and content of reform was directed from outside with fiscal considerations uppermost; it was not the result of balancing social policy options. Second, the prioritisation and design, as well as the speed and implementation of reforms were matters of contention between the authorities and the troika; they involved bargaining, some backtracking and the virtual absence public debate. Third, the pension system was radically transformed; it shed its key characteristic of fragmentation, retaining however the almost exclusive reliance on State-provided first pillar pensions financed by PAYG. Fourth, the absence of gradualism distinguishes Greece from equivalent social reforms elsewhere. Changes that in other settings have taken decades were 'telescoped' in Greece over a few years (Tinios 2020).

In consequence, the story of the bailout period, 2010 to 2018 , was characterised by an interplay between austerity policies and a forced rebalancing of pension policy. When austerity was first imposed, early retirement was still possible, resulting in a wave of early retirement by women. Cuts repeatedly imposed on existing pensions proved insufficient to prevent rises in the share of pensions in GDP, which in 2018 still absorbed the highest proportion of GDP in the EU (Nektarios and Tinios 2020). This was despite a succession of structural laws that restricted access to pensions by increasing vesting periods and rising retirement ages, both affected women more than men. Consequently, many women who could have retired under previous rules are after 2016 blocked from exiting the labour market. These radical changes were not matched by policies to make the labour market friendlier for older workers, the need for which has been ignored. In technical terms, the supply of labour was forcibly increased by blocking early retirement, while compensating changes on the demand side in the labour market are absent. This imbalance, combined with gaps in care policies, should give rise to concern about the future wellbeing of older Greeks, and of women in particular.

Older women face an uncertain future. Those who managed to retire before 2016 must live with low pensions, possibly punctuated with further cuts. Those who retire after 2016 must remain in the labour force for much longer. Older workers who lost their jobs in recent years confront ageism and the near nonexistence of a labour market for older workers, potentially contributing to an inability to qualify for a 
pension once they reach the new, older, retirement ages. Both groups, whether with or without an early pension, are called upon to meet the burden of caring for older people on their own-the State has all but resigned responsibility for long-term care (LTC). It is indicative that in the 2018 Ageing Working Group report (AWG 2018), the Greek State's fiscal outlays on LTC are given as $0.1 \%$ of GDP, while the Netherlands with a lower proportion of people aged $80+$ in the population spends $3.5 \%$.

\section{Gender, Ageing and Employment in Greece}

The generation retiring in 2009 was that of the Greek baby boom, born in the 1950s and known as the 'Polytechnic Generation'-referring to their role in the student rebellion against the dictatorship in 1973. Women of that generation were very different from their mothers: more educated and with a greater stake in paid employment. Although the need for social policy to recalibrate itself away from the familial system had been recognised, policy was lagging behind official intentions (Lyberaki and Tinios 2014). Consequently, caring responsibilities overwhelmingly fell on female members of the family. They included caring for older relatives and spouses, as the new programme for home help was provided at levels far below demand, (Tinios 2016). Childcare provision was similarly lacking which had implications for the 'sandwich generation' of women providing intensive care to children and grandchildren and their parents (Lyberaki 2017).

The picture of labour market outcomes for older workers (Table 21.1) is one of a traditional labour market, which was nevertheless changing fast in the pre-crisis period (2001-2009): employment gender gaps were wide but shrinking. The crisis is seen in an explosion of unemployment for both genders (for women it trebled from 7 to $20 \%$ ). This led to the already low employment rates for women falling further; employment rates in 2015 were no higher than a decade earlier. To interpret the figures, one must take on board that there was no single retirement age; retirement ages differed by occupation and other characteristics.

The sharp rise in the activity rate after 2015 is not a sign of economic take-off; women's unemployment had peaked in 2017 and was twice its 2009 level in 2019. It is instead an indication of labour market changes and restraints in access to retirement (Lyberaki et al. 2017). The third bailout in 2015 overturned the previous policy of tacitly encouraging early retirement (Nektarios and Tinios 2020). Retirement ages of all groups increased sharply and abruptly between 2015 and 2016, blocking labour market exits for older workers. In consequence the employment situation for older women in Greece after the end of the bailout was the worse among the EU-28; gender gaps were more than twice as wide as the EU28 average. To interpret the implications of the effects of the bailouts on older workers, we need to factor in three pension factors affecting gender (Panageas and Tinios 2017; Lyberaki 2018): 
Table 21.1 Labour market outcomes of older workers by gender in Greece 2001-2019

\begin{tabular}{|c|c|c|c|c|c|c|c|c|}
\hline $\begin{array}{l}\text { Greece, } \\
\text { persons } \\
50-64\end{array}$ & 2001 & 2009 & 2013 & 2015 & 2017 & $2019 q 3$ & $\begin{array}{l}\text { Rank\# } \\
2019 q 3^{a}\end{array}$ & $\begin{array}{l}\text { EU28 } \\
(2019 q 3)\end{array}$ \\
\hline \multicolumn{9}{|c|}{ Employment rate } \\
\hline Men $(\%)$ & 66.2 & 67.8 & 54.9 & 55.2 & 59.5 & 66.1 & 24 & 73.8 \\
\hline $\begin{array}{l}\text { Women } \\
(\%)\end{array}$ & 29.0 & 36.6 & 32.5 & 33.4 & 37.1 & 42.1 & 28 & 61.4 \\
\hline $\begin{array}{l}\text { Gender } \\
\text { Gap (in } \\
\mathrm{pp}^{\mathrm{b}} \text { ) }\end{array}$ & 37.2 & 31.2 & 22.4 & 21.8 & 22.4 & 24.0 & 2 & 12.4 \\
\hline \multicolumn{9}{|c|}{ Activity rate } \\
\hline Men $(\%)$ & 68.7 & 71.0 & 67.1 & 67.1 & 70.6 & 74.6 & 19 & 77.3 \\
\hline $\begin{array}{l}\text { Women } \\
(\%)\end{array}$ & 30.7 & 39.3 & 40.5 & 41.4 & 46.3 & 49.0 & 26 & 64.3 \\
\hline $\begin{array}{l}\text { Gender } \\
\text { Gap (in } \\
\mathrm{pp}^{\mathrm{b}} \text { ) }\end{array}$ & 38.0 & 31.7 & 26.6 & 25.7 & 24.3 & 25.6 & 2 & 13.0 \\
\hline \multicolumn{9}{|c|}{ Unemployment rate $\mathbf{b}$} \\
\hline Men $(\%)$ & 3.7 & 4.5 & 18.2 & 17.8 & 15.7 & 11.5 & 1 & 4.6 \\
\hline $\begin{array}{l}\text { Women } \\
(\%)\end{array}$ & 5.8 & 6.9 & 19.7 & 19.4 & 19.8 & 14.0 & 2 & 4.6 \\
\hline $\begin{array}{l}\text { Gender } \\
\text { Gap (in } \\
\mathrm{pp}^{\mathrm{b}} \text { ) }\end{array}$ & -2.1 & -2.4 & -1.5 & -1.6 & -4.1 & -2.5 & 27 & 0.0 \\
\hline
\end{tabular}

Source Eurostat, LFS series

Note ${ }^{\mathrm{a} R a n k}$ among the 28 Member States; ${ }^{\mathrm{b}} \mathrm{pp}=$ percentage point

1. Periodisation. The period of build up to the crisis (2001-2009) can be distinguished from the crisis itself (2010-18). Legislation up to 2015 (the first two bailouts) introduced new pension arrangements for younger workers, aiming in various ways to exempt (that is to 'grandfather') older workers. The third bailout reversed this approach, retroactively extending new regulations to everyone, even those who had already retired and to survivors' pensioners.

2. Fragmentation. The key characteristic of pre-crisis pension arrangements was fragmentation (Tinios 2020). Old age protection, despite being supplied by state bodies and financed by PAYG, was fragmented by provider (over 300 organisations supplying primary, auxiliary pensions and separation payments), financing, retirement ages and modes of pension calculation. Access to old age pensions (vesting rules and retirement ages) was exceptionally uneven by occupation, allowing retirement from 42 years of age to over 70 for some occupations. Retirement ages were systematically lower for women, especially in the public sector and for larger enterprises. As a result, the use of averages can be seriously misleading: in the largest pension provider the 'rule' for retirement 
ages ( 65 for men and 60 for women) was followed by $15 \%$ of men; $85 \%$ made use of more favourable exceptions (30 and 70\% respectively for women -Tinios 2010). Pension reforms tried to stop this fragmentation through organisational consolidation and enforcement of common rules. These moves would inevitably have a greater impact among women, as the distance between pre-crisis and new system parameters are greatest.

3. A strong cohort effect. The cohort to retire during the crisis and future cohorts are considerably different from previous cohorts, an effect particularly important for women. From the 'Polytechnic generation' on, women were more educated, more involved in the labour market, less likely to be in farming or self-employed or unpaid workers in a family business, and more likely to be in public sector employment.

The reform of the pension system left important legacy effects: Firstly, even after retirement ages increased, there remain many women pensioners who were under 60: based on administrative data (Helios System), 11\% of women pensioners in 2017 were under 60, a figure underestimated as this total does not include widows and other recipients of survivors' pensions. Secondly, many women have no access to pensions in their own right, relying instead on derived rights from their husband. Thirdly, there is a wide pension gender gap (Betti et al. 2015). The averages obscure the fact that early retirees have systematically lower pensions-which will create a problem of low pensions in the future as they will not be able to benefit from any post-crisis recovery.

The reliance on early retirement is well documented before the crisis (Tinios 2010): already at age 50,17\% of Greek women and $6.5 \%$ of men were pensioners. Siegrist et al. (2007) have shown that an effort reward imbalance and low control at work are factors behind early retirement. This is corroborated by Siegrist and Wahrendorf (2011), adding that poor quality of work is associated with poor health after retirement. People who had experienced poor quality of work were more likely to report reduced health post retirement, compared to those who had not experienced poor quality of work. Life satisfaction among older women with a full career in Greece is much lower than in other countries (Lyberaki et al. 2013).

Other studies find evidence of age discrimination affecting older people. Bratt et al. (2018) investigated perceived age discrimination across different age groups with data collected in 29 countries in the European Social Survey (European Social Survey 2019). Their analysis indicates that in Greece older people are the victims of age discrimination; moreover, this affects older respondents to a greater extent.

\section{Pension Systems Pension Policies and Extended Working Life}

The Greek pension system in 2019 is very different from 2009, when the bailout reforms commenced. Pension ages are at the high end of the EU ( 67 for both genders and 62 for a 40 year career). New state pension calculations result from applying 
the same two-tier pension scheme (composed of a fixed rate 'national pension' with a portion proportional to career length) to all pension applications. Whereas previously different occupations faced very different arrangements, after 2019 very little occupational differentiation remained (Panageas and Tinios 2017). However, the way these changes were implemented created side effects and legacy issues that will mark the next two decades.

A flavour of how the priorities of pension reform resulted from an interplay between the Greek authorities and the troika of international lenders can be gleaned from the case of Heavy and Hazardous Occupation (HHO), and the role played by its most quoted example, hairdressers. Rules for HHOs were originally designed for groups with demonstrably lower life expectancy, such as workers in underground mines. This was vastly expanded (sometimes stretching credulity) to include people whose claim to occupational health deterioration was tenuous or fictitious-swelling to account for $40 \%$ of all pension applications in the private sector (Tinios 2010). Criteria for inclusion were never specified; occupations were added case-by-case. For instance, Church cantors were included using the argument that participating in funerals was depressing. Hairdressers were added to the list of heavy occupations in 1966 and could thus receive an old age pension at age 50. Their specific case was unwittingly drawn in the high politics of the bailout. As Germany was the main source of bailout funds, the German government in 2010 was sensitive to comments in the German press; the paradox of German taxpayers (whose retirement had been recently raised to 67) paying for Greek hairdressers (among others) to continue retiring at 50, was used to argue against the bailout. Their example increased pressure to insist on strict and specific conditionality of bailout funds-including as a priority the overhaul of the HHO system.

Commentary on egregiously early retirement led to across the board retirement age increases in the first law passed after the bailout in 2010. The system of HHOs was next in line in early 2012. Hairdressers, among many other, though not all, occupations, were withdrawn from the list of HHOs; however, those with more than 10 years' working experience retained existing rights. Consequently, the vast majority of active hairdressers were exempted, or using the technical term 'grandfathered' (a technical term covering the exemption of individuals with 'legacy rights' from changes). The pension reform passed in the third bailout in 2016 partly reversed this privilege in May 2016: the reference retirement ages were increased to 67, (62 with 40 years' employment), which automatically pulled up all retirement ages. Nevertheless (until further notice) hairdressers could still retire 5 years earlier than the new reference ages.

'Grandfathering' was only part of the story. Many women in the public sector were encouraged to retire early as a substitute for being made redundant between 2010 and 2015, through the following mechanism: mothers of underage children had previously been entitled to retire at 50. At that age, most offspring were over 18, implying little impact. In 2010, the age test was moved earlier (to the age when the mother had completed 20 years' contributions). So, a woman who started work at 20 would need to prove that her children had been underage when she was aged 40 ; if so, she could retire on completion of her 50th year. In this way, thousands of 
women suddenly became 'mothers of underage children' with a right to retire at 50, even though their offspring could have been close to 30 when their mothers retired.

Another unique feature of the Greek pension reform was applying cuts to pensions already paid out. As employment earnings in Greece were in freefall, and given that there was no inflation, adjusting the pension bill could be implemented only by nominal cuts to pensions already in payment. Such cuts occurred repeatedly until 2015; as the criterion for cuts was the value of pensions, larger pensions were cut by more than $50 \%$, while lower pensions were largely spared. Given that private earnings collapsed, low income pensioners paradoxically found themselves in a privileged position. Despite cuts, pensioners' risk of poverty halved, as the median incomes on which the poverty depends fell by more than the value of pensions. Gender pension gaps also fell for the same reason, since women's pensions were typically on the lower end of pension values. However, notwithstanding major changes in pension entitlements, the underlying structure of the system remained unchanged: nearly $100 \%$ of pensions are still provided by State bodies, while little opening was created for private or collective pillars to grow (Tinios 2020).

The complex political economy of forced reform during a deep fiscal crisis means that the impact on particular groups was not the product of reasoned discussion and weighing of alternatives but could emerge as an unintended residual following more urgent considerations-a kind of 'collateral damage'. The case of widows and survivors pensions is an example (Tinios et al. 2020). Widows, both existing and future, were a group who disproportionately lost out: they bore the full brunt of pension cuts, while survivors' pensions are recalibrated as if the deceased had spent his/her life in the system inaugurated in 2016. The inherent tensions and instabilities of the Greek reform can be seen in age restrictions ( 55 years of age) on the permanent receipt of survivors' pensions: These were imposed in 2010, and further tightened in 2016. Some months after the departure of the troika, in May 2019, all age restrictions were abolished, including some that had been in force since 1997. The explanatory report of the 2019 legislation justified this, as 'in Greece surviving spouses (mostly women) stay out of the labour market during marriage, with the result of encountering great difficulties in seeking employment, especially at relatively old ages' (Hellenic Parliament 2019, p. 14).

The upshot of pension reform was twofold: Firstly, those who had managed to retire were faced with insecurity. The 2016 Legislation enforced a kind of bailout legacy, in the form of further cuts mandated to occur after 2019. That date is when all pre-2016 pensions must be recalibrated as if all careers had taken place under the new system. Any excess value using the new calculation formula will be gradually eliminated by being excluded from pension indexation. The group most affected by recalibration are widows, who are treated as recent pension applicants, implying much larger falls (Tinios et al. 2020). Secondly, those who had not retired before 2016 were faced with the prospect of working for as much as 17 years more than they had originally planned. As women had to make up the largest distance in retirement ages, they represent the largest group forced to remain in the labour market. Their number will start rising cumulatively after 2018, after the impact of the rush to retirement before 2016 wears off. 


\section{Extended Working Life Employment Policies}

The reform of pensions will force a major rise in the supply of labour, chiefly on the part of older women. This, however, has yet to be matched by equivalent compensating initiatives on the demand for older workers by employers.

To be sure, lip service to active ageing had been a feature of action plans for employment since at least 2000. However, except for a few demonstration projects, mostly in the area of training, very little has been achieved. A labour market for older workers is essentially non-existent; as a result, if an older woman loses her job, the prospect of finding another is very small. During the crisis older worker unemployment was exacerbated by the closure of large numbers of small businesses. Lyberaki and Tinios (2017) argue that the distinguishing feature of this crisis is that the closure of firms was not counterbalanced by the opening of new enterprises (as it had previously in more positive socioeconomic contexts). The large increase in social insurance contributions of the self-employed after 2016 accelerated closures and made seeking employment harder.

The second major factor discouraging employment of older workers are collective agreements linking minimum and average pay rates to age and seniority. This means that older job seekers are at a considerable disadvantage. Thus, if older workers are insiders, employment protection enables them to hold on to their jobs. Should they lose them, they join the queue of outsiders, albeit at a considerable disadvantage. Behind these policies is an ingrained and generalised ageism. Most commentators do not hide their belief in the 'Lump of Labour fallacy' i.e. that the labour market is akin to a game of musical chairs where if an older person holds a job, it is taken from a younger unemployed person.

\section{Health and Long Term Care Policies}

The 'system' of HHO has already been mentioned. This at the outset was designed as actuarial compensation to accommodate occupations with demonstrably lower life expectancies. It was quickly abused to include hundreds of occupations some with only spurious claims to health impacts. Its use as a clientelistic device can be illustrated by contrasting by its application in the Public Power Corporation: waiters were deemed an HHO, while pylon repair crews were not. In the case of real health-threatening conditions, this system operated as an incentive to retain unhealthy working conditions, discouraged improvement, and maximised risk exposure (Tinios 2010). Although the list of such occupations was reduced in 2012, no general operating principles of inclusion were debated or included in the law.

Disability pensions have been a problem for private sector pensions. They were used, sometimes fraudulently by men of retirement age with a contribution record less than the fifteen years necessary to vest an old age pension i.e. they operated as a device complementary to contribution evasion. As women had access to other early 
retirement routes, such as regulations on underage children and some HHOs, they did not use invalidity pensions to the same extent as men (Tinios 2010).

The problem was scaled down after 1992, when minimum pensions were linked to the extent of disability, which led to the proportion of disability pensions falling by more than half. As part of the bailout, disability-checking procedures were made tougher.

Much crisis commentary, such as Kentikelenis et al. (2014), a study widely reproduced in the international press, laments a 'Greek public health tragedy', of deteriorating health outcomes as a direct consequence of retrenchment. A recent study (GBD-G 2018) provides a careful analysis of all available morbidity and mortality indicators: both (though morbidity to a lesser extent) sharply deteriorated for older individuals during the crisis. This was not due to austerity but was caused by the acceleration of ageing and by unhealthy behaviour (smoking, BMI, diet), especially among recent cohorts of women. Even so, the fall of per capita health expenditure, combined with 'rooted inefficiencies' of healthcare could still be indirectly linked to health outcomes. Their overall conclusion is uncertain as to causation but is unequivocal as to the existence of ' $a$ disproportionate decrement in the health of Greeks, which parallels the course of the economic crisis' (GBD-G 2018, p. 404).

How did austerity and the crisis affect Long Term Care? Survey evidence (Lyberaki and Tinios 2018) shows that, despite worsening self-reported health, the extent of unmet care needs fell. Interestingly, this was not due to rising family provision but due to a rise in professional care. As municipal LTC services (the 'Help at Home programme') shrank (Tinios 2016), and there was no increase in other state-provided services, the increased use of LTC was mostly due to a rise in purchased professional care services paid for out of pocket by families. Lyberaki et al. (2019) speculate that a reason for this is that pensions fell by less than the wages of carers. In consequence, the overwhelming share of responsibility for care remains with the family; a larger part of this than pre-crisis now falls on family budgets.

\section{Debate on Extended Working Life}

Pension reform was the first reform bill of any kind to be passed in the first bailout in 2010; it was also the last in December 2018, three months after the third and last bailout ended. Pension policy through this long period unfolded against the background of a relentless recession, through an unsteady interplay between the international creditors, on the one hand, and successive Greek governments, on the other. The creditors pushed for fiscal retrenchment while Greek governments of the day were concerned with containing political fallout. In this tug of war, blame avoidance displaced open debate. The unsubstantiated assertion that extended working lives contributed to unemployment, which had been used before the bailout to prevent rises in retirement ages, was given a new lease of life in bailout period when early retirement was encouraged. Further, the entrenchment of ageist beliefs extended to political parties and to social partners, while the dearth of discussion about ageism or 
the plight or possibilities for older workers meant that there were no opportunities for these views to be rebutted (Tinios 2018). The fact that major changes to retirement took place independently of social conditions was responsible for four paradoxes that our analysis has uncovered:

Paradox 1: The baby boom generation received lavish pension promises which were later dramatically reversed in the crisis, by rises in retirement ages and retroactive cuts of entitlements. The kind of transformations that were phased in over decades elsewhere, were forcibly and quickly implemented in Greece. Cohorts of women now in their sixties and late fifties, who played by the rules of a Europeanising fast growing country and who prided themselves in modern careers, are in for a surprise as reality does not conform to the retirement path they were led to expect.

Paradox 2: Policy first encouraged and then penalised early retirement. In the first phase (2010-2015), considerable effort focused on exempting those near the age threshold, leading to early retirement. This was financed by cuts in pensions affecting older pensioners with relatively high pensions. The second phase (late 2015) reversed the early retirement course with large increases in the retirement age. At the same time, obstacles and disincentives to working were enforced for older workers and for the employment of pensioners.

Paradox 3: The forced increase of the labour supply as a result of delaying pension entitlement was not matched by measures to raise employment demand. This paradox is glaring in official projections for the Greek pension system included in the Ageing Working Group report (2018). The viability of the new Greek pensions system rests on the assumption of a substantial increase in women's work (by approximately 10 percentage points or $20 \%$ increase) by 2030 . Mobilising women's labour reserves is the main source for financing the pensions system and restraint of the deficit. However, few measures to support and justify such a drastic increase are mentioned or apparently planned.

Paradox 4: The dramatic future increase expected in the need for long term care (LTC), particularly if women's labour force participation increases to levels needed to sustain Greek pensions in the future, is not matched by a credible increase in supply. The projections already pledge today's informal carers to also be in paid employment, while no action is taken to support LTC. Until recently, the care gap was filled by a private, largely informal, care market supplied mainly by immigrant Eastern European women (Lyberaki 2011). Declining pensions and wages in Greece, in combination with soaring unemployment, are limiting the prospects of such jobs in the future; this is mirrored in a trend favouring the return of many carers to their countries of origin.

The four paradoxes will place older women in a maelstrom of developments over the next decade. Women are expected to shoulder the lioness's share of adjustment in pension reform, whilst being denied the means to do so. The underlying cause of their predicament is an insufficient understanding of the interplay of the role of older workers in labour markets and the normative expectations for women's unpaid care work. The costs of early retirement on the part of a large privileged minority were cushioned by external debt finance before the crisis. The costs of early exit from the labour market was also disguised by the use of averages and the lack of statistics 
documenting differences by gender. These combined with an implicit belief by policy makers in the 'lump of labour fallacy' which complemented existing sexism with heavy doses of ageism.

In consequence, Greece repeatedly went against the European mainstream, as far as active ageing is concerned. While there was token acknowledgment of European priorities in measures for older workers financed by structural funds, ageism in the labour market remains rampant. At the end of the bailouts, the costs of a policy ignoring the potential of older citizens are beginning to be apparent.

\section{Policy Recommendations}

Greece is ageing fast. Nevertheless, ageing is not seen as an integrated challenge in policymaking circles. Policy is absorbed with pension reforms and ignores the flipside, older workers. Incremental increases in retirement age have implications going far beyond legacy costs.

First, the early retired will have to live with permanently lower pensions. Under current policies, they will not share in post crisis output gains; rather, their entitlements will be permanently locked to crisis levels. For women, this means lower independence, a greater reliance on men, and a greater future poverty risk. These could be ameliorated if policies such as the following can be contemplated:

(a) Policies encouraging economic activity by early retirees, including the possibility of recall to the labour market.

(b) Involvement of women pensioners in providing LTC services.

Second, the labour market and many enterprises were emptied of female staff during the economic crisis and bailout period. Current hiring limits mean that the public sector will no longer be able to exert an equalising impact that improves prospects for women's employment. In the private sector, the hollowing out of the labour market by early retirement will mean fewer senior female cadres available for higher positions. The net result could be a lower representation of women, and a strengthening of gender stereotypes.

Third, those trapped in the labour market by the rapid rise of retirement ages will face growing difficulties to navigate a hostile labour market. To overcome this, a number of initiatives must be considered:

(a) Change in seniority loaded pay scales

(b) Measures promoting a market for older workers, including job search.

(c) Training focussed on older workers

(d) Loans for starting a business should not exclude the older self-employed. Small enterprises are the most likely source of extra employment.

Fourth, arrangements for LTC are of critical importance. There is a glaring inconsistency between planning for a major increase in involvement of today's carers in 
paid employment, without planning to assist them in any meaningful way. To correct for this the following may be needed:

(a) Policies assisting informal carers in their LTC roles (e.g. respite leave, training).

(b) Quality assurance to aid the operation and quality improvement of a private or 3rd-secror LTC market.

Greece will have to adapt from being a country where older women's place was in retirement (even if not in the home) to one where they can be active members of society.

\section{References}

Ageing Working Group (AWG). (2018). The 2018 ageing report: Economic and budgetary projections for the 28 member states (2016-2070). Institutional paper 079. Brussels. Retrieved September 6, 2018, from https://ec.europa.eu/info/publications/economy-finance/2018-ageingreport-economic-and-budgetary-projections-eu-member-states-2016-2070_en.

Betti, G., Bettio, F., Georgiadis, T., \& Tinios, P. (2015). Unequal ageing in Europe: Women's independence and pensions. New York: Palgrave Macmillan.

Bratt, C., Abrams, D., Swift, H. J., Vauclair, C.-M., \& Marques, S. (2018). Perceived age discrimination across age in Europe: From an ageing society to a society for all ages. Developmental Psychology, 54(1), 167-180.

European Social Survey (ESS). (2019). Retrieved July 16, 2019, from https://www. europeansocialsurvey.org/.

Global Burden of Disease-2016 Greece Collaborators (GBD-G). (2018). The burden of disease in Greece, health loss, risk factors, and health financing, 2000-2016: An analysis of the Global Burden of Disease Study 2016. Lancet Public Health, 3(8), 395-406.

Helios. (2013). Unitary system of Payment Control of pensions, various years. http://www.idika. gr/eseps-mhniaies-ek8eseis.

Hellenic Parliament. (2019). Explanatory report of Law 4611. https://www.hellenicparliament. gr/Nomothetiko-Ergo/Anazitisi-Nomothetikou-Ergou?law_id=9c77c665-f234-426f-a384aa450126e3c5.

Kentikelenis, A., Karanikolos, M., Reeves, A., McKee, M., \& Stuckler, D. (2014) Greece's health crisis: from austerity to denialism. Lancet Health Policy, 383, 748-753.

Lyberaki, A. (2011). Migrant women, care work, and women's employment in Greece. Feminist Economics, 17(3), 103-131.

Lyberaki, A. (2017). Women in the economy: A very short introduction. Athens, Papadopoulos.

Lyberaki, A. (2018). The family, the elderly and the crisis. In F. Karl (Ed.), Ageing in the crisis-the Greek case (pp. 87-122). Zürich: Lit Verlag GmbH.

Lyberaki, A., Tinios, P., \& Papadoudis, G. (2013). Retrospective explanation of older women's lifetime work involvement: Individual paths around social norms. Advances in Life Course Research, $18(1), 26-45$.

Lyberaki, A., \& Tinios, P. (2014). The informal welfare state and the family: Invisible actors in the Greek drama. Political Studies Review, 12(2), 193-208.

Lyberaki, A., Meghir, C., \& Nicolitsas, D. (2017). Labor market regulation and reform in Greece. In C. Meghir, C. A. Pissarides, D. Vayanos, \& N. Vetas (Eds.), Beyond austerity: Reforming the Greek economy (pp. 211-250). Cambridge Mass: MIT Press.

Lyberaki, A., \& Tinios, P. (2017). Small firms as a blind spot in Greek austerity economics. IDS working paper 491 . Brighton: IDS. 
Lyberaki, A., \& Tinios, P. (2018). Long-term care, ageing and gender in the Greek crisis. GreeSE Paper No 128, Hellenic observatory papers on Greece and southeast Europe. The London School of Economics and Political Science. Retrieved April 15, 2019, from http://www.lse.ac. uk/Hellenic-Observatory/Assets/Documents/Publications/GreeSE-Papers/GreeSE-No128.pdf.

Lyberaki, A., Tinios, P., Papadoudis, G., \& Georgiadis, T. (2019). The economic crisis, fiscal austerity and long term care: Responses of the care mix in three adjustment countries. In A. BörschSupan, J. Bristle, K. Andersen-Ranberg, A. Brugiavini, F. Jusot, H. Litwin, \& G. Weber (Eds.), Health and socioeconomic status over the life course: First results from SHARE waves 6 and 7. Berlin/Boston: De Gruyter.

Meghir, C., Pissaridis, C. A., Vayanos, D., \& Vettas, N. (2017). The Greek economy before and during the crisis-and policy options going forward. In C. Meghir, C. A. Pissarides, D. Vayanos, N. Vetas (Eds.), Beyond austerity: Reforming the Greek economy (pp. 3-72). Cambridge Mass: MIT Press.

Nektarios, M., \& Tinios, P. (2020). The Greek pension reforms: Crises and NDC attempts awaiting completion. In Holzmann, R., E. Palmer, R. Palacios, \& S. Sacchi (Eds.), Progress and challenges of nonfinancial defined contribution pension schemes, volume 1: Addressing marginalization, polarization, and the labor market (pp. 141-166). Washington, DC: World Bank. https://doi.org/ 10.1596/978-1-4648-1453-2. License: Creative Commons Attribution CC BY 3.0 IGO.

Panageas, S., \& Tinios, P. (2017). Pensions: Arresting a race to the bottom. In C. Meghir, C. A. Pissarides, D. Vayanos, \& N. Vetas (Eds.), Beyond austerity: Reforming the Greek economy (pp. 3-72) and (pp. 459-516). Cambridge Mass: MIT Press.

Siegrist, J., \& Wahrendorf, M. (2011). Quality of work, health and early retirement: European comparisons. In A. Börsch-Supan, M. Brandt, K. Hank, \& M. Schröder (Eds.), The individual and the welfare state (pp. 169-177). Berlin: Springer.

Siegrist, J., Wahrendorf, M., Von dem Knesebeck, O., Jürges, H., \& Börsch-Supan, A. (2007). Quality of work, well-being, and intended early retirement of older employees-baseline results from the SHARE Study. The European Journal of Public Health, 17(1), 62-68.

Tinios, P. (2010). The pension problem: A method to decipher. Athens: Kritiki Publishers.

Tinios, P. (2016). Forced transformation in a deep crisis. In B. Greve (Ed.), Long-term care for the elderly in Europe: Development and prospects (pp. 93-106). New York: Routledge.

Tinios, P. (2018). Pensioners and pension reforms during the Greek crisis. In F. Karl (Ed.), Ageing in the crisis-the Greek case (pp. 25-45). Zürich: Lit Verlag GmbH.

Tinios, P. (2020). Pensions. In K. Featherstone, \& D. Sotiropoulos (Eds.), The Oxford hand book of Greek politics. Oxford: Oxford University Press (forthcoming).

Tinios, P., Georgiadis, T., \& Chouzouris M. (2020). Survivors' pensions in Greece in the bailout crossfire. Retraite et société, special issue on survivors' pensions (forthcoming).

Open Access This chapter is licensed under the terms of the Creative Commons Attribution 4.0 International License (http://creativecommons.org/licenses/by/4.0/), which permits use, sharing, adaptation, distribution and reproduction in any medium or format, as long as you give appropriate credit to the original author(s) and the source, provide a link to the Creative Commons license and indicate if changes were made.

The images or other third party material in this chapter are included in the chapter's Creative Commons license, unless indicated otherwise in a credit line to the material. If material is not included in the chapter's Creative Commons license and your intended use is not permitted by statutory regulation or exceeds the permitted use, you will need to obtain permission directly from the copyright holder. 


\title{
Chapter 22 \\ Ireland
}

\section{Áine Ní Léime, Dinali Wijeratne and Nata Duvvury}

\begin{abstract}
This chapter considers the gender and health implications of policies designed to extend working lives in Ireland from a feminist political economy of ageing perspective. The socio-economic context, gender, pension and employment regime and the recent economic recession are discussed. Older Irish women's employment has increased from a low base but is still relatively low. There is a gender pay gap and a higher gender pension gap. Women's pension coverage is low compared to men's and they are more reliant on the lower non-contributory state pension. Reforms link pension amounts more closely to participation in paid employment, disadvantaging women who are more likely to leave paid employment for unpaid care-work. State pension age has increased quickly though the population is relatively young. For private sector workers, retirement age is typically 65, leaving a gap between retirement age and state pension age, currently 66 increasing to 67 in 2021 and 68 in 2028.
\end{abstract}

Keywords Extended working life $\cdot$ Gender $\cdot$ Health $\cdot$ Pension reform • Recession • Ireland

\section{Introduction}

This chapter uses a feminist political economy of ageing framework to consider the likely gender and health implications of policies introduced to extend working lives in Ireland. The discussion incorporates the socio-economic context, and the gender pension and employment regime. Ireland has recently emerged from a severe

\footnotetext{
Á. Ní Léime (四)

Irish Centre for Social Gerontology, National University of Ireland, Galway, Ireland

e-mail: aine.nileime@nuigalway.ie

D. Wijeratne

Irish Centre for Social Gerontology, National University of Ireland, Galway, Ireland

N. Duvvury

School of Political Science and Sociology, National University of Ireland, Galway, Ireland

(C) The Author(s) 2020

Á. Ní Léime et al. (eds.), Extended Working Life Policies, https://doi.org/10.1007/978-3-030-40985-2_22
} 
economic recession characterised by high levels of public debt and unemployment that peaked in 2012/3.

\section{Gender and Employment in Ireland}

Ireland was a traditionally male breadwinner state with historically low labour force participation rates (lfpr) for women due to gender discriminatory employment legislation. For example, alongside unequal pay, a 'marriage bar' compelled women working in public services to leave employment if they married, a rule that remained in place until Ireland joined the European Union in 1973 (Mahon 1998). The Irish tax regime also discouraged women's employment and there was a lack of family friendly policies. In fact, the lfpr of women aged 60-64 was only $27.2 \%$ in 2005 . By 2016 lfpr increased to $38.5 \%$ for women aged 60-64 compared to $57.1 \%$ for men (Eurostat 2017). There is both horizontal segregation in the labour market that concentrates women in lower paid jobs such as caring and cleaning, and vertical segregation clustering women in the middle and lower part of organisations (OECD 2016). Although contemporary Irish women are more likely to be employed than ever, they are still the primary unpaid carers of family members. Mitigating that somewhat, relatively generous family friendly policies in Ireland now provide 26 weeks paid maternity leave and two weeks' paid parent's leave since 2019. Parents are entitled to 22 weeks of unpaid parental leave for each child. However, Irish childcare costs are among the highest in Europe, making it difficult for mothers to remain employed while children are young. There was also a gender pay gap of 13.9\% in Ireland in 2014 (Eurostat 2017). These combined historical factors of women's gender disadvantage in paid work have contributed to a gender pension gap of $34.8 \%$.

Academic research on retirement in Ireland is fairly limited, although the availability of the Irish Longitudinal Study of Ageing (TILDA) data since 2008 has given rise to policy reports, including one which found that early retirement is linked to higher education for women (Mosca and Barrett 2011). Such policy research, however has not specifically discussed extended working life. There is even less research on the gendered implications of retirement, although one recent article found that initial socioeconomic resources, health considerations, and/or work-life trajectories limit retirement choices for women (Ní Léime 2017). Recent Irish research analysing the likely implications of pension reforms from a lifecourse perspective found that linking pensions ever more closely to employment, as current policy initiatives do, is likely to exacerbate women's existing pensions disadvantage (Duvvury et al. 2012, 2017; Ní Léime et al. 2015).

The small but growing body of research that focuses explicitly on extended working life policies, highlights the potentially negative implications of increasing state pension age not only for women, but also for anyone in precarious or physically demanding work (Ní Léime et al. 2017; Ní Léime and Street 2017, 2019). This research highlights difficulties faced by older workers in precarious work to find alternative employment should they lose jobs, due in part to widespread ageism that 
discounts older worker's value to employers (Ní Léime and Street 2019). International research highlights that women in certain occupations are regarded as 'older' at an earlier age than men (Neumark et al. 2015). Other studies documented age discrimination in the Irish labour market (Russell et al. 2008) and a recent OECD review calls into question the effectiveness of existing anti-age discrimination measures in Ireland (OECD 2018). Further complicating matters for older workers, international research shows strong links between physically demanding work and ill-health (Marmot and Bell 2010). In the Irish context, recent research based on TILDA data indicates that greater physical limitations contributed to unemployment at older ages, while a higher number of impairments and frailty status of 'pre-frail/frail' increased the likelihood of unexpected retirement (Schinkley-Ivy et al. 2017).

\section{Pension System and Pension Policies Extending Working Life in Ireland}

There are two pension tiers in Ireland - state pensions and voluntary private pensions and there are two types of state pensions. The first is a means-tested, pension (237 euro per week in 2020) called the non-contributory state pension (SPNC, DEASP 2020). The SPNC is low by international standards, replacing only $34.1 \%$ of average industrial earnings (OECD 2017). More Irish women (61\%) than men (DEASP 2020) (39\%) are beneficiaries of the SPNC (DEASP 2018c). The second is the State Contributory pension (SPC), based on the number of years spent in paid work with the maximum rate of $€ 248.30$ per week (DEASP 2020). Women constitute a minority $(37 \%)$ of recipients of the contributory pension and even when they receive them, SPC payments to women are lower than for men (DEASP 2018c). Yet some elements of the current state pension system are women-friendly. A Homemaker's scheme was introduced in 1994; time spent caring for children — up to 20 years-may be counted for pension contribution purposes. However, this is not retrospective prior to 1994 so that women involved in caring earlier cannot avail of it. The SPNC does provide a safety net to help keep older women out of poverty and the 'at risk of poverty' rates are lower for women than for men (8\% and 9.7\% respectively) in 2016 (DEASP 2018d).

Ireland's second tier pensions are voluntary occupational and private pensions. In $2015,47 \%$ of men in paid work and $46 \%$ of women have occupational or personal (private) pensions or both. However, the level of pension values for women is lower than for men. Women have less than half the level of coverage rates of personal pensions (11\%) compared to men (25\%) (Central Statistics Office 2016). In recent decades, the government has incentivised people to provide for themselves via personal pensions, by providing tax relief on contributions (Department of Social and Family Affairs 2007; Hughes 2014).

Ireland has also introduced several pension-related extended working life policies since 2012. Despite having a relatively young population, with only $13.1 \%$ aged 65 or over in 2017, the Irish government has increased the state pension age for both state 
pensions quickly (CIA 2017). Currently set at age 66 (since 2014), it will increase to 67 in 2021 and to 68 in 2028 . While this may be beneficial for workers who are healthy enough and can work longer, it will be punitive for workers in physically demanding work or who are unemployed and cannot access pensions until later. Only a limited number of public service occupations (including defence forces, the fire service and Gardaí) may retire early on full public service pensions. In 2012, the number of contributions needed to qualify for a minimum level of State contributory pension doubled from 260 to 520 (from five to ten years), linking eventual pension amounts received much more closely to employment. This increase will adversely affect women who have time out of employment for caring purposes although this will be offset for women who benefit from the Homemaker's scheme. The number of contributory rate bands increased in 2012 and lowered pension benefits for those with lower contributions-mainly women (Bassett 2017). Rate bands differentiate between those with a certain amount of contributions, say between 10-14 years who receive smaller pensions than those with between 15-19 years of contributions.

A new averaging system valued pensions averaged over the entire working life from the earliest date of employment, rather than simply totalling contributions over earning years. This has introduced an anomaly in that those employed from an early age and who subsequently had time out of paid employment to provide care for family members receive lower pensions than those who simply started to work later. A Total Contributions Approach (TCA), with pension amounts to be based on total contributions made, is to be introduced in 2021 (Coyle 2019; DEASP 2018d). However, even with the TCA, the change in bands introduced in 2012 mean that those with fewer contributions (mainly women) will lose out compared to the pre-2012 system. In another pension innovation, the government plans to introduce auto-enrolment in 2022, a mandatory private earnings-related system to which individuals, employers and the state will also contribute (DEASP 2018a, b). The details of this scheme have yet to be finalised (no concrete steps have been put in place as of December 2019) but it is proposed that workers may be able to opt out of the scheme after 9 months. While such a scheme may benefit some workers by automatically enrolling them earlier, many workers (primarily women) who are in low-paid and/or precarious employment and often work part-time may not be able to afford to contribute to such pensions and will not benefit (see Espadinha 2019 for UK experience). In the consultation document, the minister explicitly states that it is introducing this in response to the OECD's 2014 review of the Irish pension system (OECD 2014).

\section{Extended Working Life Employment Policies}

The EU set employment targets of 50\% for older workers (aged 55-64) for 2010 and $75 \%$ for all workers under retirement age in 2020. The Irish government introduced measures to help achieve this target, including strengthening anti-(age and other forms) discrimination legislation to include people aged 65 and over (Employment Equality Acts [EEA], 1998-2015). Ireland set an interim target of 69-71\% all-worker 
participation rates (FORFAS 2011) by 2014, but did not achieve this for older workers. Despite more encompassing formal anti-discrimination measures, research evidence suggests that ageism in the Irish labour market acts as a barrier to recruitment and/or retention for older workers (Russell et al. 2008). Workers can seek advice from the Irish Human Rights and Equality Commission and take a case to the Equality Tribunal if discriminated against on the grounds of age. However, the OECD stated that it is unclear whether the anti-age discrimination legislation is effective, citing a low proportion of cases brought under age grounds (OECD 2018). The former Pre-retirement Allowance provided by the government was discontinued in 2007 to discourage early retirement. Without that, there are no provisions for workers in physically demanding employment to retire early OECD 2018). Upper age limits for recruitment to the public service were removed in the 1990s. Yet the fact that state pension age has increased has not obligated employers in the private sector to retain workers to age 66, provided they give 'objective justification' for compelling them to retire. It is now the law that compulsory retirement ages set by employers will not be considered discriminatory if they are objectively and reasonably justified by a legitimate aim. The latter can include intergenerational fairness (allowing younger workers to progress), motivation and dynamism through the increased prospect of promotion, health and safety, creation of a balanced age structure in the workforce, personal and professional dignity and succession planning (Workplace Relations Commission 2017). Most Irish private sector employers have not increased the retirement age at their firms in line with the state pension (Report of the Interdepartmental Group on Fuller Working Lives 2016).

Since 2007, increased flexibility means that recipients of the SPNC can earn up to $€ 200$ per week and still receive the SPNC. This benefits older workers who are healthy enough to work and those who can find employment, but not others. The Workplace Relations Commission (WRC) published a Code of Practice on Longer Working (S.I. 2017) that gives guidance on best industrial relations practice between employers, employees and trade unions in the approach to retirement (WRC 2017) regarding utilising the skills of older workers. It recommends training management about age diversity, encouraging knowledge and experience sharing, exploring flexible working measures, age proofing policies, and procedures raising age discrimination awareness. The code of practice exhorts employers but does not compel them to follow best practice guidelines.

There is no statutory retirement age in the private sector in Ireland and it is usually set out or implied in employment contracts or organisational policy documents or in the employer's pension scheme. The Employment Equality Act 2015 mediated the protection offered to employees under previous legislation protecting against age discrimination. It is now the law that compulsory retirement ages set by employers demand objective justification on a wide range of grounds. There is concern that this gives employers a good deal of power to compel older employees to retire at younger ages than state pension age, even though state pension age has been increased. The code also states that employers should provide clear information to employees at the time of recruitment and later, to enable them to plan. It states that employers 
have the right to discuss retirement with employees and gives guidance on the retirement process-employers should provide 6-12 months' notice and explore flexible employment options. It also provides recommendations on procedures for how requests from employees to work longer should be dealt with. Yet, the OECD country report stated that no action had been taken to discourage mandatory retirement by employers (OECD 2018).

There have been some training and lifelong learning programmes provided at national level including the Department of Education and Skills Springboard plus programmes primarily aimed at up-skilling and re-skilling long-term unemployed people. This includes some older people-although it does not specifically target them. Other programmes that are planned or in development currently focus on youth and the long-term unemployed rather than older workers per se. A low proportion of older workers participate in other state-funded programmes. The issue of supporting longer working lives is one objective of the National Skills Strategy published in 2016. There are no specific employment subsidies provided to employers for hiring older workers, although there are subsidies for employing people with disabilities, regardless of age. Community Employment schemes aim to enhance the employability of unemployed persons by providing them with work experience. Since 2015 , those aged 62 and over may remain in Community Employment schemes until state pension age and those over 55 will be allowed to stay for three years (OECD demanding employment to retire early (OECD 2018). There are no Health and Safety policies aimed at older workers in particular in Ireland (Sexton 2012). Nor have actions been taken to reduce the incidence of arduous work for older workers in Ireland (OECD 2018). Apart from activation policies targeting the long-term unemployed, no specific policies have been introduced to address precarious employment for older workers.

\section{Health Policies}

Two income-replacement disability benefits in Ireland may be claimed by people who experience a disability lasting more than one year, up to retirement age. One is a disability allowance for disabled adults with insufficient social security contributions to earn a contributory benefit and the other is a disability pension for those with sufficient contributions. The allowance may be combined with earnings from rehabilitative work, while the pension may not. In 2012, a partial capacity benefit scheme was launched where people with a disability allowance or pension can be assessed for their residual work capacity, receive a partial payment and also work. Participation is voluntary, with a low take-up.

Similar to other countries (and recommended by OECD) access to illness benefits has become more restrictive in Ireland. Reforms introduced in 2012 placed time limits (two years) on illness benefits intended to provide short-term income replacement for insured persons during spells of incapacity or illness, leading to a decline in number of recipients (OECD 2018). Given that pension age is now being increased, the combination of restrictive illness benefits makes the situation potentially more 
difficult for older individuals with work-induced health problems. A survey of those receiving disability allowance found that the five most common health conditions cited by respondents were mental health, difficulties with basic physical activities, intellectual disabilities, heart problems and breathing problems (Judge et al. 2016).

Under the Carer's Benefit scheme introduced in 2000, it is possible for workers in Ireland to take up to 104 weeks paid leave to provide care for a family member in need of care and to have one's job kept open. A worker may be eligible for Carer's Benefit if they have enough Pay Related Social Insurance (PRSI) contributions (DEASP 2019). If not, they may qualify for Carer's Allowance-a means-tested payment.

\section{Debate on Extended Working Life}

Initially, there was relatively little media debate about pension reforms or extended working life policies in Ireland, apart from alarmist headlines predicting pension time bombs. Interested non-governmental organisations (NGOs) including the National Women's Council of Ireland and Age Action made pre-budget submissions and contributed to the Green Paper consultation on pensions, alerting the government to the potentially adverse effects for women (Cousins and Associates 2008). Public debate in Ireland at the time the major pension reforms were introduced in 2012 focused predominantly on the severe recession as justification for austerity policies. Consequently relatively little attention was paid to the reforms' potentially negative effects for women or those in physically demanding work, despite the concerns raised by trade unions and NGOs (Ní Léime et al. 2017). There has been more public debate about pension issues since the economy started to recover and the impacts of the pension reforms began to be felt. In 2014, some politicians raised the issue of the adverse impacts for women of pension reforms in the Irish parliament (Dáil Debates 2014). In 2017, the Citizen's Assembly on Ageing (a group set up by the government to discuss and make recommendations on ageing issues) voted that the anomaly created since state pension age was increased-whereby most workers have a retirement age of 65 set by employers, but will not receive state pensions until age 66 - must be addressed. More recently in 2017/2018, the negative impacts of one reform - the 'averaging' of pensions over the working life began to be felt in people's pension payments. Approximately 36,000 people found they were receiving a lower pension under the new system and 62\% of these were women (Bassett 2017). There was extensive media coverage and a public protest involving those affected, NGOs including Age Action and the National Women's Council of Ireland and some politicians was held (Bassett 2017). The government agreed to allow those disadvantaged due to pension averaging the option to be re-assessed under a Total Contributions Approach (TCA) and to be paid whichever is most beneficial for them (averaging or TCA approach) until 2019 (Government of Ireland 2018a, b). The government has just held consultations in 2018 with the public about the TCA and auto-enrolment which are to be introduced post 2020 (DEASP 2018b, c). The gap between retirement (typically set at age 65 in their contracts for many private sector 
workers) and state pension age, now 66 and set to increase to 67 in 2021 was raised as a major issue in the general election of 2020; some political parties have committed to reduce or at least not further increase state pension age - the outcome of this remains to be seen.

\section{Gender and Health Implications}

The Irish pension reforms introduced pension amounts linked more tightly to participation in the paid labour market (increasing the number of contributions required for a minimum pension, increasing the number of bands and paying less to those with fewer contributions) which exacerbate women's already existing pension disadvantage. Both the 'averaging' approach and the TCA will mean lower pension payments for many women since they typically have fewer contributions over the lifecourse. Increasing state pension age across the board for all workers makes it difficult for those (men and women) workers who are in physically-demanding work and/or have ill-health to work up to increasing state pension age. Both men and women in precarious employment are likely to be adversely affected by the increase in state pension age, because, if unemployed, it is likely to be difficult to find employment, due in part to ageism in recruitment. While the government has introduced recommendations to employers and a code of conduct, there is ample scope for employers to compel employees to retire at 65 if they can justify this 'on objective grounds' (Workplace Relations Commission 2017). Therefore the gap between retirement age for private sector employees and the age which they can access the state pension is likely to remain, forcing older unemployed workers to apply for jobseekers allowance.

It is not plausible that the government was unaware that the pension reforms introduced would disproportionately adversely affect women. Indeed an OECD review of the Irish pension system acknowledged that women would be disadvantaged under the reformed system, yet the government of the day implemented it (OECD 2014). While the Homemakers Scheme mitigates part of the problem for those engaged in caring post-1994, there is a large cohort of women who cannot avail of that.

\section{Policy Recommendations}

The Total Contributions Approach, auto-enrolment and all proposed future pension reforms should be gender-proofed. A universal citizens' income/pension, based on residency (not linked to participation in paid employment) would ensure that women are not discriminated against and that all forms of contributions to society, including unpaid caring and volunteering are valued. To deal with the challenge of work-related health issues, there should be provision for those engaged in physically demanding work to retire early on a full pension (OECD 2017; Ní Léime and Street 2018). Since many people in such jobs begin work at an early age, it may be fair to allow 
people to retire earlier-perhaps after a number of years worked rather than linking pension receipt to chronological age. While auto-enrolment may be helpful to those who do not consider contributing to individual pensions, it will not help those who simply cannot afford to contribute to pensions, or those in precarious employment with unpredictable tenure and income. The issue of precarious employment and its implications for pensions needs to be addressed at a government level. There is a need for further research on the gender and health implications of precarious employment to ensure a secure stream of old age income for all Irish citizens.

\section{References}

Bassett, M. (2017). Towards a fair state pension for women pensioners. Dublin: Age Action.

Central Statistics Office. (2016). Quarterly national household survey: Pension provision Quarter 42015 summary. Cork/Dublin: Central Statistics Office.

CIA. (2017). Central intelligence agency, world factbook. Retrieved September 20, 2018, from https://www.cia.gov/library/publications/the-world-factbook/geos/ei.html.

Coyle, D. (2019). Minister concedes State pension reform plans put back to 2021. Irish times (December 20th). https://www.irishtimes.com/business/personal-finance/ministerconcedes-state-pension-reform-plans-put-back-to-2021-1.4120968.

Cousins, M., \& Associates. (2008). Report on the consultation process for the green paper on pensions. Dublin: Stationery Office.

Dáil Debates. (2014). Retrieved December 8, 2018, from http://oireachtasdebates.oireachtas.ie/ debates\%20authoring/debateswebpack.nsf/takes/dail2014041600009.

Department of Employment Affairs \& Social Protection (DEASP). (2018a). A roadmap for pensions reform. Dublin: Government of Ireland.

Department of Employment Affairs \& Social Protection (DEASP). (2018b). A strawman public consultation process for an automatic enrolment retirement savings system for Ireland. Dublin: Government of Ireland.

Department of Employment Affairs \& Social Protection (DEASP). (2018c). Statistical information on social welfare services 2017. Retrieved September 7, 2018, from https://www.welfare.ie/en/ downloads/Annual_Statistics_Report_2017.pdf.

Department of Employment Affairs \& Social Protection (DEASP). (2018d). Total contributions approach consultation 2018 May to September 2018. Dublin: Government of Ireland.

Department of Employment Affairs \& Social Protection (DEASP). (2019). What is carer's benefit? Retrieved July 13, 2019, from http://www.welfare.ie/en/Pages/Carers-Benefit-SW-49.aspx.

Department of Employment Affairs and Social Protection (DEASP). (2020). Current rates of social welfare payment. Retrieved January 16, 2020, from https://www.gov.ie/en/publication/6aec4dcurrent-rates-of-payment-for-social-welfare-payments-sw19/.

Department of Social and Family Affairs. (2007). Green paper on pensions. Dublin: Stationery Office.

Duvvury, N., Ní, Léime Á., Callan, A., Price, L., \& Simpson, M. (2012). Older women workers' access to Pensions; vulnerabilities, perspectives and strategies. Galway: Irish Centre for Social Gerontology.

Duvvury, N., Ní Léime Á., \& Callan, A. (2017). Erosion of pension rights. Experiences of women in Ireland. European Journal of Cultural and Political Sociology, 5(3), 266-294.

Espadinha, M. (2019). Auto-enrolment gender gap increases to $40 \%$. Financial times adviser (March 27th) https://www.ftadviser.com/pensions/2019/03/27/auto-enrolment-gendergap-increases-40/. 
Eurostat (2017). Gender pay gap in unadjusted form. Retrieved September 11, 2018, from https:// ec.europa.eu/eurostat/statisticsexplained/index.php=Gender_pay_gap_statistics.

FORFAS. (2011). Аnпиal report 2011. Dublin: FORFAS.

Government of Ireland. (2018a). Total contributions approach consultation 2018. Dublin: Government of Ireland.

Government of Ireland. (2018b). A strawman public consultation process for an automatic enrolment retirement savings system for Ireland. Dublin: Government of Ireland.

Hughes, G. (2014). Have personal retirement accounts met their objectives in Ireland? In M. Szczepanski \& J. A. Turner (Eds.), Social security and pension reform: International perspectives (pp. 39-62). Kalamazoo, MI: Upjohn Institute for Employment Research.

Judge, C., Rossi, E., Hardiman, S., \& Oman, C. (2016). Department of social protection report on disability allowance survey 2015. Dublin: Department of Social Protection.

Mahon, E. (1998). Class, mothers and equal opportunities to work. In E. R. Drew \& E. Mahon (Eds.), Women, work and the family in Europe (pp. 170-181). London: Routledge.

Marmot, M., \& Bell, R. (2010). Challenging health inequalities-implications for the workplace. Occupational Medicine, 60, 162-166.

Mosca, I., \& Barrett, A. (2011). Retirement and labour market participation In Fifty plus in Ireland 2011: First results from the Irish Longitudinal study on ageing (TILDA). Dublin: Trinity College.

Neumark, D., Burn, I., \& Button, P. (2015). Is it harder for older workers to find jobs? New and improved evidence from a field experiment. NBER working paper No. 21669.

Ní Léime Á., Duvvury, N., \& Callan, A. (2015). Delayed retirement: Gender, ageing and work in austerity. In K. Walsh, G. Carney, \& Á. Ní Léime. (Eds.), Ageing through austerity: Critical perspectives from Ireland (pp. 63-78). Bristol: Policy Press.

Ní Léime, Á. (2017). Older women public sector workers in Ireland; decisions about retirement timing. Journal of Women and Aging, 29(5), 392-404.

Ní Léime Á., Duvvury, N., \& Finn, C. (2017). Gender and extended working life in Ireland. In Á. Ní Léime, D. Street, S. Vickerstaff, C. Krekula, \& W. Loretto (Eds.), Gender ageing and longer working lives: International analysis from a critical perspective (pp. 117-135). Bristol: Policy Press.

Ní Léime, Á., \& Street, D. (2017). Gender and age implications of extended working life policies in the US and Ireland. Critical Social Policy, 37(3), 464-483.

Ní Léime, Á., \& Street, D. (2019). Extended working life in Ireland and the U.S.: Gender implications for precarious and secure workers. Ageing \& Society. 39(10), 2194-2218.

OECD. (2014). Review of the Irish pensions system. Retrieved September 12, 2018, from https:// www.welfare.ie/en/downloads/OECD-Review-of-the-Irish-Pensions-System.pdf.

OECD. (2016). Gender wage gap (indicator). Retrieved March 24, 2019, from https://data.oecd. org/earnwage/gender-wage-gap.htm.

OECD. (2017). Pensions at a glance 2017 OECD and G20 indicators. Retrieved March 24, 2019, from http://dx.doi.org/10.1787/pension_glance-2013-en.

OECD. (2018). Ireland. Key policies to promote longer working lives. Country note 2007 to 2017. Paris: OECD.

Russell, H., Quinn, E., King O'Riain, R., \& McGinnity, F. (2008). The experience of discrimination in Ireland: Analysis of the QNHS equality module. Dublin: The Equality Authority and the Economic and Social Research Institute.

Schinkel-Ivy, A., Mosca, I., \& Mansfield, A. (2017). Factors contributing to unexpected retirement and unemployment in adults over 50 years old in Ireland. Gerontology and Geriatric Medicine. https://doi.org/10.1177/2333721417722709.

Sexton, J. (2012). Employment policies to promote active ageing. Ireland: EEO Review, European Employment Observatory, European Commission.

Workplace Relations Commission. (2017). Industrial relations act 1990 (Code of practice on longer working) (Declaration) Order 2017. Retrieved March 24, 2019, from http://www. irishstatutebook.ie/eli/2017/si/600/made/en/pdf. 
Open Access This chapter is licensed under the terms of the Creative Commons Attribution 4.0 International License (http://creativecommons.org/licenses/by/4.0/), which permits use, sharing, adaptation, distribution and reproduction in any medium or format, as long as you give appropriate credit to the original author(s) and the source, provide a link to the Creative Commons license and indicate if changes were made.

The images or other third party material in this chapter are included in the chapter's Creative Commons license, unless indicated otherwise in a credit line to the material. If material is not included in the chapter's Creative Commons license and your intended use is not permitted by statutory regulation or exceeds the permitted use, you will need to obtain permission directly from the copyright holder.

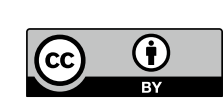




\title{
Chapter 23 \\ Israel
}

\section{Orly Benjamin, Sarit Nisim and Dikla Segel-Karpas}

\begin{abstract}
Israel's response to population ageing has included policies increasing pension age, flexible working, and privatisation of pensions. These policies have increased poverty risks for those experiencing exclusion and isolation and limited access to housing, education, quality jobs, and healthcare services. In this context, polarised gender/class positions leave women at higher risk of poverty in old age, particularly for women not living with a partner or when a pension related to a partner's work life is not available. Only a minority of Israeli women currently extend their working lives, despite very low state allowances for older people. Policymakers have paid little attention to differences between men and women or among women in different circumstances. This has contributed to an assumption that raising pension age is an appropriate one-size-fits-all solution when it clearly is not.
\end{abstract}

Keywords Poverty $\cdot$ Retirement $\cdot$ Gender $\cdot$ Employment $\cdot$ Pensions

\section{Israel's Socio-Economic Situation}

Sustainability and later life wellbeing are influenced by gender and class inequalities in housing, education, access to good jobs, healthcare services, and pension programmes. Eight ethno-national categories in Israel range from Jews of European descent at the top of the social-politico-economic hierarchy, followed by Jews from Middle Eastern and North African countries, immigrants from the former USSR, immigrants from Ethiopia, Christian Palestinians, Druze, Muslim Palestinians, and Bedouins. Ethno-national inequalities are reflected in quantitative and qualitative

\author{
O. Benjamin ( $\square)$ \\ Department of Sociology and Anthropology, Bar-Ilan University, Ramat Gan, Israel \\ e-mail: orly.benjamin@gmail.com \\ S. Nisim \\ Poverty Research Unit, Bar-Ilan University, Ramat Gan, Israel \\ D. Segel-Karpas \\ Department of Gerontology, University of Haifa, Haifa, Israel \\ (C) The Author(s) 2020


data on local poverty rates among elderly women in each of these categories. Nevertheless, apart from than repeated suggestions to increase the retirement age and activation policies, effective policies directed at creating jobs for older people to enhance inclusion and income have not been implemented. Likewise, anti-age discrimination legislation and flexibility of the labour market have not been included in debates about extended working life policies.

Currently Israeli women remain in employment longer than before. In 1998, $44.6 \%$ of women aged 55-59, and 22.9\% aged 60-64 were employed and 9.1\% of women aged 65-70 were employed and 3.3\% of women aged 70+ (Amir and Kalinov 2003). By 2017, 70\% of women aged 55-59 were employed, as were $52.3 \%$ of women aged 60-64, 30.4\% of women aged 65-69, and 6.3\% of women aged $70+$ (Central Bureau of Statistics 2018). In relation to pension coverage, Spivak and colleagues (2017) reported that increased income inequality after retirement age implies a higher risk of poverty for low income employees, regardless of gender. These authors showed that only $34 \%$ of pension savers with an income higher than the average income are women, while almost $70 \%$ of pension savers with an income lower than the minimum wage or around minimum wage are women. Savers with a stable income could expect a replacement rate of $70 \%$ of their present monthly income (Spivak et al. 2017). However, employees who work less than 12 months a year, a situation that applies to many women in precarious non-standard employment (Benjamin 2016), can expect only a 38\% replacement rate. Gendered work histories characterized by moving between low quality jobs in service and care occupations, with dependency on low state allowances after retirement contribute to this difference (Spivak et al. 2017). Spivak and colleagues' prediction about predictable risks for poverty among certain categories of older people has been validated by a recent food insecurity report indicating that $12.8 \%$ of women after retirement age live in food insecurity, and for $6.3 \%$ of them, food expense anxiety is significantly higher.

Israel's population is relatively young, with only $10.8 \%(900,000)$ older adults (aged 65 and above); half of this older cohort are over the age of 75 . Of adults 65 and above, $82 \%$ live with a partner, but among women, only $48 \%$ live with a partner. About $31 \%$ of adults over 65 reported worrying about their financial situation. These figures were calculated from the Survey of Health Ageing and Retirement in Europe (SHARE) data (2016). The data also showed that poverty rates are significantly higher among Palestinians living in Israel, for whom $47 \%$ of men and $88 \%$ of women in this age category cannot cover their expenses. In terms of labour market participation, $18.6 \%$ of older Palestinians are employed- $-27 \%$ of men and $11.9 \%$ of women. The proportion of those employed decreases with age: for the 65-69 cohort the participation rate is $38.6 \%$ (50.2\% of men, $28 \%$ of women); after 70 , only $8.2 \%$ are employed ( $13.5 \%$ of men, $4.2 \%$ of women). Reflecting the national occupational ladder, the participation rate for older Jews is higher $(19.8 \%)$ than the rate for older Palestinians living in Israel (5.1\%). In terms of working hours, $51.8 \%$ of older workers in the general population usually work full-time ( $35 \mathrm{~h}$ or more per week) and $48.1 \%$ work part-time. Among men, 63.3\% work full-time and $36.7 \%$ work part-time. Among women, 31.4\% work full-time and $68.6 \%$ work part-time. Among employed women, $34.2 \%$ work in managerial or academic occupations $10 \%$ as office clerks, and $24.1 \%$ work in sales and services and as skilled or unskilled labourers. 


\section{The Israeli Pension System}

Long-term demographic and economic changes have contributed to three decades of pension reform in countries perceiving crises in their pension systems (Williamson and Williams 2005). Decreasing birth rates for dual earner families, increasing life expectancy and the growth of the older population (considered the financially weakest economic group of the population, excluded from participating in the work force), are some of the main causes for the perception of pension crises.

In Israel, a national system for distributing pensions was first established during the pre-state period by the Histadrut Union Federation, an overarching labour union that functioned as micro-state, employer, and trade union. These pensions were workplace occupational pensions that offered up to $70 \%$ of the basic wage based on mutual monthly payments by employees (11\% of wages) and employers (5\% of the wage). These defined-benefit (DB) schemes were granted exclusively for the Histadrut union members through collective agreements. Other large business organisations granted similar employer-employee jointly funded saving programmes through expansion orders of the Labour and Welfare Minister. State employees participated in fully funded pension programmes funded from state revenues (Gal 2002). Those entitled to the latter benefitted from rank-related employer provision.

The current Israeli pension system is based on two pillars. The first is a universal retirement social security income system that has operated since the establishment of the National Insurance Institute (NII) in 1954 (Achdut and Spivak 2010). The NII is responsible for managing and distributing benefits for social insurance programmes. These social insurance benefits, which were developed during earlier periods in which social democratic welfare models were locally embraced, embrace the role of the state to guarantee a basic income for all residents. These allowances are based on the pay-as-you-go (PAYG) principle, funded through a compulsory NII incomeproportional tax paid by each citizen from the age of 18 to retirement (age 67 for men and 64 for women).

The two main insurance benefits are old-age insurance and survivors' insurance. Old-age insurance guarantees that Israeli citizens obtain a fixed monthly income during their old age regardless of their income level. Old-age insurance is approximately 1,530 NIS per month for individuals (just under 33\% of the minimum wage) and 2,300 NIS for a couple. Survivors' insurance ensures a means of subsistence for surviving kin of a breadwinner-surviving spouse and orphans of a deceased Israeli citizen. Survivors' insurance is approximately 1,550 NIS a month. Alongside the social security system, there is a supplementary means-tested allowance designed to ensure a minimum income to older people with few or no other income sources. Those entitled to such a supplement receive 2,981 NIS (64\% of the minimum wage) for an individual and 4,706 NIS for a couple. After eight years of no eligibility that followed the 2008 mandatory pension, since January 2016 those with low work pensions are also eligible for this supplemental income.

The second pillar of the Israeli pension system is the occupational fund. Traditionally, these schemes were aimed at Histadrut Union Federation members and 
employees with coverage through collective agreements. As mentioned before, these schemes are jointly funded by employers and employees, pensioners are offered up to $70 \%$ of their basic wage after 35 years of saving. Alongside the DB funds a non-contributory benefit is paid by the National Insurance Institute, granted to older Jewish immigrants who lack the required qualification time period and therefore are not eligible for the regular DB scheme (Gal 2002).

As in many other OECD countries, during the 1980s and the 1990s pension funds faced substantial actuarial deficits and their financial viability became uncertain. To avoid a financial crisis of the pension system, the Ministry of Finance's (MOF) budgeting administrators exerted pressure for reform, and after an intense negotiation between the MOF and the Histadrut representatives, a first reform was enacted in 1995 (Spivak and Troitsky 2013). The reform included a governmental guarantee to financially support the existing funds while closing them to new members and replacing them with defined contributions (DC) based on pension schemes.

An important drawback of the reform is the increase in social inequalities: DC pension schemes are based on financial market investments that expose them to risks and stock market crises. The DC monthly contribution is known, but the monthly allowance is unknown and is calculated at the time of retirement (account balance + yield-management fee divided by the national life expectancy). The management fee of the DC schemes is relatively high — about six per cent depending on individual bargaining abilities, which obviously tends to be worse for those with lower income. Although the 1995 reform was designed to increase the competition among different private pension funds, it failed to do so. The Histadrut federation established new pension funds using their financial resources and reputation to recruit new members and to remain dominant in the pension market. In 2002, the total deficit of the pension funds was estimated at approximately 109 billion NIS (OECD 2011), which led to a second reform during 2003-2004.

The second reform was quite extensive and aimed to stabilise the actuarial deficit of the old funds by transferring 80 billion NIS as a final act of government support. The financial responsibility was transferred to fund members and involved the appointment of professional managers to the fund. Other measures implemented as part of the second reform included significant reduction of government subsidies for pension savings and created a unified mechanism to establish rights and arrangements of the funds. A new calculation method for pension rates was introduced. New public sector employees were no longer able to join the employer funded scheme and instead were granted the new pension plan (DC). Another part of the reform raised the retirement age from 65 to 67 for men and from 60 to 64 for women.

The 1995 and 2003-2004 reform's main concerns were financial stability and addressing the growing deficit of the old pension funds, low rates of pension coverage, and increased poverty rates among the older population. Beginning in 2008, a mandatory pension arrangement was initiated following an agreement between the Histadrut Union Federation and the manufacturers organisations through an expansion order issued by the Minister of Industry, Commerce and Employment. Each average salaried employee became entitled to a pension fund after at least six months of employment in the same workplace. In addition, individuals and groups 
are now able to choose from the different pension funds and to switch between them, based on their own market preferences. Importantly, the mandatory programme takes $5.5 \%$ from the employee and $12 \%$ from the employer. However, of the employers' $12 \%$ contribution, only half of the funds are deposited to the pension programme while the other half is allocated to the severance package. Applied only since 2014, when calculated for minimum wages, current arrangements suggest very low future pension entitlement through these DC funds. Since January 2016, those on low pension entitlement (including individuals with no pension entitlement) are eligible to a supplemental public income.

To sum up, starting in 1980, Israel's economy took a neo-liberal turn: its pension system was gradually privatised, and the role of the government was reduced to regulation. Existing Figures (CBS 2012) reflect the main ramification of Israel's pension restructuring in terms of privilege and exclusion: only $64 \%$ of citizens over the age of 20 have at least one pension programme (for many it is only the first tier of occupational mandatory programme). As the mandatory pension blurred social distinctions, the reported gender gap in holding at least one pension programme is relatively small: $69 \%$ for men vs. $60 \%$ for women. Of men and women over age 60 , $53 \%$ have a pension programme (CBS 2012).

\section{The Debate Over Women's Pension Age}

There has been heated debate over the retirement age for women during recent years (retirement age for men was increased in 2004 to 67). In July 2017, two members of the Knesset (the Israeli parliament) proposed the abolition of retirement ages, to facilitate individual choices about when to retire while prohibiting employers from forcing retirement other than against some standardised test of contribution to the job. On the one hand, there are women in quality jobs for whom retirement means a loss of potential to accumulate more monthly contributions and attain an increased pension allowance, compensating at least partly for the disadvantages embedded in a gendered work life. On the other hand, women earning minimum wages and/or in part-time employment, and for workers who suffer physical or emotional burnout often cannot wait to retire at older ages. For those in low paid jobs, the retirement allowance would actually increase their monthly income. Financial consideration concerning the ability of social security to pay allowances with increasing longevity is the main reason for pushing for change in retirement age. Herbst-Debby (2018) has shown that for employees in low-paid jobs, the move from the 'working mum' employment track to the imperative of the self-sufficient individual citizen has undermined the very limited welfare security such women had in the past. The expectation of the ungendered self-sufficient worker has not been accompanied by Israeli policy that secures jobs with reasonable wages and working conditions, or that offers working mothers a sustainable future at pension age. Further, many older women workers have encountered ageism and are already unemployed even before retirement age (Buksbaum and Dagan 2010). An earlier pension allowance for vulnerable women is a 
matter of basic individual sustainability, while any legislation to postpone retirement would benefit those with the better pension programme.

The alternative to abolishing the retirement age would be gradually equalising the retirement age of men and women at age 67, which again leaves those outside or in the periphery of the labour market without a solution for later life income. Women's organisations have allied with feminist members of Knesset and strongly oppose any modification of the current law that does not account for women in precarious positions, in poverty, or at high risk of poverty. According to a 2018 protocol of a finance committee meeting at the Knesset, there is consensus among the Knesset supporting legislation to postpone women's retirement age. However, this is contingent upon the finance ministry's commitment to allocate appropriate compensation to fund retirement allowances for women where work history and current opportunities eliminate the possibility of employment after retirement. There is an impasse, since the finance ministry refuses to allocate such funding, stating that it would offset the advantage gained by the women's retirement age increase. Despite broad agreement that some retirees must be protected from financial difficulties as they age, the Treasury so far has refused to act. Meanwhile all those of retirement age will have reduced allowances ( $1.2 \%$ per month) to sustain pension funds rather than raise the pension age for women.

\section{After Retirement-Age Employment: Another Source of Cheap Labour}

In a representative sample of 853 adults aged 19-97, 47.2\% preferred a mandatory retirement age set in law. In contrast, $60 \%$ of adults over 55, regardless of gender, reported they would prefer to continue working past the mandatory retirement age. Higher levels of perceived ageism were related to respondents' perception of older adults' desire to retire when they reach retirement age, and to thinking that retirement age should not be set by law (Segel-Karpas and Palgi 2018). However, even with high levels of support among older Israelis in the sample, extended working life may not be beneficial for all, despite many Israelis working past the retirement age. For example, on 12 September 2018, newspapers in Israel highlighted a typical conflict between the city council and the road sweeping subcontractor, which left 60 employees without income. The employees were all residents of Israel's southern periphery aged 10-15 years after retirement age, many of whom were immigrants from Ethiopia and the former Soviet Union and spoke very little Hebrew. Others among vulnerable categories include school safety guards who were not entitled to an income when schools shut for July and August. Women in similar social categories were often employed in cleaning or caring jobs (both in the home or in residential buildings) but they did not experience seasonal interruptions in their employment. This reflects the opportunity structure for immigrants who seek employment after 
retirement age. These instances of over retirement age individuals employed in physically challenging jobs suggest the necessity of introducing the aspect of job quality in examining the implications of extended work life.

\section{Health, Work, and Ageing}

The Israeli context of mandatory retirement may have detrimental effects on adjusting to retirement, resulting in lower levels of physical and mental health. Retirement is particularly intimidating in Israel since a large majority of those over age 53 feel financially unprepared for it (Segel-Karpas and Werner 2014). Married people in this study reported feeling less prepared than non-married people, possibly because each spouse attributed responsibility to the other. These findings support earlier findings of Litwin and Meir (2013) showing that the main financial worry for adults aged 65 and older is that pension funds will not suffice for one's entire life. Other research in the Netherlands and the US suggest that, when retirement is perceived as involuntary, retirees respond with lower levels of wellbeing (Van Solinge and Henkens 2005; Schultz et al. 1998). In contrast, in a cross-sectional study of Jerusalem residents conducted between 1985 and 1987, Abramson et al. (1992) found that workers were healthier than non-workers, and that satisfaction with work was related to better health. Segel-Karpas (2015) used the Survey of Health Ageing and Retirement in Europe (SHARE) to examine that the moderating role of employment vs. retirement in the relationships among objective measures of health, subjective measures of health, and mental health. The relationship between objective health and selfperceived health was stronger among older workers than among retirees, suggesting that when health is not optimal, work roles could be an added stressor, resulting in poorer perception of health (Segel-Karpas 2015). However, the relationship between self-perceived health and depressive symptoms was stronger among the retired, suggesting that when health is perceived as less than optimal, the resources provided by the work role could mitigate its negative effects on psychological wellbeing.

The gendered path between employment and health is attributed to differences in social roles. Women are perceived, more often than men, to be responsible for the family. According to the OECD 2014 report, fertility rates in Israel are higher than in most Western countries, suggesting that the family poses a major responsibility for Israeli women. Women work an average of $8 \mathrm{~h}$ less per week than men (37 vs. $44.9 \mathrm{~h}$ per week), and the percentage of women employed in part-time positions is double that of men (31.8\% vs. $13.2 \%)$ (CBS 2019).

In a longitudinal study that examined the changes in patterns of labour market participation for Israelis aged 50-69 from 2005 to 2010 (Achdut et al. 2014), the most important finding was the persistent increase in labour market participation past retirement age. Health emerged as the most important barrier to continued employment, primarily for women. Education shaped labour market participation the opposite way - the higher the educational attainment, the stronger the tendency for continuous employment. Those committed to support more children were more 
likely to hold onto their employment. Wealth was important; individuals in the middle of the wealth distribution tend to leave the labour market while individuals at both ends are more likely to stay longer, suggesting an element of choice for wealthier individuals, and necessity for less wealthy Israelis. Those with an employed partner, particularly women, tended to leave the labour market. Generally, researchers found that people who stayed in employment longer usually tried to find a form of transitional job with reduced time and responsibility (Achdut et al. 2014).

\section{Conclusion}

Women in Israel are at a higher risk of poverty in old age than men, particularly when not living with a partner or lacking a pension related to a partner's work life. This is particularly true for those who suffered of intimate partner violence over their lifecourse. The risk of poverty increases when women support their grown-up children and it requires them to maintain their participation in the labour market in precarious jobs since they could not find quality employment in the 10 year period prior to retirement age.

More generally, after retirement age, about a fifth lives in poverty (NII 2018) and many individuals have had to go without medicines and medical treatment (Litwin and Meir 2013). Although many older Israelis require additional income, they do not benefit from high quality jobs in their extended work life. When many of the most vulnerable older Israelis participate in the labour market, they are employed as unskilled labourers or in low skill service and care occupations, and they face an opportunity structure that is of low quality. Women and immigrants are disproportionately clustered in such precarious and low-quality employment. Similarly, the situation is difficult for those living in homes that they own but need to leave because of stairs or distance from family and friends, or those who live in places in need of refurbishment, sometimes related to deteriorating health conditions. More data are needed for these groups of individuals, who need more material resources as well as support in efforts to increase their income and wellbeing. The norm of supporting older relatives is still strong among Palestinians living in Israel, but for immigrants, lack of state support may be especially detrimental with women immigrants being most vulnerable of all.

\section{References}

Abramson, J. H., Ritter, M., Gofin, J., \& Kark, J. D. (1992). Work-health relationships in middle-aged and elderly residents of a Jerusalem community. Social Science and Medicine, 34(7), 747-755.

Achdut, L., \& Spivak A. (2010). The pension system in Israel after 15 years of reforms. Policy Studies no. 8. Jerusalem: The Van Leer Jerusalem Institute.

Achdut, L., Tur-Sinai, A., \& Troytisky, R. (2014). Transitions between states of employment and patterns of retirement: The role of demography, health, wealth and perception of the quality of the job. In L. Achdut \& H. Litwin (Eds.), Changes in the second half of life: Main findings from the SHARE-Israel on those over 50, 2005-2010 (pp. 39-68). Jerusalem: The Israeli Gerontology data centre. (Hebrew). 
Amir, S., \& Kalinov, R. (2003). Changes in Men's labor force participation and rates of dropouts between 1973-1998. The Labor force planning authority at the Israeli Labor Ministry (HEB).

Benjamin, O. (2016). Gendering Israel's outsourcing: The erasure of employees' caring skills. New York: Palgrave MacMillan.

Buksbaum, Y., \& Dagan, M. (2010). Women entrapped between age and employment. Haifa: Mahut Centre.

Central Bureau of Statistics (CBS). (2012). The social survey. Israel: Jerusalem. Retrieved November 1, 2018, from http://www.cbs.gov.il/www/statistical/mw2013_h.pdf.

Central Bureau of Statistics. (2018). Table 1.10, Percentage of participants in the labor force by age and sex. Jerusalem, CBS: Monthly Labor force survey, December.

Central Bureau of Statistics (CBS). (2019). https://www.cbs.gov.il/he/mediarelease/DocLib/2019/ 075/11_19_075b.pdf.

Gal, J. (2002). How well does a partnership in pension really work? The Israeli public/private pension mix. Aging and Society, 22(2), 161-183.

Herbst-Debby, A. (2018). The economically responsible single mum who sees to her future: Welfare-to-work programs and pension savings. Journal of Social Policy. https://doi.org/10.1017/ S0047279418000594.

Litwin, H., \& Meir, A. (2013). Financial worry among older people: Who worries and why? Journal of Aging Studies, 27(2), 113-120.

NII. (2018). Poverty and social gaps in Israel-The 2017 report. Jerusalem: Israel Institute for National Security.

OECD (2011). Israel: review of the private pension system. Retrieved November 1, 2018, from https://www.oecd.org/israel/OECD-SocietyAtaGlance2014-Highlights-Israel.pdf.

Schultz, K. S., Morton, K. R., \& Weckerle, J. R. (1998). The influence of push and pull factors on voluntary and involuntary early retirees' retirement decision and adjustment. Journal of Vocational Behavior, 53(1), 45-57.

Segel-Karpas, D. (2015). Number of illnesses, self-perceived health, and depressive symptoms: The moderating role of employment in older adulthood and old age. Work, Aging and Retirement, 1(4), 382-392.

Segel-Karpas, D., \& Palgi, Y. (2018). Attitudes, perceptions and demographic mapping of the lay public regarding changing the of Flitwinficial retirement age (unpublished report for the National Social Security).

Segel-Karpas, D., \& Werner, P. (2014). Perceived financial retirement preparedness and its correlates: A national study in Israel. The International Journal of Aging and Human Development, 79(4), 279-301.

SHARE. (2016). Retrieved July 16, 2019, from http://www.share-project.org/data-documentation/ share-data-releases.html.

Spivak, A., \& Troitsky, R. (2013). Pension reform in Israel. Public and Municipal Finance, 2(1), $26-45$.

Spivak, A., Tzemach, S., \& Carmel, E. (2017). The compulsory pension insurance reform: Its characterization and success evaluation. A summarizing report for the Israeli Institute of Social Insurance. Jerusalem: Van Leer Institute.

Van Solinge, H., \& Henkens, K. (2005). Adjustment to and satisfaction with retirement: Two of a kind? Orlando, FL: Presentation.

Williamson, J. B., \& Williams, M. (2005). National defines contribution accounts: Neoliberal ideology and the political economy of pension reform. The American Journal of Economics and Sociology, 64(2), 485-522. 
Open Access This chapter is licensed under the terms of the Creative Commons Attribution 4.0 International License (http://creativecommons.org/licenses/by/4.0/), which permits use, sharing, adaptation, distribution and reproduction in any medium or format, as long as you give appropriate credit to the original author(s) and the source, provide a link to the Creative Commons license and indicate if changes were made.

The images or other third party material in this chapter are included in the chapter's Creative Commons license, unless indicated otherwise in a credit line to the material. If material is not included in the chapter's Creative Commons license and your intended use is not permitted by statutory regulation or exceeds the permitted use, you will need to obtain permission directly from the copyright holder.

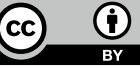




\title{
Chapter 24 \\ Italy
}

\author{
Tindara Addabbo
}

\begin{abstract}
In 2011 the legal retirement age in Italy was raised from 65 years for men and 60 years for women to 67 years for both by the year 2019. This reform remains controversial. Extending the legal retirement age has caused an increase in employment rates for the 55-64 age group. However, unemployed workers in this age group face difficulties in finding a job and in re-entering the labour market. The demanding family responsibilities of Italian women and the persistence of the gender wage gap result in lower levels of retirement pensions. Moreover, increasing the retirement age without improving childcare services and addressing work-life balance policies negatively affects the working careers of young women. Extended working life policies should be matched with gender sensitive activation policies to ensure equal access to work and age management policies to achieve better working conditions for older workers.
\end{abstract}

Keywords Retirement $\cdot$ Gender $\cdot$ Working conditions $\cdot$ Health $\cdot$ Care $\cdot$ Pension income

\section{Introduction}

Italy has been affected by population ageing and it is characterised by significant gender inequalities both in the labour market and in the allocation of family caring roles between partners (paid versus unpaid working time). This chapter discusses gender inequalities in the labour market, in unpaid work distribution and in the health status of older people and extended working life policies.

T. Addabbo $(\bowtie)$

Department of Economics Marco Biagi, University of Modena and Reggio Emilia, Modena, Italy e-mail: tindara.addabbo@unimore.it 


\section{Gender Inequalities in Paid and Unpaid Work and Employment Policies}

The employment rate in Italy for women is still much lower than for men. In 2018 among the 15-64 age group, the employment rate of women was $49.5 \%$ and for men $67.6 \%$. In the 55-64 age group these rates were $43.9 \%$ for women and $64.2 \%$ for men. Employment rates in the general population (15-64 years) decreased by four per cent from 2006 to 2018 for men and increased by seven per cent for women. The increase in employment rates in the 55-64 age group over the same period was higher for women $(+101 \%)$ than for men $(+47 \%)$. This is linked to the pension reform that increased the minimum retirement age along with an increase in the level of education of the 55-64 year age group (Istat 2016b). The gender gap in employment rates amongst the 55-64 age group is both high and stable: it was 21.9\% in 2006 and $20.3 \%$ in 2018 (author's analysis from Eurostat meta data). A gender gap to the disadvantage of women is higher in the South of Italy (Addabbo 2013). Increasing difficulties since the 2008 economic crisis have been experienced by women when returning to work after childbirth (Istat 2012) and the discouraged worker effect is prevalent among women (Addabbo et al. 2015). Approximately $68 \%$ of unemployed men and $65 \%$ of unemployed women in Italy (59.5\% of unemployed men and $58 \%$ of unemployed women in EU) in the age group 55-64 were unemployed for 12 months or more in 2018 (compared to $49.2 \%$ of men and $50 \%$ of women in the age group 15-24 years) (author's analysis from Eurostat meta data). These figures demonstrate the difficulties that older workers face in finding a job when they lose it or try to (re)enter the labour market.

Italy is characterised by a sharp inequality in the allocation of time over the lifecourse with women playing the key role in unpaid domestic and care work in later life, not only for partners and parents, but also for their children and grandchildren (Addabbo et al. 2012; Anxo et al. 2011; Aassve et al. 2012).

Flexible working arrangements and part-time work have increased for workers of all ages. The proportions of full-time employed or self-employed decreased from $86 \%$ in 2008 to $81 \%$ in 2018, while temporary contracts increased from $10 \%$ in 2008 to $13 \%$ in 2018 and a sharp increase in involuntary part-time work took place (from $5.8 \%$ in 2008 to $11.9 \%$ in 2018) (Istat 2019).

The Legislative Decree 148/2015 introduced a handover scheme for employers with the aim of allowing older workers to shift from full-time to part-time work while simultaneously hiring young workers. The scheme has been piloted at the local level without a wider diffusion due to the relatively high costs for businesses (Jessoula et al. 2016). Due to the high estimated costs of extensive implementation at the national level, the scheme is being introduced partially by businesses (Inapp and Ministero del lavoro e delle politiche sociali 2017). Age management policies are relatively rare in Italy (Inapp and Ministero del lavoro e delle politiche sociali 2017) although good practices can be observed in large (Aversa et al. 2015) and small-medium businesses (Checcucci et al. 2017). Older workers in Italy appear to be less involved in 'on the job' training than other workers in Europe (Anpal 2018). 
Although equality principles are guaranteed by the Italian Constitution and a legislative Decree in 2003 established a general framework for equal treatment in employment, there are still limits to the full application of the European Directive on Discrimination in access to employment and training (OECD 2018). Media campaigns and other actions to promote active and healthy ageing have been proposed by the government, social partners and non-governmental organisations (OECD 2018; Rospi 2018; Banfi and Fries-Tersch 2016). Also, regional legislation relating to active ageing has been introduced and training courses have been promoted at the local level for older workers by using multiple professions funds (Inapp and Ministero del lavoro e delle politiche sociali 2017). Banfi and Fries-Tersch (2016) highlight a fragmentation of policies to support older workers at the local and regional levels with lifelong learning measures only being addressed at the national level.

\section{Care Services}

The Italian welfare system is heavily centred on family support. Family support and informal care are widespread compared to other EU countries (Bettio and Plantenga 2004). Early childhood education services are widely available for children aged over three years (Addabbo et al. 2018). Primary and secondary schools are mostly scheduled on a half-day basis which is difficult to synchronise with the paid work of parents. Childcare services for children aged under three are rationed and unevenly distributed across Italian regions (Istat 2016b). A significant amount of childcare is informally provided by grandparents (Arpino et al. 2014).

Fiscal austerity has led to cuts in public health spending (Istat 2016b) which can result in an increase of informal care work by women. There has been a shift towards home-based care for older people and the employment of migrant workers in Italian households. This raises important issues in terms of discrimination, equity and sustainability of the system (Bettio and Solinas 2009; Bettio et al. 2006; Bettio and Mazzotta 2011).

\section{Pension System, Inequalities in Pension Income by Gender and Public Social Protection Expenditure}

Major labour market and pension policy reforms have been undertaken in Italy in recent decades leading to a multi-tier system where the dominant pillar is made up of a notional defined contribution system based on contributions made by employees, and self-employed workers in the public and private sectors (European Commission 2015). Some workers shift between employment and self-employment, a trend on the increase in the Italian labour market (Muehlberger and Pasqua 2006; Muehlberger and Bertolini 2008). 
The second tier of the pension system is an income tested old age allowance of approximately $€ 5,824$ annually for a single person with an additional $€ 190.26$ for those aged above 70 years. Since 1992 the use of supplementary funds and private pension plans has been promoted through tax incentives. Individuals whose contributory pension is below the minimum level may be entitled to a minimum pension supplement that will allow them to reach an annual $€ 6,524.57$ pension income. Those without a contributory pension may be eligible for a means-tested tax exempt social assistance benefit from 65 years with a further increase when they are aged 70 years or over (OECD 2017).

The 2011 reform increased the retirement qualifying age and linked it to life expectancy. The statutory retirement age prior to the 2011 reform was 65 for men and 60 for women. The pensionable age was gradually increased and by 2015 was set at 66 years and 3 months for men and women employed in the public sector. In the private sector, the pensionable age was also 66 years and 3 months for men, but 63 years and 9 months for women (European Commission 2015). In 2018 the minimum compulsory retirement age for men and women was fixed at 66 years and 7 and it rose to 67 years in 2019) within the private sector. There is an incentive to postpone retirement both within the private and the public sector by increasing the length of contributions and the provision of a flexible retirement age band up to age 70 , a band that will then move upwards due to the linking mechanism of life expectancy.

In 2016 a phased retirement scheme with subsidised part-time work was introduced aimed at employees reaching retirement age in 2018, being full-time employed and having paid the minimum contributions for the old-age pension. Under this scheme full-time employees were incentivised to switch to part-time work before retiring. However, this incentive does not appear to have been successful given the limited number of applications (OECD 2018).

At the same time, disincentives to early retirement have been introduced. Early retirement is possible without penalties only if men have paid contributions for 42 years and 10 months (41 years and 10 months for women). Individuals who retire under the age of 62 years received a reduced pension. Special provisions have been introduced for disadvantaged workers and for unemployed persons whose unemployment allowance has expired. A loan-scheme that can cover missing contributions also exists for these two categories of workers. Restrictions have been imposed on the length of time spent in hazardous jobs in order to be entitled for early retirement (OECD 2018).

Arduous/hazardous jobs are defined as particularly strenuous manual labour. A list of arduous/hazardous work was drafted in 2007 which includes work in tunnels, caves, mines, chambers with compressed air and asbestos removal work.

There is a progressive indexation of pensions which favours retirees on lower pensions (OECD 2017).

The Law Decree 4, 28/01/2019 allows early retirement at age 62 (minimum) if the qualifying contributory years are at least 38 ('Quota 100') and this measure will be introduced over the period 2019-2021. Women are estimated to be under-represented within the eligible cohort (INPS 2019) due to their average lower contributory years and over representation in low paid and unskilled jobs (Canal and Cirillo 2019). 
Workers who have reached the minimum level of contributions (40 years in 2008), can combine pension income with paid employment (as self-employed, project work or employees). The latter type of contract is not possible for those who retired early while the possibility of combining different sources of income is limited when receiving disability allowances, pensions for those employees who are moving from full-time to part-time work, and workers receiving a minimum income or workfare subsidies (OECD 2018).

The different reforms of the pension system in Italy have resulted in a lively public debate between academics, politicians and social partners. In particular, the increase in the retirement age for those employees whose retirement age was postponed by the reform for several years has been contested by unions and political parties. System failures are also related to the lack of integration between pension reforms aimed at extending working lives and limited employment policies encouraging older workers to stay longer in employment (Banfi and Fries-Tersch 2016).

Other topics of discussion concern the issue of permitting workers in physically demanding and hazardous jobs to retire earlier (OECD 2018) and the impact of extended working life conditions. Special attention has been given to employees who found themselves unemployed and without a pension for several months after the new reform (esodati). This problem was largely underestimated by the government when implementing the pension reform.

Due to the age structure of the Italian population and challenges experienced by young people in accessing the labour market (often delayed and in precarious employment) concerns have emerged regarding the sustainability of the pension system and the wellbeing of today's younger generation when they become older. Moreover, attention has been given to the impact of the 2011 reform on productivity. Gabriele et al. (2018) show that the introduction of rigid regulations and increasing retirement age has undermined a sorting mechanism that previously resulted in the retention of only productive workers (since they were less likely to retire early) and that overall this has a negative impact on productivity.

Given the crucial role played by older women in caring for grandchildren and the rationing of childcare services for children aged under three, the extension of working life without an extension of childcare services could increase the difficulties experienced by young mothers returning to work (Verashchagina and Capparucci 2014) leading to a negative effect on their labour supply. One result of the introduction of the 2011 Pension Reform on older women's labour supply in Italy has been reported by Coda Moscarola et al. (2016) who show that there has been an increase in sick leave taken by older women, especially those with a low income and living in the South of Italy where childcare facilities are less available.

Gender inequalities in employment rates and wages as well as in the length of careers and types of contract (women are more represented in part-time work than men) generate gender gaps in pensions and a higher risk for women of not having a decent standard of living when they are older (Corsi and Samek Lodovici 2013). In 2015, of the total amount of old age pensions in Italy, 56\% were received by men (Istat 2016a). According to EU-SILC 2010 data, men on average receive higher pensions than women by $31 \%$ in Italy (39\% in EU) (Bettio, Tinios and Betti 2013). 
Moreover, by comparing gross yearly pension income, men's income was $€ 6,000$ higher on average than women's (Istat 2016a).

Disability benefits (including disability pensions and early retirement pensions due to a reduced capacity to work) represent $1.5 \%$ of GDP in 2012 compared to two per cent on average in EU-28 countries. Sickness and healthcare benefits amount to $6.8 \%$ compared to the EU 28 average of eight per cent. Retirement pensions amount to $14.2 \%$ compared to $11 \%$ in EU-28 countries, survivors benefits represent $2.6 \%$ compared to $1.6 \%$ in EU-28 (Author's analysis from Eurostat metadata).

\section{Debate on Extended Working Life}

Pension reforms in Italy have been accompanied by widespread debate. The issue of pension reforms leading to an extended working life is still widely covered in the Italian media. The empirical evidence does not suggest that media coverage of the issue significantly increases information. However according to Boeri and Tabellini (2012), providing extensive information on the costs and on the functioning of the pension system encourages individuals to support pension reforms increasing retirement age. Sharing information is crucial for the successful implementation of the reforms (Tsarouhas 2012). The Greek case, characterised by limited public information, contrasts with the Italian government's extensive information sharing and consensus building campaign (Tsarouhas 2012).

The latest pension reform path in Italy has seen conflict with social partners on the labour market reforms and discontent with international constraints on public expenditure and debt stimulating co-operation between government and social partners (Maino and Neri 2011). However, the 'Fornero' reform was imposed in a top-down manner, with very few opportunities for trade unions to influence decisions (Sacchi 2013). The 2011 reform was opposed by Northern League Party, which together with the Five Stars Party, introduced 'Quota 100', approved in 2019. Three major union confederations, the General Confederation of Italian Workers (Confederazione Generale Italiana del Lavoro, Cgil); the Italian Confederation of Workers' Trade Unions (Confederazione Italiana Sindacati Lavoratori, Cisl) and the Union of Italian Workers (Unione Italiana del Lavoro, Uil) reacted in 2012 with a general strike to protest against the 'Fornero' Reform. This movement was also motivated by problems related to the living conditions of the high number of those former employees who found themselves unemployed and without a pension for several months after the implementation of the reform. Recently, following the Five Stars-League party approval of 'Quota 100', unions have protested against 'Quota 100' not considering it an effective way of tackling the problems still connected with the 'Fornero' reform. The unions are calling for a new more structural pension reform. 


\section{Health}

Life expectancy and healthy life expectancy have increased in Italy (Istat 2016b). In 2005, women had a longer life expectancy at birth (84 years compared to 78 years for men) than men (Burgio et al. 2009). However, men lived $85 \%$ of their years without disability compared to $75 \%$ for women.

Italy is characterised by regional heterogeneity in terms of available health infrastructures and services and this is reflected in self-perceived health status with a larger effect on older women's health status (Addabbo et al. 2014; Pirani and Salvini 2012b). Lower educated older people have poorer health and lower life expectancy compared to the highly educated (Istat 2016b). Involvement in social interaction as well as in working activities have a positive effect on older people's health status (Pirani and Salvini 2012a).

Lifecourse literature explores the impact of gender differences in the distribution of unpaid work in later life. By analysing retrospective data on the gender distribution of domestic and care work in the Survey of Health, Ageing, Retirement in Europe (SHARE), Addabbo et al. (2014) found a poorer global health status and residual affective problems for women with children and who defined themselves as having the main responsibilities in care work. Life expectancy significantly differs according to socioeconomic status, with a higher life expectancy for the self-employed and a difference of more than five years between individuals with different socioeconomic statuses, thus confirming large health inequalities, a finding that brings into question the fairness of the Italian public pension system (Lallo and Raitano 2018).

Analysis of the SHARE-Life study merged with SHARE data on the health status of those aged 60 and above has been undertaken on the effect of quality of work dimensions on the health status of retired older people by gender (Addabbo et al. 2011). The effect of better scores in the socioeconomic and control dimensions of the quality of work are associated with better health status later in life for both men and women. However, poor physical working conditions (whether the work was physically demanding, characterised by an uncomfortable work environment, or by a heavy time pressure) have a negative effect on both men and women in all health dimensions (mobility, cognition, affection and motivation). This effect is statistically significant only for women, and the result can be linked to the 'time pressure' dimension of physically demanding jobs, and to the higher probability that women experience work-life balance conflicts because of their higher involvement in unpaid care and domestic work. For men, higher scores in the control dimension of their quality of work life, exposes them to the risk of facing higher affective problems in later life and this can be associated with a loss in men's social sphere after retirement from a rewarding job or with the underdevelopment of caring and relational dimensions during their working life. 


\section{Conclusions}

When compared to other EU countries the Italian labour market is characterised by a high gender gap in the participation of women in paid employment and a lower participation of older workers. Extended working life has increased especially for older women due to pension reforms increasing retirement age. While equality in pensionable age can contribute to the decrease of the gender gap in employment rates, the highly gender-segregated (both horizontally and vertically) Italian labour market requires attention by policy makers regarding the impact of extended working life on working conditions and on wellbeing by gender.

From a gender perspective, increasing the retirement age without allowing for an improvement of childcare services and work-life balance policies does appear to have a negative effect on young women's labour supply due to a lack of support by grandmothers in the care of grandchildren which takes place in a still highly familycentred welfare system. Extended working life policies should also be matched with an improvement in gender sensitive age management policies in the workplace to achieve better work life balance conditions for older workers together with consistent and coordinated public social and employment policies.

\section{References}

Aassve, A., Meroni, E., \& Pronzato, C. (2012). Grandparenting and childbearing in the extended family. European Journal of Population, 28, 499-518.

Addabbo, T. (2013). Donne e lavoro: quali scelte? In E. Ales \& I. Senatori (Eds.) The transnational dimension of labour relations: a new order in the making? Turin: Giappichelli.

Addabbo, T., Caiumi, A., \& Maccagnan, A. (2012). The allocation of time within Italian couples: Exploring its unequal gender distribution and the effect of childcare services. Annals of Economics and Statistics. Special Issues on Quantitative Applications with time use data, 105/106, 209-230.

Addabbo, T., Cardinali, V., Giovannini, D., \& Mazzucchelli, S. (2018). Italy country note. In S. Blum, A. Koslowski, A. Macht, \& P. Moss (Eds.) International review of leave policies and research 2018. Retrieved October 3, 2018, from http://www.leavenetwork.org/lp_and_r_reports/.

Addabbo, T., Fuscaldo, M., \& Maccagnan, A. (2011). Quality of work and health status: A multidimensional analysis. Retrieved April 17, 2019, from http://155.185.68.2/campusone/web_dep/ CappPaper/Capp_p96.pdf.

Addabbo, T., Fuscaldo, M., \& Maccagnan, A. (2014). Care and the capability of living a healthy life in a gender perspective. Retrieved April 17, 2019, from http://155.185.68.2/campusone/web_ dep/CappPaper/Capp_p99.pdf.

Addabbo, T., Rodríguez-Modroño, P., \& Gálvez-Muñoz, L. (2015). Gender differences in labor force participation rates in Spain and Italy under the great recession. Revista de Economía Mundial, $41,21-42$.

Anpal (2018). XVIII Rapporto sulla formazione continua. Retrieved October 6, 2018, from http:// www.anpal.gov.it/Dati-e-pubblicazioni/Documents/XVIII-Rapporto-formazione-continua.pdf.

Anxo, D., Mencarini, L., Pailhe, A., Solaz, A., Tanturri, M. L., \& Flood, L. (2011). Gender differences in time use over the life course in France, Italy, Sweden, and the US. Feminist Economics, 17(3), 159-195. 
Arpino, B., Pronzato, C. D., \& Tavares, L. P. (2014). The effect of grandparental support on mothers' labour market participation: An instrumental variable approach. European Journal of Population, 30(4), 369-390.

Aversa, M. L., D’Agostino, L., \& Parente, M. (Eds.). (2015). L'age management nelle grandi imprese italiane: $i$ risultati di un'indagine qualitativa. Roma: Isfol.

Banfi, P., \& Fries-Tersch, E. (2016). Safer and healthier work at any age-Country inventory: Italy. European Agency for Safety and Health at Work (EU-OSHA).

Bettio, F., \& Mazzotta, F. (2011). The future of care in Europe. Exploring the trade-offs that are driving change. Kurswechsel, 4, 36-48.

Bettio, F., \& Plantenga, J. (2004). Comparing care regimes in Europe. Feminist Economics, 10(1), $85-113$.

Bettio, F., \& Solinas, G. (2009). Which European model for elderly care? Equity and efficiency in home-based care in three European Countries. Economia \& Lavoro, 43(1), 53-71.

Bettio, F., Tinios, P., \& Betti, G. (2013). The gender gap in pensions in the EU, European Commission-Directorate-General for Justice. Luxembourg: Publications Office of the European Union.

Bettio, F., Villa, P., \& Simonazzi, A. (2006). Change in care regimes and female migration. Journal of European Social Policy, 16(3), 271-285.

Boeri, T., \& Tabellini, G. (2012). Does information increase political support for pension reform? Public Choice, 150(1-2), 327-362.

Burgio, A., Murianni, L., \& Folino-Gallo, P. (2009). Differences in life expectancy and disability free life expectancy in Italy. A challenge to health systems. Social Indicators Research, 92(1), $1-11$.

Canal, T., \& Cirillo, V. (2019, February 21). Quota cento, opzione donna. La pollitica che con ci vee. Ingenere. Retrieved March 3, 2019, from http://www.ingenere.it/articoli/quota-cento-opzionedonna-politica-non-ci-vede.

Checcucci, P., Fefè, R., \& Scarpetti, G. (Eds.). (2017). Età e invecchiamento della forza lavoro nelle piccole e medie imprese italiane. Rome: Inapp.

Coda Moscarola, F., Fornero, E., \& Strøm, S. (2016). Absenteeism, childcare and the effectiveness of pension reforms. IZA Journal of European Labour Studies, 5(1), 1-18.

Corsi, M., \& Samek-Lodovici, M. (2013). Active ageing and gender equality. Retrieved April 17, 2019, from https://pdfs.semanticscholar.org/ac60/ff03c06112e5c55bb2777441e372bff3ef4f.pdf.

European Commission. (2015). The 2015 pension adequacy report: Current and future income adequacy in old age in the EU. Country profiles volume II. European Commission Directorate-General for Employment, Social Affairs and Inclusion and Social Protection Committee. Luxembourg: Publication Office of the European Union.

Gabriele, R., Tundis, E., \& Zaninotto, E. (2018). Ageing workforce and productivity: The unintended effects of retirement regulation in Italy. Economia Politica, 35(1), 163-182.

Inapp, \& Ministero del lavoro e delle politiche Sociali. (2017). Rapporto per l'Italia sul terzo ciclo di monitoraggio e valutazione dell' attuazione del Piano di Azione Internazionale di Madrid sull'invecchiamento e la sua strategia regionale (MIPAA/RIS) 2012-2017. Retrieved March 3, 2019, from https://oa.inapp.org/.

Inps. (2019). Audizione Presidenza Senato Roma, 4 febbraio 2019 Tito Boeri. Retrieved March 3, 2019, from https://www.inps.it/docallegatiNP/Mig/Allegati/Audizione_Presidente_Boeri_3.1. pdf.

Istat. (2012). Rapporto annuale sulla situazione del paese 2012. Rome: Istat.

Istat. (2016a). Le condizioni di vita dei pensionati. Anno 2014. Statistiche Focus. Rome: Istat.

Istat. (2016b). Rapporto annuale 2016. La situazione del Paese. Rome: Istat.

Istat. (2019). Rapporto annuale sulla situazione del paese 2019. Rome: Istat. 
Jessoula, M., Pavolini, E., \& Strati, F. (2016). ESPN thematic report on retirement regimes for workers in arduous or hazardous jobs: Italy. Retrieved April 17, 2019, from https:// www.researchgate.net/profile/Matteo_Jessoula/publication/308968536_ESPN_Thematic_ Report_on_retirement_regimes_for_workers_in_arduous_or_hazardous_jobs_-_Italy/links/ 57fb757708ae886b898b4ad9.pdf.

Lallo, C., \& Raitano, M. (2018). Life expectancy inequalities in the elderly by socioeconomic status: Evidence from Italy. Population Health Metrics, 16(1), 1-21.

Maino, F., \& Neri, S. (2011). Explaining welfare reforms in Italy between economy and politics: External constraints and endogenous dynamics. Social Policy \& Administration, 45(4), 445-464.

Muehlberger, U., \& Pasqua, S. (2006). The "continuous collaborators" in Italy. Hybrids between employment and self-employment? Retrieved April 17, 2019, from http://www.child.carloalberto. org/images/wp/child10_2006.pdf.

Muehlberger, U., \& Bertolini, S. (2008). The organizational governance of work relationships between employment and self-employment. Socio-Economic Review, 6(3), 449-472.

OECD. (2017). Pensions at a glance: OECD and G20 indicators. Paris: OECD.

OECD (2018). Italy. Key policies to promote longer working lives. Country note 2007 to 2017. Paris: OECD.

Pirani, E., \& Salvini, S. (2012a). Socioeconomic inequalities and self-Rated health: A multilevel study of Italian elderly. Population Research and Policy Review, 31(1), 97-117.

Pirani, E., \& Salvini, S. (2012b). Place of living and health inequality: A study for elderly Italians. Statistical Methods and Applications, 21(2), 211-226.

Rospi, M. (2018, July 7). L'invecchiamento attivo della popolazione all'interno della coesione sociale tra generazioni: gli strumenti della multilevel governance per i nuovi sistemi di welfare. Rivista Associazione Italiana Costituzionalisti, 3.

Sacchi, S. (2013, April). Italy's labour policy and policymaking in the crisis: From distributive coalitions to the shadow of hierarchy. Labor, Laboratorio Riccardo Revelli Working Paper no. 13.

Tsarouhas, D. (2012). Political discourse and path shaping in public policy: Comparing pension reforms in Greece and Italy. Public Administration, 90(1), 160-174.

Verashchagina, A., \& Capparucci, M. (2014). Living through the crisis in Italy: The labour market experience of men and women. In M. Karamessini \& J. Rubery (Eds.), Women and austerity: The economic crisis and the future for gender equality. New York: Routledge.

Open Access This chapter is licensed under the terms of the Creative Commons Attribution 4.0 International License (http://creativecommons.org/licenses/by/4.0/), which permits use, sharing, adaptation, distribution and reproduction in any medium or format, as long as you give appropriate credit to the original author(s) and the source, provide a link to the Creative Commons license and indicate if changes were made.

The images or other third party material in this chapter are included in the chapter's Creative Commons license, unless indicated otherwise in a credit line to the material. If material is not included in the chapter's Creative Commons license and your intended use is not permitted by statutory regulation or exceeds the permitted use, you will need to obtain permission directly from the copyright holder.

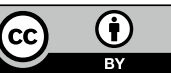




\title{
Chapter 25 \\ Lithuania
}

\author{
Jolanta Pivoriene and Kristina Ambrazeviciute
}

\begin{abstract}
Lithuania underwent radical changes in economic and social systems at the end of the 20th and beginning of the 21st century. The country has a declining and ageing population. The dependency ratio will increase to $44.9 \%$, public pension expenditure in Lithuania will reach $8.6 \%$ of GDP in 2050, and both values are lower than the corresponding values for the EU-25 average. To address such challenges, the country introduced policy measures and in 2018 a new social model came into force. The chapter discusses pension system reforms, pension policy, employment and health policy and provides a selective review of existing research on these topics. Research on extended working life is developing in Lithuania. It provides evidencebased arguments for influencing social policy for older workers. However, the gender and health implications of extending working life in Lithuania are not very favourable and do not fully support peoples' rights for sustainable wellbeing in late work and after retirement.
\end{abstract}

Keywords Pension system reforms $\cdot$ Pension policy $\cdot$ Employment policy $\cdot$ Health policy $\cdot$ Social model

\section{Introduction}

Lithuania underwent radical changes in its economic and social systems at the end of the 20th and the beginning of the 21st century. In demographic terms, the country has a declining and ageing population. The absolute number of Lithuanians will drop to 2.9 million and the dependency ratio will increase to $44.9 \%$ in 2050 , which is seven percentage points lower than the EU-25 average. Public pension expenditure in Lithuania will reach $8.6 \%$ of GDP in 2050 . These values are roughly four percentage points lower than the corresponding values for the EU-25 average (Pension funds

\footnotetext{
J. Pivoriene ( $\varangle)$

Institute of Educational Sciences and Social Work, Mykolas Romeris University, Vilnius, Lithuania

e-mail: jota.pivore@gmail.com

K. Ambrazeviciute

The Law Institute of Lithuania, Vilnius, Lithuania

(C) The Author(s) 2020

Á. Ní Léime et al. (eds.), Extended Working Life Policies, https://doi.org/10.1007/978-3-030-40985-2_25
} 
2018). To face such challenges, the country took measures and in 2018 a new social model came into force.

Those over retirement age amounted to $23 \%$ of the population in 2016. Each year, the number of people who have attained retirement age decreases slightly due to the raising of the retirement age, which will reach the 65 year mark for both men and women in 2026. In 2019, the legislated pensionable age was 62 years 8 months for women and 63 years 10 months for men (Law on Amendment 2016). In 2017, $88.3 \%$ of people in retirement age received a state social insurance old-age pension compared to $75.0 \%$ in 2014 (Ministry of Social Security and Labour 2015). In 2018 the number increased to $89.2 \%$ (Oficialiosios statistikos portalas 2019).

The employment rate in the age group 55-64 was $68.5 \%$ and was similar for men $(70.5 \%)$ and women $(66.9 \%)$ in 2018 . The employment rate of people age $65+$ increased from $5.7 \%$ of the population in 2014 to $9.2 \%$ in 2018 . There is a gender difference in employment: $13.2 \%$ of men and $7.2 \%$ of women aged $65+$ were working in 2018 (Official Statistics Portal 2019a, b).

The gender pay gap was $14.2 \%$ in 2017 , increased by $0.8 \%$ compared to 2016 due to social and economic reasons such as gender differences in employment by economic sector, profession, education, age, obligatory insurance period, etc. This led to a gender pension gap which was $17 \%$ in 2018 (Official Statistics Portal 2019a, b).

\section{Pension System Reforms}

Lithuania's first steps towards pension reform were taken in 1995, following a major economic crisis in the early 1990s. The first reform focused on parametric changes to the first pillar (regulating retirement age, insurance period for getting a full pension) and increasing the system's sustainability (Law on State Pensions 1994; Law on Reform of Pensions System 2002). Another two pillars were added to the system in 2004, comprising funded schemes and supplementary pension provision (Pension funds 2018).

The first reform implemented a two-tier system in the first pillar. There was a basic flat-rate pension that depended on years of service. The second part of the public system was supplemental and earnings related. It was PAYG schemes based on a formula comprising years of service, individual wages and average income. Adjustments for the earnings-related component were made in line with average economy-wide earnings, while the basic pension was determined by the government in an ad hoc manner. In principle, all employees were covered by the system, but the actual coverage rate was $83 \%$ of the workforce. Some categories of the selfemployed were free to join. In order to receive a full pension, 20 contributory years were required and the minimum qualifying period was 15 years. Those who did not reach the minimum qualifying period were entitled to a social assistance pension, which amounted to $90 \%$ of the basic pension. Possibilities for early retirement were re-introduced in 2004 after having been abolished in 1995, but they only applied to people who had been unemployed for a long time. If people retired early, their 
pension benefits were reduced. A new version of the Law on Amendment of Republic of Lithuania Law No I-549 on Social Insurance Pensions (2016) has reformed the pension scheme and came into force in 2018. Key provisions of the new legal regulation are as follows: a new pension structure, the introduction of pension points and indexing. The pension will consist of general and individual parts. The general part will replace the basic part of the pension and a bonus for the length of a person's employment record, while the individual pension will replace the additional part of the pension and reflect a person's contributions paid to the social insurance scheme. The new edition of the law also provides for a gradual increase of the obligatory insurance record from 30 to 35 years. At present, the average insurance record for which the old-age pension is paid is already 37 years.

Second pillar pension funds were introduced in 2004. Once the decision to join a fund has been made, it is irreversible. The second pillar was voluntary, and will become mandatory from 2019. Pension funds were established as companies (Bank of Lithuania 2016). Contributions to pension funds have increased and since 2016 consist of two per cent contribution of state social pension insurance (SODRA), two per cent additional contribution by the participant and two per cent pension benefit from the state budget. In 2014-2015, the contribution consisted of one per cent contribution of state social pension insurance, two per cent additional contribution by the participant and one per cent pension benefit from the state budget (Ministry of Social Security and Labour 2017). Since 2018 the contributions changed to formula $4+2-4 \%$ contribution by participant and two per cent contribution from the state budget, i.e. there is no contribution from SODRA (Lietuvos Respublikos socialines apsaugos ir darbo ministerija 2018).

Third pillar pensions are underdeveloped in Lithuania. Personal pension schemes were introduced in 2004. Individuals and their employers can contribute to voluntary pension funds. Contributions are tax-free up to $25 \%$ of annual income, and any amount above that level is taxed at a reduced rate of $15 \%$ (rather than the regular rate). In 2006, the Lithuanian parliament passed a law that enables the creation of occupational pension schemes and group life contracts. This could become something of a fourth pillar in the future, but a scheme has yet to be created (Pension funds 2018).

The latest reform of the third pillar was made in 2012 (Lietuvos Respublikos papildomo 2012), for the second pillar in 2016 (Law on Amendment of Republic of Lithuania Law No I-549 on Social Insurance Pensions (2016) ). At the end of 2017 there were 20 pension funds for second pillar pensions with 1,289,284 participants, and 12 funds for the third pillar with 57,780 participants (Lietuvos Bankas 2018).

\section{Pension Policies}

Pension parametric reforms in Lithuania aimed to increase the legislated pensionable age to 65 years old for both men and women and the insurance period from 20 to 35 years. The average amount of pensions in Lithuania in 2017 was at a minimum 
standard with a replacement rate of $40.2 \%$ of the average wage. So, since the maximum insurance period almost doubled and the amount of contributions increased in relative and absolute terms, the replacement rate in Lithuania remained at the level of minimum standards of International Labour Organisation Convention no. 102 which in EU Strategy 2020 was defined as $60 \%$ of the average income as the minimum standard of living (Mavrikiou et al. 2018).

In 2016, the average annual state social insurance old-age pension of persons having the mandatory social insurance record was €266.18. In 2016 the Government approved a new amount of the basic state social insurance pension and insured income. As a result, the amount of the basic state social insurance pension increased from $€ 112$ to $€ 120$ per month, while the insured income of the current year increased from $€ 445$ to $€ 476$. This increase affected about 802,000 recipients of state social insurance pensions. Due to the higher amounts of the basic pension and insured income, the average old-age pension awarded to people having the obligatory insurance record increased on average by about $€ 20$ and amounted to about $€ 287.07$ as of January 2017 (Ministry of Social Security and Labour 2017a) and was increasing to $€ 364.96$ as of November 2019 (Sodra 2019). Social contributions in Lithuania are high, amounting to $30.7 \%$ of gross wages; $23.7 \%$ of these contributions were allocated to pensions. Employers paid $21.2 \%$ of gross wages for pensions, and employees contributed 2.5\% (Ministry of Social Security and Labour 2017b).

Retirement may be delayed for a full calendar year but for no longer than 5 years. After retirement, the old-age pension is eight per cent higher for every delayed year (Law on Amendment 2016). A longer insurance period and received income results in a bigger pension and is recalculated automatically every year (Sodra 2017).

Lithuanians can both draw a pension and earn money. Statistical data shows that the employment rate for the age group 65+ is increasing. It was $9.2 \%$ in 2017 in comparison with $5.7 \%$ in 2014. In 2018, 13.2\% men and $7.2 \%$ women aged $65+$ were working (Official Statistics Portal 2019a, b).

There is no permanent law for freezing payments, but the Government can pass a temporary law; this was done for example in 2009 (Lietuvos Respublikos socialiniu ismoku 2009). However, some articles of this temporary law later were recognised as contradictory to the Constitution and the Government was obliged to compensate people for reduced pensions (Baltic News Service 2012).

Auto-enrolment is planned in 2019 for the first time in Lithuania and it will be applied to all employed people up to 40 years old with the right to say "no". If a person decides not to participate in pension accumulation in the second pillar, s/he stays only in SODRA. The auto-enrolment procedure will be repeated three times-every three years until a person reaches age 40 . For those older than 40 years old pension accumulation will remain voluntary (Lietuvos Respublikos socialines apsaugos ir darbo ministerija 2018). 


\section{Health Policies}

A person is eligible for work incapacity pension if s/he has $45 \%$ or more work incapacity and the required insurance period, which depends on the age when work incapacity was recognised-late recognition means a longer required period (Law on Amendment 2016). At the end of 2017 there were 164,100 persons who received a work incapacity pension; this amounts to $9 \%$ of all persons of working age (Sodra 2017). At the end of 2018 the number decreased by $1.2 \%$ as there were 162,200 persons who received a work incapacity pension (Oficialiosios statistikos portalas 2019). There is no difficulty in retiring through a disability route. When a person reaches retirement age s/he receives whichever pension is higher: old age or work incapacity pension (Law on Amendment 2016).

\section{Employment Policies}

The new Labour Code of Lithuania, which entered into force on 1 July 2017, introduced a more flexible regulation of labour relations. On the other hand, it retained a number of restrictive provisions. According to data provided by Doing Business 2018 and Lithuanian Free Market Institute, due to the new regulation, Lithuania would rise by 11 positions in the general EU-41 EU-OECD country rating in the employment flexibility index, i.e. from 27 to 16 (Lietuvos laisvosios rinkos institutas 2017; Lithuanian Free Market Institute 2017).

The current Labour Code establishes many flexible forms of labour contracts: fixed-term contract, temporary-work contract, seasonal contract, project work, jobsharing, working for several employers and an apprenticeship employment contract. There is also the possibility of remote work as a form of work performance. Fixedterm employment contracts can also be concluded for permanent tasks, yet such contracts must not exceed $20 \%$ of all employment contracts of a company. Usually fixed-term employment contracts are for a two-year term, with several exceptions allowing a five-year term. During the period of adoption of the Labour Code, a zero-term employment contract was rejected as not ensuring the social security of workers.

As far as working time is concerned, the maximum permitted weekly working time is $60 \mathrm{~h}$, including extra jobs and overtime hours and the maximum permitted working days are 6 days per week. The annual overtime limit is $180 \mathrm{~h}$ with a possibility to agree on a higher limit in a collective agreement. The Labour Code does not stipulate restrictions on night work and work during a weekly holiday. Overtime, night work, work on a weekly rest day or on a holiday is paid extra. The flexible working schedule, fragmented working days and individual working time regimes make it possible to organise work time more flexibly.

Provisions concerning redundancy entitle the employer to dismiss the employee, but this decision must be based on an important reason and notice periods ranging 
from two weeks to three months should be respected. Severance payments (up to two average monthly salaries) must be paid. In case of redundancies there is a set of priority rules that are applied to specific groups such as pre-retirement employees, employees with work experience exceeding ten years, employees having three or more children etc. The new Labour Code allows dismissal of employees with a notice period of three workdays but on condition of higher severance compensation (not less than six average monthly salaries).

Training for workers is mainly aimed toward unemployed persons and, to a lesser extent, toward older age employees. Support for older unemployed persons is targeted at obtaining the right education and working skills (support for learning, support for the acquisition of professional skills). These measures are implemented in the form of financial benefits, i.e. scholarship, compensation or pay subsidy etc. (Republic of Lithuania Law on Employment 2016).

Early retirement schemes have been discouraged by the aforementioned increase of the retirement age as well as by extending the mandatory length of service for obtaining an old-age pension, which is to increase to 35 years (mandatory length of service determines the retirement benefits). Lithuanian laws provide the possibility of early retirement, but in the latter case old-age pension benefits are reduced. On the other hand, retired workers are encouraged to stay in the labour market by the possibility of receiving both old-age pension benefits and wages (Law on Social Insurance Pensions 1994).

There are no legal provisions governing specific working conditions for older workers. Older workers can benefit from the general rules dealing with working conditions: flexible working schedule, fragmented working days and individual working time regimes. They can work in the regime of part-time work. In some cases, long uninterrupted employment at the same workplace (directly linked to worker's age) becomes an important factor. First, it prolongs additional annual leave (ten years of uninterrupted employment adds three days and each subsequent five year work period adds one day of additional leave) (Labour Code 2017). Second, length of service has an influence both on the length of the annual and additional annual leave of public sector employees. The length of service is often used to calculate public servants' wages.

The principle of gender equality is expressly stated in the Labour Code. Therefore, gender implications occur only as a legitimate differentiation to facilitate the participation of women in paid employment during pregnancy and also as privileges concerning work time for women who gave birth recently and for breastfeeding women. As was mentioned above, a different retirement age remains for men and women. There is a gap between the average salary of men and women, which was 14.2\% in 2017 (Official Statistics Portal 2019a, b). There are no provisions to facilitate workers who are caring for older or disabled family members. The principle of anti-age discrimination is established in the Constitution of the Republic of Lithuania, the Law on Equal Treatment and the Labour Code. In the latter the implementation of the principle of non-discrimination is strengthened by turning it into the duty of the employer. Furthermore, there are specific norms of the Labour Code implementing the principle of anti-age discrimination, for example, by ensuring a 
non-discriminatory system of remuneration (Art. 140.6 of the Labour Code 2017) or by stating that violation of equal opportunities is a gross breach of work duties (Art. 58 of the Labour Code 2017). Finally, the Labour Code establishes positive age-based discrimination: employees, who will be entitled to the full old age pension in less than five years, must be given a longer notice period about termination of employment contract (Art. 57.7 of the Labour Code 2017). Employees having less than three years until the statutory retirement age and who have at least ten years of uninterrupted employment at that workplace have the right of priority to retain the job in the case of redundancy (Art. 57.3 of the Labour Code 2017). The responsibility for age discrimination is laid down in both administrative and criminal law (Art. 81 of the Lietuvos Respublikos administraciniu 2015; Art. 169, 170, 170(1) of the Criminal Code 2000).

\section{Precarious Employment}

Precariousness applies to at least 30-35\% of the employed population in Lithuania. Firstly, there is a problem of insufficient income. Secondly, there is social insecurity, which is particularly faced by self-employed and illegal workers (Blaziene and Gruzevskis 2016). Some decisions, which are expected to improve conditions for precarious workers, were taken last year. To address the threat of poverty, from 1 January 2018, the minimum monthly wage was raised from $€ 380$ to $€ 400$ (Social statistics 2017), and also monthly non-taxable amount was raised from $€ 310$ to $€ 380$ (Lietuvos Respublikos Gyventoju pajamu mokescio 2017).

Several amendments to the Law on Social Insurance were made. First, "floors" of social insurance contributions were introduced. This means that if the employee earns less than the minimum wage, the employer will still have to pay social insurance contributions calculated from the minimum monthly wage. The new law will ensure social security for those workers, whose salary is less than the minimum monthly wage. Second, a procedure for calculation of the amount of social insurance contributions was unified for all self-employed workers. This step was aimed at ensuring equal social guarantees for self-employed persons. Finally, seeking to encourage people to start self-employment, beginners have been given the opportunity not to pay state social insurance contributions for one year (Lietuvos Respublikos Valstybinio socialinio draudimo istatymo 2017).

\section{Debate on Extending Working Lives}

The issue of extended working life lacks attention on political agenda, in scientific research and the media. Occasionally it was mentioned during the discussion on a new social model (including on website Darbo santykiu ir valstybinio socialinio draudimo teisinis-administracinis modelis, http://www.socmodelis.lt and Facebook 
https://www.facebook.com/socialinis.modelis/). However, more attention was paid to the new pension structure and more flexible labour relations than to extended working life. Projects implemented by the Lithuanian Labour Exchange may be mentioned as examples of best practice of specific employment policies, For example, the project 'Employment support for unemployed older people" involved 14448 older workers and focused on improving qualifications or competencies, creating subsidised employment and facilitating territorial mobility (Lietuvos darbo birza 2018).

\section{Existing Research}

There were isolated instances of research on social gerontology in the second half of the twentieth century, and it became a field of interest for social researchers only after Independence in Lithuania in 1990 (Mikulioniene 2011). There was no scientific research on extended working life. However, some discussion about the issue may be found in research on related topics. First, some authors stress the importance of the special measures, which can help to increase the participation of the older people in the labour market. Such measures can be related to the improvement of health (especially men's health), vocational training, availability of information and consultation services (Okuneviciute Neverauskiene and Moskvina 2008), the reform and adaptation of the social protection system (Dromantiene and Kanopiene 2004). Another policy measure suggested is to introduce more flexible labour law measures, in particular the adaptation of the forms of employment contracts which allow workers to transition gradually from active working activity to final exit from the labour market as well as the establishment of additional provisions regarding rest periods (Ambrazeviciute 2018).

A second consideration is related to age within the context of anti-discrimination law. Despite properly established prohibition of age discrimination in national legislation, discrimination on the basis of age still prevails in the labour market and ageism prevents longer participation of older people in employment (Ambrazeviciute 2018), whereas mechanisms designed to encourage the reporting of discrimination cases are not efficient (Mikulioniene 2008).

Lastly, there is a good deal of research concerning the status of women. The analysis of old age pensions, especially their gender dimension, is focused on different patterns of labour market participation among women and men in society. Women usually take care of children and have a shorter record of participation in the labour market. This means that women have a five per cent lower old age pension than men in Lithuania (Skuciene 2007). 


\section{Conclusion}

An OECD review of labour market policies (2018b) comments that recent reforms of the Labour Code, the unemployment insurance system, employment policies, minimum-income benefits and public pensions have reduced incentives for informal employment and raised income security. However, resources devoted to labour market and social policies remain limited. According to the OECD (2018a) Lithuania could do more to restrict the use of early retirement; prevent disability benefits from being used as alternative pathways to early retirement; take a balanced approach to employment protection by age; review the use of seniority wages; encourage social partners to implement better retention and hiring mechanisms targeted at older workers; and provide lifelong learning guidance services. The gender implications of extending working life in Lithuania are not addressed adequately and remain out of the policy and research agenda.

\section{References}

Ambrazeviciute, K. (2018). Vyresnio amziaus zmoniu teises $i$ darba igyvendinimas visuomenes senejimo salygomis. Vilnius: Mykolo Romerio Universitetas.

Bank of Lithuania. (2016). The review of Lithuania's second and third pillar pension funds and of the market of collective investment undertakings. Retrieved March 13, 2019, from https://www.lb.lt/en/publications/review-of-lithuania-s-2nd-and-3rd-pillar-pension-fundsand-of-the-market-of-collective-investment-undertakings-2016.

Baltic News Service. (2012). Pensiju dirbantiems pensininkams sumazinimas bei valstybiniu pensiju apribojimas priestarauja Konstitucijai.

Blaziene, I., Gruzevskis, B. (2016). The rise of the dual labour market: Fighting precarious employment in the new member states through industrial relations. Country report: Lithuania. Retrieved March 13, 2019, from https://www.dcu.ie/sites/default/files/dcubs/lithuania_precarir_national_ report_2016.pdf.

Criminal Code of Republic of Lithuania No VIII-1968. (2000). Valstybes inios, 2000-10-25, Nr. 89-2741.

Dromantiene, L., \& Kanopiene, V. (2004). Demografinis senejimas ir ES socialine politika pagyvenusiems. Socialinis darbas, 3(2), 12-23.

Labour Code of Republic of Lithuania No XII-2603. (2017). TAR, 2016-09-19, Nr. 23709.

Law on Amendment of Republic of Lithuania Law No I-549 on Social Insurance Pensions No XII-2512. (2016). TAR, 2016-07-15, Nr. 20649.

Law on Employment of Republic of Lithuania No XII-2470. (2016). 2016-07-05, Nr. 18825.

Law on reform of the pension system. (2002). Republic of Lithuania. Official Gazette, No. 123-5511.

Law on Social Insurance Pensions No I-549. (1994). Republic of Lithuania. Official Gazette, No. 59-1153.

Law on State Pensions No I-730. (1994). Republic of Lithuania. Official Gazette, No. 101-2018.

Lietuvos Bankas. (2018). Lietuvos II ir III pakopos pensijos fondu bei KIS apzvalga 2017 m. Retrieved March 13, 2019, from https://www.lb.lt/uploads/publications/docs/19269_ c8d30bf01a9c931376e375b8daefbd95.pdf. 
Lietuvos darbo birza. (2018). Vyresnio amziaus bedarbiu remimas. Retrieved March 13, 2019, from https://www.ldb.lt/Informacija/ESParama/gyvendintipercent20ESpercent20projektai/ UserDispForm. aspx? $\mathrm{ID}=50$.

Lietuvos laisvosios rinkos institutas. (2017). Darbo lankstumo indeksas 2018. ES ir EBPO salys. Retrieved March 13, 2019, from https://www.llri.lt/wp-content/uploads/2017/12/Darbolankstumo-indeksas-2018_1-12_be-u-laidu.pdf.

Lietuvos Respublikos administraciniu nusizengimu kodeksas Nr. XII-1869. (2015). TAR, 2015-0710, Nr. 11216.

Lietuvos Respublikos gyventoju pajamu mokescio istatymo Nr. IX-1007 2, 6, 16, 17, 18, 18-1, 19 , $20,22,24,27,29,33,34$ straipsniu pakeitimo ir istatymo papildymo 18-2 straipsniu istatymas Nr. XIII-841. (2017). TAR, 2017-12-20, Nr. 20568.

Lietuvos Respublikos papildomo savanorisko pensiju kaupimo istatymo pakeitimo istatymas $\mathrm{Nr}$. XII-70. (2012). Valstybes zinios, 2012-12-31, Nr. 155-7980.

Lietuvos Respublikos socialines apsaugos ir darbo ministerija. (2018). Vyriausybe pritare pensiju kaupimo pertvarkai: svarbiausi aspektai dirbantiesiems. Retrieved March 13, 2019, from https:// socmin.lrv.lt/lt/naujienos/vyriausybe-pritare-pensiju-kaupimo-pertvarkai-svarbiausi-aspektaidirbantiesiems.

Lietuvos Respublikos socialiniu ismoku perskaiciavimo ir mokejimo laikinasis istatymas Nr. XI537. (2009). Valstybes zinios, 2009-12-24, Nr. 152-6820.

Lietuvos Respublikos valstybinio socialinio draudimo istatymo Nr. I-1336 2, 3, 8, 10, 11, 12, 13, 19 , 25, 35 ir 40 straipsniu pakeitimo istatymas Nr. XIII-823. (2017). TAR, 2017-12-13, Nr. 20047.

Lithuanian Free Market Institute. (2017). Employment flexibility index 2018. EU and OECD countries. Retrieved March 13, 2019, from https://en.llri.lt/wp-content/uploads/2017/12/EmploymentFlexibility-Index-2018_-LFMI.pdf.

Mavrikiou, P., Pivoriene, J., \& Xhumari, M. (2018). The impact of pension systems on working life in Albania, Cyprus and Lithuania. In S. Kapounek \& V. K. Krutilova (Eds.), Enterprise and competitive environment (pp. 424-433). Brno: Mendel University.

Mikulioniene, S. (2008). Diskriminacija del amziaus: samprata, raiskos formos ir sritys. Socialinis darbas, 7(1), 19-25.

Mikulioniene, S. (2011). Socialine gerontologija. Vilnius: Mykolo Romerio universitetas.

Ministry of Social Security and Labour. (2015). The social report 2014-2015.

Ministry of Social Security and Labour. (2017a). The social report 2016-2017.

Ministry of Social Security and Labour. (2017b). Social statistics. Retrieved March 13, 2019, from https://socmin.lrv.lt/en/administrative-services/social-statistics.

OECD. (2018a). Key policies to promote longer working lives in Lithuania. Retrieved March 13, 2019, from http://www.oecd.org/employment/emp/Lithuania_Keypercent20policies_Final.pdf.

OECD. (2018b). OECD reviews of labour market and social policies: Lithuania OECD Reviews of Labour Market and Social Policies. Paris: OECD Publishing.

Official Statistics Portal. (2019a). Gender pay gap. https://osp.stat.gov.lt/naujienos?articleId= 5762146. Accessed 13 March 2019.

Official Statistics Portal. (2019b). Employed persons and employment rate by age group and sex. Retrieved March 13, 2019, from https://osp.stat.gov.lt/statistiniu-rodikliu-analize?hash= 5ab5f098-85a0-41dd-a961-6953f9db9da5\#/.

Oficialiosios statistikos portalas. (2019). Pensiju gavejai ir islaidos pensijoms $2018 \mathrm{~m}$. Retrieved January 6, 2020, from https://osp.stat.gov.lt/informaciniai-pranesimai?articleId=6340971.

Okuneviciute Neverauskiene, L., \& Moskvina, J. (2008). Vyresnio amziaus asmenu dalyvavimo darbo rinkoje galimybiu vertinimas. Socialinis darbas, 7(1), 26-35.

Pension funds online. (2018). Pension system in Lithuania. Retrieved March 13, 2019, from http:// www.pensionfundsonline.co.uk/content/country-profiles/lithuania/87. 
Skuciene, D. (2007). Moteru pensinio amziaus ekonomines pasekmes Lietuvoje. Gerontologija, $8(1), 17-25$.

Sodra. (2017). Pasikeitimai nuo 2018 m. sausio 1 d. Pensiju gavejai. Retrieved March 13, 2019, from http://www.sodra.lt/pasikeitimai-nuo-2018-m-sausio-1-d-pensiju-gavejai.

Sodra. (2019). Pagrindiniai socialiniai rodikliai. Retrieved January 6, 2020, from https://www.sodra. 1t/lt/situacijos/pagrindiniai-socialiniai-rodikliai.

Open Access This chapter is licensed under the terms of the Creative Commons Attribution 4.0 International License (http://creativecommons.org/licenses/by/4.0/), which permits use, sharing, adaptation, distribution and reproduction in any medium or format, as long as you give appropriate credit to the original author(s) and the source, provide a link to the Creative Commons license and indicate if changes were made.

The images or other third party material in this chapter are included in the chapter's Creative Commons license, unless indicated otherwise in a credit line to the material. If material is not included in the chapter's Creative Commons license and your intended use is not permitted by statutory regulation or exceeds the permitted use, you will need to obtain permission directly from the copyright holder. 


\title{
Chapter 26 Netherlands
}

\author{
Maria Fleischmann and Thijs van den Broek
}

\begin{abstract}
The Netherlands traditionally had ample early retirement possibilities. Several reforms introduced from the late 1990s onward contributed to the successful reversal of this early exit trend. As a result, in 2018, employees on average retired at age 65.0, representing a three-year increase in the last ten years. This chapter describes the Dutch pension system and recent employment, health and care policies and reforms that have likely shaped the changes in the effective retirement age. We conclude with a short discussion of the current debate about future changes to the statutory retirement age and consider other potential avenues through which policies could yield further increases in the effective retirement age of Dutch workers.
\end{abstract}

Keywords Retirement $\cdot$ Pension policy $\cdot$ Care policy $•$ Age stereotypes $•$ Netherlands

\section{Introduction}

The Netherlands has long been known as an early retirement country. In the 1990s and early 2000s, workers tended to retire approximately five years before reaching the statutory retirement age of 65 years, with the difference being somewhat larger for women than for men. This picture is no longer accurate. In 2018, employees on average retired at age 65.0, a more than three-year increase in the last ten years (Statistics Netherlands 2019a). In this chapter, we describe the Dutch pension system and reforms in various policy domains that have likely shaped the changes in the effective retirement age. We conclude with a short overview of the most recent changes to the statutory retirement age and other future changes. We also discuss potential avenues through which policies could yield further increases in the effective retirement age of Dutch workers.

\footnotetext{
M. Fleischmann ( $\square)$

Department of Health Sciences, Vrije Universiteit Amsterdam, Amsterdam, The Netherlands e-mail: m.s.fleischmann@vu.nl

T. van den Broek

Erasmus School of Health Policy and Management, Erasmus Universiteit Rotterdam, Rotterdam, The Netherlands

(C) The Author(s) 2020

Á. Ní Léime et al. (eds.), Extended Working Life Policies, https://doi.org/10.1007/978-3-030-40985-2_26
} 


\section{Pension Policies ${ }^{1}$ and Retirement Age}

The Dutch pension system is usually described as a hybrid version resembling a corporatist (continental) welfare type with regards to early pension regulations, and a social-democratic (Scandinavian) type when it comes to a universal state pension for each resident (Schils 2008; Van Gestel et al. 2014). It consists of three pillars. The first pillar is the universal state pension (Dutch: Algemene Ouderdomswet, AOW), introduced in 1957. All people living or working in the Netherlands accumulate state pension benefits for every year of residence. The state pension is organised as a Pay-As-You-Go scheme.

The second pillar in the Dutch pension system consists of collective pensions. Employers and employees both contribute to this part of the pension system during working life. Even though employees are not obliged by law to contribute to a collective pension fund, governments can make contributions to collective pensions obligatory if employer organisations and labour unions decide to arrange occupational pensions (Pensioenfederatie 2010). Consequently, more than $90 \%$ of all employees in the Netherlands participate in collective pension schemes (OECD 2014; Schils 2008).

The third pillar comprises private pension arrangements. These are mostly used by self-employed persons and persons employed in organisations or sectors in which no collective pensions are available (Pensioenfederatie 2010). Compared to the state pension and collective pension, fewer people are insured through private pension arrangements.

In the Netherlands, the statutory retirement age was 65 years until 2014. From 2015 onwards, the statutory retirement age was set to gradually increase to 66 years in 2018 and to 67 years by the year 2023. Later, even faster increases were agreed upon, making the statutory retirement age reach 67 years already in 2021, and linking statutory retirement age to life expectancy thereafter. However, following heated discussions regarding these increases, the Dutch government has decided in July 2019 that retirement age will increase less rapidly, effective immediately. This means that the statutory retirement age will remain 66 years and 4 months until 2021, and then increase by three months each year until reaching 67 in 2024.

\section{Employment Policies}

Traditionally, it was rather common for Dutch workers to leave the labour market before they had reached statutory retirement age, enabled by early retirement schemes. The first 'early exit' scheme (Dutch: Vervroegd uittreden, VUT), introduced in the late 1970s, offered generous possibilities of leaving the labour market around age 60 (Euwals et al. 2004; Van Oorschot and Jensen 2009). Retiring through the VUT provided older persons with an income of $70-80 \%$ of their last monthly

\footnotetext{
${ }^{1}$ The description of the Dutch pension policies partly relies on Fleischmann and Koster (2016).
} 
wage. Delaying early retirement past $V U T$ age did not increase this replacement rate, and persons choosing these early retirement benefits did not experience any reduction in their state pension.

The 1990s saw a growing awareness that the early retirement scheme $V U T$ would become unsustainable in the long-term (Euwals et al. 2004) and several changes were implemented in the late 1990s. VUT benefits were phased out and the prepension (Dutch: prepensioen) was implemented. In contrast to the VUT, the prepension was capital funded, meaning that benefits were paid from members' own contributions (as a kind of savings scheme) rather than from the current workforce's contributions. Moreover, the earlier workers exited the labour market through the prepension, the lower was their replacement rate and, thus, their retirement benefits. Through the lower replacement rate, older workers were discouraged from retiring early (Conen et al. 2011; OECD 2014). From the 2000s onward, additional changes were introduced. In 2006, the Dutch government decided to tax both the premium and the benefits received through early retirement regulations (Euwals et al. 2004; Van Oorschot and Jensen 2009). This further decreased the financial attractiveness of early retirement schemes.

Flexible employment, in terms of part-time employment, is very common in the Netherlands, especially among women. Approximately $74 \%$ of women, and $27 \%$ of men, worked part-time (i.e. less than $35 \mathrm{~h}$ per week) in 2017 (Statistics Netherlands $2019 b)$. In the last years, this percentage has been quite constant for women, but has risen from about $20 \%$ in 2003 to the current rate for men. This rise among men is mostly driven by the 25-45 year olds, who increasingly used part-time work to combine work and childcare. Among older men and women, a slight decrease in the propensity to work part-time has been noted. This decrease might be attributable to the previously described policies, which are stimulating labour market participation in this age group.

An explicit law against age-based discrimination at work was implemented in the Netherlands in 2003, in addition to a general anti-discrimination law that was in place already. Nevertheless, employers remain less likely to recruit older workers and to invest in them compared to their younger counterparts (Fleischmann and Koster 2018; Karpinska et al. 2011; Lazazzara et al. 2013). This may be related to persistent age stereotypes. Studies found that Dutch employers regarded older workers to be less interested in and to have lower acceptance of new technologies than their younger counterparts, to have a greater resistance to change, to be less capable of doing physical work and to have higher absenteeism (Henkens 2005; Remery et al. 2003). However, they also thought older workers had greater social skills, were more reliable and more careful (Henkens 2005; Van Dalen et al. 2006).

\section{Health and Care Policies}

The Work Disability Act (Dutch: Wet Arbeidsongeschiktheid, WAO), introduced in 1966, was often used to 'retire' early with generous disability benefits (OECD 2014) 
and employers had made use of disability benefits to lay off older workers (Conen et al. 2011). The very high numbers of people receiving disability benefits became known as the 'Dutch disease' (Ebbinghaus and Hofäcker 2013). In the late 1980s, access to $W A O$ benefits was limited through several reforms. Before the WAO was replaced by a new law, the replacement rate in case of full disability was $70 \%$ of the prior wage paid for six years for those aged 58 years (Van Oorschot and Jensen 2009) and until statutory retirement age for those who were older. In 2006, the WAO was succeeded by the Act 'Work and Income depending on Work Ability' (Dutch: Wet Werk en Inkomen naar Arbeidsvermogen, WIA). The WIA places a stronger emphasis on ability and rehabilitation rather than disability, for example, by stating that people are expected to re-enter the labour market and work according to their abilities (OECD 2014). The shift from a disability scheme to an ability scheme reflects the normative shift in the Netherlands toward a 'participation society' characterised by a strong emphasis on individual responsibility (cf. Van Oorschot 2006).

It has been argued that the desire of the Dutch government to encourage the labour market participation of men and women in later mid-life may clash with the longterm care (LTC) reforms that have been implemented in the Netherlands (Putters 2014; Sadiraj et al. 2009). In the Netherlands public coverage of services for LTC services, i.e. provisions helping and supporting people coping with health problems that limit them in their activities of daily living (Österle and Rothgang 2010), has traditionally been extensive. The Netherlands was among the first countries in Europe to introduce a universal social insurance scheme covering the risk of being in need of long-term care: the Exceptional Medical Expenses Act (Dutch: Algemene Wet Bijzondere Ziektekosten; AWBZ). The scope of the AWBZ was continually expanded in the years following its introduction in 1968, until the rising costs of care eventually led to a long series of changes in the way LTC was organised. From the early 1980s onwards de-institutionalisation was promoted: whenever possible, care preferably had to be provided at home, rather than in residential care settings (Da Roit 2012). From the early 2000s onwards, barriers hampering the use of LTC services were increased. Co-payments were increased substantially in 2004, particularly for homebased services (Da Roit 2012; Schut and Van Den Berg 2010) and care assessors started considering the potential availability of informal care in more stringent ways when determining eligibility for AWBZ services (Grootegoed et al. 2015; Morée et al. 2007).

With the introduction of the Social Support Act (Dutch: Wet maatschappelijke ondersteuning, Wmo) in 2007, the provision of household services, e.g. cleaning the home, became the responsibility of municipalities, and residents in need of care were no longer entitled to household help. Instead, the Wmo is based on the principle of subsidiarity: individuals are principally responsible to find ways to have their care needs met, preferably with the help of their social and family networks. People's entitlement to care services further weakened in 2015, when the AWBZ was replaced by the Long-Term Care Act (Dutch: Wet langdurige zorg, Wlz). The Wlz is a universal social insurance scheme, like the AWBZ, but with a much smaller scope. It only covers care to people who need support $24 \mathrm{~h}$ per day. Lighter forms 
of nursing care and personal care services have been transferred to the Health Insurance Act (Dutch: Zorgverzekeringswet, Zvw) and the Wmo. The end of the AWBZ meant that municipalities have become responsible for a broader range of LTC services, which they provide according to the principle of subsidiarity that underlies the Wmo (Van den Broek et al. 2019). The Wmo also obliges municipalities to support informal caregivers through the provision of information, advice and guidance, emotional support, education, practical help, financial support and material support. International research indicates that, particularly for women, providing informal care is associated with an increased risk of reducing employment hours or quitting paid work altogether (Berecki-Gisolf et al. 2008; Lee et al. 2015). Scholars have therefore expressed concerns that the stronger call in the Netherlands on the family to provide support to close relatives in need may have a particularly negatively impact on the labour market participation of women in later midlife (Van den Broek 2013; Van Hooren and Becker 2012).

\section{Debate on Appropriate Future Statutory Retirement Age}

As indicated above, the Dutch government recently agreed upon that statutory retirement age will increase less quickly than previously planned. The reforms have been accepted in July 2019 and are effective from January 2020 onwards. Several discussions concerned with socio-economic differences in work exit (e.g. early retirement for physically demanding occupations or obligated disability insurance for self-employed), are still ongoing. A heated discussion in the media centres on the particular situation of those who generally start working at young ages, tend to be employed in more physically strenuous jobs, and have a lower life expectancy (De Beer and Van der Gaag 2018). Several pundits have argued that it would be fair if these people would be granted opportunities to retire early.

Also employers, particularly those in the construction and industry sectors, are concerned about the implications of a rapidly rising statutory retirement age for the composition of their workforce (Oude Mulders et al. 2018). Moreover, $82 \%$ of employers, especially those in construction and industry, where physical work is most prevalent, are in favour of a lower retirement age for physically demanding jobs (van Dalen et al. 2019).

\section{Conclusions and Policy Recommendations}

The changes to the statutory retirement age, employment policies and health and care policies described in this chapter have resulted in clear rises in the effective retirement age. The average retirement ages for female and male employees have increased significantly over the last few years and women on average retire only slightly earlier than men (Statistics Netherlands 2018). Of all Dutch employees retiring in 2016 and 
2017, approximately half of them retired at age 65, while ten years earlier, only around ten per cent retired at age 65 (Statistics Netherlands 2019a). The current debate regarding retirement and pension focuses on the pace the statutory retirement age should be raised, as well as socio-economic and occupational differences (De Beer et al. 2018).

The OECD (2014) advised that even longer careers may become more attractive in the Netherlands if additional occupational pension rights could be accrued when working past state pension age. Furthermore, the role of employers could be addressed more strongly. Even though employers appear to be increasingly willing to retain older employees, they are still hesitant to recruit older persons (OECD 2014). Also, many employers in a recent survey reported that they considered implementing measures that would facilitate older workers' labour market participation, such as training programmes and possibilities for sabbaticals or career breaks (Fleischmann et al. 2015), but few employers actually implemented these measures (Fleischmann et al. 2015; Van Dalen et al. 2010). The OECD (2014) advised removing age barriers, enforcing age neutral personnel treatment and implementing additional legislation against age discrimination. Also, financial incentives may make employers more likely to invest in older workers. For instance, a recent study showed that government provided subsidies may reduce age-based discrimination in employers' decisions about whether or not to invest in training for employees (Fleischmann and Koster 2018). Finally, the employability of older persons is lagging behind. To advance this, the OECD (2014) suggested to provide better information on the particular training needs that older persons might have and to consider job-specific training, rather than generic training. Potential future rises in the effective retirement age may thus demand that government, employers and employees consider measures to enhance employability of older persons.

\section{References}

Berecki-Gisolf, J., Lucke, J., Hockey, R., \& Dobson, A. (2008). Transitions into informal caregiving and out of paid employment of women in their 50s. Social Science and Medicine, 67(1), 122-127. https://doi.org/10.1016/j.socscimed.2008.03.031.

Conen, W. S., Henkens, K., \& Schippers, J. J. (2011). Are employers changing their behavior toward older workers? An analysis of employers' surveys 2000-2009. Journal of Aging \& Social Policy, 23(2), 141-158. https://doi.org/10.1080/08959420.2011.551612.

Da Roit, B. (2012). The Netherlands: The struggle between universalism and cost containment. Health and Social Care in the Community, 20(3), 228-237. https://doi.org/10.1111/j.1365-2524. 2011.01050.x.

De Beer, J., \& Van der Gaag, N. (2018). Hoe kunnen verschillen in levensverwachting uitpakken voor een gedifferentieerde AOW-leeftijd? Me Judice. http://www.mejudice.nl/artikelen/detail/hoekunnen-verschillen-in-levensverwachting-uitpakken-voor-een-gedifferentieerde-aowleeftijd.

De Beer, J., Van Dalen, H., \& Henkens, K. (2018). De verbeelding van een redelijke verhoging van de AOW-leeftijd. De verbeelding van een redelijke verhoging van de AOW-leeftijd: Me Judice. 
Ebbinghaus, B., \& Hofäcker, D. (2013). Reversing early retirement in advanced welfare economies. A paradigm shift to overcome push and pull factors. Comparative Population Studies, 38(4), 807-840. https://doi.org/10.12765/cpos-2013-24en.

Euwals, R., Van Vuuren, D., \& Wolthoff, R. (2004). CPB Memorandam 101. Prepensioen en arbeidsparticipatie ouderen. The Hague: CPB Netherlands Bureau for Economic Policy Analysis.

Fleischmann, M., \& Koster, F. (2016). From early exit to postponing pension: How the Dutch polder model shapes retirement. In D. Hofäcker, M. Hess, \& S. König (Eds.), Delaying retirement: Progress and challenges of active ageing in Europe, the United States and Japan (pp. 171-193). London, UK: Palgrave Macmillan. https://doi.org/10.1057/978-1-137-56697-3_8.

Fleischmann, M., \& Koster, F. (2018). Older workers and employer-provided training in the Netherlands: A vignette study. Ageing \& Society, 38(10), 1995-2018. https://doi.org/10.1017/ S0144686X17000356.

Fleischmann, M., Koster, F., \& Schippers, J. (2015). Nothing ventured, nothing gained! How and under which conditions employers provide employability-enhancing practices to their older workers. International Journal of Human Resource Management, 26(22). https://doi.org/10.1080/ 09585192.2015.1004100.

Grootegoed, E., Van Barneveld, E., \& Duyvendak, J. W. (2015). What is customary about customary care? How Dutch welfare policy defines what citizens have to consider 'normal' care at home. Critical Social Policy, 35(1), 110-131. https://doi.org/10.1177/0261018314544266.

Henkens, K. (2005). Stereotyping older workers and retirement: The managers' point of view. Canadian Journal of Aging, 24(4), 353-366.

Karpinska, K., Henkens, K., \& Schippers, J. (2011). The recruitment of early retirees: A vignette study of the factors that affect managers' decisions. Ageing \& Society, 31(04), 570-589. https:// doi.org/10.1017/S0144686X10001078.

Lazazzara, A., Karpinska, K., \& Henkens, K. (2013). What factors influence training opportunities for older workers? Three factorial surveys exploring the attitudes of HR professionals. The International Journal of Human Resource Management, 24(11), 2154-2172. https://doi.org/10.1080/ 09585192.2012.725077.

Lee, Y., Tang, F., Kim, K. H., \& Albert, S. M. (2015). Exploring gender differences in the relationships between eldercare and labour force participation. Canadian Journal on Aging, 34(1), 14-25. https://doi.org/10.1017/S0714980814000543.

Morée, M., Van der Zee, B., \& Struijs, A. J. (2007). Formalisering van informele zorg. Over de rol van 'gebruikelijke zorg' bij toekenning van professionele zorg. The Hague: CEG The Netherlands Centre for Ethics and Health.

OECD. (2014). Ageing and employment policies: Netherlands 2014: Working better with age. Paris: OECD Publishing.

Österle, A., \& Rothgang, H. (2010). Long-term care. In F. G. Castles, S. Leibfried, J. Lewis, H. Obinger, C. Pierson, A. Österle, \& H. Rothgang (Eds.), The Oxford handbook of the welfare state (pp. 378-390). Oxford: Oxford University Press. https://doi.org/10.1093/oxfordhb/ 9780199579396.003.0026.

Oude Mulders, J., Henkens, K., \& Van Dalen, H. (2018). Werkgevers bezorgd over langer doorwerken. Demos, 34(1), 1-4.

Pensioenfederatie. (2010). The Dutch pension system. An overview of the key aspects. The Hague: Pensioenfederatie.

Putters, K. (2014). Rijk geschakeerd. Op weg naar de participatiesamenleving. The Hague: SCP Netherlands Institute for Social Research.

Remery, C., Henkens, K., Schippers, J., \& Ekamper, P. (2003). Managing an aging workforce and a tight labor market: Views held by Dutch employers. Population Research and Policy Review, 22, 21-40.

Sadiraj, K., Timmermans, J., Ras, M., \& De Boer, A. (2009). De toekomst van de mantelzorg. The Hague: SCP Netherlands Institute for Social Research. 
Schils, T. (2008). Early retirement in Germany, the Netherlands, and the United Kingdom: A longitudinal analysis of individual factors and institutional regimes. European Sociological Review, 24(3), 315-329. https://doi.org/10.1093/esr/jen009.

Schut, F. T., \& Van Den Berg, B. (2010). Sustainability of comprehensive universal long-term care insurance in the Netherlands. Social Policy \& Administration, 44(4), 411-435. https://doi.org/10. 1111/j.1467-9515.2010.00721.x.

Statistics Netherlands. (2018). Van arbeid naar pensioen, 2000-2016. Retrieved January 21, 2019, from http://statline.cbs.nl/Statweb/publication/?VW=T\&DM=SLNL\&PA=80396ned \&D1=9\& $\mathrm{D} 2=\mathrm{a} \& \mathrm{D} 3=0 \& \mathrm{D} 4=0 \& \mathrm{D} 5=1 \& \mathrm{D} 6=0 \& \mathrm{D} 7=0 \& \mathrm{D} 8=\mathrm{a} \& \mathrm{HD}=190121-1101 \& \mathrm{HDR}=\mathrm{T}, \mathrm{G} 7 \& \mathrm{STB}=$ G1,G2,G3,G4,G5,G6.

Statistics Netherlands. (2019a). Pensioenleeftijd werknemers. Retrieved January 9, 2020, from https://www.cbs.nl/nl-nl/nieuws/2019/32/werknemers-in-2018-gemiddeld-65-jaar-bijpensionering.

Statistics Netherlands. (2019b). Werkzame beroepsbevolking, arbeidsduur. Retrieved January 14, 2019, from http://statline.cbs.nl/Statweb/publication/?VW=T\&DM=SLNL\&PA= 82647 ned \&D1 $=0-1,8 \& D 2=a \& D 3=0,3,7-8 \& D 4=4,9,14,19,24,29,34,39,44,49,54,59,64,69,74 \&$ $\mathrm{HD}=190114-1412 \& \mathrm{HDR}=\mathrm{G} 3, \mathrm{~T} \& \mathrm{STB}=\mathrm{G} 1, \mathrm{G} 2 \& \mathrm{P}=\mathrm{T}$.

Van Dalen, H. P., Henkens, K., Henderikse, W., \& Schippers, J. (2006). Dealing with an ageing labour force: What do European employers expect and do? (No. 73).

Van Dalen, H. P., Henkens, K., \& Schippers, J. (2010). How do employers cope with an ageing workforce? Views from employers and employees. Demographic Research, 22, 1015-1036. https:// doi.org/10.4054/DemRes.2010.22.32.

van Dalen, H. P., Henkens, K., \& Oude Mulders, J. (2019). Increasing the public pension age: Employers' concerns and policy preferences. Work, Aging and Retirement, 5(3), 255-263. https:// doi.org/10.1093/workar/waz004.

Van den Broek, T. (2013). Formalization of informal care in the Netherlands: Cost containment or gendered cost redistribution? International Journal of Feminist Approaches to Bioethics, 6(2), 185-193. https://doi.org/10.2979/intjfemappbio.6.2.185.

Van den Broek, T., Dykstra, P. A., \& Van der Veen, R. J. (2019). Adult children stepping in? Longterm care reforms and trends in children's provision of household support to impaired parents in the Netherlands. Ageing \& Society, 39(1), 112-137. https://doi.org/10.1017/S0144686X17000836.

Van Gestel, N., Vossen, E., Oomens, S., \& Hollanders, D. (2014). Toekomst van de sociale zekerheid. Over provisie, preventie en participatie. The Hague: Boom Lemma.

Van Hooren, F., \& Becker, U. (2012). One welfare state, two care regimes: Understanding developments in child and elderly care policies in the Netherlands. Social Policy and Administration, 46(1), 83-107. https://doi.org/10.1111/j.1467-9515.2011.00808.x.

Van Oorschot, W. (2006). The Dutch welfare state: Recent teends and challenges in historical perspective. European Journal of Social Security, 8, 57-76.

Van Oorschot, W., \& Jensen, P. H. (2009). Early retirement differences between Denmark and the Netherlands. A cross-national comparison of push and pull factors in two small European welfare states. Journal of Aging Studies, 23(4), 267-278. https://doi.org/10.1016/j.jaging.2008.01.003. 
Open Access This chapter is licensed under the terms of the Creative Commons Attribution 4.0 International License (http://creativecommons.org/licenses/by/4.0/), which permits use, sharing, adaptation, distribution and reproduction in any medium or format, as long as you give appropriate credit to the original author(s) and the source, provide a link to the Creative Commons license and indicate if changes were made.

The images or other third party material in this chapter are included in the chapter's Creative Commons license, unless indicated otherwise in a credit line to the material. If material is not included in the chapter's Creative Commons license and your intended use is not permitted by statutory regulation or exceeds the permitted use, you will need to obtain permission directly from the copyright holder.

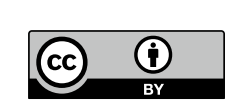




\title{
Chapter 27 \\ New Zealand
}

\author{
Judith A. Davey, Hannah Phillips and Fiona Alpass
}

\begin{abstract}
New Zealand has high rates of workforce participation for people in the $55+$ age groups. These rates have grown rapidly, and growth is expected to continue, especially for women workers. Existing policy settings support extended workforce participation. There is a universal flat rate pension at age 65 , which can be received while continuing in paid work; flexible work arrangements; and legislation against age discrimination and compulsory retirement. However, assistance for working carers, education and training for older workers and direct support for employers are all very limited. There are many calls for a comprehensive approach to the challenges and opportunities of workforce ageing in New Zealand, many from government agencies, but comparatively little provides a gender perspective. Much depends on the extent to which individual employers recognise the implications of workforce ageing and respond with appropriate policies and practices.
\end{abstract}

Keywords New Zealand · Older workers $\cdot$ Policy $\cdot$ Women workers $\cdot$ Workforce ageing

\section{Labour Force Participation by Age and Gender}

New Zealand has the third highest employment rate of workers aged 55-64 in the OECD and the fourth highest in the 65-69 age group (OECD 2020). The labour force participation rate for the over 65 age group almost trebled from 1986 to 2006 (Jackson et al. 2013). A number of factors have contributed to this situation, including policy settings which are outlined below. Employment rates for older women are high in New Zealand compared to the OECD average (OECD 2020), with strong growth since the 1990s, largely due to the availability of part-time work (Callister 2014). Women aged 60-64 were over three times more likely to be in employment in 2018

\footnotetext{
J. A. Davey (凶)

Institute for Governance and Policy Studies, Victoria University of Wellington, Wellington, New Zealand

e-mail: judith.davey@vuw.ac.nz

H. Phillips · F. Alpass

School of Psychology, Massey University, Palmerston North, New Zealand

(C) The Author(s) 2020

Á. Ní Léime et al. (eds.), Extended Working Life Policies, https://doi.org/10.1007/978-3-030-40985-2_27
} 
Table 27.1 Participation rates (\%) at age 65 plus by sex-projections 2011-2036

\begin{tabular}{l|l|l|l|l|l|l}
\hline & 2011 & 2016 & 2021 & 2026 & 2031 & 2036 \\
\hline Men & 24 & 30 & 33 & 35 & 35 & 34 \\
\hline Women & 15 & 21 & 25 & 27 & 28 & 28 \\
\hline
\end{tabular}

Source Statistics New Zealand (2011)

compared to 1987 and those aged 65+ over nearly five times more likely (OECD 2020). Both older men and older women are more likely to be working part-time as they age, with more than half employed women in the 65-69 age group working part-time (Callister 2014). Given expected demographic changes over the next few decades, numbers of people $65+$ in the work force will increase (though possibly at a slower rate), so that by 2036 almost one third of New Zealanders aged 65+ will still be in the paid workforce to some extent (Table 27.1).

\section{The New Zealand Retirement Income System}

The statutory pension scheme (New Zealand Superannuation (NZS)) is available from age 65 for all men and women who have lived in the country for 10 years or more since the age of 20 (five of those years must be since turning 50). It is noncontributory, pay as you go scheme, but the flat rates depend on whether people are single and living alone, or married/partnered or living with others and sharing accommodation. There is no early eligibility option, although unemployment and disability benefits are available before age 65 for those unable to work or find work. NZS is funded out of general government revenues and taxable on an individual basis. NZS is not income or asset tested and workers need not exit the workforce at 65 in order to receive the benefit. These features encourage workforce participation beyond the age of eligibility and help to explain the high rate of participation by older workers (Jackson et al. 2013). The age of eligibility for NZS has always been the same for men and women, but was raised from age 60 to 65 in a gradual process between 1991 and 2001. This coincided with a marked increase in workforce participation in this age group (Hurnard 2005).

NZS provides a moderate replacement income for average wage earners, amounting to $66 \%$ of the 'average ordinary time wage', after tax, for couples and $40 \%$ for single people. The current level of NZS is sufficient to assure a basic living income. However, expectations of higher living standards in retirement, especially given growing life expectancy, encourage people to remain in paid work after receiving NZS or to supplement the pension in other ways.

In 2007, KiwiSaver (KS), a voluntary, contributory, work-based initiative was introduced to encourage long term saving for retirement. KS schemes are managed by private sector companies and are not guaranteed by Government. Members receive an annual tax credit and non earners can receive the tax credit as long as they contribute a 
minimum annual payment (St John 2016). However, to receive the employer subsidy, contributors have to be in paid employment and, given interrupted work histories, women can expect to have lower balances at scheme maturity than men will receive. A recent bank survey found that women were contributing less into KS than men, had lower average balances and were less likely to have other investments to contribute to their retirement income (Westpac 2018). Compulsory enrolment in KS would ensure improved retirement income for all workers, but there are arguments against compulsion (CFFC 2014). For low income earners, especially those with dependent children, KS contributions could be a financial burden.

\section{New Zealand Employment Policies}

\section{Flexible Work}

New Zealand has legislation providing workers the 'right to request' flexible work arrangements. The right was initially confined to employees with caring responsibilities but is now extended to all workers. Employers have a 'duty to consider' any requests but do not have to agree if there is a good business reason not to. Current employment laws and contracts may accommodate flexible and part-time work, but only at the discretion of employers. Flexible work practices are widespread in New Zealand and are widely supported despite low rates of awareness of the legislation among older working carers (Alpass et al. 2015). An evaluation of the Employment Relations (Flexible Working Arrangements) Amendment Act 2007, found that a high proportion of requests were approved and only $56 \%$ related to caring responsibilities (Department of Labour 2011).

\section{Assistance to Working Carers}

Combining paid employment with eldercare is a growing issue in New Zealand. There is little research in New Zealand that focuses on unpaid/familial caregiving (often of older family members) by older working women, compared to childcare issues (Alpass et al. 2013). While several policies encourage extended labour force participation, the Government is also pursuing policies which rely on informal care for dependent older people ('ageing in place'). Middle aged women are often expected and frequently do take on eldercare responsibilities.

The Health, Work and Retirement study (HWR) (Towers et al. 2016) is a source of extensive data on older working carers. Caregiving is associated with lower levels of workforce participation, but nearly a quarter (24\%) of participants in the HWR who provided care every day were also working full-time, suggesting the potential for caregiver burden and work-related stress. Few employers have provisions to meet 
the needs of working carers. A significant proportion take annual leave, sick leave and leave without pay to provide care (Keeling and Davey 2008; Stephens et al. 2014). Contractual rights to flexible working conditions and caring leave would benefit working carers, but there are no specific government policies in this area.

\section{Education and Retraining}

Opportunities for subsidised lifelong learning are very limited in New Zealand and are becoming more restrictive with cuts to funding for adult education. This is despite calls from the business sector for more workplace based (re)training and adult apprenticeship schemes (Davey 2014a). Suggestions that older workers lack up to date technical knowledge will be self-fulfilling if they are not given upskilling opportunities. Callister (2014) highlights education and training issues in his overview of the employment of older New Zealand women. More older women lack formal qualifications compared with older men, but these statistics are changing as younger women are becoming qualified and therefore better positioned in the labour market. Women under the age of 60 are now more qualified than men. The report notes that occupational segregation by gender has decreased in most highly skilled occupations but has increased for unskilled work.

\section{Antidiscrimination Policies}

The New Zealand Human Rights Act (HRA) came into effect in February 1999 and prohibits discrimination on a number of grounds, including age and sex. Its provisions apply to all aspects of employment and bans compulsory retirement. The workplace provides the most common grounds for complaints of age discrimination, which predominantly involve older people. Despite the HRA, discriminations continued existence in New Zealand is clear from numerous reports (EEO Trust 2012; OCG Consulting 2013). Enquiries and complaints in the area of employment and preemployment made up $41 \%$ of all enquiries and complaints of unlawful discrimination to the Human Rights Commission in 2017-18, and enquiries and complaints on the grounds of age were the fourth highest after race, disability and sex-related grounds (Human Rights Commission 2016, 2018). Employers are called upon to develop effective HR policy and practice to combat age and sex discrimination. Legislation is a signal to society that age discrimination is not tolerated, but not the whole solution (Davey 2014b). It may not change employers' behaviour, but simply lead to more subtle and covert ways of discriminating. 


\section{Other Policies}

Financial and other incentives to employ older workers, such as those that exist in Australia, are not in operation in New Zealand.

\section{Health Policies}

The established health benefits (e.g. quality of life, feeling of purpose, etc.) of continued employment (Davey 2007) support the idea of extending working lives. Davey (2008), using results from the HWR study and Equal Employment Opportunity (EEO) Work and Age survey, found that 'pull' factors, such as health and 'wanting to do other things' influenced retirement decisions. Health was a factor among those still working, although a higher percentage of women than men said this was important. Women were more likely to consider the health of a family member, whether their partner was about to retire, not being able to find work, as well as employers' policy on older workers. Research on the health of older women workers in New Zealand is limited to occupationally specific studies, for example of nurses (Clendon and Walker 2013). There is also an interest in how older working carers reconcile work and care, the stress this can engender and how this impacts on wellbeing (Alpass et al. 2013).

Along with poor health, injury also impacts on workforce participation. Some older New Zealand workers lose up to a third of their work income through injuries (Davie and Lilley 2018). New Zealand is unique in providing a comprehensive state run accident insurance scheme through the Accident Compensation Corporation (ACC) which covers both work and non-work related injuries, funded through levies paid by employees and businesses. It is administered on a no fault basis; compensation is available for treatment costs, lost earnings, or vehicle and home modifications to accommodate serious injury. Careers such as teaching and care work, which are predominantly filled by women, have relatively low rates of injury (ACC 2018) but high rates of health related problems. Thus, there have been calls for ACC to offer cover for acquired illness and disability.

\section{Precarious Employment}

The work experiences of older women differ from those of men. They are more likely to be in part-time employment and this impacts on wealth and retirement savings. Over the lifecourse New Zealand women are also more likely to be in lower status jobs, earn less, and have more disrupted work histories compared to men, i.e. their employment is more likely to be precarious (Callister 2014). The growth of parttime work has made the greatest contribution to the overall growth in employment (particularly for women) in New Zealand. While increasing workforce participation 
among older people means a longer period of earning, this does not necessarily equate to greater wealth because of part-time work and generally low pay rates. This especially impacts women (Jackson et al. 2013).

\section{Research and Debate on Extending Working Lives}

New Zealand research literature covers workforce participation rates and types of employment, but there is less coverage of gender-based issues/ideas regarding extending working life. A recent report for the National Advisory Council on the Employment of Women (NACEW), outlines initiatives relevant to older women workers by various agencies including: central/local government and quasi government agencies; trade unions; business and professional organisations and voluntary sector organisations (Davey 2015). A number of agencies have programmes concerned with gender issues and work. NACEW promotes and disseminates information on women's employment; it advises and makes recommendations to the Minister for Women and makes submissions to public enquiries. Among the priorities of the Ministry for Women are supporting women and girls in education and training, using women's skills, and encouraging and developing women leaders. A lot of the work on older women in the workforce focuses on particular occupations or sectors (State Services Commission 2014), financial issues (Dwyer 2012) or equal opportunities/human rights (Hyman 2015).

The Health, Work and Retirement study (HWR) provides a longitudinal perspective on older workers' lives. This data shows that concern about future finances is often an incentive for continued workforce participation, and women at all ages reported the highest levels of concern (Noone and Alpass 2014). Women reported poorer financial expectations for retirement. However, there were fewer gender disparities in work and retirement behaviours than expected. It is possible that the broad categories of male and female may not capture important differences based on gendered lifecourses and differential exposures to work and family life

Older Māori and Pacific people in New Zealand have poorer health outcomes. This is not fully acknowledged within the literature on extending working lives despite this having a clear impact on their ability to continue working past the traditional age of retirement. This points to a large research gap where there is little examination of the culturally specific realities of an ageing population and how extending working lives may unfold for these groups.

There have been many calls over recent years for a more comprehensive approach to addressing the challenges and opportunities of an ageing workforce in New Zealand (EMA and CFFC 2018; McGregor 2007; Ministry of Social Development 2011). For instance, a working group facilitated by the Employers and Manufacturers Association was recently formed to raise awareness of New Zealand's ageing workforce. This group includes members from government ministries (e.g. Ministry of Business, Innovation and Employment, Ministry of Social Development, Statistics New Zealand, Inland Revenue Department); business organisations e.g. (Business 
New Zealand, Human Resources Institute of NZ), trade unions (New Zealand Council of Trade Unions), and NGOs (e.g. Commission for Financial Capability). The working group's 2018 report recommended a national strategy on the ageing workforce; a government led task force or advisory board; and the development of an ageing workforce toolkit for employers and workers (EMA and CFFC 2018). In addition, the Commission for Financial Capability (an autonomous crown entity) in its review of retirement policy, calls for a national conversation and attitude change towards older workers (CFFC 2016). The Commission has also called for the age of eligibility for NZS to be raised to 67 and the length of residence required to be increased to 25 years. However, much of the present debate fails to address workforce issues from a gender perspective.

The debate in favour of extended working lives argues that such policies are needed to support economic growth; and also to fund, through taxation, fiscal demands based on ageing. The burgeoning demand on NZS threatens its sustainability and puts pressure on other policies, including health services. Arguments against extended working life focus mainly on opposing any increase in the age of eligibility for NZS. These call on the disproved 'lump of labour' arguments, the belief that older workers are taking jobs away from the young, and on the entitlement of workers to supported retirement, especially when their health is deteriorating.

\section{Policy Response}

Existing policies in New Zealand, such as the freedom to engage in paid work while receiving NZS, provide a positive environment for extending workforce participation, even though this may not have been their original aim. The New Zealand Positive Ageing Strategy, dating from 2001 and recently revised to the Better Later Life - He Oranga Kaumātua 2019-2034 Strategy, stresses the benefits of prolonging workforce participation: 'Older workers have valuable skills and can help to address New Zealand's workforce shortage. ... Older people working will also have health benefits and help regions...' (Office for Seniors 2019). The Business of Ageing report, produced by the Ministry of Social Development, states: 'our competitiveness ... will hinge on building on the skills, knowledge and economic power of our older people' (Ministry of Social Development 2011). The New Zealand Human Rights Commission (2010) in their National Conversation about Work called on the Government to: 'urgently adopt a national programmatic approach to managing ageing workforce issues.' The EEO Commissioner (McGregor 2007) pointed out that there has been a variable response to Objective 9 of the original Positive Ageing Strategy, which calls for the 'elimination of ageism and the promotion of flexible work options.' She called for 'an active integrated programme' on ageing workers across the public and private sectors (p. 9).

Despite these positive statements, there is little focused policy attention to address the implications of workforce ageing in New Zealand. Raising the age of eligibility further for NZS has been proposed over recent years but this policy does not now 
appear to have political support; nor does any proposal for higher pensions if uptake is delayed. Nevertheless, emerging trends which impact on the growing numbers of people moving into retirement require a policy response. These include declining home ownership rates; reduced possibilities of family assistance for older people because of smaller family size (of special relevance to women), geographical migration and weaker family structures, and the arrival at NZS eligibility age of increasing numbers of people who have been long term benefit dependent and are in a weak financial situation (Ministry of Social Development 2013).

A common suggestion in the literature is that the public sector could act as a role model, initiating policies to encourage higher workforce participation among older people. The State Sector Act (1988) and Crown Entities Act (2004) apply 'good employer' provisions to the public sector. The Business of Ageing report (2011, p. 30) suggested that government as an employer could act as a catalyst by prioritising best workplace practice and providing more flexible options for people to remain in paid work, especially in the health and education sectors, where serious shortages are looming.

Much depends on the extent to which employers recognise the implications of workforce ageing and respond with appropriate policies and practices in individual workplaces. Recent surveys of the views of New Zealand business have not been encouraging. For instance, the most recent New Zealand Diversity Survey revealed that over a third of respondents indicated that their organisation had no specific strategies in place for engaging with older workers (Diversity Works NZ 2019). In a 2018 survey of 500 New Zealand companies, only nine per cent said they had any specific policies or strategies relating to older workers (CFFC 2018) and only 24\% were involved in active retirement planning with their employees. Workforce planning strategies mentioned by organisations that do have them include workplace health and safety, flexible working hours, training development, job design and phased retirement. These correspond well with what older workers are seeking (Alpass et al. 2015).

\section{Conclusion}

The trend for extended workforce participation in New Zealand has been supported by several factors which include increased longevity and emerging labour shortages as the workforce ages. Proponents of extended working life argue it is needed to meet the fiscal demands of an ageing population, however there is resistance to raising NZS eligibility due to the impact on vulnerable older workers. Growth in the numbers of both men and women working longer suggest that the incentives are effective. At the same time, more negative factors, including the need to meet increasing living costs in later life, covert age discrimination and the ageist attitudes of some employers, must also be recognised. 


\section{References}

ACC. (2018). Injury statistics—Work-related claims: 2017. Retrieved from https://www.stats.govt. nz/information-releases/injury-statistics-work-related-claims-2017.

Alpass, F., Pond, R., Stephens, C., Stevenson, B., Keeling, S., \& Towers, A. (2013). The influence of ethnicity and gender on caregiver health in older New Zealanders. The Journals of Gerontology Series B: Psychological Sciences and Social Sciences, 68(5), 783-793. https://doi.org/10.1093/ geronb/gbt060.

Alpass, F., Spicer, J., Stevenson, B., \& Stephens, C. (2015). Experiences of older workers: Preferences, plans and attitudes. Inclusion, contribution \& connection summary report. Palmerston North, NZ: Massey University. Retrieved from http://www.massey.ac.nz/?p697c3241c.

Callister, P. (2014). The employment of older NZ women. Paper prepared for the national advisory council on the employment of women.

CFFC. (2014). Kiwisaver evaluation: Final summary report. Wellington: National Research and Evaluation Unit, Commission for Financial Capability.

CFFC. (2016). 2016 review of retirement income policies. https://www.cffc.org.nz/ assets/RetirementIncomeReview2016/2016-Review-of-Retirement-Income-Policies-AllRecommendations-19.12.06.pdf. Commission for Financial Capability.

CFFC. (2018). Ageing workforce: Business survey results. https://www.cffc.org.nz/reviews-andreports/2016-review-of-retirement-income-policies/ageing-workforce/.

Clendon, J., \& Walker, L. (2013). The health of nurses aged over 50 in New Zealand. Contemporary Nurse, 45(1), 85-94.

Davey, J. (2007). Maximising the potential of older workers (Revised ed.). Wellington: New Zealand Institute for Research on Ageing.

Davey, J. (2008). What influences retirement decisions? Social Policy Journal of New Zealand, 33, $110-125$.

Davey, J. (2014a). Paid employment. In P. Koopman-Boyden, M. P. Cameron, J. Davey, M. Richardson (Eds.), Making active ageing a reality: Maximising participation and contribution (pp. 42-79). Hamilton: Institute of Demographic and Economic Analysis, University of Waikato.

Davey, J. (2014b). Age discrimination in the workplace. Policy Quarterly, 10(3), 42-48.

Davey, J. (2015). Environment scan: Women in their later career years. Report for the national advisory council on the employment of women. Wellington: Ministry for Women.

Davie, G., \& Lilley, R. (2018). Financial impact of injury in older workers: Use of a national retrospective e-cohort to compare income patterns over 3 years in a universal injury compensation scheme. British Medical Journal Open, 8(4), e018995. https://doi.org/10.1136/bmjopen-2017018995.

Department of Labour. (2011). Review of flexible working arrangements in New Zealand workplaces-Survey findings. Wellington, New Zealand: Department of Labour.

Diversity Works NZ. (2019). New Zealand workplace diversity survey 2019. https:// diversityworksnz.org.nz/news-resources/news/diversity-survey-reveals-top-priorities-for-newzealand-organisations/.

Dwyer, M. (2012). To what extent do individual superannuation schemes in New Zealand address needs for retirement income in a gender-neutral manner? A report to the commission for financial literacy and retirement income. Wellington: Commission for Financial Literacy and Retirement Income.

EEO Trust. (2012). Older workers: Challenging myths and managing realities. Auckland: Equal Opportunities Trust.

EMA \& CFFC. (2018). Act now, age later: Unlocking the potential of our ageing workforce. Auckland: Working Group on Ageing Workforce.

Human Rights Commission. (2010). What next? National conversation about work. Wellington: Human Rights Commission.

Human Rights Commission. (2016). Annual report: Pūrongo ā Tau, 2015/16. Wellington: New Zealand Human Rights Commission. 
Human Rights Commission. (2018). Annual report: Pūrongo ā Tau, 2017/18. Wellington: New Zealand Human Rights Commission.

Hurnard, R. (2005). The effect of New Zealand superannuation eligibility age on the labour force participation of older people (Vol. 5). New Zealand Treasury.

Hyman, P. (2015). Is active intervention still needed to improve the position of women in the New Zealand labour market. Policy Quarterly, 11(1), 2324-1101.

Jackson, N., Cochrane, B., \& McMillan, R. (2013). Workforce participation of older workers as an element of New Zealand's retirement income framework: A review of existing knowledge and data. New Zealand: National Institute of Demographic and Economic data.

Keeling, S., \& Davey, J. (2008). Working careers in New Zealand: Zones of care and contested boundaries. In A. Martin-Matthews \& J. Phillips (Eds.), Aging and caring at the interaction of work and home life: Blurring the boundaries (pp. 129-146). London: Psychology Press.

McGregor, J. (2007). Employment of older workers: Retirement commissioner's 2007 review of retirement income policy. Wellington, NZ: Retirement Commission.

Ministry of Social Development. (2011). The business of ageing: Realising the economic potential of older people in New Zealand: 2011-2051. Retrieved.

Ministry of Social Development. (2013). Description of New Zealand's current retirement income policies. Background paper prepared by the Ministry of social development for the retirement commissioner's 2013 review of retirement income policy. Wellington: Ministry of Social Development.

Noone, J., \& Alpass, F. (2014). Work and retirement. Summary report for the New Zealand longitudinal study of ageing. Palmerston North, NZ: HART, Massey University.

OCG Consulting. (2013). Coming of age: The impact of an ageing workforce on New Zealand Business. Wellington and Aucjkland: OCG Consulting.

OECD. (2020). Labour market statistics: Labour force statistics by sex and age: Indicators, OECD Employment and Labour Market Statistics (database). Retrieved January 5, 2020, from https:// doi.org/10.1787/data-00310-en.

Office for Seniors. (2019). Better later life-He Oranga Kaumātua 2019 to 2034. New Zealand: Wellington.

St John, S. (2016). New Zealand's KiwiSaver: Lesson for Ireland. Auckland: Retirement Policy and Research Centre, The University of Auckland.

State Services Commission. (2014). Women in public service. Wellington: State Service Commission.

Statistics New Zealand. (2011). Time use survey: 2009/2010 Publication no. http://www.stats.govt. nz/browse_for_stats/people_and_communities/time_use/TimeUseSurvey_HOTP2009-10.aspx.

Stephens, C., Alpass, F., \& Stevenson, B. (2014). Inclusion, contribution and connection: A study of the ageing in Aotearoa. Summary report. Palmerston North, NZ: HART, Massey University.

Towers, A., Stevenson, B., Breheny, M., \& Allen, J. (2016). Health, work, and retirement longitudinal study. In Encyclopedia of geropsychology (Vol. 10, pp. 978-981). Singapore: Springer.

Westpac. (2018). Women trail men in KiwiSaver contributions and savings. Retrieved from https://www.westpac.co.nz/rednews/women/women-trail-men-in-kiwisaver-contributionsand-savings/. 
Open Access This chapter is licensed under the terms of the Creative Commons Attribution 4.0 International License (http://creativecommons.org/licenses/by/4.0/), which permits use, sharing, adaptation, distribution and reproduction in any medium or format, as long as you give appropriate credit to the original author(s) and the source, provide a link to the Creative Commons license and indicate if changes were made.

The images or other third party material in this chapter are included in the chapter's Creative Commons license, unless indicated otherwise in a credit line to the material. If material is not included in the chapter's Creative Commons license and your intended use is not permitted by statutory regulation or exceeds the permitted use, you will need to obtain permission directly from the copyright holder.

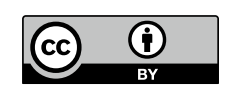




\title{
Chapter 28 \\ Poland
}

\author{
Renata Siemieńska
}

\begin{abstract}
It is estimated that Poland's population is ageing rapidly. It is expected that the proportion of working-age people will decline substantially in the coming decades, while the share of people aged $65+$ and of those in advanced old age (80+) will increase significantly. Increasingly, older Poles live in single-person households, a situation associated with loneliness, intensifying the risk of social exclusion, particularly for older people with disabilities and for women. Unlike the situation in many countries where governments have raised the retirement age, the retirement age has been decreased in 2017 in Poland, reversing previous plans to increase retirement age. There remains a gender difference in retirement age where men retire at 65 and women at age 60. This is likely to increase old-age poverty, particularly among women. Institutional long-term care for older people falls significantly short of needs. This chapter shows the complexity of the Polish context and demonstrates the serious problems facing older people, who are vulnerable under current policies.
\end{abstract}

Keywords Pensions $\cdot$ Retirement age $\cdot$ Political debates on retirement age Gender differences

\section{Introduction}

The transformation of Polish political and economic systems at the beginning of the 1990s gave rise to many changes in legislation, including those related to the provision of welfare benefits. These changes have been shaped by the economic situation in particular periods and changing contexts as successive governments have reflected different political approaches: liberal, post-communist, rightist, and finally, since 2015, a rightist, populist government. Other factors which have played an important role in the creation of new political and economic systems include a demographic shift

\footnotetext{
R. Siemieńska $(\varangle)$

Institute of Sociology, M. Grzegorzewska University, Warsaw, Poland

e-mail: siemiens@post.pl

R. Zajonc Institute for Social Studies, University of Warsaw, Warsaw, Poland
} 
to a rapidly ageing population characterized by low birth rates, longer life expectancy, and the emigration of young people. Estimates related to Poland's rapidly ageing population indicate that the proportion of working-age people could decline by $40 \%$ by 2060 . By 2035 , people aged $65+$ are estimated to reach 8.35 million $(23 \%$ of the Polish population). Growth in the advanced old age group (80+) is expected to increase from 3.5\% in 2018 to over $7.2 \%$ (2.5 million) in 2035 (CSO, Ludność w wieku 60 lat 2016: 11). That outflow of young Poles increased after the accession of Poland to the European Union in 2004, and today those emigres are having children in host countries. Additionally, the Polish employment rate is lower than that in many other EU countries, which will have an important effect on pensions in future. However, the total employment rate of the population above 15 years increased between 2010 and 2017 from 50 to $53.7 \%$. For men it rose from 57.8 to $62.0 \%$, while for women it climbed from 42.8 to $46.1 \%$. Total unemployment decreased over the same period from 9.6 to $4.9 \%$ for both men and women (CSO 2018). Low levels of economic activity and a quick withdrawal from employment by persons at retirement age is one of the basic challenges facing the Polish economy.

\section{Pension Policies}

During the transition period that began in 1989 after the fall of communism, Poland's welfare system underwent substantial decentralisation and restructuring. In 1991 and early 1992 a series of laws drastically reduced the coverage of unemployment benefits. Pension benefit levels were lowered by pegging them to the level of income in the previous ten years instead of the last three years before retirement. Reforms of the social benefits system from 2000 aimed to limit the number of beneficiaries and the amounts granted. In reality, enormous amounts have been spent while the value of individual benefits is usually relatively low, leading to increased social dissatisfaction and, recurrently, to the instability of the Polish political system (Siemienska and Domaradzka 2016).

In 2017, Poland abolished its past commitments to increase the retirement age, which had been implemented in 2013 by the former government created by a coalition of liberal Civic Platform and the Polish Peasant Party. The government installed in 2015 by the rightist, populist party 'Law and Justice', together with other parties in a coalition, re-established the previous age of retirement (65 for men and 60 for women). Instead of raising the retirement age to 67 years by 2020 for men and by 2040 for women, the government decreased the current retirement age by 14 months to 65 for men and to 60 for women from October 2017. In nine OECD countries, the retirement ages are lower for women than for men. Poland is not planning to eliminate the gender gap for people entering the labour market in 2016. The gender gap in retirement age in Poland is the highest among OECD countries. In 2016, among the age group 55-64, 38\% of women and 56\% of men were employed, compared with the OECD average of $51 \%$ and $68 \%$, respectively. Retiring at the earlier statutory pensionable age lowers monthly benefits. Polish pensions are determined by lifetime contributions and remaining life expectancy at the time of retirement. Retiring earlier lengthens the expected number of years people will be entitled to receive a pension, 
if average life expectancy remains stable. This automatically reduces pensions by approximately $6 \%$ per year.

No early retirement option exists for private-sector workers in the mandatory scheme. Retirees are free to move abroad and enjoy the same rights, benefits and health care services as the national citizens of the EU member states where they are resident. Current legislation guarantees retaining the public retirement pension in Poland (first pillar), the employment-based pension (second pillar), as well as private savings (third pillar) as an additional income (Regulation (EC) no. 987/2009 of the European Parliament and of the Council of 16 September 2009 laying down the procedure for implementing regulation (EC) no. 883/2004 on the coordination of social security systems) (OECD Poland 2018).

In 2017 , women formed $60.5 \%$ of the 5,358,682 Polish individuals aged 60 and above receiving a pension from the main source, the state Social Insurance Institution (Zakład Ubezpieczeń Społecznych). Among 887,408 persons receiving pensions from KRUS (the institution providing pensions for farmers), women constituted $69.2 \%$ of beneficiaries. A smaller number of people obtain pensions from the Ministry of National Defense, the Ministry of Internal Affairs and Administration, and the Ministry of Justice (Informacja 2018, Table 4.2).

Lower pensions will result in a greater proportion of beneficiaries, disproportionately women, relying on minimum pensions, which will in turn weaken the financial balance of the public pension scheme. Minimum pensions are not fully covered by past contributions and require additional financing sources (mainly from the state budget). Working after the statutory retirement age with or without a pension is not restricted in Poland. Each year of working longer and deferring a pension results in a benefit increase of around 6\%. The average income of 66-75 year olds and those over 75 is only $9 \%$ and $8 \%$ lower respectively than for the Polish population as a whole, while the corresponding values for the OECD are $7 \%$ and $20 \%$. Similar incomes of the 76+ and the 66-75 age group are unique to Poland. A full-career average earner can expect the net pension to be $34 \%$ of previous earnings for men and $39 \%$ for women, compared to corresponding OECD averages of $62 \%$ and $63 \%$. Between 2000 and 2016, the employment rate of people aged 55-64 years rose in Poland by $18 \%$. However, at $46 \%$, the employment rate remains substantially below the OECD average of 59\%. The recent decrease in the retirement age will make it even more challenging to increase the employment of older workers (OECD 2017).

Almost all workers newly eligible due to the drop in pension age seem to have applied for pension benefits so far. If retiring at the earliest possible date is to be the trend, it could entail heightened poverty risks, increasing the share of pensioners who have no more than a minimum pension. In this situation, fiscal costs due to a higher share of minimum pensioners could increase by up to $0.9 \%$ of GDP annually on average until 2030 (OECD Poland 2018: 36).

A lack of workers on the Polish labour market has created a new situation. According to the OECD Economic Surveys Poland document:

'Efforts to strengthen job-search assistance and training programmes for older workers will also be needed. Other measures to facilitate longer working lives include: (i) aligning the rules of special pension schemes with the general system, which are 
substantially more generous for farmers and miners in particular, but also for some other professions; (ii) harmonising employment protection for all age groups to avoid disincentives to hiring older workers, who are currently better protected; and (iii) providing government support to spreading good practices in terms of managing senior workers, in particular for SMEs' (OECD Poland 2018: 38).

According to the State Labour Inspection, at least one in six Polish persons employed on the basis of a civil law contract should be a full-time employee (this refers to people who come to work every day in the agreed place and within the specific hours), rather than a contract worker. The category of non-standard employment is 36\% higher than in 2011. Employers who offer these types of jobs reduce their costs by avoiding social insurance premiums for employees. The situation is similar for many self-employed Poles, who are often forced by their former employers to choose this mode of employment and who in reality continue to work for them. Currently, 1.3 million people run sole proprietorship companies, and have to pay their own social insurance premiums (Gazeta Wyborcza, March 21st 2013). Women constitute more than $30 \%$ of workers in this sector. These workers do not contribute to occupational pension schemes and they will not be eligible for such pensions in the future.

The recent reform concerning lowering the retirement age is the opposite to trends in most other countries and is highly criticised by economists. For example, according to W. Wojciechowski (the chief economist of Plus Bank), a retired woman who earned a minimum salary throughout her entire employment period would receive only about PLN 600 (139 euro) as the retirement benefit when leaving the labour market at age 60 if benefit levels depended solely on prior earnings. However, as the state warrants a minimum retirement benefit (which today amounts to PLN 1000 [232 euro]), she will be paid an additional PLN 400 from the state budget. In these cases, women would not gain the same amount of additional income even by working four years longer. Only the state would benefit, having to pay her less. Only by working for an additional period of six to seven years would such a woman gain a slightly higher pension benefit (Kostrzewski 2017).

The government reduced the age of retirement to gain the support of the population in elections. But as a consequence, this reform leaves a significant part of the population with very low pensions. The age of retirement and ways of financing pensions is not only a subject of discussion among economists but also has a political character. These discussions take place in circles of specialists and also in the media.

The Trade Union 'Solidarity' connected recently with the ruling party 'Law and Justice', and the government considers the earlier age of retirement for women as a justified privilege (not as discrimination) even though they receive much lower pensions than men. To recap on the causes of their lower pension incomes, women work for a shorter time (as a consequence of the regulation); because women's wages are lower than men's, their pensions are also lower; and women's life expectancy is longer (by age 50-54 years, the ratio of women to men is 103:100 (Demographic Yearbook of Poland 2018) and that disproportion increases steadily in older age groups). The trade union is encouraging new regulation to link retirement only to the number of years of work, not to the age of people (https://www.dziennik.pl/tagi/solidarnosc; wiek-emerytalny). But in this case the government is reluctant to introduce that recommended reform. The view of Solidarity in this respect is in opposition to the 
opinion of the organisations of employers e.g. 'Confederation Lewiatan' (Lewiatan zmiany 2018). Employers observe that many people will prematurely leave the labour market and that this is especially dangerous because of the scarcity of labour.

\section{Attitudes Toward Later Age of Retirement}

Most Poles were reluctant to accept the higher statutory retirement age which occurred in 2013. Being aware of the expected low pension amounts in 2016, $77 \%$ of respondents in a national representative sample were against limiting the possibilities of making extra money during retirement, while $20 \%$ backed such a limitation. More men-47\%-would choose to work only until the age of 65 and receive a lower old age pension, while $42 \%$ would prefer to work longer and receive a higher pension. Women more often declared a willingness to work longer and receive a higher pension in the future-47\%, instead of working until age 60 and receiving a lower pension-37\% (Puls HR 11.10.2016).

\section{Age and Gender Differences on the Labour Market}

Between 2012 and 2017, Polish employment rates increased slightly. In 2017, the proportion of working people aged 60 and above (calculated as the share of those working in the population aged 15 or more) was $13.8 \%$. A significant decrease in activity is observed particularly in the groups aged 50-54 and 55-59. In 2017, 62.0\% of men aged 15 and above were employed compared to $21.6 \%$ aged 60 and above; for women, these figures were $46.3 \%$ and $8.2 \%$, respectively. During that time, the statutory retirement age was slightly over 60 for women and 65 for men. The unemployment rate was $6.6 \%$, the lowest rate in 26 years (Informacja 2018, Table 4.1data for 2017). Employed women usually have higher education, postsecondary and secondary vocational education. Among employed men vocational basic education, postsecondary and vocational secondary education dominate.

The share of women working less than $40 \mathrm{~h}$ per week on average is lower than that of men by $8.4 \%$ (Statistics Poland, 2018). The gender pay gap is $7.2 \%$ (European Commission, 2019). Family and household responsibilities are the second reason, after retirement, for economic inactivity among women, while participation in education is the second reason among men (Statistics Poland, 2018).

In 2017, employed people with disabilities in the economically active population constituted $27.2 \%$ compared to $48.7 \%$ in the European Union (Hołub 2017). The rate for people with disabilities in the age group 60 and above was only $5.8 \%$ and was higher for men $(8.3 \%)$ than for women $(3.4 \%)$, and higher for inhabitants of cities $(6.4 \%)$ compared to inhabitants of rural areas $(4.4 \%)$.

Voluntary work of seniors. It seems that a large number of organisations in Poland's third sector have not yet discovered the potential of older volunteers. The main concern which is associated with the involvement of older volunteers is that their health 
and physical condition is perceived to be a barrier to work and voluntary participation. In addition, there are concerns about the ability of older people, particularly in the field of modern technology, and their openness to new experiences and working methods, even in non-paid jobs.

Good practice: Some activities are underway to increase the employment of people with disabilities. The Polish Federation of Supported Employment (PFZW) has brought together organisations since 2001 to promote supported employment for individuals with disabilities on the open labour market in Poland. The Federation: (1) integrates the stakeholders participating in supported employment initiatives and highlights the capacities and contribution of persons with disabilities to the economy and society; (2) disseminates the knowledge and standards of supported employment among institutions, organisations and representatives of businesses; (3) promotes and implements the European standards for supported employment; and (4) enables persons with disabilities to take up paid and potentially permanent employment. The Federation's activities aim to promote respect for diversity, dignity, autonomy and independence of persons with disabilities. Since 2016 over 4,500 individuals with disabilities in different age groups have taken advantage of the support of the Federation. Over 1,500 persons with disabilities have taken up employment with the support of a job coach. Almost 1,000 employers have been supported thanks to career consultancy services (http://pfzw.pl/en/category/news1/).

\section{Health of the Ageing Population}

The average healthy lifespan indicator defines for a given person (of a given gender and age) an estimate of the average number of years without disability (in good health). According to the results of Eurostat (2013), a healthy lifespan in Poland was $81.1 \%$ of the life expectancy period among men and $77.3 \%$ among women. This means that for a man born in 2013, on average the first 59 years will be free from any limitations caused by disability (for instance, chronic diseases); for women, this period will be about 63 years. For men aged 65 years, a healthy lifespan is applicable to less than one half (about 46\%) of their remaining life, that is, 7.2 years, and for women, $39 \%$, that is, 7.8 years.

According to Eurostat, at the end of year 2017 in Poland, almost $25 \%$ of people aged 60 and above classified themselves as having health problems (persons who had a limited ability of performing usual tasks). In the same age group, the disability rates were $27.1 \%$ for men and $31.3 \%$ for women, with rates often higher for those living in rural areas (Infomacja 2018: 10). Inclusion of such individuals in paid work would represent an opportunity to reduce unemployment, poverty and the future burden of the social security system. This would also increase the demand for training. Some programmes target unemployed aged people over 50 and 60 years (trainings, financial support for employers hiring those people, and funding infrastructure in work places which will facilitate work for older employees and those with disabilities) (Informacja 2018). 
In Poland, institutional long-term care for older people falls significantly short of needs (OECD 2018: 16). A large part of the care sector is provided by informal carers. Palliative private care or care outside the formal labour market is not currently monitored. Carers are usually neither trained to be the caregiver to older people nor in terms of ergonomic working conditions.

Inhabitants of small towns have a significantly lower sense of quality of life than older people from big cities. Multimorbidity and polypharmacy are present to a limited extent. Research shows that discrimination against older individuals by medical personnel affected a fifth of seniors living in villages, and one third of those living in big cities. Geriatric patients do not yet have equal opportunities for access to medical services in Poland (Blachnio and Bulinski 2015). Inequalities in access to health care may affect the ability of older people to be an active part of the labour force (Szybalska et al. 2018).

\section{Recommendation and Conclusions}

Poland has been among countries implementing the National Program of Social Activity for the Elderly for 2012-2013 (Rządowy Program na rzecz Aktywności Społecznej Osób Starszych na lata 2012-2013) (National Program 2013) and creating the Advisory Council for Seniority Policy (Rada ds. Polityki Senioralnej).

The main recommendations formulated by the Ministry of Family, Work and Social Affairs in 'Information about the situation of older people in 2015' concerning social policy directed to older persons on how to improve their situation are repeated in the documents prepared in the following years (Information about the situation of older people in 2016). These are:

- Improvement of the material situation of older people, especially people with the lowest pensions, by the introduction of additional benefits and establishing a new minimum pension.

- Improvement of social policy to promote social inclusion, especially for poorer older people, through the provision of more and better services. The actions should be undertaken on national and local levels.

- Undertaking actions to activate people in the labour market and to facilitate the creation of small businesses because today older people represent unused human capital in the Polish economy.

- Promotion of new campaigns creating positive images of ageing people and intergenerational cooperation. Education of young people about the problems of ageing people should be conducted by local governments, businesses, schools, NGOS and local communities.

- Promotion of education of older people about healthy style of life, use of new technologies.

- Improvement of support for people with disabilities and their families by state institutions; increasing financial support and additional services. 
- Improvement of cooperation by state institutions and local governments with recently created boards of seniors in different communities and on the regional level. Boards of seniors can help to articulate the needs of older people in general and specific needs in local communities.

- Creation of a catalogue of good practices in the areas mentioned above to facilitate their dissemination.

- Monitoring cases of discrimination based on age by public, private and social institutions and undertaking actions against them.

These recommended actions show the complexity and extent of the serious challenges faced by older people which have, so far, been neglected and which should be addressed in the near future in Poland. The changing age of retirement, first being increased and then decreased back to an earlier lower age of entitlement, was the focus of a very lively public discussion between 2013 and 2017. The liberal government of the Civic Platform and Polish Peasant Party considered that prolongation of work is necessary in the long run for demographic and economic reasons. The populist party Law and Justice, being aware of negative attitudes of public opinion towards the increased pension age, promised to withdraw it and to return to an earlier retirement age. For the Party, and in collaboration with the trade union Solidarity, lowering the pension age was a way to get support in parliamentary elections in 2015 . Over the next few years, retirement age and its consequences for the individual and the Polish state budget in the short and in the long run will continue to be a hot topic in public discussion.

\section{References}

Błachnio, A., \& Buliński, L. (2015). Wellbeing and older adults in primary health care in Poland from. Retrieved October 20, 2018, from http://www.aaem.pl/Wellbeing-and-older-adultsin-primary-health-care-in-Poland,85711,0,2.htm.

CSO (Central Statistical Office). (2016). Ludność w wieku 60 lat i więcej

struktura według płci i wieku, trwanie życia, umieralnośc)'. Prognoza (Population in age 60 and more (structure according of gender, age, life expectance, mortality). Retrived October 19, 2018, from https://stat.gov.pl/download/gfx/portalinformacyjny/pl/defaultaktualnosci/5468/ 24/1/1/ludnosc_w_wieku_60._struktura_demograficzna_i_zdrowie.pdf.

CSO Concise Statistical Yearbook of Poland. (2018). Warsaw.

Demographic Yearbook of Poland. (2018). Warsaw. Retrieved February 14, 2020, from https://stat. gov.pl/en/topics/statistical-yearbooks/statistical-yearbooks/demographic-yearbook-of-poland2018,3,12.html?pdf=1.

European Commission. (2019). Equal pay? time to close the gap. Factsheet on the gender pay gap 2019. Retrieved February 16, 2020, from https://ec.europa.eu/info/policies/justice-andfundamental-rights/gender-equality/equal-pay/gender-pay-gap-situation-eu_en.

Eurostat. (2013). Healthy life years (from 2004 onwards), database. Retrieved February 14, 2020, from https://appsso.eurostat.ec.europa.eu/nui/submitViewTableAction.do.

Hołub, J. (2017). Opportunities and pitfalls of the labor market. Retrieved February 14, 2020, from http://www.niepelnosprawni.pl/ledge/x/634459.

https://www.dziennik.pl/tagi/solidarnosc; wiek-emerytalny. Retrieved February 14, 2020. 
Informacja o sytuacji osób starszych. (2016). Retrieved January 24, 2020, from http://senior.gov.pl (Information about the situation of aged persons 2016).

Informacja o sytuacji osób starszych. (2018). Retrieved January 24, 2020, from http://senior.gov.pl (Information about the situation of aged persons 2018).

Kostrzewski, L. (2017). Leszek Jak długo jesteśmy zdrowi na emeryturze? Dłużej, niż myślimy. A wolimy odejść na głodową emeryturę, niż pracować (How long we are healthy when we are retired?) Gazeta Wyborcza.biz. Retrieved September 27, 2017, from http://wyborcza.pl/0,128956. html?tag=leszek+kostrzewski.

Kostrzewski, L. (2020). ZUS zaptaci za sanatorium. Kto ma szanse na wyjazd? (ZUS will pay for sanatorium. Who has a Chance to go there?) Gazeta Wyborcza.biz. Retreived February 16, 2020, from http://wyborcza.pl/0,128956.html?tag=leszek+kostrzewski.

Lewiatan zmiany. Retrieved March, 9, 2018 from http://www.bizneslubuski.pl/aktualnosci/ 8785, lewiatan-zmiany-w-emeryturach-powinny-sluzyc-pracownikom-i-gospodarce.

Long-term Senior Policy in Poland for the years 2014-2020 in outline. (2013). Retrieved 14 February, 2020, from https://www.ohchr.org/Documents/Issues/OlderPersons/MIPAA/NHRI_Poland_ Annex1.pdf.

National Program of Social Activity for the Elderly for 2012-2013 (Rządowy Program na rzecz Aktywności Społecznej Osób Starszych na lata 2012-2013). Retrieved February 14, 2020, from https://www.gov.pl/web/rodzina/rzadowy-program-na-rzecz-aktywnosci-spolecznej-osobstarszych-na-lata-20142020.

OECD. (2017). Pensions at a glance. How does Poland compare? OECD. Retrieved December 5, 2017, from, https://www.fiapinternacional.org/en/pensions-at-a-glance-2017-ocde-december$2017 /$.

OECD Poland (2018). Economic survey overview. Retrieved 14 February, 2020, from http://www. oecd.org/economy/surveys/Poland-2018-OECD-economic-survey-overview.pdf.

Polish Federation of Supported Employment. Retrieved February 14, 2020, from http://pfzw.pl/en/ category/news $1 /$.

Puls HR. (2016). Retrieved March 9, 2017, from http://wyborcza.biz/biznes/ 7,147880,21477165,emerytury-kobiet-wazne-zmiany-w-wieku-emerytalnym-i-emeryturach. html.

Rada do spraw polityki senioralnej (Advisory Council for Seniority Policy). Retrieved April 7, 2019, from http://www.rynekseniora.pl/tag/rada_ds_polityki_senioralnej,2886.html.

Siemienska, R., \& Domaradzka, A. (2016). Between constrained opportunities and social expectations: Social policy in contemporary Poland. In: K. Schubert, P. de Villota, J. Kuhlmann (Eds.) Challenges of European welfare systems (pp. 563-586). Springer.

Statistics Poland. (2018). Women and Men on the Labour Market. Warsaw. Retrieved February 16, 2020, from https://stat.gov.pl/en/topics/labour-market/studies/women-and-men-on-thelabour-market-2018,3,4.html.

Szybalska, A., et al. (2018). The utilization of health resort treatment services by older people in Poland-Results of the PolSenior stud. Gerontologia, 2018,26, 7-13.

Uchwała Nr 237 Rady Ministrów z dnia 24 grudnia 2013 r. w sprawie ustanowienia Rządowego Programu na rzecz Aktywności Społecznej Osób Starszych na lata 2014-2020. Retrieved February 14, 2020, from http://prawo.sejm.gov.pl/isap.nsf/download.xsp/WMP20140000052/O/ M20140052.pdf.

Zaklad Ubezpieczeń Spolecznych. Retrieved February 14, 2020, from https://www.zus.pl. 
Open Access This chapter is licensed under the terms of the Creative Commons Attribution 4.0 International License (http://creativecommons.org/licenses/by/4.0/), which permits use, sharing, adaptation, distribution and reproduction in any medium or format, as long as you give appropriate credit to the original author(s) and the source, provide a link to the Creative Commons license and indicate if changes were made.

The images or other third party material in this chapter are included in the chapter's Creative Commons license, unless indicated otherwise in a credit line to the material. If material is not included in the chapter's Creative Commons license and your intended use is not permitted by statutory regulation or exceeds the permitted use, you will need to obtain permission directly from the copyright holder.

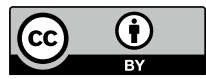




\title{
Chapter 29 \\ Portugal
}

\section{Paula Albuquerque, Sara Falcão Casaca, Heloísa Perista and Pedro Perista}

\begin{abstract}
This chapter addresses the topic of extended working life from a gendersensitive perspective, through a discussion of employment and working patterns, care arrangements, health issues, the pension system, employment policies and other relevant public policies in Portugal. Concerning employment patterns, Portugal is similar to the 'Nordic universal breadwinner model', as both women and men tend to work on a full-time and continuous basis throughout their lifecourse. From 2002 onwards, the legislated pensionable age has been rising and early retirement was increasingly penalised until the mid-2010s. Active labour market policies, such as the transition to more flexible forms of work, the possibility to accumulate pensions and wages, incentives to the hiring of older workers, or promotion of lifelong learning are examples of current policies, although they seem to have been insufficient or largely ineffective so far. In Portugal, as elsewhere in Europe, women live longer than men but have higher rates of morbidity and functional limitations in old age. This implies that it is more difficult for women, on average, to keep working until a later age. Equity in promoting good health is explicitly assumed as an objective of national health programmes.
\end{abstract}

Keywords Gender $\cdot$ Work $\cdot$ Care $\cdot$ Extended working life policies $\cdot$ Portugal

\section{Introduction}

This chapter addresses the topic of extended working life from a gender perspective, through a discussion of employment and working patterns, care arrangements, health

\footnotetext{
P. Albuquerque $(\varangle)$

SOCIUS/CSG, ISEG-Lisbon School of Economics and Management, University of Lisbon, Lisbon, Portugal

e-mail: pcma@iseg.ulisboa.pt

S. Falcão Casaca

SOCIUS/CSG, ISEG-Lisbon School of Economics and Management, University of Lisbon, Lisbon, Portugal

H. Perista $\cdot$ P. Perista

CESIS-Centre for Studies for Social Intervention, Lisbon, Portugal

(C) The Author(s) 2020

Á. Ní Léime et al. (eds.), Extended Working Life Policies, https://doi.org/10.1007/978-3-030-40985-2_29
} 
issues, the pension system, employment policies and other relevant public policies enacted in Portugal, where a comprehensive extended working life strategy has not been fully developed yet. However, for the first time a National Strategy for Equality and Non-Discrimination (2018-2030) is in place, with a specific policy focus on intersectionality and on the strategic needs of older women.

\section{Gender and Employment}

In 2017, women (aged between 15 and 64 years) in Portugal had a relatively high employment rate $(64.8 \%)$, slightly above the European average $(62.4 \%)$, with the country as whole having a gender employment gap of 6.3 percentage points (the employment rate for men was 71.1\%) (Eurostat 2018).Portugal is close to the 'Nordic universal breadwinner model', as both women and men tend to work on a full-time and continuous basis throughout their lifecourse (Casaca and Damião 2011; Wall 2007). In fact, 88.3\% of all Portuguese women in employment (aged between 15 and 64 years) work on a full-time basis in the labour market. For women working parttime, the main reason given is the difficulty in finding a full-time job, suggesting that part-time work is mostly involuntary. Moreover, the country has the second highest employment rate (81.2\%) for women (aged between 20 and 49 years years) with small children (less than six years) in the EU, immediately after Sweden (81.6\%) and well above the EU28 average (63.4\%). Furthermore, contrary to the dominant pattern of career interruption after childbirth among women in the EU, the employment rate in Portugal is slightly higher for women with small children $(81.2 \%)$ than for those women without children (78\%) (Eurostat 2018).

In addition to low wages and the need to meet the economic needs of the household, other factors may account for the trend towards women increasingly taking part in the labour market, such as the development of the public administration sector after the mid-1970s, the higher level of women's formal education and the effects of a family socialisation process based on a dual breadwinner model. Other historical reasons also explain such a tradition of a high women's participation in the economic activity of the country, particularly the recruitment of very large contingents of men in the colonial war and emigration flows in the 1960s, leaving space for women's employment, along with the need to contribute to family incomes in a context of extensive deprivation and high levels of poverty (Ferreira 1993; Casaca and Bould 2012; Addabbo et al. 2015; Casaca and Perista 2017).

Despite the aforementioned continuity and intensity in patterns of women's participation in the labour market, women nevertheless tend to be concentrated in the lowest paid and most precarious jobs in the economy (Casaca and Bould 2012). Moreover, the gender pay gap remains high, with women still earning $15.8 \%$ less in basic wages and $19.1 \%$ less in total earnings less than men in 2016 (GEP/MTSSS 2016). Such patterns of enduring low wages for the entire career of women in part explains the gender gap in pensions-31.2\% in 2016 (European Commission 2018). 
People aged 55 and above in 2017 represent $21.6 \%$ of all employees in the country, with older women less represented than men ( $45 \%$ and $55 \%$, respectively) (GEP/MTSSS 2017). From a longitudinal perspective, data provided by Eurostat (Labour Force Surveys 2000-2017) for employed people aged 50 years and above, show that the employment rate for Portuguese women over the last 17 years has increased 8.2 percentage points, but only 0.8 percentage points for men. Between 2000 and 2017, employment rates among people aged between 55 and 64 years old increased from 42 to $50.2 \%$ for women and from 62.2 to $63 \%$ for men (Eurostat 2018). Such an increase in the employment rate among older women poses key policy and social challenges. In later life, women provide essential care for ageing parents as well as grandchildren. Despite progressive legislation on gender equality and (paid) work-family reconciliation, the obstacles to defamilialisation are high, in particular due to the lack of childcare and eldercare facilities (Casaca and Bould 2012), coexisting with a strong asymmetry in terms of the burden of unpaid and caring work (activities that are still largely undertaken by women) (Perista et al. 2016). Persistent inequalities in terms of access to employment, quality jobs, pay conditions, reconciliation between paid work and family responsibilities are just some of the structural vectors of gender inequality, thereby tending to negatively affect women and their participation in the labour market (Albuquerque and Passos 2010; Ferreira and Monteiro 2015; Ribeiro et al. 2015; Perista et al. 2016).

The system of 'parenthood protection', implemented in 2009, strengthens fathers' rights and provides the incentive for parents to share initial parental leave. Such measures were designed to promote equality between women and men in combining paid work and family life. Parents are entitled to an initial parental leave of 120 fully paid) or 150 calendar days (paid at $80 \%$ ). It is mandatory for the mother to take six weeks after the birth and for the father to take 15 days; the remaining period may be divided between parents by mutual agreement. An extra 30 days ('sharing bonus') is available if both parents share the leave. The percentage of fathers sharing the initial leave for one month has increased from $8.6 \%$, in 2009 , to $35.8 \%$ in 2018 (CITE 2019).

According to data provided by the Eurobarometer, only $14 \%$ of Portuguese citizens reported having personally experienced or witnessed age discrimination in the workplace. However, $84 \%$ reported that older people (55 and over) are more likely to be excluded from training in the workplace (European Commission 2012). Other studies have also demonstrated that training and upskilling opportunities are more limited for older workers (Ferreira 2015). As reported by Casaca and Perista (2017), the Eurobarometer data also show that only half of Portuguese respondents $(52 \%)$ report that workplaces are age-friendly, meaning that they are adaptable to the needs of older people (European Commission 2012). In an intensive study on corporate practices regarding older workers, focusing on three national companies, Barroca and colleagues (2014) note that the idea of integrating an older workforce is acknowledged in these companies; however this recognition has not been translated into a coherent strategy or intervention. A few good practices include programmes of mentoring or other similar programmes aim to transfer the accumulated organisational culture and experience of older workers to younger colleagues. Only one 
company in the study reported programmes of mobility for older workers, essentially associated with their lifecourse and the need to perform different functions due to health reasons. Based on data collected by the Eurofound, Ferreira (2015) refers to two private companies with good practices involving training and skills development of older workers. A local municipality and a non-profit association also reported good practices in terms of the support provided to older workers in their transition to retirement.

Despite the relevance of the topic of extended work from a gender perspective, and apart from a few exceptions, the literature and the available information sources have not followed a gender-sensitive approach.

\section{Pension System and Extended Working Life Pension Policies}

The Portuguese welfare system, as in other Southern European countries, is a relatively recent development. It was established by the Democratic Constitution of 1976, already in the broader context of the reversal of some social rights that was taking place in many Western countries, pressured by the rising 'neoliberal turn'. According to the Constitution of 1976 (Article 63), 'all citizens are entitled to Social Security' and 'the Social Security system protects the citizens in the eventuality of sickness, old-age, disability, widowhood, orphanhood, as well as in unemployment and in every other situation where subsistence means or work abilities have diminished'.

The social security system therefore has universalistic principles in terms of coverage. However national pension arrangements are predominantly composed of the first pillar and organised on the basis of contributions and following a pay-as-you-go model (Albuquerque et al. 2010; Fernandes 2014), bringing it closer to the Bismarckian model, i.e. with a primary focus on those in stable employment. Pensions are divided into three main schemes - the general, the special regime for public servants and the non-contributory scheme. While the first two are mostly self-financed by the contributions of workers (employees, self-employed and public servants) and employers (either private companies or Public/State companies and organisations), the non-contributory scheme ('social pensions') is financed by general taxes (through State budget transfers) within the principle of redistribution.

Early retirement was favoured over extended working life policies until the beginning of the 2000s. Extended working life policies entered the national agenda from 2002 onwards, influenced by European Strategies and frameworks (Employment Strategy; Lisbon Strategy). Three major trends were identified in the light of pension reforms in this century: (1) the extension of the legislated pensionable age (including making it more difficult to retire through disability routes); (2) financial incentives to promote later retirement, through the introduction of full or partial actuarial adjustments, so that working longer is compensated by benefit supplements and retiring earlier is discouraged by benefit reductions; and (3) the extension of contribution periods necessary to qualify for a full pension and the use of lifetime earnings for the 
calculation of benefits, instead of the average salary of the last (usually best) years (thus typically lowering values of pensions).

As a consequence, early retirement has been increasingly penalised since the mid2010s. During this period, a sustainability factor was included in the formula applied to the calculation of early retirement pensions, which takes into account average life expectancy. As a consequence, in 2019 those applying for early retirement can expect to have their pensions permanently reduced by $14.8 \%$. The legislated pensionable age has also been steadily increasing, standing at 66 years and 4 months in 2018 and at 66 years and 5 months in 2019. In the last few years, a slight easing of the rules for acceding early retirement was decided and implemented in phases, although the actual coverage of these changes is still unclear. In any case, it is possible to draw a pension and earn money.

Portugal is among the fastest ageing countries in the world, with low fertility rates and, in the recent past, soaring emigration rates of youth who left the country in response to the deep economic crisis precipitated by the global meltdown of 2008 and the austerity policies that followed, particularly after 2011 (Rodrigues et al. 2016; Rodrigues 2018). Population ageing has gained increasing academic, political and social attention. The European Strategies for Employment, later embraced by Europe 2020 and the advancement of national policy reforms applying principles of working life extension have set the background for several national studies.

These studies have covered the frequently overlapping issues of pension schemes, welfare arrangements and the challenges of ageing to the sustainability of Social Security (Mendes 2011; Albuquerque 2016); activation and employability of older workers (Capucha 2014; José and Teixeira 2014; José et al. 2017); the problem of ageism and organisational practices (Barroca et al. 2014); gender inequalities (Casaca and Bould 2012; Perista and Perista 2012; Ferreira and Monteiro 2015; Wall and Aboim 2015; Perista et al. 2016); health and/or quality of life (or wellbeing) (Fernandes et al. 2012; Alcântara da Silva 2014); and the reconciliation of working life and family care work, also among caregivers (Perista et al. 2016).

\section{Extended Working Life Employment Policies}

Equality and non-discrimination on the grounds of gender and age (among other grounds) are enshrined in the Portuguese Constitutional Law as well as in the Labour Code. Older citizens who seek advice about their rights especially regarding health, social security, housing, equipment and services, may access the Senior Citizen's Line, a toll-free telephone number, run by the Ombudsperson office.

Active labour market policies, such as transitions into more flexible forms of work, the possibility to accumulate pensions and wages for those who work beyond the statutory age, incentives to the hiring of older workers and the promotion of lifelong learning are examples of policies pursued since 1999, although so far they seem to have been insufficient or largely ineffective in Portugal. As regards access to training over the lifecourse, the percentage of the Portuguese population aged 50-74 years 
that is involved in education and training activities is very low, barely above one \%; furthermore women are less likely to have undergone training over their working lives that is paid for or provided by their employer ( $24 \%$ of women and $32 \%$ of men) (Perista and Perista 2012).

Contrary to the typical decline in job insecurity among older employees on average in the EU28, especially after age group 45-54 years, job insecurity is reported to be higher for older age groups in in Portugal (as well as in some other countries) (Eurofound 2017). Workers in physically-demanding jobs are entitled to specific provisions regarding early retirement. However, the dominant policy approach, following the approval of the new Basic Social Security Law in 2007, is to encourage the postponement of retirement by increasing the financial penalty for early retirement and granting bonuses for those who delay their retirement. There is no mandatory retirement age in the private sector in Portugal. A debate recently emerged about the removal of the upper age limit to work in public administration (set at 70 years old).

National research has confirmed that, in a lifecourse perspective, gender is found to be a strong predictor of mid/later lifecourses, both in family and work trajectories (Wall and Aboim 2015). Nevertheless, in general, policies and incentives to extend working life have been gender blind and have ignored the respective gendered implications of being retained in the labour market (Casaca and Bould 2012). The urgent need for formal care provision has been largely disregarded by policy debates and reforms. The lack of attention to this issue is particularly critical in countries like Portugal where such provision remains rather low, particularly for older people and other adult people in need of care. Moreover, recent austerity reforms have imposed further cuts and restrictions in welfare provisions, in a context where people (women in particular) live longer but are often in need of care (Casaca and Perista 2017). However, for the first time, a National Strategy for Equality and Non-Discrimination (2018-2030) is in place, with a specific policy focus on intersectionality and on the strategic needs of older women. The Action Plan for Equality between Women and Men, which is one of the core policy documents included in Strategy, has incorporated measures geared towards older women's empowerment through literacy programmes and training in information and communication technologies, in addition to measures to protect them against domestic and gender-based violence (Governo de Portugal 2018).

\section{Health and Care}

Broader inequalities based on gender and socioeconomic status translate into health inequalities. Women face worse socioeconomic conditions and are more prone to suffer from higher morbidity risks than men, as well as to perceive worse subjective health, despite the higher frequency of healthy practices. Women also have more obesity problems than men. In contrast, men aged 50 years and above tend to have a better health status at the same ages as women, even though they more frequently accumulate risk factors (alcohol consumption, smoking) and thus suffer a higher 
probability of premature death (Fernandes et al. 2012). Women use health services more, which may be due to their poorer health, but also from self-awareness of health problems, which may protect them against early death (Perelman et al. 2012). However, more than gender, lifecourse events and institutional contexts (work, retirement, family, leisure) seem to influence how people experience health and illness and how they age (Fernandes et al. 2012).

Sociodemographic characteristics are related to part of the self-reported health variance: women, older, less educated and poorer individuals report experiencing worse health. These determinants lose some of their predictive characteristics when social activities are included in analyses. As expected, physical constraints or chronic illnesses are the most important set of factors affecting self-reported health, but demographic variables, the size of the social network and the involvement in social and individual activities are also significant (Alcântara da Silva 2014).

Regarding health in the workplace, occupational accidents tend to disproportionately affect men due to gender imbalances in economic sectors where injuries are more frequent (e.g. manufacturing industries, construction, wholesale and retail trade and repair of motor vehicles/cycles) (Lacomblez et al. 2014). Occupational illnesses, however, seem to unevenly affect women. In 2013, according to Eurostat, $5.5 \%$ of women and $3.5 \%$ of men reported a work-related health problem. There is also a gender effect in the probability of suffering from moderate and severe functional limitations in the $50+$ Portuguese population: $7.1 \%$ for women and $5.2 \%$ for men. The difference between men and women increases particularly after the age of 65 years (Serrano-Alarcón and Perelman 2017). Because women begin to experience functional limitations at an earlier age than men, it may be more difficult for them to work until a later retirement age. Additionally, pension reforms have increased restrictions on access to disability pensions, which makes them less of an alternative for women, despite their higher levels of disability.

Portugal had a National Programme for the Health of Older People (DGS 2006), for the period 2006-2010, which explicitly recognised gender as a determinant of health, although the idea was not clearly reflected in a proposal of action. During the same period, the European Institute of Women's Health produced a report about the discrimination of women and girls in the health sector, for which Portugal contributed. It stated that women's health in Portugal appeared to be strictly related to sexual and reproductive health issues.

In 2015, Portugal had the highest rate of informal home care in Europe, as well as the lowest rate of non-home-based care and one of the lowest coverage rates of formal care (ERS 2015). The limited availability of affordable formal long-term care particularly affects women. On the one hand, they tend to experience more functional limitations, and are therefore more dependent on care, and on the other and, they are the main caregivers.

According to the latest edition of the National Health Survey, in 2014, around one million people aged 15 years or more (i.e. 12.5\%), provided informal care or assistance to relatives or other non-family members (INE 2016). Studies have pointed out that without informal caregivers, around $80 \%$ of elderly and dependent people could be institutionalised. The work informal caregivers perform is estimated to 
represent almost $€ 4$ billion per year (Teixeira et al. 2017), which is an amount similar to approximately two per cent of the Portuguese Gross Domestic Product.

In recent years there has been growing concern about the need to develop support measures for informal caregivers. In mid-2016, various parliamentary groups issued and adopted Parliamentary Resolutions recommending support measures in favour of informal caregivers and/or the creation of a new status for them. In January 2018, a working group created to study the establishment of a new status for informal caregivers delivered its report to the Parliament's Commission for Labour and Social Security. The report summarises much of the discussion on the subject and identifies two overall aspects to take into consideration, i.e. that measures should take into account the wish and availability of the person to become an informal caregiver, and that these measures should be irrespective of the age of the care recipient. Based on these overall aspects, it draws up a set of recommendations for supporting caregivers. These comprise: (1) a support plan including respite and training; (2) leave and social benefits and/or financial support compensating for possible income loss; and (3) the reconciliation of care with professional life. In March 2018, following discussion of the report, Parliament scheduled a joint discussion of five documents: a petition, two draft Parliamentary resolutions and two draft laws. Representatives of informal caregivers have been pressing the government to include mechanisms of protection of their activity in the State Budget for 2019, but the demand has so far not been addressed.

\section{Conclusion}

The key stakeholders in the country have not integrated a gender-sensitive approach in public policy regarding extended working life. In addition to the scarce academic literature on the topic, in general the debate has not gathered the attention of media and it has been largely absent from the agenda of social partners. The policy debate has been driven by concerns about cutting costs, namely with regard to pensions, healthcare and social protection systems as well as increasing the labour supply and promoting economic growth.

Furthermore, a comprehensive extended working life strategy has never been fully developed. Policies have been designed in a fragmented and ad hoc way and the concern over retaining older workers in the labour market tends to be genderblind, ignoring the fact that gender roles in paid work and unpaid care work are not equal and that women tend to exhibit functional limitations earlier in life, all combining to create more difficult old-age support conditions for women.

Despite the relevance of the topic from a gender perspective, and apart from a few exceptions, the literature and the available information sources have not followed a gender-sensitive approach. 


\section{References}

Addabbo, T., Bastos, A., Casaca, Sara, F., Duvvury, N., \& Ní Léime, Á. (2015). Gender and labour in times of austerity: Ireland, Italy and Portugal in a comparative perspective. International Labour Review, 154(4), 449-473.

Albuquerque, P. (2016). O sistema em reforma. In A. Fernandes, P. Albuquerque, \& A. Fonseca (Eds.), A (Re)forma das Reformas. Coimbra: Edições Almedina.

Albuquerque, P., Arcanjo, M., Nunes, F., \& Pereirinha, J. (2010). Retirement and the poverty of the elderly: The case of Portugal. Journal of Income Distribution, 19(3-4), 41-64.

Albuquerque, P., \& Passos, J. (2010). Grandparents and women's participation in the labor market. Retrieved April 17, 2019, from https://www.repository.utl.pt/bitstream/10400.5/2527/ 1/wp162010.pdf.

Alcântara da Silva, P. (2014). Determinantes individuais e sociais do estado de saúde subjetivo e de bem-estar da população sênior de Portugal. Cad. Saúde Pública, 30(11), 2387-2400.

Barroca, A., Meireles, G., \& Neto, C. (2014). Estudo sobre Boas Práticas-Para o aumento da força de trabalho disponível em Portugal através da manutenção e reinserção de seniores no mercado de trabalho. Matosinhos: Advancis Business Services.

Capucha, L. (2014). Envelhecimento e políticas sociais em tempos de crise. Sociologia, Problemas e Práticas. Retrived April 17, 2019, from https://journals.openedition.org/spp/1479.

Casaca, S. F., \& Damião, S. (2011). Gender (In)equality in the Labour Market and the Southern European Welfare States. In E. Addis, P. Villota, F. Degavre, \& J. Eriksen (Eds.), Gender and Well-Being: The role of Institutions (pp. 183-199). Farnham: Ashgate.

Casaca, S. F., \& Bould, S. (2012). Género, idade e mercado de trabalho. In S. F. Casaca (Coord), Mudanças Laborais e Relações de Género. Novos Vetores de Desigualdade (pp. 87-132). Lisbon: Fundação Económicas/Almedina.

Casaca, S.F. \& Perista, H. (2017). Ageing and older workers in Portugal: A gender-sensitive approach. In Á. Ní Léime et al. (Ed.) Gender, Ageing and Extended Working Life. Cross- national perspectives (pp. 137-156). Bristol: The Policy Press.

CITE-Commission for Equality in Work and Employment. (2019). Relatório sobre o Progresso da Igualdade entre Mulheres e Homens no Trabalho, no Emprego e na Formação Profissional-2018. Retrived January 6, 2020, from http://cite.gov.pt/pt/destaques/complementosDestqs2/Relatorio\% 202018\%20Lei\%2010.pdf.

Commission, European. (2012). Special Eurobarometer 378-Active Ageing Report. Luxembourg: Publications Office of the European Union.

DGS. (2006). Programa Nacional para a Saúde das Pessoas Idosas. Lisboa: Direção Geral de Saúde.

Eurofound. (2017). Working conditions of workers of different ages: European Working Conditions Survey 2015. Luxembourg: Publications Office of the European Union.

ERS-Entidade Reguladora da Saúde. (2015). Acesso, Qualidade e Concorrência nos Cuidados Continuados e Paliativos. Retrived October 18, 2018, from https://www.ers.pt/uploads/writer_ file/document/1647/ERS_-_Estudo_Cuidados_Continuados_-_vers_o_final.pdf.

Eurostat (2018). Labour Force Surveys 2000-2017. Retrieved September 28, 2018, from https://ec. europa.eu/eurostat/data/database.

European Commission. (2018). Report on equality between women and men in the EU. Luxembourg: Publications Office of the European Union.

Fernandes, A. A., Burnay, R., Gomes, I., Gil, A. P., Marques, A. M., \& Botelho, M. A. (2012). Envelhecimento e Saúde: uma análise de Género. Lisboa: Universidade Nova de Lisboa.

Fernandes, T. (2014). Direito à Segurança Social-Cem anos depois da primeira lei que consagrou proteção social em Portugal-o Sistema atual. In Mendes \& Costa Cabral (orgs.), Por onde vai o Estado Social em Portugal? (pp. 329-368). Porto: Vida Económica. 
Ferreira, P. (2015). A gestão do envelhecimento no trabalho: Políticas, Actores e Estratégias para um prolongamento efectivo da vida activa. Lisboa, Tese de doutoramento em Serviço Social, ISCTEIUL. Retrived October 18, 2018, from https://repositorio.iscte-ul.pt/bitstream/10071/11542/1/ Tese\%20doutoramento_PFerreira.pdf.

Ferreira, V. (1993). Padrões de segregação das mulheres no emprego: Uma análise do caso português. In B. S. Santos (Coord.), Portugal: Um Retrato Singular (pp. 233-257). Porto: Edições Afrontamento.

Ferreira, V. \& Monteiro, R. (2015). Austeridade, emprego e regime de bem-estar social em Portugal: em Processo de refamilização? Ex ąquo. Retrived April 17, 2019, from http://www.scielo.mec. pt/scielo.php?pid=S0874-55602015000200005\&script=sci_arttext\&tlng=es.

GEP/MTSSS (2017). A População com 55 e mais anos no mercado de trabalho, Análise e Notas Técnicas. Retrived July 15, 2019, from http://www.gep.mtsss.gov.pt/documents/10182/80545/ pmvep_2017.pdf/c2c9e4ee-7198-4608-9282-8ac56576d78d.

Governo de Portugal (2018). Estratégia Nacional para a Igualdade e a Não Discriminação 2018-2030-Portugal + Igual (ENIND), Resolução do Conselho de Ministros 61/2018. Retrived October 18, 2018, from https://www.cig.gov.pt/wp-content/uploads/2018/07/Resol_ Cons_-Ministros_61_2018.pdf.

INE-Instituto Nacional de Estatística. (2016). Inquérito Nacional de Saúde 2014, Lisboa, INE/INSA. Retrived October 18,2018, from https://www.ine.pt/ngt_server/attachfileu.jsp?look_parentBoui= 263714302\&att_display=n\&att_download=y.

José, J. M. S. \&Teixeira, A. R. (2014). Envelhecimento ativo: Contributo para uma discussão crítica. Análise Social, 210, XLIX (1), 28-54. Retrived October 18, 2018, from http://analisesocial.ics. ul.pt/documentos/AS_210_a02.pdf.

José, J.M.S., Timonen, V., Amado, C. A. F., Santos, S. P. (2017). A critique of the Active Ageing Index. Journal of Aging Studies, 40, 49-56 (2017). https://doi.org/10.1016/j.jaging.2017.01.001.

Lacomblez, M. (coord.), Ferreira, I., Castelhano, J., Nogueira, S. (2014). Género, trabalho e saúde em Portugal. Porto and Lisbon: Centro de Psicologia da Universidade do Porto/ European Trade Union Centre.

Mendes, F. R. (2011). Segurança Social: o futuro hipotecado. Lisbon: FFMS and Relógio d'Água.

Perelman, J., Fernandes, A., \& Mateus, C. (2012). Gender disparities in health and healthcare: Results from the Portuguese national health interview survey. Cadernos de Saúde Pública, 28(12), 2339-2348.

Perista, H., \& Perista, P. (2012). Género e envelhecimento, planear o futuro começa agora-Estudo de diagnóstico. Lisbon: CIG/PCM.

Perista, H., Cardoso, A., Brázia, A., Abrantes, M., \& Perista, P. (2016). Os Usos do Tempo de Homens e de Mulheres em Portugal. Lisbon: CESIS/CITE.

Rodrigues, T. (2018). Envelhecimento e Políticas de Saúde. Lisboa: Fundação Francisco Manuel dos Santos.

Rodrigues, C. F., Figueiras, R., \& Junqueira, V. (2016). Desigualdade do Rendimento e Pobreza em Portugal: As Consequências Sociais do Programa de Ajustamento. Lisboa: Fundação Francisco Manuel dos Santos.

Serrano-Alarcón, M., \& Perelman, J. (2017). Ageing under unequal circumstances: A crosssectional analysis of the gender and socioeconomic patterning of functional limitations among the Southern European elderly. International Journal for Equity in Health, 16(1), 175.

Teixeira, A. R., Alves, B., Augusto, B., Fonseca, C., Nogueira, J. A., Almeida, M. J., et al. (2017). Medidas de intervenção junto dos cuidadores informais - documento Enquadrador, Perspetiva Nacional e Internacional. Retrived October 18, 2018, from http://cdn.impresa.pt/643/ cc0/11814574/Doc_Cuidador_Informal_VF.docx.

Wall, K. (2007). Leave policy models and the articulation of work and family in Europe: a comparative perspective. In P. Moss \& K. Wall (Eds.), International review of leave policies and related research 2007, Employment Relations Research Series No 80 (pp. 25-43). London: Department for Business, Enterprise and Regulatory Reform. 
Wall, K., \& Aboim, S. (2015). Gender in ageing Portugal: following the lives of men and women. In K. Komp \& S. Johansson (Eds.), Population Ageing from a Lifecourse Perspective: Critical and International approaches (pp. 65-84). London: Policy Press.

Open Access This chapter is licensed under the terms of the Creative Commons Attribution 4.0 International License (http://creativecommons.org/licenses/by/4.0/), which permits use, sharing, adaptation, distribution and reproduction in any medium or format, as long as you give appropriate credit to the original author(s) and the source, provide a link to the Creative Commons license and indicate if changes were made.

The images or other third party material in this chapter are included in the chapter's Creative Commons license, unless indicated otherwise in a credit line to the material. If material is not included in the chapter's Creative Commons license and your intended use is not permitted by statutory regulation or exceeds the permitted use, you will need to obtain permission directly from the copyright holder. 


\title{
Chapter 30 \\ Romania
}

\section{Daniela Şoitu and Conţiu Tiberiu Şoitu}

\begin{abstract}
This chapter discusses social, economic, and demographic realities in Romania and the public policy challenges they present. In common with many other European countries, Romania is experiencing socio-demographic changes including an increase in the number and proportion of older people in the population, increasing life expectancy, decreasing birth and fertility rates and increasing labour migration. All these phenomena have an impact on the labour market which is already under stress due to macroeconomic factors. Education, health and administration are the largest sectors of public employment. The transition to retirement in the public sector is not accompanied by support programmes such as training, shorter or more flexible working hours or intergenerational transfer of skills, all of which could stimulate older adults who wish to remain in paid work. An extension of working life after retirement is possible and salaries can be combined with pensions. Romania faces an increasing deficit in the pension system.
\end{abstract}

Keywords Extending working life $\cdot$ Romania $\cdot$ Pension systems $\cdot$ Gender $\cdot$ Labour market

\section{Introduction}

The regulation of work, wages and retirement in Romania is organised by the Ministry of Work and Social Justice. Trade unions, professional associations and retirement associations are either partners in the dialogue or they influence the government policies. Academic research and studies focus on policies set by the European Union Strategy for 2020 (European Commission 2010) or The United Nations 2030 Agenda for Sustainable Development (United Nations 2015).

In common with many other European countries, Romania has a growing proportion of people aged 65 or over in the population (Gîrleanu-Şoitu 2006). Between 2007-2017, the proportion of the Romanian population aged 65 and above in the

D. Şoitu $(\varangle)$ · C. Tiberiu Şoitu

Department of Sociology and Social Work, Alexandru Ioan Cuza University of Iasi, Iasi, Romania e-mail: danielag@uaic.ro 
total population increased by 3.1\%: from $14.7 \%$ to $17.8 \%$ (Eurostat 2018a). The fertility rate is decreasing, and dependency ratios are increasing. The total fertility rate has fallen in Romania from 3.7 children/woman of child-bearing age in 1967 to just 1.2 in 2011 . From 2014 to 2017 there has been a consistent fertility rate of 1.6 (National Institute of Statistics 2012; 2017a).

Policies related to extended working life aim to address these transformations. The main direction of public policy has been addressing low employment rates. Incentives have been provided to employ older people, the legal retirement age has been raised and restrictions have been placed on early retirement.

\section{Gender and the Labour Market in Romania}

In 2018 the employment rate of persons aged 15-64 years in Romania was $74.9 \%$ for men and $57.3 \%$ for women. Among the total working age population, there are no large differences in employment rates between urban (66.6\%) and rural areas $(65.3 \%)$ for (NIS 2018b). Labour force participation rates for women have increased and are now closer to international rates (Eurostat 2018b). In recent years, employment rates have also increased for people aged 55-64 years: from 44.4\% in 2017 (34.9\% for women and $55.3 \%$ for men) to $47.9 \%$ in 2018 . A similar trend is observed among Romanians aged 65 years or above: an increase from $8.8 \%$ (2017) to $9.2 \%$ (2018). The unemployment rate for those aged 55 years and above (2017) is relatively low: $3.1 \%$ of older men and $1.8 \%$ of older women are considered unemployed. Unemployment rates for Romanian women of all ages in 2018 were lower than for men: $3.3 \%$ compared to $4.7 \%$ for men (NIS 2018b).

According to EUROSTAT (March 2018), the unadjusted gender pay gap (difference between average gross hourly earnings of male and female employees as percentages of male gross earnings) in 2016 were very low in Romania (5.2\%), three times smaller than the EU average and almost five times smaller than the pay gap in Estonia (25.3\%). Part of the explanation for the low gender pay gap in Romania is the introduction of equal pay legislation from the end of the twentieth century.

Mothers in Romania are entitled to maternity leave and, since 1990, to paid leave in order to care for a child up to two years old. Maternity leave in Romania is 126 days and is composed of pregnancy leave (prenatal leave) up to 63 days before birth, and baby care leave (post-natal leave) up to 63 days after the birth (only the first 42 days after the birth are compulsory).

Both parents are entitled to paid maternity or paternity leave, based on their social insurance contributions. They must fulfil the following conditions: be Romanian citizens or from an EU member state; have their domicile in Romania; have paid at least one month's contributions or have an assimilated contributory period within the last 12 months prior to the month of the parental leave. Beneficiaries of paid leave and maternity/paternity leave are mothers or fathers of the new-born child. Parental leave payment is calculated as $85 \%$ of the average of the beneficiary's monthly income for the past 6 months. Parental leave for a child under two years old (three years 
old in the case of a disabled child) and the related indemnification are regulated by legislation introduced in 2016 (Law no. 66 2016). The following persons are eligible for parental leave: natural parents of the child; adoptive parents; foster parents; the child's guardian.

More than one third of mothers return to work before the end of the maximum parental leave period. This is partly due to the payment of the insertion incentive (140 euro per month, in addition to the salary), but also to labour flexibility policies (homework, personalised hours, fixed-term contracts, 84 supplementary hours per month). A return to work by mothers before the end of parental leave period takes place especially in big cities, where there is a demand for work in the services sector and in work related to new technologies. For employees with disabilities, employers must provide flexible working conditions (Şoitu 2014). Among EU and OECD countries, Romania, Norway and Germany are to be found in the middle range of the Employment Flexibility Index (Lithuanian Free Market Institute, 2017, p. 6), with a figure of $63.9 \%$ : Denmark was registered with the highest level of employment flexibility, (96.9\%) and France the lowest (39.4\%).

\section{Employees and Retired People}

Approximately $28 \%$ of the total population participate in the labour force as active employees and 26\% are retired. Millions of Romanians work abroad, especially in European Countries (The United Nations Migration Report 2017, estimates that 3.4 million-over $17 \%$ from total population-work abroad). Among pensioners, only $76.9 \%$ are older than the legal retirement age, with a majority of women $(58.3 \%)$. The higher proportion of retired women can be explained by higher life expectancy(almost seven years more than men) and a lower retirement age (60 years (and 10 months, in September 2018. The legal of age of retirement for women has increased from 57 years and it will rise to 63 years by 2030). The retirement age for men is 65 years since 2015 (it increased from 62 years between 2001 and 2015). A significant proportion of Romanian pensioners have retired before the official retirement age with or without full contributions. They receive reduced levels of pensions until they reach the legal age of retirement. More men than women receive invalidity pensions: $56 \%$ compared to only $44 \%$ of women. The overwhelming majority of persons who receive survivor's pensions are women. Among all pensioners, $0.5 \%$ are at risk of poverty and receive income support-worth approximately $60 €$ per month (National Institute of Statistics 2018a).

The calculation of pensions is based on individual monthly contributions over the working life linked to the reference value of the pension point (1,100 Ron, approximately $€ 250$ in July-December 2018). The value of this point is ser to increase in the future: from $26.5 \%$ in 2018 , to $45 \%$ of the value of the average gross wage. The average value of pensions for women are 7-12\% less than those of men for all categories of pensions. The gender pension gap is due to several reasons: the lowest paid jobs are performed by women and few are in better paid positions in top 
management; women have a shorter contribution period to the pension system; and women have an earlier retirement age. Romania has the lowest level of precarious jobs $(0.2 \%)$ among other European states (Eurostat 2018c), but, as in other cultural contexts, precarious jobs have been performed mainly by women. This low level of precarious jobs is a consequence of the unavailability of a large sector of the labour force due to two decades of emigration.

Pensioners are not the poorest categories of the Romanian population; the poverty rate in Romania is higher for children and young adults, particularly single parent families with several children. The average value of pensions for those who had worked in the public sector and who fulfilled the required of 35 years of service and age represents $60.5 \%$ of the value of the gross national minimum wage $(1,180$ Lei, approximately $€ 257$ in September 2018). This is higher than the net paying of workers employed with the minimum wage. This can be explained by the increase in pensions between 2005 and 2011. A decrease in wages of $25 \%$ occurred during the economic crisis but the level of pensions continued to increase. There were also several waves of pension recalculations in order to address inequalities that influenced the amount of the pension received and which were related to the year that the previous retirement legislation had come into force. Some of these disparities were due to changes in the insurance system: until 1999 the employer paid a quota to a salary fund, and this fund did not include social security contributions by the employee. From April 2001 a social security contribution composed of the employee's contribution and the employer's contribution was introduced-a total of $27 \%$ from the salary. From 2018 it is the employee who is responsible for most of the pension contributions (approximatively 27\%) (Law No. 227 2015).

\section{Existing Research on Older Workers and Extended Working Life}

There has not been much academic research on work, retirement and/or extended working life in Romania. There are some reports which have found that the economic situation of pensioners in Romania is relatively good comparing with other age and occupational groups. (Şoitu 2015; National Institute of Statistics 2018b). Among individuals aged over 65 years, $19.1 \%$ are at risk of poverty compared to $18.9 \%$ among individuals aged between 50 and 64 years $(37.2 \%$ of the age group of 0-17 years). According to recent research (NIS 2017b: 17) pensioners are the occupational category with the lowest risk of poverty from Romania: $15.9 \%$ compared to $50.2 \%$ among unemployed individuals.

A World Bank report (2014: 61) indicates that in Romania 'the average proportion of employed older people at risk of poverty has decreased considerably in the last five years and is close to the European average'. Yet in the case of self-employed working people - self-employed and household workers - the trend has been either as stagnation in income levels or an increase in poverty. This highlights the fact 
that in Romania, the status of being employed does not represent a guarantee for a decent income over the life course nor an escape from poverty and social exclusion (Stoiciu 2015:10). The low quality of employment in Romania, especially for older people, may explain the high level of early retirement. Most older people are engaged in agriculture or are unpaid household workers, occupational categories where the economic status is even worse than that of pensioners. The recent increase in the employment rates of older people is not enough to produce an improvement in the socio-economic condition of older people, unless it is also accompanied by an increase in the quality of employment, by shifting the emphasis away from household work, or self-employment in agriculture towards paid jobs (Stoiciu 2015).

\section{Pensions and Retirement}

Current Romanian pension legislation establishes the same minimum (15 years) and maximum (35 years) period of contribution for social security for women and men (Law No.263 2010). There are enduring professional differences between the private and public sector, both with regard to the minimum number of years of contribution and the value of pensions.

Police and army employees may retire five to ten years earlier than employees in other sectors, and they have period of social security contribution which is lower, set at a maximum of 30 years and a minimum of 20 years. Magistrates can take early retirement after only 20 years of activity, equivalent to $85 \%$ of the final month's salary or the average of earnings from the last six months. Differences between the contributions and the real value of the pension are paid from the State budget. There is a public pension system for farmers with a retirement age of 63 for men and women with minimum contributions of 15 years and maximum of 30 years. This monthly contribution covers the risks of retirement, temporary invalidity due to a working accident, death grant as well as child allowance which is part of the public pensions system).

The first pillar is a public 'Pay as you go' pensions scheme, comprising compulsory social security contributions. The second pillar also consists of compulsory contributions $(3.7 \%)$ but it is administered by the private sector. The third pillar consists of optional pensions administered by the private sector. In addition, there are also non-contributory rights (for former political prisoners and deported people). In summary, Romania has a public retirement system. Pensions are based on contributions and there are some retirees' additional rights (for some professional categories: former members of Romanian Parliament, magistrates, policemen's) as well as pensioners who benefit from 'social security allowance' or 'social assistance'.

In accordance with the Pensions Act (Law No. 263 from 2010 updated in 2018), an invalidity pension is granted to: people under the standard retirement age, who have lost some or all their working ability and have made sufficient contributions; to people who have lost all or at least half of their working abilities due to work accidents and professional illnesses; people with specified illnesses; and, people in 
certain occupations (including the military) who are also entitled to an invalidity pension, even without having paid contributions. Invalidity pensioners also have the right, in addition to their retirement, to receive financial support for carer, typically a family member. A close relative caring for a parent can receive up to half of salary paid by the local authorities (Law No. 17 2000).

\section{Working Policies After Retirement}

During the economic crisis, employees from Romania were forced to retire when they reached retirement age and were forbidden to combine retirement with a wage. It is now possible to do so. Moreover, recent changes in the Pension Law 263 (2010) end certain inequalities in the public pension system, which had allowed different levels of pensions for people who had worked the same number of years, in the same profession and with similar contributions (Ministry of Labour and Social Justice 2018). In these cases, women could actually receive larger pensions than men, because women needed (according to earlier national laws) a smaller number of years for the complete contributory period. The new provisions added by the more recent law includes study periods for Master and $\mathrm{PhD}$ degrees as non-contributory periods assimilated complementing bachelor periods, military service, invalidity pension, medical leave, parental leave allowance, unemployment, deportation, imprisonment and political detention. The condition for the assimilation of these non-contributory periods is to have a minimum contributory period of 15 years.

In the 2018 legislation, all four categories of pensions are maintained: pensions for the standard retirement age, early retirement, pension for invalidity and a survivor's pension. However, there are some modifications. In the case of pensions for the standard retirement age, an individual must fulfil cumulatively, the conditions for minimum length of service and standard retirement age. People with over eight years above the complete contributory period can retire five years before reaching retirement age. In this case an individual can earn both the pension and a wage, and the assimilated non-contributory periods can be maximised. Another element of the new pension legislation is that women with a minimum contributory period of 15 years, who have given birth to three children raised until they were 16 years old, can benefit from a reduction of their retirement age of six years. Starting with the fourth child, an extra year is added for each child (Ministry of Labour and Social Justice 2018).

\section{Ageing and the Labour Market}

One issue that is discussed in academic and international policy research concerning Romania is the loss of actual and potential resources due to the relative scarcity of older workers in the labour market (Soitu and Johansen 2017; World Bank 2014). 
Although in absolute figures the number of employed older people rose by more than 300,000 in the last ten years, it is still low. Romania is 10 percentage points below the European average for older people in the labour market, similar to countries in Southern Europe. Employment rates tend to decrease for Romanians aged 55 and above. In 2009, $40 \%$ of the people of this age category had switched to early retirement, leading to a population of younger pensioners, 7.5 years younger that the legal retirement age. People with low or no qualifications often lose their jobs from the age 50-55 years and the general tendency is for employment to decrease for this segment of population. In 1997 Romanians older than 50 years had a 52\% employment rate, and in 2013 - it was 41\% (World Bank 2014).

After the economic crisis, employment rates improved for all age groups aged over 50 years: for the age group 55-60 years to $65.2 \%$ (76.5\% for men and $54.3 \%$ for women); for the age group 60-64 years to $33.3 \%$ (44.8\% for men and $23.4 \%$ for women), for the age group 65-69 years, $17.7 \%$ (20.8\% for men and $15.3 \%$ for women), and for the age group 70-74 years, 14.4 (15.3\% for men and $13.7 \%$ for women) (statistics for 2017 from INS 2018). A study by the National Council of the Elderly (2014) concluded that the overwhelming majority of employed pensioners who have continued their activity after retirement were working in the agricultural sector $(97.0 \%)$ with a professional status of own-account worker or unremunerated family worker $(98.5 \%)$. The main reason for working $(90.5 \%)$ is the need to ensure enough income for the household (CPNV 2014).

Romania has a high concentration of employment $(60 \%)$ in the primary sector (agriculture) and the secondary sector (industry, construction, mining), well above the European average (EU 27) of 30\% (INS 2018). Working in the primary and secondary sector usually involves manual work and physical effort, which is difficult for many workers after a certain age and especially when combined with precarious health.

In the public system there is no gender pay gap. In the private system, employers can decide wages, so there can be gender gaps in earnings. Although the rate of labour market participation of women aged 15-64 years at 55\% is considered acceptable, this figure is set to rise faster than men $(75 \%)$ because of the growth in the labour market (INS 2018).

\section{Debates and Perspectives}

The Romanian labour market has some unique characteristics. The main public employment is in education, health and administration. A combination of pension and salary is possible in the education sector where employees can continue for a further three or five years above the legal retirement age, with the approval of the board of directors/ the senate of universities. In the health sector, doctors and nurses who want to continue to work above the age of 70 years can be employed in private clinics. 
Extending working life is often desirable for people with a high level of education and who work in the higher occupational professions, such as academia and medicine. During the economic crisis (2010) it was not possible to earn both a salary and a pension; the solution at that time was an expectation to forego a retirement pension and to continue to receive a paid salary. In recent years this has been reversed. It is now possible to continue a salaried activity together with receiving the state pension. Self-employed people have greater individual freedom to choose their retirement age. Beyond such exceptions, the perspective of most active people is unfavourable to prolonging the period of activity in the labour market. Moreover, certain occupational categories in the public system — such as the military, magistrates, the police-claim their right to retirement a significant number of years earlier than other workers.

With the public sector, the passage to retirement is abrupt, without preretirement support like training, reducing working time, intergenerational learning programmes, or stimulating older people who want to remain in the labour market. Introducing pre-retirement support programmes could reduce the impact of retirement stress on the health of older people. There is a need for research into the relationship between health and occupational status in later life.

As policy now stands, Romania will have to cope with an increasing budgetary deficit in the pension system. An active and healthy, and useful life for older people, for and their families, and for the community can be better prepared (Şoitu and Johansen 2017). The main policy ideas and recommendations coming from Romanian media and academic debates related to extending working life focus on a number of issues. Some revolve around the workplace, including strategies and actions for improving the Romanian labour market and encouraging work past age the age of 63 years (the current retirement age for women) and 65 years (for men) while simultaneously being optional. In terms of the pension system itself, consideration needs to be given to the sustainability of future pension reforms, the urgent need of strategies to adapt the social insurance system in the face of demographic challenges, and to relieve the public pension system from paying special pensions. Furthermore, Romanian initiatives to improve health and wellbeing and to increase healthy life expectancy are needed, alongside more and better retirement training programmes.

There is currently no consensus between political parties on a common strategy, for the medium and long term, regarding the management of social policies. The change of government since the end of 2019 (liberals replaced social democrats) brings into question changes such as: slowing the increase of the value of the pension point; the impossibility of accumulating the pension with the salary; elimination of some special pensions; increasing contributions to the second pillar of pensions. The changes, if any, will not be immediate. The Ministry of Labour plans to invite civil society to dialogue for the realization of the National Employment Strategy post-2020. 


\section{References}

CNPV [The National Council of the Elderly]. (2014). Transition from work life to retirement. Bucuresti, Romania.

European Commission. (2010). Europe 2020 Strategy. A European Strategy for smart, sustainable and inclusive growth. COM (2010) 2020, 03.03.2010, Brussel.

Eurostat (2018). 2.3\% of EU employees have a precarious job. Retrieved February 28, 2019, from https://ec.europa.eu/eurostat/web/products-eurostat-news/-/DDN-20180209-1? inheritRedirect=true. (09.02.1028).

Eurostat. (2018). Statistics Explained, gender pay gap statistics. Retrieved February 28, 2019, from https://ec.europa.eu/eurostat/statistics-explained/index.php?title=Gender_pay_gap_statistics.

Eurostat. (2018). Statistics explained, Population structure and ageing, May 2018. Retrieved February 28, 2019, from https://ec.europa.eu/eurostat/statistics-explained/index.php/Population_ structure_and_ageing\#The_share_of_elderly_people_continues_to_increase.

Gîrleanu-Şoitu, D. (2006). Vîrsta a treia (The Third Age). Iaşi, Romania: European Institute Publishing House.

Law no.17/2000 (revised in 2010) concerning the social care of old people.

Law no. 263/2010 concerning the unitary public pension system (updated in 2018).

Law no. 66/2016 for the modification and completion of the Government Emergency Ordinance No.111/2010.

Law no. 227/2015 regarding Tax Code.

Ministry of Labour and Social Justice (2018). The Pension system law. The proposed modifications. Public debate. Retrieved November 20, 2018, from http://www.mmuncii.ro/j33/index.php/ro/ comunicare/comunicate-de-presa/5209-cp-dezbatere-publica-proiect-legea-pensiilor-09082018.

National Institute of Statistics (2017). Data-metadata: Objective 1. Structural Transformations and Macroeconomic Balances, O1_10: Total Fertility Rate, Updated October 25, 2018. Retrieved November 28, 2018, from http://www.insse.ro/cms/files/Web_IDD_BD_ro/ob1.htm.

National Institute of Statistics (2018a). Labour force participation and unemployment in the third quarter of 2018 in Romania. Press release: December 20, 2018.

National Institute of Statistics (2018b). Press release no. 99 April 18, 2018.

National Institute of Statistics (2017). Dimensions of social inclusion in Romania. The year of 2016.

National Institute of Statistics/NIS (2012). The evolution of birth and fertility rate in Romania (p. 19) București, 2012. Retrieved November 20, 2018http://www.insse.ro/cms/files/publicatii/ Evolutia\%20natalitatii\%20si\%20fertilitatii\%20in\%20Romania_n.pdf.

Şoitu, C. (2014). The incidence of disability in Romania. The paradox of small numbers. The Social Work Journal. XIII, 2, 123-130.

Şoitu, D. (2015). Social vulnerabilities and ageing, Scientific Annals of Alexandru Ioan Cuza University of Iaşi. (new series) Sociology and Social Work. VIII(2), 73-82.

Şoitu, D., Johansen, K. J. (2017). The space of innovation and practice on welfare, health and social care education and practice in Romania and Norway. Scientific Annals of Alexandru Ioan Cuza University of Iaşi. (new series) Sociology and Social Work, X(1),5-17.

Stoiciu, V. (2015). Social and Labour Market Inclusion. Bucuresti: The Friedrich Ebert Stiftung Foundation.

Lithuanian Free Market Institute (2017). Employment Flexibility Index 2018 for the European Union (EU) and the Organisation for Economic Co-operation and Development (OECD). Vilnius, December 7, 2017. Retrieved February 28, 2019, from https://en.llri.lt/news/economic-policy/ employment-flexibility-index-2018/lrinka.

United Nations General Assembly (2015). Resolution 70/1 Transforming our World: The 2030 Agenda for Sustainable Development. September 25, 2015.

United Nations (2017). International Migration Report. ST/ESA/SER.A/403. December 2017.

World Bank. (2014). Long, active and forceful life. Human Development Network for Central Europe and Central Asia: Promoting active aging in Romania. 
Open Access This chapter is licensed under the terms of the Creative Commons Attribution 4.0 International License (http://creativecommons.org/licenses/by/4.0/), which permits use, sharing, adaptation, distribution and reproduction in any medium or format, as long as you give appropriate credit to the original author(s) and the source, provide a link to the Creative Commons license and indicate if changes were made.

The images or other third party material in this chapter are included in the chapter's Creative Commons license, unless indicated otherwise in a credit line to the material. If material is not included in the chapter's Creative Commons license and your intended use is not permitted by statutory regulation or exceeds the permitted use, you will need to obtain permission directly from the copyright holder.

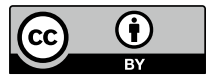




\title{
Chapter 31 \\ Serbia
}

\section{Mihajlo Jakovljevic, Mirjana Jovanovic, Olivera Milovanovic and Svetlana Radevic}

\begin{abstract}
Serbia is a post-socialist country with approximately 7.1 million people undergoing a strong and continuous process of demographic ageing. The average age of the population has increased to 43.2 years and the proportion older than 65 years has increased to $17.4 \%$. The period of rapid ageing of the population coincided with political and economic crisis in Serbia during the last decade of the 20th century. This period was marked by extensive emigration of the younger population, the delay of birth and a strong decline in fertility. The major economic challenges ahead include: high unemployment rates, the need for job creation in the public sector, structural reforms of state-owned companies, strategic public sector reforms and the need for new foreign direct investment. Serbia has been gradually implementing structural economic reforms needed to ensure the country's long-term prosperity. Policies designed to extend working life have been one of the dominant responses to population ageing.
\end{abstract}

Keywords Population $\cdot$ Ageing $\cdot$ Pension reform $\cdot$ Delayed retirement $\cdot$ Older workers $\cdot$ Women $\cdot$ Labour market $\cdot$ Serbia

M. Jakovljevic ( $\varangle)$

Department of Global Health Economics and Policy, University of Kragujevac, Kragujevac, Serbia e-mail: sidartagothama@gmail.com

M. Jovanovic

Department of Psychiatry, University of Kragujevac, Kragujevac, Serbia

O. Milovanovic

Faculty of Medical Sciences, Department of Pharmacy, University of Kragujevac, Kragujevac, Serbia

S. Radevic

Faculty of Medical Sciences, Department of Social Medicine, University of Kragujevac,

Kragujevac, Serbia

(C) The Author(s) 2020

Á. Ní Léime et al. (eds.), Extended Working Life Policies, https://doi.org/10.1007/978-3-030-40985-2_31 


\section{Introduction}

Aiming to create financially and socially sustainable pension systems, most European countries have undertaken reforms to increase employment at older ages and establish a balance between the number of years of contributing to a pension fund and disability insurance, and the number of years of receiving pension benefits (Jakovljevic et al. 2016a, b; Rancic and Jakovljevic 2016). Numerous measures have been undertaken to achieve these goals, such as increasing the retirement age, abolishing or reducing early retirement, and introducing stricter criteria for accessing a disability pension (Jakovljevic et al. 2017a; Rakić and Nikolić 2016; Jakovljevic 2015, 2017). A key measure recommended to member states for reforming pension systems to improve their financial sustainability and adequacy is to harmonise retirement age and increased life expectancy, which was implemented in specific degrees in different countries (European Commission 2018). Given that it is an economic imperative to maintain a healthy workforce and increase the number of older workers, this chapter provides a critical overview of the current pension system reforms and policy initiatives concerning extending working life in Serbia.

\section{Pension Policies}

Historically, the retirement age in Serbia was not linked to increased life expectancy; it remained unchanged from the 1960s to the early 21st century (Jakovljevic et al. 2016a, b). Pension reforms in Serbia date back to 2001, when legislated pensionable age for full pension eligibility was increased from 60 to 63 years for men and from 55 to 58 years for women. The following reform, proposed in 2005, imposed even higher age limits for retirement and it was adopted at the beginning of 2006, with a phased implementation from 2008 to 2011. During this period, legislated pensionable age was raised by six months every year. This increased legislated pensionable age to 60 years for women and to 65 years for men by 2008, when legislated pensionable age was 58.5 years for women and 63.5 years for men.

According to the current Law on Pension and Disability Insurance, implemented since January 2015, legislated pensionable age for retirement will increase for both men and women, to reach age 65 by 2023, with the clear aim of equalising retirement ages and years of contributions necessary for a pension. Article number 19 of this Law states that an individual has a right to receive an old age security pension when s/he reaches 65 years of age and has a minimum of 15 years of service, or after attaining 45 years of service (Government of Republic of Serbia 2014). Besides the pensionable age, the other crucial factor is the number of years of contributions. Even though legislated pensionable age is the same for men and women, the requirements for years of contribution have differed. For women, the number of years of contributions has increased from 35 to 38 years, while for men it is 40 years. Legislation from 2020 specifies the standard pensionable age of 63 years for women and 65 years for men to qualify for retirement. The raise in standard pensionable age will affect women 
disproportionately. Taking into consideration the current gap in age limits and the equalisation of eligibility in terms of retirement age and years of service, women will have more adjustments to make than men and they will have shorter periods of time to prepare for these changes (Government of Republic of Serbia 2014).

Increases to legislated pensionable age are not always accompanied by an increase in the effective retirement age. To extend working life, in addition to increasing the legal retirement age or length of contributions required for retirement it is also necessary to reduce early retirement, or put another way, to extend working lives. In Serbia, early retirement is widespread. At the beginning of the second decade of the 21 st century, about $70 \%$ of men and $50 \%$ of women retired before legislated pensionable age (Altiparmakov 2013). At this time, it was possible to retire at 55 years of age and with 35 years of service for men and at 50 years of age with 30 years of contributions for women. The reform that was launched in 2014 created much stricter qualifying conditions by increasing the minimum age for early retirement to 60 for both men and women, or 40 years of contributions, in gradual annual phases until the end of 2023. The tightened conditions for early retirement were accompanied by a $0.34 \%$ reduction in pension value for each month of retirement before the statutory age for legislated pension, which creates a permanently lower pension. Finally, apart from the obvious possibility of reducing the difference between the minimal legal retirement age and the introduction of major actuarial penalties and rewards for early or delayed retirement, there are also other measures to reduce early retirement. Firstly, it is necessary to improve the health care of older workers, improve the conditions that enable prolonged work, allow older workers to work part-time and to consider the introduction of partial retirement, i.e. the combination of pensions and work. Furthermore, it is important to reduce the number of privileged professions (such as police, civil servants, and military) which enable very early retirement.

Public pensions in Serbia are funded by the Pay-As-You-Go (PAYG) schemes, which means that the Republic Funds for Pension and Disability Insurance are obtained from the income of current workers. The contribution rate for mandatory pension insurance has been divided between employers and employees since 2013. Employers contribute $11 \%$, employees $13 \%$, and the remainder is financed from the state budget. The relatively low employer and employee contributions are the main weaknesses of this type of PAYG pension due to population ageing and a constant increase in the number of pensioning recipients in Serbia. There is no flexible opportunity in the current legislation on pensions that allows for simultaneously receiving pensions and earnings from paid work that could make longer working more attractive.

Several measures to lower the value of pensions in Serbia have been undertaken to preserve and stabilise the pension fund, which is in accordance with Statutory funded pension schemes. A defined benefit (DB) scheme of this reform was the replacement of the previous calculation system, based on the ten years with the highest income, with calculations based on earnings during the entire working life. This reform in 2003 was followed by a further step of pension freezing, which was implemented at the end of 2008. Pension freezing implied that there was no possibility of growth in pension value for the designated period. An additional step in this process was made 
in 2014 when, besides lowering pensions received before the age of 65, an additional measure consisting of a $20 \%$ decrease in pension value was applied for pensions above $200 €$ per month (calculated according to the available value for euro at the end of 2014) (Government of Republic of Serbia 2014).

The Serbian pension system is organised somewhat differently compared to most EU countries. Most EU countries have pension pillars organised at three levels, whereas in Serbia there are only two levels. The first level pillar is the public pension system, which provides mandatory pension and disability insurance. The other level is the third pillar of voluntary private pension insurance. This level of pension insurance system in Serbia was introduced in 2006. There is no second pillar-occupational pension schemes.

A special component of the Serbian pension system is disability retirement. Individuals have rights to disability retirement if they have a disability that interferes with employment without fulfilling the age criteria for pension eligibility. The precise conditions for the entitlement for disability pensions are defined in the Law on Pension and Disability Insurance, according to which the necessary condition for disability retirement is a complete loss of working ability. If a cause of working disability is an injury at work or an occupational disease, there are no special requirements concerning years of contributions. However, if a cause is an injury or a disease encountered outside employment, a person would need to have five years of contributions as an additional condition for disability pension eligibility.

The number of disability pensions in Serbia, according to the Statistical Annual Bulletin for 2018, showed that this kind of retirement has the lowest share, with only $16.6 \%$ in the total number of pension users with respect to family and retirement pensions (amounting to 20.1 and 63.3\% respectively) (Pension and Disability Insurance Fund Republic of Serbia 2019). The number of claimants is lower than in earlier statistical reports, which may be explained by the changes introduced by the Law on Disability Insurance in 2003. Earlier requirements for disability retirement did not impose a complete loss of working ability but allowed a partial working disability, which resulted in significantly more disability pensioners. For example, in 1997 disability pensions accounted for $30 \%$ of all pensions. The value of a disability pension has been calculated in the same way as a legislated pension. The exception to the above-mentioned rules is insured persons whose disability occurred before the age of 30 . If a working disability exists before the age of 20 , then a person requires one year of insurance service. Individuals younger than 25 need two years of insurance service and for those younger than 30 , three insurance service years are required.

Statistical reports on the causes of disability retirement in Serbia from 2008 to 2017 showed the trends in disease type, with the three most prevalent causes of working disability being tumours, diseases of the circulatory system and mental disorders. The data from 2017 showed that the distributions of the above-mentioned causes were 29.9, 27.0 and 9.8\% respectively. In the future, increases in tumour diseases at older ages are likely to produce even more individuals claiming disability pensions. According to the current law, disability pension eligibility is reviewed after three years. The exceptions from the rules demanding a regular review are those persons above the age of 58 years and individuals with medical conditions where 
there is no possibility for health improvement. Deadlines are applied for disability pension eligibility reviews and if they are not undertaken in time, the disability pension is withdrawn.

The available data indicate that the average length of contributions for a disability pension in 2018 was 26 years for men and 23 years for women, while for a legislated pension it was 36 and 31 years of service respectively. In 2017, the average age of disability pension recipients was 68 for men and 67 for women, while retirement pension recipients averaged 72 and 70 years respectively. An interesting observation from the Annual Statistical Report is that the average number of years of receiving a disability pension until death was 20 years; 19 years for men and 22 years for women (Pension and Disability Insurance Fund Republic of Serbia 2019).

Based on data from the Republic Fund for Pension and Disability Insurance for 2018 , the average pension value for all categories of pension was $250 €$ per month (calculated according to the available value for euro on the 13th of December 2018). The highest value was for retirees who had been previously employed, while the lowest rate was recorded for individuals from the agricultural sector (Pension and Disability Insurance Fund Republic of Serbia 2019). The structure of the pension systems does not allow people to be lifted out of poverty. There are no policies that address higher pensions in cases of retirement delay or auto-enrolment.

\section{Employment Policies}

The basic characteristic of the labour market in Serbia is a high rate of unemployment, particularly for women, and the younger and older segments of the population. The available data show that the employment rate in Serbia is lower than in many other European countries. In 2007 it was 50\% and it increased to 53.5\% in 2008 (Matković et al. 2010). The average employment rate over an extended period was approximately $41.8 \%$ from 2008 to 2017 (Statistical Office of the Republic of Serbia 2017). The lowest rate of approximately $34.3 \%$ was recorded in the first quarter of 2012, while the highest rate of about $48.2 \%$ was recorded in the third quarter in 2017 (Serbia Employment Rate 2019).

According to the Europe 2020 strategy, the employment rate for the age group $20-64$ should be $75 \%$ by 2020 . The data from 2015 concerning the employment rate for persons in the age group 20 to 64 in EU-28 indicate a high rate of employment of $77.1 \%$. However, the employment rate of men was $12.5 \%$ higher than the rate for women. In contrast to the activity rate for women for the EU $(65.3 \%)$, for Serbia, it is slightly lower, with $62.1 \%$ of women aged 20-64 employed. Although the overall employment rates are lower in Serbia than the EU average, the gender gap in employment rates in the EU-28 was lowest in Serbia (less than 20\%) during the given period (Eurostat 2016, 2018).

Unfortunately, Serbia's unemployment rate is higher compared to the European average. In 2018, the unemployment rate was $14.7 \%$, while the unemployment rate for the third quarter of 2019 decreased to $9.5 \%$ compared to the same period from the previous year, when it was $12.9 \%$. During the period 2008-2019, unemployment rates in 
Serbia averaged $16.61 \%$, reaching the highest point of $25.5 \%$ in the first quarter of 2012 and the lowest point of $11.8 \%$ in the second quarter of 2017 (Serbia Employment Rate 2019). Another characteristic of unemployment in Serbia, besides being high, is the duration of unemployment. Large numbers of the population have been unemployed for extended periods (one or more years), which undermines knowledge and working skill preservation. The main concern is that the skills of long-term unemployed individuals will be reduced and out of date as time passes.

Although the position of Serbian women in terms of equal access to the labour market has been significantly improved, gender differences in employment still exist. Women still have significantly lower activity rates, even though the disparity is lower today than it was in the past. Based on the Labour Force Survey from III Quarter 2019 , the employment rate for all workers was $49.6 \%$, while in the same period for 2018 it was $49.2 \% ; 57.3 \%$ for men and $41.7 \%$ for women. Up to now there is no data about the unemployment rate for 2019 according to gender. The unemployment rate from III Quarter 2019 was 9.5\%. Data from 2018 showed that distribution of this rate regarding gender was $10.5 \%$ for men and $12.2 \%$ for women. Women's labour market inactivity in Serbia reflects broader gender norms: the extent of their unpaid work in households, inadequate support to women in reconciling work and family responsibilities, employers' discriminatory treatment of young women, the existing wage gap, women's lower statutory retirement age, as well as the existence of a statutory minimum social insurance contributions base which discourages formal part-time work, an option more commonly used by women with family responsibilities in other countries (Government of the Republic of Serbia 2016). The differences between men's and women's participation are most visible in older age groups (from 55 to 64 years), among those with low education, and in rural settlements (Milovanovic et al. 2016).

In Serbia, over the last two decades, the unemployment rate among individuals older than 50 years has been very high and this is perceived as a major problem. The inactivity rate of older Serbians was $59.1 \%$ in the fourth quarter of 2014, which is equal to that at the beginning of the financial crisis (October 2008), and rates had only slightly improved with respect to the peak of the crisis (October 2011), when it was $63.5 \%$ (Employment and Social Reform Programme in the Process of Accession to the European Union 2016). The explanations for the high unemployment of older Serbians may be different from those relevant for other European countries due to privatisation and reconstruction that happened after the world financial crisis, when bankruptcies and liquidations occurred daily in most cities across Serbia (Serbia Foreign Policy and National Security Yearbook 2014). The gender employment gap is most pronounced among older workers. Among workers in the 55-64 age group, the gap is $18.7 \%$ because of the higher inactivity rate among women $(66.3 \% \mathrm{vs}$. $41.5 \%$ among men) (Žarković-Rakić and Vladisavljević 2016). The greater economic activity of men compared to women can be partly explained by gendered differences in education, unpaid care giving in families, and the position of women in this age group in terms of opportunities for professional training and opportunities on the labour market. Other possible reasons for gender differences in the economic activity of older workers could also be related to different positions in terms of entitlement for retirement and the early exit of women from the labour market. Regarding specific 
employment policies covering issues such as training for older workers, flexible employment, the creation of proper working conditions for older workers and work after retirement, Serbia has not yet created any well-designed policies which could effectively deal with these issues.

\section{Health Policies}

Another important aspect when considering pension reforms is the effect of extending working life on health and differentiating the gender effects (Jakovljevic and Laaser 2015; Jakovljevic et al. 2015, 2017b; Jakovljevic 2016; Ogura and Jakovljevic 2014). Currently, little research on extending working life has been carried out in Serbia that recognises gender differences in health issues. A citizen's own health status perception is a significant indicator of overall quality of life. According to the Serbian National Health Survey, 21.4\% of respondents in the age group 50-64 evaluated their health as poor (17.9\% as bad and $3.5 \%$ as very bad), while $37.9 \%$ of respondents assessed their health as good (31.2\% as good and $6.7 \%$ as very good). Women more often evaluated their health as poor ( $24.8 \%$ with $4.0 \%$ as very bad and $20.8 \%$ as bad), while men evaluated their health more positively (17.5\% with $3.0 \%$ as very bad and $14.5 \%$ as bad) (The Institute of Public Health of Serbia 2013).

Among Serbians aged 50-64, 73.2\% of the respondents reported having at least one of the 17 examined chronic diseases and conditions: $24.2 \%$ with only one and $49 \%$ with two or more chronic diseases (multimorbidity). The most common diseases were hypertension (48.5\%), deformities of the lower back and neck, or other chronic back problems $(26.1 \%)$, elevated blood lipids $(22.5 \%)$, coronary heart disease or angina pectoris (13.6\%) and arthritis (13.1\%). A significantly greater incidence of chronic diseases has been observed in women compared to men (80.4\% vs. $64.7 \%)$. Symptoms of depression were present in $10 \%$ of older Serbians and this rate was significantly higher among women $(12.6 \%)$ than among men $(6.5 \%)$ (The Institute of Public Health of Serbia 2013).

Just over one third of the respondents in the 50-64 age group had at least some difficulties in mobility (38.4\%), and difficulties in performing everyday activities $(31.6 \%)$, and almost one in ten older Serbians had difficulties in performing activities of daily personal care $(9.6 \%)$. Women were more likely than men to report difficulties in performing everyday domestic activities, while men more often than women reported needing other people's help in performing most daily activities (The Institute of Public Health of Serbia 2013). Given that the benefits of longer life expectancy can only be fully achieved if additional years are spent in good health, further studies of gender differences among older Serbians are needed. These could provide information for the development of an action plan to address gender differences in health status and promote healthy, active ageing for both men and women (Jakovljevic et al. 2018) and, by extension, improve their ability to extend working life. It is crucial to integrate a gender perspective of public health and to acknowledge 
gender differences and inequalities so that they can be considered when policies, programmes and strategies are implemented, since these should take into consideration the specific needs of women and men at older ages.

\section{Debate on Extended Working Life}

The debate on extending working life in Serbia has in general been held only among policy makers. The need to keep Serbian's ageing population economically active has prompted government policies aimed at extending working lives. The problems of financing the pension system were originally observed in the mid-80s, due to the deficit in the public pension system. In the period 1980-1990, workers opted for early retirement, as soon as they reached the minimum legal requirements. Increasing the retirement age in the government programme in Serbia was first implemented in 2001 by extending the minimum age limits of eligibility for retirement from 60 to 63 years for men, and from 53 to 58 years for women. The retirement conditions within the statutory pension scheme have been amended several times since 2003, the latest amendments being introduced in 2014 . The 2014 pension reform imposed a phased-in equalisation of the retirement age for women, raising it to 65 by 2032, and introduced penalties for early retirement. The 2014 fiscal-consolidation measures have imposed cuts on pensions above the national average.

Government and representatives of employees viewed the proposed amendments to the Law on Pension and Disability Insurance in different ways. According to the Government, reforms should ensure the stability and sustainability of the pension system and prevent early departure from the labour market. However, according to the representatives of employees, the adopted measures are less acceptable because of a negative impact on the quality of life of future retirees, especially those with hard physical jobs, or women who, in addition to paid work, have to work full-time at home, and those who have lost their jobs and have no chance of re-employment in the labour market. The representatives of employees also believe that any increase in the retirement age is directly harmful to young unemployed citizens of Serbia. In 2017 the Ministry of Labour, Employment, Veterans and Social Policy established a working group to consider amendments to the current Law on Pensions and Disability Insurance. There have been no announcements on planned changes. Public debate has been lacking.

Lately, public discussions have been more focused on the elimination of pension cuts, than on the extension of the age limit. The Association of Autonomous Trade Unions of Serbia has expressed dissatisfaction with the 'penalty measure' for workers under 65 years of age at the time of retirement. Amendments to the Law on Pension and Disability Insurance in 2018 abolished the law on reducing the level of pensions. MPs of the opposition parties and the Fiscal Council negatively assessed proposed amendments to the Law on Pension and Disability Insurance which, in addition to the abolition of the law on the temporary reduction of pensions, also abolished the formula for pension adjustments and gave the Government discretionary possibilities to pay a 'monetary increase' to pensions. However, even though the statutory 
retirement age is now progressively increasing to 65 years, it is a scarcely discussed subject.

If the initiative to change the labour law passes, Serbia might extend working life to 70 years of age for those who wish to remain active. Employees could voluntarily remain active to up to five years after they meet the requirements for an old-age pension, providing that the employer needs their services at the same time. The new legislation covering possibilities of employment for those older than 65 allegedly would not interfere with the existing Law on Retirement and Disability Insurance.

The move for extending working life will be addressed to the ministries in charge, which have the authority to propose amendments and additions to the labour law to the Serbian Government. The final authority on the matter lies in the hands of the Serbian Parliament.

\section{Conclusion}

In order to develop a high quality of life for older men and women in Serbia, officials need more scientific evidence that could help policy makers develop adequate policies and programmes aimed at reducing gender differences in the quantity and quality of years lived, improving opportunities for people to extend working life if they so desire or to retire from paid work at appropriate times, and provide equal opportunities for both men and women. According to the data presented in this chapter, there is insufficient research on older people in Serbia to support age and gender sensitive policies. Official policies on issues ranging from active ageing, age discrimination, lifecourse and end-of-career psychology and management are still in their initial stages of implementation in Serbia. The establishment of appropriate legal frameworks and research initiatives could open this research area, with the potential for more precise monitoring and a deeper understanding of the issues in the foreseeable future. To date, employment policies for older Serbian workers remain mostly underdeveloped. The population is somewhat left to itself to provide income security in later life, either by being supported through the social and pension systems via government provided measures or, in a more traditional way, through their own families.

\section{References}

Altiparmakov, N. (2013). Is there an alternative to the pay-as-you-go pension system in Serbia? Economic Annals, 58(198), 89-114.

European Commission. (2018). The 2018 pension adequacy report: Current and future income adequacy in old age in the EU. European Commission. Retrieved January 04, 2020, from https:// ec.europa.eu/social $/$ main.jsp?catId=738\&langId=en\&pubId=8084\&furtherPubs=yes.

Eurostat. (2016). Enlargement countries-labour market statistics. Retrieved September 30, 2017, from http://ec.europa.eu/eurostat/statistics-explained/index.php/Enlargement_countries__labour_market_statistics\#Employment_rates. 
Eurostat. (2018). Enlargement countries-labour market statistics. Retrieved January 05, 2019, from http://ec.europa.eu/eurostat/statistics-explained/index.php/Enlargement_countries__labour_market_statistics\#Employment_rates.

Government of Republic of Serbia. (2014). Law on pension and disability insurance. Retrieved August 30, 2018, from www.paragraf.rs/propisi/zakon_o_penzijskom_i_invalidskom_ osiguranju.html.

Government of the Republic of Serbia. (2016). Employment and social reform programme in the process of accession to the European Union. Retrieved August 30, 2018, from http:// socijalnoukljucivanje.gov.rs/wp-content/uploads/2016/06/SIPRU-ESRP-2016-English.pdf.

Jakovljevic, M. (2015). The aging of Europe. The unexplored potential. Farmeconomia. Health Economics and Therapeutic Pathways, 16(4), 89-92.

Jakovljevic, M., \& Laaser, U. (2015). Population ageing from 1950 to 2010 in seventeen transitional countries in the wider region of South Eastern Europe. SEEJPH, 3. Retrieved February 21, 2015, from https://doi.org/10.12908/seejph-2014-42.

Jakovljevic, M., Folic, M., \& Dagovic, A. (2015). Hospital oncology costs among the cohort of elderly in an aging South-Eastern European nation. Farmeconomia. Health Economics and Therapeutic Pathways, 16(1), 3-5.

Jakovljevic, M. (2016). Commentary: Patient cost sharing and medical expenditures for the elderly. Frontiers in Pharmacology. Retrieved March 30, 2016, from https://doi.org/10.3389/fphar.2016. 00073.

Jakovljevic, M. B., Vukovic, M., \& Fontanesi, J. (2016a). Life expectancy and health expenditure evolution in Eastern Europe-DiD and DEA analysis. Expert Review of Pharmacoeconomics \& Outcomes Research, 16(4), 537-546.

Jakovljevic, M., Vukovic, M., Chen, C. C., Antunovic, M., Dragojevic-Simic, V., \& VelickovicRadovanovic, R. (2016b). Do health reforms impact cost consciousness of Health care professionals? Results from a nation-wide survey in the Balkans. Balkan Medical Journal, 33(1), $8-17$.

Jakovljevic, M. (2017). Population ageing alongside health care spending growth. Srpski arhiv za celokupno lekarstvo, 145, 534-539.

Jakovljevic, M., Romeu-Gordo, L., Vukovic, M., \& Krstic, M. (2017a). Gender-specific healthseeking behavior and income status among the elderly citizens of Serbia. Eastern European Business and Economics Journal, 3(1), 67-86.

Jakovljevic, M. M., Arsenijevic, J., Pavlova, M., Verhaeghe, N., Laaser, U., \& Groot, W. (2017b). Within the triangle of healthcare legacies: Comparing the performance of South-Eastern European health systems. Journal of Medical Economics, 20(5), 483-492.

Jakovljevic, M. M., Netz, Y., Buttigieg, S. C., Adany, R., Laaser, U., \& Varjacic, M. (2018). Population ageing and migration-history and UN forecasts in the EU-28 and its east and south near neighborhood-one century perspective 1950-2050. Global Health, 14(1), 30.

Matković, G., Mijatović, B., \& Petrović, M. (2010). Impact of the financial crisis on the labour market and living conditions outcomes. Center for Liberal-Democratic Studies. Retrieved April 21, 2017, from http://www.mdgfund.org/sites/default/files/YEM_STUDY_Serbia_Impact\%20of\% 20economic\%20crisis\%20on\%20labour\%20market.pdf.

Milovanovic, O., Radevic, S., \& Jovanovic, M. (2016). Legal framework and retirement policies in Serbia from 1990 to 2016-gendered perspective. Front Public Health, 27(4), 208.

Ogura, S., \& Jakovljevic, M. (2014). Health financing constrained by population aging-an opportunity to learn from Japanese experience. Serbian Journal of Experimental and Clinical Research, 15(4), 175-181.

Pension and Disability Insurance Fund Republic of Serbia. (2019). Statistical annual report for 2018. Retrieved January 04, 2020, from http://www.pio.rs/images/dokumenta/statistike/2018/ GODISNJI_BILTEN_2018.pdf.

Rancic, N., \& Jakovljevic, M. M. (2016). Long term health spending alongside population aging in N-11 emerging nations. East European Journal of Economics and Businessis, 2(1), 2-26. 
Rakić, B., \& Nikolić, M. (2016). The role of public and private pension funds in creating financially sustainable pension system. In B., Krstić \& A. Chodyński (Eds.), Improving the competitiveness of the public and private sector by networking competences (pp. 131-145). Niš: Faculty of Economics.

Serbia Employment Rate. (2019). Retrieved January 04, 2020, from https://tradingeconomics.com/ serbia/employment-rate.

Serbia Foreign Policy and National Security Yearbook. (2014). Volume 1 strategic information and developments volume 184 of world foreign policy and government library. Lulu.

Statistis Office of the Republic of Serbia. (2017). Registered employment, 2nd quarter 2017. Retrieved February 20, 2018, from http://www.stat.gov.rs/en-us/oblasti/trziste-rada/.

The Institute of Public Health of Serbia 'Dr Milan Jovanović Batut'. (2013). Results of the National Health Survey of Serbia, 2013. Retrieved May 25, 2018, from http://www.batut.org.rs/download/ publikacije/2013SerbiaHealthSurvey.pdf.

Žarković-Rakić, J., \& Vladisavljević, M. (2016). Women's access to economic opportunities in Serbia. Retrieved August 15, 2018, from http://socijalnoukljucivanje.gov.rs/wp-content/uploads/ 2016/11/Womens-Access-to-Economic-Opportunities-in-Serbia.pdf.

Open Access This chapter is licensed under the terms of the Creative Commons Attribution 4.0 International License (http://creativecommons.org/licenses/by/4.0/), which permits use, sharing, adaptation, distribution and reproduction in any medium or format, as long as you give appropriate credit to the original author(s) and the source, provide a link to the Creative Commons license and indicate if changes were made.

The images or other third party material in this chapter are included in the chapter's Creative Commons license, unless indicated otherwise in a credit line to the material. If material is not included in the chapter's Creative Commons license and your intended use is not permitted by statutory regulation or exceeds the permitted use, you will need to obtain permission directly from the copyright holder.

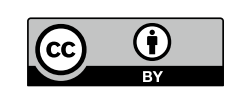




\title{
Chapter 32 Slovakia
}

\author{
Anna Pilková and Juraj Mikuš
}

\begin{abstract}
Although ageing is a universal process that concerns most countries, so far there are great differences particularly in relation to post-socialist countries. In Slovakia, population ageing appears to be irreversible in the coming decades at least up to 2050. Therefore, society must prepare to function under changed conditions and adapt to the increasing number and proportion of older people. The ageing of the population brings serious economic, social and political consequences. In addition, the effects of ageing cannot be eliminated or mitigated by isolated measures in a short period of time. They require comprehensive solutions made over time. For this reason, social, employment, health and education reforms are essential. The purpose of this chapter is to provide an overview of such measures in Slovakia. The chapter starts with an introduction which gives a brief socio-demographic context and the rest of the chapter provide a concise overview of pensions, of the employment of older people, of precarious work and of health policies as well as the underlying particular characteristics and challenges in Slovakia.
\end{abstract}

Keywords Ageing population - Late employment • Pension system • Slovakia • Gender $\cdot$ Health

\section{Introduction}

Slovakia belongs to a group of countries, where the increase in the employment rate of older adults is well below the OECD average. A steady increase in the older population, emigration of young people, declining fertility rates, and concerns about the increasing economic burden, brought about national efforts to focus on issues of employment policies and retirement income systems. The older worker cohort

\footnotetext{
A. Pilková $(\varangle)$

Faculty of Management, Comenius University in

Bratislava, Bratislava, Slovakia

e-mail: Anna.Pilkova@fm.uniba.sk

J. Mikuš

Faculty of Management, Comenius University in

Bratislava, Bratislava, Slovakia 
(55-64 years old) in Slovakia in 2017 represented $13.4 \%$ of the population. It is expected to increase to $26.1 \%$ by 2040 (European Commission 2015). Over the same period, Slovakia is likely to experience a significant decrease in the total number of inhabitants. In 2017 the employment rate of people aged 55-64 was 53\%, which is low in comparison to EU28 countries (57.1\%) (Eurostat 2019a). While men employment rate was $56.6 \%$ compared to $63.7 \%$ in Europe, older women in Slovakia have employment rates close to EU levels (49.6\% compared with 50.9\%).

Even though Slovakia has had the highest increase in labour force participation of individuals aged 55-59, the rate increased from $34.5 \%$ in 2004 to $57.9 \%$ in 2014 , participation in the labour market was still low compared to other European countries. The average employment rate in the same age cohort across all Organization for Economic Cooperation and Development (OECD) countries reached 67\% in 2015 (European Union 2015).

In 2017, the old age dependency ratio (population aged 65 or over in relation to the population aged 15-64) in the EU was $29.9 \%$. This means that the EU had just over 3.3 working age individuals for every person aged 65 or over. The old-age dependency ratio in Slovakia was one of the lowest among all EU countries (21.5\%). Even though the ageing of the Slovak population is not yet very pronounced, the evolution of the age structure of the population points to an acceleration of the population ageing process. Baby boomers continue to represent a major part of the working age population, who are now reaching retirement age and there are fewer births than in the first half of the $1990 \mathrm{~s}$ (European Commission 2015).

The female employment rate (age category 15-64 years) in Slovakia has not only been lower than the employment rate of men $(60.3 \%$ compared to $72.0 \%$ in 2017) but has also been lower than the average EU employment rate of women $(62.5 \%)$. Women also have a higher unemployment rate, which in 2017 was at $7.6 \%$, compared to a $7.0 \%$ rate for males (age 25-74). There is a persistent gender wage gap and regional disparities in wages. Slovak women earned $80.2 \%$ of men's average gross wage in 2017 (lower than the EU proportion of 84\%). The main purpose of this chapter is to provide an overview of social, pension, employment, health and education measures that should contribute to mitigate impacts of the ageing population in Slovakia in future.

\section{Pension Policies in Slovakia}

The adverse development of demography has been challenging traditional conservative pension systems in many developed and transitioning countries, including Slovakia. As a reaction, reforms of pension systems have been introduced, adopting more liberal schemes, in which complete or partial responsibility for old age wellbeing is transferred onto individuals. The Slovak Republic inherited a public pay as you go (PAYG) pension system from the old Czechoslovakia, which incorporated significant elements of redistribution within a social insurance system, where contributions from current workers were immediately used to pay benefits to current 
retirees. The former PAYG pension system was changed to a three-pillar system in 2003, with a mandatory first pillar being PAYG, a second pillar based on individual accounts, and a third one being for voluntary pension savings.

1. The first pillar is a Social Insurance System comprised of pension insurance and of other types of pension benefits. The retirement age introduced by the Act on Social Insurance, is being extended gradually (until the end of year 2023, by 2 months every year). In 2019, the retirement age is 62.5 years for both men and women and will increase until it reaches 63 years and two months. Additionally, starting in 2017, the retirement age of people born after 31 December 1954, will be linked to life expectancy (men and women taken together). The qualifying conditions for entitlement to the old age pension are 15 years of insurance and reaching pensionable age. According to the Act on Social Insurance, the following types of pension benefits are provided from the pension insurance system:

- Old age pension: The amount is determined by the average personal wage point (person's salary compared to average salary), the period of pension insurance acquired on the day of occurrence of the claim and the current pension value.

- Early old age pension: The insuree needs to have at least 15 years of pension insurance and to be within two years of retirement age.

- Invalidity pension: The qualifying condition is a reduction of the capacity to perform gainful activity due to a long-term unfavourable health condition (more than 40\%) and achieving the required insurance period while not qualifying for the old-age pension, or early old-age pension.

- Survivors' pension: this is $60 \%$ of the insured deceased person's pension. An orphan's pension amounts to $40 \%$ of the insured deceased parent/adopter's old age or invalidity pension. Sickness benefit: This is provided per day; in the first three days the benefit equals $25 \%$ of the daily assessment basis, from fourth day of the temporary incapacity for work, the sickness benefit is $55 \%$ of the daily assessment basis up to one year. After this period the health condition must be re-examined. The insuree is entitled to unemployment insurance if he/she had unemployment insurance for at least two years within the past three years before being included into the registry of unemployed job seekers. The amount of unemployment benefit equals $50 \%$ of the daily assessment basis for the first six months of unemployment. Slovakia has strict eligibility criteria for unemployment benefits, with the longest required period of insurance contributions in the whole EU.

2. Second Pillar: The Old-Age Pension Scheme. Since 2005, the Slovak private pension provision has included a system of individual retirement accounts, which serve as an important source of income for pensioners. Contributions, which by law may be mandatory or voluntary, are deposited to the personal savings account of the contributor. The amount of compulsory contributions is determined by the percentage of the basis of tax assessment achieved in the deciding period. Benefits are paid to savers who have reached retirement age and saved for at least fifteen 
years. People aged up to 35 years old can decide whether they join the second pillar or stay only in the first one. In case a worker is in both, the contributions to first and second pillar pension insurance are equally split and amount to nine per cent. Once joined, it is impossible to quit the second pillar. Nevertheless, the Slovak government temporarily opened the second pillar in 2015 for the fourth time since its creation; consequently, more than 160,000 clients left the pillar. The reason was low private pensions and that the system is not advantageous for older people with lower incomes. The private pension system is beneficial for young people whose monthly income is above the average wage.

3. Third Pillar: This is a supplementary Pension Scheme introduced in 2006, a fully funded defined contribution pension plan, based on the principle of voluntary saving. Payment of contributions to this scheme is voluntary for most participants; the contributions are paid by a participant as well as the employer and under the conditions agreed in the employer's contract. The group of participants for whom an employer is obliged to contribute to the system (employees carrying out socalled risky work) is defined by law. However, even after a decade of existence of the private pension savings schemes (since 2005), the participation rates in Slovakia have remained rather low, slightly above $30 \%$ of active population (National Bank of Slovakia 2017).

Since July 2015, a minimum pension was introduced. A person with 30 or more years of pension insurance receives a pension calculated at 1.36 times the minimum subsistence level. The relatively high level of social benefits in Slovakia, especially unemployment benefits, reduces inequality and poverty, however, provide fewer incentives to work, and does not stimulate active job searching of some unemployed people (Leszko and Bugajska 2017). In 2017, 14.2\% of pensioners in the European Union were at risk of poverty. Individuals are identified as being at risk of poverty if their equivalised disposable income is less than $60 \%$ of the national median equivalised disposable income after social transfers have been taken into account. Slovakia has the second lowest pensioner poverty rate among EU countries accounting for $7.6 \%$ in 2017 . For women, the pensioner poverty rate is slightly higher than the rate for men (8.6 compared with 6.2). Pensioners with the lowest rate at risk of poverty are in France (7.0\%) (Eurostat 2018).

People who have reached retirement age can continue working. Even though they are receiving a pension, they do not have to leave the job and the employer cannot force them to leave for that reason. Slovakia is one of handful countries which does not decrease the pension of working pensioners or increase taxes on the working income of pensioners (on the contrary, pensioners even those working full-time, pay lower taxes). One of the most attractive policies in Slovakia, is the possibility of increasing the pension by working. Working pensioners are entitled to a higher pension regardless of whether they are working on a contract or on an agreement. The amount of the increase depends mainly on the income of working pensioners. Even though early retirees can work, the Social Insurance Company will stop their retirement. 


\section{Employment Policies in Slovakia}

In the context of increasing numbers of older adults, employment policies have become a prominent issue. Lacking life-long learning is a persistent challenge in Slovakia (Ministry of Labour and Social Affairs of Slovakia 2014). An information system for life-long learning was established as well as the National Institute for Life-long Learning in 2010, but only three per cent of adults (25-64) participate in life-long learning, compared to the $10.7 \%$ EU average (Ministry of Labour and Social Affairs of Slovakia 2014). The government recognises the importance of increasing participation in the working age population and providing them with equal workplace opportunities. Therefore, several measures to enhance employment have been introduced by the Ministry of Labour and Social Affairs of Slovakia.

A National Program for the Protection of the Elderly (1999)_-based on the analysis of demographic trends, economic conditions in the Slovak Republic and social policy in relation to older people, the programme represented identification with the necessity to apply UN principles for older people in Slovak conditions at all levels (individual, family, commune, etc.). The principles introduced were as follows: the principle of independence, the principle of participation, the principle of care, the principle of self-realisation, and the principle of dignity, all which have been applied in different areas (social policy and insurance, healthcare, education, and so on). Based on the above-mentioned UN principles for older people individual authorities have developed these principles within their sectoral competencies.

National Project on Active Ageing (Balaž et al. 2013)—until 2013, Slovakia did not have a national document in which it would recognise the issue of active ageing as a national policy. Many of the measures and policies that were developed, corresponded to the principles and interests in this field. This document focuses on the detailed development of the demographic ageing context, with a special emphasis on the labour market and the pension system, including the strategic goals in this area and the design of measures to meet these goals. The main goals of the program were to reduce the unemployment rate for people over the age of 50, to attract more people to productive ageing with a lifelong approach to work and to elaborate strategic measures for a policy to increase and improve the employability of older people, especially between the ages of 55 and 64 .

The National Program for Active Ageing for the years 2014-2020 (2014)—provides a comprehensive understanding of supports for older adults and is developed based on the lessons and experiences of the implementation of the National Programs for the Protection of the Elderly (1999) and Active Ageing (2013). The program goes beyond employment policy, focusing on the rights of older adults, support policies, lifelong learning, social and civic rights, outside of the formal labour market, promoting their independence, dignity, economic security, and social development, including protection against mistreatment in all spheres of social life. The program ensures the right to employment of individuals aged 50+ and introduces antidiscrimination policies based on age. In addition, the National Program draws attention to the low awareness of age-management for not recognising the benefits of employing 
older people. The implemented program emphasises the necessity of special support for individuals aged 50+ who remain disadvantaged in the labour market.

A document has been published by the government outlining the definition of age management and the creation of age management principles for employers (in private and public administration) (Ministry of Labour and Social Affairs of Slovakia 2017). This document was published in January 2018. It was created in a joint effort by the Ministry of Labour, Social Affairs and the Family of the Slovak Republic in cooperation with all relevant entities, i.e. the Ministry of Health, the Ministry of Interior, the Associations of Employers, the Confederation of Trade Unions of the Slovak Republic, etc. It defines what age management is and its benefits for different stakeholders, the principles of its application and different models as well as good practices. Flexible employment options are explained as well as their benefits for employers.

Women's employment rates in Slovakia has been steadily rising faster than the average for the EU. However, there is one group of women which is much lower than the EU average. That group is women with children under the age of six $(43.5 \%$ for Slovakia and 62.4\% for EU) (Eurostat 2019b). Therefore, the Ministry of Labour and Social Affairs of Slovakia has promoted the employment of mothers with small children with flexible forms of work, through the National project 'Family work for the regions outside Bratislava' since 2015. Flexible forms of work have been implemented - shorter working hours, job sharing and telework. At the same time, 33 childcare facilities have been supported as well, which have provided flexible forms of childcare. The main aim of the program is to improve conditions for work and family life and to increase the employment of women with parental responsibilities.

The other option for flexible employment policy presented by Ministry of Labour, Social Affairs and Family is entrepreneurship. In Slovakia, there is a very low level of senior entrepreneurial activity (6.7\% compared to $10.3 \%$ of the overall population in 2017) (Pilková et al. 2018) due to a lack of skills in this group. A course launched by the Faculty of Management, Comenius University in Bratislava can be taken as an example of good practice. The course 'Development of Entrepreneurial Skills in Cross Generation Teams' was prepared by lecturers in the Department of Strategy and Entrepreneurship, with the aim of creating a cross-generational environment for the students. Senior volunteers came from the University of the Third Age and joined a group of undergraduate students. Their role was threefold: (1) to develop their enterprising spirit and entrepreneurial mindset; (2) to learn the basic techniques applicable to new venture creation to cover their missing skills and (3) to advise young students in areas where seniors have expertise during the process of new micro-business development. Young students contributed particularly with their I.T. technology skills, enthusiasm and energy. The project is unique in Slovakia and surrounding Central and Eastern European countries as it combines mentorship of seniors while also improving their own knowledge about the latest techniques from entrepreneurship. All participants together are also part of a team that is assigned to create micro-businesses during the semester. Some of these micro-businesses were successful and continued well after the semester finished and are currently on-going (European Commission 2016). 


\section{Health Policies}

While the average European is healthy up to the age of almost 64, and only then begins to develop ill-health, in Slovakia this occurs more than seven years earlier (Eurostat 2016). The indicator Healthy Life Years at birth measures the number of years that a person is expected to live in a healthy condition. A healthy condition is defined by the absence of limitations in functioning/disability. The average life expectancy in Slovakia is 77.3 years. Healthy life years are only 56.7 , which means that an average Slovak would not retire in good health. Considering that the retirement age is slightly above 62 now, people have to keep working for more than five years before they can retire. There is a large gender gap in Slovakia. Women live more than seven years longer than men (80.2 compared with 73.1 years). There are also large disparities between socioeconomic groups. People with a low level of education live on average 10 years less than those with a university education. The most common cause of death for both men and women are cardiovascular diseases followed by cancer. Both account for almost three-quarters of deaths in the Slovak Republic (OECD/European Observatory on Health Systems and Policies 2017). According to the latest available data from Eurostat, in 2011 there were more than 31,000 unemployed people aged 55 to 64 . Out of those people $22 \%$ had difficulties in working caused by a health condition or difficulty in basic activities.

The aim of the government's health policy is to improve the health status of the population, to build a health system that faces the changing needs of the population and to protect socially weaker individuals from the high cost of healthcare. It will be necessary to ensure that the healthcare system develops in line with demographic developments. This will ensure the effectiveness of healthcare, while maintaining its availability and to support prevention measures. Demographic developments must be reflected in legislation; it is therefore necessary to continue adjustments in order to improve the health status of the population (not only the ageing population) and to achieve a prolongation of life expectancy while reducing the health problems of the population. These tasks are embedded in the national programmes that the Ministry of Health of the Slovak Republic has provided since 2008.

\section{Precarious Work}

In Slovakia, the legally stipulated standard employment contract is an open-ended contract with full-time working hours ( $40 \mathrm{~h}$ per week). These contracts cover social security and health insurance deductions and entitlements, with remuneration exceeding the statutory minimum wage. In contrast, precarious employment has characteristics, which include uncertainty in job security, low levels of wages and lack of sufficient social protection. Precarious work in Slovakia mostly takes the form of legal employment rather than illegal employment, which differs from standard employment contracts mainly in labour rights and social security entitlements. Industries 
which are traditionally characterised by the highest level of precarious work are metal, construction, healthcare and retail (Kahancová 2016).

The Labour code is the most important piece of legislation in Slovakia, regulating employment conditions and labour relations. It is also the most important regulation tool for precarious work. The only relevant legislative change has been the introduction of obligatory social security and health insurance contributions in work agreements (in 2015). This measure has produced a decrease in the use of work agreements as well as allowing retirees to increase their pensions. It also made work agreements less precarious than they were before 2015. These changes affected labour costs of employers. Other forms of flexible employment, temporary agency work, and self-employment have started to increase. However, after 2011 most regulatory stipulations were geared towards decreasing precarious employment and stabilising working conditions.

\section{Debate on Extended Working Life}

All pension system reforms in Slovakia were more or less coercive, and although the pension system is a matter that affects and influences the entire society in the long-term, there has been no attempt to find a social consensus.

The main Slovak pension reform was launched in 2004. It was a process of changing the rules on pension security, the Social Insurance Act and the adoption of a completely new act on retirement pension savings. The goal of pension reform has been to create higher and fairer pensions, which citizens can decide upon themselves. Until then, everybody had approximately the same pensions regardless of how much they have earned and what they had paid during their lives. The Social Insurance Act of 2003 unified the retirement age for men and women to 62 years from 2024. The unions were against its introduction because the health of the citizens was poor and only a minority of employees would reach the pension age in good health. This is also due to the fact that Slovaks work during nights, on shifts and have the most overtime work in Europe. However, their comments have not been taken into account. The minimum pension has been introduced into the pension system since 1 July 2015, which contributes to raising the standard of living of low-income retirees while ensuring that people who have worked all their lives have no material need after retirement. At the end of May 2018, a group of deputies of the National Council of the Slovak Republic delivered a draft of Constitutional Act to Parliament which sets the upper limit of the retirement age at 64 years (the so-called pension age ceiling). Opposition parties blame the plan for populism, and state that the proposed steps are aimed at gaining votes from older groups of voters. OECD Secretary-General José Ángel Gurría visited Slovakia in February 2019 and has identified the Slovak pension system as one of the biggest challenges for the country. The OECD points out in the latest economic report on Slovakia that the introduction of a pension age ceiling would significantly weaken the whole system. The Association of Entrepreneurs of Slovakia also disagrees with the pension age ceiling and promotes the return of 
pension funding to the family level. In addition to the pension age ceiling and the minimum pension there is also a discussion in Slovakia about Christmas contributions for retirees or the so-called thirteenth pension. These changes do not stimulate people to remain active at the labour market.

\section{Conclusion}

Slovakia has introduced public policy changes due to an ageing population, low fertility rates and rising social security costs, which significantly affect older adults. Such changes have included raising the retirement age. Although increasing the retirement age seems to be inevitable, many older adults are dissatisfied, and those changes are met with strong resentment from many people. According to the leader of the trade union for heavy industry around 200,000 of their members are opposed to the increase of the retirement age. Another measure introduced is to raise the participation levels of the actively unemployed labour force. It seems that it is necessary to implement strategies used in developed countries such as subsidising wages, creating additional jobs, introducing vocational training, lifelong learning programmes or programmes for the reintegration of the unemployed, taking additional measures to address longterm unemployment by improving activation measures, second chance education and introducing high-quality training tailored to individuals' needs, improving incentives for women to remain in or return to employment by improving the provision of childcare facilities. In Slovakia senior entrepreneurship as a means of active ageing which brings both social and economic benefits is neglected and deserves special attention particularly from policy-makers and national strategies. Slovakia is ageing and the number of people reaching retirement age is increasing. Many changes need to be made in the form of national programmes or strategies, and additional reforms may also be needed to sustain the pension system. Further research on extended working life in the local context is necessary.

\section{References}

Balaž, V., Feik, M., Gramata, J., Husáriková, V., Jankurová, A., Němec, M., et al. (2013). Strategy of Active Aging. Retrived february 19, 2019, from http://www.nocka.sk/uploads/9e/92/ 9e92bd1c274fbc1f1b08e2c0ecff8705/strategia-aktivneho-starnutia.pdf.

European Commission (2015). The 2015 Ageing Report: Economic and budgetary projections for the 28 EU Member States (2013-2060). Retrived february 19, 2019, from http://ec.europa.eu/ economy_finance/publications/european_economy/2015/pdf/ee3_en.pdf.

European Commission (2016). Senior entrepreneurship good practices manual.. Retrived february 19, 2019, from https://publications.europa.eu/en/publication-detail/-/publication/8fdadabd-9ac811e6-868c-01aa75ed71a1/language-en.

European Union (2015). Short Analytical Web Note. Retrived february 19, 2019, from http:// ec.europa.eu/eurostat/documents/3217494/6917833/KE-BM-15-003ENN.pdf/76dac490-917647bc-80d9-029e1d967af6. 
Eurostat (2016). Healthy life years and life expectancy at birth, by sex. Retrived february 19, 2019, from https://ec.europa.eu/eurostat/tgm/refreshTableAction.do?tab=table\&plugin=1\& pcode $=$ tps00150\&language $=e$.

Eurostat (2018). At-risk-of-poverty rate by poverty threshold and most frequent activity in the previous year-EU-SILC survey [ilc_li04]. Retrived february 19, 2019, from https://ec.europa.eu/ eurostat/web/products-news/-/DDN-20190115-1.

Eurostat (2019a). Employment and activity by sex and age - annual data. Retrived february 19, 2019, from http://appsso.eurostat.ec.europa.eu/nui/submitViewTableAction.do.

Eurostat (2019b). Employment rate of adults by sex, age groups, educational attainment level, number of children and age of youngest child. Retrived february 19, 2019, from http://appsso. eurostat.ec.europa.eu/nui/show.do?dataset=lfst_hheredch.

Kahancová, M. (2016). The rise of the dual labour market: Fighting precarious employment in the new member states through industrial relations (PRECARIR). Slovakia: Country report. Retrived february 19, 2019, from https://celsi.sk/media/research_reports/19_CELSI_RR_1.pdf.

Leszko, M., \& Bugajska, B. (2017). The Evaluation of Employment Policies for Older Adults in the Czech Republic, Poland, and Slovakia. In Ł. Tomczyk \& A. Klimczuk (Eds.), Selected contemporary challenges of ageing policy (pp. 69-87). Kraków: Uniwersytet Pedagogiczny w Krakowie.

Ministry of Labour and Social Affairs of Slovakia (1999). National Program for the Protection of the Elderly. Retrived february 19, 2019, from https://www.mpsvr.sk/files/5578_subor.pdf.

Ministry of Labour and Social Affairs of Slovakia. (2014). Národný program aktívneho starnutia na roky 2014-2020 (National program for active aging for years 2014-2020). Bratislava: Ministry of Labour, Social Affairs and Family of the Slovak Republic.

Ministry of Labour and Social Affairs of Slovakia. (2017). Definition of age management and creation of age management principles for employers (in private and public administration). Bratislava: Ministry of Labour, Social Affairs and Family of the Slovak Republic.

National Bank of Slovakia (2017). Doplnkové dôchodkové sporenie (Supplementary pension scheme). Retrived february 19, 2019, from https://www.nbs.sk/sk/dohlad-nad-financnym-trhom/ dohlad/dochodkove-sporenie/doplnkove-dochodkove-sporenie.

OECD/European Observatory on Health Systems and Policies (2017). Slovak Republic: Country Health Profile 2017, State of Health in the EU. Retrived february 19, 2019, from http://www. euro.who.int/_data/assets/pdf_file/0009/355995/Health-Profile-Slovak-Rep-Eng.pdf?ua=1.

Pilková, A., Holienka, M., Kovačičová, Z., Rehák, J., \& Mikuš, J. (2018). Podnikanie na Slovensku: vysoká aktivita v problematickom prostredí (Entrepreneurship in Slovakia; high activity in problematic environment). Bratislava: Kartprint.

Open Access This chapter is licensed under the terms of the Creative Commons Attribution 4.0 International License (http://creativecommons.org/licenses/by/4.0/), which permits use, sharing, adaptation, distribution and reproduction in any medium or format, as long as you give appropriate credit to the original author(s) and the source, provide a link to the Creative Commons license and indicate if changes were made.

The images or other third party material in this chapter are included in the chapter's Creative Commons license, unless indicated otherwise in a credit line to the material. If material is not included in the chapter's Creative Commons license and your intended use is not permitted by statutory regulation or exceeds the permitted use, you will need to obtain permission directly from the copyright holder. 


\title{
Chapter 33 \\ Slovenia
}

\author{
Tanja Rener and Ana Kralj
}

\begin{abstract}
Slovenia is among the fastest ageing European countries and one with the most accentuated gender pension gap. Partly, we can explain this by the fact that women spent more time engaged in domestic and care work and consequently less time in employment. However, the working conditions of the employed in general are not favourable for extending working life, which is the principal reason why the vast majority of people who reach the conditions for retirement, opt to do so immediately in spite of pension system incentives to postpone retirement. As far as gender and health perspectives of extending working life in Slovenia are concerned, the following research data should be considered: poor physical and mental health has been linked to a low income, low levels of education, working class and gender.
\end{abstract}

Keywords Slovenia $\cdot$ Ageing $\cdot$ Pension gap $\cdot$ Pension system $\cdot$ Working life $\cdot$ Health

\section{Introduction}

Prior to 1991, Slovenia was part of the Yugoslav state, which was constituted after World War Two as a socialist federation. After the fall of the Berlin wall and the major political upheaval in the states of Eastern and Central Europe, the Slovenian Parliament proclaimed independence in June 1991 and succeeded in getting full international recognition as an independent state in 1992.

Slovenia was never a male breadwinner society since from after the World War II on, the employment rate of women was one of the highest in the world. It reached its peak at the end of the 1980 s with $47 \%$ of women among the employed (Kozmik and Jeram 1997). In the ideology of socialist societies, women were one of the social subjects of emancipation and social change although their roles in private life remained almost unchanged.

T. Rener $(\bowtie)$

Faculty of Social Sciences, University of Ljubljana, Ljubljana, Slovenia

e-mail: Tanja.Rener@fdv.uni-lj.si

A. Kralj

Faculty of Social Work, University of Ljubljana, Ljubljana, Slovenia

(C) The Author(s) 2020

Á. Ní Léime et al. (eds.), Extended Working Life Policies,

https://doi.org/10.1007/978-3-030-40985-2_33 
Yet, the collapse of state socialism also led to the collapse of traditional economic opportunities for women and to their increased unemployment. Despite restructuring and economic growth, many women continue to prevail among structurally unemployed, meaning that they are too old, lacking skills and mobility. For many of them it represents a severe obstacle as far as extending working life is concerned.

As a new state, Slovenia inherited from the former Yugoslavia the legislation of its pension system, which was based on inter-generational solidarity. Pensions were financed on a pay-as-you-go (PAYG) basis through taxes and employers' social contributions. Economic and social consequences of the transition in the 1990s posed a severe strain on pension system. Therefore, in Slovenia, as in the majority of Central and Eastern European countries radical reforms of their pension systems were undertaken, also due to population aging. A three-pillar system (PAYG tier, mandatory pension funds, and voluntary pension funds) was introduced. The second pillar of the Slovenian pension system has undoubtedly undergone considerable growth, since more than half of the active working population are included in voluntary pension insurance. However, most of these insured persons were involved via collective insurance, while the individual pension saving segment remains marginal.

\section{Socio-Economic Context, Labour Market and Older Workers}

In the period after 2000, the social and economic conditions in Slovenia were mostly influenced by two processes: the integration of Slovenia into the European Union in 2004 and into Eurozone in 2007 and the crisis of the world-economy in 2008 which has put pressure on the welfare system. Economic crises usually affect the socially and politically weaker segments of the population. In Slovenia, during the crisis, young educated women were mostly affected in the area of labour market and employment.

In recent years Slovenia's employment rate was just a bit higher than the EU average $(72.2 \%$ in EU, $73.4 \%$ in Slovenia in 2017) and the employment rate of women was slightly above average (69.7\% compared to $66.5 \%$ in EU). The overall employment rate of people in the age group 55-64 is rather weak (42.7\% compared to $57.1 \%$ in EU) and even weaker for women (37.5\% compared to $50.9 \%$ in EU) (Eurostat News Release 2018).

It was stated that this unfavourable situation might be seen as a result of several factors:

- after Slovenia's independence its economy lost its former Yugoslav markets, hence it was forced to redirect itself towards more demanding western markets. It was a harsh process during which many of relatively young low-skilled workers lost their jobs and chose early retirement;

- limited investments into upgrading new skills for older workers which prevented them from remaining competitive and productive in the labour market; 
- the ongoing restructuring of the economy with massive dismissals hit especially older workers and increased demands for a more skilled and younger workforce (Zupančič 2012).

However, is this situation really unfavourable? What lies behind the curtain? In Slovenia, $70 \%$ of people who reach the conditions for retirement, opt to retire immediately, another $17 \%$ choose an early retirement scheme and the third reason for retirement is health-related issues (Kavaš et al. 2016).

According to the data (Humer and Hrženjak 2015; Leskošek 2017), older women are most at risk of poverty. A more detailed insight into the risk of poverty (see Table 33.1) shows that poverty has a greater impact on women, people, aged 65 years or more, unemployed people as well as older households and single households. Women are twice as likely to be classified as poor compared to men-mostly due to the horizontal segregation of labour market - which is why we can speak about the feminisation of poverty in old age. In the age group 75 and over, the gender gap further widens and the comparison with other EU countries reveals how unsatisfactory the situation in Slovenia is-while the at-risk-of-poverty rate among men in this age group in Slovenia is lower than the EU average, the rate among women is much higher than the average.

\section{Pension System and Extending Working Life Policies}

There are different kind of pensions in Slovenia: old age pensions based on pension contributions during the working life, family pensions, widowhood pensions and pensions for disabled persons. State pensions were available during the period 1999 to 2012 for people over 65 years of age who were not employed or whose pension contributions didn't suffice for a pension. The state pension was abolished in 2012 by the Social Security Act and replaced by two other policy instruments, by financial social assistance which in 2018 amounts to of 385 Euros per month, and by care assistance. The two combined could overpass the state pension which was far below the poverty line.

In spite of financial incentives to prolong working life available from January 1st 2013 on, the majority of employees opt for retirement as soon as they can. These facts are in clear contrast with the basic aims of the pension system reform act from 1999, which gradually raised the full retirement age at 61 years for women and 63 years for men penalising retirement before this age by lower pensions and the last pension reform entitled Pension and Invalidity Insurance Act from 2013. Its main goal is to prolong the working life with the help of various legal and policy measures:

- by increasing the retirement age to 65 years and 40 years of pension contributions for both genders;

- by lowering pensions in case of early retirement and

- by increasing pensions for $1 \%$ for 3 months of delay, $4 \%$ per year and up to $12 \%$ in total if retirement is postponed. 


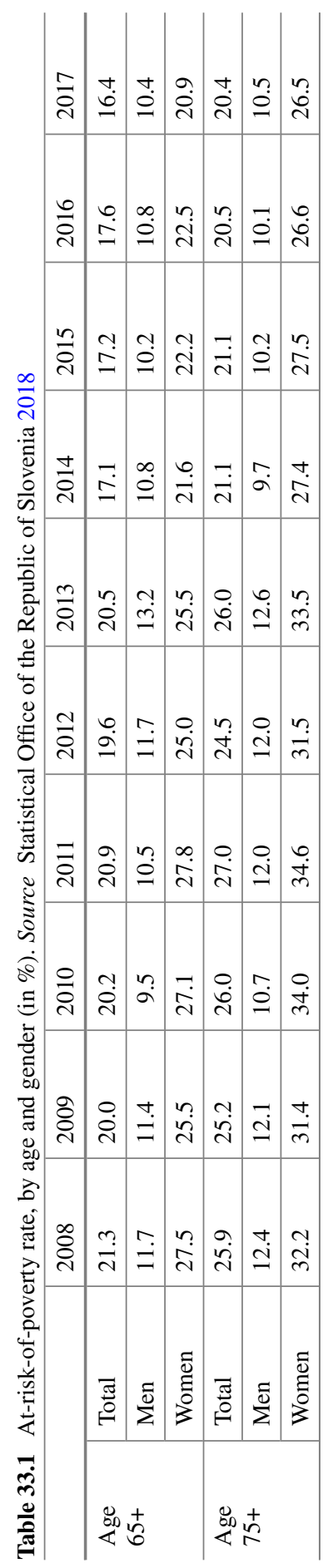


As far as the psychosocial risks of older workers are concerned, the European Working Conditions Survey (2012) reports that $34.6 \%$ of workers aged 55 and more in Slovenia experience stress at work always or most of the time, a figure that is almost twice as high compared to the 25-39 age group. It appears that age management within labour market in Slovenia is not well developed since the majority of enterprises do not reflect about a more ageing friendly environment. Moreover, $42 \%$ of employers stated that they do nothing to adapt to an ageing workforce or to meet their needs in any way. According to Zupančič (2012), it appears that the major constrains to longer working life are likely to be adverse working conditions rather than a lack of motivation to work since work is still considered as one of the most important values in Slovenia. Lack of lifelong learning access, lack of individual self-confidence along with the increased ideological pressures of individual responsibility for one's own life as well as general negative attitude towards prolonged working life supposedly on behalf of unemployed youth are hindering the higher employment participation of older people in Slovenia.

State policies aimed at prolonging working life help to a certain extent: there are, for example, initiatives such as Comprehensive support to enterprises for active ageing workforce with 30 million of euros available for inclusion of 12.500 older workers in the period from 2017 to 2022 . Another policy measure which is already in place is the state compensation via deduction of taxes to enterprises which employ older workers. The new pension reform act which is in its preparation phase will emphasise the following measures as far as the prolonging working life is concerned: introduction of financial support for mentorship schemes for older workers, part-time employment and adjustment of work place for older workers. From the mid-1990s on in the public debate about policies concerning the situation of older people there are several important actors. Besides the Ministry of Work, Family and Social Affairs there is a non-governmental Federation of Pensioners' Association and a political party Democratic Party of Pensioners that gets from 4 to $10 \%$ of vote and is politically rather strong due to its often crucial role within the various coalitions in power.

A new proposal for pension reform and a new increase in the retirement age to 67 was intensively discussed by the government and the social partners in the period between June 2016 and March 2017. The main proposals of the White book on pensions, a document which precedes the next pension reform, issued in April 2016 by an inter-ministerial commission, were:

- an increase in the retirement age to 67 years (from 65 at present);

- an extension of the length of Services to 42 years;

- an extension of the period for calculating the pension basis from the current 24 years to 34 years.

The employer organisation, the Chamber of Commerce and Industry (GZS), fully supported the government's proposals and called on social partners to facilitate the adoption of the pension reform by 2020 at the latest.

The Association of Free Trade Unions of Slovenia (ZSSS), the largest trade union organisation in Slovenia, opposed the increase in the retirement age stating that due to health reasons, a retirement age of 67 years is a too harsh retirement condition 
and leads to the poverty of all those who would not be able to cope with the high intensity of work.

Furthermore, in the opinion of ZSSS, raising the retirement age will be acceptable only under the conditions that health and safety at work are actually improved, that young people actually enter into regular employment immediately after completion of schooling and not at the age of 30 , and that employers really provide jobs for workers aged from 60 to 67 years (ZSSS 2017).

Some of the positive examples of the activities, which provide older people with opportunities to prolong working life, escape loneliness and further marginalisation, have been initiated by non-governmental organisations, often at the level of local community. One such movement in Slovenia, building on intergenerational cooperation, is Simbioza, where young people were mobilised to teach elderly the use of ICT, especially basic skills like e-mail and Internet. What started as a local activity in the Slovenian capital Ljubljana became an all-Slovenian phenomenon with more than 25,000 participants.

\section{Gender and Health Impacts}

As far as gender implications of extending working life are concerned, women's activities and concerns within the private sphere appear to be very important. What follows is a short review of some family life phenomena we consider important and are somewhat specific to Slovenia.

Research studies inquiring into the division of labour in Slovenia paint a similar picture: women as homemakers and caregivers devote a disproportionate amount of time to family life and to household (Švab et al. 2012; Humer and Hrženjak 2015). In 75-80\% of cases it was exclusively women who, in addition to bearing a full workload, did the majority of housework and childcare in Slovenia in 2011. The figures on the amount of time spent on household work even more clearly demonstrate an unequal division of domestic labour. In Slovenia, women aged 20-74 spend almost 5 hours per day on domestic work (including childcare), which is about twice as much as men do (ک̌vab et al. 2012).

Due to lifelong care for children, elderly relatives or other dependent persons, women experience pension penalties, a high risk of poverty and economic dependency in old age. For example, results for Slovenia show quite a substantial gender pay gap (23\% in years 2003-2007 in the same position at the same employer), that will have an impact on the gender pension gap. In 2016, the Slovenian gender gap in pensions was $18.9 \%$ (European Commission 2018). It is higher for older cohorts; one out of four women born before 1945 had been in employment less than 14 years. Thus, an important issue emerges which has to be addressed in future research and policy measures. According to Hrženjak (2016) the consequences of the unequal division of labour and especially women's long-term care work together with projections of extending working life for women and men to 67 years of age have not 
been researched yet and were not addressed properly in the so called White Book, a document which precedes the next pension reform in Slovenia.

In order to understand the health impacts of prolonging working life in Slovenia we have to mention some characteristics of the transition into the neoliberal capitalist system at the beginning of the 1990s and their influence on social security and health care systems. The Slovenian welfare system was reorganised by means of partial privatisation of social and health services. The cost of health care, which was fully covered by compulsory health insurance, was relocated on individual optional health insurance combined with the old compulsory one which now covers just basic healthcare needs. Therefore, old age became even more important risk factor. Along with structural system changes a strong neoliberal ideology of individual responsibility for one's own health' pervaded popular media and medical consulting rooms.

In the area of health and older people there is a very interesting discourse analysis carried out by Pahor and Domanjko (2006) who analysed 352 bibliographical units written by professionals from various disciplines. The authors discovered that regarding health related issues older persons are treated primarily as older bodies, prone to health risks and diseases. The examined sources frequently use terms such as problems, help, save, rescue in relation to older people and there is a general tendency to essentialise (unite and generalise) characteristics of older people. Their voices and experiences are overlooked or considered unreliable. There were only a few units, which tackled discrimination, exclusion and abuse of older people who are often stereotyped as fragile and passive rather than active and vital. The analysed sources are characterised by the biomedical model and there is an absence of gender sensitive language.

In 2013, a thematic issue of the Slovenian Journal of Public Health reported results of various research studies about gender and health. The data show a strong correlation between the subjective perception of health and socioeconomic status. Poor physical and mental health has been linked to low income, gender, low levels of education, working class and other indices of disadvantage. Furthermore, the data has shown that problems identified by government statistics and medical experts do not necessarily correspond to the health problems identified by women and men themselves. To fully understand their health issues and women's in particular, it must be recognised that health is determined by both contextual factors and the structural sources of people's lives (Ule and Kurdija 2013).

Due to rising health care costs in an ageing society, the key problems faced by health policies and individuals is how to stay healthy and vital for as long as possible. The most frequent background of contemporary health policies is emphatically neoliberal - the individualisation of care for one's own health. Health promotion activities that focus on diet, smoking prevention and exercise without addressing poverty, social isolation, gender discrimination, socioeconomic inequalities, occupational and household hazards and environmental pollution thus remain very partial and deeply unfair. 


\section{Concluding Remarks}

Ageing policy in Slovenia was severely affected by the economic crisis and consequent austerity measures, which had an extensive impact on the quality of life of older generations. A more comprehensive approach to ageing policies in Slovenia is becoming one of the major issues that should be tackled by the Slovenian welfare state in the future (Hlebec and Rakar 2017: 45). There is a strong need for research in the area of extended working life in Slovenia for the aging policy instruments should rely much more on research findings. Changing the attitudes of employers towards older people, such as the prevailing perspective that they are less productive and competent, more susceptible to disease and disability, more reluctant to embrace professional development, more sensitive to changes and less willing to accept them in comparison to their younger counterparts, remains a challenge. However, when thinking about the future possibilities of European welfare and considering the intersections of gender, age, class and other factors that influence the lifecourse of majority of people, one cannot but wonder about less discussed options of future development.

Accounts of changes in education, health and social policy architecture in recent decades in post-industrial Western countries followed faithfully by Slovenia focus on several themes under varying labels: neoliberalism, investment state, enabling society, activation, and similar. Among the key dimensions characterising recent policy changes are: an eclipsing of the social by economic concerns, a turn toward social investment, accentuation of individual responsibilities of citizens, and recognition of lifecourses in flux. Each of these themes separately and together prioritise labour market participation or market citizenship over other contributions citizens make or might make to society. Instead to view a prolonging working life in terms of various forms of prolonged employment we might consider a replacement with other possible concepts. One is a concept of autonomous versus heteronomous work, the other is the capability approach, developed by Sen (1992) and Nussbaum (2000) whichsimilarly to the first one-speaks of meaningful contributions to society instead of employment based on market value of work. The third one is the discourse of the universal basic income (UBI) which would enable the other two concepts to show better their social, intellectual and political superiority compared to the mainstream discourses embedded in pension systems and reforms. The UBI in its gradual form would contribute significantly to raise not only the livelihood but the human dignity of two population groups mostly affected by the crisis, children and youth on one hand and older people on the other.

\section{References}

Eurofound (2012). Fifth European Working Conditions Survey. Luxembourg: Publications Office of the European Union. Retrieved March 6, 2019, from https://www.eurofound.europa.eu/sites/ default/files/ef_publication/field_ef_document/ef1182en.pdf. 
Eurostat News Release (2018). Europe 2020 employment indicators. Retrieved March 6, 2019, from https://ec.europa.eu/eurostat/documents/2995521/8818246/3-20042018-AP-EN.pdf/ c4d4085d-7e32-438b-bc44-61eca9a6998b.

European Commission (2018). 2018 Report on equality between women and men in the EU. Luxembourg: Publications Office of the European Union. Retrieved March 6, 2019, from https://op. europa.eu/en/publication-detail/-/publication/950dce57-6222-11e8-ab9c-01aa75ed71a1

Hlebec, V., \& Rakar, T. (2017). Ageing Policies in: Before and After "Austerity". In Ł. Tomczyk \& A. Klimczuk (Eds.), Selected Contemporary Challenges of Ageing Policy (pp. 27-51). Kraków: Uniwersytet Pedagogiczny w Krakowie.

Hrženjak, M. (2016). Nekaj misli o Beli knjigi o pokojninah in enakosti spolov. Retrieved March 6, 2019, from https://spol.si/blog/author/majda/.

Humer, Ž., \& Hrženjak, M. (2015). Pravična plača, dostojna pokojnina. Mirovni Inštitut. Retrieved March 6, 2019, from http://www.mirovni-institut.si/wp-content/uploads/2015/01/Pension_gap_ porocilo_slo.pdf.

Kavaš, D., Koman, K., Kump, N., Majcen, B., Sambt, J., \& Stropnik, N. (2016). Aktivno in zdravo staranje za aktivno in zdravo starost. Analitsko poročilo DR3 projekta AHA.SI. Institute for Economic Research. Retrieved March 6, 2019, from http://www.staranje.si/sites/www.staranje.si/ files/upload/images/aktivno_in_zdravo_staranje_za_aktivno_in_zdravo_starost-analiza-2.pdf.

Kozmik, V., \& Jeram, J. (1997). Položaj žensk v Sloveniji v devetdesetih: poročilo Urada za žensko politiko za obdobje 1990-1995. Ljubljana: Vlada Republike Slovenije, Urad za žensko politiko.

Leskošek, V. (2017). Revščina starejših žensk v Sloveniji. Javno zdravje, 1(1), 66-73 (2017).

Mrčela, A. K., \& Ignjatović, M. (2013). Women, work and health. In M. Ule (ed.), Slovenian Journal of Public Health, 52(2), 137-147 (2013). Retrieved March 6, 2019, from https://content.sciendo. com/view/journals/sjph/52/2/sjph.52.issue-2.xml, https://doi.org/10.2478/sjph-2013-0015.

Nussbaum, M. (2000). Women and Human development. The Capability Approach. Cambridge: Cambridge University Press.

Pahor, M. \& Domanjko, B. (2006). Zdravje starejših v očeh strokovnjakov. Delovno gradivo s posvetovanja Celostna obravnava starostnikov, 24. November 2006. Visoka šola za zdravstvo. Retrieved March 6, 2019, from http://www2.zf.uni-lj.si/ri/publikacije/starostniki2006/3_PahorDomajnko. pdf.

Sen, A. (1992). Inequality Re-examined. Oxford: Clarendon Press.

Statistical Office of the Republic of Slovenia (2018). At risk of poverty rate by age and gender, Slovenia, annually. Retrieved March 6, 2019, from https://pxweb.stat.si/pxweb/Dialog/varval. asp?ma=0867206E\&ti=\&path=../Database/Demographics/08_level_living/08_silc_poverty_ indic/10_08672_at_risk_poverty_rate/\&lang=1.

Švab, A., Kuhar, M., \& Rener, T. (2012). Behind and beyond Hajnal's line: Families and family life in Slovenia. Journal of Comparative Family Studies, 43(3), 419-437.

Ule. M., \& Kurdija, S. (2013). Self-related health among women and their assessment of the health care system. In M. Ule (ed.), Slovenian Journal of Public Health, 52(2), 87-98 (2013). Retrieved March 6, 2019, from https://content.sciendo.com/view/journals/sjph/52/2/sjph.52.issue-2.xml, https://doi.org/10.2478/sjph-2013-0011.

Zupančič, M. (2012). Silver workers-source of knowledge sharing and potential for the. Ljubljana: Ministry of Labour, Family and Social Affairs.

ZSSS (The Association of the Free Trade Unions of Slovenia). (2017). Odziv Zveze svobodnih sindikatov Slovenije na Belo knjigo o pokojninah.. Retrieved March 6, 2019, from https://www. zsss.si/wp-content/uploads/2016/07/deklaracija-BK-o-pokojninah.pdf. 
Open Access This chapter is licensed under the terms of the Creative Commons Attribution 4.0 International License (http://creativecommons.org/licenses/by/4.0/), which permits use, sharing, adaptation, distribution and reproduction in any medium or format, as long as you give appropriate credit to the original author(s) and the source, provide a link to the Creative Commons license and indicate if changes were made.

The images or other third party material in this chapter are included in the chapter's Creative Commons license, unless indicated otherwise in a credit line to the material. If material is not included in the chapter's Creative Commons license and your intended use is not permitted by statutory regulation or exceeds the permitted use, you will need to obtain permission directly from the copyright holder.






\title{
Chapter 34 \\ Spain
}

\section{Jeroen Spijker, Juan Manuel García González and Dolores Puga}

\begin{abstract}
This chapter describes recent developments and debates on older workers' participation in the labour force, retirement decisions and the pension system in Spain, from a social class, health and gender perspective. Spain is one of the most aged countries in the world. However, the Spanish population has one of the lowest levels of employment among people aged 50+ in Europe. Women retire later than men, mainly because they cannot afford to retire earlier. Women have a lower probability of achieving the requisite minimum contributions that give them the right to receive a pension. For women transition to post-employment life depends on perceiving retirement as forced upon them for family reasons or the need to care for other family members in poor health. Health is an important variable in determining the rate of activity among people under 60 years old, however this becomes less important as the incentives of the pension system become more evident. Women are more likely to have temporary work contracts, greater job insecurity and more exposure to emotional pressure. If women also care for relatives, extending working life may further worsen their mental and physical health status.
\end{abstract}

Keywords Extending working life $\cdot$ Employment $\cdot$ Retirement $\cdot$ Policy $\cdot$ Gender $\cdot$ Spain

\section{Introduction}

This chapter briefly describes recent developments debates on the older workers' participation in the labour force, precarious employment, (early) retirement decisions and the pension system in Spain, from a social class, health and gender perspective.

\author{
J. Spijker (凶) \\ Centre for Demographic Studies (CED), Bellaterra, Barcelona, Spain \\ e-mail: jspijker@ced.uab.es \\ J. M. G. González \\ Department of Sociology, Universidad Pablo de Olavide, Seville, Spain \\ D. Puga \\ Spanish National Research Council—CSIC, Madrid, Spain \\ (C) The Author(s) 2020 \\ Á. Ní Léime et al. (eds.), Extended Working Life Policies, \\ https://doi.org/10.1007/978-3-030-40985-2_34
}




\section{Gender and Employment in Spain}

Spain, like other European countries, is faced with an ageing population. Currently, $19 \%$ of the total population is 65 years or older, which is expected to rise to $34 \%$ in 2050 (Instituto Nacional de Estadistica 2018). At the same time, it has one of the lowest labour force participation rates among people aged 50+ in Europe. Partly to blame is the fact that Spain has historically had a more rigid labour-market structure than other western European countries (Jaumotte 2011). Consequently labour market deregulation occurred later than in other countries. Since the 1990s, Spanish macro-economic policy has increasingly been determined at European level (López and Rodríguez 2011). Educational expansion, the legalisation of divorce (1981) and the economic boom (1995-2007) have contributed to rising female labour force participation rates since the early 1980 s, causing gender differences to reduce markedly (Table 34.1).

Spain's historic specialisation in sectors such as tourism and property development seemed perfectly suited to the age of globalisation. However, the rapid growth of the Spanish economy was matched by rapid decline when the economic crisis hit. The housing bubble was the first cause of the crisis, however the economic crisis also affected consumer goods and services industries. Due to the high proportion of employees on short-term and temporary contracts, big businesses were able to reduce their workforces quickly and at very little cost in response to falling demand. This also contributed to the rising unemployment levels (López and Rodríguez 2011), although the employment rate of women aged 50+ was barely affected. Possible explanations include the proliferation of part-time contracts and being pushed into the labour market by family economic demands during the economic crisis (Murcia-López et al. 2016).

\section{Labour Market Exit and Pensions Policies in Spain}

The age at which adults left the labour market also fell markedly during the economic crisis, although this trend already started half-a-century earlier (Gendell 2001). Despite the increase in life expectancy and the delay in labour market entry as a result of educational expansion, the mean exit age dropped from 68 years in 1960 to 60 in 2001 and is about 62 today (OECD 2017), far off the current statutory retirement age (65.5 years in 2018). Behind the decline in the 1980s and 1990s was the increasing use of early retirement schemes for disabled workers or specific dangerous occupations and labour force adjustment plans. The latter were legal procedures initially designed to save companies in a bad short-term economic situation and simultaneously guarantee workers certain rights. However, nowadays this is an instrument used by many companies to maintain or increase profits.

The Spanish social security pension system is a Defined Benefit scheme based on the principle of contributions of employers and workers (de Cos et al. 2017). This 


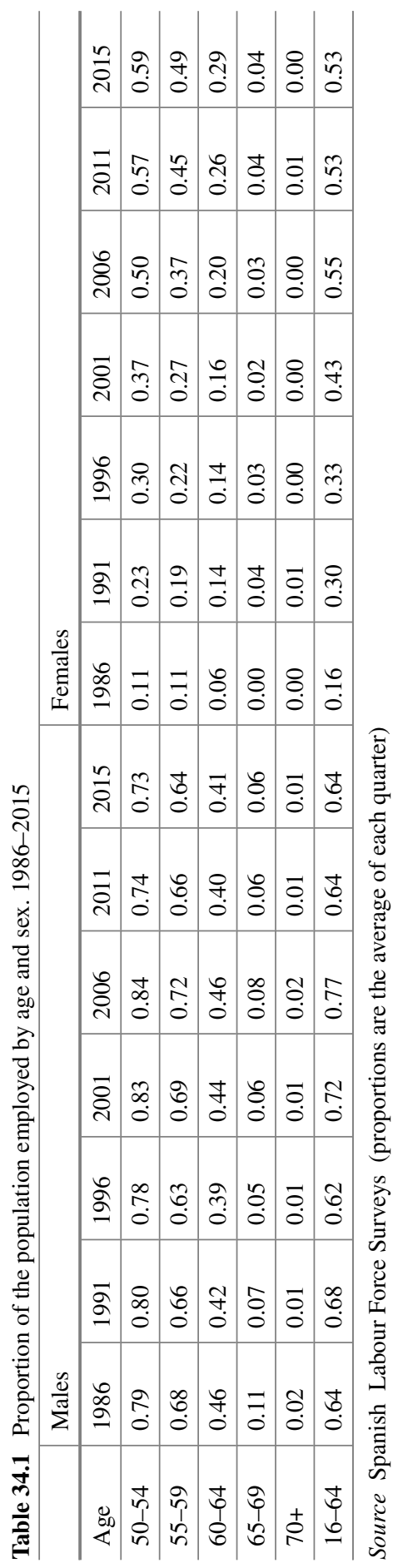


discriminates against women as they were less active on the labour market. In 2016, the Social Security system paid 3,605,892 retirement pensions to men compared to $2,125,985$ women. Although the average monthly pension for men equalled just over $€ 1,200$ and barely $€ 760$ for women, gender differences are declining in the new admissions (46.7\% in 2006 compared to $22.5 \%$ in 2016 (Ministerio de Empleo y Seguridad Social 2017)).

Notwithstanding, the gender gap in Spanish pensions exceeds the European average when calculated on the basis of the total population $(+28 \%)$. A considerable proportion of Spanish elderly women lack a contributory retirement pension (Burkevica et al. 2015), due to lack of remunerated employment during their working lives or lack of years in employment to access a contributory retirement pension (Ayuso and Chuliá 2018). The relationship between gender and retirement age in Spain is paradoxical, given the average retirement age amongst women is higher than for man as they cannot afford to retire earlier (Radl 2013b).

The pension system itself is financed through a Pay-As-You-Go model. There is no law that imposes a mandatory retirement age, although there are some sector-specific regulations. The state pension age, the age an individual can apply for $100 \%$ of a retirement pension, is based on the number of years in employment and contributions made to the pension system. In Spain, the state pension age was 65 for both sexes until 2013 when the pension system was reformed. However, as was explained earlier, the mean exit age has consistently been lower for the last three decades. For instance, workers in dangerous occupations can still leave the labour market and receive a pension from the age of 52 .

From 2013 three main measures were introduced in the Spanish pension system: (1) Retirement age gradually increases from 65 to 67 years by 2027 and the early retirement age (possible if certain conditions are met) from 61 to 63 years; (2) The contributory period used for the calculation of the amount increases from 15 to 25 years in 2022; (3) The number of years of income tax required to access to the maximum pension increases from 35 to 37 years. Since the reform, it is also possible for individuals above the normal retirement age to combine retirement benefit receipt and work. However, in these cases the amount of the pension benefit is reduced by $50 \%$. Since 2014, pension benefits are indexed annually to a new Adjustment Index calculated according to the number of contributory pensions, the variation of the average pension amount and balance between revenues and expenses of the Social Security system. From 2027, the initial pension benefit paid to new retirees will be adjusted every five years based on life expectancy gains (Alda García 2016).

Finally, an increase in minimum pensions after policy reforms in 2005 especially benefitted women as they are more likely to receive non-contributory pensions. This includes the widow's pension that was introduced in Spain in 1955 to protect situations of need for women who had lost their husbands in a family model with strong gender roles. 


\section{Extended Working Life Employment Policies}

Although employment protection legislation is stricter in Southern European countries than in liberal economies, there has recently been a tendency in Spain towards higher deregulation of the labour market, for instance by using temporary contracts (OECD 2013). The aim of the 2012 labour market reforms was therefore to develop a framework which would allow efficient management of labour relations, employment creation, employment stability and to achieve a better balance in the use of open ended and temporary contracts, although until now the impacts of the reform are mixed (Corral 2015).

Following recommendations from social partners, the Global Strategy for the Employment of Older Workers 2012-2014 (Strategy 55+) highlighted 'the maintenance of older workers' employment as a way to contribute to the extension of working lives' and promote reintegration into the labour market (Ysàs 2016). Vocational training was recommended, with a particular focus on unemployed women aged 55+ with lower levels of education employed in catering, personnel, security or sales sectors (Programa Acreditate) as well as victims of gender-based violence. Unfortunatley this initiative was not effectively implemented. In 2011 a Royal Decree on workers regulations (Estatuto de los Trabajadores) was enacted to allow flexible retirement through a replacement contract under collective agreements when the worker has not yet reached legal retirement age. According to the National Service of Employment, there were 15,537 replacement contracts in Spain in 2016. This labour reform also facilitated the return of older workers to the labour market through: (1) a reduction of $40 \%$ in the social security contribution for one year for workers aged $59+$ with four or more years of service in the same company; (2) permitting part-time work while receiving a pension; (3) promoting open-ended employment contracts for workers aged $45+$; (4) enabling workers aged $52+$ to juggle between unemployment benefit and a salary under certain circumstances and entitling companies to grants. Spain still has no specific anti-age discrimination policies.

\section{Working-Condition Related Policies}

Ill-health and unemployment remain obstacles to prolonging working life (Radl 2013a). Regardless of age, employees who experience physical and psychosocial risks, high demands and low levels of autonomy are more likely to experience poor health. Employers should consider the potential discrepancy between a worker's physical work capacity and the demands and barriers they face. This would decrease the risk of dropping out of the labour market via alternative exit routes to retirement, such as disability or long-term unemployment benefits as well as social exclusion and poverty.

Policies surrounding working conditions are important in promoting work-life extension while minimising health risks and supporting active and healthy ageing in 
the workplace. Standard strategies have focused on the ageing workforce by considering older workers as a sensitive group that need special protection, permitting older workers with health conditions or employed in jobs which are considered dangerous for health to exit the labour force. The Strategy 55+ contains measures oriented to: (1) promote new skills at work, (2) offer more flexible work schedules, breaks, paces, shifts... adapted to physical condition, (3) develop prevention programmes according to job risks, age, and physical condition, (4) provide information and courses about health prevention and labour risk prevention, (5) promote healthy habits at work and daily life. It also considers the specific risks for older women.

\section{Precarious Employment}

Over the last two decades, Spain has had six labour reforms which proved ineffective in reverting a strongly established precarious and temporary labour market. The 2012 labour reform did not improve employment security; a problem affecting both workers aged 50+ and those with a precarious job or who had recently lost their job. Older female workers are more likely to have temporary employment contracts, and consequently greater job insecurity and more exposure to emotional pressure, the prevalence of physical and mental health conditions is higher among women than among men (Eurofound 2012). If women also combine employment with care for relatives, extending working life may actually further exacerbate their already worse mental and physical health states. While significant gender differences in retirement behaviour exist, these appear to be largely driven by women's lower-class positions, as social class influences retirement timing in a similar way for women and for men $(\operatorname{Radl} 2013 a)$.

\section{Debate on Extended Working Life}

The political support for generous early retirement pensions in Spain relies on the existence of a significant group of older people with incomplete working history, and therefore not entitled to an old age pension (Conde-Ruiz and Galasso 2003). Although the Spanish system does not pay a particularly generous average pension relative to GDP per capita, its 'generosity' lies in providing relatively large minimum pensions to individuals with below-average working histories and/or low wages. This generates very strong incentives for people to retire as early as possible (Jiménez-Martín and Sánchez-Martín 2007).

While the ageing Spanish workforce is still less of an issue than in other European countries due to a later baby boom and a large influx of working-age migrants during the 2000s, the recent economic crisis has cultivated uncertainty among politicians, media and academics, questioning the sustainability and purchasing power of 
the current pension. Popular mobilisations by retirees during the previous government provoked by the non-revaluation of pensions and subsequent loss of purchasing power were highly instrumental in positioning pensions in the public debate. There is a permanent parliamentary committee (Toledo Pact) since 1995 that addresses the retirement and pension system and issues recommendations for changes to the public pension system. However, in 2017 and 2018 significant attention was afforded towards the pension system. All the committee's political parties agreed that more money was needed for pensions, however the parties did not agree on how pensions would be financed. While the political left advocated raising more money by increasing the maximum contribution bases, this proposal was not shared by the rest of the political spectrum, especially if maximum pensions would not be raised in parallel. There was greater consensus on increasing the contribution from taxes, although not regarding the origin of this (raising taxes by introducing a new tax or through debt issuance).

The adequacy of pensions is the next item on the agenda. Some political parties would like to see the minimum pension linked to the average salary and pension, reducing control of governments in power to intervene. Centre-right parties are calling for a redefinition of widow's and orphans' pensions, proposing these benefits are paid through taxes rather than social security contributions. However, the political left fears that this encourages increaseds reliance on welfare assistance. The current debate on the annual revaluation of pensions has neglected one of the fundamental aspects of the 2012 reform, namely linking the amount of pension received at the time of retirement to life expectancy. Yet, despite the fact that the statutory retirement age now progressively increases to 67 , it is a scarcely discussed subject. Moreover, there is still no political consensus as left-wing parties continue to reject its implementation. Finally, in this debate unions mainly strive for pensions to be annually revaluated based on changes in the cost of living and that pensions are financed by the national budget or a final tax. Other organisations, such as the Bank of Spain, insist on the need to stimulate savings during adult life, encouraging investment in financial instruments.

There is some concern about the relationship between health and retirement. Health status plays an important role explaining transitions out of employment as individuals in the worst health quintile are twice as likely to retire compared to individuals in the best health quintile (Prieto et al. 2002). The effects of the incentives from the different social security schemes on employment behaviour are concentrated among individuals in worst health, while other groups seem not to be affected (GarcíaPérez et al. 2013). Employment rates of healthy and less healthy individuals converge from age 60 , the age at which retirement plays a predominant role. Health is an important variable in determining the rate of activity among people younger 60 years old, but it becomes less important as the incentives of the pension system become more evident (Jiménez-Martín 2011). Individuals with deteriorated health move not only towards economic inactivity, but also towards unemployment. This result raises an important question: If we want to design integration policies to keep individuals at work, it is important to understand the role that health plays when individuals are deciding whether to go back to work? 
Regarding the relationship between caregiving and retirement, in Spain providing intensive informal care decreases the probability of employment by about $10 \%$ (Moya-Martínez et al. 2012). Labour effects appear to be concentrated in intensive carers, co-resident carers and those who provide care for long periods (Casado-Marín et al. 2011).

The debate about age discrimination has only just started. Discrimination against older workers is high and, moreover, may start at a surprisingly young age, perhaps already in the late thirties (Albert et al. 2011). The efficacy of policies which rely only upon economic disincentives to reverse the early exit trend is called into question by widely internalised age norms which are incompatible with later retirement (Radl 2012). Instead of merely being faced with monetary punishment for early retirement, actors need to be persuaded that older workers are more productive than often assumed.

Training policy needs to reach out to the numerous Spanish adults who left education with poor skills. On the job learning opportunities are less frequent in Spain than in other EU countries and a substantial share of workers are poorly skilled (Jin et al. 2017). In a context where the cost gap between permanent and temporary workers is so high, employers have few incentives to invest in training their temporary workers. This underinvestment may have negative consequences on the skills competences that workers acquire at the workplace (Cabrales et al. 2014). Although during the recession the training needs of the population increased, there has not been an increase in participation in training programmes, partly because of cuts in the financing of employment training. Contrary to most EU-15 countries, Spain does not have programmes aimed at providing adults with basic educational competences beyond the return to school in the regulated education system (Felgueroso 2015).

Spanish employers' views on older workers are less outspoken than in other European countries and limited policy initiatives have been taken. Only $28 \%$ of Spanish employers expect the average age at which people leave the workforce to increase during the next ten years; and only $17 \%$ expect the same for their own organisation (Van Dalen et al. 2009). Spanish employers expect an ageing workforce to provide an increase in know-how and experience but also in labour costs and resistance to change. For example, just one in ten Spanish employers report offering training programmes for older workers (ibid.).

\section{Gender and Health Implications}

Health is an important variable in determining the rate of activity among people under 60 years old, but it becomes less important as the incentives of the pension system become more evident. In general women are more likely to have temporary work contracts, greater job insecurity and more exposure to emotional pressure. Regarding reasons for early retirement, pursuing personal interests is more important for women than for men. Men highlighted health problems and pressures from employer as reasons for early retirement to a greater extent than women (Fernández et al. 2008). 
Gender also plays a role in a forced retirement model, as especially women with a retired partner have a lower probability of remaining in employment or returning to work following a spell of inactivity (Jiménez-Martín et al. 2006). Nevertheless, in Spain women retire on average two years later than men as they often cannot afford to retire earlier ( $\operatorname{Radl} 2013 \mathrm{~b}$ ). This is because women have a lower probability of achieving the requisite minimum contributions that give them the right to receive a pension. Consequently, their retirement is more conditioned by their husband's retirement or is forced upon them for family reasons, including the need to care for family members in poor health (Alcover et al. 2012).

\section{Policy Recommendations}

It would be an error to think that the main reason that the state cannot assume the cost of retirement or that there will be a shortage of workers is because of population ageing (Spijker and MacInnes 2013). Disability pensions and collective redundancies are behind the low labour force participation rates among older adults in Spain. Therefore solely raising the retirement age will not solve the current crisis of state pension funds. Rather, lowering unemployment, particularly among young people, raising the employment rate of women and people aged 50-64 years, as well as combatting the grey or black economy, are important policy factors to consider.

The Spanish social security pension system discriminates against women. Gender differences in the labour lifecourse must be taken into consideration in the design of retirement policies. The implications of precarious employment for pensions, in current and future generations, is an issue that should be urgently addressed by public policy. Moreover, employers should consider the potential discrepancy between a worker's physical work capacity and the demands and barriers they face. Subsequent research on the implications of the extension of working life in gender and health is necessary to ensure a safe old age for the entire population.

\section{References}

Albert, R., Escot, L., \& Fernández-Cornejo, J. A. (2011). A field experiment to study sex and age discrimination in the Madrid labour market. The International Journal of Human Resource Management, 22(02), 351-375. https://doi.org/10.1080/09585192.2011.540160.

Alcover, C.-M., Crego, A., Guglielmi, D., \& Chiesa, R. (2012). Comparison between the Spanish and Italian early work retirement models: A cluster analysis approach. Personnel Review, 41(3), 380-403. https://doi.org/10.1108/00483481211212995.

Alda, G. M. (2016). La última reforma del sistema público de pensiones en España: de la ampliación a los 67 años al factor de sostenibilidad. Análisis Financiero, 130, 62-77.

Ayuso, M., \& Chuliá, E. (2018). ¿Hacia la progresiva reducción de la brecha de género en las pensiones contributivas? Documentos de Trabajo Instituto BBVA de Pensiones, 22. https://www.jubilaciondefuturo.es/recursos/doc/pensiones/20160609/esfe/las-pensiones-yla-brecha-de-genero.pdf. 
Burkevica, I., Humbert, A. L., Oetke, N., \& Paats, M. (2015). Gender gap in pensions in the $E U$, Research note to the Latvian Presidency. Vilnius: European Institute for Gender Equality Retrieved from https://eige.europa.eu/sites/default/files/documents/MH0415087ENN_Web.pdf.

Cabrales A., Dolado J., \& Mora, R. (2014). Dual labour markets and (lack of) on-the-job training: PIAAC evidence from Spain and other EU countries. IZA Discussion Papers, No. 8649.

Casado-Marín, D., García-Gómez, P., \& López-Nicolás, Á. (2011). Informal care and labour force participation among middle-aged women in Spain. SERIEs, 2(1), 1-29. https://doi.org/10.1007/ s13209-009-0008-5.

Conde-Ruiz, J. I., \& Galasso, V. (2003). Early retirement. Review of Economic Dynamics, 6(1), 12-36. https://doi.org/10.1016/S1094-2025(02)00018-2.

Corral, A. (2015). A first assessment of the 2012 labour market reform European Observatory of Working Life (EurWORK), Eurofound. Retrieved from https://www.eurofound.europa.eu/ observatories/eurwork/articles/labour-market-law-andregulation/spain-a-first-assessment-ofthe-2012-labour-market-reform.

de Cos, P. H., Jimeno, J. F., Ramos, R. (2017). The Spanish public pension system: Current situation, challenges and reform alternatives Banco de España \& Occasional Papers Homepage. Retrieved from https://www.bde.es/f/webbde/SES/Secciones/Publicaciones/ PublicacionesSeriadas/DocumentosOcasionales/17/Fich/do1701e.pdf.

Eurofound. (2012). Fifth European Working Conditions Survey-Overview report Retrieved from https://www.eurofound.europa.eu/ewcs-2010-e-book.

Felgueroso, F. (2015). Claves para mejorar la educación y formación de adultos en España en la post-crisis Fundación de Estudios de Economía Aplicada (FEDEA) Retrieved from http://www.sociedadyeducacion.org/site/wp-content/uploads/Claves-para-lamejora-educacion-de-adultos.pdf.

Fernández, J. J., Crego, A., \& Alcover, C. M. (2008). Relaciones entre factores sociodemográficos, motivación hacia el retiro temprano y satisfacción en la vida postlaboral: análisis exploratorio en una muestra de prejubilados españoles. Revista de Psicología del Trabajo y de las Organizaciones, 24(3), 417-439.

García-Pérez, J. I., Jiménez-Martín, S., \& Sánchez-Martín, A. R. (2013). Retirement incentives, individual heterogeneity and labor transitions of employed and unemployed workers. Labour Economics, 20, 106-120. https://doi.org/10.1016/j.labeco.2012.11.006.

Gendell, M. (2001). Retirement age declines again in 1990s. Monthly Labor Review, 124(12), 12-21.

Instituto Nacional de Estadistica. (2018). Proyecciones de población 2018-2068. Resultados nacionales. Retrieved 3/9/2019, from INE http://www.ine.es/dynt3/inebase/es/index.htm?padre= $4749 \&$ capsel $=4752$.

Jaumotte, F. (2011). The Spanish labor market in a cross-country perspective International Monetary Fund Working Paper 11/11. https://www.imf.org/ /media/Websites/IMF/imported-full-text-pdf/ external/pubs/ft/wp/2011/_wp1111.ashx.

Jiménez-Martín, S. (2011). Bienestar 4: Salud, mortalidad y participación laboral en edades avanzadas Apuntes FEDEA. Barcelona: Universitat Pompeu Fabra.

Jiménez-Martín, S. M., Labeaga, J., \& Vilaplana Prieto, C. (2006). A sequential model of older workers' labor force transitions after a health shock. Health economics, 15(9), 1033-1054. https:// doi.org/10.1002/hec.1163.

Jiménez-Martín, S., \& Sánchez-Martín, A. R. (2007). An evaluation of the life cycle effects of minimum pensions on retirement behavior. Journal of Applied Econometrics, 22(5), 923-950. https://doi.org/10.1002/jae.956.

Jin, Y., Caldera Sánchez, A., \& Garcia Perea, P. (2017). Reforms for more and better quality jobs in Spain. OECD Economics Department Working Papers, 1386.

López I., \& Rodríguez E. (2011). The Spanish Model New Left Review, 69, 5-28. http://www. miguelangelmartinez.net/IMG/pdf/2011_Lopez_Rodriguez_Spanish_model_NLR.pdf.

Ministerio de Empleo y Seguridad Social. (2017). Anuario de Estadísticas 2016. Ministerio de Empleo y Seguridad Social. Retrieved from http://www.mitramiss.gob.es/es/estadisticas/ contenidos/anuario.htm. 
Moya-Martínez, P., Escribano-Sotos, F., \& Pardo-García, I. (2012). La participación en el mercado laboral de los cuidadores informales de personas mayores en España. Innovar, 22(43), 55-66.

Murcia-López, G., Delclós-Clanchet, J., Ubalde-López, M., Calco-Bonacho, E., \& GarcíaBenavides, F. (2016). Has the Spanish economic crisis affected the duration of sickness absence episodes? Social Science and Medicine, 160, 29-34. https://doi.org/10.1016/j.socscimed.2016. 05.009.

OECD. (2013). OECD Employment outlook 2013. Paris: OECD Publishing.

OECD. (2017). Pensions at a Glance 2017: OECD and G20 indicators. Paris: OECD Publishing.

Prieto J., Romero D., \& Álvarez S. (2002). Estado de salud y participación laboral de las personas mayores Papeles de Trabajo del Instituto de Estudios Fiscales, 15/02. https://econpapers.repec. org/paper/hpewpaper/y_3A2002_3Ai_3A15.htm.

Radl, J. (2012). Too old to work, or too young to retire? The pervasiveness of age norms in Western Europe. Work, Employment \& Society, 26(5), 755-771. https://doi.org/10.1177/ 0950017012451644.

Radl, J. (2013a). Labour market exit and social stratification in Western Europe: The effects of social class and gender on the timing of retirement. European Sociological Review, 29(3), 654-668. https://doi.org/10.1093/esr/jcs045.

Radl, J. (2013b). ¿Por qué las mujeres en España se jubilan más tarde que los hombres? Revista Española de Investigaciones Sociológicas, 142(1), 109-122. https://doi.org/10.5477/cis/reis. 142.109.

Spijker, J., \& MacInnes, J. (2013). Population ageing: the timebomb that isn't? British Medical Journal, 347, f6598. https://doi.org/10.1136/bmj.f6598.

Van Dalen, H. P., Henkens, K., \& Schippers, J. (2009). Dealing with older workers in Europe: a comparative survey of employers' attitudes and actions. Journal of European Social Policy, 19(1), 47-60. https://doi.org/10.1177/0958928708098523.

Ysàs H. (2016). Older workers and employment policies: which role do the social partners play? IUSLabor, 1, 1-22. https://www.upf.edu/iuslabor/_pdf/2016-1/Ysas.pdf.

Open Access This chapter is licensed under the terms of the Creative Commons Attribution 4.0 International License (http://creativecommons.org/licenses/by/4.0/), which permits use, sharing, adaptation, distribution and reproduction in any medium or format, as long as you give appropriate credit to the original author(s) and the source, provide a link to the Creative Commons license and indicate if changes were made.

The images or other third party material in this chapter are included in the chapter's Creative Commons license, unless indicated otherwise in a credit line to the material. If material is not included in the chapter's Creative Commons license and your intended use is not permitted by statutory regulation or exceeds the permitted use, you will need to obtain permission directly from the copyright holder.

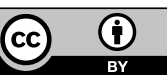




\title{
Chapter 35 Sweden
}

\section{Lars-Gunnar Engström, Satu Heikkinen and Clary Krekula}

\begin{abstract}
Extended working life in Sweden is discussed using the old age pension reform of 2001 and debates and policies following this reform as a starting point. Extended working life is also discussed in relation to flexible work, unpaid caregiving, employers' attitudes toward older workers and working environment. The implications of different outcomes of an extended working life for men and women and possible health effects are considered. Several issues with gender as well as health implications have to be further analyzed and evaluated to ensure not only financial sustainability of the pension system but also equal opportunities for men as well as for women both in an extended working life and in life after retirement.
\end{abstract}

\section{Introduction}

This chapter focuses on extended working life (EWL) in Sweden outlining the old age pension reform of 2001 and debates and policies following this reform. Furthermore, implications on different outcomes for men and women and possible health effects are considered. Sweden has reached a point in time where evaluation and a better comprehension of the consequences of the 2001 reform is possible.

\section{The Swedish Pension System}

A state pension system was implemented in Sweden in 1913 for people once they turn 67. The retirement age remained unchanged in the first major pension reform in 1959 when the Allmän Tilläggspension (Supplementary Pension) (ATP) system was implemented. The old-age pension from 1913, based on a flat rate, was now

L.-G. Engström $(\bowtie) \cdot S$. Heikkinen · C. Krekula

Department of Social and Psychological Studies, Karlstad University, Karlstad, Sweden

e-mail: lars-gunnar.engstrom@kau.se; lars-gunnar.engstrom@jamy.se 
complemented by income-related benefits. The pension system was based on payas-you-go (PAYG) principles where current pension contributions, collected through payroll taxes, financed current pension expenditure (Sundén 2006).

In the 1980s and early 1990s, the pension system became prioritised on the political agenda and led to a new pension reform, implemented in 2001. It was framed by concerns about financial sustainability problems with the benefit-based pension schemes due to demographic developments with greater life expectancy and the young starting employment later than before. The new pension system was still based on PAYG, however on a so-called life-long principle, to achieve better financial sustainability due to a strong link between contributions and benefits. For those with low lifetime earnings, the pension system includes a minimum guaranteed benefit as a poverty safety net. With regard to EWL, the system includes measures to prolong working life, for example, a raised minimum age for pension eligibility and higher gross replacement rate when retiring after 65 years of age (SOU 2012).

Forecasts of the new pension system predicted that women would have higher replacement rates than men (Ståhlberg et al. 2006). However, later studies showed that women received a lower pension in relation to final income than men. Women also to a higher degree than men receive the minimum guaranteed pension. In 2014, $56 \%$ of women with pensions received a full or part-guaranteed pension, compared to $16 \%$ among men (Swedish Pensions Agency 2016). Explanations are lower wages and that part-time work is more common among women (Öjemark 2016).

Even if the pension reform in 2001 seemed to contribute to an increasing retirement age, it was in political debate judged as not being enough. A new commission of inquiry, the Government Commission for Longer Working Life and Retirement Age, was formed in 2011 with the explicit objective of analysing age limits in the pension system and opportunities of extending the working life (Committee Directive 2011). The media debate was limited until February 2012 when the prime minister claimed that there was a need to work until age 75 (Dagens Nyheter 2012-02-07) which led to several articles and replies from societal actors. Several trade unions replied that their members were not even able to work until the present retirement age and how were they then supposed to work until 75 ?

In 2013 the Government Commission for Longer Working Life and Retirement Age presented its final report suggesting raising the minimum age limit in the pension system from 61 to 62 in 2015 and to 63 in 2019; raising the age limit for guarantee pension from 65 to 66 in 2019; and raising the age limit in the Employment Protection Act (LAS) from 67 to 69 in 2016. They also proposed a recommended retirement age following the development of average life expectancy. Generally, the consulted stakeholders agreed upon the need to extend working life. However, there were many critical standpoints. Trade unions and pensioner organisations pointed out that the report was too restricted in focus on the latter part of life course since extended working life also need to be discussed in relation to labour market entry, work environment and opportunities of full-time work (Ministry of Health and Social Affairs 2013-11-29). The main pensioner organisations maintained that "Before the proposal of raising the retirement age is implemented we find that measures in the work environment must be taken in order to enable all to work until the present 
norm of retirement age" (PRO et al. 2013-08-30). Several organisations noted a lack of gender perspective and of gender analysis of the consequences of the proposals (Ministry of Health and Social Affairs 2013-11-29).

The proposals from the final report were handled in a multi-party Pension group. In 2015 an inquiry on gender inequality was initiated, resulting in an action plan (Government 2017-01-23); for example a proposal to the Pension group on a raise of the guarantee pension (Government 2018-03-06). In late 2017 the Pension group had agreed upon a proposal raising the minimum age limit from 61 to 62 in 2020, to 63 in 2023 and 64 in 2026. The age limit of LAS will be raised from 67 to 69 (Tidningarnas telegrambyrå 2017-12-14). Once again, criticisms were made by some trade unions and pensioner organisations due to inequalities between different groups of workers. However, political agreement on raising the retirement age among the involved parties resulted in a Government bill in 2018. In October 2019 the parliament finally decided that the retirement age will be raised, starting 1 January 2020 with a change of the lower age limit from 61 to 62 , continuing with a change to 63 in 2023 . A new age concept ("benchmark age for pensions") relating to the developments of the average age expectancy was introduced. From 2026 onwards increases to the retirement age should be related to the benchmark age (Government 2018-05-23). To summarise the Swedish debate; the process ending in an increase in the retirement age was anything but smooth. Even if there was initially a consensus among most political parties in Sweden on the need to raise the retirement age, the political proposals were severely challenged by several stakeholders resulting in modifications of the proposals and new inquiries. The reform was delayed but nevertheless finalized in the end.

Sweden has a high average age of retirement compared to the EU. The actual average retirement age among people aged 50-69 was 64 years in Sweden in 2012 (Statistics Sweden 2014b). For the EU the average was 59 years. In the age group 50-64 years Sweden had the third lowest percentage of retirees among European countries. The proportion was $13.8 \%$ in Sweden, while the EU average was $27.9 \%$ (Statistics Sweden 2014b). The retirement age has also been rising, from 61,8 years for women and 62,7 years for men in 1998 to 62,7 and 63,7\%, respectively in 2008 (Klevmarken 2010). Despite these high numbers and an increasing retirement age, it was stated by a commission of inquiry that the retirement reform in 2001 has not created sufficient incentives for individuals to retire later (SOU 2013). More efforts are claimed to be needed in order to motivate and facilitate older people to work. It is also stated that an increasing number of older people both have the ability and want to do so. However, older workers are not a homogenous group and there are groups which already have difficulties reaching today's normal retirement age such as certain groups of women in sectors of care and generally professions with a tough physical and psychosocial work environment (for discussion see Krekula et al. 2017).

Research on retirement has for instance focused on the transition into retirement in terms of well-being and health. Nordenmark and Stattin (2009) concluded that those who were forced to retire, e.g. due to health reasons or labour market factors, showed less psychosocial well-being than others, particularly for men. Halleröd et al. (2013) showed that individuals depending on income from the welfare system, e.g. health insurance, part-time pension or unemployment insurance, prior to retirement 
experienced a considerably lower sense of well-being also as pensioners. Statistical analyses show that health and wellbeing for pensioners is related to the accumulation of positive and negative factors during the life course rather than the retirement transition itself (cf. Hult et al. 2010).

SOU (2012: 28) presents poor health, reduced work ability, having straining or monotonous work tasks, the retirement of a close family member and the wish to have more leisure time and time with family and friends as factors leading to early retirement. Strong traditional norms on when to retire can be seen in that an overwhelming majority continue to retire at the age of 65 despite that this retirement age was abolished more than 10 years ago.

\section{EWL and Flexible Work}

Research focusing specifically on late work conditions and flexible work opportunities during the transition to retirement is still very limited in Sweden. There are some studies investigating which factors may extend working life. Klevmarken (2010) notes that the increase in employment among older people which has been noticeable since the start of the 21 st century can be explained, for example, by better health and a higher educational level, and by political decisions having made it profitable from an economic perspective to postpone retirement. He concludes by adding that entrepreneurs, highly-qualified people, single people, people with low incomes and more men than women tend to work after age 65. In addition, a study from Arnek (2012) suggests that economic incentives, opportunities for part-time and flexible working hours may contribute to postponed retirement, and that a lot of people $(41 \%)$ continue to work because they find it stimulating. However, the possibility to extend working life is also related to whether an individual is caring for close family members. There are clear gender differences in this regard with more women working part time or leaving work to care for an older family member (Szebehely 2014).

Studies note that the opportunity to work until age 65 and beyond is unequally divided between men and women. People with professions requiring a lot of social contact with caregivers or clients, so called contact professions, run a greater risk of leaving the labour market early due to heavy workloads, strain and lack of control over their work situation (Wall 2014; see also Anxo et al. 2014). Within the municipal sector, part-time and temporary employment have become close to normative within female dominated care and welfare professions, which can lead to a weaker connection with the labour market and greater difficulties in remaining in working life in the long term (Wall 2014).

Two committees on flexible employment have recently been formed by the Swedish government. The first concerning flexible measures to improve the ability for people with disabilities to get and maintain a job (Committee directive 2017a). The other commission concerns safety and development in employment with regard to working hours and time off from work (Committee directive 2017b). In the directive, 
it is mentioned that an ageing population puts higher demands on society's ability to utilize the full potential of the workforce throughout its working life. Against this background, measures that can contribute to facilitate further education and career changes in later life is emphasized.

\section{Age Discrimination/Ageism}

In the current Government Commission for Longer Working Life and Retirement Age (SOU 2013), age discrimination is explicitly related to the issue of EWL. The report stresses the necessity of measures against age discrimination, for example, through tougher legislation. Research on Swedish working life displays that discrimination against older workers seems to be widespread (Stålhammar 2009; Krekula 2011; Arnek 2012). A survey of 1,053 persons applying for jobs in Sweden showed that a third of those experienced that their age was an issue, this was especially pronounced among the youngest and oldest applicants (Mild Nygren and Sjöberg 2012). Other studies have discussed age discrimination in working life in relation to age codings, i.e. the assumption that age groups are more or less suitable for different work tasks. Age codings function as a basis to organise the workplace resulting in age-segregated workplaces (Krekula 2010, 2011). With regard to EWL there is still little knowledge on how age discrimination and ageism affect retirement behavior (Krekula et al. 2017).

\section{Caregiving}

Swedish research on the consequences of family care for individuals' health, their connection with the labour market and retirement behaviour is limited (Sand 2014; Szebehely 2014). Studies show that family care in Sweden today has great consequences for the caregivers' well-being, gainful employment and economy (Szebehely et al. 2014). A survey of the age group 45-66 showed that it is equally common among men and women to provide care for a close family member at least once a month. This applies to $42 \%$ of both women and men. However, closer comparisons reveal gender differences in terms of how often men and women act as caregivers. It is more common among the women to provide care for a close family member every day; $6 \%$ of women and $4 \%$ of the men provided care on a daily basis. On average, female caregivers provided assistance $5.4 \mathrm{~h}$ per week, whereas male caregivers provided assistance $3.8 \mathrm{~h}$ per week (Szebehely et al. 2014).

Women were also affected negatively by their role as caregivers to a greater extent, i.e. when it comes to their own well-being and participation in working life (ibid). More than half of female caregivers stated that the caregiver role was psychologically stressful, compared to a third of the men. Almost twice as many women as men stated that it was physically demanding (27 and $15 \%$ respectively). The connection between 
the extent of family care and its consequences is described as very strong; the more care an individual provides for a family member, the greater the likelihood that the well-being, gainful employment and economy is affected negatively. Women also risk ending up in a situation in the later part of their working life where family care has significant consequences for their gainful employment to a greater extent than men. This is related to the cuts in publicly funded geriatric care, resulting in older people having less access to assistance.

\section{Employer's Attitudes to EWL}

A few studies have been conducted on employer's attitudes towards older workers or EWL in Sweden. The studies have explored the relationships between managers' attitudes and retirement. Nilsson et al. (2011) investigated managers' attitudes among other factors in a study with 1,792 older respondents and the results showed that managers' attitudes to older workers is an important factor that influences whether older workers want to work until age 65 or beyond. Another study, shows how the managers' attitudes to older workers retirement time is connected to their own retirement planning (Nilsson 2018). Those managers who plan to work beyond age 66 were more positive to older workers extending their working life than managers who were planning to retire at age 66 . The study also showed both positive and negative attitudes towards older workers. They are viewed as more careful, experienced and skilled and able to guide younger employees. On the other hand, negative views were also common, for example that older people are resistant to change and slower.

\section{Working Environment}

Working environment has been presented as central in relation to extended working life (SOU 2013). Recently the Swedish Work Environment Authority conducted a knowledge compilation called Healthy workplaces for men and women of all ages (2016) focusing on older workers and EWL. Inequality in health has increased in Sweden in relation to education and gender. Data from Statistics Sweden show that the gap between groups with secondary and tertiary education levels in average life expectancy at age 30 has increased from 4.1 years to 5.4 years for women and from 4.6 years to 5.8 years for men. Women have more health problems and a higher amount of sick leave than men. One explanation is the gendered labour market where female-dominated sectors often perform tasks leading to sustaining repetitive strain injuries. In addition, tools, protective equipment and workstations are usually designed for men, not women. Psychosocial stress is more common among women as they work more often than men in occupations that include encounters with other people. 


\section{Conclusion}

The Swedish pension reform of 2001 aimed at establishing a financially sustainable old age pension system. Benefits were closely linked to contributions to achieve this but also economic incentives for an extended working life was an important feature introduced to achieve sustainability. However, there was soon a broad political consensus that these measures were not enough, resulting in new inquiries and proposals focusing on raising the retirement age. Critique from several stakeholders caused delays of the reform, which after some modifications was put into practice 1 January 2020.

Several issues related to gender and health implications need to be further analyzed and evaluated to ensure not only financial sustainability but also equal opportunities for men as well as for women both in an extended working life and in life after retirement. Among these issues can be noted the working environment in a gender segregated labour market, the division of unpaid care between men and women and the normative approach to retirement age among both employers and employees.

\section{References}

Anxo, D., Månsson, J., \& Ivarsson, E. (2014). Sambandet mellan arbetsmiljö och beslutet att lämna arbetskraften. Arbetsmiljöverket. Rapport 2014-8.

Arnek, M. (2012). Skäl till att gå i pension eller inte [Reasons to retire or not], Pensionsmyndigheten analyserar 2012:1. Stockholm: The Swedish Pensions Agency.

Committee Directive. (2017a). Flexiblare insatser (exempelvis flexjobb) för attförbättra möjligheten för personer med funktionsnedsättning att få och behålla ett arbete [Flexible measures (e.g flex job) to improve opportunities for people with disabilities to get and maintain a job]. Committee directive 2017:41 Stockholm: Ministry of Labour.

Committee Directive. (2017b). Trygghet och utveckling $i$ anställningen vad gäller arbetstid och ledighet [Security and development in employment regarding working hours and leaves]. Committee directive 2017: 56, Stockholm: Ministry of Labour.

Committee Directive. (2011). Översyn av pensionsrelaterade åldersgränser och möjligheter för ett längre arbetsliv. [Review of retirement-related age-restrictions and opportunities for an extended work life] 2011:34. Stockholm: Ministry of Health and Social Affairs.

Dagens Nyheter (2012-02-07). "Fler måste kunna byta karriär mitt i livet"-statsministern om framtidens arbetsmarknad [More people will have to change career in the middle of life". The Prime minister about future labour marker]. Ewa Stenberg.

Government 2017-01-23. Handlingsplan för jämställda pensioner [Actionplan for equal pensions]. https://www.regeringen.se/rattsliga-dokument/departementsserien-och-promemorior/ 2017/01/handlingsplan-for-jamstallda-pensioner/ (2018-10-02).

Government 2018-03-06. Förslag om höjd garantipension och förbättrat bostadstillägg. [Proposal about a raised guarantee pension and an improved housing supplementary allowance]. https:// www.regeringen.se/pressmeddelanden/2018/03/forslag-om-hojd-garantipension-och-forbattratbostadstillagg/ (2018-10-02).

Government 2018-05-23. Regeringens proposition 2018/19:133. En riktålder för höjda pensioner och följsamhet till ett längre liv. [Government proposal on a benchmark age for pensions related to average age expectancy]. 
Halleröd, B., Örestig, J., \& Stattin, M. (2013). Leaving the labour market: the impact of exit routes from employment to retirement on health and wellbeing in old age. European Journal of Ageing, $10(1), 25-35$.

Hult, C., Stattin, M., Janlert, U., \& Järvholm, B. (2010). Timing of retirement and mortalwellbeingity: A cohort study of Swedish construction workers. Social Science and Medicine, 70(10), $1480-1486$.

Klevmarken, A. (2010). Vem arbetar efter 65 års ålder? —en statistisk analys. Social Politics: Official Reports of the Swedish Government (SOU) 2010:85, Stockholm: Fritzes.

Krekula, C. (2011). Åldersdiskriminering $i$ svenskt arbetsliv: Om ålderskodningar och myter som skapar ojämlikhet [Age discrimination in Swedish working life: On age codings and myths which create inequality]. Stockholm: Official report from the Ombudsman for Discrimination.

Krekula, C. (2010). Age coding: on age-based practices of distinction. International Journal of Ageing and Later Life, 4(2), 7-31.

Krekula, C., Engström, L-G., \& Alvinius, A. (2017). Sweden: An extended working life policy which neglects gender and health considerations. In A. Ní Léime, D. Street, S. Vickerstaff, C. Krekula \& W. Loretto (eds) (2017), Gender and extended working life: Cross-national perspectives. London: Policy Press. sid $157-174$.

Mild Nygren, G., \& Sjöberg, A.-S. (2012) Du har fel ålder: Om åldersnojan på arbetsmarknaden [You have the wrong age: On age anxiety on the labour market], Stockholm: Trygghetsrådet. Available at: https://www.trr.se/globalassets/dokument/material/du-har-fel-alder.pdf.

Ministry of Health and Social Affairs. (2013-11-29). Summary of public consultations of the final report Åtgärder för ett längre arbetsliv. [Measures for an extended working life] SOU 2013:25. Dnr S2013/2830/SF. Stockholm.

Nilsson, K. (2018). Managers' attitudes to their older employees: A cross-sectional study. Work, 59(1), 49-58.

Nilsson, K., Hydbom, A. R., \& Rylander, L. (2011). Factors influencing the decision to extend working life or retire. Scandinavian Journal of Work, Environment \& Health, 6, 473-480.

Nordenmark, M., \& Stattin, M., Psychosocial wellbeing and reasons for retirement in Sweden. Ageing \& Society, 29(3), 413-430.

PRO, RPG, SKPF, SPF \& SPRF 2013-08-30. Yttrande över slutbetänkande av Pensionsåldersutredningen SOU 2013:24 Åtgärder för ett längre arbetsliv. Consultation of of the final report by the Government Commission for Longer Working Life and Retirement Age SOU 2013:25 Measures for an extended working life] (Five retirement organisation).

Sand, A-B. (2014) "Det handlar också om tid och pengar". Anhörigomsorg, försörjning, lagar. ["It is also about time and money". Family care, support, legislation]. Kalmar: Nationellt kompetenscentrum anhöriga.

SOU. (2012). Längre liv, längre arbetsliv, förutsättningar och hinder för äldre att arbeta längre [Longer life, longer working life, conditions and obstacles for older people to work longer], Official Reports of the Swedish Government 2012:28, Stockholm: Ministry of Health and Social Affairs.

SOU. (2013). Åtgärder för ett längre arbetsliv. Slutbetänkande av Pensionsåldersutredningen [Measures for an extended working life. Final report by the Government Commission for Longer Working Life and Retirement Age], 2013:25. Official Reports of the Swedish Government, Stockholm: Ministry of Health and Social Affairs.

Stålhammar, J. (2009). Sweden, in N. ten Bokum, T. Flanagan, R. Sandsand \& R. von SteinauSteinrück (eds) Age discrimination law in Europe, Wolter Kluwer Law \& Business, pp. 347-52.

Swedish National Audit Office. (2001). Vad får oss att arbeta till 65? [What drives us to work until 65] RFV Analyserar 2001:4. https://www.forsakringskassan.se/wps/wcm/connect/8cc67f37-cc614ce38b834ab9ba4cd050/analyserar_2001_04.pdf?MOD=AJPERES (Retrieved 11 Nov., 2017).

Szebehely, M. (2014). Anhörigomsorg, förvärvsarbete och försörjning [Family care, gainful employment and livelihood], in Swedish Delegation for Gender in Working Life (ed) Lönsamt arbete -familjeansvarets fördelning och konsekvenser [Gainful work - the division and consequences of family responsibilities], SOU 2014:28, Stockholm: Fritzes. 
Szebehely, M., Ulmanen, P. \& Sand, A-B. (2014). Att ge omsorg mitt i livet: hur påverkar det arbete och försörjning? [To provide care in middle life: how does if affect work and income?] Stockholm: Department of Social Work, Stockholm University.

Tidningarnas telegrambyrå (2017-12-14). Regeringen avvisar kritik mot ny pensionsålder [The government rejects critique against a new retirement age]. Peter Wallberg.

Ulmanen, P. (2015). The cost of caring in the Swedish welfare state. Feminist perspectives on family care for older people. Diss. Stockholm: Stockholm University.

Wall, A. (2014). Halva arbetstiden, hela ansvaret: En rapport om kvinnors deltidsarbete [Half the working hours, all the responsibility: A report on women's part-time employment, our translation]. Stockholm: The Swedish Municipal Workers' Union.

Open Access This chapter is licensed under the terms of the Creative Commons Attribution 4.0 International License (http://creativecommons.org/licenses/by/4.0/), which permits use, sharing, adaptation, distribution and reproduction in any medium or format, as long as you give appropriate credit to the original author(s) and the source, provide a link to the Creative Commons license and indicate if changes were made.

The images or other third party material in this chapter are included in the chapter's Creative Commons license, unless indicated otherwise in a credit line to the material. If material is not included in the chapter's Creative Commons license and your intended use is not permitted by statutory regulation or exceeds the permitted use, you will need to obtain permission directly from the copyright holder. 


\title{
Chapter 36 Switzerland
}

\author{
Nicky Le Feuvre, Maurice Avramito and Valérie Hugentobler
}

\begin{abstract}
This chapter explores the situation of older workers in Switzerland and reflects on the gender implications of extending working life policies and practices. Firstly, we describe the current employment patterns of older workers in the Swiss context, paying particular attention to gender differences over the life-course. In a second section, we present the three-pillar Swiss pension system, before going on to analyse the nature and the origins of the gender pension gap. In a final section, we summarize the most important extended working life policy initiatives that have taken place in recent years and discuss the mismatch between these reforms and the conservative gender regime that has influenced the life-course of current generations of older workers.
\end{abstract}

Keywords Ageing $\cdot$ Employment $\cdot$ Extending working life $\cdot$ Gender $\cdot$ Pensions $•$ Switzerland

\section{Introduction}

As in most other OECD countries, the Swiss population is ageing: from $17.8 \%$ in 2014, the over 65 s will represent $28 \%$ of the population by 2060 (Knüsel et al. 2015, p. 344). The employment rate of older people (50+) is high by European standards (Le Feuvre et al. 2014, 2015), but with a sharp drop after the legislated pensionable age, which stands at 65 for men and 64 for women. Nevertheless, at $18 \%$ of persons aged above 65 in the labour market, Switzerland has one of the highest post-retirement employment rates in Europe. Those working beyond 65 are more likely to be in parttime jobs, to be on fixed-term contracts and to be self-employed than those in the pre-retirement age groups.

Recent policy initiatives have focussed on guaranteeing the long-term financial viability of the pension system rather than on increasing the share of older workers

\footnotetext{
N. Le Feuvre ( $\varangle)$

Faculty of Political and Social Sciences, Lausanne University, Lausanne, Switzerland e-mail: Nicky.LeFeuvre@unil.ch

M. Avramito · V. Hugentobler

HESSO, Applied University of Western Switzerland, Lausanne, Switzerland

(C) The Author(s) 2020

Á. Ní Léime et al. (eds.), Extended Working Life Policies,

https://doi.org/10.1007/978-3-030-40985-2_36
} 
in the labour force per se. However, by increasing the relative importance of occupational and personal pension schemes for the economic wellbeing of retirees, Swiss policy makers have tried to promote an 'individualised adult worker' model of social protection in later life. This policy has been promoted without due consideration for the underlying, highly differentiated, patterns of labour market participation for men and women across the lifecourse, or for the structural deficit in the provision of affordable childcare and elder care services across the country.

In order to explore this issue more closely, the present chapter is divided into four subsections. Firstly, we describe the current employment patterns of older workers in the Swiss context, paying particular attention to gender differences over the lifecourse (I). In a second section, we present the three-pillar pension system (II), before going on to analyse the nature of the Swiss gender pension gap (III). In a final section, we summarise the most important extended working life policy initiatives that have taken place in recent years (IV) and discuss their gender implications.

\section{Highly Differentiated Gendered Employment Patterns Across the Lifecourse}

The Swiss labour market is weakly regulated, but has been relatively protected from the effects of the post-2008 financial crisis. Unemployment rates are low, buffered by the presence of a highly qualified migrant labour force, from neighbouring countries or further afield. Understanding the implications of policies aimed at extending working lives requires a close analysis of the Swiss gender regime, which is still largely predicated on a set of 'modified male breadwinner' (Crompton 1999) norms and structural constraints (Giraud and Lucas 2009), with labour market withdrawal and/or part-time employment expected for most mothers. The Swiss fiscal system is unfavourable to dual-earner households, notably because childcare costs are high and means-tested. Any additional income gained through an increase in mothers' working hours risks being entirely eaten up by the combined shift of the household to a higher income tax bracket and the associated increase in the cost of day-care services (Bütler 2006).

As a result, women's labour force participation rates are high across all age groups, but their employment patterns differ considerably from those of their male counterparts. The division of domestic labour is skewed, with women carrying out the lions' share of household tasks and care duties, even in couples who are morally committed to gender equality (Levy and Widmer 2013). This widespread pattern of 'one-anda-half income households' is clearly at odds with a pension system that rewards continuous and full-time engagement in the labour market.

In comparison to other OECD countries, Switzerland is characterised by relatively high employment rates by older male and female workers. According to Labour force survey data, the labour market participation rates of 55-64 year-olds increased from $70.5 \%$ to $75.8 \%$ between 2010 and 2015 (Avenir Suisse 2016). This increase is 
principally due to changes in older women's employment patterns, which rose from $56 \%$ in 2004 to $67 \%$ in 2014 , whereas the rate for men remained relatively stable, at round $80 \%$ (OFS 2018). Despite this overall convergence in working patterns in later life, the labour market participation patterns of older men and women vary considerably: notably because only $31.5 \%$ of women aged 55-64 work full-time, compared to $82 \%$ of men (OECD 2018).

Older workers are less likely to experience redundancy or unemployment than their younger counterparts. However, if they do lose their jobs, they find it hard to return to the labour market. This 'age penalty' appears in different employment policies. On the one hand, there is no legal provision against age discrimination in Switzerland. Beyond a certain age, workers who are made redundant are entitled to less compensation than their younger colleagues because economic prejudice is calculated on the basis of the potential number of years in gainful employment with the same company. But, on the other hand, older workers (55+) are entitled to longer periods of full unemployment benefit than younger age groups and they are also given priority for some 'active employment' policies, including re-training. Switzerland has a good record for on-the-job training for qualified workers, but a very poor record of offering life-long learning opportunities to those with low levels of education (OECD 2014).

In 2015, about a quarter of 55-64 year olds were not employed, i.e. not working and not actively seeking employment. This rate is much higher for women (32\%) than for men $(18 \%)$. The reasons given for non-employment also vary significantly by gender. Women are ten times more likely than men to cite 'personal reasons/family obligations', whereas more men than women had taken early retirement (SECO 2016, p. 10). Almost $30 \%$ of the non-employed 55-64 year-olds are not working for health reasons; two-thirds of them are recognised as permanently invalid, and the rest were on sick-leave and were temporarily unable to work. More non-employed men than women are recognised as permanently invalid (SECO 2016, p. 11).

Only a small proportion (3\%) of the non-employed cite a lack of employment opportunities as the main reason for not working. For both women and men, the share of 'early or on-time retirement' as the main reason cited for non-employment at ages 55-64 fell between 2005 and 2015. The number of women citing 'personal/family duties' as the main reason for not working has also fallen (from 74,000 in 2005, to 55,000 in 2015), whereas the number of men mentioning this reason doubled over the same period, albeit from a very low base (from 3,000 in 2005, to 6,000 in 2015). Overall, the proportion of women who declare that they are involuntarily nonemployed (due to poor health, invalidity or difficulties in finding a job) has increased over the past 10 years, whilst this proportion has remained stable for men (SECO 2016, p. 11).

Nevertheless, older workers do not seem to be particularly affected by precarious jobs in the Swiss context. In the 10 years before they reach full retirement age, only $2.2 \%$ of older workers had changed jobs in the previous 12 months, compared to $28 \%$ of the under $25 \mathrm{~s}$ and $6 \%$ of the $40-54$ year-olds (OFS 2012, p. 5). For those in salaried jobs, the proportion of fixed-term employment is relatively modest, at under 5\% for 55-64 year olds. However, beyond the legislated pensionable age, the 
proportion of fixed-term contracts increases significantly, particularly for men (15\%) (OFS 2018, p. 17). Older workers are also more likely to be self-employed: this is the case for $21 \%$ of the 55-64 year-olds, but for almost $44 \%$ of the over 65 s (OFS 2012, p. 3).

After a steady decrease throughout the $1990 \mathrm{~s}$, the employment rate of pensionable age men and women has risen in Switzerland over the past 10 years. According to Eurostat data, at $23.4 \%$ in 2016, the employment rate of Swiss 65-69 year-olds is the third highest in Europe, just behind Iceland and Norway. In 2015, the employment rate for the 64-74 age group reached $18 \%$. The vast majority of pensionable age workers are employed on a part-time basis. Thus, the average working time for men drops from $97 \%$ of a full-time position at 55-64 years to $54 \%$ beyond 65 years. The equivalent decrease for women is from $69 \%$ to $35 \%$ beyond 64 years (SECO 2016:13).

Finally, it is important to note that the proportion of older workers varies quite considerably by economic sector and occupation. In the health and social services sectors, where labour shortages are frequent, the rate of early retirement is almost five times lower than in the banking and finance sector, which shed a large number of older workers following the post-2008 recession.

\section{The Swiss Pension System}

In 1972, a so-called three-pillar pension system was inscribed in the Swiss Federal constitution (RS 101, art.111 et 113). The legislated pensionable age currently stands at 65 years for men and 64 years for women. This is not a mandatory labour market exit threshold, but simply the age at which people automatically start to receive the basic (AVS) pension payment. It is possible to combine a pension with income from employment or self-employment, but retirees are required to pay pension contributions on any income beyond an annual 16,800 CHF (approx. 14,600€) ceiling. Some job contracts have an age-related contract termination clause, which prevents their incumbents from continuing to work beyond a pre-defined cut-off point.

The three pillars of the Swiss pension system can be summarised as follows:

1st Pillar (AVS): Universal Basic Pension Scheme

Introduced in 1948, the old-age, survivors [widows'] and invalidity insurance scheme (AVS) aims to cover the basic daily needs of retirees, widows/widowers and the disabled. It is obligatory for everyone living or working in Switzerland, beyond the age of 17 for those in gainful employment and beyond 20 for those not in the labour market. The AVS contributions of those not in employment are calculated on the basis of the household income and wealth, including property ownership. A married housewife is exempt from paying AVS contributions once her husband's contributions are above $964 \mathrm{CHF}$, i.e. twice the minimum annual threshold (see: www.ahv-iv.ch/p/2.03.f). 
Contributions to the 1st pillar are tax deductible. Employers cover at least 50\% of the AVS contributions of their employees, which are calculated as a percentage of the employee's salary and vary by age group: from $7 \%$ for 25 to 34 year-olds, up to $18 \%$ for 55 to 65 year-olds, with an average rate of about $10.1 \%$ (Rosende and Schoeni 2012). Due to this sliding scale, older workers objectively cost more to employ than their younger counterparts. They are often also entitled to a number of 'perks', such as an additional week of paid holiday beyond the age of 60 . However, these extra costs do not seem to have a negative impact on their access to jobs, except after redundancy, a career-break, or a spell of unemployment.

The (relatively modest) pensions received through the 1st pillar depend both on the number of years spent in employment, the income of the recipient over the whole of his or her working life, and the household composition. Years spent out of employment for childcare or other informal care duties are taken into consideration, but reduce the average annual salary, as does any period of part-time employment. The combined basic pension payments of a married couple can't exceed $150 \%$ of the maximum AVS allocation.

In class and gender terms, the 1st pillar is highly redistributive, but it does not necessarily provide all beneficiaries with sufficient income to cover their daily needs. Those with average annual earnings below 14,100 CHF who have contributed for the maximum number of years (i.e. 45 for men, 44 for women) can expect to receive a monthly pension of $1175 \mathrm{CHF}$ (approx. 1035€). Those with average annual earnings above $84,600 \mathrm{CHF}$ who have contributed for the maximum number of years can expect to receive the maximum monthly pension of $2350 \mathrm{CHF}$, a sum equivalent to the poverty line in Switzerland (Reiner et al. 2015).

In short, women make $33 \%$ of the AVS contributions, but they receive $57 \%$ of the pension benefits (OFAS 2015: 60). However, they are more likely than men to receive a basic pension that is below the Swiss poverty line. This does not necessarily mean that older women are under pressure to work beyond the full retirement age, since households that fail to reach the upper ceiling of the AVS through a combination of their total pension entitlements, can apply for means-tested 'additional welfare benefits' (prestations complémentaires), funded from cantonal taxes. According to Assi (2015), these top-up welfare payments have become an integral part of the Swiss pension system, although they are rarely mentioned in pension reform policy documents. In 2012, 12.2\% of AVS beneficiaries were receiving means-tested top-up benefits, almost all of them women (OECD 2014).

\section{2nd Pillar (LLP): Occupational Pension Schemes}

Prior to the mid-1980s, occupational pension schemes were reserved for certain categories of workers, usually in the public sector or in private-sector managerial and professional jobs. At the end of the 1960 s, only $50 \%$ of people working in Switzerland - two-thirds of men and a quarter of women-were covered by an occupational pension scheme (Höpflinger 2014). About two-thirds of older workers are now covered by such a scheme, but this proportion is still higher for men $(81.7 \%)$ than for women $(56.8 \%)$. 
The 2nd pillar occupational pension is supposed to 'maintain the previous standard of living' of retirees, through a monthly pension or a lump-sum payment, or a combination of the two. Taken together, the 1 st and 2 nd pillars are supposed to enable Swiss retirees with a maximum level of contributions to receive the equivalent of $60 \%$ of their final salary (Assi 2015), offering a relatively high potential replacement rate by European standards.

Currently, anyone earning more than 21,150 CHF a year (approx. 18,600€) is obliged to contribute to an occupational pension fund. This threshold explains why part-time workers are often excluded from such schemes. Employers must match the contributions of their employees, and all payments are tax deductible. Anyone earning below threshold can make voluntary contributions to an occupational pension fund of their choice, but without the matching employers' contribution.

Swiss occupational pension funds can be operated either as defined benefit (DB) schemes, usually at 70-80\% of the end-of-career earnings, or as defined contribution (DC) schemes. A 2010 survey of the largest Swiss pension schemes estimated that almost half of the public-sector occupational pension funds operated a DB scheme, compared to only $7.4 \%$ of the private occupational pension funds (cited in Assi 2015, p. 363). In reaction to increased life expectancy, the minimum conversion rate-used to calculate the monthly returns on accumulated savings - has been progressively reduced, from $7.2 \%$ in 2005, to 6.8\% at present (Höpflinger 2014).

In the event of divorce, a 1997 Law permits the equal 'splitting' between spouses of any 2nd pillar savings accrued during the marriage. It is nevertheless difficult to document the extent to which this rule is applied in practice, since women may forego their share of the couple's pension rights in order to ensure smooth divorce proceedings (Kuehni et al. 2013).

All occupational pension schemes are now 'portable'. When a worker changes jobs, the savings accrued with a given pension fund are automatically transferred to the fund of the new company or to a temporary holding fund (caisse de libre passage) for those made redundant or taking a career-break. In certain circumstances (acquisition of real estate, setting up a private business, definitively leaving Switzerland for a non-EU or EFTA destination, etc.), it is possible to withdraw at least part of the accrued savings as a lump sum well before reaching the legislated retirement age (Lenz and Staechelin 2017). Any occupational funds placed in a temporary holding fund can only be redeemed as a lump-sum payment and not as a monthly pension. Finally, a national regulatory body protects all registered pension funds from insolvency.

\section{3rd Pillar (PPS): Personal Pension Schemes}

The third pillar of the Swiss pension system is based on voluntary contributions by individuals to personal pension schemes, offering different levels of tax benefits. The stated objective of voluntary pension contributions is to compensate for insufficient income from the 1 st and 2 nd pillars and to allow retirees to maintain their previous standard of living. Anticipated withdrawal of funds is subject to financial penalties that vary according to the type of insurance contract. 
Table 36.1 Share of salaried and self-employed [men aged 55-64 years, women aged 55-63 years] who contribute to the different pillars of the Swiss pension system 2008

\begin{tabular}{l|l|l|l|l|l|l}
\hline & \multicolumn{3}{|l|}{ Employed } & \multicolumn{2}{l}{ Self-employed } \\
\cline { 2 - 7 } & Total & Men & Women & Total & Men & Women \\
\hline Pillars 1, 2 \& 3a & 57.7 & 64.9 & 48.9 & 29.4 & 34.2 & {$[19.7]$} \\
\hline Pillars 1 \& 2 & 26.9 & 27.6 & 26.1 & 11.6 & 12.1 & {$[10.5]$} \\
\hline Pillar 1 only & 9.3 & 4.0 & 15.6 & 29.2 & 23.9 & 39.8 \\
\hline Pillars 1 \& 3a & 6.2 & 3.5 & 8.5 & 29.9 & 29.8 & 30.1 \\
\hline
\end{tabular}

OFS (2012, p. 6)

Men are twice as likely to contract a personal pension scheme $(42.3 \%)$ then women $(25.3 \%)$. As shown in Table 36.1, 57.7\% of salaried workers in Switzerland are currently contributing to all three pillars of the pension system, whereas this is the case for under $29.4 \%$ of the self-employed. Within each of these employment categories, men generally have a more diversified pension cover than women. The share of self-employed women making no contributions beyond the basic pension scheme $(39.8 \%)$ is particularly noteworthy.

\section{The Swiss Gender Pension Gap}

Historically, male-breadwinner married couples were entitled to a 'spouse allowance' that was added to the husband's pension once his wife had reached the age of 60 , whereas single and divorced women were obliged to work until age 64 to qualify for a full basic pension (Perriard 2017). In 1997, legislation put a stop to this differential treatment, by introducing individual pension rights for all women, irrespective of their marital and employment status. In parallel, a widower's pension allowance was also introduced for men. However, the Swiss pension system clearly rewards those with continuous and full-time employment histories more than those with a more typically female life-course, resulting in a large gender pension gap (GPG).

A 2015 study of the generations born between 1937 and 1948 and whose working lives had covered the period 1957-2002 (for the older age group) and 1967 and 2012 (for the younger age group) found that - at 37\% — the Swiss GPG is one of the largest of all OECD countries. However, as shown in Table 36.2, this gap varies considerably according to the type of pension benefit under consideration.

The GPG also varies significantly by marital status: it is $10 \%$ higher than the average for married persons (47\%) and is $10 \%$ lower than the average for divorced and widowed persons $(27 \%)$. There is virtually no GPG for single (never married) persons (Table 36.3). In addition, parental status also counts. The GPG amounts to $41 \%$ amongst parents, but is limited to $17 \%$ for persons without children (OFAS 2015: 63). Even with the relatively protective post-divorce pension 'splitting' rule (in a country with a $40 \%$ divorce rate), the rules for calculating occupation pension 
Table 36.2 Gender pension gap by type of pension entitlement 2012

\begin{tabular}{l|l|l|l|r}
\hline \multirow{2}{*}{ Source of pension entitlement } & \multicolumn{4}{|l}{ Annual Pension Income (in Swiss Francs) } \\
\cline { 2 - 5 } & Average Women & Average Men & Gender Gap & $\%$ \\
\hline 1st Pillar Basic Pension (AVS) & 21,663 & 22,269 & 606 & 2.7 \\
\hline $\begin{array}{l}\text { 2nd Pillar Occupational Pension } \\
\text { (LLP) }\end{array}$ & 10,948 & 29,622 & 18,674 & 63.0 \\
\hline - As a pension & 8,959 & 24,417 & 15,457 & 63.3 \\
\hline - As a lump-sum & 2,000 & 5,125 & 3,124 & 61.0 \\
\hline 3rd Pillar Personal Pension (capital) & 681 & 1,494 & 813 & 54.4 \\
\hline $\begin{array}{l}\text { Overall difference in annual pension } \\
\text { income }\end{array}$ & 33,169 & 52,755 & 19,585 & 37.1 \\
\hline
\end{tabular}

Source OFAS (2015, p. 94)

Table 36.3 Gender pension gap by type of pension and marital status 2012

\begin{tabular}{l|c|c|l}
\hline \multirow{2}{*}{ Marital status } & \multicolumn{3}{|c}{ Gender pension gap } \\
\cline { 2 - 4 } & AVS (\%) & LLP $(\%)$ & Private (\%) \\
\hline Single/never married & -2.2 & 0.9 & 46.4 \\
\hline $\begin{array}{l}\text { Married/civil } \\
\text { partnership }\end{array}$ & 8.0 & 74.8 & 59.5 \\
\hline Divorced/separated & 4.8 & 49.3 & 38.9 \\
\hline Widowed & 2.1 & 50.8 & 53.6 \\
\hline Total & 2.7 & 63.0 & 54.4 \\
\hline
\end{tabular}

Source OFAS (2015, p. 104)

benefits severely penalise women for their discontinuous and part-time employment histories. This is all the more important because the 2 nd pillar accounts for the largest share of pension income for this generation of Swiss retirees, and this is particularly detrimental to those women who divorce in middle age.

\section{Swiss Pension Reforms from a Gender Perspective}

Pension reforms have a chequered history in the Swiss context. Since 2004, three successive attempts to align full retirement ages at 65 years for men and women have been rejected by Swiss voters. Recent public debate and media coverage of extended working life issues have focussed on the financial viability of the Swiss pension system and there has been relatively less public debate, academic research or media coverage of other extended working life issues (Le Feuvre et al. 2015). However, gender issues were central to the most recent rejection of a comprehensive pension reform proposal. 
In September 2017, the Prevision 2020 White paper was presented as a longterm solution to the financial viability of the 1 st and 2 nd pillar pension schemes, but also as a means to reduce the gender pension gap (OFAS 2017). This reform was defeated in the popular referendum. Opposition came from several sides of the political spectrum. Right-wing parties and employers' organisations were opposed to the proposed (modest) increase in employers' contributions to occupational pension schemes. Despite initial support from the Socialist Party, trade unions and most of the municipal or cantonal Gender Equality Offices, public demonstrations against the reform were organised by feminist organisations. These groups argued that the solution to the gender pension gap should come from reducing the gender pay gap, improving child-care provision and thus the career prospects of women across the life-course, rather than through an increase in their legislated pensionable age. Feminist opposition to the reform highlighted the fundamental ambivalence of Swiss politicians with regard to gender equality issues, since the Federal Council that was arguing in favour of a gender-neutral, 'adult worker' model for the future of the Swiss pension system had previously voted against the adoption of two weeks of statutory paternity leave (Lanfranconi and Valarino 2014) and had also refused to increase the very modest federal budget allocated to the provision of public pre-school childcare, thus making it virtually impossible for mothers to adopt a continuous, full-time employment pattern.

This stalled pension reform provides an interesting example of the difficulties and dangers associated with the adoption of extended working life measures based on an egalitarian ideal, whilst the historical structural framing of national gender norms is left largely untouched.

\section{References}

Assi, J. (2015). Les défis de la prévoyance vieillesse suisse: Entre responsabilité individuelle et rationalité limitée. Swiss Journal of Sociology, 41(3), 359-375.

Avenir Suisse. (2016). Working life does not end at 65 [author: Jérôme Cosandey]. https://www. avenir-suisse.ch/en/older-workers-working-life-does-not-end-at-65/. Accessed April 42019.

Bütler, M. (2006). Le rendement effectif du travail pour les familles avec des petits enfants. Department of political economics. St Gallen: St Gallen University.

Crompton, R. (Ed.). (1999). Restructuring gender relations and employment: The decline of the male breadwinner. Oxford: Oxford University Press.

Giraud, O., \& Lucas, B. (2009). Le renouveau des régimes de genre en Allemagne et en Suisse: bonjour 'néo maternalisme'? Cahiers du genre, 46(1), 7-46.

Höpflinger, F. (2014). Prévoyance vieillesse, In Dictionnaire historique de la Suisse. http://www. hls-dhs-dss.ch/textes/f/F25624.php Accessed April 42019.

Knüsel, R., Bickel, J.-F., Höpflinger, F., \& Vatron-Steiner, B. (2015). Transformations des politiques de retraite Introduction. Swiss Journal of Sociology, 41(3), 341-358.

Kuehni, M., Rosende, M., \& Schoeni, C. (2013). Maintien en emploi et inégalités de sexe: quelques repères à partir du cas suisse. Lien social et politiques, 69, 197-213.

Lanfranconi, L., \& Valarino, I. (2014). Gender equality and parental leave policies in Switzerland: A discursive and feminist perspective. Critical Social Policy, 34(4), 538-560. 
Le Feuvre, N., Kuehni, M., Rosende, M., \& Schoeni, C. (2014). Le genre du 'vieillissement actif': Du principe de traitement équitable à la multiplication des injonctions contradictoires. Swiss Journal of Sociology, 40(2), 307-324.

Le Feuvre, N., Kuehni, M., Rosende, M., \& Schoeni, C. (2015). Gendered variations in the experience of ageing et work in Switzerland. Equality, Diversity, Inclusion, 34(2), 168-181.

Lenz \& Staechelin [legal practice]. (2018). Pensions \& Benefits in Switzerland. https://www. lexology.com/library/detail.aspx?g=4ba3362d-e9f5-4e29-b40b-27941757ec76. Accessed April 42019.

Levy, R., \& Widmer, E. D. (Eds.) (2013). Gendered life-courses between Standardization and individualization. A European Approach Applied to Switzerland. Zurich: Lit Verlag Editions.

OECD. (2018). Pensions at a Glance 2017. Paris: OECD Publications.

OECD. (2014). Working better with age. Paris: OECD Publications.

OFAS-Office fédéral des assurances sociales (2017). Conséquences de la réforme pour les femmes, Fiches d'information Prévoyance 2020. On-line publication. https://www.bsv.admin.ch/ bsv/fr/home/sozialversicherungen/ahv/reformen-revisionen/altersvorsorge2020/dokumentation/ medienunterlagen.html. Accessed April 42019.

OFAS_-Office fédéral des assurances sociales. (2015). Écart de rentes en Suisse. Différence entre les rentes de vieillesse des femmes et des hommes, Berne: Research report HETS Berne $n^{\circ} 12 / 16$.

OFS—Office fédéral de la statistique. (2012). Active Ageing, DEMOS Newsletter 1/2012.

OFS-Office fédéral de la statistique. (2018). Active Ageing, DEMOS Newsletter, 1/2018.

Perriard, A. (2017). Les figures de la dépendance problématique des adultes: Analyse intersectionnelle des politiques sociales liées à l'âge et à l'emploi dans le canton de Vaud. Ph.D. Thesis. Lausanne: EESP, HES SO.

Reiner, G., Oris, M., Studer, M., \& Baeriswyl, M. (2015). The persistence of social stratification? A Life-Course Perspective on Poverty in Old-Age in Switzerland, Swiss Journal of Sociology, 41(3), $465-487$.

Rosende, M., \& Schoeni, C. (2012). Deuxième partie de carrière, régime de retraite et inégalités de sexe. Revue française des affaires sociales, 3, 131-148.

SECO-Secrétariat d'État à l'économie. (2016). Indicateurs de la situation des travailleuses et travailleurs âgés sur le marché suisse du travail. Berne: Département fédéral de l'économie, de la formation et de la recherche.

Open Access This chapter is licensed under the terms of the Creative Commons Attribution 4.0 International License (http://creativecommons.org/licenses/by/4.0/), which permits use, sharing, adaptation, distribution and reproduction in any medium or format, as long as you give appropriate credit to the original author(s) and the source, provide a link to the Creative Commons license and indicate if changes were made.

The images or other third party material in this chapter are included in the chapter's Creative Commons license, unless indicated otherwise in a credit line to the material. If material is not included in the chapter's Creative Commons license and your intended use is not permitted by statutory regulation or exceeds the permitted use, you will need to obtain permission directly from the copyright holder.

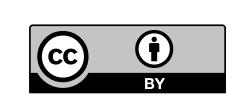




\title{
Chapter 37 \\ Turkey
}

\author{
Murat A. Mercan
}

\begin{abstract}
Turkish residents 65 and older comprise $8.8 \%$ of the total population yet the academic literature on the relationships among the effects of ageing, gender and the labour market is very limited. This chapter describes the characteristics of older workers and discusses changes in the legal structure of the labour market and their implications in Turkey. It also focuses on the Social Security system (especially the pension scheme) and the historically very low female labour force participation rates which reduce self-sufficiency for women at older ages. Finally, the chapter considers precarious employment and work-related health policies in Turkey.
\end{abstract}

Keywords Turkey $\cdot$ Social security $\cdot$ Older workers $\cdot$ Health insurance $\cdot$ Pensions $\cdot$ Gender

\section{Introduction}

In Turkey, almost seven million people ( $8.8 \%$ of the total population) are at or above 65 years old, a relatively low proportion by international standards. According to the Turkish Statistical Institute (TUIK), in 2017 just $29.4 \%$ of people aged 50 or older were in paid employment, with $45.6 \%$ of men and only $15.9 \%$ of women who are 50 years old or older in paid work. For those over $65,19.2 \%$ of men and only $6.4 \%$ of women were in paid employment in 2017. According to data from the TUIK's Household Labour Force Survey (2017), 57.3\% of Turkish women aged 50 or older are not in paid work due to household responsibilities. In contrast, for men who are 50 years old or older the most common reason for being outside paid employment is retirement (75.4\%). Among those 50 and older, only $1.15 \%$ of men reported never working in paid employment, compared to $25 \%$ of women never in paid employment in their lifetimes.

Population ageing is becoming an important issue for Turkey. The World Bank uses the age dependency ratio as one way to measure the effect of ageing on national

M. A. Mercan ( $₫)$

Faculty of Business Administration, Department of Economics, Gebze Technical University, \#145, Kocaeli, Turkey

e-mail: mamercan@gtu.edu.tr

(C) The Author(s) 2020

Á. Ní Léime et al. (eds.), Extended Working Life Policies, https://doi.org/10.1007/978-3-030-40985-2_37 
populations. The World Bank defines the age dependency ratio as the ratio of dependents-people younger than 15 or older than 64-to the working-age population-those aged 15-64 per 100 working-age population. According to the World Bank, the age dependency ratio decreased to $49.55 \%$ in 2018 from $82.12 \%$ in 1960 (World Bank 2018). However, the dependency ratio shows only the age composition of a population and many working-age people are economically dependent on others, especially women. Therefore, the decline might be misleading.

Turkey, historically, has had very low female labour force participation rates compared to many other countries (Mercan 2019). The TUIK's Household Labour Force (HLF) surveys from 2000 to 2017 reveal that female labour force participation rates have been around $30 \%$ during that period. In 2018, Turkey's female labour force participation rate was lowest among OECD countries for both women aged 1564 years old and women aged 55-64 years old. In 2018, the labour force participation rates for Turkish women aged 15-64 years old and 55-64 years old were 38.3\% and $20.3 \%$, respectively (OECD 2018). However, the labour force participation rate of women with at least a college degree is similar to that in developed countries. According to OECD (2014), the gender wage gap, which is defined as the difference between male and female median wages divided by the male median wages, was $6.9 \%$ for Turkey compared to $14.3 \%$ for the OECD average.

Table 37.1 shows the author's calculations for labour force participation rates from the HLF surveys for older people. In 2017, 32.5\% of people aged between 60 and 64 years and $13.8 \%$ aged 65 and above were in the labour force. In 2017, the average labour force participation rates of OECD countries was $52.4 \%$ and $14.8 \%$ for people aged between 60 and 64 years and 65 years or older, respectively. The labour force participation rate for those 65 or older in Turkey is not too far away from the average of OECD countries, despite Turkey's comparatively low labour force participation rates among OECD countries (OECD 2018).

TUIK's the Time Use Survey (TUS 2014) is the only nationally representative time-use survey for Turkey. From the TUS, our estimates show that women are the main providers of care for children and older people in the family. For instance, on average married men in Turkey spend 56.6 and $63.7 \mathrm{~min} /$ day providing childcare and elder-care, respectively, while on average married women spend 114.5 and $32.5 \mathrm{~min} /$ day on these activities. In addition, Turkish women are expected to do housework in the family. On average, married women spend $170.1 \mathrm{~min} /$ day cooking and on average married men spend just $40.1 \mathrm{~min} /$ day cooking. Also, for washing, ironing, and cleaning, on average married women and married men spend 84.2 and $40.8 \mathrm{~min} /$ day, respectively.

Unfortunately, there is no available dataset which focuses on or gives enough information about older workers in Turkey. Although it is impossible to know the particular reasons behind older people's labour force participation decisions, in the 2017 Household Labour Force Survey there is a question in which survey respondents mention the reasons why they are not in the labour force. Table 37.2 shows the author's calculations of the responses from the survey for women and men, separately.

Table 37.2 suggests that personal ill health is an important reason for older people not being in the labour force, particularly for women. In Turkey, there are few articles 


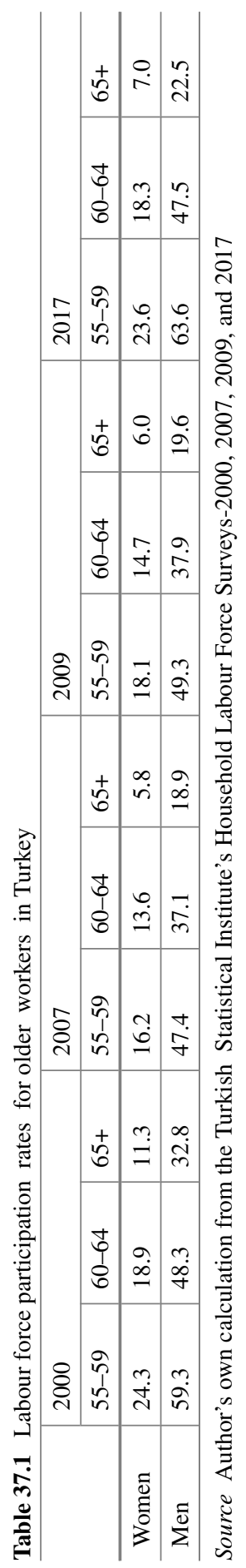


Table 37.2 The reasons for not being in the Labour Force (\% of all respondents)

\begin{tabular}{l|l|l|l|l|l|l}
\hline & \multicolumn{3}{|l|}{ Disabled, elders, ill, etc. } & \multicolumn{3}{l}{ Personal or family reasons } \\
\cline { 2 - 7 } & $55-59$ & $60-64$ & $65+$ & $55-59$ & $60-64$ & $65+$ \\
\hline Women & 6.6 & 10.3 & 54.2 & 2.1 & 1.2 & 0.3 \\
\hline Men & 16.7 & 11.0 & 25.2 & 2.7 & 1.4 & 0.2 \\
\hline
\end{tabular}

Source Author's own calculations from the Turkish Statistical Institute's Household Labour Force Survey-2017

investigating the effects of the pension system and none that provide information on its impact for older people's health. Therefore, in the following section a small number of studies that focus on the Turkish pension system are discussed.

\section{Pension Policies}

In Turkey, the Social Security Institution (SGK) for blue-collar workers, the Retirement Fund for civil servants (Emekli Sandigi) and the Social Security Institution of Craftsmen, Tradesmen and other Self-Employed (Bag-Kur) were set up in 1946, 1950, and 1971, respectively. Even though the social security system had a long history in Turkey, it was entirely restructured by the Turkish government since 2002. The Justice and Development Party (abbreviated officially AK Parti) came to power in Turkey in the general election of 2002 and it has made many changes to labour market policies during the last 16 years. For example, employment laws completely changed in 2003 and a substantial reform occurred in 2008. Those changes have affected many aspects of the labour market, ranging from part-time working conditions to breastfeeding rights. Older workers who work after their retirement were affected by a change that requires a contribution from their salary to have continued social security support. The aim of this measure was to reduce the deficit in Social Security. In addition, in 2012 Turkey revised the rules on occupational safety and health, introducing a more modern perspective (in the light of 89/391 EEC, a directive approved by European Union Council on 12 June 1989). The new law introduced several new concepts to workplaces in Turkey, i.e., employers are required to appoint occupational safety expert(s), workplace physician(s) and other health personnel amongst their employees, who also have gained the right to reject working in case of severe and imminent danger.

The social security system in Turkey was also reorganized in 2007. The new system integrated the control of different social security funds, namely SSK, Emekli Sandigi and Bag-Kur, into a single institution, the Social Security Institution (SSI). In addition, a private pension scheme, the Individual Pension System (IPS), was introduced in 2003. On January 1, 2017, auto-enrolment for the Individual Pension System was introduced (Şahin and Elveren 2014). In November 2018, there were 6.8 
million people, about $24 \%$ of workers, in the IPS as compared to 2004 , when only about $2 \%$ of all workers participated.

There are three types of pensioners in Turkey: old age, dependent, and disability pensioners. In October 2019, the Social Security Institution (SSI) reported there were $12,927,222$ pensioners in Turkey, with $69.17 \%$ being old age pensioners. Furthermore, $29.1 \%$ of the pensioners were dependents and the remaining $1.73 \%$ were disability pensioners. Between July 2019 and December 2019, the minimum monthly pension for private sector workers was 1,906.4 Turkish Liras and the maximum monthly pension for them was 3,653.5 Turkish Liras (about $€ 300$ and $€ 574$, respectively). In addition, the minimum monthly pension for people who had been employed in the public sector was 2,425.5 Turkish Liras and the maximum monthly pension for them was 9,630.6 Turkish Liras (about $€ 380$ and $€ 1512$, respectively). Elveren (2008) emphasised that the majority of women in Turkey have pension benefits as a dependent of their husbands or fathers, not as retirees in their own right. To the extent that dependent benefits are lower than workers benefits, it suggests that the gender pension gap is large in Turkey. Kar and Elveren (2008) estimate the gender gap in pension from simulations for four different scenarios, i.e., changing some working years to part-time work rather than full-time work, and they find that women's benefits vary between 55 and $76 \%$ of men's. Elveren (2008) also estimates the benefits vary between $30 \%$ for people living in Turkey's rural areas and $79 \%$ in urban areas.

Elveren (2013) points out that the social security reforms also significantly increased the early retirement age in Turkey. It became 58 and 60 for women and men respectively who started to work for the first time after the previous reform in 1999. Prior to 8 September 1999, the early retirement age was 38 and 43 for women and men, respectively. The main reason for this very low retirement age was populist policies during the early 1990s. Recent law has reset the retirement age to 65 for both men and women by 2048 in a series of gradual increases starting after 2036. In other research, Elveren (2013) highlights that $60 \%$ of working Turkish women are not covered by the pension system because they tend to work in the informal sector. He claims that new regulations are likely to cause a higher poverty rate among older women because women account for a high percentage of workers in informal sectors and because of low overall female labour force participation. Both of these factors contribute to lower pensions for women (Elveren, 2015; Şahin et al., 2010). In addition, Elveren observes that low pension coverage among Turkish women is partly due to a system based on a male-breadwinner model in which women are defined extensively as dependents, who then tend to have lower pensions. Therefore, he claims that Turkey needs a gender-sensitive social security system, not a gender-blind system.

\section{Employment Policies}

Even though part-time working is not common among formal workers in Turkey, a larger proportion of women are part-time workers compared to men. According 
to TUIK's HLF 2017 survey, only $10.5 \%$ of all workers were working part-time in 2017. Table 37.3 shows the author's calculations for the part-time rates from the survey for older women and men, separately.

In the HLF, there is one question that asks 'Are you registered in the Social Security Institution due to your job?' People who respond yes to the question are defined as formal workers. As shown in Table 37.3, 20.1\% of female workers 65 or older working in the formal sector and $37 \%$ working in the informal sector were working part-time in 2017. Similarly, part-time working is more common among men working in the informal sector, e.g., $20.5 \%$ of men aged between 60 and 64 work part-time in the informal sector compared to only $4.4 \%$ of older men working in the formal sector. Furthermore, Table 37.3 highlights that older women are more likely to work part-time than older men.

Even though Turkey was among the earlier countries to introduce women's suffrage (e.g., in Turkey women were allowed to vote and run for local office in 1930), regulations to encourage gender equality in the labour market are relatively recent, for example, recent changes to the Civil Code (in 2001), the Labour Law (in 2003), and the Penal Code (in 2004). Dedeoğlu (2012) emphasises that new laws on the principles of equal pay for work of equal value and non-discrimination against part-time workers or recognising sexual harassment at the workplace have been introduced for the first time. In 2004, a constitutional amendment was approved and positive discrimination in respect of women was introduced. In 2010, this was introduced in respect of older people, too. Before this, legal structures to combat discrimination were very weak. Gender differences in policies are not unusual. For example, Elveren (2013) points out that the entitlement to survivor benefits by children whose parents are deceased, differs in terms of gender. Boys are entitled to benefits only until age 18 ( 25 if enrolled in higher education) while daughters can receive survivor benefits as long as they are single and unemployed. Further, Elveren claims that the main flaw of the Turkish pension reforms is that they depend on the assumption of higher female labour force participation in the future. However, Turkey may not significantly increase its current low levels of female labour force participation. There are several reasons for this low rate, ranging from patriarchal norms to women's preferences; for example, From the TUIK's Family Structure Survey, our estimates show in 2016, $21.9 \%$ of men think that working is not appropriate for women.

\section{Health Policies}

One of the most significant health policies that has been implemented by the AK Parti is the General Health Insurance (GHI) system, which aims to cover every citizen with the provision of basic health services and which was introduced in 2006. However, there has been no scientific debate or significant public discussion on its possible impacts on extended working life. Therefore, the Turkish case has the potential to measure the impacts of universal health coverage on older workers' health. In addition, in 2013 the Social Security Institution extended the possibility of early 


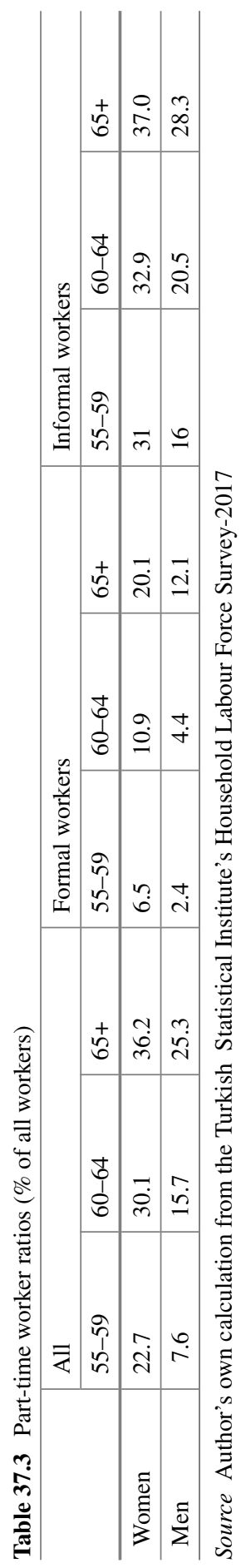


retirement because of illnesses. Employees who lost at least $60 \%$ of work capacity due to 21 specified types of illnesses may retire early. Furthermore, the Mineworkers' Pension Scheme is different than those for other workers. In Turkey, mineworkers may retire at age 50 .

\section{Precarious Employment}

Unfortunately, there are few studies that focus on precarious employment in Turkey. Emre et al. (2017) highlights that in Turkey fewer employees $(20.9 \%)$ have stable labour contracts compared to European Union member countries $(65.7 \%)$. They also point out that approximately $40 \%$ of employees are working without a contract in Turkey and in the EU the comparable ratio is just around $4.8 \%$. This indicates that precarious employment forms a large share among the labour market in Turkey. However, as yet there has been no debate on the impacts of precarious employment on extending working life.

\section{Debate on Extended Working Life}

One of the main political issues debated by major political parties are proposals for early retirement. In Turkey, some members of the public support an exemption to workers who were affected by the retirement age reform. They even established a nationwide advocacy group. In February 2018, the ruling AK Parti and the Nationalist Movement Party (MHP) established the People's Alliance. However, on October 24, 2018, the MHP voted in favour of a proposal by the Good Party (IP) about early retirement. Although it was just a motion for establishing a parliamentary inquiry on the issue of early retirement, this shows the issue is critical for political parties in Turkey. The proposal was also supported by other major opposition parties, the Republican People's Party (CHP) and the Peoples' Democratic Party (HDP). AK Parti opposes the early retirement proposals because of budgetary concerns; the president claims that the proposal will cover 6.2 million workers and the yearly cost will be around 26 billion Turkish Liras (about $€ 4.2$ million).

In Turkey, another hotly debated issue which is related to extending working lives is the amount of the minimum State Pension. Even though in January 2019 AK Parti raised it to 1,000 Turkish Liras (about $€ 160$ ) per month, opposition parties unsuccessfully tried to increase it to 2,000 Turkish Liras (about $€ 320$ ) per month during the committee stage in the parliament. 


\section{Assessment and Conclusion}

For Turkey, the lack of gender equality is strongly related to the female labour force participation rate, which is historically very low. For example, Turkey is the 130th country (out of 149 countries) in the World Economic Forum's The Global Gender Gap Report (2018). Even though the report also highlights that Turkey is the 16th country according to the concentration of their Artificial Intelligence (AI) talent pool, Turkey's overall low ranking is mainly caused by low female labour force participation rates (World Economic Forum 2018). In addition, low female labour force participation causes women to be dependent rather than self-sufficient in older age. Furthermore, Turkey needs to increase male participation in housework to reach greater gender equality because childcare is one of most common reasons for the low female labour force participation.

Although Turkey has made many changes to labour market policies to achieve a more gender equal society, there is still a need to do significantly more. In February 2019, the president organised the 1st Council on Ageing, which aims to support active ageing and strengthen the rights of older persons in Turkey. The council highlights that the population of older people will reach 8.6 million by 2023 and 19.4 million by 2050 and stresses the importance of health care and social services for older people in Turkey. A road map is going to be prepared to reach action goals. This shows that the government is aware of the challenges posed by population ageing.

For Turkey, there are several important issues that should be researched in the near future in relation to extended working life. For example, in an OECD context, Turkey has one of highest proportions of workers who work long hours in the workforce. It is well established that working long hours has many negative side effects including obesity (Mercan 2014). Therefore, researchers need to investigate the effects of obesity both on workers' health and on extending working life. In addition, Turkey has one of lowest union membership rates among OECD countries. This might offer an important opportunity to explore the effect of a non-unionised workforce on societal efforts to extend working life.

\section{References}

Dedeoğlu, S. (2012). Gender equality policies and female employment: The reforms in the EU accession process. In Gender and society in Turkey: The impact of neoliberal policies, political Islam and EU accession (pp. 125-140).

Elveren, A. Y. (2008). Assessing gender inequality in the Turkish pension system. International Social Security Review, 61(2), 39-58.

Elveren, A. Y. (2013). A critical analysis of the pension system in Turkey from a gender equality perspective. Womens Studies International Forum, 41, 35-44. https://doi.org/10.1016/j.wsif. 2013.04.003.

Elveren, A. Y. (2015). The impact of informal employment on the social security deficits in Turkey. World Journal of Applied Economics, 1(1), 3-19. 
Emre, O., Polat, V., \& Duman, Y. S. (2017). Precarious work in Turkey: A comparison with EU member countries. Journal of Business Research-Turk, 9(4), 436-454.

Kar, M., \& Elveren, A. Y. (2008). Özel Emeklilik Sistemlerinde Cinsiyete Dayalı Gelir Farkı: Türkiye Örnegi. TISK Academy/TISK Akademi, 3(5).

Mercan, M. A. (2014). A research note on the relationship between long working hours and weight gain for older workers in the United States. Research on Aging, 36(5), 557-567. https://doi.org/ $10.1177 / 0164027513510324$.

Mercan, M. A. (2019). Assortative mating and women's working-hours decisions in Turkey. İstanbul Üniversitesi Sosyoloji Dergisi, 39(2). Advance Online Publication. https://doi.org/10.26650/SJ. 2019.39.2.0103.

OECD. (2014). OECD statistics. https://data.oecd.org/earnwage/gender-wage-gap.htm.

OECD. (2018). OECD statistics. https://stats.oecd.org/Index.aspx?DataSetCode=PAG.

Şahin, Ş., \& Elveren, A. Y. (2014). A minimum pension guarantee application for the individual pension system in Turkey: A gendered approach. Journal of Women, Politics \& Policy, 35(3), 242-270.

Şahin, Ş., Rittersberger-T11ıç, H., \& Elveren, A. Y. (2010). The individual pension system in Turkey: A gendered perspective. Ekonomik Yaklaşım, 21(77), 115-142.

TUS. (2014). Time Use Survey Micro Data Set. http://tuik.gov.tr/MicroVeri/ZKA_2014/english/ index.html Accessed 02 Feb 2020.

World Bank. (2018). World Bank statistics. https://data.worldbank.org/indicator/SP.POP.DPND. OL?locations=TR\&view $=$ chart.

World Economic Forum. (2018). The global gender pay gap report. In World Economic Forum (Ed.), World economic forum.

Open Access This chapter is licensed under the terms of the Creative Commons Attribution 4.0 International License (http://creativecommons.org/licenses/by/4.0/), which permits use, sharing, adaptation, distribution and reproduction in any medium or format, as long as you give appropriate credit to the original author(s) and the source, provide a link to the Creative Commons license and indicate if changes were made.

The images or other third party material in this chapter are included in the chapter's Creative Commons license, unless indicated otherwise in a credit line to the material. If material is not included in the chapter's Creative Commons license and your intended use is not permitted by statutory regulation or exceeds the permitted use, you will need to obtain permission directly from the copyright holder.

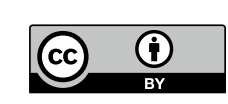




\title{
Chapter 38 \\ United Kingdom
}

\author{
Laura Airey and Jakov Jandrić
}

\begin{abstract}
In response to concerns about the rising cost of State Pensions and the prospect of skills shortages, successive United Kingdom (UK) governments have introduced a range of legislative changes designed to extend working life. Policy discourse emphasises individual responsibility for saving towards retirement, and in recent years there has been a shift away from collective pension provision. Changes to employment regulations and pension schemes have been portrayed both as an economic necessity and as offering older workers greater choice and control over work in later life. However, gendered patterns of paid employment and unpaid caring work over the lifecourse mean that women are systematically disadvantaged in terms of employment opportunities in later life and access to pension income in retirement. Extended working life policies may also negatively impact upon older workers in poor health, since the UK does not have a disability pension and individuals cannot claim their State Pension early.
\end{abstract}

Keywords Extending working lives $\cdot$ UK pension reforms $\cdot$ Employment patterns by gender $\cdot$ Health of older workers

\section{Introduction}

The United Kingdom (UK) has an ageing population; by the mid-2030s, 50\% of adults will be aged 50+ (DWP 2017a). Life expectancy has steadily increased in recent decades, leading to growing numbers of adults above State Pension age (SPA) and decreasing numbers of working age adults. Economic concerns about the cost of funding State Pensions, alongside concerns about skills shortages, have prompted legislative changes designed to extend working life (Vickerstaff and Loretto 2017; WEC 2018). This chapter presents an overview of these changes and considers their potential impacts in terms of gender and health.

L. Airey $(\varangle) \cdot$ J. Jandrić

University of Edinburgh Business School, Edinburgh, UK

e-mail: Laura.Airey@ed.ac.uk 


\section{Extended Working Life: The Policy Context and Debate}

UK governments have implemented a range of measures designed to delay individuals' withdrawal from paid employment. In 2006, age-related discrimination was outlawed. In 2011, the default retirement age was abolished, meaning that workers cannot be forced to retire on the basis of age. Policy discourse regarding later life employment has shifted over time, from 'reversing early retirement' to 'extending working life', and now 'fuller working lives' (DWP 2017b). The Government seeks to encourage 'employer-led change' through the appointment of the Business in the Community (BiTC) Age at Work leadership team as Business Champion for Older Workers; their remit is to support employers to 'retain, retrain and recruit' workers aged 50+. Policy discourse also clearly places responsibility upon individuals to ensure that they continue in paid work for long enough to be able to support themselves financially through retirement (DWP 2017b).

Since the mid-1990s, successive governments have sought to extend working life through raising SPA. The Pensions Act of 1995 equalised men and women's SPA by incrementally raising women's SPA from 60 to 65 between 2010 and 2020 (Vickerstaff and Loretto 2017). The Pensions Act 2011 brought forward this equalisation timetable to November 2018, whilst also raising SPA to 66 in phases between December 2018 and October 2020. The Pensions Act 2014 raised SPA again to 67 by 2028 and introduced a framework of regular reviews to consider the implications of increases in average life expectancy (DWP 2017b). In 2017, the Cridland review recommended increasing SPA to 68 between 2037 and 2039 (Cridland 2017); the Government has indicated that it intends to follow this recommendation (DWP 2017b).

Consistent with the prevailing neo-liberal economic and political context, these legislative changes to employment regulations and pension schemes have been framed both as an economic necessity, and as offering greater choice and control over work in later life (Foster and Ginn 2018). However, some of the assumptions underpinning employment and pension reforms have been challenged by a range of stakeholders, including older workers themselves. For example, the Women Against State Pension Inequality campaign claims that 3.8 million women have been adversely affected by the rapid rise in SPA, as they were not notified of changes following the 1995 and 2011 Pensions Acts (WASPI 2018). This has led to a significant increase in the number of women in their early sixties who left the labour market due to poor health or caring responsibilities, and who now have no independent income (Ginn and MacIntyre 2013). Health is also a key issue: almost half of workers aged $50+$ experience at least one long-term health condition (Mouland 2018) and concerns have been raised about workers' physical capacity to remain in the labour market until their late sixties (Vickerstaff and Loretto 2017). The Government's approach to older workers and employment has recently been scrutinised in a Parliamentary Inquiry by the House of Commons Women and Equalities Committee (WEC 2018). Their report made wide-ranging recommendations to improve the position of older 
workers, such as enforcement of age-discrimination legislation, statutory paid leave for carers, and the default provision of flexible work options by all employers.

\section{Age, Gender and Employment in the UK: Trends Over Time}

Table 38.1 shows that employment rates for both men and women aged 50+ have steadily increased over the past two decades. Average age of exit from the labour market has also risen during this period. In 2017, men's average age of exit from the labour market was 65.1 years, compared with 63.2 years in 1997 . Women's average age of exit from the labour market was 63.6 years in 2017, compared with 60.8 years in 1997 (DWP 2017c: 1). Nevertheless, the average age of leaving the labour market for both men and women is still lower than it was in 1950 (DWP 2017a). Above the age of 65 , there is a significant fall in the employment rate for both men and women.

The UK labour market is gender-segregated both horizontally and vertically, with women over-represented in low paid sectors and jobs. As Table 38.1 shows, patterns of full-time and part-time employment across the lifecourse are strongly associated with gender. The dominant pattern amongst men is full-time work until 65 , followed by retirement (Loretto and Vickerstaff 2015). Women's working lives are typically shorter, more fragmented, and characterised by much higher rates of part-time work compared to men (Vickerstaff and Loretto 2017). This reflects normative expectations about gendered social roles; traditionally, women have been expected to prioritise unpaid domestic caring roles, and engage in part-time paid employment to supplement the wages of male full-time breadwinners (Ginn and MacIntyre 2013). The gender pay gap widens with age. In 2017, the overall gap for employees of all ages was $18.4 \%$. However, it was the largest for employees aged 50-59, at 26.6\%-more than twice as high as the gap at ages 30-39 (12.7\%) (ONS 2017).

A substantial body of academic research in the UK has explored the gendered dimensions of issues such as ageing and employment, unpaid caring roles in later life, decision-making around retirement, and access to state and private pensions. Research on women's work histories has demonstrated that the gendered nature of employment over the lifecourse has significant financial implications for later life (e.g. Blackburn et al. 2016). Women's concentration in lower-paid, part-time employment means they are more constrained in their ability to build up independent pension savings prior to retirement compared to men (Foster and Ginn 2018; Ginn and MacIntyre 2013). Recent studies highlight how the domestic context influences men and women's decisions about retirement timing (Loretto and Vickerstaff 2013), and how the complexities of women's working lives shape their pathways into retirement (Duberley and Carmichael 2016; Loretto and Vickerstaff 2015). Studies have also revealed a range of barriers to extended working life, from ageist attitudes amongst employers, to caring responsibilities and poor health (Lain 2016; Loretto et al. 2017; Mouland 2018). 


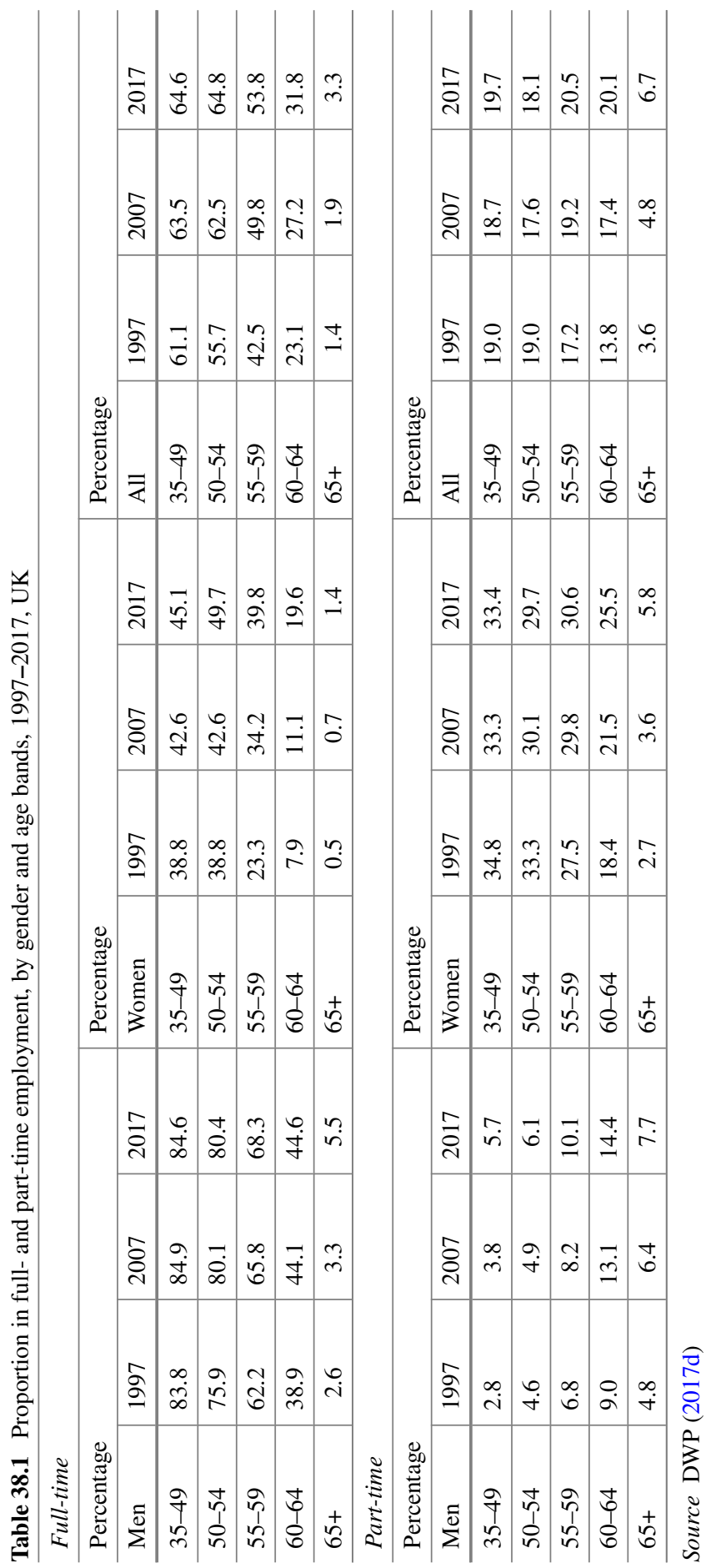




\section{UK Pension System Reforms}

The UK pension system has recently undergone major reforms. Up until 2016, there was a complex three-tier system: (1) the basic State Pension; (2) the earnings-related Additional State Pension; (3) private pensions (Grady 2015). In 2016, the two State Pension elements were replaced with a flat-rate, single-tier State Pension designed to be simpler and fairer than the previous basic State Pension. The Government claimed that the new State Pension would provide a guaranteed income for all because it is set at a higher weekly rate than the previous basic State Pension. However, to qualify for the full State Pension, individuals must have paid 35 full years of National Insurance (NI) contributions, compared to 30 years under the old system. Individuals who have paid between 10 and 34 years of NI contributions are awarded lower rates of State Pension along a sliding scale. People with fewer than 10 years' worth of NI contributions are not eligible for a State Pension. It is possible to claim NI credits for periods of time out of the labour market due to circumstances such as caring responsibilities and disability (Gov.UK 2018). The Department of Work and Pensions (DWP) estimates that low-paid women who have a full contribution record will be better-off under the new State Pension system (DWP 2015). Despite this, critics argue that State Pension entitlement in the UK is based upon the assumption of a male worker model of continuous adult employment (Grady 2015). This model obscures the fact that women's work histories and position in the labour market are different to those of men, largely due to their unpaid caring responsibilities (Foster and Heneghan 2017). The feasibility of women being able to reach the full 35 years of credits is questionable (Grady 2015; Vickerstaff and Loretto 2017).

By international standards, the UK State Pension provides a very low level of income. For 2018/19, the maximum weekly State Pension was $£ 164.35$ ( $£ 8,546.20$ per annum). In 2017, the UK was ranked bottom of all OECD countries in terms of the net replacement rate of the State Pension for individuals entitled to the full State Pension: 29\% for full-career average earners, compared to an OECD average of $63 \%$ (OECD 2017). The value of the State Pension increases every year, based either on the increase in average earnings in Great Britain, or on the inflation rate, or a rate of $2.5 \%$, whichever is higher (Gov.UK 2018). This increase does not apply to expats who moved to countries that are not a part of EEA, or do not have social security agreements with the UK (Thurley and Keen 2018).

Women in the UK already receive approximately 25\% less in State Pension than men, which reflects their lower lifetime earnings and more fragmented employment histories (Silcock et al. 2016). Pension Credit is a means-tested state benefit for people above SPA who are on a very low income; it brings up their weekly income to a minimum level. Women are more likely to be eligible for Pension Credit than men, due to their lower State Pension income (Silcock et al. 2016). From May 2019, Pension Credit is no longer available to individuals on the basis on their partner reaching the qualifying age; both partners must have reached the qualifying age (DWP 2019). 
In contrast to many other European countries, it is not possible to claim a reduced level of State Pension before SPA (Lain 2016). Individuals who have reached SPA may continue in employment and claim State Pension at the same time. These individuals are exempt from paying NI contributions - a policy designed to encourage extended working life (OECD 2018). The income from State Pension is offset against individuals' tax-free personal allowance, which is $£ 11,850$ for $2018 / 19$.

Individuals who defer claiming their State Pension are entitled to a one per cent increase for every nine weeks of deferment (equivalent to $5.8 \%$ for a full year) (Gov.UK 2018). This increased pension is paid on top of the weekly State Pension. Deferment rules are less generous than the old State Pension system, under which each year of deferral increased State Pension by $10.4 \%$. Previously, it was also possible to take this extra State Pension as a taxable lump-sum payment (if State Pension was deferred for at least 12 months), or as additional weekly payments.

\section{Occupational Pensions and Auto-Enrolment}

Concern about individuals' failure to save for retirement led to a major expansion in the UK private pensions system through the introduction of 'auto-enrolment' into occupational pension schemes. In October 2012, employers became legally obliged to automatically enrol all employees aged between 22 and SPA, who earn at least $£ 10,000$ per annum, into a workplace defined contribution (DC) pension scheme. Auto-enrolment has led to a significant increase in the proportion of employees who contribute to a workplace pension: coverage now stands at $73 \%$ of employees, compared to around 47\% in 2012 (ONS 2018a). Since 2012, more than 9.5 million workers have been automatically enrolled into workplace pension schemes, with an opt-out rate of under 10\% (ONS 2018b).

The level of contributions that employers and employees are required to pay into workplace pensions has increased in stages over time, from the initial minimum contribution rate of $2 \%$ of an employee's qualifying earnings (equally divided between employers and employees), to 8\% in April 2019 (3\% from the employer and 5\% from the employee) (ONS 2018a). While employees have the right to opt-out of paying the increased rates of contribution, the opt-out rate has risen by less than $1 \%$ since contribution rates were increased in April 2018 (Collinson 2018). In 2017/18, auto-enrolment led to an additional $£ 6.9$ bn being saved into workplace pensions, a figure projected to rise to almost $£ 20$ bn in the year 2019/20 (DWP 2017e: 67). Nevertheless, evidence indicates that very few employers or employees contribute above the minimum levels required by law (ONS 2018b), leading to concerns that auto-enrolment will not provide adequate pension income in retirement (Foster and Heneghan 2017).

The introduction of auto-enrolment has led to an increased proportion of occupational DC pension schemes, and a corresponding decline in the proportion of occupational defined benefit (DB) schemes. Whereas DB schemes provide a guaranteed income, DC pensions increase individual exposure to financial risk, as the level of savings is linked to stock market performance (Foster and Ginn 2018). This 
shift away from DB schemes to DC schemes is consistent with an increased policy focus on individual responsibility for financial provision in retirement (Foster 2018). However, there are some key differences between the private and public sectors in terms of pension coverage and pension types. In $2017,89 \%$ of employees in the public sector were members of a workplace pension scheme, of which almost all (93\%) were DB schemes (ONS 2018a). By contrast, workplace membership rates in the private sector are significantly lower (67\% in 2017), and DC schemes predominate (ONS 2018a).

Amongst full-time employees in both the private and public sectors, there is virtually no gender disparity in terms of workplace pension membership (ONS 2018a). Amongst part-time workers in both sectors, a higher proportion of women than men are enrolled in workplace pensions. Whilst this trend is encouraging, older women are nonetheless over-represented amongst part-time workers whose incomes are below the $£ 10,000$ per annum threshold for auto-enrolment (TUC 2014). Unlike the State Pension, private DC pension schemes do not provide credit for periods of unpaid caring. As such, women's earnings-related private pension savings over the lifecourse are typically much lower than those of men. ONS figures indicate that between July 2014 and June 2016, median private pension wealth for men aged 65+ was $£ 160,700$ - over twice as much as for women of the same age $(£ 67,500)$ (ONS 2018c). Thus, private pensions are a significant source of gendered income inequality in later life (Foster and Ginn 2018).

In 2015, the Government launched a range of measures to offer pension flexibility for individuals aged 55+ with savings in DC pension schemes. Individuals are now permitted to withdraw all their savings as a lump sum, or purchase an annuity, or draw an income from their savings. These measures were designed to facilitate more flexible retirement pathways and encourage extended working life by allowing people to combine income from earnings with retirement savings (OECD 2018).

\section{Employment and Health Policies}

The Government's approach to employment policies for older workers has been to combine legislation in specific areas (e.g. abolition of default retirement age) with voluntary, employer-led action to create more age-inclusive workplaces. In 2014, the Government extended the right to request flexible working to all employees who have six months of continuous service with their employer. Employers are legally obliged to consider requests for flexible working made by qualifying employees and may only refuse requests for specific reasons detailed in the legislation, such as the burden of additional costs (Pyper 2018). This action was designed to support older workers who may have caring responsibilities, yet research evidence suggests that awareness and take-up of flexible work options amongst older workers is low (Loretto et al. 2017). In June 2018, the Government launched its Carers Action Plan, in which it stated that it is considering granting dedicated employment rights to carers, many of whom are aged 50+ (DHSC 2018). 
A range of stakeholders have identified best practice amongst employers of older workers (Loretto et al. 2017; WEC 2018). In 2018, the Centre for Ageing Better published five specific employer recommendations: (1) increase the range of flexible work options available to older workers; (2) minimise age bias in recruitment processes; (3) support workers with health conditions; (4) encourage career development at all ages; (5) promote an age-positive culture (CAB 2018).

UK policy relating to the health of older workers is limited. There is currently no Government provision for older workers in hazardous occupations (OECD 2018), nor is any protection offered to older employees in precarious employment. The UK does not have a disability pension, and as mentioned previously, individuals are not permitted to claim their State Pension early. Data from the English Longitudinal Study of Ageing suggests that, in 2014-2015, 6.6\% of men aged between 55 and SPA reported that they were economically inactive due to permanent sickness/disability (Matthews and Nazroo 2016). Prior to 2007, Incapacity Benefit provided a route out of the labour market for those unable to work due to poor health; male manual workers commonly exited work this way (Vickerstaff and Loretto 2017). In 2007, Incapacity Benefit was replaced with Employment Support Allowance (ESA), which has more stringent eligibility criteria. Increasing numbers of older workers report that health problems have curtailed their ability to remain in paid employment. However, if they do not qualify for ESA, they may have very limited access to other sources of income until they reach SPA (Vickerstaff and Loretto 2017).

\section{Conclusions}

UK policy and practice has framed the extension of working life as a moral and economic imperative. The policy rhetoric of increased choice and freedom to work in later life does not adequately engage with potential barriers to employment in later life, such as poor health, caring responsibilities and ageism in the labour market. There has been increased focus on individual responsibility for saving towards retirement. However, women's typical paid employment and unpaid caring patterns over the lifecourse mean that they are at greater risk of poverty in retirement compared to men, due to their systematic disadvantage within masculinised, earnings-related private pension systems.

\section{References}

Blackburn, R. M., Jarman, J., \& Racko, G. (2016). Understanding gender inequality in employment and retirement. Contemporary Social Science, 11(2), 38-252.

CAB. (2018). Becoming an age-friendly employer. Report. Centre for Ageing Better. Retrieved September 11, 2018 from https://www.ageing-better.org.uk/publications/being-age-friendlyemployer. 
Collinson, P. (2018, August 24). Pension opt-outs have not jumped since auto-enrolment rate rise. The Guardian.

Cridland, J. (2017). Smoothing the transition: Independent review of the state pension age. Independent report. HMSO. Retrieved September 23, 2018 from https://www.gov.uk/government/ publications/state-pension-age-independent-review-final-report.

DHSC. (2018). Carers action plan 2018-2020: Supporting carers today. Policy paper. Department of Health and Social Care. HMSO. Retrieved September 28, 2018 from https://www.gov.uk/ government/publications/carers-action-plan-2018-to-2020.

Duberley, J., \& Carmichael, F. (2016). Career pathways into retirement in the UK: Linking older women's pasts to the present. Gender, Work and Organization, 23(6), 582-599.

DWP. (2015). Impact of new state pension (nSP) on an Individual's pension entitlement-first 15 Years of nSP. Policy paper. Department for Work and Pensions. Retrieved September 12, 2018 from https://www.gov.uk/government/publications/new-state-pension-impact-on-anindividuals-pension-entitlement-during-the-first-15-years.

DWP. (2017a). Fuller working lives: Evidence base 2017. Research and analysis. Department for Work and Pensions. Retrieved September 28, 2018 from https://www.gov.uk/government/ publications/fuller-working-lives-evidence-base-2017.

DWP. (2017b). Fuller working lives: A partnership approach. Policy paper. Department for Work and Pensions. Retrieved September 28, 2018 from https://www.gov.uk/government/publications/ fuller-working-lives-a-partnership-approach.

DWP. (2017c). State pension age review. Policy paper. Department for Work and Pensions. Retrieved September 23, 2018 from https://www.gov.uk/government/publications/state-pensionage-review-final-report.

DWP. (2017d). Economic labour market status of individuals aged 50 and over, trends over time: September 2017 (experimental). Official statistics \& data tables. Department for Work and Pensions. Retrieved September 16, 2018 from https://www.gov.uk/government/statistics/economiclabour-market-status-of-individuals-aged-50-and-over-trends-over-time-september-2017.

DWP. (2017e) Automatic enrolment review 2017: Analytical report. Department for Work and Pensions. Retrieved October 1, 2018 from https://assets.publishing.service.gov.uk/ government/uploads/system/uploads/attachment_data/file/668657/automatic-enrolment-review2017-analytical-report.pdf.

DWP. (2019). Pension credit extra information. Department for Work and Pensions. Retrieved January 29, 2019 from https://assets.publishing.service.gov.uk/government/uploads/system/ uploads/attachment_data/file/771615/pension-credit-extra-information-factsheet.pdf.

Foster, L. (2018). Active ageing, pensions and retirement in the UK. Journal of Population Ageing, 11(2), 117-132.

Foster, L., \& Ginn, J. (2018). Transmitting inequality: Pensions policy and the gendered life course. In S. Shaver (Ed.), Handbook on gender and social policy (pp. 179-196). Cheltenham: Edward Elgar Publishing Ltd.

Foster, L., \& Heneghan, M. (2017). Pensions planning in the UK: A gendered challenge. Critical Social Policy, 38(2), 345-366.

Ginn, J., \& Macintyre, K. (2013). UK pension reforms: Is gender still an issue? Social Policy \& Society, 12(1), 91-103.

Gov.UK. (2018). The basic state pension. Retrieved September 08, 2018 from https://www.gov.uk/ state-pension.

Grady, J. (2015). Gendering pensions: Making women visible. Gender, Work and Organization, 22(5), 445-458.

Lain, D. (2016). Reconstructing retirement: Work and welfare in the UK and USA. Bristol: Policy Press. 
Loretto, W., Airey, L., \& Yarrow, E. (2017). Older people and employment in scotland. Research report. The Scottish Government. Retrieved September 12, 2018 from https://www.gov.scot/ publications/older-people-employment-scotland/.

Loretto, W., \& Vickerstaff, S. (2013). The domestic and gendered context for retirement. Human Relations, 66(1), 65-86.

Loretto, W., \& Vickerstaff, S. (2015). Gender, age and flexible working in later life. Work, Employment \& Society, 29(2), 233-249.

Matthews, K., \& Nazroo, J. (2016). Retirement, well-being, engagement and social status. In J. Banks, G. D. Batty, J. Nazroo, \& A. Steptoe (Eds.), Wave7. The dynamics of ageing: Evidence from the english longitudinal study of ageing 2002-2015. London: The Institute of Fiscal Studies.

Mouland, J. (2018). Health warning for employers: Supporting older workers with health conditions. Report. Centre for Ageing Better. Retrieved August 30, 2018 from https://www.som.org.uk/sites/ som.org.uk/files/Health_warning_for_employers.pdf.

OECD. (2017). Pensions at a glance 2017: How does the United Kingdom compare? Briefing paper. OECD. Retrieved September 17, 2018 from https://www.oecd.org/unitedkingdom/PAG2017GBR.pdf.

OECD. (2018). Key policies to promote longer working lives. Country note 2007-2017. Report. OECD. Retrieved September 17, 2018 from https://www.oecd.org/els/emp/United\% 20Kingdom\%20_Key\%20policies_Final.pdf.

ONS. (2017). Annual survey of hours and earnings (ASHE) gender pay gap tables. Dataset. Office for National Statistics. Retrieved September 16, 2018 from https://www. ons.gov.uk/employmentandlabourmarket/peopleinwork/earningsandworkinghours/datasets/ annualsurveyofhoursandearningsashegenderpaygaptables.

ONS. (2018a). Annual survey of hours and earnings pension tables, UK: 2017 provisional and 2016 revised results. Statistical Bulletin. Office for National Statistics. Retrieved September 16, 2018 from https://www.ons.gov.uk/releases/ annualsurveyofhoursandearningspensiontables2017provisionaland2016revisedresults.

ONS. (2018b). Pension participation at record high but contributions cluster at minimum levels. Article. Office for National Statistics. Retrieved September 16, 2018 from https://www.ons.gov.uk/employmentandlabourmarket/peopleinwork/workplacepensions/ articles/pensionparticipationatrecordhighbutcontributionsclusteratminimumlevels/2018-05-04 .

ONS. (2018c). Individual private pension wealth by age and sex: Great Britain, July 2014 to June 2016. Dataset. Office for National Statistics. Retrieved October 1, 2018 from https://www.ons.gov.uk/peoplepopulationandcommunity/ personalandhouseholdfinances/pensionssavingsandinvestments/adhocs/ 008146individualprivatepensionwealthbyageandsexgreatbritainjuly2014tojune2016.

Pyper, D. (2018). Flexible working. Briefing paper. House of Commons Library, No: 01086. Retrieved October 1, 2018 from https://researchbriefings.parliament.uk/ResearchBriefing/ Summary/SN01086\#fullreport.

Silcock, D., Popat, S., \& Pike, T. (2016). The under pensioned. Research paper. Pensions Policy Institute. Retrieved October 11, 2018 from https://www.tuc.org.uk/sites/default/files/TheUnderpensioned.pdf.

Thurley, D., \& Keen, R. (2018). Frozen overseas pensions. Briefing paper. House of Commons Library, No: CBP-01457. Retrieved December 14, 2018 from https://researchbriefings. parliament.uk/ResearchBriefing/Summary/SN01457.

TUC. (2014). Age immaterial. Women over 50 in the workplace. London: Trades Union Congress.

Vickerstaff, S., \& Loretto, W. (2017). The United Kingdom-a new moral imperative: Live longer, work longer. In A. N. Leime, D. Street, S. Vickerstaff, C. Krekula, \& W. Loretto (Eds.), Gender, ageing and extended working life: Cross-national perspectives (pp. 175-191). Bristol: Policy Press.

WASPI. (2018). Women against state pension inequality. Retrieved October 08, 2018 from https:// www.waspi.co.uk. 
WEC. (2018). Older people and employment. Fourth report of the session 2017-2019. House of Commons Women and Equalities Committee. Retrieved July 27, 2018 from https://publications. parliament.uk/pa/cm201719/cmselect/cmwomeq/359/359.pdf.

Open Access This chapter is licensed under the terms of the Creative Commons Attribution 4.0 International License (http://creativecommons.org/licenses/by/4.0/), which permits use, sharing, adaptation, distribution and reproduction in any medium or format, as long as you give appropriate credit to the original author(s) and the source, provide a link to the Creative Commons license and indicate if changes were made.

The images or other third party material in this chapter are included in the chapter's Creative Commons license, unless indicated otherwise in a credit line to the material. If material is not included in the chapter's Creative Commons license and your intended use is not permitted by statutory regulation or exceeds the permitted use, you will need to obtain permission directly from the copyright holder.

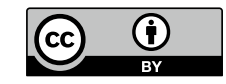




\title{
Chapter 39 \\ United States
}

\author{
Debra Street
}

\begin{abstract}
For decades, American discourse about the future of Social Security has trumped meaningful discussion of extending working lives. Similar to patterns of public debate and policymaking elsewhere, in the US pensions and delayed retirement has received most of the policy focus with relatively little attention paid to the gendered structure of the US labour market, and the systematic disadvantages built into its retirement income regime. Nor have debates come to grips with the real likelihood as opposed to imagined potential for most older Americans remain employed longer, given the mismatch between available jobs and older workers' skills, their physical capacities, and competing family care responsibilities. Complicating the US context further is the sheer complexity arising from significant regional differences in employment prospects, interactions between federal and state policies that shape employment and retirement outcomes, and the very exceptional character of US health insurance arrangements to contend with, all within an ageist and age-denying culture. This chapter explores why there has been little debate and no consensus in US policymaking about how to expand good employment opportunities that could help Americans to extend their working lives, but plenty about raising retirement ages and contribution levels for Social Security.
\end{abstract}

Keywords Retirement $\cdot$ Extended work $\cdot$ Older workers $\cdot$ Gender $\cdot$ United states pensions

\section{Introduction}

In some regards, the American experience of pensions and extended work is quite unique (Street and Tompkins, 2017). Job creation and lower rates of unemployment post-recession set the US apart from macroeconomic experiences elsewhere. Its older population is relatively smaller and increasing less quickly than most of the other countries considered in this volume. The unusual US health care system

D. Street $(\bowtie)$

Department of Sociology, The State University of New York at Buffalo, 430 Park Hall, Buffalo, NY, USA

e-mail: dastreet@buffalo.edu 
often locks workers into jobs for fear of losing employment-based health insurance, since guaranteed health insurance through Medicare is not available until age 65. A larger proportion of older Americans work to later ages than in all but a handful of affluent countries. Finally, increasing the US normal retirement age (NRA) to receive full Social Security OAS retirement benefits was accomplished by amendments to the Social Security Act in 1983, although implementation was not even begun until twenty years later, in 2003. The NRA age increased gradually from 65 to 67 between 2003 and 2025. Not only was the NRA age increased less abruptly, but the time horizon for planning for retirement at older ages was also much longer in the US than in most European countries. There, most countries increased the state pension age twenty or thirty years later than in the US and increased the full retirement age much more quickly, giving European workers much less time to adapt to working longer than those in the US.

Yet similarities are also apparent. The familiar refrain 'live longer, work longer' described in Part 1 Chap. 5 permeate debates about older Americans, yet policy discussions often overlook the feasibility or quality of older workers' potential employment. Emphasized instead are more concrete plans to delay retirement further. Another similarity is that many older American workers have health and disability impairments that make continued employment to older ages difficult or impossible. Similar to the other countries in this volume, older Americans often lack the particular skills or pay expectations that employers demand when recruiting or retaining older workers. Finally, gender gaps in American pay and pensions reflect systematic disadvantages built into labour markets and retirement income systems. Women need higher retirement incomes than men because, on average, they have longer retirements, spend more time living alone, with higher medical costs and are less likely to have a spouse to help care for them than do their male counterparts. US policies fail to adequately accommodate such differing trajectories of women's and men's working lifecourses and women's disproportionate normative burden of responsibility associated with reproductive work and unpaid caregiving, just as in many European countries. This chapter highlights some key factors affecting older people associated with retirement and employment regimes that shape the US extended working life debate.

\section{The US Retirement Income System}

The US retirement income system has often been referred to as a 'three-legged stool' (Turner and Watanabe 1995) comprised of Social Security (the state pension), employment-based pensions or savings schemes, and individual assets/personal savings. This idea of the three-legged stool is somewhat different from how retirement income is categorized in OECD/EU 'three pillar' parlance (OECD 2005). Meanstested Supplemental Security Income (SSI) provides social assistance for impoverished elders from general revenues, which would be the first pillar. The second pillar would comprise retirement benefits (hereafter Social Security) under the mandatory 
Social Security Old Age, Survivors, and Disability Insurance (OASDI) earningsrelated program. OASDI is by far the largest social transfer program in the US, with outlays exceeding US $\$ 950$ billion in 2017 , funded in 2018 by matching contributions from employees (6.4\% of pay) and employers (6.4\%) up to a ceiling of US $\$ 128,400$ earnings. Benefits go to 43.1 million retired workers, 8.6 million disabled workers, 4.1 million widows and widowers, and 2.5 million spouses (NASI 2018). Analagous to the third pillar would be voluntary employer-provided DB and DC plans covering less than half of American workers, and tax incentivised individual schemes such as Individual Retirement Accounts (IRAs) and Roth IRAs. In the spirit of American exceptionalism, the following discussion uses the more typical US 'three legged stool' approach rather than the three pillars to discuss the characteristics of the US retirement income system as it bears on debates about extended work.

\section{Public Pensions}

The first leg of the US retirement income stool, the contributory Social Security Old Age and Survivors pension (OAS), provides pension benefits for over $85 \%$ of American aged 65 and older, with OAS comprising nearly $40 \%$ of American retirees' income. Among older Americans, 28\% of married couples and $43 \%$ of unmarried individuals rely on Social Security for at least $90 \%$ of their income. Social Security benefits are at least $50 \%$ of income for $48 \%$ of married couples and $71 \%$ of unmarried people (NASI 2018). The average monthly benefit for an individual retired beneficiary in 2019 is $\$ 1,461$ and for a married couple $\$ 2,448$ (SSA 2019).

Social Security is a pay-as-you-go (PAYG) defined benefit (DB) public pension, financed through payroll taxes levied on wages up to US\$132,900 in 2019 (SSA 2019). The earnings ceiling on Social Security contributions makes funding Social Security regressive, but there are some progressive elements in benefit payouts. Social Security's retirement benefit formula replaces a smaller percentage of higher earners' pre-retirement earnings (around 25\% at maximum taxable earnings) and a higher rate for low-wage earners' pre-retirement earnings (about 52\%) (NASI 2018). Workers earn entitlement to Social Security retirement benefit through at least 40 quarters of contributions (10 years of Social Security-covered employment) and then the actual OAS retirement benefit is calculated based on lifetime earnings, using the highest 35 years.

The Social Security amendments of 1983 gradually increased the NRA from age 65. From the prior NRA of 65, the NRA gradually increased by two months from 2003 for each subsequent birth year cohort after 1938, with a hiatus at NRA age 66 for the 1943-1954 birth cohorts, then increasing again by two months per birth cohort from 1955 to 1960 . Under current law, the SS NRA will reach age 67 in 2025 for everyone born later than 1960.

At the NRA of 66 , retiring up to 48 months early at age 62 is permitted, but it decreases the monthly benefit permanently by $25 \%$. Retiring 60 months early at 62 when the NRA becomes 67 permanently reduces monthly benefits by 30\% (SSA 
2019). For beneficiaries who work while receiving OAS retirement benefits before reaching the NRA (currently 66 for workers born up to 1954), wages earned above an annual limit (US\$17,640 in 2019) receive Social Security retirement benefits decreases by US $\$ 1$ for every US $\$ 2$ earned above the limit. Once beneficiaries reach NRA, OAS benefits earnings limits are removed (SSA 2019), incentivizing work for those aged 66 and older. Finally, postponing receipt of OAS benefits past the NRA yields a monthly actuarially determined increase, amounting to $130 \%$ of the full NRA retirement benefit if it is not taken up until age 70 (SSA 2019). The continuing accrual of retirement benefits supports an interpretation that the NRA is not actually 66 or 67 , but rather that 70 has become the de facto age of 'full benefits' (Munnell 2013). Increasing the NRA for all workers, eliminating the earnings test once the NRA is reached, and adding to OAS retirement benefit values for 3 extra years for those working up to age 70 are a series of Social Security that extended the financial viability of Social Security. The changes can also be construed as extended working life policies, since they were also enacted to encourage Americans to work longer. The consequences of continued employment and changes in Social Security benefit accrual at different ages indicate that Social Security is, arguably, the major extended working life policy in the United States.

\section{Private Sector Pensions}

The second leg of American retirement income is occupational pensions and retirement savings plans. In 1983, the same year that Social Security amendments raised the NRA, $61 \%$ of workers who had occupational retirement benefits were in DB pension plans and only $12 \%$ were in DC plans. By 2016 , only $17 \%$ had access to DB plans only, while $73 \%$ had access only to DC plans (CRR 2018). Unlike the pooled risk of secure defined benefit monthly pensions (and survivor benefits they provided), changes in occupational retirement plans have created the individualised risks of DC savings plans (Russell 2014). Most private sector US employers now offer only defined contribution retirement plans, providing the mechanism for individual savings and often making matching contributions (up to a limit) to individual accounts. However, eventual retirement income depends entirely on the accrued value of individual contributions and investment returns, rather than any pooled risks. Payouts can be lump sums, annuity purchases or the withdrawal of savings. Unlike the guaranteed monthly amount of traditional defined benefit pensions, retirees can, and often do, outlive their defined contribution savings. Many others have no employer facilitated retirement savings at all (Russell 2014; Weller 2016). The shrinking numbers of defined benefit plans still operating are mainly in the public sector; even in the public sector DB plans are typically being phased out and replaced with DC plans for new hires.

The transformation in occupational pensions away from DB pensions to DC savings plans contribute to extended work. Defined benefit retirement plans determine predictable lifetime payments according to a fixed formula based on salary, years of 
service, and age. DC plans determine the value of individual accounts on the basis of contributions and the rate of investment return. DB plans created incentives for older workers to retire early, just as soon as they had maximized the combination of age, years of service and salary into a maximum pension benefit, a feature that is not part of DC plans. DC retirement plans do permit workers to maximize contributions at older ages because tax treatment becomes more generous once a worker hits age 50, likely encouraging workers to stay on in employment to build greater DC savings.

\section{Individual Retirement Savings}

The third leg of US retirement income is individual savings and income from assets and investments. Like DC occupational plans, Individual Retirement Accounts (IRAs) receive preferential tax treatment, both in terms of savings and returns on investment. Once money is invested in an IRA, withdrawing it before age 59.5, except due to hardship conditions, carries a $10 \%$ penalty from the Internal Revenue Service. Once individuals withdraw from IRAs, they pay taxes on the proceeds. Given that most Americans say they would have trouble coming up with an immediate $\$ 400$ for an emergency (Federal Reserve 2019), it is no surprise that only 39\% of Americans do have IRAs. Among those who do, savings are modest. Currently, about half of all American workers work in jobs with no occupational retirement plans, and about a quarter of working aged adults have no retirement savings or access to pension plans beyond Social Security (Federal Reserve 2019).

As Social Security benefits are based on a long work history (35 years) and lifetime wages, retirement benefits are permanently undercut by time out of paid work or by many years in low-wage jobs. Although the OAS benefit formula partly adjusts by providing higher rates of return to low-income earners, it does not completely remedy the impact of a lifetime of low wages or gaps in paid work. Even when employed full time, women earned only 80.5\% of men's earnings in 2017 (Fontenot et al. 2018). Earlier pay gaps lead to Social Security benefit gaps, where retired women receive about 76 cents on the dollar when compared to similar retired men (Herd 2009). Women carers' lost wages and retirement income is substantial. Over a lifetime, it adds up to an average of US\$142,693 in lost wages, US\$131,351 in lost Social Security benefits, and another estimated US\$50,000 in lost retirement income from other sources (MetLife 2011). Lower lifetime pay, time out of the labour market or part time work to accommodate caring mean that women have gaps in pay, in pension contributions and coverage, and in later life incomes.

Women's systematic retirement income disadvantage and heavier dependence on Social Security is demonstrated in Table 39.1 As Table 39.1 shows, women depend more on Social Security than do men, who receive more income and are more likely to have income in the first place from more sources. Among Americans having any income from each of the sources, women receive less in every category. Total income from all sources shows that older women's median income is just 55\% that of men's. Keep in mind that for the data in this table that, other than Social Security for both 
Table 39.1 Median annual income received from each source among women and men aged 65 and older who received any income from each source

\begin{tabular}{l|l|l|l|l}
\hline Source & Women & $\begin{array}{l}\text { \% with income from } \\
\text { the source }\end{array}$ & Men & $\begin{array}{l}\text { \% with income from } \\
\text { the source }\end{array}$ \\
\hline Social security & $\$ 11,357$ & 85 & $\$ 15,567$ & 84 \\
\hline Asset income & $\$ 600$ & 48 & $\$ 906$ & 56 \\
\hline Pensions & $\$ 9,600$ & 29 & $\$ 15,600$ & 46 \\
\hline Earnings & $\$ 19,000$ & 16 & $\$ 30,000$ & 27 \\
\hline Other & $\$ 4,600$ & 7 & $\$ 5,800$ & 5 \\
\hline All income sources & $\$ 15,323$ & & $\$ 27,657$ & \\
\hline
\end{tabular}

Source Fischer and Hayes (2013)

women and men, and assets for men only, most Americans have no income from the other sources-no pension income, no earnings, or no other income.

The increasing individualization of risk represented in occupational DC retirement plans and individual retirement savings is worrisome. The 2008 economic crisis wreaked havoc on the value of older Americans' individual retirement resources. The value of defined contribution plan balances shrunk as the stock market dropped, equity in housing plummeted, and many had to tap into retirement savings in preretirement years to make ends meet. Many older Americans dealt with the aftermath of the Great Recession by postponing retirement. Transformations in the second and third legs of the pension stool have contributed to older Americans' decisions to retire or to try to remain employed, by-products of economic trends rather than purposive policies to extend working lives. However, the sheer size and scope of Social Security may make it a singular influence on extending working lives.

\section{Employment}

Despite remaining employed to later ages and increasing rates of older women's employment in recent decades, employment prospects for older American workers are not uniformly positive. The boundaries between employment and retirement statuses are fluid, featuring bridge employment, second careers, flexible working and unretirement (Wang and Schultz 2010). The aftermath of the 'Great Recession' of 2008-09 featured high levels of unemployment, yet simultaneously accelerated a trend towards (Copeland, 2014). Employed older Americans attempted to weather the reversal in their retirement security by hanging on to the jobs they had during a period when good jobs for displaced older workers were very elusive. Once unemployed, older worker $\mathrm{s}$ are the age group at highest risk of remaining longterm unemployed (six months or longer with a comprehensive 'U-6' unemployment rate (which includes the aforementioned 'officially' unemployed, plus discouraged workers, part-time workers who would prefer full time and workers underemployed 
in jobs that do not fully use their skills and qualifications) (BLS 2016). Long-term unemployment increases with age; older women's long term rate more than tripled in the aftermath of the Great Recession (Federal Reserve Bank of St. Louis 2015).

Older individuals who want or need jobs often self-identify as retired, either because they can afford to retire despite wanting employment, or to avoid the stigma of being unemployed. When older jobseekers do find work, it is often with fewer hours of work or lower pay, or both (GAO 2012; Lain 2012). Skills-job mismatches make re-employment especially difficult. When older workers are displaced due to factory or businesses closing or downsizing, they often lack the technical skills needed for other available jobs. Workplace stereotypes and ageism also mean that they have fewer training opportunities to enable them to compete (Charness 2013). Whether sufficient jobs, private or public can be created to enable extended working life, how they can be distributed throughout the US, what skills would be needed and what pay could be offered are all missing pieces in the extended working life puzzle. Demand-side issues receive scant attention in extended working life debates; asserting labour shortages and experiencing low levels of unemployment alone does not mean that employers are eager to retain or recruit older workers.

\section{Work-Family Balance, Health, and Anti-age Discrimination}

Paid family leave in the US is rare and usually at the employer's discretion. The Family and Medical Leave Act (FMLA) has provisions for leave due to parenthood or providing care to immediate family members, covering employees meeting minimum standards of job tenure and hours worked annually and who are employed by the government or large private sector organisations (50+ workers). Job-protected FMLA leave can be taken for up to six months, but there is no requirement that workers on leave be paid. Most American workers have no entitlement to paid or unpaid leave at all. All caregivers face short and long-term costs associated with caregiving-ranging from out of pocket expenses, the need to shift to part time work, lower incomes (and thus less surplus to save for retirement or to contribute to Social Security). While the 35 highest years of pay used in Social Security benefit formula calculations for retirement benefits may give caregiving individuals who are employed some leeway in maximising public pension benefits despite shorter periods of employment, there is no deliberate policy mechanism within Social Security to compensate employed family carers for essential but unpaid work (Ní Léime and Street 2016).

A unique component of the American political economy that encourages older workers to remain employed is the structure of its health-care system, and the linkage of health insurance to employment. Most Americans younger than 65 depend on employers to be eligible for affordable group health insurance, which is a source of 'job lock' that keeps many Americans in full-time employment until they become eligible for state-provided Medicare at age 65. The Patient Protection and Affordable Care Act 2010 (aka Obamacare) might have minimized the perverse effects embedded in the structure of US health insurance, but the Trump Administration has made 
rolling back those gains a top political priority despite spiking medical bills being a major source of vulnerability for older Americans. The irony is that US health policy does not support older workers with health problems or the onset of disabilities to remain in employment, although it often compels them to try to remain employed to have any health insurance coverage at all.

Workplace policies to improve older workers' employment prospects are piecemeal at best. In 1986, Congress abolished mandatory retirement by amending the Age Discrimination in Employment Act, except for certain public safety professions. The Workforce Investment Act of 1998 established local 'one-stop centers' to provide access to employment and training services for displaced workers under several federal and state programs. 'One-stop centers' provided services to terminated or laid-off workers (not just older workers) who had exhausted or were ineligible for unemployment benefits, and who were unlikely to return to work in their previous industry or occupation (GAO 2012). The only federal program specifically targeted at older workers is the Senior Community Service Employment Program (SCSEP). SCSEP provides subsidised, community service-based on-the-job training and internships for individuals age 55 and over with incomes less than $125 \%$ of federal poverty guidelines, who are unemployed, have poor prospects for re-employment (GAO 2012). It serves approximately 70,000 workers nationwide each year, with an average age of 64 (DOL 2015). SCSEP jobs and training are part-time with low wages-in many ways, quite the opposite of the good jobs needed for ideal extended working life conditions. Even the fragmented 'one-stop centers' and SCSEP programs that do exist are unevenly implemented geographically and variously effective across the states.

Even when jobs are relatively abundant, most evidence points to employers preferring to hire younger rather than older workers. While the US was a world leader in enacting anti-age discrimination legislation with the Age Discrimination in Employment Act (ADEA) - its de facto impact has been limited to only isolated cases, despite the widespread perception that age discrimination is pervasive in the American workplace (GAO 2012; AARP 2014; Ghilarducci 2015). Age discrimination can be a barrier to older Americans seeking employment, and can also be a factor in pushing willing older workers out of employment they would prefer to keep. Another potentially helpful policy to help older workers remain in employment is the American with Disabilities Act (ADA) enacted in 1990. If a (older) worker is deemed to have an eligible disability, workplaces of a certain size must offer "reasonable accommodation" to employees who need adaptations to their conditions of work. On their face, both anti-age discrimination and disability accommodation legislation (if effective) would appear to be potentially helpful to older individuals seeking to remain in work. However, neither the ADEA nor the ADA have shown particular effectiveness in helping older workers extend their working lives (Wegman and McGee 2004).

On the demand side of the extended working life equation, employers seem to have few jobs for which the skills of most older workers in are high demand. Even when age is not an overt part of the job recruitment strategy, language in job ads such as 'fun workplace' or targeting job ads only to younger adults on social media reflect 
some of the subtleties of ageism that feature in the modern American workplace. Although unemployment rates in 2019 skirt record lows, whether the strong demand for labour will translate into demand-side conditions favourable for extending work is unknown.

\section{Discussion}

The United States has few social policies that are particularly woman- or familyfriendly, and a complex health insurance system that still leaves many Americans uncovered. In fact, older workers without employment-based insurance in the immediate pre-retirement years and before Medicare eligibility at age 65 face serious barriers to arranging health insurance. Routine access to high quality, affordable child and eldercare institutions is rare. With few affordable services available, Americans (often older women) have to figure out for themselves how to provide or arrange care for children and grandchildren, frail elder parents or partners, or disabled family members. Rates of poverty among older Americans are high, compared to most OECD countries, and are especially so for women.

There are certainly some paradoxes when considering the American case for extended working lives. At first glance, conditions seem favourable for potentially good outcomes. The population is younger, the pension age was raised earlier and over a longer period, and the political turmoil in the US has paralyzed policy debates in ways that, so far, have safeguarded the structure of the redistributive Social Security program. The United States was an early adopter of legislation that aimed to protect workers' rights, including the ADEA and ADA. As many contemporary older Americans have higher levels of education than previous cohorts, prospects for continued employment in rewarding jobs seems feasible for some, especially for those living in job markets that support it. Individuals who are able to delay retirement until age 70 continue acquiring credits towards Social Security OAS benefits, improving their financial security in retirement. For some working women, extended working life could mean that their public pensions will be calculated based on a full 35 years of employment earnings, with fewer missing quarters than in the past (unless benefit formulas change). Raising the NRA and leaving the calculation formula intact at 35 years will create a larger cohort of women eligible for retirement benefits in their own right as workers, rather than dependent Social Security benefits derived from marital status. The booming economy means that there are more jobs to go around.

Nonetheless, policies that bear on extended working lives tend to be piecemeal, underfunded and unevenly implemented and experienced across the country. The adversarial US political climate gives little reason to expect that the policy compromises needed to support work-life balance or employment practices that could better support extended working lives will materialize. Although extra quarters of Social Security credit for lost earnings for carers who must quit jobs or work part time to do it would address some of the gendered disadvantages experienced in the US, it would not resolve the intransigent gender pay and gender pension gaps. Better 
support for flexible work arrangements or mechanisms for phased retirement could help older workers stay in employment longer. Putting teeth into anti-age discrimination regulations for employers could also help Americans extend their working lives. However, none of these policy innovations seem likely to appear on the near horizon.

Politicians, think tanks as diverse as the leftish Economic Policy Institute and the right-leaning Cato Institute, academic research institutes and advocacy organisations ranging from the American Association of Retired Persons, to the Institute for Women's Policy Research, have weighed in on the merits and risks of extending working life or delaying retirement, but not with a single voice. The fragmented and strident nature of current US policymaking and the non-aligned interests of various political actors stymies integrated discussion of what extending working life means for Americans with different life circumstances.

Lifecourse scholars underscore the accumulation of advantages and disadvantages over entire life courses that feed into outcomes in later life, whether due to gender, lower levels of education, or compromised health status. Future directions for research and policy include reformulating the idea of extended working life, fully comprehending the roles of age, gender and other social statuses intersecting with employment structures, and accommodating the unequal life chances that structure individual lifecourses through carefully refined policies. In the increasingly bifurcated world of employment, the 'job-rich' older worker may 'extend work' in the later phase of their professional, satisfying, highly-compensated careers and feel empowered while being enriched by working to later ages. However, for 'job-poor' workers with a lifetime of low wages and unfulfilling and often precarious or insecure employment, the demand to extend work ignores their persistent disadvantages and barriers to working longer (see Chap. 5 in Part I). Policy innovations could adjust Social Security-credited earnings by adequately taking time out of employment for motherhood and caring into account, compel employers to sustain 'age-friendly' workplaces and employment practices, and take into account the kinds of work that actually compel workers in some occupations to retire earlier. Proponents of extending working lives must confront the challenges of employment capacity and adequately remunerative employment given other bifurcations that occur for older workers, what Ghilarducci (2015) characterises as the contrasts between 'elders who must work, and those who can afford not to.' Gender and compromised health statuses are heavily implicated in the between 'must work' and 'can afford to stop', and between 'need the money' and 'love to work'.

The neoliberal turn happened in the US political economy earlier than in many other countries. To the extent that extended work policy initiatives exist in the US, they are less about empowering older individuals' choices to pursue satisfying employment and more about disempowering older workers by having to settle for poor quality employment and pinching pennies in retirement income systems. That requires discouraging retirement for as many as possible and for as long as possible, regardless of life circumstances. Workers in high-quality jobs may well perceive staying in work as a good personal choice. Disadvantaged and vulnerable individuals compelled to be employed even longer to make ends meet would see the situation much 
differently. A fair assessment of the United States' extended working life policies would note that, such as they are, they do little to help older workers stay employed longer, but do plenty to compel them to. 'Live longer, work longer' might be a more convincing argument if, as Burgess (2015) observed, "increases in life expectancy were spread evenly across the workforce. They are not."

The US welfare state is under renewed assault by the current Republican administration that has slashed taxes for high earners and launched expensive trade wars. The ballooning budget deficits those actions have created will starve the government of resources and tie the policy hands of future governments for years, maybe decades, to come. Many pundits regard the combination of political tenor, antipathy to redistributive government programs, and business de-regulation as making it nearly inevitable that pension ages and contribution levels to Social Security will have to rise in the future and that employers will have free rein to hire workers of the ages they prefer. The upshot given current circumstances is that older Americans will need to save even more themselves but have fewer chances for retirement income security, and to work even longer if demand for their work supports that. Raising retirement age is relatively easy to enforce, even if politically unpopular for some, so that seems to be the likeliest catalyst to extending working lives. After all, shifting governmental priorities, a thriving economy, and neoliberal enthusiasms have failed to coalesce to create meaningful debate about what policies it would actually take to extend working lives beyond their current limits.

\section{References}

AARP (American Association of Retired Persons). (2014). Staying ahead of the curve 2013: The AARP work and career study, older workers in an uneasy job market, Washington, DC: AARP.

BLS. (2016). Local area unemployment statistics. Retrieved July 21, 2019 from http://www.bls. gov/lau/stalt.htm.

Burgess, G. (2015). Pro-con: Should the retirement age go up? Heritage Foundation, Washington. Retrieved July 21, 2019 from https://www.heritage.org/social-security/commentary/pro-conshould-the-retirement-age-go.

CRR. Center for Retirement Research at Boston College. (2018). Workers with pension coverage by type of plan, 1983, 1998, and 2016. Retrieved July 21, 2019 from http://crr.bc.edu/wp-content/ uploads/2015/10/figure-16.pdf.

Charness, N. (2013). Job security in an insecure world: Adaptations of older workers in the IT industry. In P. Taylor (Ed.), Older workers in an ageing society: Critical topics in research and policy, Edward Elgar (pp. 109-114).

Copeland, C. (2014). Labor-force participation rates of the population ages 55 and older 2013. Notes, 35(4), 2-8.

DOL (US Department of Labor). (2015). FY 2015 congressional budget justification. Employment and Training Administration, Community Service Employment for Older Americans. Retrieved July 21, 2019 from https://www.dol.gov/dol/budget/2015/PDF/CBJ-2015-V1-07.pdf.

Federal Reserve Bank of St. Louis. (2015). Age and gender differences in long-term unemployment: Before and after the Great Recession, Economic Synopses 26. Retrieved July 21, 2019 from https://research.stlouisfed.org/publications/economic-synopses/2015-11-10/age-andgenderdifferences-in-long-term-unemployment-before-and-after-thegreat-recession.pdf. 
Federal Reserve Board of Governors of the Federal Reserve System. (2019, May). Report on the economic well-being of U.S. households in 2018. Washington, DC.

Fischer, J., \& Hayes, J. (2013). The importance of social security in the incomes of older Americans: Differences by gender, age, racelethnicity, and marital status. Institute for Women's Research, Briefing Paper IWPR \# D503. Retrieved July 21, 2019 from http://www.iwpr.org/publications/pubs/the-importance-of-social-security-in-theincomesof-older-americans-differences-by-gender-age-raceethnicity-and-marital-status.

Fontenot, K., Semega, J., \& Kollar, M. (2018). U.S. census bureau, current population reports, P60-263. Income and poverty in the United States: 2017. U.S. Government Printing Office, Washington, DC.

GAO. (2012). Unemployed older workers: Many experience challenges regaining employment and face reduced retirement security, GAO 12-445. Washington, DC: GAO.

Ghilarducci, T. (2015). Senior class: America's unequal retirement. American Prospect. Retrieved July 21, 2019 from https://prospect.org/article/senior-class-americas-unequal-retirement.

Herd, P. (2009). The two-legged stool: The reconfiguration of risk in retirement income security. Generations, 33(3), 12-18.

Lain, D. (2012). Working past 65 in the UK and the USA: Segregation into 'lopaq' occupations? Work, Employment \& Society, 26(1), 78-94. Retrieved July 21, 2019 from https://doi.org/10. 1177/0950017011426312.

MetLife. (2011). The MetLife study of caregiving costs to working caregivers double jeopardy for baby boomers caring for their parents. Westport, CT: MetLife Mature Market Institute.

Munnell, A. (2013). Social security's real retirement age is 70. Issue Brief 13- 5. Boston, MA: Center for Retirement Research at Boston College.

NASI. National Academy of Social Insurance. (2018). Social security benefits, finances and policy options: A primer. Washington, DC: National Academy of Social Insurance. https://www.nasi. org/sites/default/files/research/2018_Social_Security_Primer_Final.pdf.

Ní Léime, A., \& Street, D. (2016). Gender and age implications of extended working life policies in the US and Ireland. Critical Social Policy. https://doi.org/10.1177/0261018316666211csp. sagepub.com.

OECD. (2005). Pensions at a glance. Public policies across OECD countries. Paris: OECD Publishing.

Russell, J. (2014). Social insecurity 401(k)s and the retirement crisis. Boston, MA: Beacon Press. SSA. (2019). Fact sheet: 2019 social security policy changes. Washington, DC: Social Security Administration.

Street, D., \& Tompkins, J. (2017). Is 70 the new 60? Extending American women's and men's working lives. In Á. Ní Léime, D. Street, S. Vickerstaff, C. Krekula, \& W. Loretto (Eds.), Gender, ageing and extended working lives: International analysis from a critical perspective. Bristol: Policy Press.

Turner, J. A., \& Watanabe, N. (1995). Private pension policies in industrialized countries: A comparative analysis. Kalamazoo, MI: W.E. Upjohn Institute for Employment Research. Retrieved July 21, 2019 from https://doi.org/10.17848/9780880995320.

Wang, M., \& Schultz, K. (2010). Employee retirement: A review and recommendations for future investigation. Journal of Management, 36(1), 172-206.

Wegman, D. H., \& McGee, J. P. (Eds.). (2004) Programs and policies related to the older workforce and safe work. In US national research council and institute of medicine committee on the health and safety needs of older workers Health and Safety Needs of Older Workers. Washington, DC: National Academies Press. Retrieved July 21, 2019 from https://www.ncbi.nlm.nih.gov/books/ NBK207714/.

Weller, C. E. (2016). Retirement on the rocks: Why Americans can't get ahead and how new savings plans can help. New York: Palgrave Macmillan. 
Open Access This chapter is licensed under the terms of the Creative Commons Attribution 4.0 International License (http://creativecommons.org/licenses/by/4.0/), which permits use, sharing, adaptation, distribution and reproduction in any medium or format, as long as you give appropriate credit to the original author(s) and the source, provide a link to the Creative Commons license and indicate if changes were made.

The images or other third party material in this chapter are included in the chapter's Creative Commons license, unless indicated otherwise in a credit line to the material. If material is not included in the chapter's Creative Commons license and your intended use is not permitted by statutory regulation or exceeds the permitted use, you will need to obtain permission directly from the copyright holder.

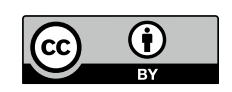




\section{Glossary}

Reproduced from European Commission (2018). Pension Adequacy Reports, Vol. 1. Brussels: Directorate-General for Employment, Social Affairs and Inclusion.

Defined benefit (DB) schemes - pension schemes where the benefits accrued are linked to earnings and the employment career (the future pension benefit is predefined and promised to the member). It is normally the state (in public DB schemes) or scheme sponsor (in occupational DB schemes) who bears the investment risk and often also the longevity risk (see also: Defined contribution (DC) schemes).

Defined contribution (DC) schemes-pension schemes where the level of contributions, and not the final benefit, is pre-defined: no final pension promise is made. DC schemes can be public, occupational or personal: contributions can be made by the individual, the employer and/or the state, depending on scheme rules. The pension level will depend on the performance of the chosen investment strategy and the level of contributions. The individual member therefore bears the investment risk. PAYGfinanced defined contribution schemes are known as notional defined contribution (NDC) schemes (see also: Defined benefit (DB) schemes).

FMLA (Family and Medical Leave Act).

Funded scheme - a pension scheme whose benefit promises are backed by a fund of assets set aside and invested for the purpose of meeting the scheme's liability for benefit payments as they arise. Funded schemes can be either statutory, occupational or personal (see also: Pay-As-You- Go).

IRA (individual retirement account).

Legislated pensionable age-legislated age at which a member of the pension scheme is eligible to receive full pension benefits, subject to meeting qualifying conditions. 


\section{OAS (Old Age Security).}

Occupational pension schemes - a pension plan where access is linked to an employment or professional relationship between the plan member and the entity that sets up the plan (the plan sponsor). Occupational pension schemes may be established by employers or groups of employers (e.g. industry associations) or labour or professional associations, jointly or separately, or by self-employed persons. The scheme may be administered directly by the sponsor or by an independent entity (a pension fund or a financial institution acting as pension provider). In the latter case, the sponsor may still have responsibility for overseeing the operation of the scheme.

Pay-As-You-Go (PAYG) schemes-pension schemes where current contributions finance current pension expenditure (see also: Funded schemes).

Pension pillar-different types of pension schemes are usually grouped into two, three, four or more pillars of the pension system. There is however no universally agreed classification. Many pension systems distinguish between statutory, statutory funded, occupational and individual pension schemes.

Personal pension schemes - supplementary pension schemes, access to which does not depend on an employment relationship. The schemes are set up and administered directly by a pension fund or a financial institution acting as pension provider without the involvement of employers. Individuals independently purchase and select material aspects of the arrangements. The employer may nonetheless make contributions to personal pension schemes. Some schemes may have restricted membership.

Standard pensionable age (SPA) - the earliest age at which an individual with a 40-year career can retire without any exit penalty (used in the calculations of the Theoretical Replacement Rates).

Statutory pension scheme-social security and similar programmes administered by the general government (that is central, state, and local governments, plus other public sector bodies such as social security institutions), access to which is based on legislation. Public pension plans can be financed from social security contributions or general taxation and have traditionally been of the PAYG type, but can also be funded (see also: Statutory funded pension schemes).

Statutory funded pension schemes-funded pension schemes, access to which is based on legislation. In statutory funded schemes, part of participants' social security contributions are converted into funded assets, typically administered by authorised private managers. Participation in these schemes can be mandatory or voluntary.

Supplementary pension schemes - pension schemes, which can be accessed on the basis of employment relationship (occupational pension schemes) or an individual pension saving contract (personal pension schemes), generally providing additional retirement income to the statutory pension schemes. (See also: Occupational pension schemes; Personal pension schemes). 
SSI (Supplemental Security Income).

Theoretical Replacement Rate (TRR)—generally refers to an indicator showing the level of pension income after retirement as a percentage of individual earnings at the moment of takeup of pensions or of average earnings. Replacement rates measure the extent to which pension systems enable typical workers to preserve their previous living standard when moving from employment to retirement. 


\section{Index}

A

Ability, 16, 17, 21, 32, 35, 40, 49, 54, 98, 106, 107, 122, 180, 196, 218, 244, $246,254,255,312,313,344,356$, $368,376,389,398,401,441-443$, 471,476

Absenteeism, 343

Access to pensions, 284, 287, 469, 485

Accumulate, 72, 253, 313, 342, 373, 377, 378

Acqui Communitarie, 118

Activation policies, 302, 310, 319

Active

ageing, 7, 38, 56, 81, 103, 146, 149, 195, 196, 201, 245, 290, 293, 321, 401, 403, $411,415,421,467$

labour market policies, 135, 236, 237, 373, 377

lip service, 290

workforce, 179, 421

Active Ageing Index (AAI), 56, 58

Active working population, 418

Adult Education Survey (AES), 56, 58

Age

barriers, 346

diverse workforce, 277

group, 8-11, 15, 22, 23, 35, 38, 60-64, $66,67,123,124,149,156,157,165$, 166, 176-178, 180, 184, 198, 206-209, $212,218,219,222,242,245,247,262$, $263,272,287,319,320,330,332,343$, 351, 352, 363-365, 367, 368, 378, 388, 391, 399-401, 418, 419, 421, 441, 443, 449-453, 455, 486

neutral personnel, 346

stereotypes, 221, 343

Age-based discrimination, 335, 343, 346
Age dependency ratio, 72, 118, 255, 408, 459,460

Age discrimination, 30, 35, 37, 40, 91, 92, 102, 130, 136, 143, 148, 177, 178, 190, 196, 220, 221, 245, 247, 252, 254, 277, 287, 299, 301, 335, 336, $346,351,354,358,375,403,434$, $443,451,488$

Ageing

demographic, 7, 230, 236, 276, 395, 411 population, $3,7,12,30,31,38,39,42$, $47,59,72,73,78,81,85-88,92,103$, 105, 106, 108, 110, 163, 178, 183, 205, $251,283,284,309,319,329,356,358$, $363,368,377,395,397,402,407,408$, $413,415,428,435,443,459,467,469$

Ageism, 30, 40, 91, 92, 97, 135, 148, 190, 191, 226, 284, 290, 291, 293, 298, 301, 304, 313, 314, 336, 357, 377, $443,476,487,489$

Age management policies, 254, 319, 320, 326

Albania, 50, 98, 99, 117-121, 123-125

Albanian, 118-125

Anti-age discrimination, 94, 168, 191, 299, $301,310,334,431,487,488,490$

Antidiscrimination, 158, 177, 277, 301, 336, 343

policies, 354, 411

Apprenticeship, 333, 354

At-risk-of-poverty rate, 198, 419, 420

Attitude

towards extended work, 64

Austerity

policies, 284, 303, 377

Australia, 18, 53, 98, 99, 129, 130, 132, 135, $136,188,355$

(C) The Author(s) 2020 
Australian, 9, 53, 129-133, 135-137

Australian Longitudinal Study Ageing (ALSA), 53, 58

Austria, 18, 32, 52, 55, 94, 98, 99, 103, 105, $106,141-149$

Austrian, 142-149

Auto-enrolment, 300, 303, 304, 332, 399, $462,474,475$

Automation, 20, 23, 24, 102, 109, 110, 226

Average

income, 185, 189, 310, 330, 332, 365

wage, 121, 332, 352, 410

'Averaging', 303, 304

\section{B}

Baby-boomer, 30, 55, 262, 408

Bailout, 283-289, 291, 293

Basic income, 251, 257, 311, 424

Belgium, 8, 18, 54, 55, 59, 98, 99, 107, 108, 153-157, 159, 160

Benefit formula, 224, 483, 485, 487, 489

Benefits

disability, 196, 244, 264, 302, 324, 337, $343,344,352$

health, 38, 355, 357

pension, 4, 77, 88, 95, 96, 98, 105, 120, $122,148,166,168,175,230-232,243$, $255,275,300,331,334,342,364-366$, 396, 409, 430, 453, 455, 456, 463, 483, $485,487,495$

state, 30, 105, 187, 473

Best practice, 72, 80, 96, 136, 301, 336, 476

Bosnia-Herzogovina, 99, 163-170

Bulgaria, 5, 8, 9, 98, 99, 173-175, 177, 178, 180

Burden of caring, 285

\section{C}

Capable, 75, 343

Care

child, 14, 47

credits, 72, 271-273, 278

entitlements, 273

formal, 189, 197, 378, 379

gap, 292

informal, 57, 98, 159, 283, 321, 344, 345, $353,379,434,453$

paid, 59, 179

responsibilities, 35, 38, 72, 104, 198, $271,272,276,353,481$

unpaid, 59, 67, 142, 230, 292, 297, 325, 380,445
Career breaks disrupted, 147

Careful, 87, 93, 291, 343, 444

Caregiving, 15, 109, 129, 131, 135, 137, 159, 189, 190, 276, 353, 434, 439, 443, 482, 487

Carer's Allowance, 303

Carer's Benefit, 303

Caring, care, caregiving, 6, 14, 15, 17, 24, 35, $38,40,47,51,56-61,67,72,86-89$, 96, 98, 101, 104, 105, 107, 109, 110, $119,124,125,129,131,134,135$, 137, 141, 147-149, 155, 156, 159, $160,167,169,173,174,178,179$, 183, 187, 189, 190, 195, 197, 198, 200, 205, 207, 211-213, 217, 218, 220, 224, 229, 230, 243, 247, 248, 252, 256, 263, 268, 271-273, 276278, 283-285, 291, 292, 297-300, 303 , 304, 309, 310, 314, 316, 319$321,323-326,334,336,341,343-$ $345,353-355,363,365,369,373$, $375,377-380,386,390,397,400$, $401,411-415,417,419,422,423$, 427, 432, 434, 435, 439, 441-445, 450, 453, 457, 460, 467, 469-471, 473, 475, 476, 481, 482, 485, 487, 489, 490

Caring responsibilities, 24, 35, 38, 40, 88, $89,104,105,109,110,207,273,285$, $353,470,471,473,475,476$

Childcare provision costs, 415

credits, 14,72

services, 450

Chile, 98, 99, 183-191

Chronic disabilities, 159 disease, 61, 124, 178, 368, 401

Clash, 344

Class, 16, 20, 21, 30, 32, 33, 38, 39, 73, 81, 129, 132, 137, 143, 148, 149, 207, 212, 309, 417, 423, 424, 427, 432, 453

Cleaning, 131, 211, 298, 314, 344, 460

Closure, 267, 290

Collective agreement(s), 132, 144, 147, 233, 277, 290, 311, 312, 333, 431

Combine pension income with paid employment, 323

Compulsory social insurance, 119, 167, 208

Conflict, 103, 143, 197, 314, 324, 325 
Consensus, 31, 81, 274, 314, 324, 392, 414, $433,441,445,481$

Continental, 342

Contribution

employee, 397

employer, 131, 223

evasion, 290

state, 223

Contributory pension, 299, 300, 322, 430

Contributory years, 322, 330

Corporatist, 143, 342

Country, HR+SL, 53, 58

Coverage rates, 299, 330, 379

Credits

caring, 14, 271-273, 278

childcare, 14, 72, 104

homemakers, 299

Crisis, 15, 50, 78, 97, 107, 108, 157, 174, 178, 207, 209, 213, 218, 229, 237, 254, 267, 283-287, 289-293, 312, $320,330,377,388,390-392,395$, 400, 418, 424, 428, 432, 435, 450, 486

Croatia, 8, 12, 31, 41, 49, 50, 53, 55, 99, 102, 195-201

Crowdworking, 20

Cuts to pensions, 289

Cypriot, 205-208, 210, 212, 213

Cyprus, 51, 59, 65, 99, 205-213

Czech Republic, 8, 9, 14, 19, 23, 31, 51, 98, 99, 217-223, 226

D

Data sets

qualitative, 48,67

quantitative, $6,47,48,59,67$

Debate

open, 291

Decreasing birth rates, 311

Defamilialisation, 154, 375

Deficit, 88, 164, 167, 292, 312, 385, 392, $402,450,462,491$

Defined

benefits, 4, 37, 93, 94, 96, 105, 106, 167, 223, 311, 312, 397, 428, 454, 474, 475, 483-485, 495

contributions, 4, 5, 14, 37, 73, 94, 96, 97, $105,106,119,167,223,231,237,312$, 313, 321, 410, 454, 474, 475, 483-486, 495

Defined Benefit (DB), 4, 37, 93, 94, 96, 105, 106, 167, 223, 311, 312, 397, 428, 454, 474, 475, 483-485, 495
Defined Contribution (DC), 96, 97, 105, 106, $119,167,223,231,237,312,313$, 321, 410, 454, 474, 475, 484-486, 495

De-institutionalisation, 344

Delayed retirement, 93, 95-97, 103, 106, $109,145,397,481$

Delay retirement age, 489

Demand, 17, 18, 20, 22, 24, 86, 87, 92, 94, $105,107,122,125,129,134,143$, $149,175,199,218,225,230,234$, 267, 283-285, 290, 292, 301, 346, $357,358,368,380,387,419,428$, 431, 435, 443, 482, 488, 490, 491

Demographic

changes, 31, 86, 104, 117, 164, 213, 262, 352,385

Denmark, 8, 9, 18, 55, 95, 98, 99, 105, 188, $229,230,232,233,236,242,387$

Dependency ratio(s), 72, 87, 118, 120, 121, 169, 195, 198, 255, 329, 386, 408, 459, 460

Depression, 21, 106, 124, 125, 155, 156, 189, 251, 283, 401

Deregulation, 87, 132, 428, 431

Derived rights, 287

Digitalisation, digital, 3, 19-23

Disability

allowance, 166, 302, 303, 323

benefit, 196, 244, 264, 302, 324, 337, $343,344,352$

pathway, 276

pension, 30, 39, 98, 142, 144, 166, 167, $176,219,224,235,244,255,275,276$, 278, 279, 290, 291, 302, 324, 379, 396, $398,399,435,469,476$

pensioners, 231, 276, 279, 398, 463 route, 333,376

Disadvantage, 14, 15, 39, 77, 104, 105, 108$110,132,133,137,174,187,220$, 264, 290, 298, 304, 313, 320, 423, 476, 481, 482, 485, 489, 490

Discrimination age, 30, 35, 37, 40, 91, 92, 102, 130, 136, 143, 148, 177, 178, 190, 196, 220, 221, 245, 247, 252, 254, 277, 287, 299, 301, $335,336,346,351,354,358,375,403$, 434, 443, 451, 488 gender, 136, 236, 423

Discussion

lack of, 33, 88, 137, 213, 291, 464, 482, 490

Diseases 
cardiovascular, 61, 164, 178, 413

diabetes, 61

musculoskeletal, 61, 276

non-communicable, 124

prevention, 124

Disincentives, 167, 236, 266, 283, 292, 322, 365,434

Disincentive to early retirement, 167,322

Diversity management, 148, 149, 234

Double burden, 276

Dual earner families, 311

Dutch, 7, 14, 49, 90, 341-345

\section{E}

Early

exit, 7, 31, 157, 233, 246, 247, 255, 257, 276, 292, 341, 342, 400, 434

retirement, $7,10,15,31,36,47,51,54$, $61,95,97,98,106,117,119,120,122$, $124,125,141-145,155-157,167,175$, 179, 180, 195, 196, 198, 199, 205, 209, 218, 219, 224, 225, 233-235, 237, 243, 244, 255, 256, 262, 265, 268, 272, 273, $277,278,284,285,287,288,291-293$, $298,301,322,324,330,334,337,341-$ 343, 345, 373, 376-378, 386, 389-391, 396, 397, 402, 418, 419, 428, 430, 432, $434,442,451,452,463,466,470$

Early retirement schemes, 234

Earnings

from benefits, 484

from employment, 104, 174, 275, 497

high, 491

low, 144

preretirement, 483

Earnings-related, 104, 143, 207, 208, 223, 224, 253-255, 300, 330, 473, 475, 476,483

Economic

crisis, 78, 157, 218, 291, 293, 320, 330, $377,388,390-392,395,424,428,432$, 486

status, 49, 101, 129, 190, 389

systems, 119,363

violence, 102

Economically active population, 367

Economy, 18, 19, 30, 37, 38, 55, 76, 90, 108, 120, 129, 148, 180, 191, 199, 207, $218,229,236,242,251,255,284$, $289,303,313,364,368,370,374$, $418,419,428,435,443,444,487$, 489-491
Educated, 109, 143, 189, 190, 222, 245, 256, $285,287,325,379,418$

Education

postgraduate, 33, 267

primary, 66, 165, 196

secondary, 33, 66, 165, 196, 367

tertiary, 66, 174, 245, 444

EF European Company Survey (ECS), 54, 58

Effective retirement age, 10, 142, 144, 341, $345,346,397$

Egalitarianism, 122

EHSIS/EDSIM, 58

Electoral politics, 92

Eligibility criteria for pensions, 119

Employability, 3, 17, 18, 49, 93, 94, 97, 102, $107,122,125,145,235,245,247$, $277,302,346,377,411$

Employees, 13, 15, 17, 19, 20, 22, 50, 51, $54,63,72,79,90,93,96,106,108$, $110,118-120,122,123,131,132$, $134,136,137,143-149,156,164$ $166,170,176,179,180,185,187$, 188, 196, 198, 199, 206-209, 211, $212,218-223,231,234,244,254$. 256, 264-266, 274, 275, 301, 302, $304,310-314,321-324,330,333-$ $335,341,342,345,346,353,355$, $358,366,368,374,376,378,386-$ 391, 397, 402, 403, 410, 414, 419, $428,431,444,445,453,454,462$, $466,471,474-476,483,487,488$

Employer associations, 236

Employers, 3, 17-19, 24, 37, 39, 40, 53, 74, 88-96, 102, 103, 105-108, 110, 118 $120,122,123,125,129,131-135$, $137,141,144,145,147,149,154$, $156,160,166,174,175,177,179$, 180, 186-189, 197, 199, 200, 208210, 218, 221-223, 226, 231, 234, 236, 237, 253, 254, 256, 265-268, 275, 277, 290, 299-304, 311-313, 320 , 331-335, 342-346, 351, 353$358,366,368,376,378,387,388$, $391,397,400,403,410,412,414$, $418,421,422,424,428,431,434$, $435,439,444,445,453,454,457$, 462, 470, 471, 474-476, 482-484, $487,488,490,491,495,496$

Employment contract, 17, 146, 200, 301, 333, 335, $336,413,431,432$

full-time, 15, 174, 271, 455, 457, 487 
gender gaps, 285

patterns, 241, 373, 449-451

permanent, 368

policy, 133, 145, 163, 168, 170, 176, 179, 195, 198, 199, 205, 209, 217, 218, 222 , 226, 233, 245, 253, 266, 277, 290, 300, $320,323,326,333,336,337,342,345$, $353,373,377,399,401,403,407,411$, $412,431,451,463,475$

protection, 39, 199, 236, 290, 337, 365, 431,440

rate(s), 8, 9, 11, 18-23, 34, 35, 39, 71, 74, 141, 142, 155-158, 163-166, 176, 195, 196, 206, 229, 237, 241, 242, 247, 251-253, 256, 262-264, 271-273, 285, 286, 319, 320, 323, 326, 330, 332, 351, $364,365,367,374,375,386,389,391$, $399,400,407,408,412,417,418,428$, $433,435,449,450,452,471$

regulations, 469,470

targets, 300

temporary, 432, 442

total, 142, 158, 206, 272, 364

under-, 59, 134, 137

English Longitudinal Study of Ageing (ELSA), 53, 58, 60

\section{Entitlements} cuts to, 132

Equality

gender, 9, 21, 29-31, 34-36, 41, 64, 81, 118, 131, 201, 206, 207, 252, 334, 375, $450,456,457,464,467$

Equality principles, 321

Equal opportunities in the labour market for people aged $50+$

treatment, 54

Equation, 92, 488

Establishment Survey on Working Time and Work-Life Balance (ESWT), 51, 58

Estonia, 8, 11, 32, 65, 95, 98, 99, 229, $241-247,386$

Estonian, 242-245, 247

European Commission, 7, 31, 32, 34, 35, 38, $41,47,74,81,94,118,196,198,208-$ $211,245,252,284,321,322,374$, 375, 385, 396, 408, 412, 422, 495

European Community Household Panel (ECHP), 52, 58

European Directive on Discrimination, 321

European Health Interview Survey (EHIS), 56,58

European Parliament, 31, 365
European Quality of Life Survey (EQLS), $50,58,61,64-67,119,123-125$

European Social Survey, 287

European Union tax-benefit microsimulation Model (EUROMOD), 56, 58

European Working Conditions Survey (EWCS), 50, 58, 196

Eurostat, 5, 8, 9, 11, 13, 14, 16, 17, 19, 23, $58,61,72,75,101,141,142,155$, 176, 195, 196, 206, 229, 232, 236, $242,244,246,252,262,263,286$, $298,301,320,324,368,374,375$, $379,385,386,388,399,408,410$, 412, 413, 418, 452

EU-Statistics on Income and Living Conditions (EU SILC), 49, 58, 61, 67

Evidence based decision-making, 88

Extending/ed working life policies, 3-5, 40, $86,98,108,110,163,166,175,191$, 205, 298, 299, 303, 310, 319, 326, $376,419,449,469,484,491$

F

Familial system, 285

Family business(es), 117, 287

extended, 66

member, 15, 35, 66, 104, 119, 159, 189, 197, 247, 248, 263, 276, 298, 300, $303,334,353,355,379,390,427,435$, 442-444, 487, 489

model, 430

responsibilities, 14, 119, 125, 276, 278, $319,375,400$

status, 65,66

Family friendly policies, 101, 298

Family support, 106, 321

Farming, 287

Female, 13, 32, 62, 88, 119, 131, 132, 136, 144, 146, 154, 173, 189, 206, 213, $229,236,237,246,247,252,262$, $271,275,278,285,293,345,356$, $386,408,428,429,432,442-444$, $450,455,459,460,463,464,467$

Financial benefits, 187, 210, 222, 334

Financial incentives, 133, 145, 186, 209, $213,278,346,376,419$

Financing, 57, 178, 286, 292, 365, 366, 402, 434

Finland, 8, 9, 18, 31, 52, 55, 93-96, 98, 99, $103,108,229,236,251-257$

Finnish, 72, 86, 108, 110, 251, 252, 254-257 
First pillar, 131, 201, 223, 231, 243, 284, $330,342,365,376,389,409,482$

Fiscal retrenchment, 291

Fit2work, 146

Fixed term contracts, 200,333, 387, 449, 452

Flat-rate pension, 299, 330, 351

Flexibility, 12, 17-19, 22, 23, 71, 72, 76, 90, $122,123,129,134,137,156,200$, $242,247,251,253,301,310,333$, 387,475

Flexible

labour law, 336

work, 59, 90, 96, 134, 234, 247, 252, 255, $351,353,357,432,439,442,471,475$, 476,490

Flexible regulation, 333

Flexible retirement age band, 322

Floors of social insurance, 335

Forcibly implemented, 292

Formal care provision, 378

Fragmentation, 284, 286, 287, 321

France, 4, 5, 8, 10, 55, 93-95, 98, 99, 105, $106,109,261-263,268,387,410$

Freeze statutory retirement age, 301

Freezing payments, 332

French National Employment Survey, 54, 58

Full-time

employment, 15, 174, 271, 455, 457

work, 90, 272, 440, 463, 471

G

G2ageing, 57, 58

Gap

between pension and retirement age, 297

gender, 5, 9, 12, 14, 15, 35, 72, 104, 118, $124,131,133,142,165,166,183,185$, 186, 206-208, 244, 246, 253, 272, 285287, 313, 320, 323, 326, 364, 367, 374, 391, 399, 413, 419, 422, 430, 463, 467, 482

pay, $12,13,38,104,148,149,174,179$, 180, 206, 208, 213, 225, 273, 297, 298, $330,374,386,391,422,457,471,485$ pension, 3, 12, 14, 15, 38, 141, 149, 208, 213, 273, 278, 289, 297, 298, 330, 387, $417,422,449,450,455-457,463,490$

Gender

blind, 378

differences, 33, 85, 90, 125, 141, 143, $148,149,157,158,163,166,180,191$, 196, 217, 232, 235, 237, 253-255, 257, $262,267,268,325,330,367,400,401$,
403, 428, 430, 432, 435, 442, 443, 449, 450,464

employment gap, 149, 206, 272, 374

equality, 9, 21, 29-31, 34-36, 41, 64, 81, 118, 131, 201, 206, 207, 252, 334, 375, $450,457,464,467$

gap, $5,9,12,14,15,35,72,104,118,124$, $131,133,142,165,166,183,185,186$, 206-208, 244, 246, 253, 272, 285-287, $313,320,323,326,364,367,374,391$, $399,413,419,422,430,463,467,482$ implications, 48, 131, 334, 337, 422, 449, 450

perspective, 59, 173, 232, 326, 351, 357, $373,376,380,401,427,441,456$

role, $12,15,125,130,380,430$

segregation, 129, 131, 149, 206, 242

stereotypes, 293

Gender distribution of care work, 325

Gendered

statistics, 163

work histories, 310

Gender pay gap, 12, 13, 38, 104, 148, 149, 174, 206, 208, 213, 225, 273, 297, 298, 330, 374, 386, 391, 422, 457, 471

Gender pension gap, 14, 15, 38, 141, 149, 213, 273, 278, 289, 297, 298, 330, $387,417,422,449,450,455-457$, 463,490

Gender pension regime, 297

Gender-proofed, 304

Gender-segregated, 21, 326, 471

Gender segregation, 129, 131, 149, 206, 242

Gender-sensitive

indicators, 6, 47, 48

measures, $6,47,48$

policies, 48

policy approach, 380

Gender wage gap, 129, 131, 132, 137, 242, $245,252,319,408,460$

Generational Transmissions in Finland (GENTRANS), 55, 58

Generations and Gender in Belgium (GGP), $54,58,59$

German Ageing Survey (DEAS), 49, 58, 60

Germany

East, 271, 274, 278

West, 271, 272, 274, 275, 278

Gig economy, 18, 90

Globalisation, 17, 18, 64, 102, 109, 110, 428

Good jobs, 91, 309, 486, 488 
Good practice, 69, 71-74, 76, 77, 80, 89, 277, $320,366,368,370,375,376,412$

Grandchildren, 59, 219, 230, 268, 283, 285, $320,323,326,375,489$

Grandfathered, 288

Greece, Greek, 8, 23, 31, 95, 98, 100, 283 289, 291-294, 324

Gross Domestic Product (GDP), 72, 120, 121, 164, 198, 232, 263, 284, 285, $324,329,365,432$

Gross wages, 168, 332, 387, 408

Guaranteed Minimum Income (GMI), 176, 210,212

\section{H}

Hairdressers, 288

Harassment, 21, 102, 464

Hazardous, 5, 16, 197, 210, 244, 261, 266, $268,288,322,323,476$

Health, 3, 5, 6, 12, 15-18, 21, 22, 24, 32, $33,38-40,42,47-56,58-61,64-67$, $71,81,85,86,88-94,96,97,101$, $102,105,106,108-110,117,118$, $122-125,129,132,134-137,143$, $144,146-149,155,158-160,163-$ $166,169,170,173,174,178-180$, 183-185, 188, 189, 191, 195-197, 201, 205, 206, 212, 213, 217-220, 226, 230, 232, 235, 244, 246, 247, 251-257, 263, 266-268, 272, 275$279,284,287,288,290,291,297-$ $299,301-305,310,315,316,319$, $321,324,325,329,333,336,341$, $344,345,353,355-358,365,367-$ $369,373,376-380,385,391,392$, 397, 399, 401, 407-409, 411-414, 417, 419, 421-424, 427, 431-435, 439-445, 451, 452, 459, 460, 462, 464, 467, 469, 470, 475, 476, 481, 482, 487-490

conditions, 22, 38, 53, 61, 102, 106, 134, 146, 188, 219, 303, 316, 409, 413, 432, 470, 476

considerations, 298

effects, 129, 137, 147, 148, 439

expenditure, 291

functional, 53

gap, 12,124

insurance, 159, 166, 169, 197, 212, 345, 413, 414, 423, 441, 464, 481, 482, 487-489

mental, 21, 38, 39, 60, 61, 132, 136, 155, $276,279,303,315,417,423,432$ perspective, 67,417

physical, 21, 48, 59, 60, 427, 432

policies, 56, 135, 146, 163, 164, 169, 173, $178,195,200,235,246,254,255,266$, $302,329,333,355,401,407,413,423$, $459,464,475,488$

reasons, $60,135,220,263,376,421,441$, 451

status, $17,32,47,53,54,56,60,85,88-$ $90,93,97,105,106,109,122,135,188$, $247,319,325,378,401,413,433,490$

Health and safety, 16, 50, 197, 301, 302, 358, 422

Healthcare

system, 178, 256, 380

Health deterioration, outcomes, 288

Health implications, 86, 117, 123, 125, 170, 179, 201, 205, 247, 267, 272, 297, $304,305,329,434,439,445$

Health-threatening conditions, 290

Health Work and Retirement study (HWR), $51,58-60,353,355,356$

Healthy life expectancy, 33, 40, 60, 101, 243, $246,325,392$

Heavy and Hazardous Occupations (HHO), $288,290,291$

Higher

incomes, 10, 179, 450

pensions, 92, 95, 118, 122, 145, 154, 247. $323,358,366,367,399,410$

wages, 122

Home

based working, 90

care, 252, 276, 379

help, 285

Homemaker's scheme, 299, 300, 304

Horizontal segregation, 298, 419

Hybrid, 254, 342

Hypertension, 124, 401

I

i.bus, 57,58

Illness

chronic, 60, 379

insurance, 302

mental, 303

physical, 379

psychological, 16

Income

disposable, 61

ICT, 21, 422

Ill-health, 170, 299, 304, 413, 431 
Inactivity rate, 165,400

Incapacity pension, 333

Incentive to postpone retirement, 231, 322

Income

adequate, 4, 5, 31, 268

disability, 132, 189, 302, 323

disposable, 61, 410

employment, 12, 105, 180

high, 143, 264

low, 89, 96, 109, 132, 133, 147, 189, 212, $289,310,323,353,370,417,423,442$, 473

redistribution, 231

retirement/pension, 6, 7, 14, 96, 98, 105, $106,129,131-133,183,185,186,190$, 208, 211, 230-232, 237, 245, 253, 256, 262, 278, 322-324, 352, 353, 366, 407. 455, 456, 473, 474, 481-485, 490, 491, 496, 497

security, 311, 482, 497

Increased number contributions, 4, 7, 98, $122,145,147,179,290,300,304$, 322, 331, 392, 396, 397, 419, 457, 474

Increase in retirement age, 243

Increasing life expectancy, 40, 251, 311, 385

Independence lower, 293

Indexation

pension, 289

Indicators

performance, 75

social, $69,71-75,80$

Individual

pensions, 186, 187, 223, 230, 231, 304, $331,418,455,462,496$

Individualisation

of risk, 40, 486

retirement income responsibility, 106

Individual responsibility, 4, 11, 37, 38, 41, $344,421,423,424,469,475,476$

Industry 4.0, 19-21

Inequality

gender, 375, 441

health, 12

Inflation, 473

Informal

care, $98,159,321,344,353$

caregivers, 143, 159, 188, 345, 379, 380

work, 117

Information sharing, 324

Insiders, 290

Insurance record, 331, 332
Integrated approach education, 117

Intergenerational

conflict, 103

equity, 130

inequity, 130

solidarity, 41, 166, 179, 268

workplaces, 301

Interrupted employment, 137, 178

International Labour Organisation (ILO), $75,122,332$

Intimate partner violence, 316

Invalidity pensions, 144, 196, 200, 201, 291, $387,389,390,409$

Ireland, 4, 49, 57-59, 95, 96, 98, 100, 102, 297-303

Irish, 49, 297-301, 303-305

Israel, 9, 49, 55, 57, 58, 95, 98, 100, 309-311, 313-316

Israel Gerontological Data Center (IGDC), 55,58

Israeli, 9, 309-311, 313-316

Italian, 53, 319, 321, 323-326

Italy, 14, 18, 23, 53, 55, 95, 96, 98, 100, 196, 319-321, 323-325

IT_SI-IT-Health, 58

$\mathbf{J}$

Job

characteristics, 60, 105, 225

demands, 17

insecurity, 105, 378, 427, 432, 434

resources, 17

security, 107, 137, 236, 254, 413

Job-sharing, 134, 333, 412

Job-specific training, 346

Joint Programme Initiative (JPI), 55, 58

L

Labour Code, 119, 125, 266, 333-335, 337, 377,414

Labour contracts, 125, 167, 333, 466

Labour force

participation, 8, 9, 16, 35, 39, 41, 118, $119,129,130,165,166,174,184$, $191,229,252,257,261,262,272,292$, $298,351,353,386,408,428,435,450$, 459-461, 463, 464, 467

skilled, 20, 23

Labour force participation rates (lfpr), 118 , 130, 184, 229, 261, 298, 351, 386, $428,435,450,459-461,467$ 
Labour Force Survey (LFS), 22, 51, 52, 56, $58,118,119,123,155,157,158,200$, 207, 253, 286, 400, 429, 450, 459, $460,462,465$

LFS ad hoc module 2011., 58

Labour market

changing, 17, 229, 237

global, 87

national, 7, 87, 93

participation, 15, 18, 60, 87, 146, 183, 187, 246, 252, 272, 275, 277, 310, 315, $336,343-346,391,424,450,451$

Labour unions, 311, 342

Lack of adequate skills, 117

Law on equal treatment, 334

Legacy

costs, 293

issues, 288

Legal retirement age, 141, 153, 155, 261, 264, 277, 278, 319, 386, 387, 391, 397,431

Lifecourse

events, 47, 58, 60, 379

framework, 191

literature, 325

perspective, 117, 119, 242, 298, 378

trajectories, $88,98,109$

Life expectancy/ies

calculations, 377

Life-long learning, 35, 56, 145, 170, 247, $277,302,321,337,354,373,377$, $411,415,421,451$

Lifespan, 217, 368

Lifetime contributions, 364

Linking pensions to employment, 298

Lip service, 290

LIS, 58

Lithuania, 5, 8, 9, 12, 18, 55, 98, 100, 229, 329-337

Lithuanian, 55, 331, 333, 334, 336, 387

Lithuanian Data Archive for Social Sciences and Humanities (LiDA), 55, 58

Living arrangements, 60

Loan scheme to cover missing contributions, 322

Longevity, 29, 30, 103-106, 133, 179, 231, 252, 255, 313, 358, 495

Longitudinal Study Aging in Spain (ELES), $54,58-60$

Long-Term Care (LTC)

policies, 290

Long-term unemployed, 176, 177, 302, 400, 486
Low base, 130, 297, 451

Low employment rates, 195, 285, 386

Lower life expectancy, 5, 101, 288, 290, 325, 345

Low/er pensions old age pensions, 122, 336, 367

Low income job, 96

Low paid

employment, 89, 274, 275, 278

work, 274,275

Lump of labour fallacy, 290, 293

M

M65+, 57, 58

Macro level, 37, 39, 92-95

Male breadwinner/female homemaker society, 417

state, 298

Mandatory

retirement age, 30, 37, 39, 265, 314, 378, 430

Market (older workers), 18-20, 110, 262, 277, 284-286, 290, 293, 380, 390, 418

Marriage bar, 298

Masculinity, 34

Material deprivation, 61, 63, 125, 244

Maternity leave, 119, 166, 200, 211, 224, 298, 386

Means-tested, 119, 124, 131, 144, 230-232, $273,299,303,311,322,450,453$, 473,482

Mechanisms, 4, 7, 71, 73, 96, 106, 229, 236, $288,312,322,323,336,337,380$, $484,487,490$

Media campaigns, 321

Media debate, 147, 303, 440

Median hourly wage, 274

Men, 5, 6, 8-17, 31-36, 38, 47, 48, 54, $59,61,63,86-88,92,98-101,104$, $117-120,123-125,130,131,133-$ $135,137,141-144,146,148,154-$ $158,160,164-169,174-180,184$ 188, 191, 195, 196, 198, 199, 201, 205-210, 213, 219, 224, 232, 234, 235, 237, 242-244, 246, 252-256, 261-265, 267, 268, 272, 273, 276, 278, 284, 286, 287, 290, 291, 298, 299, 304, 309-316, 319, 320, 322, $323,325,330-332,334,336,341$, $343-345$, 352-355, 358, 363-368, 
$373-375,378,379,386,387,389-$ 392, 396, 397, 399-403, 408-410, 413, 414, 419, 420, 422, 423, 427, $430,432,434,435,439-445,449$ $456,459-465,470-473,475,476$, $482,485,486$

Mental health problems, 155, 276, 279

Meso level, 39, 93, 95

Micro level, 95

Migration, 23, 60, 118, 147, 148, 164, 358, 385,387

Mini-jobs, 275

Minimum wage level of pension, 388

Moral economy of ageing, 108

Morbidity indicators, 291

Mortality indicators, 291 rate, $74,164,178,186$

Musculoskeletal diseases, 61, 276

\section{N}

Negotiations, 132, 153, 160, 254, 256, 312

Neoliberal, 11, 38, 41, 42, 87, 94, 96, 130, $160,376,423,490$

Neoliberalism, 38, 424

Netherlands, 14, 18, 20, 32, 41, 49, 53, 55, $65,95,100,102,285,315,341-346$

Netherlands Kinship Panel Study (NKPS), $53,58,60$

New technologies, 40, 102, 343, 370, 387

New Zealand, 9, 18, 51, 59, 100, 351-358

Non-contributory pension, 120,430

Non-existent, 290

Non-governmental organisations, 70, 92, $147,186,246,303,321,357,370$, 422

Non-market services sector, 118

Normative shifts, 344

Norms

family, 101

gender, 98, 400, 457

NoWork, 55, 58

\section{O}

Objective justification, 301

Obligatory, 198, 330-332, 342, 414, 452

Occupational differentiation, 288

Occupational health deterioration, 288
Occupational pensions, 14, 60, 93, 96, 104, $106,125,144,208,211,213,230$ 232, 273, 311, 331, 342, 346, 366, 398, 453, 454, 456, 474, 484, 496

Occupations

civil servants, 119, 154, 397

geologists, 119

metallurgists, 119

miners, 119, 122, 210

teachers, 119, 175

Old age pensions

insurance, 120, 122

Older people, 29-41, 64, 65, 85-89, 92, 95, 97, 103-105, 108, 109, 118, 123, 132 , $134,153,163,164,167-169,177-$ 179, 183, 184, 188, 189, 197, 211, 218, 219, 226, 233, 237, 241, 242, 245-247, 256, 276, 284, 285, 287, $302,310,311,319,321,325,336$, $353,354,356-358,363,368-370$, $375,378,379,385,386,388-392$, 403, 407, 410-412, 421-424, 432, 441, 442, 444, 449, 460, 462, 464, 467,482

Older women

women's own advocacy, 137

Older workers, 3-5, 7, 9, 18-23, 31, 32, 34, $35,37-40,48,53,55,72,74,85,86$, 89-98, 101-104, 106-110, 118, 120, $122,123,125,136,141-143,145-$ 149, 153-158, 160, 163, 165, 170, $176,179,180,184,185,187,190$, 195-197, 199, 206, 218, 220, 222, 225, 226, 229, 233-237, 242, 243, 245, 247, 253-257, 261-263, 266268, 272, 277, 283-286, 290, 292, 293, 298-302, 310, 315, 319-321, $323,326,329,334,336,337,343$, $344,346,351,352,354-358,365$, $373,375-377,380,390,396,397$, 400, 401, 407, 418, 419, 421, 427, 431, 432, 434, 439, 441, 443, 444, 449-453, 459-462, 464, 469-471, $475,476,481,482,485-491$

One-size-fits-all, 309

Organisation for Economic Co-operation and Development (OECD), 3-6, 10, $15,30,39,58,60,61,71,72,75$, 87, 92, 94, 96-98, 101, 105-108, $131,136,142,144,145,183-185$, 188, 236, 251-253, 256, 273, 276, 
277, 298-302, 304, 312, 315, 321$323,337,342-344,346,351,363-$ 366, 387, 407, 408, 413, 414, 428, 431, 449-451, 453, 455, 460, 467, 473-476, 482, 489

Outlays, 284, 285, 483

Outsiders, 290

Overtime limit, 333

$\mathbf{P}$

Paid workforce, 131, 352

Paradox, 90, 92, 123, 288, 292, 489

Parametric reforms, 117, 331

Parental leave, 54, 133, 156, 157, 174, 176, 200, 224, 242, 251, 252, 257, 276, $375,386,387,390$

Partial retirement, 39, 146, 156, 157, 243, 397

Participate, 9, 102, 130, 133, 166, 222, 230, $302,316,332,342,387,411$

Participation in paid labour market, 304

Part-time

employment, 18, 136, 146, 157, 158, 235, $251,272,273,277,278,313,343,355$, $421,450,453,456,471,472$

jobs, 12, 18, 141, 148, 218-220, 243, $262,263,268,449$

retirement, 145,146

Paternity leave, 211, 252, 298, 386, 457

Pathways to retirement, 24, 337

Pay-As-You-Go (PAYG)

model, 119, 376

pension scheme, 147, 185, 342, 397, 496 system, 96, 122, 167, 198, 408

Penalised, 7, 10, 205, 209, 218, 225, 292, 373,377

\section{Pension}

age, 11, 100, 120-123, 132, 133, 142, 147, 166-168, 201, 208-210, 212, 217, $223,224,244,253,255,275,286,288$, 290, 322, 323, 330-332, 334-336, 367, 403, 409, 419, 432, 439, 445

applications, 288

cuts, 219, 289, 402

defined benefit, 4, 94, 96, 106, 483, 484

defined contribution, 4, 96, 119, 312, 474, 475

disability, 30, 39, 98, 142, 144, 166, 167, $176,219,224,235,244,255,275,276$, 278, 279, 290, 291, 302, 396, 398, 399, 435, 469, 476

expenditure, 31, 207, 329, 440, 496 funds, 156, 166-168, 175, 185, 187, 188, $225,231,232,237,243,312-315,330$, 331, 342, 396, 397, 418, 435, 454, 496 income, $7,14,96,98,105,106,183,185$, 186, 190, 208, 231, 237, 245, 253, 256, 262, 278, 322-324, 366, 456, 473, 474, 497

indexed, 430

individual, 186, 187, 223, 230, 231, 304, $331,418,455,462,496$

insurance, 145, 146, 166-168, 198, 223225, 272, 273, 275, 276, 331, 397, 398, 409, 410, 418

lack of, 316,323

occupational, 14, 60, 93, 96, 104, 106, 125, 144, 208, 211, 213, 230-232, 273, $311,331,342,346,366,398,453,454$, 456, 457, 474, 484, 496

outlays, 284

pay as you go, 122, 389, 397, 408, 418, 440, 483, 496

personal, 144, 231, 299, 331, 450, 454, 456, 496

policy, 73, 89, 95, 97, 101, 108, 109, 120, $125,141,145,175,183,198,205,207$, 209, 230, 233, 243, 254, 263, 272, 274, 277, 278, 284, 287, 291, 299, 321, 329, $331,342,364,376,396,408,462$

programme, 309, 311, 313, 314

promises, 4, 87, 88, 96, 104, 106, 292, 495

public, 95, 98, 100, 109, 164, 166, 175, 223, 243, 263, 265, 272, 273, 325, 329, $337,365,389,390,392,397,398,402$, 433, 483, 487, 489, 496

reform, 72, 73, 81, 98, 117, 120, 125, 147, $148,163,164,167,174,175,179,180$, 185, 187-190, 209, 217, 223, 235, 243, $253,255,256,263,266,271,272,274$, 276, 278, 287-289, 291-293, 298, 303, $304,311,320,323,324,326,330,376$, 379, 392, 396, 401, 402, 414, 419, 421, 423, 439, 440, 445, 453, 456, 457, 464, 470

schemes, 74, 122, 143, 144, 147, 185, $208,211,223,231,243,244,263,273$, $276,278,288,301,331,342,352,365$, $377,397,402,410,440,454,455,457$, 459, 462, 466, 469, 470, 474, 475, 495, 496

state, 4, 10, 14, 30, 33, 37-39, 89, 91-93, 95-99, 104-106, 108, 123, 167, 175, 223, 225, 230-234, 243, 262, 273, 287, 
297, 299-301, 303, 304, 330, 342, 343, 346, 392, 419, 430, 439, 466, 469, 470, 473-476, 482

supplementary, 208, 211, 230, 273, 278, $330,410,439,496$

systems, 3, 4, 7, 14, 23, 31, 34, 36, 37, 41, 88, 92, 96-98, 101, 106, 119-123, 141, 143-145, 154, 156, 163, 164, 166-168, 175, 178, 185-187, 189, 190, 196, 198, 201, 205, 207, 208, 213, 217, 218, 223, 225, 230-233, 236, 237, 241, 243, 246, 252, 263-265, 271-273, 275, 278, 284, 287, 292, 299, 300, 304, 311, 312, 321$325,329,330,341,342,373,376,385$, $387,389,390,392,396,398,402,403$, 408, 410, 411, 414, 415, 417-419, 424, $427,428,430,433-435,439,440,449$, $450,452-455,457,462,463,473,474$, 476, 496, 497

transformation, 119, 484

Physical health, 21

Physically demanding

job, 102, 106, 107, 170, 325, 345

work, 102, 298-300, 303, 304

Pillar, 131-133, 144, 147, 154, 166, 167, $175,195,198,199,205,208,210$, 213, 223, 230-234, 243, 247, 263, $265,273,289,311,321,330-332$, $342,365,389,392,398,408-410$, 418, 449, 450, 452-457, 482, 483, 496

first, 131, 201, 223, 231, 243, 284, 330, $342,365,376,389,409,482$

second, 131, 144, 154, 175, 199, 223, $243,247,263,265,311,331,332,342$, $365,389,392,398,409,410,418,482$ third, 131, 154, 198, 213, 223, 231, 243, $331,342,365,389,398,410,454,483$

Poland, 19, 51, 54, 65, 93, 95, 98, 100, 102, $107,109,363-370$

Polarisation, 20, 21

Polarised, 309

Policy/ies

analytic, 70, 71, 80, 245

assessment, 70, 73

choice, 37, 88, 89, 92, 93, 131, 476

cycle, 79-81

design, 36, 76, 80, 86, 87, 109, 110, 191, 199, 241, 297, 380, 395, 401, 433, 435, 474

employment, 133, 145, 163, 168, 170, 176, 179, 195, 198, 199, 205, 209, 217, $218,222,226,233,245,253,266,277$,
290, 300, 320, 323, 326, 333, 336, 337 , $342,345,353,373,377,399,400,403$, 407, 411, 412, 431, 451, 463, 475

evaluation, 76, 79, 80

extending working life, 3, 70, 87, 93, 125 , $169,217,243,252,253,265,266,299$, $337,392,396,402,419,449,470,490$ flexible employment, 134, 199, 401

for older workers, 329

gender responsive, 137

implementation, 4, 79, 179

lifecourse, 89, 94, 109, 191, 278, 435, 490

neoliberal, 129, 131, 423

pension, 73, 89, 95, 97, 101, 108, 109, $120,125,141,143,145,175,183,198$, $205,207,209,230,233,243,254,263$, $272,274,277,278,284,287,291,299$, 321, 329, 331, 342, 364, 376, 396, 408, 462

process, 70, 78-81

public, 12, 38, 75-77, 79, 81, 129, 136, $157,176,183,187,188,271,272,276$, $278,326,373,380,385,386,415,435$ social, 22, 87, 218, 326, 337, 392, 489

strategic, 70, 374, 378, 411

toolkits, 6, 69-71, 78-81, 89

Policy makers, 22, 24, 51, 70, 71, 88, 89, 92, 93, 96, 103, 124, 131, 134, 191, 213, 225, 246, 268, 293, 309, 326, 402, 403,450

Policy mix, 86

Polish, 363-368, 370, 371

Political agenda, 80, 87, 257, 335, 440

Political economy of ageing, 297

Political fallout, 291

'Polytechnic Generation', 285, 287

Poor health, 33, 87, 106, 109, 135, 236, 247, 287, 355, 427, 431, 435, 442, 451, $469-471,476$

Population

ageing, 3, 7, 12, 30, 31, 38, 39, 42, 47, 59, 72, 73, 81, 85-88, 92, 103, 105, 106, $108,110,163,178,183,205,251,283$, $284,309,319,329,356,358,363,368$, $377,395,397,402,407,408,413,415$, 428, 435, 443, 459, 467, 469

screening, 124

Portugal, 12, 18, 31, 57, 98, 100, 102, 373, 374, 377-379

Portuguese, 374-377, 379

Post-Socialist countries, 395, 407

Poverty 
level, 74

rates, $72,74,180,309,310,312,388$, 410, 463

risk, 177, 186, 241, 244, 293, 309, 365

wages, 335

Precarious

conditions, 37,184

employment, 22, 102, 170, 235, 278, 300, $302,304,305,323,335,355,413,414$, $427,432,435,459,466,476$

job, 21, 96, 200, 316, 374, 388, 432, 451

work, 21, 137, 184, 200, 254, 298, 335, 407, 413, 414

Precarity, 31, 90, 129, 136, 137, 267

Pre-retirement

decisions, 60, 427

employees, 334

planning, 265

years, 97, 486, 489

Prevention, 124, 158, 191, 197, 276, 278, $279,369,413,423,432$

Primary unpaid carers, 298

Private pensions, 73, 91, 119, 166, 186, 187, 190, 211, 232, 243, 263, 299, 312, $322,342,398,409,410,462,471$, 473-476

Private sector, $75,79,86,90,92,95,96,106$, $117,119,122,123,154,169,180$, $208,210,211,213,253,255,263-$ 265, 288, 290, 293, 297, 301, 304, $321,322,352,357,378,389,463$, $475,484,487$

Privatisation, 133, 225, 237, 273, 309, 400, 423

Privileged

minority, 292

Productive workers, 323

Productivity, 23, 34, 55, 61, 75, 87, 129, 131, $176,179,180,226,323$

Public

authorities, 117, 233, 265

debate, 73, 80, 81, 125, 178, 199, 201, 202, 246, 284, 303, 323, 402, 421, 433, 456,481

debt, 298

services, 72, 117, 125, 154, 298, 300, 301

Public pension expenditure, 31

Public pensions, 31, 95, 98, 100, 109, 164, $166,175,223,243,263,265,272$, $273,325,329,337,365,389,390$, $392,397,398,402,433,483,487$, 489, 496
Public sector pensions, 201, 208, 211, 253, 286, 322, 389, 453, 463, 475, 496

Q

Qualify for pension, 7, 95, 97, 217, 285, 376, 455,473

Quality of work poor, 287

$\mathbf{R}$

Recalibration, 289

Recession, 72, 97, 242, 251, 254, 283, 291, 297, 298, 303, 434, 452, 486, 487

Reconciliation of care, $276,277,377,380$ work, 35, 278, 377

Recruit, 39, 234, 312, 343, 346, 470, 487

Reducing employment hours, 345

Redundancies, 95, 97, 109, 262, 333-335, $435,451,453$

Rehabilitation, 144, 146, 169, 246, 255, 276, $278,279,344$

Reliable, 80, 343

Reliance on men, 293

Remote working, 117, 333

Replacement rate income, 143

lower, 11, 122, 186, 343

Residential care, 344

Respite, 294, 380

Restrictions on length of career in hazardous jobs, 322

Retain, 5, 96, 180, 199, 234, 290, 301, 335, $346,470,487$

Retention in work, 158

Retirees, 88, 89, 97, 106, 109, 130, 136, 144, 156, 179, 186, 190, 197, 223, 236, $244,253,264,265,287,293,314$, $315,322,364,389,399,402,408$, $410,414,415,430,433,441,450$, $452-454,456,463,483,484$

\section{Retirement}

age(s), 5, 7, 9-11, 24, 31-33, 35-37, 40, 41, 92, 94-101, 104-106, 117-120, 122-125, 130, 133, 135, 142, 144, 145, $147,155,160,166,169,175-177,179$, $180,184,186,190,205,210,211,218-$ 220, 223-225, 231, 233, 237, 241, 243, $246,247,252,254-256,264,266,283-$ 293, 297, 300-304, 310, 312-316, 319, 320, 322-324, 326, 330, 333-335, 341, 342, 344-346, 363-367, 370, 371, 379, 
387-390, 392, 396, 397, 400, 402, 403, 408-410, 413-415, 419, 421, 422, 428, 430, 433, 435, 439-442, 445, 451, 453, $454,456,463,466,470,475,481,482$, 491

behaviour, 15, 36, 37, 48, 59, 148, 356, 432, 443

benefits, 95, 97, 104, 109, 110, 233, 334, $343,366,430,482-485,487,489$ decisions, 15, 58, 60, 97, 355, 427 delayed, 93, 95, 399

early, 7, 10, 15, 31, 36, 47, 51, 54, 61, 95, $97,98,106,117,119,120,122,124$, 125, 141-145, 155-157, 167, 175, 179, 180, 195, 196, 198, 199, 205, 209, 218 , $219,224,225,233-235,237,243,244$, 255, 256, 262, 265, 268, 272, 273, 277, 278, 284, 285, 287, 288, 290-293, 298, $301,322,324,330,334,337,341-343$, $345,364,373,376-378,386,389-391$, 396, 397, 402, 418, 419, 428, 430, 432, $434,442,451,452,463,464,466,470$ entry, 273

flexible, 125, 255, 322, 431, 475

income, 129, 481, 482

income security/system, 106, 131, 230, 232, 407, 482, 483, 490, 491

later, 91, 93, 187, 198, 217, 247, 376, 379,434

partial, 39, 146, 156, 157, 243, 397

pension, 167, 264, 265, 268, 319, 324, $365,392,398,399,414,430$

policies, 357,435

routes, 256,291

transition, 37, 187, 442

un-, 486

Rising costs

of care, 344

Risk

ill health, 5

individualised, 41, 484

mutualisation, 4

poverty, 177, 186, 241, 244, 293, 309, 365

Romania, 5, 65, 98, 100, 107, 385-392

Rural areas, 166, 367, 368, 386, 463

\section{S}

Sabbaticals, 346

Safety net, 39, 87, 98, 299, 440

Savings, 14, 31, 37, 38, 93, 94, 96, 97, 105, $106,131,185,186,189,190,230$ $232,311,312,343,352,355,365$,
$409,410,414,418,433,454,469$, 471, 474-476, 482, 484-486, 496

Scandinavian, 20, 153, 342

Seasonal

contract, 333

work, 90, 200

Second pillar, 131, 175, 199, 223, 243, 331, $365,409,410,482$

Secure, 4, 5, 7, 11, 23, 37, 91, 106, 121, 137, 147, 149, 179, 209, 210, 244, 267, $268,313,484$

Security, 12, 50, 86, 89, 90, 95, 96, 100, 106-108, 122, 133-137, 142, 144, $147,159,160,173,175,179,180$, 185, 198, 206, 208, 209, 232, 236, $254,275,277,302,311,313,330$ $333,335,337,365,368,376-378$, $380,388,389,396,400,403,411$, $413-415,419,423,428,430-433$, $435,459,462-464,473,481-487$, 489-491, 496, 497

Self-

employed, 20, 50, 62, 63, 118, 122, 133, 154, 165-167, 186, 188, 207, 208, 211, 212, 222, 273, 287, 290, 293, 320, 321, $323,325,330,335,342,345,366,376$, $388,392,449,452,455,462,496$

employment, 117, 119, 154, 165, 184, 200, 209, 321, 335, 389, 414, 452

Senior education, 221

Senior entrepreneurial activity, 412

Seniority wages, 337

Serbia, 50, 100, 395-403

Services, 19-21, 24, 30, 53, 55-57, 72, 78, $102,117,118,122,125,129-132$, $135,143,146,154,155,159,167$, $169,175,176,178,180,189,206-$ 208, 211-213, 218, 222, 224, 242, 251, 252, 256, 257, 276, 283, 290, 291, 293, 298, 300, 301, 309, 310, $316,319,321,323,325,326,330$, $332,334,336,337,344,345,357$, $365,368-370,377,378,387,388$, 390, 396-399, 403, 421, 423, 428, 431, 450, 452, 464, 467, 475, 485, 488,489

Severance payments, 334

Sexism, 191, 293

Sickness and healthcare benefits, 324

Skills

mismatch, 94, 107

outdated, 400

Slovakia, 18, 19, 98, 101, 102, 407-415 
Slovenia, 51, 53, 65, 98, 101, 102, 197, $417-424$

SMEs, 366

Social

class, 16, 38, 148, 149, 427, 432

democratic, 225, 229, 230, 234, 236, 237. 274,311

inequality, 72, 81, 105, 312

pension system, 88, 92, 435

security, 96, 100, 122, 142, 144, 147, 159, 160, 175, 179, 180, 206, 208, 209, 275, 277, 302, 311, 313, 330-333, 335, $365,368,376-378,380,388,389,413-$ 415, 419, 423, 428, 430, 431, 433, 435, 459, 462-464, 473, 481-487, 489, 491, 496

Social assistance benefit, 322

Social insurance

pensions, 96, 331, 332, 334

record, 332

scheme, 207, 208, 210, 211, 331, 344

Social interaction, 325

Social partners, 22, 108, 146, 147, 160, 213 , 231, 246, 256, 274, 291, 321, 323, $324,337,380,421,431$

Social policy, 22, 40, 87, 88, 93, 218, 225, $257,267,284,285,329,337,369$, $370,392,402,411,424,489$

Social protection, 11, 22, 117, 118, 124, 153, $154,169,179,251,283,321,336$, $380,413,450$

Social security, 330-333, 483

Social skills, 343

Socio-economic differences, 256, 345

Socioeconomic resources, 298

Spain, 5, 15, 18, 23, 32, 41, 54, 55, 59, 65, 79, $96,98,101,107,427,428,430-435$

Spanish, 54, 427-430, 432, 434, 435

Specific supports for older worker, 72, 103, 180, 226, 321, 376, 475

Stakeholders, 31, 74, 76, 79, 81, 117, 118, 137, 149, 169, 368, 380, 412, 440, $441,445,470,476$

Standard of living, 125, 175, 264, 323, 332, 414,454

State pension age, 4, 30, 33, 37, 38, 91, 92, $95,98,99,105,108,123,230,233$, 234, 297-299, 301-304, 346, 430, 469,482

Statutory retirement age, 10, 100, 145, 184, $186,243,264,301,322,335,341$, $342,344-346,365,367,400,403$, 428,433
Stereotypes, 64, 136, 190, 220, 221, 293, 343,487

Stress

work-related, 353

Stressful

job, 91

occupation, 89,110

work, 91

Study on Transitions in Employment, Ability and Motivation (STREAM), 49, 58,60

Subsidies, 107, 120, 135, 147, 186, 190, 273, $302,312,323,346$

Subsidised employment, 336

Supplementary pension provision, 330

Supplementary social insurance, 119

Supply of labour, 218, 236, 284, 290

Survey of Health, Ageing and Retirement in Europe (SHARE), 15, 49, 55, 58, 60, 146, 196, 310, 315, 325

Survivor's

benefits, 66, 144, 464, 484

insurance, 311

Sustainability, 7, 23, 73, 81, 86, 120-122, $147,159,167,213,223,225,230$, $252,255,274,309,314,321,323$, 330, 357, 377, 392, 396, 402, 432, $439,440,445$

Sweden, 4, 8, 9, 18, 32, 33, 35, 40, 52, 55, $65,73,98,101,102,229,242,374$, $439,441-444$

Swedish, 33, 36, 225, 264, 439-445

Swiss, 41, 449-457

Switzerland, 5, 8, 41, 49, 56, 98, 101, 188, 449-455

\section{T}

Targeting, 189, 209, 302, 489

Tax, 15, 56, 60, 72, 87, 88, 92, 107, 133, $143,154,175,187,199,207,218$, $223,225,230-232,234,235,237$, 241, 247, 271, 273, 298, 299, 311, $322,331,343,352,376,409,410$, $418,421,430,433,440,450,453$, $454,474,483,485,491$

cuts, 87,88

premium, 234, 343

relief, 299

Technology, technologies, 20, 21, 40, 55, $102,177,245,343,368,370,378$, 387,412

Temporary contracts, 63, 267, 320, 428, 431 
Tensions, 104, 120, 242, 289

The Irish Longitudinal Study of Ageing (TILDA), 49, 58, 60, 298, 299

Third pillar, 131, 154, 198, 223, 231, 243, $331,365,389,398,454$

Time credit, 156-158

Total contributions approach, 300, 303, 304

Trade-offs, 81

Trade unions, 41, 74, 110, 118, 120, 122, $123,148,153,156,160,199,213$, $231,236,256,266,267,274,301$, $303,311,324,356,357,366,370$, $385,402,412,415,421,440,441$, 457

Traditional, 4, 15, 18, 48, 58, 87, 96, 101, $106,130,145,166,285,356,403$, $408,417,442,484$

Training

job, 107, 143, 185, 451, 488

opportunities, 123, 266, 487

retraining, 354

Transnational

actors, 92

institutions, 86, 92

Turkey, 9, 49, 50, 56, 98, 101, 459-464, 466, 467

Turkish, 9, 23, 459-466

Two tier pensions, 288

$\mathbf{U}$

Uncertain future, 284

Undifferentiated, 31, 38, 98

Unemployment

of older workers, 180

pension, 255

rate(s), 23, 54, 71, 74, 107, 118, 123, 164, $166,196,218,222,223,229,237,251$, 257, 261, 262, 286, 367, 386, 395, 399, 400, 408, 411, 450, 486, 489

Unpaid (care) work

workers, 88, 104, 165, 188, 230, 287, 292, 297, 389, 400, 439

Unification, 119, 271

Uninterrupted employment, 334, 335

United Kingdom (UK), 4, 5, 12, 16, 18, 22, $33,39,52,55,57,74,95,98,101$, $105,300,469-474,476$

United States (US), 39, 57, 71, 76, 79, 95, 97, 98, 101, 105, 107, 315, 481-485, 487-491

Universal, 4, 14, 97, 189, 212, 223, 230, 232, $304,311,342,344,351,373,374$, $407,424,464$
Unskilled work, 354

Unsustainable, 3, 96, 201, 236, 343

Urban areas, 119, 463

V

Vertical segregation, 206, 298

Viability, 292, 312, 449, 456, 484

Vocational training, 125, 336, 415, 431

Voluntary

social insurance, 119

work, 15, 268, 267

Volunteering, 38, 304

VOW/QFT, 54, 58

Vulnerable

groups, 18, 20, 24, 105, 147, 209, 212

W

Wages

citizens, 94, 230, 313, 377

fall in, 164, 471

guaranteed, 242, 440

minimum, 263, 313

social, 19, 22, 87, 94, 120, 122, 132, 164, 174, 225, 231, 234, 242, 311, 313, 330, $332,334,335,337,375,385,413,415$, $471,484,485,490$

stagnant, 87

universal, 311, 373

Welfare

social, 64, 166, 211

state, $11,30,37,39,74,81,87,143,147$, $148,187,229,230,232,237,424,491$

state expenditure, 232

$\operatorname{system}(\mathrm{s}), 4,154,255,321,326,364$, $418,423,441$

Wellbeing, 5, 6, 17, 47, 48, 50, 53, 55, 58$61,64,67,74,86,90,108,124,135$, 137, 146, 148, 185, 189, 191, 251, $283,284,309,315,316,323,326$, $329,355,377,392,408,442,450$

Widows, 15, 144, 147, 262, 287, 289, 452, 483

Women

labour reserves, 292

older, 6, 21, 35, 86, 104, 124, 125, 130, $133,134,137,160,164,191,212,229$, 235-237, 241, 244, 262, 268, 283-285, 287, 290, 292, 294, 299, 313, 323, 325, $326,351,352,354-356,374,375,378$, $386,408,419,432,451,453,463,464$, $475,485-487,489$

pensions, 124, 387, 463 
Women's pension disadvantage, 304

Work

disability, 257, 343

experience, 135, 168, 266, 302, 334, 355

flexible, 59, 90, 96, 134, 234, 247, 252, 255, 351, 353, 357, 432, 439, 442, 471, $475,476,490$

full time, 485,487

incapacity pension, 333

paid, $4,7,10,11,38,59,61,88,90,107$, $109,118,119,134,147,165,183,248$, 262, 263, 275, 276, 298, 299, 321, 345, $351,352,357,358,368,375,380,385$, $397,402,403,459,470,485$

part time, 442, 485, 487, 489

precarious, 21, 90, 184, 200, 254, 298, $335,407,413,414$

secure, 4, 7, 91, 106, 121, 137, 179, 268

unpaid, 38, 104, 109, 147, 149, 319, 325 , 400, 487

Work Ability Index (WAI), 17, 54

Worker

older, 3-5, 7, 9, 18-24, 31, 32, 34, 35, 37$40,48,53,72,74,85,86,89-91,93-$ 98, 101-104, 106-110, 118, 120, 122, $123,125,135,136,141-143,145-149$, 153-158, 160, 163, 165, 170, 176, 179, 180, 185, 187, 190, 195-197, 199, 206, 218, 220, 222, 225, 226, 229, 233-237, $242,243,245,247,253-257,261-263$, 266-268, 272, 277, 283-286, 290, 292, 293, 298-302, 310, 315, 319-321, 323, $326,329,334,336,337,343,344,346$, 351, 352, 354-358, 365, 373, 375, 377, 390, 396, 397, 400, 407, 418, 419, 421, 427, 431, 432, 434, 439, 441, 443, 444, 449-453, 459-462, 464, 469, 470, 475, 476, 481, 482, 485-491

unskilled, 4,18

Workforce, 47, 58, 60, 72, 129, 131-135, $142,158,166,173,174,176-180$,
233, 237, 243, 256, 257, 267, 274, $277,301,330,343,345,351-353$, $355-358,375,396,419,421,428$, 432, 434, 443, 467, 488, 491

Working

environment, 5, 124, 439, 444, 445

life, 3-7, 9-12, 14-17, 19, 24, 29-37, 40, 41, 47, 48, 58-61, 64, 66, 67, 70, $72,78,79,81,86-88,90-93,96,98$, $102,103,105,108-110,117,119,121$, $122,125,131,137,142-147,149,153$, $160,163,164,168,169,173-180,186$, 191, 195, 196, 201, 205, 206, 208, 209. $213,217,225,229,233,236,237,241$, $243,245,246,251,252,257,261-$ 268, 272, 278, 290, 291, 298-300, 303, $310,314,319,323-326,329$, 335$337,342,356-358,373,374,376-$ $378,380,385-388,391,392,395-397$, 401-403, 414, 415, 417-419, 421-424, $427,431,432,435,439,440,442-$ 445, 449, 450, 453, 456, 464, 466, 467, 469-471, 474-476, 482, 484, 487-491

Working age, 48, 59, 61, 87, 124, 145, 165, $168,173,198,241,247,276,333$, $386,408,411,469$

Working conditions for older workers, 108, 199, 319, 334, 401

Work life balance, 50, 51, 59-61, 65, 197, $220,229,319,325,326$

Work-life trajectories, 298

Workplace health and safety, 358

Workplace Relations Commission, 301, 304

World Values Survey (WVS), 64, 65, 67

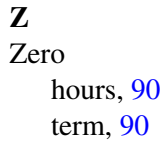

term, 90 